TESIS DOCTORAL

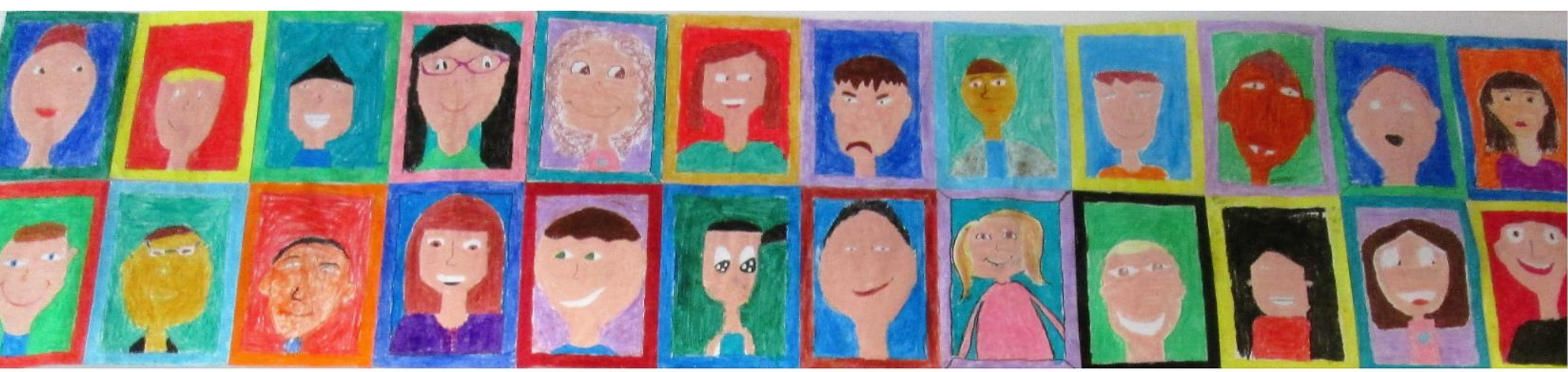

\title{
Diferenciación pedagógica y participación democrática en el aula inclusiva: estudio de casos múltiples
}

Différenciation pédagogique et participation démocratique dans la classe inclusive : étude multicas

Presentada por: Aida Sanahuja Ribés

Co-dirigida por:

Dra. Odet Moliner García Dra. Lidón Moliner Miravet

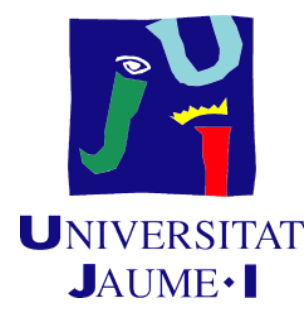

Marzo 2017 



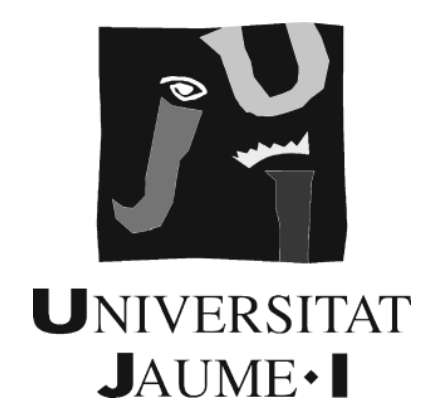

TESIS DOCTORAL

Mención Doctorado Internacional

\section{Diferenciación pedagógica y participación democrática en el aula inclusiva: estudio de casos múltiples}

$$
* * *
$$

Différenciation pédagogique et participation démocratique dans la classe inclusive : étude multicas

\section{Presentada por:}

Aida Sanahuja Ribés

\section{Co-dirigida por:}

Dra. Odet Moliner García

Dra. Lidón Moliner Miravet

Facultad de Ciencias Humanas y Sociales

Departamento de educación

Programa de doctorado: Educación Secundaria

Código: 14034

(R.D. 1393/2007)

Universitat Jaume I 
(C) Aida Sanahuja Ribés, 2017

Universitat Jaume I, Castellón de la Plana

La presente tesis doctoral se encuentra bajo una licencia Creative Commons:

Reconocimiento - NoComercial - SinObraDerivada (cc-by-nc-nd):

https://creativecommons.org/licenses/by-nc-nd/3.0/es/

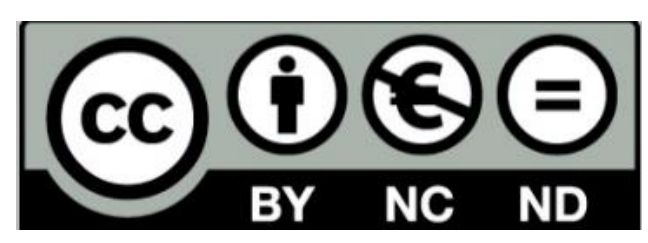

Sanahuja, A. (2017). Diferenciación pedagógica y participación democrática en el aula inclusiva: estudio de casos múltiples (Tesis Doctoral). Universitat Jaume I, Castellón de la Plana. 


\section{$\sim$ Agradecimientos}

Desde el inicio de esta tesis doctoral, son varias las personas que han contribuido en su elaboración. Quiero agradecérselo a todas ellas.

Quiero dar mis más sinceros agradecimientos a la Dra. Odet Moliner García y a la Dra. Lidón Moliner Miravet por sus directrices en el diseño y confección de este trabajo de investigación, unidas a sus enseñanzas transmitidas día a día fruto de su gran conocimiento en este campo.

A Manolo, a Mati, a Amèlia y a Cristina por abrirme las puertas de sus respectivas aulas y mostrarme detalladamente su encomiable labor docente. A los dos estudiantes del prácticum del grado en magisterio. Al alumnado y a sus familias que en el curso académico 2014/2015 realizaron: $5^{\circ}$ de educación primaria en el CEIP Isidoro Andrés de Castellón, $2^{\circ}$ A y $2^{\circ}$ B de educación primaria en el CEIP Cervantes J. Dualde de Betxi y $5^{\circ}$ y $6^{\circ}$ de educación primaria en el aulario de Quart de les Valls del CRA Benavites - Quart de les Valls. Sin su colaboración y sus aportaciones no se hubiera podido realizar este trabajo. ¡MUCHAS GRACIAS!

Agradezco al grupo de investigación Mejora Educativa y Ciudadanía Crítica (MEICRI) por compartir numerosas horas de trabajo, formaciones, reflexiones... que sin duda me han enseñado y ayudado, y han enriquecido notablemente el trabajo de investigación que aquí presento.

Asimismo, quiero agradecer al Ministerio de Economía y Competitividad (MINECO) por concederme un contrato predoctoral para la formación de doctores correspondiente al programa Estatal de Promoción al Talento y su Empleabilidad en I+D+i. Subprograma Estatal del Ministerio de Economía y Competitividad (Convocatoria 2014). Y por otorgarme una ayuda a la movilidad para la realización de una estancia de investigación de tres meses en l'Haute École Pédagogique de Lausanne, Suisse (Convocatoria 2015).

Al Dr. Serge Ramel (profesor de l'Haute École Pédagogique de Lausanne, Suisse) por acogerme, por mostrarme el sistema educativo del Canton Vaud, por compartir reflexiones dentro de la investigación PIDOPÉ y por facilitarme la realización de una mirada en un aula suiza. A Ysabel por abrirme su aula y compartir conmigo su filosofía docente. Al Laboratoire International Sur l'Inclusion Scolaire (LISIS) por poder compartir, reflexionar y aprender en el marco internacional.

A Isabel por nuestras conversaciones inspiradoras, por sus consejos y por su acompañamiento a lo largo de toda mi formación universitaria. Por sus lecturas de este trabajo, que sin duda lo han enriquecido fruto de su sabia mirada en torno a las situaciones de aula.

A Alicia, compañera y amiga, por compartir congresos, jornadas, formaciones, inquietudes y preocupaciones. Sin duda una buena aliada para compartir jutas este camino, nuestro camino.

A mi madre, a mi padre, a mi abuelo y a mi amiga Marina por el ánimo y apoyo incondicional que siempre me dan. A mi abuela, que siempre la llevo en el corazón, y que sin duda contribuyó a que hoy sea cómo soy. 
< ¿Para qué sirve la utopía?

Yo también me lo pregunto siempre.

Porque ella está en el horizonte.

$Y$ si yo camino dos pasos, ella se aleja dos pasos.

Y si yo me acerco diez pasos, ella se coloca diez pasos más allá. ¿Para qué sirve la utopía? Para esos sirve, para caminar $\gg$. .* 


\section{Resumen}

Uno de los mayores retos educativos a los que se enfrenta la sociedad actual es abordar las prácticas de aula desde una perspectiva inclusiva y democrática. Una opción pedagógica para realizar dicho cometido descansa en la diferenciación de la enseñanza, un enfoque escasamente referenciado y poco materializado en el contexto español. El objetivo general de esta tesis doctoral es comprender en profundidad y con matices la manera de articular la diferenciación pedagógica y la participación democrática desde la perspectiva de la educación inclusiva. Se trata de indagar sobre la diferenciación pedagógica como herramienta docente para combatir el fracaso escolar y las desigualdades, y de esta manera poder propiciar una participación y un aprendizaje óptimo para todo el alumnado. El diseño metodológico de este trabajo se enmarca en la investigación cualitativa, concretamente se aborda mediante el estudio de casos múltiples. Los métodos de recogida de datos empleados han sido: la entrevista, un inventario de prácticas de aula, la observación no participante y el análisis documental o material. Se ha realizado un análisis de contenido de los datos recogidos mediante la herramienta ATLAS.ti. Los resultados evidencian cómo se articulan los presupuestos teóricos en cada uno de los 4 casos analizados ( 3 del contexto español y 1 del contexto suizo). Las conclusiones teóricas, apoyadas por los datos empíricos, explican la vinculación entre la diferenciación pedagógica y la participación democrática en el aula inclusiva. Los casos relatados a partir del estudio empírico muestran diversas posibilidades de materializar y articular la diferenciación pedagógica (diferenciación de las estructuras, el contenido, el proceso y el producto) y la gestión democrática del aula (cultura colaborativa, liderazgo compartido, participación democrática y vinculación de la escuela con el territorio), con el objetivo de apoyar una formación hacia una ciudadanía crítica y desarrollar un sentido de pertenencia hacia la comunidad educativa.

Palabras clave: educación inclusiva, educación democrática, diferenciación pedagógica, participación democrática, estudio de casos múltiples, prácticas de aula.

\section{Résumé}

L'un des plus grands défis éducatifs de la société actuelle est d'aborder les pratiques de classe dans une perspective inclusive et démocratique. Une option pédagogique pour réaliser cette tâche réside dans la différenciation de l'enseignement, une approche à peine abordée et peu matérialisée dans le milieu espagnol. L'objectif général de cette thèse doctorale est de comprendre en profondeur et de façon nuancée la manière d'articuler la différenciation pédagogique et la participation démocratique dans la perspective de l'éducation inclusive. Il s'agit d'enquêter sur la différenciation comme outil pédagogique pour combattre l'échec scolaire et les inégalités, et de cette manière promouvoir une participation et un apprentissage optimal pour l'ensemble des élèves. La démarche méthodologique retenue s'inscrit dans un paradigme qualitatif interprétatif. Elle consiste à faire une étude en profondeur de quatre cas qui rendent compte d'une pratique de différenciation. Pour ce faire, différents outils de collecte de données ont été retenus: l'entretien, un inventaire de pratique de classes, l'observation non-participante et l'analyse documentaire ou matérielle. C'est par l'analyse du contenu, assisté par le support informatique ATLAS.ti., que les données qualitatives ont été traitées et analysées. Les résultats mettent en évidence la façon dont s'articulent, dans chacun des quatre cas analysés ( 3 dans le milieu espagnol et un dans le milieu suisse), les présupposés théoriques. Les conclusions théoriques (tirés de l'étude empirique) expliquent le lien entre la différenciation pédagogique et la participation démocratique dans la classe inclusive. Les cas relatés dans cette étude empirique montrent diverses possibilités de matérialiser et de définir la différenciation pédagogique (différenciation des structures, du contenu, du processus et du produit) et la gestion démocratique de la classe (culture collaborative, leadership partagé, participation démocratique et lien de l'école avec le territoire), dans la visée de soutenir la formation d'une citoyenneté critique et de développer un sens d'appartenance au sein de la communauté éducative.

Mots clés : éducation inclusive, éducation démocratique, différenciation pédagogique, participation démocratique, étude multicas, pratiques de classe. 



\section{ÍNDICE}

INTRODUCCIÓN

CAPÍTULO 1: Hacia una educación inclusiva y democrática ........................................................................9

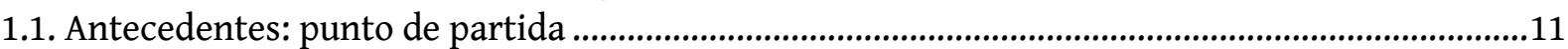

1.2. El rol docente: competencias personales, creencias, actitudes y valores .....................................14

1.2.1. Reconocimiento y valoración positiva de la diversidad .............................................18

1.2.1.1. Inclusión social del alumnado: sentido de pertenencia..........................................22

1.2.2. Valores democráticos: hacia una ciudadanía crítica.......................................................25

1.2.2.1. Participación y colaboración entre la Escuela-Familias-Comunidad ...................27

1.2.2.2. La escuela incluida en el territorio .......................................................................31

CAPÍTULO 2: Diferenciación pedagógica desde una perspectiva inclusiva: de su conceptualización

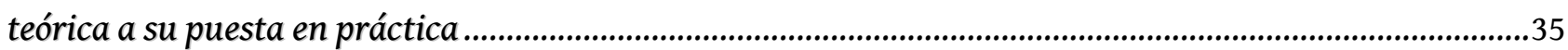

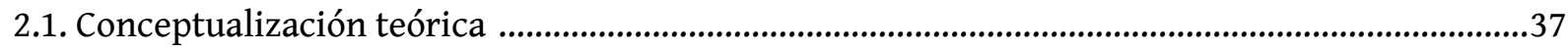

2.1.1. Antecedentes: origen y evolución conceptual .....................................................................37

2.1.2. Delimitación conceptual: ¿Qué es la diferenciación pedagógica? ........................................47

2.1.2.1. Factores y elementos constituyentes del aula diferenciada................................58

2.1.2.2. Lineamiento y alianzas entre la diferenciación pedagógica y la participación

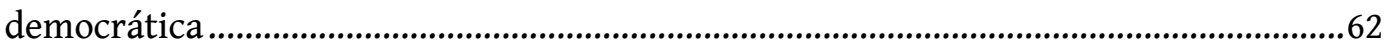

2.2. Algunas pistas de acción: cómo articular los presupuestos teóricos en la práctica educativa ..66

2.2.1. Organización del aula: diferenciación de las estructuras.

2.2.2. Metodologías didácticas inclusivas y democráticas: diferenciación del contenido y

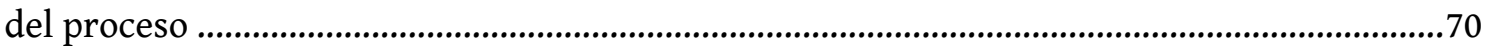

2.2.3. Evaluación inclusiva y democrática: diferenciación del producto ....................................77

\section{ESTUDIO EMPÍRICO}

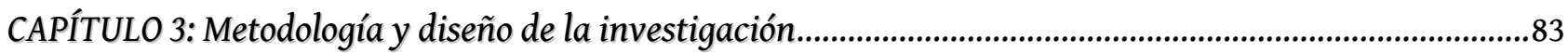

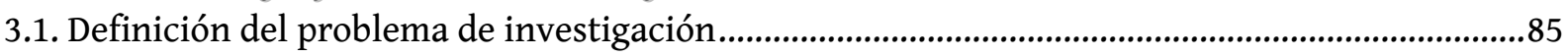

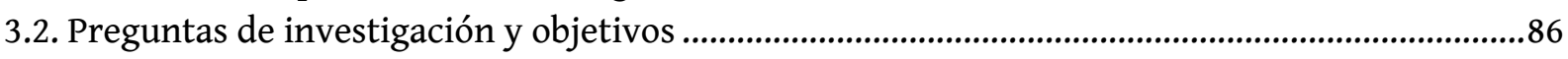

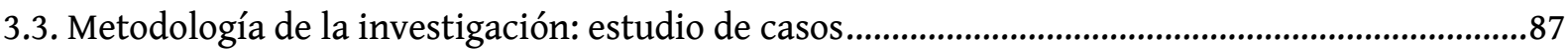

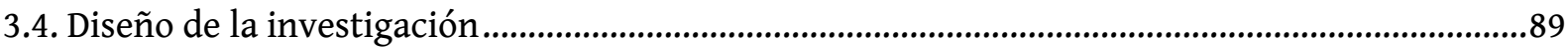

3.4.1. Descripción del proceso de la investigación ...........................................................................89

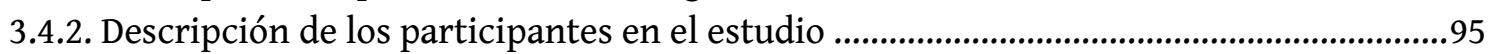

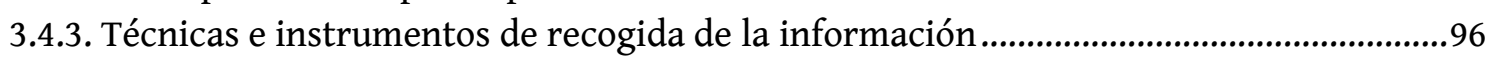

3.4.3.1. La entrevista: guión de entrevista semiestructurada..............................................96

3.4.3.2. Inventario de prácticas de aula...............................................................................98

3.4.3.3. Observación no participante: hoja de apoyo a la observación de aula, notas de campo, vídeos y audios ........................................................................................................99

3.4.3.4. Análisis documental o material ..........................................................................99

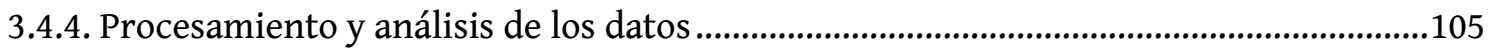

3.4.5. La investigación educativa: cuestiones éticas y profesionales ..........................................111 
4.1. Diferenciación pedagógica y participación democrática: modelo teórico relacional ...............................115

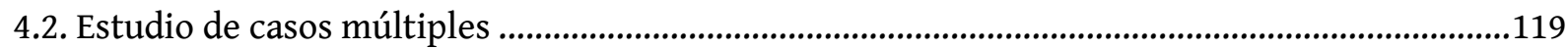

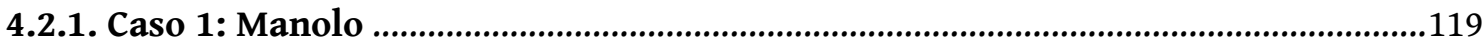

4.2.1.1. Desarrollo de prácticas diferenciadas y democráticas .......................................................119

4.2.1.1.1. Contexto general: localidad y centro educativo .............................................119

4.2.1.1.2. Los miembros de la clase: el maestro y su alumnado.......................................120

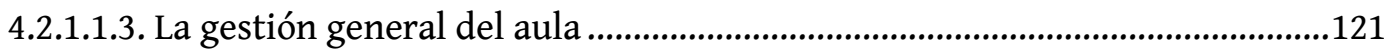

4.2.1.1.4. Metodologías de trabajo: diferenciación pedagógica.......................................127

4.2.1.1.4.1. Los grupos de investigación...................................................................127

4.2.1.1.4.2. Leemos en pareja......................................................................................131

4.2.1.1.4.3. Tertulia literaria dialógica ..................................................................135

4.2.1.1.4.4. Exposiciones de libros ........................................................................137

4.2.1.1.4.5. Cuentacuentos y teatro a infantil ......................................................139

4.2.1.1.4.6. Las cartas a la escuela Censal y otras producciones escritas.............143

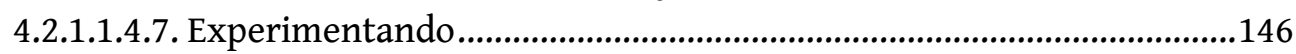

4.2.1.1.4.8. La evaluación: rúbricas y voz del alumnado.......................................150

4.2.1.2. Creencias, actitudes y valores que sustentan la práctica ........................................................... 154

4.2.1.2.1. El sentido del aprendizaje...............................................................................154

4.2.1.2.2. Una educación más justa para todos ............................................................156

4.2.1.2.3. Una educación más solidaria..............................................................................158

4.2.1.2.4. Una educación más participativa y abierta ........................................................160

4.2.1.2.5. Reflexión continúa sobre la propia práctica docente .....................................163

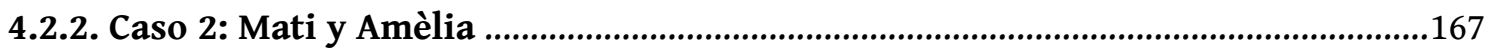

4.2.2.1. Desarrollo de prácticas diferenciadas y democráticas ....................................................167

4.2.2.1.1. Contexto general: localidad y centro educativo .............................................167

4.2.2.1.2. Los miembros de la clase: las maestras y su alumnado...................................167

4.2.2.1.3. La gestión general del aula .........................................................................169

4.2.2.1.4. Metodologías de trabajo: diferenciación pedagógica........................................170

4.2.2.1.4.1. Proyectos de trabajo ..........................................................................170

4.2.2.1.4.1.1. La prehistoria: el origen del ser humano ...............................171

4.2.2.1.4.1.2. ¿Cómo pasa el tiempo? Betxí, nuestro pueblo .........................186

4.2.2.1.4.2. Grupos interactivos ..............................................................................203

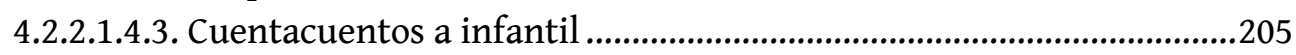

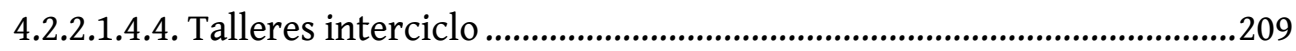

4.2.2.1.4.5. Evaluación: dilemas y dificultades suscitadas .....................................210

4.2.2.2. Creencias, actitudes y valores que sustentan la práctica ......................................................... 213

4.2.2.2.1. Dar valor a la persona, a lo humano ....................................................................213

4.2.2.2.2. Las clases no son nunca homogéneas.............................................................213

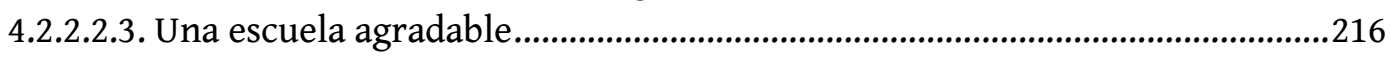

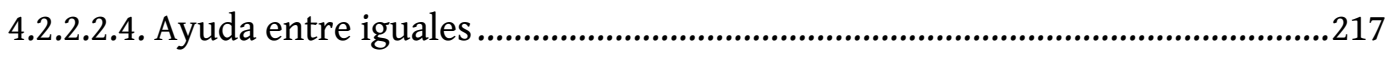

4.2.2.2.5. Participación del alumnado y de las familias ..................................................218

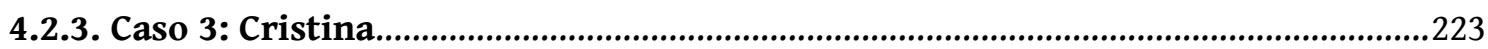

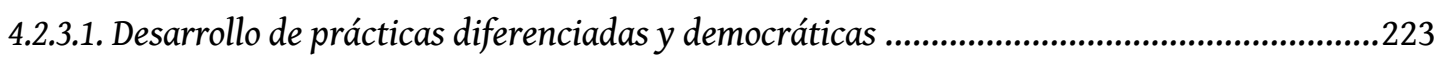

4.2.3.1.1. Contexto general: localidad y centro educativo ...............................................223 
4.2.3.1.2. Los miembros de la clase: la maestra y su alumnado .......................................224

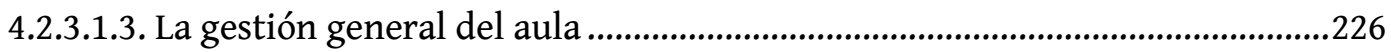

4.2.3.1.4. Metodologías de trabajo: diferenciación pedagógica.......................................229

4.2.3.1.4.1. El plan de trabajo ...................................................................................230

4.2.3.1.4.2. Del proyecto de centro "EL CINE" a las actividades de aula ..............232

4.2.3.1.4.3. Leemos en pareja.......................................................................................234

4.2.3.1.4.4. Puzle de Aronson o rompecabezas.......................................................2238

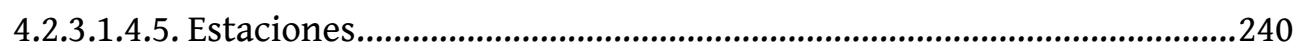

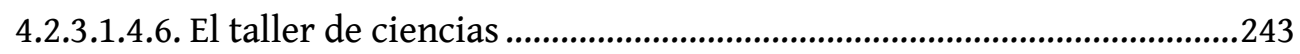

4.2.3.1.4.7. Tertulia literaria dialógica y exposición de libros ...............................245

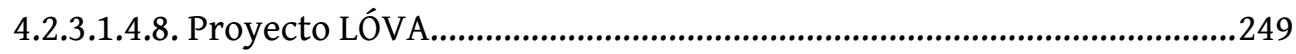

4.2.3.1.4.9. Talleres de los jueves .......................................................................257

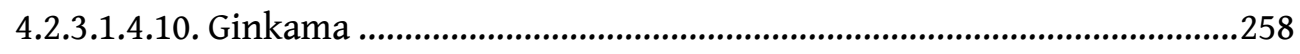

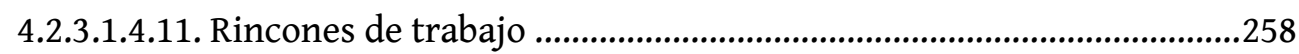

4.2.3.1.4.12. Evaluación de los aprendizajes........................................................265

4.2.3.2. Creencias, actitudes y valores que sustentan la práctica ......................................................... 267

4.2.3.2.1. Reflexión colectiva sobre la propia práctica docente ....................................267

4.2.3.2.2. Escapar del aburrimiento ................................................................................267

4.2.3.2.3. Atendiendo a la heterogeneidad del aula .........................................................268

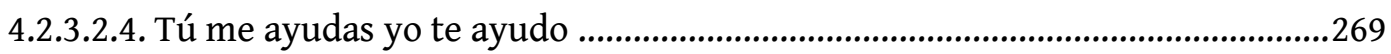

4.2.3.2.5. Participación del alumnado y de las familias .................................................271

4.2.4. Cas 4 : Ysabel............................................................................................................................ 277

4.2.4.1. La Suisse : contexte général de l'éducation .................................................................................... 277

4.2.4.1.1. Principales lois et des principaux accords...........................................2279

4.2.4.2. Cadre des pratiques de différenciation et participation............................................................. 281

4.2.4.2.1. Contexte : L'établissement primaire de Payerne ....................................281

4.2.4.2.2. Les membres de la classe : les enseignantes et les élèves .....................281

4.2.4.2.3. Gestion de classe ...............................................................................282

4.2.4.2.4. Méthodologie de travail : différentiation, matériel et évaluation......288

4.2.4.3. Croyances, attitudes et valeurs de l'enseignante......................................................................... 300

4.2.4.3.1. Reconnaissance de la diversité dans la classe .......................................300

4.2.4.3.2. Enseignement partage et culture collaborative .......................................300

4.2.4.3.3. Participation démocratique.....................................................................301

4.2.4.3.4. Bien vivre ensemble...................................................................................304

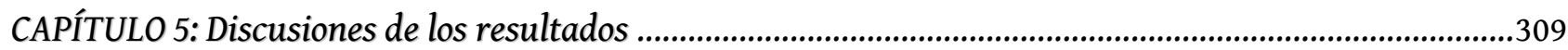

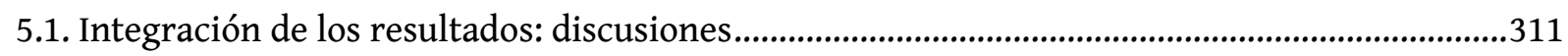

5.1.1. Teóricas: clarificación y relación conceptual................................................................312

5.1.2. Empíricas: el cómo y el porqué de las prácticas educativas.............................................314

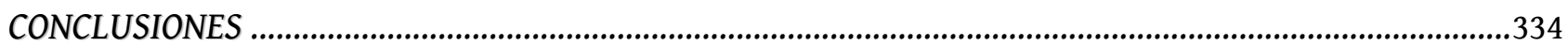

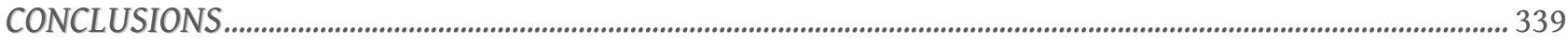

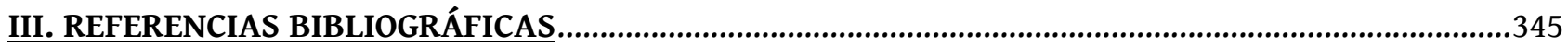

IV. ANEXOS

LISTA DE TABLAS, FIGURAS, CUADROS, IMÁGENES Y CÓDIGOS QR _.................................................413 



\section{$\sim$ Introducción}

Origen y justificación del estudio

$\mathrm{H}$ e de deciros que nunca me había planteado el hecho de realizar un doctorado en educación. Sin embargo, un poco sin buscarlo, las circunstancias me han hecho recorrer un emocionante y apasionante camino. Esta investigación nace de mis inquietudes e intereses en relación a cómo ofrecer una educación de calidad a todo el alumnado, basada en los principios de heterogeneidad y de participación activa en el aula. En otras palabras, nace de mi preocupación respecto a la mejora educativa de las prácticas didácticas emanadas desde los parámetros de la educación inclusiva y democrática.

Las personas que me conocen saben que, desde que tengo uso de razón, siempre he querido ser MAESTRA. De pequeña, a través del juego simbólico, imitaba y simulaba situaciones que me acontecían en el contexto escolar. Las muñecas, no eran bebés, eran alumnas. Bastaba con un bolso, un pintalabios, unos zapatos de tacón y unos cuantos libros y libretas para pasar largas y entretenidas tardes de juego. En ellas simulaba una enseñanza en la cual el alumnado adoptaba un rol pasivo, con exámenes y ejercicios individuales, y con algún que otro castigo. ¿Esta era la maestra que quería ser o simplemente reproducía lo que veía en mi clase?

En septiembre del 2007, gracias a los esfuerzos acontecidos en el bachillerato y en la selectividad para obtener una nota suficiente que me permitiera estudiar la carrera que siempre había deseado, empecé la Diplomatura de Magisterio en Educación Infantil en la Universitat Jaume I de Castellón. Los tres años de carrera me suscitaron otros interrogantes, los cuales unidos a mi afán y preocupación por la mejora educativa me hicieron seguir formándome y estudiar la Licenciatura en Psicopedagogía, la cual completó notablemente mi formación universitaria. Transcurridos estos primeros cinco años en la UJI, emprendí el Máster en Intervención y Mediación Familiar, gracias al cual y a una beca de colaboración del Ministerio de Educación y Cultura (MEC) empecé mi formación en el ámbito de la investigación. Este hecho me llevó a iniciar el Doctorado en Ciencias de la Educación. No me resultó difícil centrar el tema de investigación. Al comentarle a la Dra. Odet Moliner mis principales preocupaciones e inquietudes, sobre la mejora de las prácticas de aula, enseguida me habló de la diferenciación 
pedagógica y del Laboratoire International Sur l'Inclusion Scolaire (LISIS) ${ }^{1}$. Ahora, en el 2017, transcurridos prácticamente diez años en la universidad presento mi tesis doctoral: Diferenciación pedagógica y participación democrática en el aula inclusiva: estudio de casos múltiples. En el día de hoy, más qué nunca, sé qué tipo de MAESTRA quiero ser y sobre que principios pedagógicos quiero asentar mi profesión docente. A lo largo de estos últimos cuatro años he aprendido y reflexionado sobre la realidad del aula junto a 5 docentes que me han permitido realizar una mirada sobre sus prácticas educativas.

Creo que la principal incertidumbre que tenemos los maestros ${ }^{2}$ recae en las prácticas educativas que llevamos a cabo en el aula. Esta duda se incrementa cuando la diversidad del alumnado es mayor, ya que como señala Ainscow (2001a, p.20) los docentes a menudo nos preguntamos: ¿Cómo puedo trabajar con todo el grupo y al mismo tiempo llegar a todos y cada uno de los alumnos de mi clase? Es más que evidente la heterogeneidad del alumnado que está presente en cada una de las aulas, este hecho supone un reto y un desafío en las prácticas educativas. A pesar de eso, hay maestros que conciben la diversidad de sus aulas como una condición que dificulta la práctica educativa, mientras que otros la entienden como una dimensión que la mejora y la enriquece ampliamente (Moriña, 2008).

Asimismo, no podemos pasar por alto las demandas y exigencias que suponen vivir en una sociedad globalizada como en la cual estamos inmersos. Para definir los procesos de cambio socioculturales, que vienen promovidos especialmente por las tecnologías de la información y la comunicación, Bauman (2006) - recientemente fallecido, utilizaba una metáfora que ilustra muy bien el cambio hacia esta sociedad llamada de la información. Este autor hablaba del paso de la cultura sólida a la información líquida. Actualmente, a causa de la cultura digital imperante, existe un goteo de conocimientos eventual, inconstante y en infatigable transformación. Así pues, ante este panorama, no significa que necesariamente la sociedad de la información sea una sociedad con un mayor conocimiento. La gran cuantía de información existente hace ineludible el hecho de dotar de herramientas al alumnado para que desarrolle la capacidad de entenderla, procesarla, seleccionarla, organizarla y transformarla en conocimientos, y así poder aplicarla posteriormente en las diferentes situaciones o contextos de su vida cotidiana (Pérez, 2008). Esto es, hay que desarrollar en cada persona la capacidad para que pueda actuar y participar de forma autónoma, culta y crítica (Area y Pessoa, 2012). Sin embargo, estos cambios desatados en la sociedad no se vislumbran entre la mayoría de las paredes de las aulas o los centros educativos. Este hecho es reflejado por Ainscow (2001a) en el siguiente ejemplo:

Un cirujano del siglo XIX que aterrizara en un quirófano de nuestros días no tendría ni idea de dónde se encontraba, mientras que un maestro de ese mismo período que se hallara de repente en un día lectivo actual se limitaría a coger la tiza y seguir la clase donde la hubiese dejado. (p.144) 
Por consiguiente, es necesario revisar las formas más tradicionales de enseñanza y buscar nuevas respuestas que estimulen y apoyen la participación y el aprendizaje de todo el alumnado. Santos Guerra (2000a) afirma que:

Las circunstancias no son las mismas, el contexto no es el mismo, los niños y jóvenes no son como nosotros éramos en los años en que asistíamos a la escuela. Entregarse a la rutina es condenarse al fracaso. Por eso es necesario que la escuela sea una institución que aprende, no sólo una institución que enseña. (p.79)

Por ende, no se puede seguir concibiendo la enseñanza como la mera transmisión de conocimientos del maestro (experto) hacia el alumnado (inexperto), potenciando solamente esa relación unidireccional. El aula es un contexto socialmente rico donde se generan numerosas interacciones tanto entre el docente y el alumno, como entre el alumnado (relaciones entre iguales) e incluso con otros agentes comunitarios participantes en los quehaceres de la clase. Hay que otorgarle el protagonismo al alumnado en su propio proceso de aprendizaje y socialización, haciéndole plenamente partícipe de éste. Por tanto, bajo estas premisas no se puede concebir una enseñanza homogénea para todo el grupo clase, dado que por todos es sabido que no existen ni han existido dos seres humanos idénticos, en ese sentido todos somos diferentes (López Melero, 2004). Por ello, no osaríamos a decir que todos los alumnos son iguales. A pesar de eso, a menudo, en las escuelas se trata a los alumnos como si lo fueran. Durante años se ha planteado la misma lección y la misma forma de enseñar para todos, sabiendo que algunos alumnos se aburren mientras que otros se pierden porque no están preparados para consolidar ese aprendizaje (Arnaiz, 2011; Gregory y Chapman, 2013). La experiencia, así como las investigaciones realizadas sobre el cerebro humano, nos revelan que los alumnos son diferentes, que aprenden de manera diferente y tienen diferentes gustos, preferencias y necesidades. Este hecho lo ilustran Gregory y Chapman (2013) a través de la analogía una misma talla no sirve para todos. O lo que es lo mismo en palabras de Beaudoin (2013), la mayoría de las escuelas hacen que sus alumnos marchen al compás del mismo tambor, y el enfoque es diferente, hay que tocar al compás de cada alumno.

En este estudio nos proponemos comprender la manera de articular la diferenciación pedagógica y la participación democrática en el aula inclusiva, a través de un estudio de casos múltiples. El principal propósito es presentar un relato de los casos estudiados para que sirvan de estímulo y reflexión sobre la mejora de la práctica educativa, promoviendo en todo momento el respeto a la diversidad y fomentando la participación activa de todo el alumnado y de otros agentes de la comunidad educativa en el aula.

Es necesario remarcar que la presente tesis doctoral pretende contribuir, desde el contexto español, a un estudio más amplio realizado por el Laboratoire International Sur l'Inclusion Scolaire (LISIS) para un análisis de las prácticas de diferenciación pedagógica que se está llevando a cabo junto a investigadores canadienses y suizos. 
El presente trabajo consta de cinco capítulos y está dividido en dos partes: la primera engloba toda la fundamentación teórica y la segunda comprende el trabajo empírico. En la fundamentación teórica encontramos un total de dos capítulos.

En el Capítulo 1: Hacia una educación inclusiva y democrática, se introducen los diferentes elementos o factores que caracterizan una educación asentada en los parámetros de la inclusión y la gestión democrática del aula. Para ello, se parte del rol docente como principal pieza que articula y propicia dichos propósitos. Nos centramos en los dos principales presupuestos que imperan a lo largo de todo el trabajo: 1) el reconocimiento y la valoración positiva de la diversidad y 2) los valores democráticos.

En el Capítulo 2: Diferenciación pedagógica desde una perspectiva inclusiva: de su conceptualización teórica a su puesta en práctica, se realiza una reconstrucción de los orígenes y la evolución del constructo de diferenciación pedagógica. Este capítulo nos ayuda a entender qué es la enseñanza diferenciada, así como a reconocer algunos términos afines a dicho vocablo. Además, se presentan algunas pistas teóricas que nos ayudan a esclarecer la manera de ponerla en práctica en el aula.

Una vez finalizada la fundamentación teórica en la que se sustenta este trabajo se pasa a desarrollar la segunda gran parte del mismo, la cual corresponde al estudio empírico, constituida por tres capítulos.

En el Capítulo 3: Metodología y diseño de investigación, se describe de manera pormenorizada: la definición del problema, las preguntas y objetivos de investigación y la metodología utilizada. Posteriormente, se pasa a desarrollar el diseño de la investigación en el cual se presenta: la descripción del proceso de la investigación, los participantes en el estudio, las técnicas e instrumentos de recogida de la información y el procesamiento y análisis de los datos. Se termina el capítulo haciendo alusión a las cuestiones éticas y profesionales de la investigación educativa.

En el Capítulo 4: Resultados de la investigación, se presentan los resultados obtenidos en esta tesis doctoral. En primer lugar, se muestran los resultados referentes a los elementos que vinculan la diferenciación pedagógica y la participación democrática en el aula inclusiva. En segundo lugar, se presenta el relato de cada uno de los casos abordados y las creencias, actitudes y valores que sustentan las prácticas educativas de cada uno de ellos. 
En el Capitulo 5: Discusión de los resultados, se recogen las principales discusiones de los resultados que se extraen de la investigación efectuada. Este cometido se efectúa a partir de la agrupación de las discusiones referentes a dos ejes principales: 1) discusión de los resultados teóricos, es decir, clarificación y relación conceptual y 2) discusión de los resultados empíricos, esto es, el cómo y el porqué de las prácticas educativas.

Con el propósito de optar a la mención de doctorado internacional y tal como viene establecido en la normativa de la Universitat Jaume I: Procedimiento y criterios aplicables para la obtención de la mención internacional en el título de doctorado (Aprobada por el Consejo de Gobierno núm. 21 de 30 de marzo del 2012), además de realizar una estancia de investigación al extranjero de como mínimo 3 meses, se debe de redactar parte de la tesis doctoral, como mínimo el resumen y las conclusiones, en una de las lenguas habituales para la comunicación científica en el campo de conocimiento. No obstante, y tal como se regula en dicha normativa, también se acompañan las conclusiones y el resumen en castellano. Por esta razón, las principales conclusiones que se derivan de la tesis doctoral, se presentan tanto en castellano, como en francés. Asimismo, en susodicho apartado se mencionan las limitaciones del estudio y las futuras líneas de investigación.

El trabajo finaliza con las referencias bibliográficas empleadas para la fundamentación del estudio, los anexos y una lista donde se enumeran las tablas, figuras, imágenes y códigos QR referenciados a lo largo del informe de la tesis doctoral. 



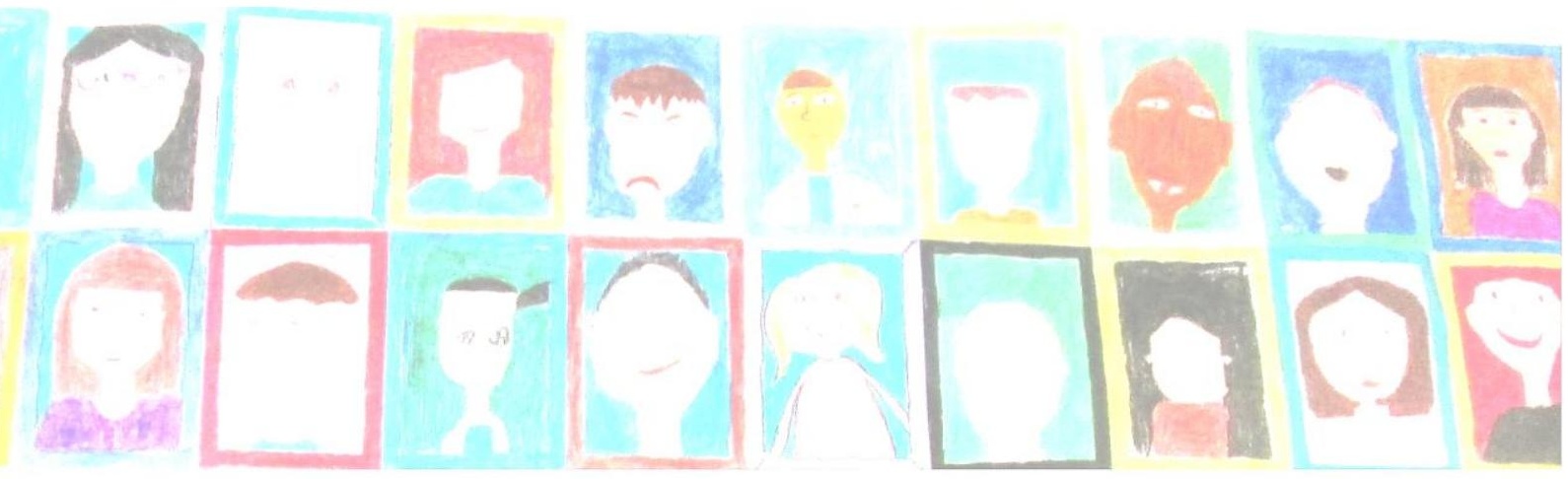

\section{FUNDAMENTACIÓN TEÓRICA}

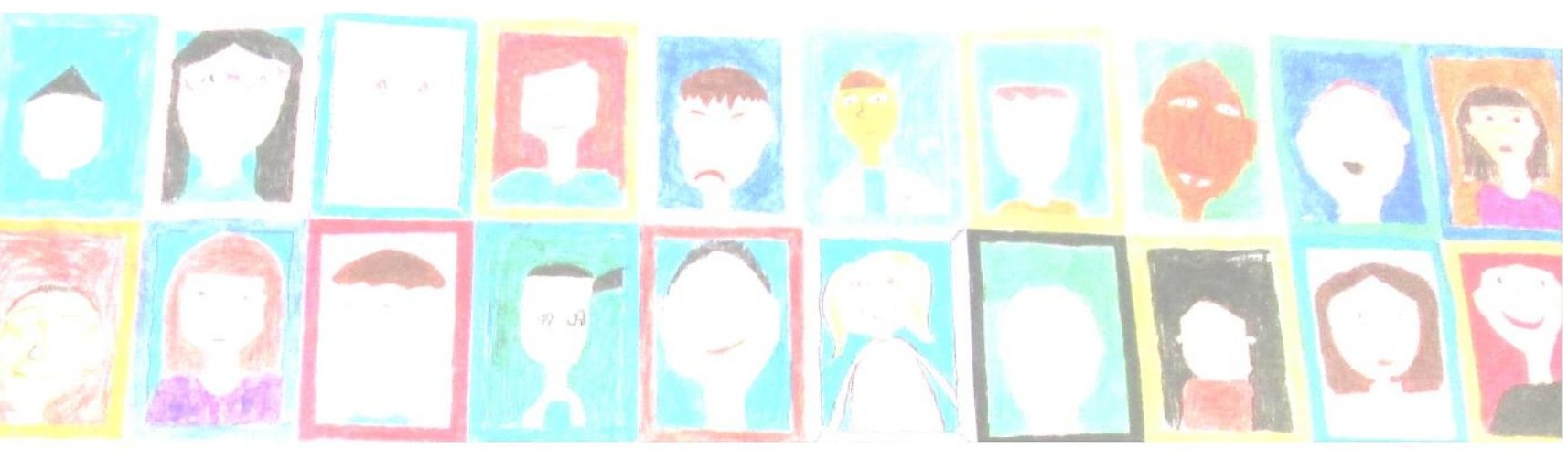





\section{CAPÍTULO 1}

\section{$\sim$ Hacia una educación inclusiva y democrática}

1.1. Antecedentes: punto de partida

1.2. El rol docente: competencias personales, creencias, actitudes y valores........................ 14

1.2.1. Reconocimiento y valoración positiva de la diversidad ............................... 18

1.2.1.1. Inclusión social del alumnado: sentido de pertenencia ........................ 22

1.2.2. Valores democráticos: hacia una ciudadanía crítica ....................................25

1.2.2.1. Participación y colaboración entre la Escuela-Familias-Comunidad .... 27

1.2.2.2. La escuela incluida en el territorio................................................. 31 


antecedentes que acontecen a una educación basada en la inclusión y en la participación activa del alumnado en su propio proceso de aprendizaje. El objetivo de este capítulo es introducir los diferentes elementos o factores que caracterizan una educación asentada en los parámetros de la inclusión y la gestión democrática del aula. Para ello, se parte del rol docente como principal pieza que articula y propicia un marco escolar que permite avanzar hacia escuelas más inclusivas y democráticas. Nos centramos en los dos presupuestos generales que subyacen en las creencias, actitudes y valores de los docentes que ofrecen una respuesta educativa desde la perspectiva inclusiva y democrática: 1) el reconocimiento y la valoración positiva de la diversidad y 2) los valores democráticos. A partir de estos dos principios se van estructurando los demás elementos o factores que caracterizan este marco de acción docente. En el primer presupuesto también se aborda y se pone de relieve que la educación inclusiva se preocupa tanto por la función social como educativa de la escuela, se incluye un apartado que hace alusión a la importancia de la inclusión social del alumnado (respeto y tolerancia hacia la diversidad de todos los compañeros del aula), partiendo de la premisa de la necesidad de ser aceptados en el contexto escolar. En cuanto al segundo presupuesto presentado, desde una visión más democrática, se expone la necesidad de avanzar hacia una ciudadanía crítica a partir del fomento, principalmente por parte de los docentes, de una cultura colaborativa, un liderazgo compartido y una participación democrática que no se limite meramente a la participación activa del alumnado en el aula, sino que se extienda a la colaboración entre la Escuela-Familias-Comunidad y promueva una escuela incluida en su territorio.

\subsection{Antecedentes: punto de partida}

A menudo, la inclusión escolar se concibe como una verdadera utopía (Boutin y Bessette, 2009). También puede pensarse como un ideal o un mito, o como una fórmula políticamente correcta que excede el campo de la educación y denota un proyecto de sociedad (Bonvin, 2010).

Hace 23 años de la Declaración de Salamanca (UNESCO, 1994), en la cual 92 gobiernos y 25 organizaciones internacionales ratificaron su compromiso con la Educación para Todos, reconociendo la necesidad y la urgencia de impartir enseñanza a todos los niños, jóvenes y adultos con necesidades específicas de apoyo educativo (n.e.a.e.) dentro del sistema común de educación. Siendo este propósito evaluado y renovado en 2009, en la Conferencia Mundial sobre Educación Inclusiva: Volviendo a Salamanca - Afrontando el reto: Derechos, Retórica y Situación Actual (Gastón, Lafuente y Santiago, 2010). No obstante, la integración escolar suele ser la orientación educativa 
mayoritariamente adoptada en las escuelas españolas y de otros muchos países. Según indica Arnaiz (2004), en la mayoría de los casos, la respuesta educativa que se suele dar al alumnado que presenta alguna discapacidad, dificultades de aprendizaje o algún diagnóstico en n.e.a.e. corresponde a una propuesta individual y descontextualizada de lo que realiza el grupo clase. Asimismo, es habitual que este alumnado asista de manera regular al aula de pedagogía terapéutica o de apoyo educativo. En palabras de Ainscow (2001a), este hecho tiene su origen en la importación de las prácticas procedentes de las experiencias producidas en la educación especial. Cada vez existe una mayor convicción en la idea de que los modelos tradicionales basados en las necesidades específicas de apoyo educativo que proporcionan servicios distintos o adicionales a los proporcionados a los otros niños de una edad similar son injustos, dado que conllevan a la segregación y perpetúan la discriminación (Florian, 2013).

Existe la creencia que los docentes difícilmente pueden responder a las exigencias del currículum y al sistema escolar cuando mayor diversidad hay en sus aulas. Por esta razón, la articulación pedagógica inherente a la inclusión escolar suscita muchas dudas. Además, la excesiva focalización sobre las características particulares de algunos alumnos ha forjado, a lo largo de los últimos años, una representación social de la inclusión esencialmente centrada en la discapacidad o en el hándicap, lo que origina que la educación para todos se convierta en la integración de algunos pocos (Ramel, 2015a). La tarea de mejorar la calidad de la enseñanza debe hacerse con la perspectiva en mente de todo el alumnado, y no sólo pensando en mejorar la enseñanza que reciben algunos de esos niños o jóvenes (Echeita, 2006). Siguiendo a Stainback y Stainback (1999), lo deseado sería hablar de dar una educación de calidad para todos los alumnos. No obstante, todavía hay personas excluidas de la vida escolar y comunitaria.

Al hilo de lo anterior, conviene enfatizar en el concepto de inclusión plena, ya que hay que incluir a todos los niños o jóvenes en la vida educativa y social de las escuelas (AuCoin, 2014). Es importante recordar que Beauregard y Trépanier (2010), distinguen tres enfoques que conciernen a la integración: mainstreaming (integración), la inclusión parcial y la inclusión total. Vienneau (2006), por su parte, también habla de la inclusión total o full inclusion model. Este mismo autor propone un cuadro comparativo entre las principales diferencias que residen entre la integración y la inclusión (Ver Tabla 1). 
Tabla 1

Principales diferencias entre integración e inclusión

\begin{tabular}{l|l}
\hline \multicolumn{1}{c|}{ INTEGRACIÓN } & \multicolumn{1}{c}{ INCLUSIÓN } \\
\hline -Empieza en los años 1970. & -Empieza en los años 1990. \\
\hline $\begin{array}{l}\text {-Se limita a los alumnos con discapacidad o hándicap } \\
\text { leves. }\end{array}$ & $\begin{array}{l}\text {-Anula cualquier forma de exclusión (filosofía de } \\
\text { exclusión 0). }\end{array}$ \\
\hline $\begin{array}{l}\text {-Permite la existencia de servicios segregados } \\
\text { (sistema en cascada). }\end{array}$ & $\begin{array}{l}\text {-Un sólo lugar para todos los alumnos (la clase } \\
\text { ordinaria). }\end{array}$ \\
\hline $\begin{array}{l}\text {-La presencia en la clase ordinaria se puede limitar a } \\
\text { una integración física. }\end{array}$ & $\begin{array}{l}\text {-El alumno está integrado pedagógicamente y } \\
\text { socialmente. }\end{array}$ \\
\hline $\begin{array}{l}\text {-Los servicios de apoyo son reservados a los alumnos } \\
\text { con hándicap o dificultad. }\end{array}$ & $\begin{array}{l}\text {-Los recursos son puestos a la disposición de la } \\
\text { clase ordinaria y son ofrecidos al conjunto de los } \\
\text { alumnos. }\end{array}$ \\
\hline
\end{tabular}

Nota. Fuente: Vienneau, R. (2006). De l'intégration scolaire à une véritable pédagogie de l'inclusion. In C. Dionne et N. Rousseau (Dir.), Transformation des pratiques éducatives. La recherche sur l'inclusion scolaire (pp.

7-32). Collection éducation-recherche. Québec, Canada : Presses de l'Université du Québec.

No obstante, tal como señalan Echeita y Ainscow (2011) existen diferentes concepciones y definiciones de lo que se entiende por el término inclusión, lo que lleva a confusión tanto a nivel nacional como internacional. Tomando de referencia la UNESCO (2005):

La educación inclusiva puede ser concebida como un proceso que permite abordar y responder a la diversidad de las necesidades de todos los educandos a través de una mayor participación en el aprendizaje, las actividades culturales y comunitarias y reducir la exclusión dentro y fuera del sistema educativo. (p.14)

Si focalizamos en la definición anterior y nos apoyamos en palabras de Echeita (2008), la educación inclusiva implica tanto un aprendizaje y un rendimiento escolar de calidad (exigente con las capacidades de cada alumno) como un sentimiento de pertenencia o bienestar emocional y relacional (inclusión social del alumnado). Hay que destacar también la idea de mayor participación, lo que nos remite al ideario de la escuela democrática. Para Feito y López (2008), existen tres principios que la caracterizan: 1) la educación obligatoria debe constituirse de tal manera que se creen las condiciones que avalen el éxito escolar para todo el alumnado, 2) el alumnado debe terminar la escuela con la capacidad para cuestionarse sobre lo que les rodea, para analizar con criterios propios la realidad, para ser alguien dispuesto a seguir aprendiendo a lo largo de su vida, y 3) se debe facilitar y promover la participación de los docentes, los alumnos y las familias tanto en el control como en la gestión del centro.

De todo lo anterior emana un gran desafío para la sociedad actual (Porter y Stone, 1998; Rousseau, 2010) y también para los docentes, los cuales deben atender a la diversidad de sus aulas desde un marco escolar común, esto es, tienen que encontrar formas de atender a todos los alumnos en su 
diversidad en una escuela en la que están todos (Pujolás, 2001). Así pues, ante este panorama y una vez que el concepto de educación inclusiva empieza a formar parte del lenguaje escolar políticamente correcto, es necesario revitalizar el ideario de la escuela inclusiva (Susinos y Rodríguez, 2011).

\subsection{El rol docente: competencias personales, creencias, actitudes y valores}

La literatura consultada parece indicar que los docentes son los principales actores y artífices en ofrecer tanto una enseñanza de calidad (Messina y Rodríguez, 2006; Low, 2007) como una educación inclusiva (Prud'homme, Vienneau, Ramel y Rousseau, 2011). La Agencia Europea para el Desarrollo de la Educación del Alumnado con Necesidades Educativas Especiales (2012), en contra de una pedagogía de la exclusión, resalta cuatro valores subyacentes en la enseñanza y el aprendizaje de los docentes considerados inclusivos: 1) valorar la diversidad del alumnado, considerando las diferencias como un recurso y un valor educativo, 2) apoyar a todo el alumnado (inclusión social y educativa), 3) colaborar y trabajo en equipo y 4) desarrollo profesional y aprendizaje permanente del profesorado.

La confianza de los docentes en sus propias competencias personales, sus creencias en relación a las capacidades de progresar de sus alumnos y sus actitudes frente a esta consideración, subyacen en el hecho de que los maestros lleven o no a cabo una pedagogía que favorezca la diversidad y las competencias colectivas (Curchod-Ruedi, Ramel, Bonvin, Albanese y Doudin, 2012). Asimismo, Day y $\mathrm{Gu}$ (2013) hablan de la resiliencia cotidiana de los maestros, es decir, la capacidad de mantener el equilibrio, de gestionar con éxito las situaciones educativas y del compromiso que se requiere en los mundos cotidianos en los que los docentes enseñan. Poco a poco se va forjando una identidad docente (Hammerness, Darling-Hammond y Bransford, 2005), la cual es importante para garantizar el compromiso de los maestros hacia su labor educativa (acorde con las normas profesionales), dado que dicho desarrollo de la identidad personal da forma a las disposiciones que los maestros llevan a cabo en su aula.

Según indica Caena (2014), el constructo de competencias personales del profesorado corresponde tanto al conocimiento formalmente adquirido como a la posterior carrera profesional. La Comisión Europea (2013), conduce a concebir la profesión docente en cuatro ámbitos: 1) aprender a pensar como docente (pensamiento crítico sobre las creencias pedagógicas), 2) aprender a saber como docente (conocimiento derivado de la propia práctica), 3) aprender a sentir como docente (identidad profesional, actitudes, valores...) y 4) aprender a actuar como docente (integrar creencias, saberes y actitudes en la práctica didáctica).

Si hacemos un repaso a algunas de las principales competencias del profesorado, decir que Perrenoud (2007a) insiste en diez grandes familias: 1) organizar y animar situaciones de aprendizaje, 2) gestionar la progresión de los aprendizajes, 3) elaborar y hacer evolucionar dispositivos de diferenciación, 4) implicar a los alumnos en sus aprendizajes y en su trabajo, 5) trabajar en equipo, 6) 
participar en la gestión de la escuela, 7) informar e implicar a los padres, 8) utilizar las nuevas tecnologías, 9) afrontar los deberes y los dilemas éticos de la profesión y 10) organizar la propia formación continua. En relación a la novena competencia introducida y siguiendo a Escudero (2011), la ética de la profesión docente implica: i) conciencia social y crítica educativa, ii) cuidado y personalización educativa, iii) formación y desarrollo profesional, iv) implicación y compromiso con la comunidad y v) reconocimiento y compromiso con el derecho a la educación. Asimismo, se considera necesario, atendiendo al principal tema objeto de nuestro estudio, hacer una especial mención a la tercera competencia aportada por Perrenoud (2007a), ésta se refiere a la capacidad del maestro a hacer frente a la heterogeneidad del grupo-clase, extender la gestión de clase a un espacio más amplio, practicar el apoyo integrado y desarrollar la cooperación y enseñanza mutua en el aula.

En esta misma línea Alegre (2010) propone diez competencias del profesorado que son indispensables para hacer frente a la diversidad del alumnado presente en el aula: 1) lingüística, 2) enfoque globalizador y metacognitivo de la enseñanza, 3) responder a la diversidad del alumnado, 4) nuevas tecnologías, 5) promover el aprendizaje cooperativo entre iguales, 6) competencia cultural y artística, 7) mentor para desarrollar en su alumnado la competencia de aprender a aprender, 8) desarrollo de autonomía e iniciativa personal, 9) planificación: desarrollo profesional docente y 10) capacidad reflexiva. Fernández Batanero (2013), por su parte, establece que las competencias implícitas para avanzar hacia una educación inclusiva y, por ende, mejorar la calidad de la educación son: investigar, actualizarse, dinamizar, emplear la creatividad, liderar y abrirse al cambio. En relación a las competencias docentes y la educación inclusiva, el autor anteriormente referenciado concluye que el desarrollo de la inclusión precisa de maestros coherentes con sus principios y sus creencias, que sean capaces de transmitir valores y crean en lo que están haciendo y lo que deben de hacer.

Si pasamos a abordar las representaciones mentales de los maestros (p.ej. creencias, actitudes, valores...), autores como Latorre y Blanco (2007) señalan que éstas son constructos difíciles de delimitar, ya que poseen perfiles cognitivos, actitudinales y simbólicos-afectivos. Por tanto, definir aquello que es intangible resulta complicado y poco objetivo, y más aún cuando se detecta que no existe unanimidad entre los diferentes investigadores que se han ocupado de su estudio.

En palabras de Oliver (2009), por centrarnos en una definición, la creencia hace alusión a: Una parte de la dimensión personal, afectiva y emocional, íntimamente ligada a la propia cultura que se manifiesta en el ambiente en el que estamos y en el que configuramos, influyendo, a su vez, en nosotros y en lo que hacemos. (p.63)

Quintana (2001), añade que el origen de las creencias radica en: 1) la razón (conocimiento intelectual), 2) el sentimiento (deseo o necesidad), 3) las influencias sociales y culturales (personas) y 4) la voluntad del propio sujeto. Añadir también que las creencias de la persona influyen en sus 
percepciones de la realidad y en sus valoraciones sobre la misma, se detecta en sus comportamientos y aseveraciones (Cardona, Fandiño y Galindo, 2014). De esta manera, se puede considerar que las creencias pedagógicas son las concepciones que tienen los docentes en referencia a los diferentes procesos de enseñanza-aprendizaje (Cortez, Fuentes, Villablanca y Guzmána, 2013). Por tanto, indagar en el pensamiento de los maestros supone entender la enseñanza como algo que va más allá de lo que meramente éstos hacen en sus aulas (Messina y Rodríguez, 2006). Hutner y Markman (2016), en un estudio con docentes que impartían asignaturas científicas, corroboran lo que muchas investigaciones han demostrado en relación a la vinculación entre las creencias docentes y las prácticas educativas. Generalmente, las creencias de los maestros hacia la diversidad son positivas y se encuentra una relación significativa entre los años de experiencia docente y las creencias profesionales, siendo los maestros sin experiencia los que presentan mayor tolerancia hacia la diversidad (Chines, Cardona y Gómez, 2015). Por su parte Su-Chuan (2009), concluye que cuanto más conscientes sean los docentes de su régimen de creencias, mejor podrán influir éstos sobre sus propias acciones e interacciones en el proceso de enseñanza- aprendizaje.

Berruezo (2006), se apoya con el dicho popular las cosas no las hace quien puede, sino quien quiere, para ilustrar y resaltar la importancia de la actitud de los maestros como un elemento clave a la hora de determinar el tipo de atención educativa que recibe el alumnado. Una definición clásica, del vocablo actitud, aportada desde el campo de la psicología social es la de Allport (1935), el cual la define cómo: un estado mental y neurológico de predisposición, mediante la experiencia, que ejerce una influencia directiva o dinámica en la respuesta de los individuos en todos los objetivos y situaciones con los que se relaciona. Hay que señalar que la actitud parece tener tres componentes básicos: el componente cognitivo (creencias y valores), el componente afectivo o emocional y el componente conductual (Olson y Zanna, 1993; Shapiro, 1999). No podemos pasar por alto, de entre los distintos modelos actitudinales existentes en la literatura, el aportado por Ajzen y Fishbein (1980). La Teoría de la Acción Razonada (theory of reasoned action), propuesta por estos últimos autores citados, afirma que la conducta está influida por la intención de conducta, y ésta a su vez por la actitud y la norma subjetiva. Esto es, al tomar una decisión se realiza en función de la valoración de los resultados de determinado comportamiento y de las expectativas sobre dicho comportamiento en relación a los resultados que se derivarán de éste. Posteriormente, Ajzen (1988) amplió susodicho modelo agregando un componente de percepción de controlabilidad de la conducta (percepción de los obstáculos internos, p.ej. falta de habilidades o competencias, y externos o situacionales). Varios trabajos (Cardona, 2000; Alemany y Villuendas, 2004; Álvarez, Castro, Campo y Álvarez, 2005) exponen que las actitudes docentes hacia la inclusión educativa son favorables, pero éstos se muestran reticentes ante su puesta en práctica, dado que conciben complicada su articulación en el aula. En una reciente investigación (Turabik y Gün, 2016) se muestra cómo las actitudes democráticas de los maestros hacia la gestión de las aulas es un predictor significativo de la disposición del pensamiento crítico de los alumnos. Así pues, la acción del docente, con actitudes positivas, es totalmente 
necesaria e indispensable en el conocimiento y el aprendizaje escolar, para lograr aprendizajes significativos en el alumnado (Cervantes, Cappello y Castro, 2009). Tal y como muestran Sales, Moliner y Sanchiz (2001), es de vital importancia desarrollar actitudes positivas hacia la diversidad y la inclusión y un buen espacio para ello es en las universidades, en la formación inicial del profesorado.

El constructo de valor es considerado como un término más amplio que el de actitud, dado que supone una estructura más compleja, compuesta por un conjunto de actitudes estructuradas jerárquicamente (Pallí y Martínez, 2004). Desde el campo de las humanidades el constructo valor puede ser definido como la significación de las propiedades de objetos, procesos o fenómenos para la dignidad humana en un sentido amplio y a la satisfacción de necesidades normales de nuestra especie en un sentido estrecho (Sánchez, 2005). Booth y Ainscow (2011) recogen los valores que deben imperar y deben ser llevados a la acción en el marco de la inclusión, para así poder superar la exclusión y promover la participación. Los valores que proponen y sus opuestos (que propician la pedagogía de la exclusión) son: equidad (vs. jerarquía), compasión (vs. individualismo), confianza (vs. desconfianza), honestidad (vs. conformidad), belleza (vs. imagen), respeto a la diversidad (vs. monocultura), no violencia (vs. eficiencia), alegría (vs. recompensa/castigo), derechos (vs. oportunidad), participación (vs. consumo), sabiduría (vs. poder), coraje (vs. competición), amor (vs. autoridad), esperanza (vs. determinismo), comunidad (vs. aislamiento) y sostenibilidad (vs. explotación).

Encontramos articulados los tres principales elementos que se vienen desarrollando (creencias, actitudes y valores) en lo que la educación inclusiva debería ser considerada según Arnaiz (1996):

Una actitud, un sistema de valores, de creencias, no una acción ni un conjunto de acciones [...]. Se centra, pues, en cómo apoyar las cualidades y las necesidades de cada alumno y de todos los alumnos en la comunidad escolar, para que se sientan bienvenidos y seguros, y alcancen éxito. (p. 27-28)

En este epígrafe se han introducido los aspectos relativos a las competencias personales, creencias, valores y actitudes de los maestros, entendiendo a éstos como los principales artífices para articular un marco de acción docente que nos permita avanzar hacia una educación inclusiva y democrática, pero no hay que olvidar que toda la comunidad educativa (Luengo, 2006; Bell, Illán y Benito, 2010; Simón, Giné y Echeita, 2016) juega un papel importante para caminar hacia los presupuestos que se vienen apuntando (esta idea se recoge de manera más detallada en los puntos finales del presente capítulo). Seguidamente, se exponen los dos pilares generales que estructuran y fundamentan el presente trabajo: 1) Reconocimiento y valoración positiva de la diversidad y 2) Valores democráticos. Asimismo, se presentan y desmenuzan los diferentes elementos o factores característicos de este modelo de acción docente. 


\subsubsection{Reconocimiento y valoración positiva de la diversidad}

La indiferencia a la diferencia (Bourdieu, 1966) o el dilema de las diferencias (Dyson y Milward, 2000), apelan a la necesidad de reconocer y valorar de manera positiva las manifestaciones de la diversidad a beneficio de todos los integrantes del aula, con el principal objetivo de ofrecer a todos los alumnos la oportunidad de progresar y desarrollar al máximo su potencial. Según Moliner y Moliner (2010), a lo largo de la historia de la educación, se han ido adoptando diferentes concepciones o perspectivas en referencia al constructo de diversidad: 1) la diversidad como déficit (modelo segregacionista y asimilacionista), 2) normalización de la diversidad (modelo integracionista), 3) empowerment y pluralismo y 4) valoración positiva de la diversidad (modelo intercultural e inclusivo).

Adoptando esta última concepción mencionada y siguiendo a Arnaiz (2011), a partir de las declaraciones o informes que se han fraguado en el seno de la educación inclusiva, existen dos elementos clave para que ésta se dé: 1) la consideración de la educación como derecho y 2) la consideración de la diversidad como un valor educativo esencial para la transformación de los centros. $\mathrm{Y}$ es que, basta con observar el aula desde múltiples miradas para tomar conciencia de la gran pluralidad presente en ella. Éste hecho está muy bien ilustrado en el siguiente relato presentado por Tomlinson (2005):

A la maestra le importa su trabajo. Le gustan los niños y le gusta enseñar. Pone mucho empeño y se siente orgullosa de su profesión. Los niños y las niñas lo saben, y la aprecian por todas esas cosas. Pero la jornada escolar a menudo les parece demasiado larga. A veces, la maestra se da cuenta. A menudo, no se entera.

Lin no sabe castellano. Además, nadie parece entender su idioma. La maestra le sonríe y encarga a un compañero de clase que la ayude. Ese compañero no habla su idioma. También le sonríe. Algunas veces, las sonrisas ayudan. Otras veces, parecen música sin sonido. En matemáticas, Lin entiende más. Los números encierran menos significados ocultos que las palabras. Pero nadie espera que ella entienda, así que no le piden que pase al pizarrón para resolver problemas. Eso está bien, porque si pasara, no tendría palabras para referirse a los números.

Rafael quiere leer en voz alta, quiere pedir más libros sobre personajes históricos, quiere sumar sus propias preguntas a las que hicieron otros. No lo hace. Sus amigos desprecian la escuela. Dicen que no es para ellos. El estudio es para otra clase de gente, dicen. ¿De qué le serviría a él sacar buenas calificaciones? Tal vez tengan razón. Rafael sabe que no irá a la universidad ni conseguirá un buen trabajo, aunque piensa en ello en secreto. Y quiere saber cosas. Pero le cuesta preguntar.

Serena en casa lee los libros de su madre. Lee las revistas que vienen con la edición dominical del periódico. Junto con sus amigas, escribe y produce obras de teatro en el barrio cada verano a las que asisten muchísimas personas. En la escuela está aprendiendo reglas de ortografía. Saca las notas más altas en los exámenes. Saca las mejores calificaciones en todo. No se esfuerza, a diferencia de cuando prepara las obras teatrales. En la escuela está incómoda, tiene la sensación de estar incurriendo en una falsedad. Inventa historias en su mente mientras espera que los demás alumnos aprendan. Ellos ponen mucho empeño y no obtienen buenas notas. Eso también la hace sentirse como una impostora.

Julián detesta leer. Se porta mal algunas veces, pero lo hace sin querer. Es que está cansado de quedar como un tonto frente a todos. Cuando lee en voz alta le parece que es el peor de la clase. Lo raro es que entiende de qué se tratan los textos cuando los leen otros. ¿Cómo es posible que uno entienda lo que no sabe leer? ¿Y cómo se puede ser un estudiante normal y no saber leer?

Laura sabe que no aprende como los demás. Sabe que la gente dice que ella es "lenta". Tiene una maestra especial que viene a clase para ayudarla, o la lleva a otra aula para que aprenda cosas. Le gusta esa maestra. También le gusta la de la clase. No le gusta tener dos maestras porque se siente diferente. No le gusta que lo que ella estudia sea distinto de lo que estudian los demás. No le gusta sentir que está casi al margen de la acción todo el tiempo. 
A Daniel le gusta ir a la escuela porque allí no le gritan todo el tiempo. Nadie le pega en la escuela, o si lo hacen, reciben una reprimenda. La maestra le sonríe. Le dice que se alegra de que haya ido. Él no entiende bien por qué. No le va bien. Le gustaría, pero es difícil concentrarse. Se preocupa por su mamá. Se preocupa por su hermana. Se olvida de prestar atención. En la casa, le cuesta hacer la tarea. Se atrasa.

Tadeo escucha las preguntas esperando que alguna le suene familiar. Espera escuchar un lenguaje que suene como el suyo. Espera una señal de que las personas con las que estudia en la escuela tienen algo en común con él. Espera ver cómo puede encajar el conocimiento en su vecindario. No le molesta estudiar. Sólo desearía saber para qué. Está inquieto.

La maestra de estos alumnos se toma mucho trabajo para preparar las clases. Ellos lo saben. A veces -muchas vecesparece que está enseñando lecciones, y no a los alumnos. A veces parece que ella piensa que todos son una sola persona. A veces es como si ellos fueran nada más que un número, el que sacan en el examen. A veces la escuela es como un zapato hecho para calzar en un pie ajeno. (p. 29-31)

Esta narración nos muestra, de manera muy explícita, la realidad que encontramos en numerosas aulas. Para comenzar con el análisis de la enseñanza diferenciada podemos ver la gran pluralidad, gama de aptitudes, intereses y necesidades diferentes que el alumnado trae consigo al contexto escolar. Conviene recordar que existen diferentes tipos de diversidad (Arnaiz, 2005): 1) diversidad de capacidades para aprender, 2) diversidad de estilos de aprendizaje, 3) diversidad de niveles de desarrollo y aprendizajes previos, 4) diversidad de ritmos, 5) diversidad de intereses, motivaciones y expectativas, 6) diversidad cultural, 7) diversidad social y 8) diversidad sexual.

Si hacemos un breve repaso a la tipología introducida, vemos como la diversidad en el contexto educativo puede traducirse en diferentes ritmos y niveles de aprendizaje y en múltiples características individuales (Kahn, 2010). En la misma línea, Tomlinson (2008) defiende que los alumnos presentan diferentes aptitudes, intereses y estilos de aprendizaje. Según el diccionario de la Real Academia Española (2012), una aptitud es la capacidad para operar completamente en una determinada actividad. El interés hace referencia a la curiosidad, afinidad o pasión de un niño por un asunto o habilidad determinada (Tomlinson, 2008). Lozano (2000) define el término estilo como: "un conjunto de preferencias, tendencias y disposiciones que tiene una persona para hacer algo y que se manifiesta a través de un patrón conductual y de distintas fortalezas que lo hacen distinguirse de los demás" (p.17). Así pues, se trata de las condiciones educativas bajo las cuales el alumno está en la mejor situación para aprender, esto es, qué estructuras son necesarias para aprender de la mejor manera (Hunt, 1979). Theisen (2002), explica que el perfil del estudiante muestra si el alumno aprende mejor individualmente, en grupo, prefiere actividades de desarrollo, de construcción o aprenden mejor con actividades actitudinales o desarrollo de análisis. Por su parte Tomlinson (2008), completa que el perfil de aprendizaje guarda relación con el modo en que los individuos adquirimos y asimilamos la información y está influenciado por las preferencias de nuestro intelecto, el género y la cultura. Todo este discurso nos recuerda a la teoría de las Inteligencias Múltiples propuestas por Gardner (1983), que tal y como es conocido por todos propuso ocho tipos de inteligencias. Por otra parte, recordar también la teoría triárquica de la inteligencia propuesta por Sternberg (1985), la cual 
defiende que existen tres tipos de inteligencia: la analítica, la práctica y la creativa. Otro elemento clave a tener en cuenta en el proceso educativo es la motivación. En psicología este concepto se utiliza para exponer las razones del comportamiento. Como señala Wong (2000), dichas razones pueden ser analizadas como mínimo en dos niveles: 1) a nivel del porqué un individuo exhibe ciertas manifestaciones conductuales y 2) a nivel del cómo se llevan a cabo tales manifestaciones. Como señala Reeve (2001), la motivación se refiere al proceso psicológico que trata de explicar las causas de la conducta y sus variaciones, es decir, qué factores despiertan, orientan y mantienen la conducta hasta que se termina. En este proceso, y siguiendo las palabras de Kelly (1955), esta energía, da lugar a dos grandes formas de concebir la motivación: 1) como tracción, basada en las necesidades o determinantes intrínsecos del comportamiento y 2) como propulsión, basada en los estímulos o determinantes extrínsecos del comportamiento. Así pues, en el terreno educativo, la motivación se produce cuando alguna enseñanza apela a la imaginación, a la curiosidad, suscita opiniones... Es un imán que atrae la atención del alumnado y la sostiene de manera que pueda producirse el aprendizaje (Tomlinson, 2008). Tal como se ha mencionado, otro tipo de diversidad es la cultural, ésta hace alusión al grado de diferencia encontrada en un área geográfica en la que están presentes diferentes culturas (Álvarez y Urbano, 2013). Si nos centramos en el contexto educativo, la diversidad cultural se concibe como un recurso valioso que enriquece y desafía el proceso de enseñanza- aprendizaje (Sales, 2005). La diversidad social es entendida como aquella que hace mención a la procedencia geográfica, al nivel socioeconómico, al rol o grupo social... (Cela, Gual, Màrquez y Ustet, 1997). Finalmente, la diversidad sexual hace alusión a la orientación sexual del sujeto, una propuesta que pretende educar en el respeto a la diversidad sexual en el aula de educación secundaria obligatoria, consiste en introducir dichas temáticas a través de la educación en medios (Francisco y Moliner, 2011).

AuCoin y Vienneau (2010), proponen adoptar una lógica de desnormalización en contra de una lógica de normalización en la cual el alumnado puede "vivir plenamente sus diferencias sin tener que modificarlas para ser aceptados en la sociedad" (p.68). La aceptación y la valoración de la diversidad, es una característica inherente en las aulas inclusivas (Stainback y Stainback, 1999; Duk y Narvarte, 2008). En éstas la diversidad no se ve como un problema o como un aspecto que hay que superar en la práctica educativa, sino que es entendida como un extraordinario recurso para apoyar y fomentar el aprendizaje de todas las personas integrantes en el aula (Moriña, 2008; Booth y Ainscow, 2011).

En cuanto a la gestión pedagógica de la diversidad en el aula, Bergeron (2015) introduce dos lógicas operantes: 1) la lógica reactiva: que consiste en planificar la enseñanza para el alumno medio e intervenir en el alumnado que presenta mayor dificultad o quien no llega a efectuar con éxito las tareas y 2) la lógica proactiva: se trata de planificar la enseñanza en función de la diversidad del alumnado y de sus necesidades. Además de planificar intervenciones suplementarias, llevándolas a cabo si se requiere. Siguiendo con la misma premisa y en palabras de Pujolás (2001), cuando un alumno no aprende aquello que se le enseña, hay dos formas de afrontar ese suceso. Por un lado, el 
maestro puede preguntarse: ¿Qué le pasa a ese alumno?, ¿Qué dificultades, limitaciones o deficiencias personales le impiden aprender? $\mathrm{O}$, por otro lado, el docente puede cuestionarse: Lo que he querido enseñarle, ¿se ajusta a sus posibilidades y necesidades? ¿Habría una forma alternativa de organizar y plantear la enseñanza de estos contenidos? Notemos como el primer bloque de interrogantes está centrado en el alumno, mientras que el segundo bloque se centra en la manera de presentar el currículum, primando la reflexión sobre las actuaciones docentes. Aquellos que se interesan por una educación de calidad para todos, le van otorgando mayor atención a la segunda alternativa, entendiendo una buena educación, como aquella que ayuda a los alumnos a maximizar su capacidad de aprendizaje. La misma idea es introducida por Ainscow (1999) al plantear tres presupuestos que el maestro puede adoptar para gestionar su aula: 1) pensar que los miembros de la clase que no responden sufren algún problema que impide su participación, 2) reducir las expectativas al pensar que algunos alumnos nunca serán capaces de alcanzar los niveles exigidos y 3) desarrollar nuevas respuestas didácticas que puedan estimular y fomentar la participación y el aprendizaje de todo el alumnado. Este autor propone diferentes ingredientes que ayudan a propiciar el aprendizaje y la participación en el aula inclusiva: a) empezar con los conocimientos previos, b) planificar teniendo en cuenta a todos los miembros del aula, c) considerar las diferencias como oportunidades para el aprendizaje, d) analizar los procesos que conducen a la exclusión y e) utilizar los recursos disponibles para apoyar el aprendizaje.

Rousseau y Bélanger (2004) insisten en el hecho que los actores escolares deben creer en el potencial de logro de cada uno de los individuos. Por tanto, educar en la diversidad es, según Moliner (2015) “adoptar y seguir prácticas inclusivas que poseen como filosofía el respeto y la valoración de las diferencias como bien humano y como recurso de mejora de las aulas y de los centros" (p.13). En esta perspectiva subyace una cultura de la diversidad (López Melero, 1990,1997; Arnaiz e Illán, 1996). Desde esta premisa se desprende un amplio movimiento a favor de una educación para todos, cuya intención principal es constituir una comunidad, que proporcione a todos los alumnos situaciones y oportunidades educativas para que se sientan miembros de una colectividad y profundicen en sus relaciones para crecer colectivamente (Giné y Ruiz, 1996). Esta escuela se interesa por su función social y educativa, para favorecer el desarrollo de todos los alumnos de acuerdo con sus características personales y las de su entorno. 


\subsubsection{Inclusión social del alumnado: sentido de pertenencia}

Desde una perspectiva constructivista del aprendizaje se concibe a la persona como un ser social protagonista de múltiples interacciones (Vygotsky, 1978). Masip y Rigol (2000) apuntan que el aula es un espacio de intercambio de experiencias y de conocimientos en el cual tienen cabida el conjunto de diversidades del alumnado. En palabras de Medina y Salvador (2009) estas múltiples relaciones y situaciones tienen una gran influencia en la formación integral del alumnado. Por tanto, es importante que los alumnos reconozcan, valoren y respeten la diversidad de sus iguales, al mismo tiempo que se sientan aceptados y valorados en el contexto escolar.

Los diferentes autores que se han ocupado del estudio de las necesidades básicas y motivos del ser humano (Murray, 1938; Maslow, 1954; Deci y Ryan, 2000) coinciden en remarcar la importancia de las necesidades afectivas, de pertenencia y de contacto social en el individuo. Baumeister y Leary (1995), sustentan que todos necesitamos formar parte de un grupo y mantener relaciones sociales: "los seres humanos poseen un impulso omnipresente de formar y mantener al menos una mínima cantidad de relaciones interpersonales duraderas, positivas y significativas" (p.497). Sabemos que no forzosamente tenemos que gustar a todo el mundo, pero si que esperamos que los demás no nos encuentre deficientes (Leary, 2001). Según López (1995), los distintos contextos sociales en los que los niños participan son los encargados de atender y satisfacer las necesidades de desarrollo y educación durante la niñez. La familia, la escuela y el grupo de iguales constituyen los principales microsistemas en los que se fragua su desarrollo. La participación en los procesos interactivos y de aprendizaje que tienen lugar en estos tres escenarios es fundamental y necesaria para el correcto desarrollo infantil (Menéndez, Jiménez y Lorence, 2008).

Si nos centramos en el grupo de iguales, vemos como las relaciones entre éstos no siempre se desarrollan de una forma apropiada. Bierman (2004) muestra que durante la infancia hay pocos problemas que conllevan un elevado nivel de estrés y daño como el producido por el rechazo crónico de los iguales. El ostracismo es entendido por Williams (2001) como el acto de ignorar, rechazar o excluir a un miembro del grupo, o a otra persona en una relación interpersonal. Leary (1990), por su parte, intentó describir la aceptación y el rechazo mediante un status continuum constituido por siete categorías de inclusión social (Ver Tabla 2).

Tabla 2

Status continuum de la inclusión social

\begin{tabular}{ll}
\hline \multicolumn{1}{c}{ ESTATUS } & \multicolumn{1}{c}{ DEFINICIÓN } \\
\hline Inclusión máxima & $\sim$ Los otros hacen un esfuerzo para buscar al individuo. \\
Inclusión activa & $\sim$ Los otros dan la bienvenida al individuo (pero no lo buscan). \\
Inclusión pasiva & $\sim$ Los otros permiten entrar al individuo. \\
Ambivalencia & $\sim$ Los otros no se preocupan si el individuo es incluido o excluido. \\
Exclusión pasiva & $\sim$ Los otros no hacen caso del individuo. Lo ignoran. \\
Exclusión activa & $\sim$ Los otros evitan al individuo. \\
Exclusión máxima & $\sim$ Los otros físicamente rechazan, condenan al ostracismo, abandonan o destierran al \\
& individuo.
\end{tabular}

Nota. Fuente: Leary, M. R. (1990). Introduction to behavioral research methods. Belmont, CA: Wadsworth. 
Es necesario recordar que la sociometría es el principal método que nos permite establecer el estatus social del alumnado en el contexto escolar (García y González, 2010). La tipología sociométrica más desarrollada fue la que diferencia entre alumnos promedios, preferidos, rechazados, ignorados y controvertidos (Coie, Dodge y Coppotelli, 1982).

Una línea de investigación a mencionar dentro de la inclusión social del alumnado corresponde al estudio de los motivos o razones que los pares emiten a la hora de aceptar o rechazar a sus iguales. Williams y Asher (1993), en su investigación sobre las razones para el rechazo entre iguales, plantearon que los niños se hacen a sí mismo las siguientes preguntas para decidir si aceptan o no a otros niños: ¿Es divertido estar con este niño?, ¿Nos influimos mutuamente en la dirección que a mí me gusta?, Este niño, ¿es digno de confianza?, ¿Me ayuda a conseguir mis metas?, ¿Me hace sentir bien?, ¿Es similar a mí? Otro trabajo efectuado para conocer los motivos que subyacen en la exclusión social de los niños del primer ciclo de educación primaria es la categorización de los mismos que se recoge en la Tabla 3.

Tabla 3

Categorías y subcategorías de motivos de rechazo

\begin{tabular}{lcc}
\hline \multicolumn{1}{c}{ CATEGORÍAS } & \multicolumn{2}{c}{ Total } \\
\cline { 2 - 3 } & $\mathbf{N}$ & $\mathbf{\%}$ \\
\hline 0. No emiten ninguna razón de rechazo. & 27 &, 9 \\
1. Contra la identidad del individuo o del grupo. & 357 & 12,0 \\
1.1. Contra la identidad relacional del & 228 & 7,7 \\
individuo. & & \\
1.2. Prejuicios sociales. & 129 & 4,4 \\
2. Preferencias y gustos distintos. & 410 & 13,8 \\
3. Conductas sociales y escolares problemáticas. & 467 & 15,8 \\
4. Molesta al bienestar. & 595 & 20,1 \\
5. Dominancia. & 135 & 4,6 \\
5.1. Mandar. & 121 & 4,1 \\
5.2. Prepotente/Chulo. & 14 &, 5 \\
6. Agresión. & 974 & 32,8 \\
6.1. Agresión verbal y gestual. & 109 & 3,7 \\
6.2. Agresión física. & 730 & 24,6 \\
6.3. Intimidación. & 135 & 4,6 \\
\hline
\end{tabular}

Nota. Fuente: Sanahuja, A. (2013). Necesidades básicas y motivos de rechazo de los niños y niñas del primer ciclo de educación primaria. Trabajo de investigación: Universitat Jaume I (material inédito).

De esta investigación se deriva que los motivos más frecuentes que emiten, para manifestar su rechazo, los niños de 7-8 años son: la agresión $(32,8 \%)$ y más concretamente la agresión física. Seguidamente encontramos los motivos referentes a molestar al bienestar $(20,1 \%)$, después conductas sociales y escolares problemáticas $(15,8 \%)$. Otros motivos bastante importantes, pero con frecuencias inferiores son: preferencias y gustos distintos $(13,8 \%)$, seguidos de motivos que van contra la identidad del individuo o del grupo $(12,0 \%)$ y finalmente vemos como la categoría menos nombrada con un 4,6\% corresponde a la de dominancia (Sanahuja, 2013). 
El rechazo entre iguales más que una característica del individuo hay que entenderlo en su contexto interpersonal (Williams, 2001), es por esa razón que no sólo nos tenemos que centrar en lo que hacen o cómo son los niños rechazados, sino que también es importante conocer las conductas que los rechazadores llevan a cabo para manifestar el rechazo (Asher, Rose y Gabriel, 2001). Estos últimos autores mencionados las resumen en: 1) excluir y terminar la interacción; 2) no permitir el acceso; 3) agresión; 4) dominancia; 5) desaprobación moral e 6) involucrar a una tercera parte.

El hecho de conocer los motivos de rechazo o las conductas de los rechazadores tienen implicaciones educativas que pueden ayudar en la elaboración e implementación de programas de intervención (Luca de Tena, Rodríguez y Suerda, 2004) y fomentar en el alumnado la competencia social que permita mejorar la calidad de las relaciones de convivencia en el contexto escolar (Monjas, Suerda y García, 2008). Y es que, tal y como ya se ha apuntado, promover la plena participación social de todo el alumnado es uno de los objetivos centrales de la educación inclusiva. Sin embargo, a menudo, los alumnos con n.e.a.e. incluidos en aulas ordinarias están en riesgo de ser excluidos socialmente por sus compañeros. Así lo evidencia una investigación (Monjas, Martín-Antón, García y Sanchiz, 2014) realizada con alumnado con n.e.a.e., los cuales en comparación con sus compañeros del aula sin n.e.a.e., son más rechazados, tienen peor reputación social, se autoperciben más negativamente, se sienten víctimas de malos tratos y son considerados menos competentes por sus maestros. Además, dicha investigación añade que al comparar alumnos rechazados con y sin n.e.a.e., los primeros tienen peor reputación social y el profesorado les califica más bajo en su competencia social. Garrote y Sermier-Dessemontet (2015), con el fin de lograr la inclusión social del alumnado con n.e.a.e., afirman que se requieren intervenciones en el aula para promover la participación social de todo el alumnado. Estas investigadoras han trabajado sobre un programa de intervención multicomponente que abarca las siguientes estrategias de intervención: 1) proporcionar a los alumnos la oportunidad de aprender habilidades sociales en diadas de aprendizaje entre iguales (nivel individual), 2) forjar una identidad común de grupo mediante la celebración de asambleas regulares para discutir las metas sociales (nivel grupal) y 3) apoyar a los maestros para mejorar sus comentarios (nivel docente). Existen otros estudios que fomentan la inclusión social en el aula a partir de actividades socioemocionales (Roselló, García, Marande, Rubio, Milán y Sanahuja, 2015).

Por consiguiente, es muy importante trabajar en el aula desde el respeto y la tolerancia, así como potenciar un buen clima en ésta que favorezca y propicie la convivencia entre todos sus integrantes. Dos razones de peso para potenciarlo son: 1) los iguales proporcionan apoyo emocional (Bisquerra, 2000) y 2) su influencia se extiende también al desarrollo cognitivo y al ajuste escolar (Gifford-Smith y Brownell, 2003). En palabras de Monjas (2008), la convivencia y el buen clima interpersonal son necesarios para que se produzca el aprendizaje. Una enseñanza en y para la diversidad es el único camino para alcanzar un aprendizaje de los valores fundamentales para la convivencia como son: el respeto, la solidaridad o la tolerancia (Del Carmen, 2000). Kreidler (2007) acuña el concepto de «aula 
pacífica» la cual reúne las siguientes cinco cualidades: 1) cooperación: los alumnos trabajan conjuntamente y manifiestan confianza entre ellos, se ayudan y comparten; 2) comunicación: el alumnado aprende a comunicarse y a escucharse de manera sensible; 3) tolerancia: respeto a la diversidad de sus compañeros; 4) expresión de las emociones positivas: el alumnado aprende a expresar sus sentimientos y autocontrolarse y 5) resolución de conflictos: aprenden habilidades para responder a los conflictos en una comunidad que brinda apoyo y afecto. Además, una investigación sobre resiliencia señala que las relaciones afectuosas, las expectativas elevadas y las oportunidades de participar y contribuir que se ofrece al alumnado en el contexto educativo son los factores fundamentales de su desarrollo (Bernard, 2004).

En suma, se precisa que los alumnos reconozcan y respeten la diversidad de todos los compañeros, desde esta premisa se concibe el aula como un espacio socialmente rico para que el alumnado aprenda a ser y aprenda a vivir conjuntamente (UNESCO, 2015).

\subsubsection{Valores democráticos: hacia una ciudadanía crítica}

Aprender a vivir no es más que aprender a decidir (Cortina, 2007). La democracia es pues, según Dewey (1995), una manera de vivir. Galichet (2002) apunta que un proyecto de educación para la ciudadanía democrática pasa por definir y reconocer la diversidad. En la misma línea, Arnaiz (2005) sostiene que educar para la diversidad se sustenta en una convivencia democrática donde la solidaridad, la tolerancia y la cooperación guíen las relaciones entre el alumnado. Una educación democrática que pretenda el ejercicio de una ciudadanía crítica y activa, debe fomentar la participación democrática para vivir el propio ejercicio de la democracia en el contexto escolar (Bolívar, 2007). Según la literatura consultada podemos diferenciar entre tres tipos de ciudadanía: 1) ciudadanía personalmente responsable: respeto de las leyes y los demás ciudadanos, 2) ciudadanía participativa: engagement hacia los quehaceres sociales y políticos de la comunidad a nivel local, nacional o internacional y 3) ciudadanía orientada hacia la justicia social: preocupación constante por la resolución de situaciones de injusticia (Fillion, Bergeron, Prud'homme y Traver, 2016).

Apple y Beane (1999), referentes clásicos en esta temática, proponen que hay que crear estructuras y procesos democráticos mediante los cuales se configure la vida escolar y un currículum que propicie experiencias democráticas. Por lo que refiere a los procesos de democratización de la escuela, decir que investigadores como Moliner, Traver, Ruiz y Segarra (2016), proponen siete estrategias que posibilitan la construcción de escuelas democráticas, éstas son: 1) propiciar una cultura colaborativa, 2) luchar contra la exclusión y valorar la diversidad, 3) redefinir los valores democráticos, 4) que la comunidad participe y tome decisiones, 5) utilizar la investigación-acción participativa cómo estrategia, 6) autoformación sobre participación democrática y 7) desarrollar proyectos compartidos entre el centro educativo y su territorio. 
Guarro (2005), añade que para que se den procesos democráticos debe prevalecer una cultura colaborativa o cooperativa, este hecho supone la coparticipación, la confianza y el apoyo. Tal y como señalan Ortiz y Lobato (2003), uno de los elementos clave para desarrollar u obstaculizar prácticas inclusivas es la cultura escolar de los centros, ésta debe de caracterizarse por ser innovadora, colaborativa, con un liderazgo inclusivo y vinculada con la comunidad. Estas mismas autoras relacionan las dimensiones de la cultura escolar con la inclusión. Concluyen que en los contextos educativos en los cuales está presente la cultura del cambio existe una colaboración externa (vinculación con la comunidad, que se materializa a partir de la colaboración de las familias y la comunidad) e interna (colaboración) y se propicia la flexibilidad en el uso de estrategias de enseñanza y aprendizaje, de esta manera los docentes cuentan con más recursos para responder a las necesidades de su alumnado. Los elementos que subyacen en una cultura de colaboración docente, son principalmente tres (Escudero, 2006):

1) que los valores, principios y contenidos del currículo democrático sean asumidos y comprometidos por todo el profesorado; 2) que se lleven a cabo dinámicas de trabajo en colaboración que permitan construir tal currículo como un empeño colegiado; 3 ) que la institución escolar, todos y cada uno de los centros, lo asuman como una prioridad colectiva, incluyendo en su empeño a la administración, la comunidad, las familias y diversas fuerzas sociales. (p. 14)

El liderazgo compartido (también denominado: distribuido, inclusivo o democrático), es otro elemento a tener en cuenta en la cultura de cambio (Murillo, 2006) para aquellos contextos escolares que persiguen la inclusión y la democracia. Siguiendo a Robinson, Hohepa y Lloyd (2009) el liderazgo educativo adoptado tiene una gran influencia en los sujetos para hacer cosas que se espera mejoren los resultados de aprendizaje de todos los alumnos. Este tipo de liderazgo, es concebido como más sostenible, contribuye a la mejora de la eficacia de las escuelas, dado que persigue una mejora continua, para abordar la variación dentro de la escuela y para la planificación de la sucesión (OCDE, 2011). Vázquez, Bernal y Liesa (2014), sostienen que los líderes educativos se conciben como: orientadores y guías, con influencia y persuasión, dinamizadores o movilizadores de personas y/o grupos, conocedores de lo pedagógico y curricular y poseedores de una visión. Además, éste debe ser distribuido, democrático y compartido.

Otro elemento importante que nos permite avanzar hacia escuelas inclusivas y democráticas es la participación. El término participar puede tener diferentes connotaciones o grados de implementación para cada individuo. Es por ello que se toma como referencia la definición propuesta por Hart (1993), el cual la entiende como la capacidad para expresar decisiones que sean reconocidas por el entorno social y que afectan a la vida propia y/o a la vida de la comunidad en la que el sujeto vive. Existen numerosos modelos de participación, un trabajo a destacar es la compilación realizada por Karsten (2012), el cual recopila diferentes propuestas de diversos investigadores en su obra «A Potpourri of 
Participation Models». En esta ocasión, nos centramos en la metafórica escalera de participación propuesta por Hart (1993), en la cual recoge diferentes estadios que pasan de una participación simbólica a una participación auténtica. Éste propone tres escalones donde no hay una verdadera participación, éstos son: 1) manipulación (los adultos utilizan a los niños, acciones que no entienden y que responden totalmente a intereses ajenos a los suyos), 2) decoración y 3) participación simbólica o "fachada" (la participación es sólo aparente). Asimismo, propone 5 escalones más donde los niños sí que realizan una auténtica participación, éstos son: 4) asignados, pero informados 5) informados y consultados, 6) decisiones iniciadas por otros adultos, pero con decisiones compartidas con los niños 7) decisiones iniciales y dirigidas por los niños y 8) decisiones iniciadas por los niños, pero coordinadas o compartidas con otros adultos. La participación a distintos niveles (gestión del centro y del aula, de la convivencia, etc.), es un valor de primer orden en una educación democrática (Bolívar, 2016). Continuando con las aportaciones de este mismo autor referenciado, decir que para construir un currículum y una escuela democrática es necesaria la participación, la cual garantiza con eficacia una buena educación para todos los alumnos y contribuye a que éstos puedan ejercer una ciudadanía activa. La participación educativa está asociada, según San Fabián (2005), a la eficacia de los propios procesos educativos, la cual subyace en la mejora de los resultados académicos y en la formación de la ciudadanía.

En síntesis, la educación está obligada a capacitar a los futuros ciudadanos para que puedan ser partícipes activos en la esfera pública sin riesgo de exclusión, lo que supone asegurar que toda la población adquiera aquellas virtudes, conocimientos y habilidades ineludibles para la participación política y la inserción social (Bolívar, 2016). Los alumnos, familias, agentes comunitarios y maestros deben dejar de ser pasivos para adoptar un rol más activo en la esfera escolar y social. Para ello es necesario el trabajo colectivo guiado por los intereses comunes de la comunidad educativa para, de esta manera, sobrepasar terrenos todavía no compartidos ni explorados (Gale y Densmore, 2007).

\subsubsection{Participación y colaboración entre la Escuela-Familias- Comunidad}

En palabras de Luengo (2006), la escuela, la familia y la comunidad son tres ámbitos que según el grado en el que éstos se solapen influirán en mayor o menor medida en la educación del alumnado. Hay que aludir a las notorias contribuciones realizadas por Bronfenbrenner (1979), el cual formuló, desde una perspectiva ecológica, el desarrollo de la conducta humana. Éste concibió un conjunto de estructuras a diferentes niveles (el microsistema, el mesosistema, el exosistema y el macrosistema), en donde cada uno de éstos contiene al otro. El mesosistema hace referencia a la relación entre dos microsistemas (entendido éste como el escenario inmediato que contiene a dicha persona), como por ejemplo las relaciones entre la familia y la escuela. La relación entre ambos microsistemas debe ser de 
coherencia, es decir, una alta calidad de las interacciones familiares normalmente va unida a relaciones positivas del niño en la escuela o con su grupo de iguales (Arranz, 2004).

Y es que, la interrelación escuela-familias-comunidad se piensa indispensable para poder lograr las altas pretensiones que persigue la inclusión, subrayando la importancia de crear una sociedad inclusiva, en la que todos los seres humanos tengan la posibilidad real de participar, crear y contribuir a su desarrollo (Bell et al. 2010; Simón et al. 2016). Al hilo de lo anterior, Calvo, Verdugo y Amor (2016), matizan que para que una educación sea considerada de calidad y sea capaz de formar a ciudadanos comprometidos, propios del siglo XXI, es necesaria la participación activa de todos los miembros y agentes ya mencionados.

Actualmente, la sociedad y la escuela han sufrido numerosos cambios y trasformaciones, pasando de una escasa participación familiar a una participación más activa en el contexto escolar. Vogels (2002), ilustra dicho cambio a partir de los siguientes hitos: 1) padres como consumidores: los padres escogen un tipo u otro de educación según su satisfacción; 2) padres como clientes: los padres entienden a los maestros como expertos, los cuales son los últimos responsables de la educación de sus hijos; 3 ) padres como participantes: las familias se implican en la educación de sus hijos y 4) padres como socios: grado máximo de participación e implicación de las familias en el contexto escolar, los cuales colaboran con los docentes en la educación de sus hijos.

Seguidamente, se realiza un sucinto repaso sobre algunos modelos de participación familiar, considerados más relevantes, en el contexto escolar. Y es que, al igual que en la participación del alumnado (ilustrada anteriormente con las aportaciones de Hart, 1993), también existen diferentes grados o niveles de participación familiar.

En primer lugar, resaltar las aportaciones de Hornby (1990), el cual propone el modelo bipiramidal jerarquizado para explicar la participación entre la familia y la escuela. En dicho modelo se examina la participación desde dos coordenadas: 1) los recursos disponibles y las necesidades percibidas por los familiares a la hora de participar y 2) el tiempo que requieren y que disponen éstos para ejercer la participación, y del grado de especialización que necesitan para tal fin. La primera coordenada se compone por cuatro elementos (de menor a mayor): 1) información: por parte de las familias a los docentes de aspectos relacionados con el menor (p.ej. hechos acontecidos); 2) colaboración: además del anterior los familiares refuerzan en casa los aprendizajes realizados en la escuela; 3) recursos: realizar actividades en la escuela y 4) política: participación en temas decisivos de los padres en el centro escolar. La segunda coordenada se compone por cuatro elementos (de menor a mayor): 1) comunicación: tanto entre la escuela y la familia como entre la familia y la escuela; 2) coordinación padre-profesor: los padres ven necesaria la coordinación para mejorar la coherencia educativa entre los dos entornos; 3) educación familiar; orientación y formación a las familias en su labor docente y 4) apoyo institucional: los familiares son miembros decisorios de la escuela. 
En segundo lugar, mencionar las contribuciones en este campo de Eccles y Harold (1996), los cuales concretan la participación familiar en la escuela a través de cinco categorías: 1) dialogar sobre las acciones que las familias hacen cuando apoyan el aprendizaje de los hijos por petición del maestro (monitoring); 2) las familias efectúan actividades en la escuela (volunteering); 3) llevar a cabo actividades en el hogar por iniciativa de las propias familias (involvement); 4) la familia contacta con el centro escolar de manera voluntaria para informarse de los avances de sus hijos y 5) relación entre familia y escuela para pedir una ayuda puntual.

En tercer lugar, Kohl, Lengua y McMahom (2000) plantean seis modos de llevar a cabo la participación familiar: 1) los padres participan en el contexto educativo; 2) los padres participan en la educación de sus hijos realizando tareas en el hogar; 3) los padres ofrecen apoyo al centro educativo; 4) contacto entre padres y docentes; 5) calidad de la relación entre padres y profesores y 6) percepción por parte de los maestros sobre el rol que ejercen los padres.

Por último, hay que matizar que según lo que se entienda por participación se va a establecer un tipo relacional distinto entre los padres y la escuela (Epstein, 2001). La autora anteriormente citada identifica seis opciones: 1) apoyo o ayuda a los padres en su tarea de crianza de sus hijos (parenting), 2) potenciar la comunicación entre maestros y la familia (communicating), 3) voluntariado de las familias en las actividades que organiza la escuela (volunteering), 4) orientado a desarrollar el aprendizaje en casa bajo las directrices de la escuela (learning at home), 5) implicar a las familias y el alumnado en los órganos de gobierno y gestión de la escuela (decision making) y 6) relaciones que el centro educativo establece en su contexto próximo (collaborating with community).

Según Llevot y Bernad (2015), cuando se hace referencia a la "participación de las familias», principalmente se centraliza en la participación de los padres y madres en el colegio donde están escolarizados sus hijos. No obstante, las personas más mayores también pueden adoptar un papel activo y participar en el contexto escolar, generando interacciones y aportaciones valiosas ${ }^{3}$. De hecho, las relaciones entre jóvenes y mayores es una de las bases de la sociedad inclusiva, la cual suscita el intercambio, el diálogo, el apoyo mutuo y la solidaridad (Delgado-Acosta, Calero-Martín y GonzálezBencomo, 2016). La Organización de las Naciones Unidas (ONU, 2002), en la Segunda Asamblea Mundial sobre el Envejecimiento, se focalizó en la solidaridad intergeneracional para el logro de una sociedad para todas las edades. Entendida ésta como aquella que ajusta sus estructuras y funcionamiento, sus políticas y planes a las necesidades y capacidades de todos, aprovechando por tanto sus posibilidades para beneficio propio, con el objetivo de fortalecer la solidaridad mediante los principios de equidad y reciprocidad entre generaciones. Generalmente, para favorecer la participación social en la cual concurren personas pertenecientes a diferentes generaciones se llevan

\footnotetext{
${ }^{3}$ La razón de aludir, de manera explícita en el marco teórico, las aportaciones y beneficios de la participación de las personas mayores o abuelos en el contexto escolar viene justificado por su gran implicación en dos de las prácticas educativas ilustradas empíricamente en esta tesis doctoral.
} 
a cabo los programas intergeneracionales. Éstos son definidos como los vehículos para el intercambio determinado y continuado de recursos y aprendizajes entre las generaciones más viejas y más jóvenes para lograr beneficios individuales y sociales (McCrea, Weissman y Thorpe-Brown, 2004). Así mismo, ya existen experiencias, en el contexto escolar, que favorecen el encuentro y el intercambio entre los más jóvenes y los más mayores como, por ejemplo, la llevada a cabo por alumnos de primaria y secundaria y miembros de un casal de jubilados, en el llamado teatro intergeneracional (Puigví, Calvó, Posa y Noguer, 2016).

Siguiendo a Johnson (2000), las primeras relaciones sociales se dan, generalmente, en el contexto familiar entre las personas mayores y los niños dándose una interacción bidireccional en la que ambos se implican y se benefician. Las relaciones intergeneracionales tienen un notorio valor en el proceso de socialización, puesto que las personas de mayor edad sirven como modelos de comportamiento cediendo normas, actitudes y valores morales a otros miembros de diferentes generaciones (Kopera y Wiscott, 2000). En palabras de Williams y Nussbaum (2001), la figura del abuelo aporta beneficios en el desarrollo global y en el proceso de socialización de los nietos. Además, el intercambio intergeneracional en la esfera académica, evidencia mejoras en el alumnado en cuanto a su compromiso con la escuela favoreciendo la adquisición de nuevos contenidos y habilidades (Strotmann, 2012). Igualmente, estas relaciones e intercambios también presentan beneficios en las personas mayores. Las relaciones intergeneracionales tienen beneficios en el envejecimiento cognitivo (Whitehouse, 2013) y también derivan beneficios en el bienestar psicosocial (Belgrave, 2011).

Murillo y Krichesky (2015), aluden a diferentes experiencias que contribuyen a fomentar mecanismos que propician el aprendizaje con la comunidad desde múltiples vertientes, éstas son: 1) aprender de la comunidad: invitar a familiares $\mathrm{u}$ otros agentes a que compartan su conocimiento o experiencia en el contexto educativo, 2) aprender con la comunidad: familias y maestros aprenden de manera conjunta sobre una temática (p.ej. curso), 3) aprender para la comunidad: fomentar hábitos y actitudes que propicien una mejor convivencia y la formación de la ciudadanía (p.ej. alumnos mentores, Aprendizaje -Servicio -APS) y 4) aprender cómo comunidad: mejorar la calidad y los resultados de los aprendizajes de todos los alumnos.

Un instrumento de utilidad para conocer las necesidades e identificar las fortalezas y debilidades del centro educativo es el Index for Inclusion (Booth y Ainscow, 2011), el cual incita a la reflexión y a la acción. Concretamente, se identifican en dicha herramienta una serie de indicadores que hacen referencia a la relación familias-escuela-comunidad. Éstos son: A.1.5. Existe colaboración entre profesorado y las familias; A.1.7. Todas las instituciones de la comunidad están involucradas en el centro; A.2.2. El profesorado, los miembros del consejo escolar, el alumnado y las familias comparten una filosofía de inclusión; B.2.4. El código de prácticas se utiliza para reducir las barreras al aprendizaje y la participación de todos los alumnos; C.2.2. Se conocen y aprovechan los recursos de la comunidad. Otras herramientas que pueden ayudar al centro educativo en la reflexión sobre la relación familias-escuela-comunidad son la Guía 
CEIN para la Construcción de la Escuela Intercultural Inclusiva (Sales, Moliner y Traver, 2010) y la Guía ACADI para la autoevaluación de centros en relación a la atención a la diversidad desde una perspectiva inclusiva (Arnaiz y Guirao, 2015).

\subsubsection{La escuela incluida en el territorio}

Tal y como se ha indicado anteriormente, dos de los procesos de democratización de la escuela y con ella de la mejora del centro escolar desde la colaboración y el compromiso con el propio territorio y con sus agentes educativos y comunitarios descansa en: 1) los presupuestos emanados de la investigación-acción participativa (Traver, Sales y Moliner, 2010; Moliner et al. 2016) y 2) a partir de proyectos educativos compartidos entre el centro educativo y su territorio (Moliner et al. 2016). Por ello, se considera de vital importancia establecer y fomentar redes, consorcios y acuerdos entre los centros educativos, las familias y los municipios o localidades donde éstos se inscriben (Luengo, 2006). Para materializar los propósitos de la educación inclusiva y democrática, que se vienen desarrollando, es de vital importancia que la sociedad civil sea partícipe en la escuela y que ésta, a su vez, forme parte de su entorno inmediato en el cual está inscrita, como entidad transformadora y de cambio social.

En palabras de Aguirre, Traver y Moliner (2012) para poder hablar de escuela incluida y de comunidad inclusiva, es necesario potenciar que todas las personas puedan analizar la realidad, se conciencien de lo que les rodea y se enriquezcan de la diversidad. Por ende, hablar de escuela incluida en el territorio pasa por abordar el término de comunidad en su sentido más amplio. Para Jiménez y Pozuelos (2001), este concepto hace referencia al: "barrio, la localidad, el territorio, no es sólo el espacio por el que se transita y se desarrollan nuestras acciones cotidianas es también un entorno educativo y de convivencia..." (p. 13). Dewey (1962), ya hacía mención en sus escritos del importante papel de la comunidad y sus notorias contribuciones en la formación de ciudadanos "cabales".

Según Santos Guerra (2000b), un factor esencial para permitir que escuela y territorio se vinculen, se abran a la vida colectiva y construyan un saber común, es el de permeabilidad. Para ello se necesita, desde un sentido metafórico, que las paredes del centro educativo sean porosas, esponjosas, penetrables. Los centros educativos que favorecen y potencian la participación de las familias y de la comunidad en la que el centro se ubica lo conciben como un elemento no solamente para la calidad, sino que también de calidad. De esta manera, el entorno es entendido como un objeto de aprendizaje, esto es, un contenido más sobre el cual aprender y reflexionar, a la vez es entendido como un recurso didáctico para el propio proceso de enseñanza (Jiménez y Pozuelos, 2001).

Una estrategia que se viene utilizando en el Grupo de investigación Mejora Educativa y Ciudadanía Crítica (MEICRI) es el Diagnóstico Social Participativo (DPS) como una herramienta que brinda espacios de diálogo, reflexión, transformación y concienciación (Aguirre, 2012). En esta línea, encuadramos el “mapeo social participativo", el cual permite extraer un conocimiento exhaustivo de un territorio 
(Habegger y Mancila, 2006). Éste ubicado en una jornada de convivencia, genera un marco de acción que permite movilizar a la comunidad para que ésta examine, analice y reflexione sobre su contexto inmediato y trace las líneas prioritarias en referencia a los recursos educativos disponibles en su territorio (Sales, Traver, Benet y Sanahuja, 2016; Moliner, Sales y Sanahuja, 2017).

Calvo (2012) encuentra una correspondencia directa entre la ciudad y el sistema educativo en cuatro niveles: 1) familia y territorio, 2) escuela y territorio, 3) población y territorio y 4) saber y territorio. Al hilo de lo anterior, nombrar también el concepto de "ciudades educadoras", en éstas, siguiendo a Figueras (2007), se entiende la educación:

En un sentido amplio, que va más allá de las instituciones educativas tradicionales- es un eje fundamental y transversal del proyecto político de la ciudad. La familia y la escuela siguen jugando un papel muy importante, si bien se incorporan nuevos agentes no reconocidos hasta hoy que no sólo transmiten conocimientos sino también educan en valores y comportamientos. (p.25)

Éstas son un referente insoslayable para la función socializadora de la educación, visto que promueven el desarrollo integral de cada persona en concordancia con una mejora global del territorio en el que se asientan (Caballo y Castro, 1995). En suma, la escuela ya no se concibe fuera de su territorio, ésta se piensa como el espacio social en el que se van rompiendo barreras entre el “dentro" y el "fuera" (Aguirre, Sales y Escobedo, 2014).

En este capítulo se ha partido de la figura del maestro y a partir de éste se han ido desarrollando y desmenuzando las diferentes convicciones, elementos o factores que conforman un marco de acción docente que nos permite avanzar hacia una escuela inclusiva y democrática. Pero antes de pasar a abordar el segundo capítulo de esta tesis doctoral se considera interesante terminar reflexionando sobre la manera en que se pueden concretizar todas estas ideas presentadas en las prácticas de aula. Así pues, nos preguntamos ¿qué es un currículum democrático? ¿cómo podemos hacer que el currículum sea democrático y propicie experiencias democráticas en el aula? Zavala (2007) matiza que, mayoritariamente, el currículum es entendido como el programa de estudios, pero le parece más adecuado abordarlo como el conjunto de experiencias que acontecen en el contexto escolar. Este mismo autor añade que de esta manera la escuela y el alumnado enseñan y aprenden mucho más de lo que realmente creen. Ashenden, Blackburn, Hannan y White (1988) indicaron que un currículum democrático debería descansar sobre los siguientes principios: común, cooperativo, útil, inclusivo, práctico, realizable, crítico, moral, planificado y coherente. Según Escudero (2006) un currículum es democrático: 1) si sustenta los valores de justicia social (imperativo social y ético de proveer a todas las personas una buena educación), 2) si los contenidos y los procesos son resultados de la participación, 3) si es 
pensado y establecido a través de procedimientos democráticos de participación y 4) si tiene tensiones y dosis de utopía, pero anclado con realismo en el pasado y el presente del contexto.

En concordancia con todo lo que se viene desarrollando se precisa de nuevas estrategias que faciliten el desarrollo profesional docente (Agencia Europea para el Desarrollo de la Educación del Alumnado con Necesidades Educativas Especiales, 2012), que impliquen el aprender a trabajar juntos y con la comunidad (Nixon, Allan y Mannion, 2001). En todo este proceso cobra una gran importancia el sentido de pertenencia que generan estas experiencias en el individuo, tanto hacia el grupo aula y/o el centro escolar como hacia su territorio más inmediato donde éste se inscribe. De esta manera y siguiendo estos parámetros, las personas aprenden a relacionarse con los demás y aprenden a relacionarse con su entorno (Delval y Lomelí, 2013). 



\section{CAPÍTULO 2}

\section{$\sim$ Diferenciación pedagógica desde una perspectiva inclusiva: de su conceptualización teórica a su puesta en práctica}

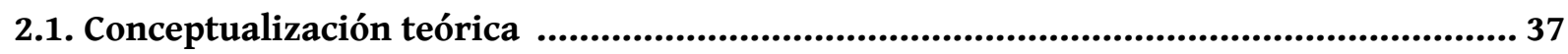

2.1.1. Antecedentes: origen y evolución conceptual............................................... 37

2.1.2. Delimitación conceptual: ¿Qué es la diferenciación pedagógica? .....................47

2.1.2.1. Factores y elementos constituyentes del aula diferenciada...................58

2.1.2.2. Lineamiento y alianzas entre la diferenciación pedagógica y la participación democrática.....................................................................62 62

2.2. Algunas pistas de acción: cómo articular los presupuestos teóricos en la práctica educativa ..............................................................................................................66 6

2.2.1. Organización del aula: diferenciación de las estructuras ..............................6 67

2.2.2. Metodologías didácticas inclusivas y democráticas: diferenciación del contenido y del proceso ....................................................................................... 70

2.2.3. Evaluación inclusiva y democrática: diferenciación del producto ................... 77 


propósito de este capítulo es doble, por una parte se pretende realizar una clarificación conceptual y por otra parte se proyectan algunas pistas teóricas sobre la manera de poner en práctica la diferenciación pedagógica desde una perspectiva inclusiva. En primer lugar, se intenta reconstruir el origen del concepto de diferenciación pedagógica. Este capítulo nos ayuda a entender qué es la enseñanza diferenciada y los principales factores y elementos que la constituyen. Además, se revisan algunos trabajos que abordan la vinculación entre la diferenciación pedagógica y la participación democrática. El capítulo aporta algunas pistas de actuación para materializar en el aula los presupuestos teóricos. Para ello, se hace un sucinto repaso sobre los principales elementos que están presentes en la organización del aula inclusiva y democrática. Se abordan aspectos organizativos como los referentes a la tipología de agrupamientos, modalidades de trabajo, a la gestión del tiempo y los espacios físicos del aula y los recursos: personales y materiales (diferenciación de las estructuras). Se presentan las principales metodologías didácticas que se caracterizan por respetar los diferentes ritmos y la voz del alumnado (diferenciación del contenido y del proceso). Se concluye el capítulo con la evaluación inclusiva y democrática (diferenciación del producto).

\subsection{Conceptualización teórica}

\subsubsection{Antecedentes: origen y evolución conceptual}

Según establecen Zakhartchouk (2001) y Perrenoud (2007b) reconstruir el camino de las representaciones y prácticas de la diferenciación pedagógica no es una tarea sencilla, puesto que nos encontramos ante una evolución paralela de perspectivas teóricas y militantes (p.ej. individualización y personalización de la enseñanza). Seguidamente, en la Figura 1, se intentan plasmar algunos de los principales hitos históricos que nos permiten comprender y conocer el origen y evolución de esta perspectiva educativa. 


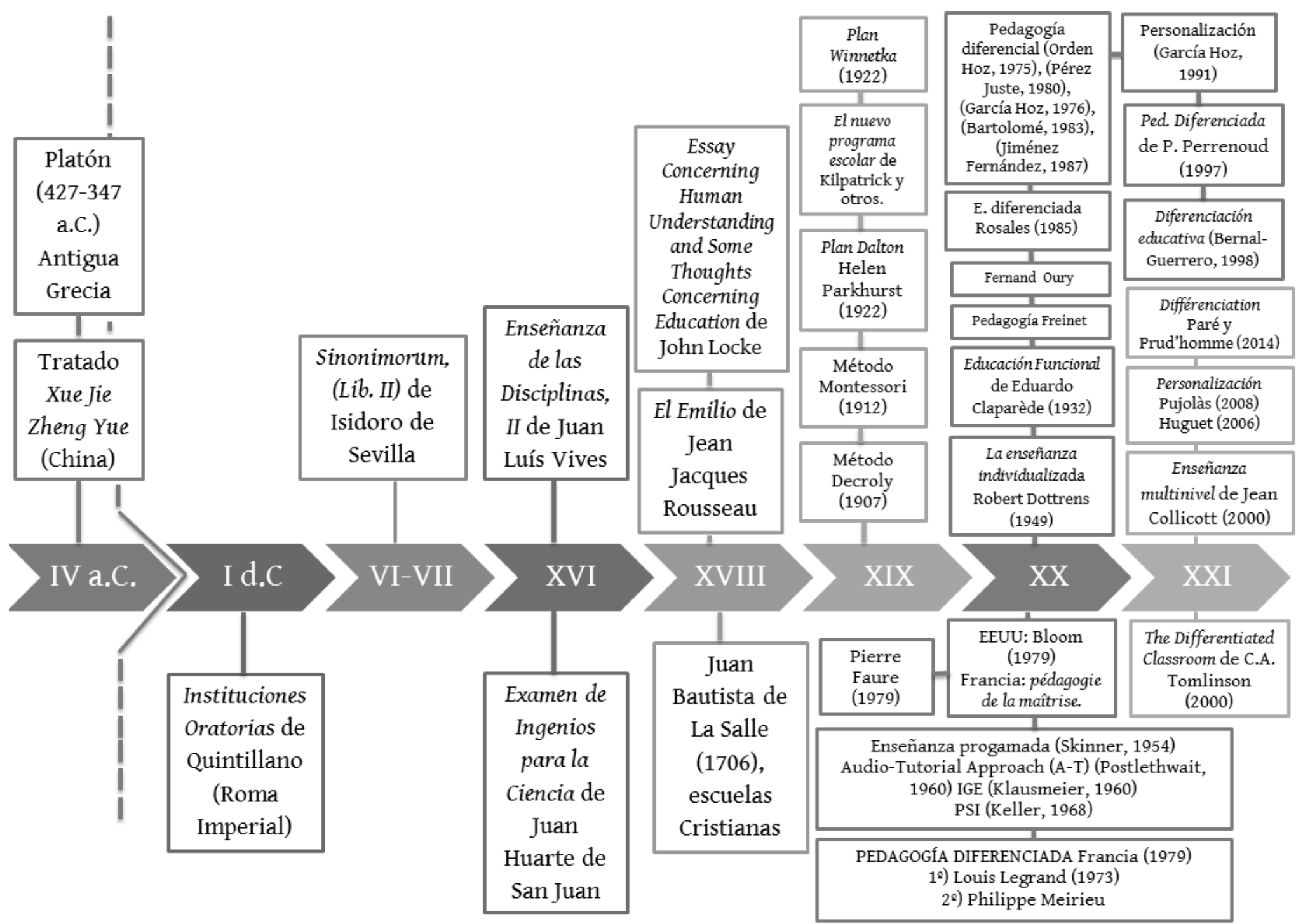

Figura 1. Origen y evolución de las representaciones y prácticas de diferenciación pedagógica. Nota. Elaboración propia a partir de la literatura consultada. 
La idea de adaptar la enseñanza en función de las características del alumnado para suscitar su aprendizaje no es una intención nueva, en palabras de Guay (2007), existen indicios de que ya estaba presente en el siglo IV a.C. en el Tratado Xue Jie Zheng Yue (China). Asimismo, en los tiempos en los cuales la educación era privilegio de los hombres libres como en la antigua Grecia, pensadores como Platón (427-347 a.C.) propugnaban una educación diferenciada que tuviera en cuenta las capacidades innatas de los sujetos, de modo que pasasen a formar parte del estamento de los filósofos, los militares o los artesanos (Jiménez Fernández y González Galán, 2011). Esta idea también se encuentra recogida, según indican Corno y Snow (1986), en los escritos de Romain Quintillien, el siglo I d.C., en su libro De Institutione Oratoria. Quintiliano (39-95d.C.) aconsejaba al profesor adaptarse a los talentos de cada alumno, dando especiales orientaciones para la educación de lo que serían los regidores de la res pública. Entre los siglos VI y VII, la figura de Isidoro de Sevilla (Sinonimorum, Lib. II) también podía ser considerada, según Bernal-Guerrero (1998), referente de esta preocupación diferencial. Siguiendo con las indicaciones de este último autor citado, precursores del principio pedagógico de la diferenciación educativa mucho más cercanos a nuestros tiempos (siglo XVI) son: Juan Luis Vives (Enseñanza de las Disciplinas, II), quien hablaba explícitamente de la orientación de los niños en función de sus aptitudes y de la conveniencia de examinar los ingenios antes de realizar la enseñanza. Y el médico Juan Huarte de San Juan, autor de Examen de Ingenios para las Ciencias, obra predecesora de la orientación profesional.

Si pasamos al siglo XVIII, es necesario mencionar la figura de John Locke por sus conocidas obras Essay Concerning Human Understanding y Some Thoughts Concerning Education. Hay que destacar también a Jean Jacques Rousseau por su trabajo titulado El Emilio (Bernal-Guerrero, 1998). Los escritos de Juan Bautista de La Salle (siglo XVIII, hacia el año 1706), son otra contribución que no hay que pasar por alto en esta reconstrucción, éste trabajó en escuelas cristianas en Francia, sus aportes reflejaban la preocupación de los pedagogos de la época por diferenciar la enseñanza (Meirieu, 1997; Guay, 2007).

Según indica Guay (2007), el Método Decroly (1907) también se asienta sobre las bases de la diferenciación pedagógica, dado que éste tomó en consideración las necesidades del niño, este hecho permite conocer sus intereses para atraerlo y, de esta forma, mantener su atención hacia la adquisición del nuevo conocimiento. Otro tributo a este campo fueron las referentes al método Montessori de educación diferencial (Orem, 1980).

Dos obras básicas, según Cousinet (1972), sobre el trabajo individualizado son: El nuevo programa escolar de Kilpatrick, Rugg, Washburne y Bonner y Education on the Dalton Plan (1922) desarrollado entre los siglos XIX-XX por Helen Parkhurst. Los aspectos más relevantes a destacar del Plan Dalton se pueden resumir en las siguientes: la libertad en la elección del trabajo en relación a un plan predeterminado, el respeto al ritmo e interés de cada alumno, los laboratorios de trabajo, contratos de trabajo escolar para cumplir los mínimos establecidos, el uso de materiales, el docente como orientador o asesor, entre otros (Parkhurst, 1922). Otro plan menos conocido, y que también 
contribuyó a la historia de la diferenciación pedagógica según Guay (2007), es el que planteó Carleton Washburne (1922) denominado Plan Winnetka. Éste se caracteriza por su flexibilidad, consta de un programa donde se combinan estímulos morales, intelectuales y afectivos. También se caracteriza por centrarse en las preferencias e intereses del alumnado, se potencia la autocorrección y la autoevaluación, principios que descansan en la autoinstrucción.

Sin embargo, Perrenoud (2007b) recalca que la pedagogía diferenciada tiene sus raíces en instituciones muy antiguas que desarrollaron los primeros movimientos de educación moderna. Este mismo autor mencionado, al igual que Meirieu (1997), subrayan las relevantes aportaciones de autores como Dottrens (1949), Claparède (1932) y Freinet (1966). Se pasa, a continuación, a realizar un breve repaso sobre las principales contribuciones de dichos autores.

Robert Dottrens (1949), en su libro La enseñanza individualizada, explicó que sus técnicas se basaban en dos ideas esenciales: libertad individual y el trabajo a la medida del alumno. Dicha libertad individual, no significaba dejar hacer al niño lo que le plazca, sino hacer un trabajo que permita al niño liberarse de todas sus trabas, desarrollarse, progresar a su ritmo. Parece interesante remarcar la distinción que el autor realiza entre el trabajo individual o personal y el trabajo individualizado:

El trabajo individual ha sido practicado en las clases en todos los tiempos. Después de la lección colectiva, cada niño ejecuta los ejercicios de aplicación por cuenta propia, e incluso con prohibiciones, bajo amenazas de castigo de hacerse ayudar o de ayudar. Pero en ese caso se trata de un trabajo impuesto: para todos la misma tarea, cualesquiera sean el nivel de la inteligencia, el grado de comprensión, el desarrollo de las aptitudes y el ritmo de trabajo. Ninguna posibilidad de elección. [...] Para nosotros, el trabajo individualizado no consiste en hacer ejecutar individualmente el mismo trabajo a todos, sino en escoger para cada uno el trabajo particular que le conviene. Tampoco consideramos el trabajo individualizado como un objetivo en sí mismo, sino como un medio utilizable, conjuntamente con otros, para asegurar al niño un desarrollo normal y una mejor formación de su espíritu. (p. 13-14)

Dottrens (1949), también hacía hincapié en la importancia de la enseñanza colectiva. El autor remarcaba que una educación a la vez colectiva e individualizada era, pues, la que mejor respondía a los intereses del individuo y de la sociedad, la que confiaba al educador mayor seguridad y eficiencia.

Según García Hoz (1981), el término de enseñanza individualizada es un intento de armonizar la enseñanza individual (la cual ofrece la posibilidad de una atención constante a las dificultades y posibilidades especiales que el alumno encuentra en el proceso educativo) y la enseñanza colectiva (la cual ofrece la posibilidad de socialización de los escolares y representa una mayor economía en tiempo y esfuerzo). 
Por su parte Claparède (1932), centró su trabajo en la educación funcional, la cual tomaba las necesidades del niño y su interés para alcanzar un fin. Este autor ya hablaba de acercarse cada vez más al ideal de la escuela a la medida, teniendo en cuenta las aptitudes individuales de sus integrantes. Expuso, después de sus trabajos de observación, que el individuo no rinde más que en la medida de sus capacidades naturales y que se pierde el tiempo en el empeño de desarrollar en él capacidades que no posee.

Muchas han sido las aportaciones y contribuciones de la pedagogía Freinet. Elise Freinet (2005), apuntaba que ante la escuela que pretende ser homogénea causante del fracaso escolar, surge la necesidad de una escuela que apoye la diferencia y permita una práctica pedagógica diversificada que reconozca las distintas potencialidades de todo el alumnado. La Pedagogía Freinet promueve una enseñanza que respete a los individuos, su ritmo de aprendizaje y su cultura. De esta manera, ofrece a cada cual la posibilidad de desarrollar sus capacidades mediante una pedagogía basada en el logro. Promulga que esta nueva escuela es posible a través de los equipos pedagógicos, que desarrollan una pedagogía cooperativa, garantizan la continuidad pedagógica otorgando una mayor seguridad a la persona, y favorecen la autonomía de los individuos y de los grupos, lo que propicia una reducción del fracaso escolar. Fernand Oury fue otro precursor, según Meirieu (1997), el cual se esforzó por instrumentalizar esta idea. Concretamente, éste profundizó en la puesta en práctica de las técnicas Freinet.

Posteriormente, según Anderson (1994), hay que esperar hasta mediados de la década de los 60 y de los 70, para ver el desarrollo de otros modelos bajo la influencia de la genética y la psicología diferencial y los valores sociales dominantes como son la democracia y la igualdad. Autores como Astolfi (2004), consideran la pedagogía diferenciada como una variante de la pédagogie de la maitrise (pedagogía por objetivos). Bloom (1979) ha sido el principal precursor de la taxonomía de objetivos de la educación. En Bélgica, los trabajos referentes a la diferenciación pedagógica concernieron a varios legados. Destacar la influencia derivada del constructivismo piagetiano, cercano a corrientes de la escuela activa, los cuales descansaban en dispositivos orientados por objetivos y en una evaluación formativa (Perrenoud, 2007b).

Siguiendo con la evolución y avanzando en el tiempo, distintos métodos de individualización fueron desarrollados (Guay, 2007). Destacar la enseñanza programada (Programmed Instruction; Enseignement programmé) propuesta por Skinner (1954). Éste diseñó una máquina de enseñanza, que utilizaba los principios de conducta para mejorar el proceso de aprendizaje de conceptos académicos. Consistía en diseñar un programa educativo individualizado, definiendo objetivos, tareas y actividades para trabajar determinados contenidos didácticos. Destacar también Individually Guided Instruction (IGE), que surgió desde la psicología educativa y se desarrolló entre los años 60 y 70 . Este acercamiento implicaba la diferenciación, la agrupación multi-edad y la participación directa en la planificación, implementación y evaluación de las actividades escolares. Entre sus principales 
componentes destacan: 1) la organización de la escuela multiunitaria; 2) la instrucción programada al individuo; 3) la evaluación para la toma de decisiones educativas; 4) los materiales curriculares compatibles con la enseñanza y la evaluación; 5) las relaciones entre casa- escuela- comunidad; 6) el entorno y 7) el desarrollo continuado de la investigación (Wiersma, 1986). Hay que mencionar también el audio-Tutorial Approach (A-T). Este enfoque fue desarrollado para enfrentarse a la diversidad entre estudiantes. Conserva atributos importantes como el contacto personal entre alumno - maestro, pero ante las clases crecientes empleaba dispositivos de comunicación para proporcionar mejores oportunidades de aprendizaje. Se valían del uso de cintas donde se registraban explicaciones suplementarias para los estudiantes más lentos. El sistema desarrolló una serie de explicaciones/conferencias con experiencias integradas, juegos, demostraciones, experimentos y otras actividades de utilidad para la comprensión de los contenidos (Postlethwait, 1966; Meierhenry y Postlethwait, 1966). Por último, otro método a destacar es el Personalized System of Instruction - PSI. Éste fue diseñado con la intención de lograr mejoras en el aprendizaje del alumnado y estaba compuesto por unidades moduladas donde las guías de estudio dirigían al alumnado por los diferentes módulos. Keller (1968), describió las operaciones del sistema en un aula real. Esto condujo a una creciente investigación sobre PSI, las cuales concluyeron que este método era más eficaz respecto a la instrucción más tradicional.

En los EE.UU., el interés en los modelos de educación individual decae a finales de 1970 (Anderson, 1994). Mientras que en Francia el término de pedagogía diferenciada, se adoptó oficialmente en 1979. Según Aylwin (1992), fue introducido por Louis Legrand (hacia el año 1973) y posteriormente por Philippe Meirieu para resaltar las diferencias que existían entre los alumnos. Aylwin indica que la pedagogía diferenciada se corresponde con el vocablo clásico de enseñanza individualizada, aunque sus propulsores tienen un especial interés en remarcar las diferencias presentes no sólo en los individuos sino también en los subgrupos.

Meirieu (1997), señala la proximidad entre la pedagogía diferenciada y lo que Pierre Faure (1979) denominaba "enseignement personnalisé et communautaire", éste sugería la necesidad de, como mínimo en una parte del tiempo escolar, romper con la dinámica impositivo-colectivo de la clase centrada en la homogeneidad para pasar a actividades individuales y de pequeños grupos permitiendo a los alumnos ser activos e implicarse en una enseñanza a su medida.

Philippe Meirieu (1997), también se hace eco de como la pedagogía diferenciada se ha ido nutriendo de las aportaciones de diferentes corrientes o perspectivas educativas:

[...] la pedagogía diferenciada ha aparecido como un pensamiento al mismo tiempo de síntesis y de apertura: integraba las aportaciones de las diferentes corrientes pedagógicas $\mathrm{y}$, sin negar su especificidad ni travestir sus propuestas, permitía hacerlas coherentes al servicio de los alumnos. Reconocía sus deudas y cultivaba el préstamo pero sin por ello caer en una mezcolanza heteróclita: una filosofía del "alumno como 
sujeto", una pedagogía de la autonomía como capacidad de guiar uno mismo, progresivamente, sus propios aprendizajes, una concepción de las relaciones sociales que deberían ser, a la vez, reconocimiento de la diversidad y búsqueda de la solidaridad, promoción de lo que especifica y búsqueda de lo que une... Todo ello permitía inscribir instrumentaciones a veces ya existentes en una "ética pedagógica" que les otorgaba, sin duda, más peso y más sentido. (p. 194-195)

En el contexto español, se detecta cómo Rosales (1985) realiza sus aportaciones en el sentido de la enseñanza diferenciada como un concepto renovado. Éste se apoya en que el concepto vuelve a suscitar interés bajo las siguientes cuatro iniciativas: 1) enseñanza para el dominio (basado en teorías instructivas de autores como Bruner, Carroll y Bloom), 2) enseñanza en equipo (variada posibilidad de agrupamientos de los alumnos en función de las diversas actividades y de la utilización de los distintos medios), 3) evaluación formativa e 4) investigación activa (proceso de acomodación continua de la metodología de enseñanza a las condiciones y características de partida del alumnado). También se localizan algunas referencias sobre pedagogía diferencial (Orden Hoz, 1975; Pérez Juste, 1980; García Hoz, 1976; Bartolomé, 1983; Jiménez Fernández, 1987) y sobre diferenciación educativa (BernalGuerrero, 1998). Por tanto, otro concepto afín que parece emerger y compartir en su base el mismo propósito que la diferenciación y la individualización es el de personalización (García Hoz, 1981). Este concepto será, en nuestros días, empleado por Pujolàs (2008) para ajustar la acción educativa a la heterogeneidad del aula y por Huguet (2006) reforzando la idea de una educación enmarcada en el grupo- clase. Existen indicios que la enseñanza multinivel definida por Collicott (2000), es otro constructo que se apoya en las mismas bases o perspectivas educativas que se vienen desmenuzando. Hay que subrayar que Collicott le da una gran relevancia a presentar las actividades siguiendo la Taxonomía aportada por Benjamin Bloom (1979). Jean Collicott (2000) la define como:

La enseñanza multinivel se basa en la premisa de que una lección debe enseñarse al conjunto de la clase. Es una aproximación a la planificación que asume la individualización, la flexibilidad y la inclusión de todos los alumnos, sin distinción de su nivel personal de habilidades. La enseñanza multinivel permite que el maestro planifique una lección para todos los alumnos, y así disminuye la necesidad de seguir programas diferentes, y a la vez posibilita la introducción de objetivos individuales en el conjunto de las estrategias educativas del aula. (p.87)

Resulta llamativo que, desde el contexto español, para Calderero, Aguirre, Castellanos, Peris y Perochena (2014) la educación personalizada sea una concepción abordada desde la teoría y la práctica por autores precursores como: Claparède, Dottrens (1973), Parkhurst con el ya mencionado "Plan Dalton", Washburne con del denominado "Plan Winnetka" en 1922, Keller, Faure hasta llegar a la alusión de los escritos de García Hoz. Este hecho es otro indicio de cómo existen diferentes perspectivas militantes que se van nutriendo unas de otras. 
Avanzando cronológicamente, y en el ámbito internacional, no podemos pasar por alto las notorias aportaciones en el campo de la diferenciación educativa introducidas por Perrenoud (1997), Tomlinson (2000) y Paré y Prud'homme (2014). Estos dos últimos investigadores canadienses abordan la diferenciación pedagógica desde una perspectiva inclusiva.

A pesar de que, al intentar reconstruir el origen y la evolución del concepto de diferenciación pedagógica nos hemos encontrado con otros términos afines, se puede comprobar en la literatura (Fletcher, 1992) cómo los autores franceses van distanciando cada vez más el término de diferenciación pedagógica de los términos de educación individualizada o individualización, visto que éstos últimos se asocian a los modelos estadunidenses de 1960. Por ejemplo, Astolfi (2004) subraya la idea de que practicar la diferenciación pedagógica no implica preparar diferentes actividades de aprendizaje para cada uno de los 30 alumnos del grupo, ni la idea de identificar, con certeza, en cada instante, la solución óptima para permitir a cada uno el aprendizaje. En la misma dirección Tomlinson (2005), desde el ámbito anglófono, especifica que la pedagogía diferenciada no es la enseñanza individualizada de los años 70, en la que se trataba de hacer algo distinto para cada uno de los alumnos que había en el aula.

Por lo que se desprende de los diferentes aportes recogidos, parece haber indicios que, sobre la base de cada una de estas corrientes, e independientemente de cada uno de los matices o sentidos aportados por los diferentes estudiosos, radica la idea de respetar al individuo (individualización), la persona (personalización) y la diversidad o la diferencia existente en el aula (diversificación o diferenciación) para permitir a todos los sujetos progresar en su propio proceso de aprendizaje. No obstante, Bray y McClaskey (2012) recogen las diferencias entre los términos: personalización, diferenciación e individualización, basándose en el Education Technology Plan (2010) propuesto por el departamento de educación de EE.UU. (Ver Tabla 4). 
Tabla 4

Clarificación conceptual: Individualización vs. Diferenciación vs. Personalización

\section{INDIVIDUALIZACIÓN}

Se refiere a la enseñanza que se acomoda a las necesidades de aprendizaje de los diferentes alumnos. Los objetivos de aprendizaje son los mismos para todos los estudiantes, pero éstos pueden progresar, a través del material que se les ofrece, a diferentes velocidades de acuerdo a sus necesidades de aprendizaje. Por ejemplo, los estudiantes pueden invertir más tiempo para avanzar en un tema determinado, omitir temas que cubren la información que ya conocen, o repetir temas para los que necesitan más tiempo.

\section{DIFERENCIACIÓN}

Se refiere a la enseñanza que se adapta a las preferencias de aprendizaje de los diferentes alumnos. Los objetivos de aprendizaje son los mismos para todos los estudiantes, pero el método o enfoque de la enseñanza varía de acuerdo a las preferencias de cada alumno o lo que la investigación ha encontrado que funciona mejor para los estudiantes concretos.

\section{PERSONALIZACIÓN}

Se refiere a la enseñanza que se acomoda a las necesidades de aprendizaje de acuerdo con las preferencias y los intereses específicos de los diferentes alumnos. En un entorno que está totalmente personalizado, los objetivos de aprendizaje y contenidos, así como el método y ritmo pueden variar mucho (la personalización abarca la diferenciación e individualización).

Nota. Fuente: Bray, B., \& McClaskey, K. (2012). Personalization vs Differentiation vs Individualization.

https://education.alberta.ca/media/3069745/personalizationvsdifferentiationvsindividualization.pdf

En el informe Personalization vs. Differentiation vs. Individualization efectuado por Barbara Bray y Kathleen McClaskey, co-fundadoras de Personalize Learning. Transfrom learning for All Leraners, apuntan lo que caracteriza cada una de estas tres corrientes (Ver Tabla 5). 
Tabla 5

Individualización vs. Diferenciación vs. Personalización

\begin{tabular}{|c|c|c|}
\hline $\begin{array}{c}\text { INDIVIDUALIZACIÓN } \\
(\text { El maestro...) }\end{array}$ & $\begin{array}{l}\text { DIFERENCIACIÓN } \\
(\text { (El maestro...) }\end{array}$ & $\begin{array}{l}\text { PERSONALIZACIÓN } \\
\text { (El alumno...) }\end{array}$ \\
\hline $\begin{array}{l}\text { Ofrece enseñanza a un alumno en } \\
\text { particular. }\end{array}$ & $\begin{array}{l}\text { Ofrece enseñanza a un grupo de } \\
\text { estudiantes. }\end{array}$ & Conduce su propio aprendizaje. \\
\hline $\begin{array}{l}\text { Se acomoda a las necesidades de } \\
\text { aprendizaje de un alumno } \\
\text { singular. }\end{array}$ & $\begin{array}{l}\text { Se ajusta a las necesidades del grupo } \\
\text { de alumnos. }\end{array}$ & $\begin{array}{l}\text { Concreta su aprendizaje con sus } \\
\text { intereses, pasiones } \\
\text { aspiraciones. }\end{array}$ \\
\hline $\begin{array}{l}\text { Adapta la enseñanza de acuerdo } \\
\text { con las necesidades individuales } \\
\text { de aprendizaje. }\end{array}$ & $\begin{array}{l}\text { Diseña la enseñanza basándose en las } \\
\text { diferentes necesidades de aprendizaje } \\
\text { del grupo de alumnos. }\end{array}$ & $\begin{array}{l}\text { Participa activamente en el } \\
\text { diseño de su aprendizaje. }\end{array}$ \\
\hline $\begin{array}{l}\text { El maestro es el responsable de } \\
\text { modificar la enseñanza } \\
\text { basándose en las necesidades de } \\
\text { cada aprendiz en particular. }\end{array}$ & $\begin{array}{l}\text { El maestro crea o adapta la enseñanza } \\
\text { y escoge diversos roles o modos de } \\
\text { enseñanza para diferentes grupos de } \\
\text { aprendices. }\end{array}$ & $\begin{array}{l}\text { El alumno tiene voz y capacidad } \\
\text { de elección respecto a cómo y } \\
\text { qué aprender. }\end{array}$ \\
\hline $\begin{array}{l}\text { Mismos objetivos para todos los } \\
\text { estudiantes, con objetivos } \\
\text { específicos para aquellos } \\
\text { estudiantes que reciben apoyo } \\
\text { uno-uno. }\end{array}$ & $\begin{array}{l}\text { Mismos objetivos para un grupo de } \\
\text { estudiantes. }\end{array}$ & $\begin{array}{l}\text { Diferentes objetivos para cada } \\
\text { alumno. }\end{array}$ \\
\hline $\begin{array}{l}\text { Selecciona la tecnología y los } \\
\text { recursos que apoyan las } \\
\text { necesidades de aprendizaje de un } \\
\text { alumno singular. }\end{array}$ & $\begin{array}{l}\text { Selecciona la tecnología y los } \\
\text { recursos que apoyan las necesidades } \\
\text { de aprendizaje de diferentes grupos } \\
\text { de alumnos. }\end{array}$ & $\begin{array}{l}\text { Selecciona la tecnología y los } \\
\text { recursos que apoyan y mejoran } \\
\text { su aprendizaje. }\end{array}$ \\
\hline $\begin{array}{l}\text { Los aprendizajes dependen de las } \\
\text { orientaciones y apoyos ofrecidos } \\
\text { por el docente. }\end{array}$ & $\begin{array}{l}\text { Los aprendizajes dependen de los } \\
\text { pares, maestros y otros que guían y } \\
\text { apoyan su aprendizaje. }\end{array}$ & $\begin{array}{l}\text { El alumno establece una red de } \\
\text { compañeros, expertos y } \\
\text { profesores que guían y apoyan su } \\
\text { aprendizaje. }\end{array}$ \\
\hline $\begin{array}{l}\text { Se basa en un sistema cerrado de } \\
\text { tiempo y nivel escolar. }\end{array}$ & $\begin{array}{l}\text { Se basa en un sistema cerrado de } \\
\text { tiempo y nivel escolar. }\end{array}$ & $\begin{array}{l}\text { El alumno demuestra el dominio } \\
\text { del contenido en un sistema } \\
\text { basado en el desarrollo y } \\
\text { adquisición de competencias. }\end{array}$ \\
\hline Evaluación del aprendizaje. & Evaluación para el aprendizaje. & Evaluación como aprendizaje. \\
\hline $\begin{array}{l}\text { La evaluación es sumativa, se } \\
\text { basa en pruebas e implica } \\
\text { tiempo, está basada en los datos } \\
\text { que confirman los saberes } \\
\text { adquiridos o no. }\end{array}$ & $\begin{array}{l}\text { La evaluación implica tiempo y } \\
\text { pruebas, los maestros proporcionan } \\
\text { retroalimentación a los alumnos para } \\
\text { avanzar en los aprendizajes. }\end{array}$ & $\begin{array}{l}\text { Los docentes desarrollan la } \\
\text { capacidad en los alumnos de ser } \\
\text { independientes, los cuales } \\
\text { establecen los objetivos, } \\
\text { tutorizan el progreso y } \\
\text { reflexionan sobre el aprendizaje. }\end{array}$ \\
\hline
\end{tabular}

Nota. Fuente: Bray, B., \& McClaskey, K. (2012). Personalization vs Differentiation vs Individualization. https://education.alberta.ca/media/3069745/personalizationvsdifferentiationvsindividualization.pdf

En este trabajo nos preocupamos y ocupamos de qué manera el docente articula la enseñanza en el aula para hacer frente a la heterogeneidad del grupo clase, por tanto, nos centramos en el término de diferenciación pedagógica entendida esta desde una perspectiva inclusiva y democrática. 


\subsubsection{Delimitación conceptual: ¿Qué es la diferenciación pedagógica?}

Para poder ver más claramente qué es la diferenciación pedagógica nos apoyaremos en la revisión de algunas de las diferentes definiciones empleadas por los estudiosos de este campo. A continuación, se recogen dichas definiciones clasificadas según el origen de procedencia (literatura francófona, literatura anglófona y literatura hispánica), el autor y el año, así como el término o la denominación utilizada. En la Tabla 6, se presentan algunas de las definiciones más características del vocablo, procedentes de la literatura francófona.

Tabla 6

Revisión de algunas definiciones: literatura francófona

\begin{tabular}{|c|c|c|}
\hline \multicolumn{3}{|r|}{ LITERATURA FRANCÓFONA } \\
\hline AUTOR Y AÑO & TÉRMINO & DEFINICIÓN \\
\hline $\begin{array}{l}\text { Raymond } \\
\quad(1989)\end{array}$ & $\begin{array}{l}\text { différencier la } \\
\text { pédagogie }\end{array}$ & $\begin{array}{l}\text { Es un enfoque que busca poner en ejecución un conjunto diversificado } \\
\text { de medios, de procedimientos de enseñanza y de aprendizaje, con el fin } \\
\text { de permitir a los alumnos con edades, aptitudes, comportamientos, } \\
\text { destrezas heterogéneas pero reagrupados en la misma división, } \\
\text { alcanzar, por diferentes vías, los objetivos comunes, o en parte } \\
\text { comunes. }\end{array}$ \\
\hline $\begin{array}{c}\text { Aylwin } \\
(1992)\end{array}$ & $\begin{array}{l}\text { pédagogie } \\
\text { différenciée }\end{array}$ & $\begin{array}{l}\text { Una pedagogía diferenciada ofrece simultáneamente actividades de } \\
\text { aprendizaje tan diversas como lo exige la variedad de las diferencias } \\
\text { presentes en el grupo. }\end{array}$ \\
\hline $\begin{array}{l}\text { Fresne } \\
(1994)\end{array}$ & $\begin{array}{l}\text { pédagogie } \\
\text { différenciée }\end{array}$ & $\begin{array}{l}\text { Una práctica de enseñanza que se basa en las diferencias inter- } \\
\text { individuos y que intenta organizar los aprendizajes teniendo en cuenta } \\
\text { a cada uno de ellos. }\end{array}$ \\
\hline $\begin{array}{l}\text { Legrand } \\
\text { (1995) }\end{array}$ & $\begin{array}{c}\text { différenciations de la } \\
\text { pédagogie }\end{array}$ & $\begin{array}{l}\text { Son todas las acciones o métodos diversos que se utilizan para } \\
\text { satisfacer las necesidades de los alumnos. }\end{array}$ \\
\hline $\begin{array}{c}\text { Meirieu } \\
(1996)\end{array}$ & $\begin{array}{l}\text { pédagogie } \\
\text { différenciée }\end{array}$ & $\begin{array}{l}\text { Un proceso mediante el cual el profesor multiplica las oportunidades } \\
\text { de aprendizaje basándose en las diversidades. }\end{array}$ \\
\hline $\begin{array}{l}\text { Perrenoud } \\
\quad(1996)\end{array}$ & $\begin{array}{l}\text { différenciation de } \\
\text { l'enseignement }\end{array}$ & $\begin{array}{l}\text { Actuar de modo que cada alumno se encuentre, lo más frecuente que se } \\
\text { pueda, en situaciones de aprendizaje productivas para él. }\end{array}$ \\
\hline $\begin{array}{l}\text { Fournier } \\
\text { (1996) }\end{array}$ & $\begin{array}{l}\text { pédagogie } \\
\text { différenciée }\end{array}$ & $\begin{array}{l}\text { Para los maestros que promueven esta práctica, diferenciar no es } \\
\text { repetir de otra manera, consiste en variar lo máximo posible las } \\
\text { acciones, para que cada uno pueda encontrar, en un momento u otro } \\
\text { del transcurso, las situaciones en las cuales mejor pueda progresar. }\end{array}$ \\
\hline $\begin{array}{l}\text { Perraudeau } \\
\quad(1997)\end{array}$ & $\begin{array}{l}\text { différenciation } \\
\text { pédagogique }\end{array}$ & $\begin{array}{l}\text { Diversificación de los apoyos y de las maneras de aprender para un } \\
\text { grupo de alumnos con necesidades heterogéneas, pero con objetivos } \\
\text { comunes. }\end{array}$ \\
\hline $\begin{array}{l}\text { Caron } \\
(2003)\end{array}$ & $\begin{array}{l}\text { différenciation des } \\
\text { apprentissages }\end{array}$ & $\begin{array}{l}\text { Un modo de aprender de las diferencias, de vivir con ellas, de } \\
\text { explotarlas y de sacarles el máximo partido. }\end{array}$ \\
\hline $\begin{array}{l}\text { Przesmycki } \\
\quad(2004)\end{array}$ & $\begin{array}{l}\text { pédagogie } \\
\text { différenciée }\end{array}$ & $\begin{array}{l}\text { La pedagogía diferenciada se inscribe en un enfoque colectivo de la } \\
\text { enseñanza del saber y saber hacer (destrezas) comúnmente exigidas. }\end{array}$ \\
\hline $\begin{array}{l}\text { Legendre } \\
(2005)\end{array}$ & individualisation & $\begin{array}{l}\text { Un principio y una práctica en la que se recomienda que las actividades } \\
\text { de planificación y de enseñanza respeten las diferentes características } \\
\text { de los alumnos, importantes para su éxito en el aprendizaje. }\end{array}$ \\
\hline $\begin{array}{l}\text { Guay, Legault } \\
\& \text { Germain } \\
\quad(2006)\end{array}$ & $\begin{array}{l}\text { différenciation } \\
\text { pédagogique }\end{array}$ & $\begin{array}{l}\text { El docente puede hacer que la mayoría de sus estudiantes tengan éxitos } \\
\text { si ajusta sus fórmulas pedagógicas y el entorno de aprendizaje a los } \\
\text { conocimientos previos y características de los alumnos en relación al } \\
\text { objeto de aprendizaje. }\end{array}$ \\
\hline
\end{tabular}




\begin{tabular}{|c|c|c|}
\hline $\begin{array}{l}\text { Gouvernement } \\
\text { du Québec } \\
\text { (2006) }\end{array}$ & $\begin{array}{l}\text { différenciation } \\
\text { pédagogique }\end{array}$ & $\begin{array}{l}\text { La enseñanza diferenciada es sobre todo una forma de pensar sobre la } \\
\text { enseñanza, el aprendizaje y la evaluación, una filosofía que guía a todas } \\
\text { las prácticas educativas. Es una manera de explotar las diferencias y } \\
\text { aprovecharlas. }\end{array}$ \\
\hline $\begin{array}{c}\text { Saint-Laurent } \\
(2007)\end{array}$ & $\begin{array}{l}\text { pédagogie } \\
\text { différenciée }\end{array}$ & $\begin{array}{l}\text { Consiste en organizar la clase de manera que permita a cada alumno } \\
\text { aprender en las condiciones que mejor les convenga. Diferenciar la } \\
\text { pedagogía, es pues, poner en práctica en una clase o en una escuela los } \\
\text { dispositivos para el tratamiento de las dificultades de los alumnos para } \\
\text { facilitar la adquisición de los objetivos. }\end{array}$ \\
\hline $\begin{array}{l}\text { Prud'homme } \\
\text { \& Bergeron } \\
\text { (2012) }\end{array}$ & $\begin{array}{l}\text { différenciation } \\
\text { pédagogique }\end{array}$ & $\begin{array}{l}\text { Es una manera de pensar acerca de la enseñanza donde el profesor } \\
\text { diseña situaciones lo suficientemente flexibles para permitir a todos } \\
\text { los estudiantes progresar, al tiempo que estimula la creación de una } \\
\text { comunidad de aprendizaje donde se reconoce la diversidad, se explota } \\
\text { y se valora dentro de un clima de interdependencia y de comprensión } \\
\text { mutua. }\end{array}$ \\
\hline $\begin{array}{l}\text { Prud'Homme, } \\
\text { Paré, Leblanc, } \\
\text { Bergeron, } \\
\text { Sermier- } \\
\text { Dessemontet } \\
\quad \& \text { Noël } \\
\text { (2016) }\end{array}$ & $\begin{array}{l}\text { différenciation } \\
\text { pédagogique dans } \\
\text { une perspective } \\
\text { inclusive }\end{array}$ & $\begin{array}{l}\text { La diferenciación pedagógica desde una visión inclusiva, en términos } \\
\text { de una perspectiva de enseñanza o capacidad de reconocer, valorar y } \\
\text { tomar parte de la diversidad de una situación pedagógica que } \\
\text { contribuye al aprendizaje individual y colectivo, en tanto que favorece } \\
\text { el reconocimiento de las similitudes y de las diferencias en el seno del } \\
\text { grupo (intercomprensión) y en un proyecto compartido de educación } \\
\text { para todos (interdependencia). }\end{array}$ \\
\hline
\end{tabular}

Nota. Elaboración propia a partir de la literatura consultada.

Hay que resaltar, de este conjunto de definiciones aportadas, cómo este constructo teórico se centra en la filosofía docente y en cómo éste entiende la diversidad o heterogeneidad de los diferentes alumnos que configuran su grupo clase. Engloba todos aquellos medios, métodos, dispositivos, procedimientos o acciones que el maestro articula durante el proceso de enseñanzaaprendizaje para que todo el alumnado pueda adquirir los objetivos comunes establecidos, pero por diferentes vías. Seguidamente, en la Tabla 7, se presentan algunas de las definiciones más representativas procedentes de la literatura anglófona. 
Tabla 7

Revisión de algunas definiciones: literatura anglófona

\begin{tabular}{|c|c|c|}
\hline \multicolumn{3}{|r|}{ LITERATURA ANGLÓFONA } \\
\hline AUTOR Y AÑO & TÉRMINO & DEFINICIÓN \\
\hline $\begin{array}{l}\text { Convery \& } \\
\text { Coyle } \\
(1993)\end{array}$ & differentiation & $\begin{array}{l}\text { La diferenciación es el proceso por el cual los profesores proporcionan } \\
\text { diferentes oportunidades de aprendizaje a sus alumnos para alcanzar } \\
\text { su máximo potencial, trabajando a su propio ritmo a través de una } \\
\text { variedad de actividades de estudio. }\end{array}$ \\
\hline $\begin{array}{l}\text { Forsten, } \\
\text { Grant, \& } \\
\text { Hollas } \\
(2002)\end{array}$ & $\begin{array}{l}\text { differentiated } \\
\text { instruction }\end{array}$ & $\begin{array}{l}\text { La enseñanza diferenciada consiste en conocer una gran variedad de } \\
\text { estrategias de enseñanza y saber cuándo y con quién usarlas. }\end{array}$ \\
\hline $\begin{array}{l}\text { Heacox } \\
(2002)\end{array}$ & $\begin{array}{l}\text { differentiating } \\
\text { instruction }\end{array}$ & $\begin{array}{l}\text { Diferenciar la enseñanza significa cambiar el ritmo, el nivel o el tipo de } \\
\text { enseñanza para dar respuesta a las necesidades, estilos e intereses } \\
\text { individuales de aprendizaje. }\end{array}$ \\
\hline $\begin{array}{l}\text { Tomlinson } \\
\quad(2005)\end{array}$ & $\begin{array}{l}\text { the } \\
\text { differentiated } \\
\text { classroom }\end{array}$ & $\begin{array}{l}\text { La enseñanza diferenciada implica "remover" lo que sucede en el aula } \\
\text { de modo que los estudiantes tengan múltiples opciones para captar } \\
\text { información, comprender ideas y expresar lo que aprenden. En otras } \\
\text { palabras, una clase diferenciada provee diversos caminos para adquirir } \\
\text { contenidos, procesos o comprender ideas y elaborar productos, para } \\
\text { que cada alumno pueda aprender de manera eficaz. } \\
\text { El docente planifica proactivamente y lleva adelante diversos enfoques } \\
\text { del contenido, proceso y producto de la enseñanza, anticipándose en } \\
\text { respuesta a las diferencias de aptitud, interés y necesidad de } \\
\text { aprendizaje de los alumnos. }\end{array}$ \\
\hline $\begin{array}{c}\text { Subban } \\
(2006)\end{array}$ & $\begin{array}{l}\text { differentiated } \\
\text { instruction }\end{array}$ & $\begin{array}{l}\text { Diferenciar significa saber analizar y ajustar la práctica educativa y el } \\
\text { entorno de aprendizaje para tener en cuenta las características de uno } \\
\text { o varios alumnos respecto al objeto particular de aprendizaje. }\end{array}$ \\
\hline $\begin{array}{l}\text { Levy } \\
(2008)\end{array}$ & $\begin{array}{l}\text { differentiated } \\
\text { instruction }\end{array}$ & $\begin{array}{l}\text { La enseñanza diferenciada es un conjunto de estrategias que utilizan } \\
\text { los maestros, las cuales les ayudan a conocer en qué punto del } \\
\text { aprendizaje está cada uno de los alumnos, para que puedan progresar } \\
\text { en sus aprendizajes el máximo que sea posible. }\end{array}$ \\
\hline $\begin{array}{l}\text { Campbell } \\
(2008)\end{array}$ & $\begin{array}{l}\text { differentiated } \\
\text { instruction }\end{array}$ & $\begin{array}{l}\text { Hay muchas definiciones que describen la enseñanza diferenciada } \\
\text { como el transcurso de una acción para enseñar a los estudiantes con } \\
\text { diferentes habilidades en la misma clase. Es un enfoque diseñado para } \\
\text { satisfacer estratégicamente las necesidades de cada estudiante. } \\
\text { También es un método de aprendizaje centrado en el alumno que se } \\
\text { basa en la práctica para mejorar los logros de los estudiantes. Es una } \\
\text { forma diferente de pensar y planificar que se ocupa de las necesidades } \\
\text { de la amplia gama de estudiantes en las aulas de hoy en día. }\end{array}$ \\
\hline $\begin{array}{l}\text { Brender } \\
(2012)\end{array}$ & $\begin{array}{l}\text { differentiating } \\
\text { instruction }\end{array}$ & $\begin{array}{l}\text { La enseñanza diferenciada es la mejor conceptualización en la cual el } \\
\text { maestro se apoya para responder a las diversas necesidades de } \\
\text { aprendizaje de los estudiantes. }\end{array}$ \\
\hline $\begin{array}{l}\text { Gregory \& } \\
\text { Chapman } \\
\quad(2013)\end{array}$ & $\begin{array}{l}\text { differentiated } \\
\text { instructional }\end{array}$ & $\begin{array}{l}\text { Mediante el uso de una variedad de estrategias de enseñanza } \\
\text { diferenciada y actividades, los docentes están implementando esta } \\
\text { filosofía diariamente en las aulas a través de los niveles de grado y } \\
\text { áreas de contenido. Cada vez que un maestro satisface las necesidades } \\
\text { individuales de un estudiante, está diferenciando la enseñanza. }\end{array}$ \\
\hline $\begin{array}{l}\text { Kline } \\
(2015)\end{array}$ & $\begin{array}{l}\text { differentiated } \\
\text { instruction }\end{array}$ & $\begin{array}{l}\text { Es la manera de demostrar cómo los docentes pueden incorporar } \\
\text { estrategias de enseñanza para atender a las necesidades, los intereses y } \\
\text { los estilos de aprendizaje de los estudiantes. }\end{array}$ \\
\hline
\end{tabular}

Nota. Elaboración propia a partir de la literatura consultada. 
Con este bloque de definiciones se detecta la idea de que el docente es quién proporciona una variedad de estrategias, esto es, diversos caminos que propicien diferentes oportunidades de aprendizaje según los ritmos, niveles, necesidades, estilos o intereses del alumnado. Por tanto, se ajusta la práctica educativa para que todos los alumnos puedan progresar en su aprendizaje.

Apoyándonos en la literatura consultada y siguiendo los parámetros que caracterizan el reconocimiento de la diversidad, decir que nos emerge con fuerza el vocablo de diseño universal del aprendizaje (en francés: «pédagogie universelle» y en inglés «universal design for learning»). Corresponde con un diseño pedagógico apoyado en la labor docente, el cual reconoce la diversidad del alumnado y propicia un contexto fundamentado en la inclusión escolar (Rousseau, 2010; Bergeron, Rousseau y Leclerc, 2011). Bender (2012) establece que hay diversos modelos de diferenciación de la enseñanza y un principio que está impulsando la manera sobre la cual los docentes pueden estructurar sus clases y conducir su enseñanza es el principio universal del aprendizaje. Hall, Strangman y Meyer (2003) presentan los vínculos de unión entre la diferenciación de la enseñanza y el diseño universal del aprendizaje (DUA). Dichas autoras defienden que la diferenciación de la enseñanza es una práctica de aula que está bien adaptada a los tres principios generales del DUA, en los cuales convergen ambos enfoques pedagógicos, éstos son: 1) reconocer la heterogeneidad del alumnado, 2) apoyar estrategias de aprendizaje (proporcionar múltiples métodos flexibles de aprendizaje y expresión) y 3) apoyar el aprendizaje afectivo, proponer múltiples opciones para el compromiso (involucrar al alumnado en su propio proceso de aprendizaje).

Por consiguiente, esta premisa anima a la reflexión docente para que éstos tomen en consideración las preferencias individuales del alumnado en el proceso de aprendizaje. Este modo de hacer en el aula garantiza la accesibilidad a una variedad de recursos, además de una elección de intervenciones pedagógicas destinadas a responder a un abanico de necesidades individuales (Bergeron et al. 2011). Estos mismos autores establecen los siguientes principios de la pedagogía universal:

$\sim$ Recurre a más de un método para presentar la información y los conceptos. Al mismo tiempo que favorece diversos modos de adquirirlos.

Ofrece vías alternativas de participación y caminos diferentes para comprometerse en las tareas, propone al alumnado un amplio abanico de posibilidades.

$\sim$ Favorece una variedad de medios de expresión tomando en consideración las habilidades y los intereses del alumnado, iniciándolos a que acepten desafíos y que desarrollen su motivación, comprometiéndose más en las actividades pedagógicas.

Asimismo, también implica una variedad de modos de reagrupación de los alumnos siguiendo una estructura flexible y también requiere de un espacio físico organizado de modo que se puedan 
realizar una variedad de actividades al mismo tiempo y para que el alumnado pueda acceder a un amplio abanico de herramientas o materiales.

La planificación del currículum que parte de la proposición de apoyar a todos los alumnos es un desafío que pretende tomar en consideración la diversidad del aula para que todos los individuos que la conforman progresen. Para ello el Center for Applied Special Technology - CAST (2004), desarrolló el modelo denominado planning for all learners (PAL), un proceso para desarrollar y proporcionar enseñanzas basadas en el diseño universal del aprendizaje. Dicho modelo consiste en: 1) definir fines y desafíos claros adaptados al alumnado a partir de los estándares de aprendizaje y teniendo en cuenta el contexto; 2) identificar el material, los métodos pedagógicos y la evaluación analizando los obstáculos potenciales; 3 ) redactar una planificación universal que ofrece diferentes vías para superar dichos obstáculos y ofrecer diferentes recursos para hacer el aprendizaje accesible a todos y 4) variar la enseñanza, evaluar la progresión de los alumnos y revisar la planificación.

Estas aproximaciones no están exentas de desafíos o dilemas. Rose y Meyer (2002) consideran que uno de los desafíos más grandes asociados a la gestión de la diversidad en el aula es mantener las exigencias elevadas para todos los alumnos con el fin de favorecer la progresión de todos, y de esta manera desarrollar sus capacidades. Por su parte, Bergeron et al. (2011), añaden que la pedagogía universal se sustenta en el principio de la zona de desarrollo próximo (ZDP) de Vygotsky, dado que el desafío que se le propone al alumnado es bastante grande para que aprenda y bastante accesible para que pueda acceder con total confianza. Bergeron (2015) plantea los siguientes ejemplos de dilemas en la planificación de la enseñanza ante la diversidad de alumnado (Ver Figura 2).

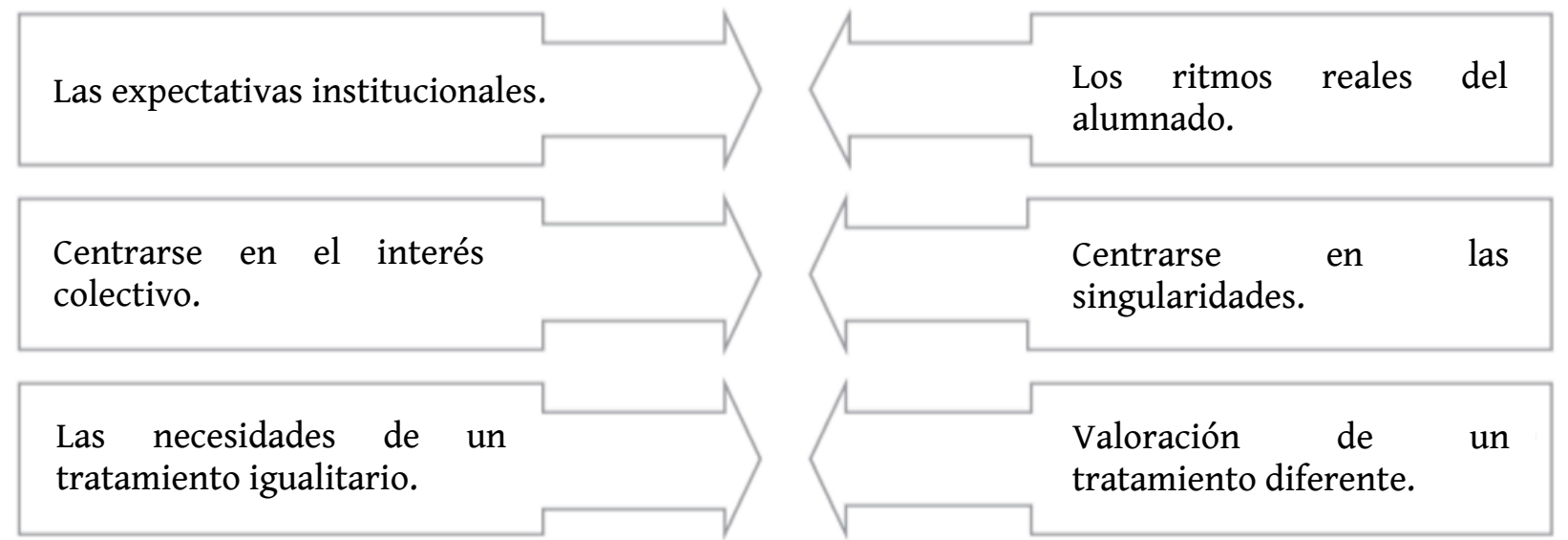

Figura 2. Ejemplos de dilemas en la planificación de la enseñanza ante la diversidad del alumnado.

Nota. Fuente: Bergeron, L. (2015). La planification de l'enseignement a priori en fonction de la diversité des élèves. Une logique préventive et proactive. In N. Rosseau (dir.), La pédagogie de l'inclusion scolaire : Un défi ambitieux et stimulant (pp.375-397). Québec, Canada : Presses de l'Université du Québec. 
En referencia al tema que nos compete, Bergeron et al. (2011), remarcan que otros enfoques pedagógicos que se inscriben en una perspectiva de apertura y que toman en consideración las diferencias, como por ejemplo la diferenciación pedagógica no son incompatibles con el diseño universal del aprendizaje. Y, es más, para Hall et al. (2003) la enseñanza diferenciada cuando se combina con las prácticas y principios del DUA, puede proporcionar a los maestros herramientas tanto teóricas como prácticas para responder al desafío que supone atender las diversas necesidades de todos los alumnos en el aula. En definitiva, el maestro puede diferenciar su enseñanza apoyándose en los principios del DUA (Prud'Homme et al. 2016).

Después de esta vinculación entre el DUA y la diferenciación pedagógica continuamos con algunas de las definiciones más características procedentes de la literatura hispánica (Ver Tabla 8).

Tabla 8

Revisión de algunas definiciones: literatura hispánica

\begin{tabular}{|c|c|c|}
\hline \multicolumn{3}{|r|}{ LITERATURA HISPÁNICA } \\
\hline AUTOR Y AÑO & TÉRMINO & DEFINICIÓN \\
\hline $\begin{array}{l}\text { Orden Hoz } \\
(1975)^{4}\end{array}$ & $\begin{array}{l}\text { pedagogía } \\
\text { experimental y } \\
\text { diferencial }\end{array}$ & $\begin{array}{l}\text { Conocimiento científico de la educación diferenciada, apoyada en las } \\
\text { diferentes características de los grupos e individuos humanos. }\end{array}$ \\
\hline $\begin{array}{l}\text { García Hoz } \\
(1976)^{4}\end{array}$ & pedagogía diferencial & $\begin{array}{l}\text { (...) toma como objeto de estudio los rasgos diferenciales del tipo de } \\
\text { educación originado por cada paidocenosis. }\end{array}$ \\
\hline $\begin{array}{l}\text { Pérez Juste } \\
\quad(1980)^{4}\end{array}$ & $\begin{array}{l}\text { pedagogía } \\
\text { experimental y } \\
\text { diferencial }\end{array}$ & $\begin{array}{l}\text { Se interesa por dos grandes núcleos de contenidos, el referente al } \\
\text { estudio de las diferencias humanas y el correspondiente a la } \\
\text { adecuación de la acción educativa a tales diferencias. }\end{array}$ \\
\hline $\begin{array}{l}\text { Bartolomé } \\
(1983)^{4}\end{array}$ & pedagogía diferencial & $\begin{array}{l}\text { Ciencia que estudia aquellas cuestiones pedagógicas basadas en la } \\
\text { incidencia que las diferencias humanas y ambientales tienen sobre el } \\
\text { proceso educativo y que permiten una cierta tipificación de su } \\
\text { tratamiento. }\end{array}$ \\
\hline $\begin{array}{l}\text { Rosales } \\
(1985)\end{array}$ & $\begin{array}{l}\text { enseñanza } \\
\text { diferenciada }\end{array}$ & $\begin{array}{l}\text { La enseñanza diferenciada, de forma sistemática, planificada y a partir } \\
\text { de las diferencias existentes de carácter intergrupal e interindividual } \\
\text { pongan las bases para la elaboración de una metodología de enseñanza } \\
\text { adaptada al logro de una igualdad de posibilidades de formación en } \\
\text { todos los alumnos. }\end{array}$ \\
\hline $\begin{array}{l}\text { Jiménez } \\
\text { Fernández } \\
\text { (1987) }\end{array}$ & $\begin{array}{l}\text { bases diferenciales de } \\
\quad \text { la educación }\end{array}$ & $\begin{array}{l}\text { Ciencia que estudia la incidencia que sobre el proceso y producto } \\
\text { educativo ejercen las diferencias humanas en interacción con } \\
\text { ambientes particulares, en cuanto determinantes de patrones de } \\
\text { intervención diferenciados que afectan la calidad de dicho proceso y } \\
\text { producto. }\end{array}$ \\
\hline $\begin{array}{l}\text { Bernal- } \\
\text { Guerrero } \\
(1998)^{5}\end{array}$ & $\begin{array}{l}\text { diferenciación } \\
\text { educativa }\end{array}$ & $\begin{array}{l}\text { Pretende que cada persona sea capaz, mediante las oportunas ayudas, } \\
\text { de alcanzar su plenitud como ser humano, su autorregulación, de } \\
\text { lograr los recursos necesarios para poder llevar una forma de vida } \\
\text { personal dentro de la sociedad en la que ha de integrarse y realizarse, } \\
\text { no sólo adaptarse. }\end{array}$ \\
\hline $\begin{array}{l}\text { Pujolàs } \\
(2003)\end{array}$ & personalización & $\begin{array}{l}\text { Ajuste de la acción educativa a las características personales de cada } \\
\text { alumno. }\end{array}$ \\
\hline
\end{tabular}

\footnotetext{
${ }^{4}$ Citados por López López, Tourón y González Galán (1992).

${ }^{5}$ Si se presta atención a los diferentes trabajos realizados por este autor, se ve como también utiliza el término educación personalizada, tanto antes como después del trabajo que aquí se ha referenciado.
} 


\begin{tabular}{|c|c|c|}
\hline $\begin{array}{l}\text { Huguet } \\
(2006)\end{array}$ & personalización & $\begin{array}{l}\text { Significa adecuar al alumno el trabajo que se hace a nivel colectivo, } \\
\text { dentro del grupo, ofreciendo posibilidades diferentes, dándole un trato } \\
\text { distinto (si es necesario), favorecer que le ayuden en ciertas actividades } \\
\text { dentro de un mismo planteamiento de trabajo, compartiendo los } \\
\text { objetivos generales y la situación de relación general de la clase. }\end{array}$ \\
\hline $\begin{array}{l}\text { Zúñiga } \\
\text { (2010) }\end{array}$ & $\begin{array}{c}\text { pedagogía de la } \\
\text { diversidad }\end{array}$ & $\begin{array}{l}\text { Constituye una postura pedagógica que parte del reconocimiento de las } \\
\text { diferencias de capacidades, de sexo, culturales y del desarrollo en el } \\
\text { aprendizaje de los alumnos. }\end{array}$ \\
\hline $\begin{array}{l}\text { Jiménez } \\
\text { Fernández } \\
\text { \& González } \\
\text { Galán } \\
\text { (2011) }\end{array}$ & pedagogía diferencial & $\begin{array}{l}\text { El estudio diferencial de la educación es ante todo una perspectiva, un } \\
\text { enfoque. Es un modo de observar la realidad educativa que aparece } \\
\text { siempre envuelta en la diversidad. La pedagogía diferencial como } \\
\text { disciplina científica reflexiona sobre cómo actuar desde el sistema } \\
\text { educativo, en sentido amplio, para lograr una educación de calidad } \\
\text { para todos que conjugue la excelencia y la equidad desde la diversidad. }\end{array}$ \\
\hline $\begin{array}{l}\text { Rojas } \\
(2012)\end{array}$ & $\begin{array}{c}\text { pedagogía } \\
\text { diferenciada }\end{array}$ & $\begin{array}{l}\text { La pedagogía diferenciada es para reconocer la multiplicidad de } \\
\text { realidades y expresiones culturales que traen consigo los educandos, } \\
\text { los docentes y padres de familia dentro de la escuela, para no caer en la } \\
\text { pretensión de que una cultura ahogue o les imponga sus valores a las } \\
\text { otras. } \\
\text { [...] para construir nuevas escuelas que respondan a las necesidades de } \\
\text { las sociedades contemporáneas y, de las comunidades que } \\
\text { históricamente han estado marginadas o invisibilizadas por la visión } \\
\text { hegemónica y vertical occidental que se ha instituido en las esferas } \\
\text { gubernamentales y en los consejos directivos de las instituciones } \\
\text { educativas. }\end{array}$ \\
\hline $\begin{array}{l}\text { Rodríguez } \\
\text { (2012) }\end{array}$ & $\begin{array}{c}\text { enseñanza } \\
\text { diferenciada }\end{array}$ & $\begin{array}{l}\text { La enseñanza diferenciada se caracteriza por estar centrada en el } \\
\text { alumno. Tiene como objetivo maximizar su capacidad de aprendizaje. } \\
\text { Asume como compromiso favorecer y facilitar el éxito de todos y cada } \\
\text { uno de los miembros de la clase, teniendo en cuenta que no hay dos } \\
\text { alumnos que aprendan a la misma velocidad, utilicen las mismas } \\
\text { técnicas para estudiar, resuelvan los problemas de la misma manera, } \\
\text { tengan el mismo repertorio de conductas, tengan el mismo perfil de } \\
\text { intereses, persigan los mismos objetivos, etc. } \\
\text { Consiste en variar los métodos para dar cuenta de la heterogeneidad de } \\
\text { las clases, la diversidad de los patrones y las necesidades de aprendizaje } \\
\text { de los estudiantes. }\end{array}$ \\
\hline
\end{tabular}

Nota. Elaboración propia a partir de la literatura consultada.

En el contexto hispano, se detecta como el primer bloque de definiciones giran en torno al estudio de las diferencias humanas y los ambientes que interceden en la práctica educativa empleando el término de pedagogía diferencial. Hay que señalar que autores como García Hoz, que utilizan dicho palabro, posteriormente emplea la expresión de educación personalizada (1981) o personalización educativa (1991). Es necesario decir que Rojas (2012) relaciona la pedagogía diferenciada con el término de interculturalidad, de ahí los matices que caracterizan su definición (realidades y expresiones culturales). Se sospecha que en el contexto español no ha proliferado y no es muy común utilizar el vocablo diferenciación educativa (en el sentido que se concibe en este trabajo) debido a que éste se emplea para hacer alusión a la educación que reciben, por separado, los niños y niñas. Así se ha comprobado a partir de la revisión bibliográfica efectuada, de la cual han emergido diferentes 
trabajos en el sentido de diferenciar la enseñanza separando a chicos y a chicas (single-sex) en aulas apartadas (Calvo, 2005 y 2009; Moreno, 2009; Setuáin, 2012; Sánchez, 2012; Aguiló, 2015; Ahedo, 2015).

Ante esta connotación del término, se considera relevante subrayar que la diferenciación pedagógica (tal y como se enmarca en esta tesis doctoral), así como las diferentes corrientes educativas citadas y desarrolladas, no se basan en la diferencia como elemento característico para separar o agrupar. Sino más bien, todo lo contrario, se valora y se respeta la diferencia como riqueza para la propia práctica educativa (Moriña, 2008) donde todos pueden aportar y participar.

Al hilo de lo anterior, se considera necesario mencionar el trabajo de Susan Hart (1992) denominado Differentiation. Part of the problem or part of the solution? en el artículo, la autora recoge dos corrientes: 1) la primera defiende que la diferenciación es el medio por el cual se logra el aprendizaje a partir de un marco curricular común y 2) la segunda enfatiza en la idea de que la diferenciación refuerza y perpetua las desigualdades ya existentes.

Si se ahonda un poco en los argumentos propuestos por los partidarios y por los detractores se percibe como el término de diferenciación parece no estar exento de controversia. Los adeptos al vocablo, esto es, los que defienden que la diferenciación es parte de la solución, argumentan que los niños difieren en sus capacidades, aptitudes y necesidades. Por tanto, los objetivos educativos pueden ser comunes a todos, pero se debe flexibilizar o propiciar diferentes medios o caminos para adquirirlos. Los que critican esta corriente educativa, es decir, los que defienden que la diferenciación es parte del problema, argumentan que la diferenciación es una palabra cargada de largos debates y polémicas. Asimismo, se escudan en que hacer frente a las diferentes necesidades del alumnado puede perpetuar la desigualdad, propiciando la selección y segregación. Hart (1992), en el trabajo anteriormente mencionado, arguye que se trata de una cuestión difícil de resolver. Ésta señala que la perspectiva del desarrollo del currículum se ocupaba más bien en crear condiciones óptimas de aprendizaje para cada niño, en lugar de las perspectivas más antiguas que se apoyaban en la función selectiva de "clasificación" de los niños. Por tanto, en ese sentido, la diferenciación cumple una función pedagógica más que una estrategia organizacional. La autora introduce una idea que ya se ha puesto de manifiesto en el primer capítulo de esta tesis doctoral, se necesita reformular la concepción de las "dificultades" como un problema del currículum o la manera de presentarlo, en lugar de un problema del niño ante los aprendizajes (Ainscow, 1999; Pujolás, 2001; Bergeron, 2015). Hart (1992) sugiere que hay que propiciar oportunidades de aprendizaje basadas en el diálogo y la práctica, poniendo énfasis en el trabajo cooperativo y las actividades autodirigidas. Concluye su trabajo proponiendo una alternativa a la diferenciación, la cual denomina interactive critique. Esta alternativa asume que: 1) los logros y comportamientos de los alumnos tienen mucho que decir sobre las cualidades y características particulares del currículum sobre las habilidades y características individuales, 2) las respuestas individuales del alumnado en el ambiente de aprendizaje tienen que proveer las posibilidades curriculares y el desarrollo pertinente de cada uno de los niños y 3) la 
escuela tiene responsabilidades para asegurar que el currículum sea evaluado de forma continua para mejorar el aprendizaje individual y colectivo.

Para continuar con la clarificación conceptual, nos apoyamos en los aportes de Tomlinson (2005) la cual contesta a la pregunta ¿Qué NO es la diferenciación pedagógica?: 1) la "enseñanza individualizada" de los años setenta (no consiste en hacer cosas diferentes para cada uno de los alumnos de la clase), 2) no es caótica (el temor a perder el control es un obstáculo que impide a muchos maestros a desarrollar clases más flexibles), 3) no es otra manera de conformar grupos homogéneos (un rasgo de las aulas diferenciadas eficaces es el empleo de agrupamientos flexibles) y 4) no es "reformar una prenda" (estirar una prenda demasiado estrecha o ajustar una demasiado holgada no será tan conveniente como adquirir una ropa de la talla adecuada. Por ejemplo, ante un contenido esencial de aprendizaje no tiene ningún sentido que el alumno se salte una pregunta o se le califique con "menos severidad". Esto no ayudará en su proceso de aprendizaje). A esta lista añadiremos que la enseñanza diferenciada no es separar o segregar al alumnado por sexos (tal y como es entendido por algunos investigadores en el contexto español). Siguiendo con la misma autora y tratando de contestar a la cuestión: ¿Qué es la diferenciación pedagógica?, ésta apunta a que: 1) es proactiva (distintas maneras de alcanzar y expresar el aprendizaje. En este caso, el concepto no alude meramente a una disposición activa, sino a la actitud dinámica, creativa y anticipadora de los maestros), 2) es más cualitativa que cuantitativa (la diferenciación no consiste en dar más tareas a algunos alumnos y menos a otros, eso parece un castigo. Consiste en que si un alumno ya ha adquirido unos conocimientos puede comenzar a abordar otros), 3) se basa en el diagnóstico (busca oportunidades para conocer a todos los alumnos. Se realiza al inicio para determinar los puntos de partida de cada estudiante), 4) proporciona múltiples enfoques del contenido, el proceso y el producto (diferentes enfoques de lo que aprenden los alumnos, cómo lo aprenden y cómo demuestran que lo han aprendido), 5) está centrada en el alumno (proponer experiencias de aprendizaje estimulantes, atractivas, relevantes e interesantes para todos), 6) combina la enseñanza global a toda la clase, la grupal y la individual y 7) es orgánica (evolutiva, es decir, alumnos y maestros aprenden juntos. Los maestros constantemente están aprendiendo sobre cómo aprenden sus alumnos. Es lo que les hace reflexionar y seguir diferenciando la práctica educativa).

Otra matización que se considera importante mencionar dentro del marco de la clarificación conceptual es la relativa al vocablo de diversificación o diferenciación. Aunque mayoritariamente en la literatura que se ha hallado se utiliza el término de diferenciación, también se encuentran algunos trabajos que emplean los vocablos de diversificación o pedagogía diversificada y en algunos casos combinados con el de diferenciación o pedagogía diferenciada. Barry (2004) realiza una clarificación conceptual entre ambos términos, los cuales considera polimorfos y nómadas. Apunta que ambos conceptos se utilizan en diferentes ámbitos: diferenciación (educación, biología y psicología) y diversificación (educación, biología y economía). En el campo de la educación los estudiosos se 
centran principalmente en la definición del concepto de diferenciación y prestan poca atención al significado de diversificación, del cual se centran más en detallar cómo se hace y en las actualizaciones pertinentes. Barry (2004) propone, citando a Meirieu (1991), que ambos conceptos (diferenciación y diversificación) pertenecen al mismo campo semántico que el de la individualización. Y señala tres ejes (Ver Tabla 9) que ayudan a encontrar los matices o elementos que caracterizan ambos términos: el eje pedagógico y didáctico (estrategias y actividades de aprendizaje), el eje de los contenidos o de los programas y el eje de la estructura (organización de la formación).

Tabla 9

Sistema de utilización de los conceptos de diferenciación y de diversificación en la literatura.

\begin{tabular}{|c|c|c|}
\hline EJES & DIFERENCIACIÓN & DIVERSIFICACIÓN \\
\hline 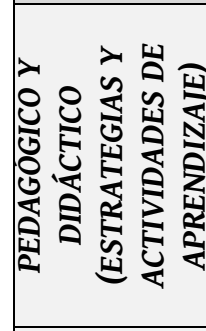 & $\begin{array}{l}\text { Pedagogía diferenciada (Perrenoud, 1997; Meirieu, } \\
\text { 1991; Legrand, 1998). } \\
\text { Pedagogía por objetivos (maîtrise) (Perrenoud, } \\
\text { 1997; Meirieu, 1991). } \\
\text { Diferenciación pedagógica (Perraudeau, 1997). } \\
\left.\text { Enfoques pedagógicos diferenciados (CSE }{ }^{6}, 1999\right) \text {. } \\
\text { Ciclos de aprendizaje (CSE, 1999; Perrenoud, 1991; } \\
\text { Fresne, 1994). }\end{array}$ & $\begin{array}{l}\text { Diversificación de los enfoques y de las } \\
\text { prácticas pedagógicas (CSE, 1989). }\end{array}$ \\
\hline 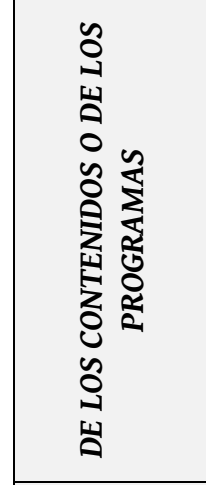 & $\begin{array}{l}\text { Diferenciación de programas. } \\
\text { Programas diferenciados (disminuidos y } \\
\text { enriquecidos). } \\
\text { Programas de estudios opcionales }\left(\mathrm{CPE}^{7}, 1998\right) \text {. } \\
\text { Diferenciación según el contexto de realización } \\
\text { (CPE, 2002). } \\
\text { Programa intermediario (CPE, 1998). } \\
\text { Enseñanza modular (Wandflush y Perrenoud, } \\
\text { 1999). } \\
\text { Opciones dentro de un programa (CSE, 1999). } \\
\text { Opciones enriquecidas o de alcance (CSE, 1999). } \\
\text { Opciones de inserción profesional (CSE, 1999). }\end{array}$ & $\begin{array}{l}\text { Diversificación de los contenidos (CSE, } \\
\text { 1989). } \\
\text { Cours à option valorisants (CSE, 1989). }\end{array}$ \\
\hline 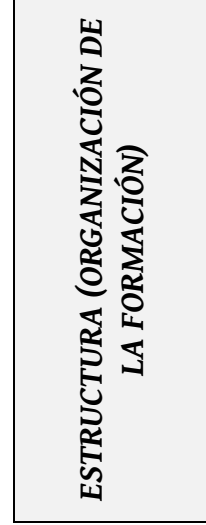 & $\begin{array}{l}\text { Diferenciación de las carreras escolares (Duru- } \\
\text { Bellat, 1998). } \\
\text { Sectores enriquecidos o de alcance. } \\
\text { Sectores de inserción. } \\
\text { Ciclos de aprendizaje o de formación (CSE, 1999). }\end{array}$ & $\begin{array}{l}\text { Diversificación de los trayectos. } \\
\text { Escuelas de vocación internacional. } \\
\text { Reagrupación diversificada de los } \\
\text { alumnos. } \\
\text { Diversificación de los sectores. } \\
\text { Diversificación de los progresos (MEQ, } \\
\text { 1997; GPR, 1999). } \\
\text { Progresos diferenciados (MEQ, 1997; CSE, } \\
\text { 1999; CPE, 2000). } \\
\text { Diversificación del sector de las clases } \\
\text { Especializadas (CSE, 1999). } \\
\text { Estructuras de recepción para niños de } \\
\text { inmigrantes (Perrenoud, 1997). }\end{array}$ \\
\hline
\end{tabular}

Nota. Fuente: Barry, A. (2004). Différenciation et diversification : clarification conceptuelle et enjeux. Vie Pédagogique : Dossier, Une formation diversifiée et qualifiante, 130, 20-24

\footnotetext{
${ }^{6}$ CONSEIL SUPÉRIEUR DE L'ÉDUCATION (Ministre de l'Éducation, Québec).

${ }^{7}$ COMMISSION DES PROGRAMMES D'ÉTUDES (Ministre de l'Éducation, Québec).
} 
Por tanto, siguiendo a Barry (2004), la diferenciación parece centrarse más en el eje pedagógico y en el eje de los contenidos. Ésta consiste en poner en práctica dispositivos pedagógicos y didácticos, realizar intervenciones educativas y favorecer las interacciones que aumentan las posibilidades de aprendizajes productivas para cada alumno. La diversificación se centra más en el eje de las estructuras. Así pues, ésta puede ser considerada en términos organizativos de la formación para tener en cuenta los centros de interés y las potencialidades de los alumnos. El autor, en su trabajo, propone que la toma en consideración de las diferencias puede llevarse a cabo mediante: la diferenciación pedagógica, propiciando múltiples ocasiones de aprendizaje (contextos variados de aprendizaje, diversos métodos de enseñanza...) y permitiendo a cada alumno desarrollar sus competencias y adquirir aprendizajes a partir de diferentes estrategias; la diferenciación de los contenidos, variar los contenidos o su organización de tal modo que el alumnado adquiera determinadas competencias del programa de estudios (currículum) y la diversificación de los trayectos de formación, actuar sobre el tiempo, las estructuras o la organización de la formación que permita a cada alumno adquirir determinados aprendizajes del programa. Efectivamente, Combaz (1999) en su trabajo utiliza el término de diversificación en cuanto a la autonomía otorgada por las autoridades francesas a des établissements, éste realiza una crítica ante las desigualdades que puede suponer que el Estado ceda la autonomía en propiciar "caminos de aprendizaje diversificados". Sin embargo, Larcher y Peterfalvi (2006) utilizan el término pédagogiques diversifiés, en su contribución en referencia a la diversificación de los enfoques pedagógicos en la clase de ciencias. Schneuwly, Rosat, Pasquier y DolzMestre (1993) titulan su trabajo Différencier-diversifier ou : la didactique et l'hétérogénéité des élèves. Se ha visto como estos autores utilizan los dos conceptos a lo largo de su contribución. Sharan (2010) habla del aprendizaje cooperativo como una pedagogía diversificada (diversified pedagogy), esto es, como una oferta pedagógica para gestionar las aulas interculturales. Vélez y Psacharopoulos (1987) también utilizaban en el término diversificada (diversified) para hacer referencia a la eficiencia de la diversificación de la escuela secundaria en Colombia. La traducción española del libro de C.A. Tomlinson (2008) El aula diversificada. Dar respuesta a las necesidades de todos los estudiantes resulta tener el título en su versión original The Differentiated Classroom. Así pues, esta disyuntiva parece no estar del todo resuelta.

A modo de síntesis, la diferenciación pedagógica se enmarca en una filosofía y un marco de acción docente que se sustenta en unas creencias y actitudes positivas de los docentes hacia la diversidad y que consiste en ajustar o flexibilizar la práctica educativa a las necesidades, ritmos, intereses y estilos de aprendizaje de cada alumno, pero sin perder la referencia del grupo clase (Sanahuja, Moliner y Moliner, 2014). 


\subsubsection{Factores y elementos constituyentes del aula diferenciada}

Para extraer los principales factores y elementos que caracterizan y constituyen las aulas diferenciadas nos apoyaremos con el esquema propuesto por Tomlinson (2008), el cual se presenta en la Figura 3.
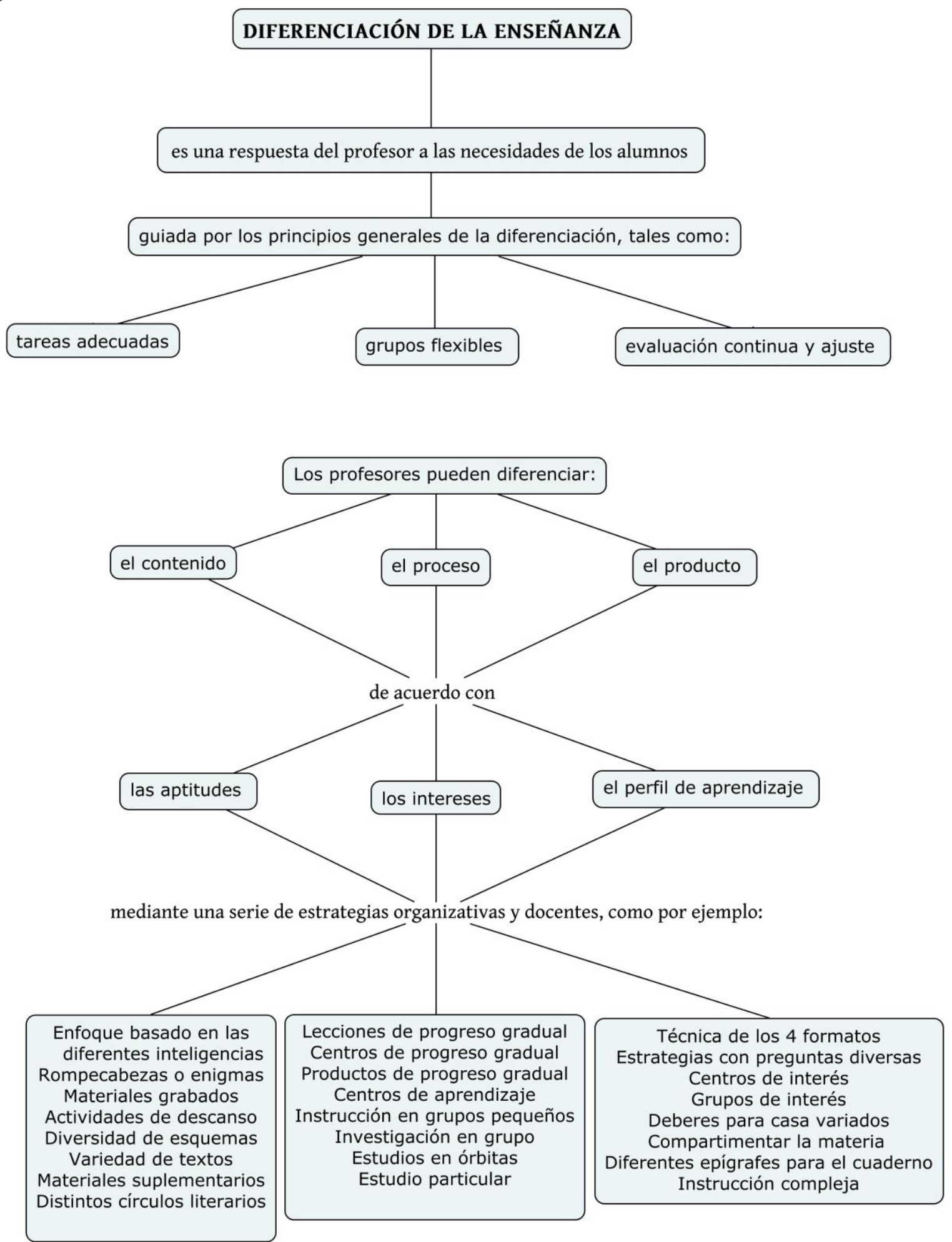

Figura 3. Esquema general de la enseñanza diferenciada.

Nota. Fuente: Tomlinson, C.A. (2008). El aula diversificada. Dar respuesta a las necesidades de todos los estudiantes. Barcelona, España: Octaedro. 
En este apartado no se va a focalizar sobre las estrategias educativas o docentes para propiciar la diferenciación en el aula, puesto que dicho cometido se aborda en el apartado 2.2. Algunas pistas de acción: cómo articular los presupuestos teóricos en la práctica educativa. No obstante, se considera relevante resaltar la idea de que no existe una sola fórmula única y correcta de materializar la diferenciación pedagógica en el aula (Tomlinson, 2008).

Como ya se ha mencionado, en muchas de las definiciones aportadas sobre el vocablo, la diferenciación pedagógica depende principalmente de la filosofía educativa del docente y como éste entiende y afronta la heterogeneidad del alumnado presente en su aula (Convery y Coyle, 1993; Meirieu, 1996; Fournier, 1996; Tomlinson, 2005; Guay et al. 2006; Gouvernement du Québec, 2006; Levy, 2008; Campbell, 2008; Prud'homme y Bergeron, 2012; Sanahuja et al. 2014; Kline, 2015). Otro factor que parece influir en la puesta en práctica de la diferenciación pedagógica en el aula por parte de los maestros es su formación. En palabras de Wan (2017), existen estudios previos que concluyen que los docentes no están bien preparados para llevar a cabo de manera satisfactoria la diferenciación de la enseñanza en sus aulas, esto es, no cuentan con las suficientes habilidades ni conocimientos necesarios para ello. Un estudio realizado por Edwards, Carr y Siegel (2006) que examinaba los resultados de futuros maestros participantes en un programa de formación sobre la articulación de la diferenciación pedagógica en las aulas inclusivas, evidenciaban resultados significativos en el sentido de cómo estos futuros docentes estaban mejor capacitados en el uso y planificación de estrategias y técnicas de enseñanza diferenciada en sus aulas. Además, la eficacia percibida de los docentes noveles en cuanto a la diferenciación de la enseñanza, esto es, las ideas preexistentes de cómo articular la diferenciación estaba condicionada por sus creencias sobre la enseñanza y la imparcialidad, limitando sus intentos de diferenciación de la enseñanza a un nivel muy superficial (Casey y Gable, 2012). Wan (2017), también recoge que los docentes aún teniendo herramientas y estrategias para su articulación rara vez lo traducen automáticamente a su práctica educativa. Y es que Brighton, Hertberg, Moon, Tomlinson y Callahan (2005) sugieren que la diferenciación de la enseñanza y la evaluación son esfuerzos complejos que requieren tiempo y voluntad por parte del profesorado. Para Heacox (2002, p.5) existen 4 rasgos que caracterizan la enseñanza diferenciada, la cual es:

Rigurosa: el docente proporciona la enseñanza de manera desafiante para motivar a los estudiantes a esforzarse. Además, el maestro reconoce las diferencias individuales y las metas establecidas para el aprendizaje basado en las capacidades particulares de los alumnos. No establece el listón tan bajo que los estudiantes no necesitan hacer esfuerzos, ni tan alto que éstos fallen y se sienten desmotivados.

$\sim$ Relevante: se centra en el aprendizaje esencial. Diferenciar no significa más de lo mismo para llenar el tiempo, diferenciar no significa actividades que son divertidas para los estudiantes, pero no se centran en el aprendizaje significativo. 
$\sim$ Flexible y variada: Los alumnos toman decisiones acerca de cómo van a aprender y cómo van a mostrar lo que han aprendido. Éstos pueden tener la posibilidad de seleccionar los temas que desean explorar en mayor profundidad. También pueden negociar el tiempo y si van a trabajar de forma individual, con pareja o en grupo. Con la diferenciación, los docentes emplean diferentes estrategias de enseñanza.

Compleja: no navega sobre la parte superficial de los conceptos. Más bien, reta a los estudiantes a que piensen y a que participen activamente en el contenido que se transmite en profundidad y amplitud.

En las manos de los maestros está diferenciar el contenido, el proceso y el producto (Caron, 2003; Tomlinson, 2005; Levy, 2008; Kline, 2015; Leroux y Paré, 2016; Wan, 2017). Además, Caron (2003) y Leroux y Paré (2016) añaden que los docentes también pueden diferenciar las estructuras.

La diferenciación del contenido hace referencia a aquellos elementos del currículum o plan de estudios objeto de ser enseñados (Caron, 2003). Siguiendo con Levy (2008), el contenido a enseñar es el mismo para todos los alumnos, dado que viene marcado por el plan de estudios, pero éste puede ser cuantitativamente o cualitativamente diferente. Así pues, en palabras de Tomlinson (2008), el contenido es aquello que un alumno debe llegar a conocer (hechos), comprender (conceptos y principios) y ser capaces de hacer (habilidades) como resultado de un segmento concreto de estudio (una lección, unidad o experiencia de aprendizaje). El contenido es lo adquirido. Asimismo, Tomlinson (2008) y Leroux y Paré (2016) añaden que el contenido hace referencia a todos los medios que ponen al alumno en contacto con la información objeto de ser aprendida, por ejemplo: variedad de textos, saberes y conocimiento, el grado de complejidad o profundidad y los diferentes materiales didácticos. En referencia a los contenidos, Meirieu (1997) se apoya en las palabras de Philippe Perrenoud, en un coloquio que este último había realizado en 1989:

Trabajando en la diferenciación de la enseñanza, se puede iniciar un nuevo estadio de reflexión: interrogarse acerca del sentido del trabajo escolar y de los saberes por parte de los alumnos. Por más diferenciada que esté, la enseñanza no será eficaz si los contenidos permanecen también a menudo extraños a las experiencias y a los intereses de los alumnos, y si el contrato dialógico deja también poco lugar a las personas y a su experiencia extraescolar. (p. 200)

Algunas de las razones que nos pueden llevar a diferenciar el currículum es que, según propone Waterman (2007), éste es a menudo irrelevante, está muy ajustado a presiones y plazos independientemente de los aprendizajes de los alumnos y está fragmentado y no transfiere el contenido de un área a otra o de un concepto relevante a otro.

La diferenciación del proceso es, según Caron (2003), la manera en que los alumnos aprenden el contenido a través de los diferentes caminos de aprendizaje, atendiendo a los ritmos de los alumnos y 
a las diferentes estrategias de enseñanza utilizadas. En palabras de Leroux y Paré (2016) se diferencia el proceso según el campo de interés del alumnado, los conocimientos previos y el nivel de competencias, las retroalimentaciones entre el alumno y el docente o el alumno y sus pares, nivel de desarrollo del alumnado (motor, cognitivo, social...), motivación y compromiso hacia la tarea y el modo de vida del alumnado. Para Tomlinson (2008), el proceso es la oportunidad que tienen los alumnos de dar sentido a los contenidos. Los aprendices deben procesar las ideas para apropiarse de ellas. En suma, el proceso incluye cómo los docentes enseñan (las actividades que ofrecen deben de abordar las diferentes capacidades de los alumnos) y cómo los alumnos aprenden (Levy, 2008).

La diferenciación del producto hace referencia a la manera en que los alumnos demuestran los aprendizajes que han adquirido (Caron, 2003; Levy, 2008). Esto es, las diferentes modalidades de expresión, los destinatarios, los proyectos o creaciones, las modalidades de evaluación del aprendizaje, así como, los criterios y niveles de aprendizaje (cualitativos o cuantitativos) (Leroux y Paré, 2016). Tomlinson (2008), por su parte lo entiende como el vehículo mediante el cual el alumno muestra (y amplía) lo que ha llegado a comprender y a saber hacer como resultado de un segmento de aprendizaje de cierta magnitud.

La diferenciación de las estructuras, se refiere a aquellos elementos que están directamente relacionados con la organización del aula (Caron, 2003; Leroux y Paré, 2016): agrupaciones, modalidades de trabajo, tiempo, espacios y los recursos materiales y/o personales.

En Differentiating Instruction in the Regular Classroom, Heacox (2002, p.13) propone las cualidades del ambiente escolar propicio para la diferenciación. Según esta investigadora, un ambiente de apoyo en el aula es vital para el éxito de la diferenciación de la enseñanza, éste debe:

$\sim$ Promueve la aceptación de las diferencias.

$\sim$ Afirmar que todos los estudiantes tienen fortalezas de aprendizaje.

$\sim$ Reconoce que los estudiantes aprenden a ritmos diferentes y de diferentes maneras.

$\sim$ Reconoce que para que el trabajo sea justo, a veces, tiene que ser diferente.

$\sim$ Reconoce que el éxito significa diferentes cosas para diferentes personas.

$\sim$ Permite a los estudiantes trabajar con compañeros varios para fines varios.

$\sim$ Reconoce que la clave de la motivación es el interés, y que todos los estudiantes tienen diferentes intereses.

$\sim$ Promueve la responsabilidad personal hacia el aprendizaje.

$\sim$ Construye sensación de competencia personal y confianza en el aprendizaje.

$\sim$ Valora el esfuerzo y la mejora personal.

$\sim$ Nutre habilidades de independencia.

$\sim$ Apoya y celebra el éxito del estudiante en su trabajo desafiante.

$\sim$ Anima a la exploración de los intereses de cada estudiante, las fortalezas y las preferencias de aprendizaje.

$\sim$ Nutre el espíritu creativo en todos los estudiantes.

$\sim$ Ensalza el trabajo de todos. 
En suma, recalcar que los factores y elementos clave que constituyen un aula diferenciada se basan principalmente en la filosofía docente, su formación y como éstos entienden la heterogeneidad del alumnado presente en su aula (diferentes motivaciones, intereses, aptitudes y estilos o perfiles de aprendizaje). A partir de estos principios el maestro diferencia las estructuras (agrupamientos y modalidades de aprendizaje, espacios, tiempos y recursos materiales y/o personales flexibles y variados), el contenido (centrarse en lo esencial, reto en el aprendizaje), el proceso y el producto creando un ambiente escolar propicio para la diferenciación de la enseñanza.

\subsubsection{Lineamiento y alianzas entre la diferenciación pedagógica y la participación democrática}

Llegados a este punto nos preguntamos ¿existen alianzas entre la diferenciación pedagógica y la participación democrática en el aula inclusiva? Para poder llevar a cabo una educación para una ciudadanía democrática, Bolívar (2016) propone que hay que potenciar un conjunto de prácticas escolares que contribuyan a consolidar los valores que pavimentan una sociedad democrática. Para ello, además de formar ciudadanos, hay que estructurar la vida en el contexto escolar de manera que se propicie la participación activa (debate, diálogo, consenso en la toma de decisiones). Siguiendo la misma idea, Santos Guerra (2000c) afirma que las decisiones democráticas deben nacer del diálogo, de la libertad, de la negociación, de la deliberación racional de las opiniones de todos los miembros. Apple y Beane (1999) señalan que en las escuelas democráticas se propician prácticas que fomentan: 1) la aventura de investigar (p.ej., trabajo por proyectos, que implican la utilización de variadas bibliotecas y de las TIC. Asimismo, fomentan una relación con el entorno inmediato), 2) la creación de escenarios deliberativos (p.ej. las asambleas, aprendizaje cooperativo...) y 3) la promoción de una convivencia democrática (consenso de normas y su aplicación). Así pues, las metodologías y estrategias de aprendizaje activas facilitarán el compromiso y la acción, en los implicados, de los valores democráticos (Bolívar, 2016).

Las orientaciones que guían a los maestros, en cuanto a la diferenciación pedagógica desde una perspectiva inclusiva, en la toma de decisiones respecto a su propia acción docente, se basan en la diversidad y en los valores democráticos (Prud'Homme et al. 2016). Estos mismos investigadores apuntan que poner en práctica la diferenciación pedagógica en el aula inclusiva conlleva: 1) reconocer, valorar y tomar parte de la diversidad en clase; 2) crear una comunidad de aprendizaje y gestionar el aula de manera participativa en vistas de simular intercomprensión e interdependencia entre los alumnos; 3) flexibilidad ante las situaciones pedagógicas colectivas, siguiendo los progresos individuales de cada uno de los alumnos a lo largo de una situación; 4) agrupar a los alumnos de manera variada y eficaz, en función de sus diferentes necesidades que se manifiestan en una situación; 5) crear un ambiente que favorece el desarrollo de autonomía del alumno en una situación pedagógica y 6) hacer que los alumnos alcancen sus objetivos y ayuden a otros a alcanzar los suyos. 
Siguiendo a Guarro (2016), uno de los rasgos de la escuela democrática, y que también se encuentra en una escuela diferenciada, es que ésta tiene que ser justa. La justicia escolar implica básicamente una ética de la crítica y supone la eliminación de las barreras que dificultan el aprendizaje a todo el alumnado. Por tanto, se propone brindar una educación equitativa, es decir, una buena educación para todos los alumnos (Bolívar, 2016). En la misma dirección, Delval y Lomelí (2013), hablan de mejorar la escuela en el sentido de que todos los alumnos reciban una educación de calidad que satisfaga sus necesidades, atienda su diversidad y les prepare para su vida futura, ayudándoles a ser buenos ciudadanos. Estos últimos añaden que: "no se puede aprender a ser buen ciudadano simplemente escuchando sermones o mediante consignas, sino que es necesario practicar las virtudes ciudadanas desde el comienzo" (p.32).

En un reciente trabajo, titulado L'éducation à la citoyenneté démocratique : un enjeu fondamental associé au projet d'inclusion scolaire et aux pratiques de différentiation pédagogique (Fillion et al. 2016), se trazan los puntos de convergencia entre la inclusión escolar, la educación ciudadana y la diferenciación pedagógica, siendo éstos: 1) los valores democráticos de justicia y equidad, 2) el reconocimiento y la toma en consideración de la diversidad y 3) la participación y el aprendizaje de la convivencia. En la Figura 4, se representan los puntos de convergencia entre los tres constructos ya citados.

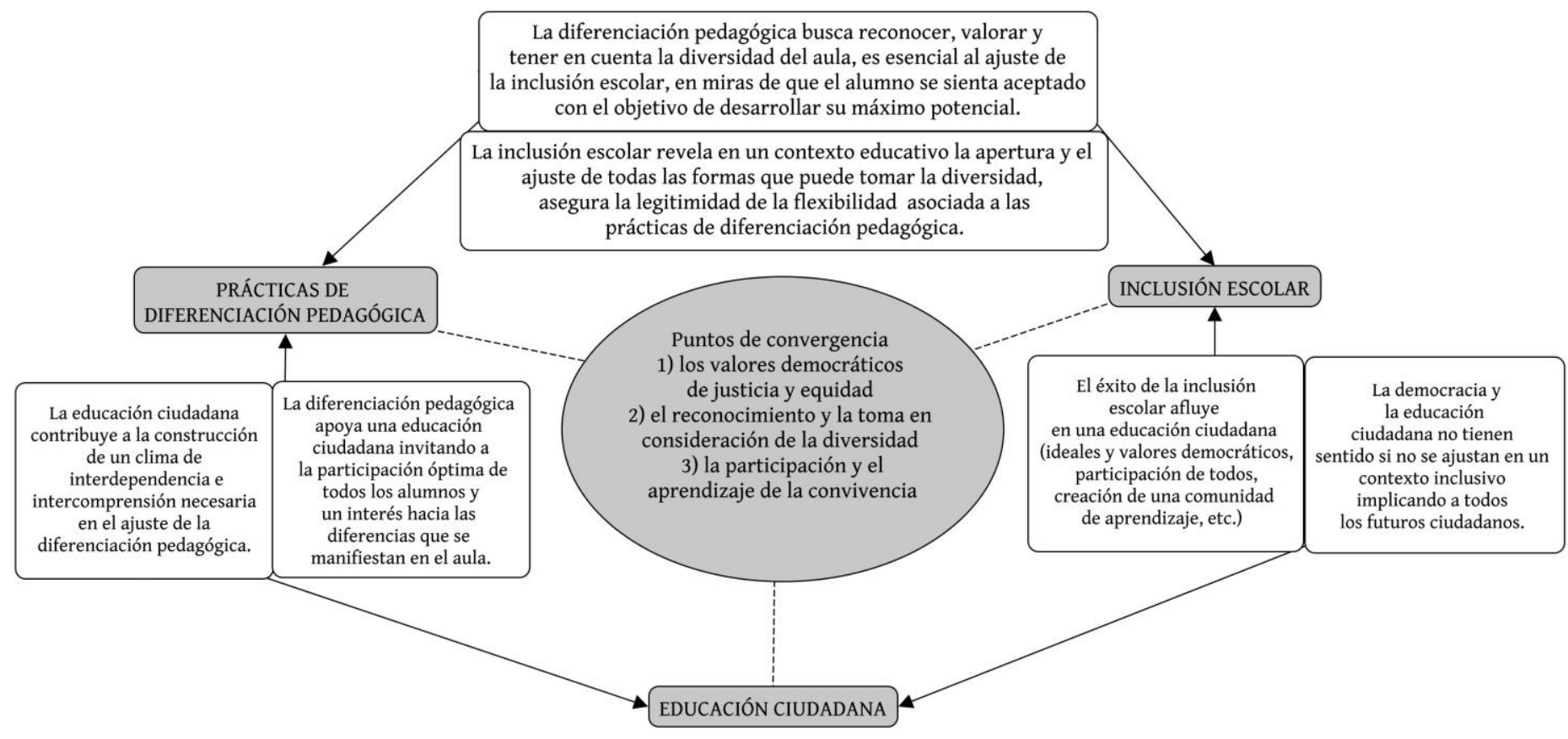

Figura 4. Puntos de convergencia y de interdependencia entre la inclusión escolar, la educación ciudadana y la diferenciación pedagógica.

Nota. Fuente: Fillion, P.L., Bergeron, G., Prud'homme, L. y Traver, J. (2016). L'éducation à la citoyenneté démocratique: un enjeu fondamental associé au projet d'inclusion scolaire et aux pratiques de différenciation pédagogique. In L. Prud'homme, H. Duchesne, P. Bonvin, \& R. Vienneau (Eds.), L'inclusion scolaire: ses fondements, ses acteurs et ses pratiques. Bruxelles : De Boeck Supérieur. 
Waterman (2007), por su parte, acuña el concepto de aula democrática diferenciada con el intento de unificar dos tendencias educativas como son: 1) el aula diferenciada, en la cual los maestros organizan su enseñanza para satisfacer las necesidades individuales de los alumnos y 2) el aula democrática, en la cual los estudiantes están intrínsecamente motivados por el aprendizaje, ya que se les brinda la oportunidad de tomar decisiones. En un aula democrática, subyace la creencia de que los estudiantes son miembros de una comunidad en la cual la responsabilidad de aprender es compartida. Ésta autora se apoya, en los trabajos de Tomlinson por lo que refiere a la diferenciación de la enseñanza y en los aportes de autores como Dewey, Nelson, Adler y Dreikurs, en cuanto a la democratización de la enseñanza y también en los trabajos sobre motivación intrínseca de Deci y Jenson.

Según Waterman (2007) el aula democrática diferenciada es aquella en la que los docentes trabajan al lado de sus alumnos para escuchar sus puntos de vista y sus deseos en relación con el aprendizaje y para ayudarlos después a traducir esos puntos de vista y deseos en competencias, conocimientos y actitudes valiosas. De esta manera, los maestros no son dictatoriales, sino que presentan un liderazgo compartido con los estudiantes. Los alumnos tienen libertad en cuanto a poder aportar sus opiniones y puntos de vista, pueden escoger e incluso pueden cuestionarse el sistema. Para Waterman el modelo de aula democrática diferenciada es más fácil de implementar para el docente, dado que el alumno se responsabiliza en gran parte de la diferenciación de la enseñanza. La única parte difícil de este proceso es que el maestro debe arriesgarse a ceder un poco de control y estar dispuesto a confiar en que sus alumnos puedan tomar decisiones responsables. En la misma línea, se favorece que sea el propio alumnado quien reconozca su propia diversidad y la de sus iguales (Prud'Homme et al. 2016).

El aula democrática diferenciada promueve 5 conceptos (Waterman, 2007): 1) currículum integrado (todos los contenidos de todas las áreas); 2) enseñanza reflexiva (promueve el desarrollo de habilidades metacognitivas en los alumnos); 3) aprendizaje activo (rol activo de los alumnos, trabajo colaborativo en grupo, habilidades sociales, responsabilidades compartidas); 4) transferencia reflexiva (el docente facilita su plan de actividades de manera relevante para un aprendizaje real) y 5) evaluación auténtica (pregunta a los alumnos). A continuación, en la Tabla 10, se presentan las características del aula democrática diferenciada en comparación con el aula tradicional y el aula constructivista propuesta por la misma autora que se viene referenciando. 
Tabla 10

Características del aula democrática diferenciada

\begin{tabular}{|c|c|c|}
\hline \multicolumn{3}{|c|}{ AULA } \\
\hline TRADICIONAL & CONSTRUCTIVISTA & DEMOCRÁTICA DIFERENCIADA \\
\hline $\begin{array}{l}\text { Los docentes presentan las ideas } \\
\text { como parte de un todo y acentúan } \\
\text { las capacidades básicas. }\end{array}$ & $\begin{array}{l}\text { Los docentes presentan las } \\
\text { ideas como un todo, esto es, } \\
\text { acentúan los grandes } \\
\text { conceptos. }\end{array}$ & $\begin{array}{l}\text { Los docentes colaboran con los } \\
\text { estudiantes para determinar las ideas } \\
\text { generales y conceptos, usan una } \\
\text { inducción colaborativa. }\end{array}$ \\
\hline $\begin{array}{l}\text { Los docentes se ciñen rígidamente a } \\
\text { un plan de estudios fijo y } \\
\text { prescriptivo. }\end{array}$ & $\begin{array}{l}\text { Los docentes se dedican a las } \\
\text { cuestiones planteadas por los } \\
\text { estudiantes. }\end{array}$ & $\begin{array}{l}\text { Los docentes no sólo se dedican a las } \\
\text { cuestiones planteadas por los } \\
\text { estudiantes, también ayudan a que } \\
\text { los alumnos aprendan a realizarse } \\
\text { importantes } \\
\text { metacognitivas. }\end{array}$ \\
\hline $\begin{array}{l}\text { Los docentes confían en los } \\
\text { manuales, cuadernos de ejercicios y } \\
\text { hojas de trabajo. }\end{array}$ & $\begin{array}{l}\text { Los docentes encuentran las } \\
\text { fuentes primarias de } \\
\text { información y materiales sobre } \\
\text { el terreno práctico. }\end{array}$ & $\begin{array}{l}\text { Los docentes colaboran con los } \\
\text { estudiantes o preguntan a los } \\
\text { estudiantes donde pueden encontrar } \\
\text { ellos mismos sus propios materiales. }\end{array}$ \\
\hline $\begin{array}{l}\text { Los docentes ven a los alumnos } \\
\text { como vasos vacíos o pizarras en } \\
\text { blanco que deben llenar. }\end{array}$ & $\begin{array}{l}\text { Los docentes ven a los alumnos } \\
\text { como pensadores valiosos } \\
\text { cuyas ideas y teorías son } \\
\text { importantes para el proceso de } \\
\text { aprendizaje. }\end{array}$ & $\begin{array}{l}\text { Los docentes muestran a los alumnos } \\
\text { que sus pensamientos son respetados } \\
\text { y colaboran con ellos en el proceso de } \\
\text { aprendizaje. }\end{array}$ \\
\hline $\begin{array}{l}\text { Los docentes proporcionan la } \\
\text { información de manera expositiva. }\end{array}$ & $\begin{array}{l}\text { Los docentes actúan como } \\
\text { facilitadores y mediadores de } \\
\text { aprendizaje. }\end{array}$ & $\begin{array}{l}\text { Los docentes facilitan el desarrollo de } \\
\text { los alumnos como líderes y } \\
\text { planificadores de su propio } \\
\text { aprendizaje. }\end{array}$ \\
\hline $\begin{array}{l}\text { Los docentes se centran en las } \\
\text { preguntas correctas (razonamiento } \\
\text { convergente) para validar el } \\
\text { aprendizaje. }\end{array}$ & $\begin{array}{l}\text { Los docentes buscan las } \\
\text { perspectivas de los alumnos, } \\
\text { de tal manera que ellos pueden } \\
\text { saber cómo abordar mejor los } \\
\text { conceptos erróneos y el } \\
\text { dominio. }\end{array}$ & $\begin{array}{l}\text { Los docentes usan las perspectivas de } \\
\text { los alumnos para planificar e } \\
\text { implementar decisiones del } \\
\text { currículum. }\end{array}$ \\
\hline $\begin{array}{l}\text { Los docentes ven la evaluación } \\
\text { como un aspecto separado de la } \\
\text { enseñanza. }\end{array}$ & $\begin{array}{l}\text { Los docentes evalúan a los } \\
\text { alumnos, quienes aprenden } \\
\text { mediante una variedad de } \\
\text { productos. }\end{array}$ & $\begin{array}{l}\text { Los docentes y los alumnos colaboran } \\
\text { para determinar una evaluación } \\
\text { auténtica de los productos. }\end{array}$ \\
\hline $\begin{array}{l}\text { Los docentes asignan el trabajo de } \\
\text { manera individual. }\end{array}$ & $\begin{array}{l}\text { Los alumnos trabajan en } \\
\text { grupo. }\end{array}$ & $\begin{array}{l}\text { Los alumnos trabajan de la manera } \\
\text { que mejor satisface sus aprendizajes. }\end{array}$ \\
\hline
\end{tabular}

Nota. Fuente: Waterman, S.S. (2007). The Democratic Differentiated Classroom. New York: Eyes on education.

En el capítulo de los resultados, del presente estudio, se aporta más luz en cuanto a los vínculos y alianzas entre la diferenciación pedagógica y la participación democrática en el aula inclusiva, para ello se propone un mapa teórico relacional. 


\subsection{Algunas pistas de acción: cómo articular los presupuestos teóricos en la práctica educativa}

Siguiendo a Guarro (2016), las decisiones del docente a la hora de construir el currículum deben ser equitativas para todo el alumnado. Crear una escuela inclusiva en la cual se reconozca, valore y respete a todo el alumnado supone prestar atención tanto a lo que se enseña como al modo de enseñarlo (Stainback y Stainback, 1999). Por tanto, es necesario crear ambientes de aprendizaje donde todos los estudiantes puedan aprender sean cuales sean sus características (Arnaiz, 2011) y evitar, de esta manera, el modelo de déficit. Ante este propósito los maestros nos podemos preguntar ¿Cómo me divido el tiempo, los recursos, y cómo me divido yo mismo, para ser un catalizador eficaz que potencie al máximo el talento de todos mis estudiantes? (Tomlinson, 2008, p.16). La intención de este epígrafe es intentar aportar algunas pistas de actuación que nos ayuden a articular los presupuestos teóricos que se vienen desarrollando en la práctica didáctica del aula.

Siguiendo con la autora anteriormente citada, se considera de vital importancia enfatizar en la idea de que no hay una única forma para crear un aula diferenciada. Asimismo, la diferenciación puede adoptar varias formas, ésta puede ser mecánica (aplicación más rígida a partir de una evaluación diagnóstica) o regularizada (ajustándola a medida que se va realizando) y planificada o espontánea. Una autentica diferenciación se da cuando es planificada, simultanea, regularizada y tiene en cuenta los cuatro ejes de diferenciación: estructuras, contenido, proceso y producto (Tomlinson, 2008; Carron 2008 y Leroux, Fontaine y Sinclair, 2015). Además, la diferenciación, en términos generales se puede graduar de máxima a mínima. En palabras de Aylwin, (1992):

La diferenciación es mínima cuando se limita a ofrecer, en el aula, en conjunto, una cierta variedad de medios de comunicación, modos de interacción, las operaciones intelectuales, enfoques de aprendizaje y ejercicios y la diferenciación es máxima cuando ofrece a cada alumno la elección de la fórmula de enseñanza (cursos, tutorías, trabajo en equipo...), contenido (dentro de un menú), ritmo de estudio (en el trimestre), la forma de evaluación o de producción (según convenciones planificadas), y así sucesivamente. (p.33)

Seguidamente, se van a revisar los principales elementos que permiten poner en práctica la diferenciación pedagógica y favorecen la participación democrática en el aula inclusiva. En un primer momento, se abordan los elementos que subyacen ante la diferenciación de las estructuras: agrupamiento y modalidades de trabajo, tiempo, espacio y recursos (Leroux y Paré, 2016). Posteriormente, se realiza un breve repaso sobre algunas metodologías didácticas inclusivas y democráticas que ayudan en la diferenciación del contenido y del proceso. Siguiendo a Pujolàs (2003), una metodología didáctica que atienda a la diversidad del alumnado se debe centrar en estrategias que apoyen a la personalización de la enseñanza y del aprendizaje (p.ej. planes de trabajo 
personalizado o contratos de aprendizaje), el aprendizaje cooperativo y los mecanismos de regulación, coregulación y autorregulación del aprendizaje. La autoregulación o la self-regulation es un elemento clave que ayuda a potenciar la enseñanza diferenciada (Bender, 2012; Gregory y Chapman, 2013). Cuando más alumnos autónomos haya en el aula, más posibilidad tendrá el docente de estar con aquellos que más lo necesiten. Por tanto, es importante que se dé en el contexto educativo: 1) la regulación de las actividades de enseñanza y aprendizaje por parte del docente tomando en consideración las necesidades de su alumnado, 2) la autoregulación por parte de los alumnos en referencia a sus propios aprendizajes y 3) la coregulación o regulación mutua, es decir, la ayuda entre iguales a partir del aprendizaje cooperativo (Pujolàs, 2003). Finalmente, se termina este bloque de contenidos con algunos aspectos a tener en consideración en referencia a la evaluación inclusiva y democrática (diferenciación del producto).

\subsubsection{Organización del aula: diferenciación de las estructuras}

En los primeros elementos que se focaliza para organizar el aula inclusiva y materializar los presupuestos teóricos desarrollados son los referentes a la diferenciación de las estructuras, tal como se ha introducido, éstos hacen referencia a los diferentes agrupamientos y modalidades de trabajo, a la gestión del tiempo, los espacios y los recursos o apoyos utilizados o que intervienen a lo largo del proceso de enseñanza- aprendizaje. En la Tabla 11 se presentan los elementos, que según Leroux y Paré (2016), permiten diferenciar las estructuras.

Tabla 11

Diferenciación de las estructuras

\section{DIFERENCIACIÓN DE LAS ESTRUCTURAS}

La perspectiva inclusiva aboga por actividades que requieren de agrupamientos heterogéneos de estudiantes, con éstos se favorece la colaboración entre los alumnos, potenciando la calidad y equidad educativa al mismo tiempo que aumenta la motivación del alumnado hacia la tarea (Muntaner, 2014). Por tanto, en palabras de Baines, Blatchford y Kutnick (2016), crear un ambiente inclusivo a través de la estructuración del aula en grupos eficaces fomenta las habilidades sociales, comunicativas y la ayuda mutua, y al mismo tiempo propicia una participación más activa, más enfocada en la tarea y con mayores niveles de logro.

Tipo de agrupamientos y modalidades de trabajo
La agrupación flexible es un rasgo característico de la diferenciación de la enseñanza (Heacox, 2002; Gregory y Chapman, 2013), ya que en ésta se promueven varias formas de agrupamiento y modalidades de trabajo, por ejemplo, combinando el trabajo individual, con el trabajo en parejas (p.ej. leemos en pareja propuesto por Duran y Monereo, 2003), en pequeño grupo (aprendizaje cooperativo) y en el grupo clase. Por lo que respecta a las agrupaciones, Pujolàs (2003) propone la distribución del alumnado en tres tipos de equipos: 1 ) de base (son permanentes, mínimo un trimestre y heterogéneos), 2) esporádicos (se forman a lo largo de una clase y como mucho duran el tiempo de una sesión) y 3) de expertos (redistribución de los equipos de base durante algunas sesiones de clase). Los grupos de aprendizaje cooperativo presentan 5 características esenciales (Johnson, Johnson y Holubec, 1999): 1) interdependencia 
positiva (uno depende de los compañeros y los compañeros dependen de uno), 2) responsabilidad individual (rol o tarea a desempeñar), 3) interacción personal (trabajo codo a codo), 4) integración social (resolución de conflictos) y 5) evaluación grupal (reflexión sobre su propio trabajo y de la manera en que se ha realizado). A estos 5 componentes, Kagan (1999) añade dos más: 6) participación igualitaria e 7) interacción simultánea.

La asamblea es otro mecanismo a través del cual los alumnos pueden participar o deliberar (Poveda, Sebastián y Moreno 2003; Pujolàs, 2003; Bolívar, 2016). Campbell (2008) en su propuesta de diferenciación de la enseñanza a partir de las inteligencias múltiples propone grupos de estudiantes teniendo en cuenta las siguientes consideraciones: 1) agrupación de capacidades mixtas; 2) agrupación de género mixto; 3) roles o cargos para la gestión del grupo (liderazgo compartido); 4) la agrupación cambia cada mes y 5) el grupo trabaja un centro de interés. Waterman (2007), en la misma línea, explica que uno de los aspectos más importantes del aula democrática diferenciada es la habilidad del docente en organizar grupos efectivos de alumnos que se ayuden entre ellos en el aprendizaje. Siguiendo con la misma autora, los grupos pueden estar basados en: los estilos de aprendizaje, los intereses, las habilidades o capacidades, grupos seleccionados por los alumnos y grupos basados en la personalidad.

Asimismo, en palabras de Aylwin (1992), la diferenciación pedagógica puede ser colectiva o individual, según la forma de diferenciación de la tarea que esté realizando el grupo.

$\sim$ La diferenciación es colectiva cuando todos los alumnos están sujetos a las mismas formas de diferenciación. Como, por ejemplo, en el caso de los medios de comunicación utilizados por el docente ante todo el grupo, o las mismas operaciones son requeridas a todos los alumnos, o los mismos pasos para todos, etc.

$\sim$ La diferenciación es individual cuando cada subgrupo, o cada alumno tiene sus propios objetivos, sus contenidos, sus ejercicios, su forma de expresión y un tiempo asignado.

Bernal (2007) apunta que el tiempo es un recurso más en los procesos de enseñanzaaprendizaje que incide en el aprendizaje de los alumnos. Por tanto, éste debe de ser flexible y adaptarse a los ritmos y necesidades educativas y sociales. Éste mismo autor propone que se deberían de romper con las estructuras rígidas, ya que éstas fragmentan tanto los horarios como el conocimiento.

Los propulsores de la diferenciación pedagógica establecen que ésta, en cuanto a su materialización en el tiempo, puede ser simultánea o sucesiva (Aylwin, 1992; Meirieu, 1997; Tomlinson, 2008; Caron, 2008; Leroux, Fontaine y Sinclair, 2015).

$\sim$ La diferenciación es simultánea cuando:

Se ofrecen simultáneamente diferentes tareas o ejercicios a varios subgrupos, en función de sus intereses, habilidades o ritmos, haciendo que unos hagan, por

Gestión del tiempo ejemplo, un estudio de caso, otros respondan a unas cuestiones relacionadas con un texto, otros comparen y corrigen el texto de sus ensayos, otros resuelvan un problema... Cuando el docente utiliza diversos medios de comunicación: explicación, transparencias, texto, objetos... o cuando los alumnos hacen varias acciones en el mismo tiempo: lectura, debate, escritura, usando una variedad de operaciones intelectuales (Aylwin, 1992, p.32).

$\sim$ La diferenciación es sucesiva cuando:

La variedad se encuentra en las etapas: exposición magistral, después ejercicios individuales, después discusiones en subgrupo, después asamblea, después trabajo para casa... o en las secuencias de las operaciones intelectuales: definición, estudio de caso, aplicaciones, resolución de problemas, etc. Una u otra forma de variación oscila en un periodo de tiempo más o menos corto (Aylwin, 1992, p.32).

La diferenciación simultánea es más difícil de lograr, pero es también la que respeta de una forma continua todas las diferencias individuales del grupo. 


\begin{tabular}{|c|c|c|}
\hline $\begin{array}{r}\text { Espacio } \\
\text { aprendiz } \\
\text { disposic } \\
\text { física del }\end{array}$ & & $\begin{array}{l}\text { Laorden y Pérez (2002) conciben el espacio como un elemento facilitador del } \\
\text { aprendizaje, para ello es necesario organizarlo y estructurarlo adecuadamente. } \\
\text { Para diferenciar las tareas, los agrupamientos, los tiempos... se precisa de una } \\
\text { distribución espacial que posibilite y facilite la autonomía en el trabajo (Puigdellívol, } \\
\text { 1998, Pujolàs, 2003). Carrión y Sánchez Palomino (2002) proponen una distribución de } \\
\text { aula como espacio versátil que favorezca la comunicación, la interacción y el trabajo } \\
\text { individual, en grupo y de toda la clase. Esta distribución consiste en que las mesas } \\
\text { estén dispuestas en grupos de } 4 / 5 \text { y que faciliten sin la necesidad de cambiar de } \\
\text { disposición del mobiliario, la realización de las actividades en las que participa toda la } \\
\text { clase (p.ej.: asambleas, exposiciones...). Las mesas (agrupadas con espacio para } 4 / 5 \\
\text { alumnos) deben estar dispuestas en semicírculo, con una amplia zona central. Estos } \\
\text { aspectos favorecerán tanto un buen espacio físico como un adecuado ambiente físico. } \\
\text { El espacio físico es la zona donde se realizan las actividades y el ambiente físico alude } \\
\text { a las relaciones interpersonales que se establecen en él (Iglesias, 1996). Éste último } \\
\text { coincide con la propuesta de Illán (2011), la cual defiende el aula como un espacio de } \\
\text { interacción propicio para fomentar las habilidades sociales y las relaciones humanas. } \\
\text { La diferenciación pedagógica, en cuanto a los espacios, se puede dar en clase o fuera de } \\
\text { ésta (Aylwin, 1992, p.33): } \\
\text { La diferenciación en el aula es más compleja de organizar, ya que debe gestionar la } \\
\text { variedad de enfoques en el mismo tiempo, en un mismo lugar y en una misma } \\
\text { duración. } \\
\text { La diferenciación fuera del aula se hace simultáneamente en diferentes espacios } \\
\text { (biblioteca, laboratorios, salas de trabajo, clase, etc.) o se hace en tiempos y } \\
\text { espacios distintos, de esta manera es más fácil de manejar, ya que cada alumno o } \\
\text { subgrupo es responsable de la gestión de su trabajo. }\end{array}$ \\
\hline $\begin{array}{c}\text { Recursos } \\
\text { o } \\
\text { apoyos }\end{array}$ & 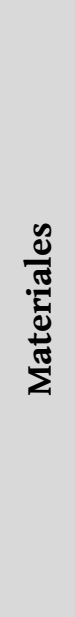 & $\begin{array}{l}\text { Asensio y Forteza (2014) apoyan su trabajo en la idea de que una escuela que se centra } \\
\text { exclusivamente en el libro de texto ofrece una educación que excluye. Y en efecto, los } \\
\text { recursos materiales que se emplean en el aula diferenciada son muy diversos y } \\
\text { variados (libros, textos, carteles, guías, sitios Web...), favoreciendo que cada } \\
\text { estudiante haga uso de los recursos que precise en función de sus necesidades de } \\
\text { aprendizaje y habilidades (Heacox, 2002). } \\
\text { Siguiendo a Parcerisa (1996), tomar en consideración la heterogeneidad en el aula } \\
\text { requiere, desde una perspectiva democrática y participativa, que el docente tome las } \\
\text { decisiones curriculares y sea capaz de elaborar, seleccionar y utilizar los recursos } \\
\text { materiales que mejor convengan a su práctica educativa con el fin de propiciar un } \\
\text { aprendizaje significativo en su alumnado. } \\
\text { No podemos pasar por alto, en la sociedad de la información en la cual estamos } \\
\text { inmersos, el potencial que ofrecen las Tecnologías de la Información y la } \\
\text { Comunicación (TIC) en el aula (Montserrat y Hernández, 2013). }\end{array}$ \\
\hline
\end{tabular}




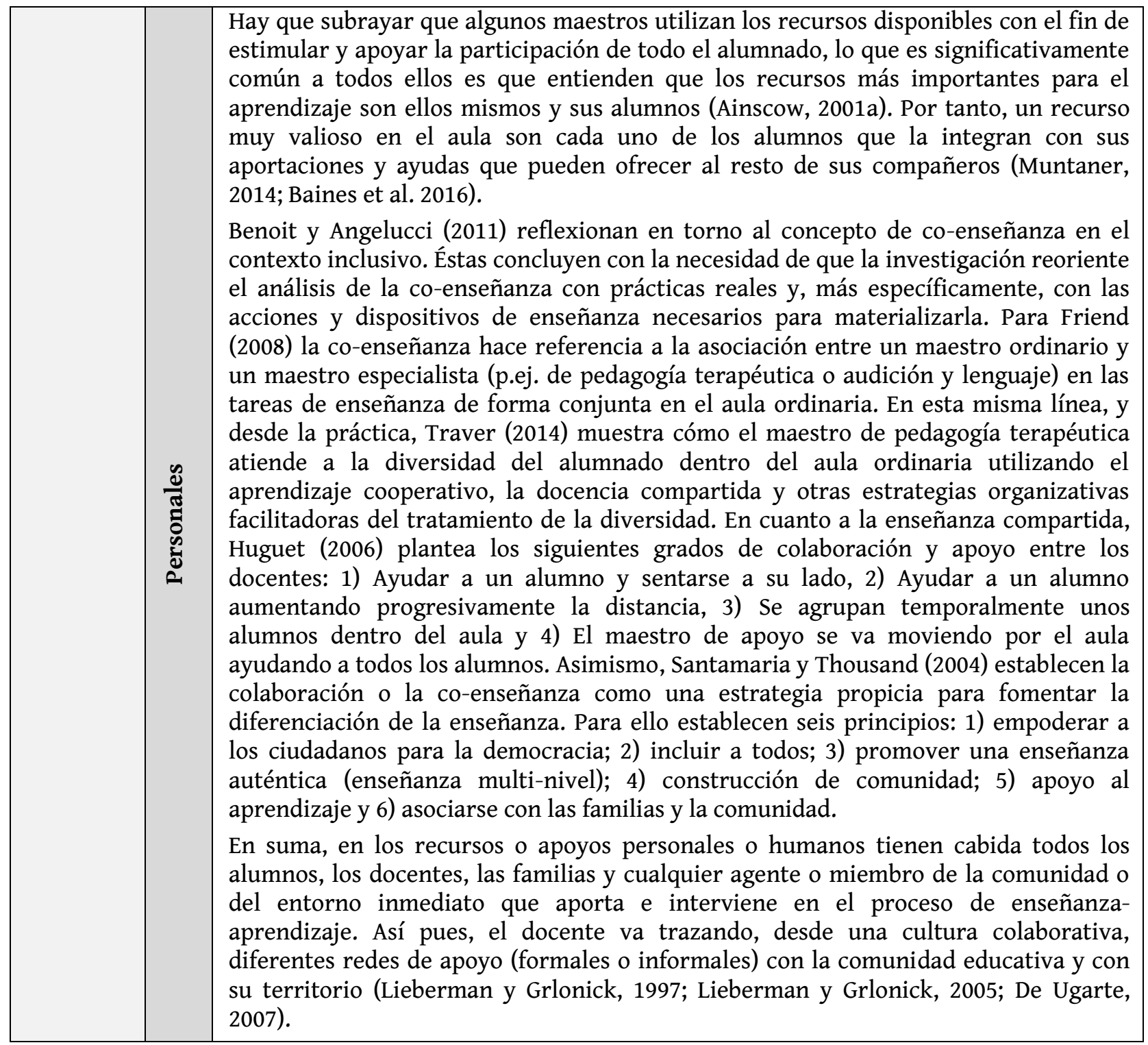

Nota. Elaboración propia a partir de la literatura consultada.

\subsubsection{Metodologías didácticas inclusivas $y$ democráticas: diferenciación del contenido y del proceso}

Existen diferentes estrategias o metodologías que ayudan y promueven una enseñanza diferenciada, según la literatura consultada estas pueden ser: trabajo en equipo, tutoría, aprendizaje por módulos, enseñanza programada, aprendizaje autorregulado, paneles, seminarios, discusiones o debates, juegos de rol, demostraciones, laboratorio, prácticas, proyectos, entrevistas, estudio de casos, investigaciones, lecturas individuales, diarios y diversidad de producciones escritas (Aylwin, 1992); estaciones, centros, agendas, instrucción compleja, actividades escalonadas, contrato de aprendizaje, aprendizaje basado en la resolución de problemas, investigación en grupo y paneles de elección (Tomlinson, 2008); construcción de conocimientos de fondo a través de lectura silenciosa sostenida, desarrollo del vocabulario: característica de la enseñanza de vocabulario directo eficaz, 
aprendizaje basado en problemas (ABP), ideas cinestésicas, elecciones, equipos de investigación, ampliar el aprendizaje más allá de las paredes del aula, seminarios en pequeños grupos, revistas de doble entrada y discurso de un minuto (Waterman, 2007); inteligencias múltiples, centros y proyectos (Campbell, 2008); centros, proyectos, tabla de elecciones, aprendizaje basado en problemas (ABP) y contratos académicos (Gregory y Chapman, 2013); flipped classroom, aprendizaje basado en problemas (ABP), aprendizaje basado en proyectos y centros de interés (Brender, 2012); talleres, plan de trabajo, tutoría, actividad en "peldaños", índices y proyectos personales o colectivos (Descampe, Robin y Tremblay, 2014). Seguidamente, en la Tabla 12, se hace un repaso sobre algunas estrategias metodológicas que se ilustran en la parte empírica de esta tesis doctoral. Se es consciente que existen otras, como las ya citadas o como es el caso del APS- aprendizaje servicio (Batlle, 2013) que pensamos que también contribuyen al marco educativo defendido en este trabajo, pero no se abordan de manera detallada puesto que están ampliamente referenciadas en la literatura existente.

Tabla 12

Diferenciación del contenido y del proceso: algunas estrategias metodológicas

\begin{tabular}{|c|}
\hline DIFERENCIACIÓN DEL CONTENIDO Y DEL PROCESO \\
\hline 1. Estrategias de aprendizaje cooperativo: cultura colaborativa y ayuda mutua \\
\hline $\begin{array}{l}\text { Enmarcados en la diferenciación de la enseñanza, Corno y Snow (1986) señalan la gran utilidad del } \\
\text { aprendizaje cooperativo para aumentar la mediación y la ayuda entre iguales, la cual cosa fomenta un } \\
\text { aprendizaje más autónomo. López, Salmerón y Salmerón (2010) manifiestan que el aprendizaje } \\
\text { cooperativo es eficiente para el desarrollo de la competencia social y ciudadana. Por tanto, es importante } \\
\text { fomentar una interacción cooperativa en el aula, en lugar de una interacción más competitiva o } \\
\text { individualista (Pujolàs, 2003; 2008). Siguiendo con las aportaciones de este último autor referenciado, } \\
\text { existen tres ámbitos de intervención para implementar el aprendizaje cooperativo: a) cohesión de grupo, } \\
\text { b) trabajar en equipo como recurso para enseñar y c) trabajar en equipo como recurso que hay que } \\
\text { enseñar. Las estructuras cooperativas pueden ser más simples o más complejas. Para una descripción } \\
\text { detallada de las estrategias del aprendizaje cooperativo véase: }\end{array}$ \\
\hline
\end{tabular}

EL PROGRAMA CA/AC: ("Cooperar para Aprender / Aprender a Cooperar") PARA APRENDER A ENSEÑAR EN EQUIPO. Implementación del aprendizaje cooperativo en el aula.

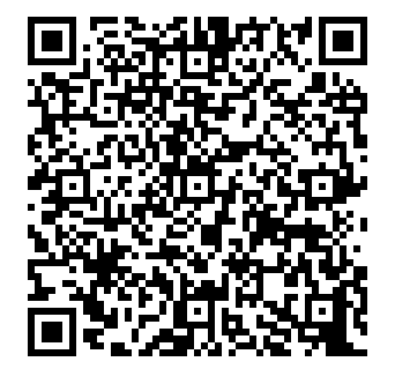




\begin{tabular}{|c|c|}
\hline $\begin{array}{c}\text { 1.a) } \\
\text { Roles y } \\
\text { técnica de la } \\
\text { instrucción } \\
\text { compleja: } \\
\text { hacia un } \\
\text { liderazgo } \\
\text { compartido }\end{array}$ & $\begin{array}{l}\text { Según Tomlinson (2008) la técnica de la instrucción compleja requiere reflexión } \\
\text { (generar ideas, plantear cuestiones, representar conceptos simbólicos) y planificación, } \\
\text { ayuda a construir un aula en la que se valoran las contribuciones de todos los alumnos, } \\
\text { recibiendo todos una enseñanza de calidad. La máxima representante de esta técnica es } \\
\text { Cohen (1999), la cual profundiza en el trabajo en pequeños grupos heterogéneos } \\
\text { mediante propuestas orientadas a la resolución de problemas de solución múltiple o } \\
\text { que impliquen simultáneamente diversas habilidades. Esta autora propone la asunción } \\
\text { por parte de cada miembro del grupo de un rol determinado y claramente definido. Así } \\
\text { pues, esta técnica consiste en la asignación o distribución de roles entre los } \\
\text { componentes de cada grupo para que cada miembro se ocupe de la gestión y } \\
\text { organización del trabajo. A través, de la asunción de diferentes responsabilidades, se } \\
\text { mantienen activos todos los miembros. Se organizan algunas sesiones de trabajo en } \\
\text { grupos de } 5 \text { personas y se asigna un rol o tarea diferente a cada miembro. En cada tema, } \\
\text { se produce una rotación en la asignación de roles, de manera que cada integrante } \\
\text { trabaje en una tarea diferente cada vez. }\end{array}$ \\
\hline $\begin{array}{c}\text { 1.b) } \\
\text { Algunas } \\
\text { estructuras } \\
\text { simples de } \\
\text { aprendizaje } \\
\text { cooperativo }\end{array}$ & 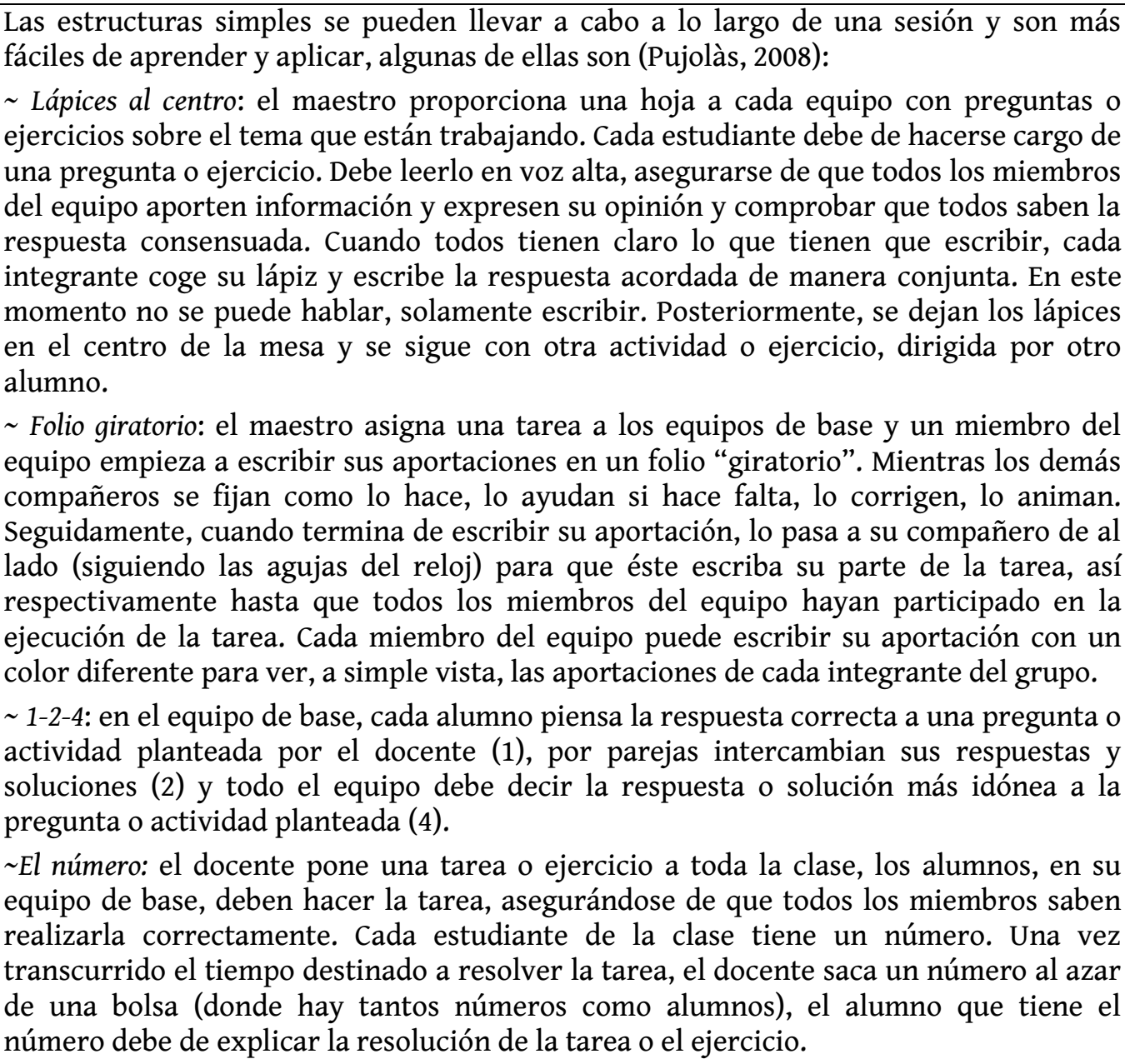 \\
\hline \multirow{3}{*}{$\begin{array}{l}\text { 1.c) } \\
\text { Algunas } \\
\text { estructuras } \\
\text { complejas de } \\
\text { aprendizaje } \\
\text { cooperativo }\end{array}$} & 1.c.1) Tutoría entre iguales (peer tutoring) \\
\hline & $\begin{array}{l}\text { La tutoría entre iguales se puede definir como un método de aprendizaje cooperativo } \\
\text { basado en la confección de parejas, con una relación asimétrica, emanada de las tareas } \\
\text { características de cada uno de los roles (tutor y tutorado), donde ambos alumnos tienen } \\
\text { un objetivo compartido que es el aprendizaje o mejora de alguna competencia } \\
\text { curricular, que se adquiere a través de una interacción planificada por el docente } \\
\text { (Duran, Torró y Vila, 2003). }\end{array}$ \\
\hline & $\begin{array}{l}\text { Moliner (2015) recoge dos subtipos de esta actividad, esto es, la tutoría entre iguales } \\
\text { puede ser recíproca (existe un intercambio de roles y las parejas que se forman deben de } \\
\text { tener niveles de competencias similares) o fija (no existe un cambio de roles, es decir, el } \\
\text { tutor es siempre tutor y el tutorado siempre desempeña dicho rol). Asimismo, existe } \\
\text { una clasificación de la misma según la edad de los participantes: diferentes edades }\end{array}$ \\
\hline
\end{tabular}




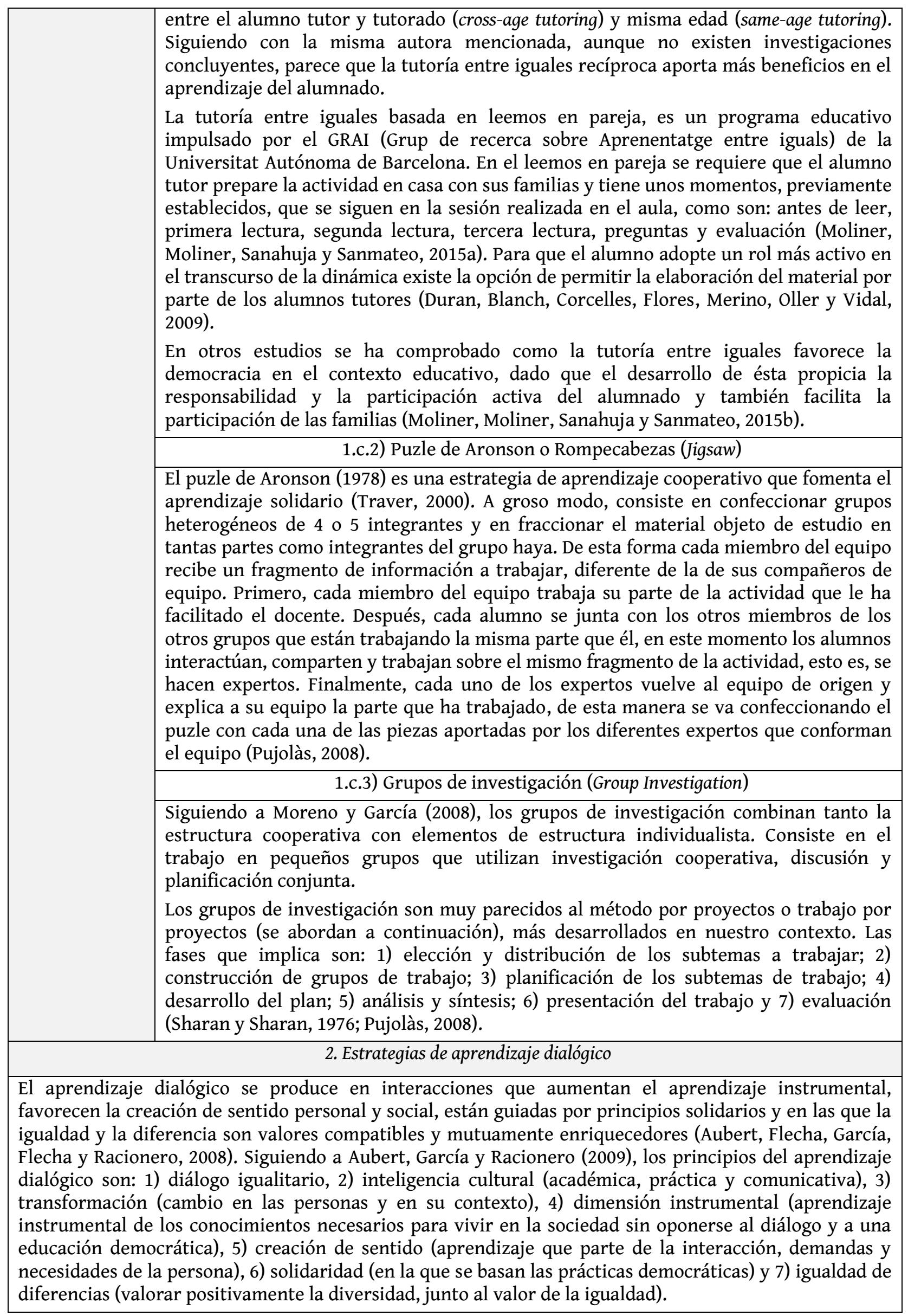


Dos estrategias que ayudan a materializar el aprendizaje dialógico en el aula son la tertulia literaria dialógica y los grupos interactivos.

La tertulia literaria dialógica consiste en que un grupo de personas se reúna para reflexionar y dialogar a partir de un libro considerado de la literatura clásica universal (Aguilar, Pallarés y Traver, 2013). Siguiendo a estos últimos autores referenciados, el diálogo igualitario, la ayuda mutua y la comprensión conjunta se convierten en tres elementos básicos que ayudan a cada una de las personas asistentes a transformar la realidad a partir del acto lector.

Por tanto, a partir de un acontecimiento comunicativo y a través del diálogo se procede a iniciar un proceso de interpretación interactiva de los textos leídos (Pulido y Zepa, 2010). Previamente a la sesión se escoge la lectura a realizar y se marca el fragmento que se debe de leer. La persona que asume el rol del moderador es quien se encarga de fomentar la participación de los asistentes y dar los turnos de palabra, en la sesión se crea un clima en el que todos pueden aportar y dialogar desde su propia experiencia.

2.a)

Tertulia literaria dialógica

2.b)

Grupos interactivos
Un estudio realizado por Hargreaves y García-Carrión (2016) concluye que la tertulia literaria dialógica es una acción que fomenta la inclusión y la cohesión social, propiciando que más del $75 \%$ de la clase participe en el diálogo y contribuya en un $80 \%$ a la tertulia. Además, esta metodología aumenta la motivación y el logro hacia la lectura.

Hay que mencionar que, últimamente, están aflorando diversos tipos de tertulias dialógicas como las musicales, artísticas, matemáticas, científicas, pedagógicas... Para saber más sobre esta tipología de tertulias véase:

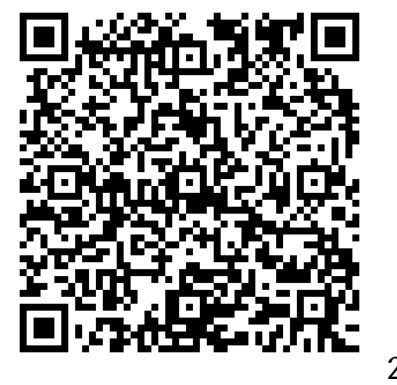

Uno de los autores de referencia es Vygotsky (1978), con su aporte sobre la perspectiva constructivista del aprendizaje, el cual entiende el acto de aprender como un acto social en el cual el sujeto es protagonista de múltiples interacciones.

Los grupos interactivos son un modo de trabajo en clase que se beneficia de los parámetros emanados del aprendizaje dialógico, de las interacciones entre las personas y para ello, el alumnado se agrupa de manera heterogénea bajo la tutela de una persona adulta, cuya responsabilidad es garantizar la participación de todos sus miembros (Chocarro y Sáenz, 2016).

Así pues, los grupos interactivos son una forma flexible de organizar el trabajo educativo en el aula. Consisten en intensificar el aprendizaje a través de las interacciones que se establecen entre todos los participantes (alumnos, docentes, voluntariado...). Se favorece la interacción entre los iguales y se impulsa el trabajo en equipo, ya que se trata de conseguir unos objetivos compartidos a través de las contribuciones de cada uno de los miembros del grupo. El principio básico de este procedimiento es ampliar el intercambio de conocimientos mediante una trama de interacciones entre el alumnado y entre el alumnado y las personas adultas (voluntarios) que estén en el aula (Flecha y Puigvert, 2002).

En palabras de Peirats y López (2013), el docente adopta un rol de facilitador y coordinador. Éste gestiona los tiempos y señaliza el cambio de actividad, esto es, transcurridos aproximadamente unos 10 minutos, los alumnos cambian de mesa donde hay un nuevo voluntario con otra tarea a realizar. 


\begin{tabular}{|c|c|}
\hline \multicolumn{2}{|r|}{ 3. Estrategias de aprendizaje interdisciplinares y globalizadas } \\
\hline $\begin{array}{l}\text { Proyectos de } \\
\text { trabajo }\end{array}$ & 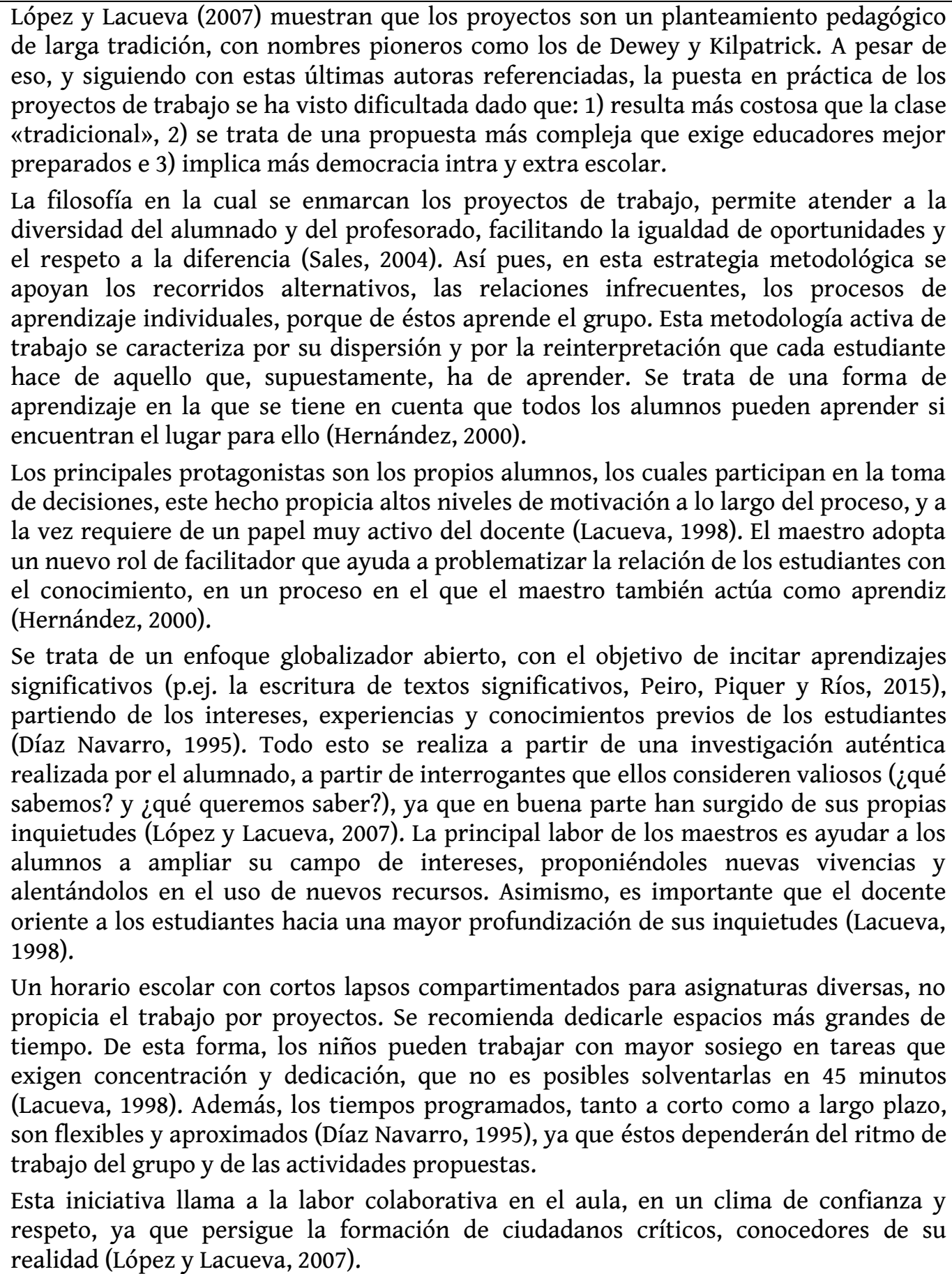 \\
\hline $\begin{array}{l}\text { 3.b) } \\
\text { Rincones de } \\
\text { trabajo }\end{array}$ & $\begin{array}{l}\text { Siguiendo a Laguía y Vidal (2008), el trabajo por rincones no es una metodología nueva, } \\
\text { sino que más bien cuenta con una amplia tradición escolar y con pioneros como Dewey, } \\
\text { Kilpatrick y Freinet. } \\
\text { En otros estudios hemos podido comprobar cómo esta metodología de trabajo apoya la } \\
\text { importancia del papel inclusivo que tiene la organización del aula (Benet, Sanahuja y } \\
\text { Moliner, 2016). En la misma dirección, y según Gispert y Ribas (2010), los rincones } \\
\text { permiten atender a la diversidad de estilos, niveles y situaciones de aprendizaje, ya que } \\
\text { el alumnado puede realizar actividades diversas y simultáneas que funcionan al mismo } \\
\text { tiempo. Así pues, los rincones son una forma de organizar el trabajo en el aula que } \\
\text { permite al alumnado actuar con autonomía y decidir sobre las actividades que quiere } \\
\text { realizar en función de sus necesidades e intereses (Martín y Vieira, 2000). Continuando } \\
\text { con estas últimas autoras citadas, el desarrollo del trabajo por rincones cuenta con tres }\end{array}$ \\
\hline
\end{tabular}




\begin{tabular}{|c|c|}
\hline & $\begin{array}{l}\text { momentos esenciales: i) la asamblea (entre todos planifican lo que se va a hacer en los } \\
\text { diferentes rincones), ii) el trabajo en cada uno de los rincones y iii) la puesta en común. } \\
\text { En palabras de Jiménez y Vilà (1999), los rincones pueden ser realizados de manera } \\
\text { individual o en pequeño grupo, pueden ser lúdicos o de trabajo y abordan todas las } \\
\text { áreas curriculares, aunque son más adecuados para el aprendizaje de las áreas } \\
\text { instrumentales. } \\
\text { El trabajo por rincones consiste en organizar la clase en pequeños grupos de manera } \\
\text { que se permita a los alumnos escoger las actividades que quieran realizar, se } \\
\text { incorporan diferentes utensilios y materiales y el alumno adopta un rol activo a través } \\
\text { de la realización de actividades manipulativas y con sentido (Laguía y Vidal, 2008). } \\
\text { Aunque principalmente los rincones de trabajo son una estrategia ampliamente } \\
\text { utilizada en la educación infantil, existen cada vez más experiencias que se incorporan } \\
\text { en la educación primaria. Un buen ejemplo de ello es la propuesta de Majó (2016), en la } \\
\text { que se realizan diferentes rincones de ciencias para promover el desarrollo personal } \\
\text { del alumnado mediante valores como el trabajo en equipo, la curiosidad por investigar } \\
\text { el entorno, el rigor en el trabajo, la imaginación en la resolución de problemas y la } \\
\text { perseverancia para alcanzar los objetivos propuestos. }\end{array}$ \\
\hline $\begin{array}{c}\text { 3.c) } \\
\text { Aprendizaje } \\
\text { en estaciones }\end{array}$ & $\begin{array}{l}\text { Las estaciones son diferentes puntos de trabajo dentro del aula, donde los alumnos se } \\
\text { ocupan, simultáneamente, realizando diferentes actividades. Éstas se diferencian de los } \\
\text { centros de aprendizaje en que éstos últimos son nítidamente diferentes (los alumnos no } \\
\text { necesitan realzar todos los centros), esto es, las estaciones funcionan de manera } \\
\text { coordinada (Tomlinson, 2008). En la misma línea, Espiñeira (2005) explica que estas } \\
\text { están dispuestas en diferentes espacios del aula, de tal modo que los alumnos deben de } \\
\text { ir realizando un recorrido de aprendizaje o circuito de aprendizaje. Los estudiantes se } \\
\text { encuentran, en cada estación, ante una actividad que deben realizar de forma } \\
\text { individual, en pareja o en grupo. } \\
\text { Suazo (2006) a través de su trabajo sobre cómo aplicar las inteligencias múltiples en el } \\
\text { aula defiende la idea de presentar } 8 \text { estaciones, esto es, una para cada una de las } \\
\text { diferentes inteligencias múltiples. }\end{array}$ \\
\hline $\begin{array}{c}\text { 3.d) } \\
\text { Talleres } \\
\text { didácticos }\end{array}$ & $\begin{array}{l}\text { Los talleres didácticos fomentan la interrelación grupal interclase e interciclo (Ibáñez, } \\
\text { 1995). Fillat y Silva (2000), valoran el hecho de que el trabajar por talleres aporte } \\
\text { flexibilidad en la organización del aula, autonomía y motivación para el alumno, } \\
\text { favorezcan el trabajo en equipo y apoyen la atención a la diversidad de los estudiantes. } \\
\text { Entre las ventajas de orden psicopedagógico de los talleres, Trueba (1999) apunta que } \\
\text { se basan en la socialización y se multiplican las posibilidades de fomentar la } \\
\text { cooperación y el aprendizaje en la interacción tanto entre los iguales como si hay algún } \\
\text { adulto. }\end{array}$ \\
\hline
\end{tabular}

Nota. Elaboración propia a partir de la literatura consultada. 


\subsubsection{Evaluación inclusiva y democrática: diferenciación del producto}

Elola y Toranzos (2000), en su trabajo Evaluación Educativa: una aproximación conceptual, recogen en la siguiente escena los significados más frecuentes que suscita, a los docentes, el acto de evaluar:

Son las cuatro de la tarde de un miércoles cualquiera en una escuela, los profesores van entrando a la sala de profesores para iniciar una reunión de trabajo. Sería un miércoles cualquiera sino fuera porque se aproxima el fin de curso. Ya se sabe, en estos últimos días son siempre especiales: se incrementa el ritmo de trabajo, hay más prisa y tensiones. También aflora el cansancio acumulado durante todo el año y resulta inevitable la saturación de exámenes, notas, informes, entrevistas finales, etc... Se nota cierta mezcla de disgusto y desazón.

- ¿y si no existieran las evaluaciones? -pregunta una profesora de lengua mientras se deja caer en una silla.

- ¡cómo cambiaría todo!... nos dedicaríamos sólo a enseñar, que de hecho es lo nuestro, ¿no les parece? Podríamos emplear el tiempo en otras cosas, porque siempre nos falta tiempo jal menos a mí! - responde otra profesora responsable del área de matemática.

-Es cierto, si no fuera por la cantidad de pruebas y observaciones que hacemos podríamos desarrollar más los contenidos y no tendríamos la sensación de ir siempre contrarreloj. Además, no sé ustedes, pero yo después del primer trimestre ya sé cómo terminarán el curso mis alumnos- comenta una tercera docente.

-Estoy de acuerdo, tanto control, tanto control, resulta exasperante. Pero suprimir las evaluaciones.... eso es soñar.

-No sé qué decirles, creo que depende mucho de cómo se lo tome uno, de cómo se organice; creo que la evaluación podría servirnos mucho a nosotros como profesores porque...

-Vos leíste mucho sobre el tema - le interrumpe la profesora de matemática- pero el asunto es complicado, hace tiempo que hablamos sobre el tema y no encontramos una solución que nos convenza a todos, en todas las áreas...

A partir de este fragmento, las autoras, extraen las representaciones más comunes que tienen los docentes en torno a la evaluación: 1) la evaluación se asocia a los exámenes, 2) emisión de juicios de valor sobre los alumnos a partir de información muy elemental, 3) asociar la nota como un instrumento de control disciplinario (altas calificaciones -premios y bajas calificaciones- castigo), 4) desfase entre la teoría y la práctica (atender a la burocracia, falta de tiempo, rutina... práctica de evaluación más tradicional), 5) identificar evaluación en calificación (deterioro del concepto de evaluación educativa), 6) los instrumentos diseñados para la evaluación se centran en competencias cognitivas (reducidas principalmente a la memorización) y 7) connotaciones más frecuentes de la evaluación: i) control externo, ii) función penalizadora, iii) calcular el valor de una cosa, iv) calificación y v) grado de suficiencia o insuficiencia de determinados aspectos.

Ante este panorama y siguiendo las palabras de Sanmartí (2010), desarrollar un currículum por competencias y que respete la heterogeneidad del alumnado requiere un cambio de mirada en la evaluación. Esta autora establece dos funciones principales de la evaluación: 1) evaluar para regular los aprendizajes (dificultades y errores que emergen a lo largo del proceso de enseñanzaaprendizaje) y 2) evaluar para comprobar que se ha aprendido (valorar los resultados del proceso de enseñanza- aprendizaje).

Aprender a autorregular el aprendizaje, asumiendo autonomía en su planificación y evaluación, no es una tarea sencilla, para ello es necesario: 1) generar un contexto global apropiado, 2) propiciar 
marcos de actividad conjunta entre el maestro y los alumnos en los que sea factible el aprendizaje contextualizado de las estrategias más apropiadas en cada caso para afrontar la preparación, realización y supervisión de las actividades y tareas de evaluación y 3) proporcionar al alumnado diversas y variadas guías para el desarrollo de competencias de autorregulación (Rochera y Naranjo, 2007). El desarrollo de la capacidad de autorregularse requiere, según Sanmartí (2010), identificar los objetivos de la actividad, anticipar y planificar la acción de la actividad y compartir los criterios de evaluación.

A menudo, la evaluación del aprendizaje cooperativo supone un reto para los docentes. Naranjo y Jiménez (2015) establecen que se trata de una evaluación reguladora y formativa, a través de la cual los equipos van reflexionando y "modelando" su propio funcionamiento, consolidando lo que hacen bien y proponiéndose objetivos de mejora. Éstas proponen que en el Programa CA/AC la evaluación del "trabajo en equipo" contempla: 1) una valoración de las diferentes contribuciones de los integrantes del equipo en cuanto a su buena gestión y funcionamiento, 2) una evaluación independiente de la del equipo (p.ej. un equipo con una valoración baja en cuanto a su funcionamiento como equipo, la contribución de uno de sus miembros es alta) y 3) una evaluación individual (calificación). Los grupos pueden realizar la evaluación mediante el Diario de Sesiones y los Planes del Equipo. Una buena herramienta para ayudar a trabajar con los grupos cooperativos es la carpeta del equipo (Traver, Rodríguez y Caño, 2008; Traver y Rodríguez, 2010). Se trata de un instrumento que permite ayudar al alumnado a organizar y realizar las tareas delegadas y, al mismo tiempo, el docente puede, a partir de éstas, hacer un seguimiento de aquello que los equipos van realizando. Asimismo, la carpeta facilita y orienta el trabajo en grupos cooperativos estructurando las tareas que hay que hacer en torno a las siguientes preguntas: ¿Quiénes somos?, ¿Cómo nos organizamos?, ¿Qué queremos?, ¿Qué hacemos? y ¿Cómo nos valoramos? (Traver, 2007).

Para que la evaluación sea democrática es necesario que los alumnos participen y tengan voz en la misma. Siguiendo a Jiménez y Naranjo (2014), para los docentes el hecho de que los alumnos tomen parte de su propio aprendizaje y tengan responsabilidades en el mismo es importante. No obstante, éstas afirman que, en el ámbito B, del aprendizaje cooperativo, sólo el $2 \%$ de los maestros utiliza estructuras cooperativas con el propósito de evaluar. Del mismo estudio se extrae que el $81 \%$ del profesorado utiliza estructuras cooperativas al inicio de la unidad didáctica para extraer los conocimientos previos de los alumnos, pero no para ajustar el producto al programa didáctico. Y al final del proceso, el 19\% utiliza estructuras cooperativas con el objetivo de evaluar. Continuando con las aportaciones de López (2005), se precisa fomentar la participación del alumnado en los procesos de evaluación a partir de la autoevaluación (que el alumno se evalúe a él mismo), coevaluación (evaluación entre pares) y evaluación compartida (diálogo entre alumnado y docente sobre la evaluación del aprendizaje). López, González y Barba (2006) hablan de la evaluación democrática, la cual presenta las siguientes características básicas: importancia del intercambio de información; 
participación del alumnado en el proceso de evaluación; desarrollo de estrategias para la negociación y cogestión del currículum; existencia de unas relaciones de comunicación, diálogo y respeto entre profesorado y alumnado; avanzar hacia procesos de autocalificación, entendida como poder compartido y dialogado (calificación dialogada), y llevar a cabo una metaevaluación. Completando lo anterior, en palabras de Murillo y Hidalgo (2016), el rumbo que debe adoptar el sentido de la citada evaluación democrática de los alumnos consiste en: 1) empoderar a los alumnos en su propio proceso de aprendizaje, 2) pasar de la evaluación de los alumnos a la evaluación con los alumnos (estrategias de autoevaluación que fomenten la reflexión personal), 3) que el alumnado reflexione críticamente y aporte sus puntos de vista alternativos, creativos y críticos (no hay una "verdad única" que el maestro posee y el alumnado desconoce), 4) la justicia (atención diferencial a los estudiantes, dando más a los que más lo necesitan y utilizando estrategias variadas para no favorecer a un determinado tipo de alumno), 5) no ser jerárquica (rol del docente como facilitador o mediador en el proceso de enseñanza - aprendizaje), 6) ser cooperativa (trabajar de forma conjunta, colaborativa y participativa favorece el desarrollo de una evaluación democrática, debiendo de ser extendida a la familia) y 7) ser social (evaluación transformadora).

Tal y como ya se ha apuntado, diferenciar el producto consiste en las diferentes maneras que los alumnos muestran y expresan aquellos conocimientos que han alcanzado (Caron, 2003; Levy, 2008; Tomlinson, 2008; Leroux y Paré, 2016). Continuando con Tomlinson (2005), las evaluaciones en el aula diferenciada permiten a los alumnos partir del punto en que se encuentran, para crecer y desarrollarse como estudiantes y personas. Es importante valorar a los alumnos en comparación con ellos mismos y sus logros, en lugar de compararlos con los logros alcanzados por otros estudiantes. Además, es trascendental que el docente utilice la información recabada en la evaluación para planificar las predecesoras experiencias de aprendizaje más apropiadas para el grupo. No solamente se debe valorar al alumnado, sino que también es importante que el docente evalúe y reflexione sobre su propia actuación en el proceso de enseñanza- aprendizaje (Rosales, 1990), así como los recursos o materiales que ha utilizado y han intervenido en el transcurso de dicho proceso. En definitiva, tanto los alumnos como los maestros aprenden juntos. Los docentes aprenden sobre cómo aprende su alumnado. Esto les lleva a reflexionar y seguir diferenciando su práctica didáctica (Tomlinson, 2005).

En el aula donde se toma en consideración la diversidad, el docente debe realizar una evaluación formativa, esto es, una evaluación para aprender (Fernández Batanero, 2009; Sanmartí, 2010; Gregory y Chapman, 2013). Asimismo, la evaluación tiene que ser continua, para poder comprobar los aprendizajes de los alumnos a lo largo del proceso de enseñanza- aprendizaje, además se deben de emplear diferentes instrumentos de evaluación (Heacox, 2002). Algunas herramientas que ayudan y favorecen una evaluación más democrática y diferenciada (y como complemento de las pruebas individuales o exámenes) son: 1) las rúbricas (Campbell, 2008), éstas son un instrumento que presentan un conjunto de criterios o de parámetros desde los cuales se valora un determinado 
conocimiento del proceso educativo (Martínez-Rojas, 2008); 2) los portafolios (Campbell, 2008; Bender, 2012: Gregory y Chapman, 2013), se trata de una carpeta que reúne el conjunto de tareas efectuadas a lo largo de todo el proceso de enseñanza- aprendizaje; 3) los informes personales o KPSI- Knowledge and Prior Study Inventory (Sanmartí, 2010), consiste en un cuestionario de autoevaluación que permite realizar una evaluación inicial para extraer la percepción sobre el grado de conocimiento adquirido que el alumnado cree tener en referencia al contenido que se va a trabajar; 4) la conferencia de evaluación colaborativa (Campbell, 2008), radica en propiciar un diálogo que permita negociar, entre el docente y el alumnado, los criterios a través de los cuales se va a evaluar la eficacia de sus trabajos, de esta manera se democratiza el proceso de evaluación..., entre otras.

En síntesis y por todo lo aportado, se considera de vital importancia destacar que en la "evaluación diferenciada" (tal y como entendemos la diferenciación pedagógica en este trabajo), no se solicita bajar la exigencia de las evaluaciones según sugiere Fernández Batanero (2009). Se pretende potenciar una evaluación que valore al individuo según sus posibilidades personales y sus logros, dándole voz en el proceso evaluativo y sobre todo fomentando una evaluación para el aprendizaje.

A modo de recapitulación decir que en todo este marco que se viene desarrollando el papel del docente es clave para promover experiencias y emplear herramientas capaces de movilizar diferentes formas de representación en el aula. Para ello, es necesario otorgar el protagonismo a los alumnos, adoptando éstos un rol activo y siendo los referentes para la selección de recursos, teniendo en cuenta sus capacidades, intereses y necesidades; personales, sociales y académicos (Escamilla, 2014). Así pues, una educación para todos implica reconocer, especialmente por parte de los maestros, la diversidad y asumir la igualdad como valor ético de la escuela (Aguado, 2011). Por consiguiente, los docentes tienen que ser capaces de diferenciar sus prácticas para que sean accesibles a todos los alumnos, acomodar las modalidades y las condiciones de aprendizaje para ciertos alumnos o modificar los objetivos inicialmente previstos (Paré, 2011). Todo ello exige, por tanto, un cambio organizativo y curricular del centro escolar, del pensamiento y la actitud del profesorado y, así mismo, de las prácticas educativas (Fernández Batanero, 2012). 


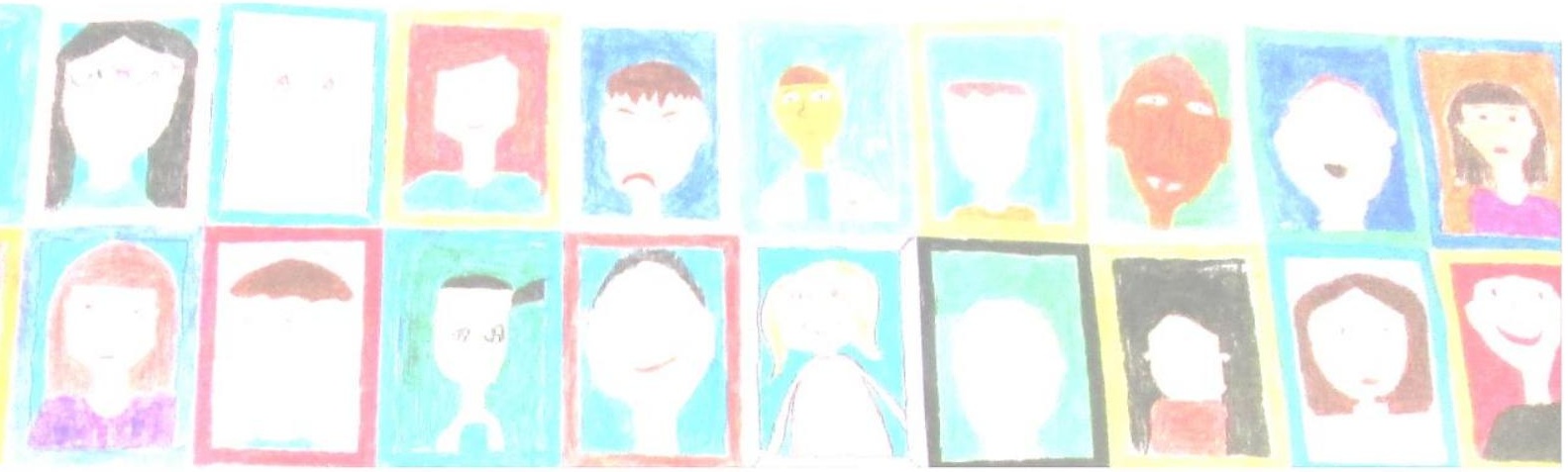

\section{ESTUDIO EMPÍRICO}

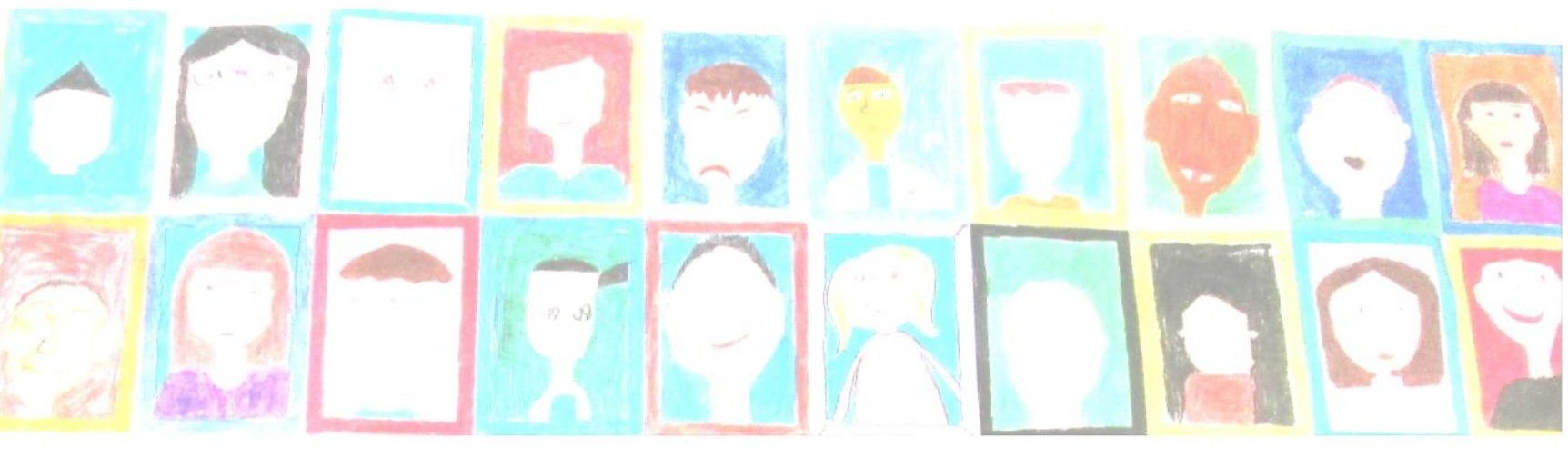





\section{CAPÍTULO 3}

\section{Metodología y diseño de la investigación}

3.1. Definición del problema de investigación ........................................................... 85

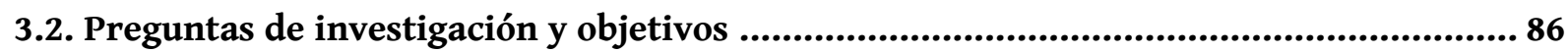

3.3. Metodología de la investigación: estudio de casos ....................................................... 87

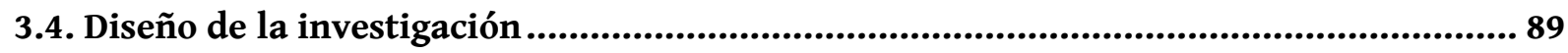

3.4.1. Descripción del proceso de la investigación ....................................................89

3.4.2. Descripción de los participantes en el estudio .................................................. 95

3.4.3. Técnicas e instrumentos de recogida de la información.................................96

3.4.3.1. La entrevista: guión de entrevista semiestructurada ................................. 96

3.4.3.2. Inventario de prácticas de aula ........................................................98

3.4.3.3. Observación no participante: hoja de apoyo a la observación de aula, notas de campo, videos y audios ........................................................................... 99

3.4.3.4. Análisis documental .................................................................. 99

3.4.4. Procesamiento $y$ análisis de los datos .....................................................105

3.4.5. La investigación educativa: cuestiones éticas y profesionales ........................111 

lo largo de este capítulo se hace un repaso a todos aquellos elementos que hacen
referencia a la metodología y al diseño de la investigación de este trabajo. Se describe de
manera pormenorizada: la definición del problema, las preguntas y objetivos de investigación. Se presenta también la metodología de investigación utilizada, centrada en el estudio de casos. Posteriormente se pasa a desarrollar el diseño de la investigación, focalizando en: la descripción del proceso, la descripción de los participantes en el estudio, las técnicas e instrumentos de recogida de la información y el procesamiento y análisis de los datos. Se termina este capítulo haciendo alusión a las cuestiones éticas y profesionales de la investigación educativa.

\subsection{Definición del problema de investigación}

En palabras de Hernández (1998, p.10): “El problema de investigación se convierte en el elemento desencadenante del paradigma de la investigación, así como del método y de la metodología que se adopte". Siguiendo a este mismo autor, las principales características del problema, para que éste sea objeto de ser investigado son: factibilidad (que se cuenten con los medios), claridad, significación (relevante) y descripción (de algún aspecto de la realidad).

La génesis de este estudio se centra en los paradigmas de la educación inclusiva y democrática. Concretamente, se considera de vital importancia avanzar hacia postulados pedagógicos inclusivos y de esta manera ver cómo se articulan los presupuestos teóricos en la realidad del aula, en el terreno educativo.

Como señala Rousseau (2010), la perspectiva inclusiva es uno de los mayores retos a los que se enfrenta la sociedad actual, dado que ésta se ocupa y preocupa tanto por la función social como educativa de la escuela. Desde que comenzó este movimiento, la tendencia internacional de muchos sistemas escolares es caminar hacia la dirección de una escuela más inclusiva (OCDE, 2004). Aunque, tal y como ya se ha citado anteriormente, en términos generales, la respuesta educativa mayoritariamente ofrecida en las aulas españolas parece estar atrancada en la integración escolar (Arnaiz, 2004).

La diversidad del alumnado en el aula es un tema que se hace explícito e implica, a su vez, un cuestionamiento de la educación que se ofrece en las aulas de las escuelas (Ruijs y Peetsma, 2009; Armstrong, Armstrong y Spandagou, 2010). Y es que, en palabras de Tomlinson (2005) y Forlín (2010), 
las prácticas uniformes llevadas a cabo en las aulas no contribuyen al éxito y desarrollo de los estudiantes.

En vista del propósito de ofrecer una educación de calidad para todo el alumnado que propicie altos niveles de aprendizaje y participación, sin perpetuar ningún tipo de exclusión (UNESCO, 2008), los docentes nos preguntamos cómo podemos llevar a cabo dicho cometido en nuestras aulas. Para lograr esta idea, hay que cambiar la escuela y una opción pedagógica (ampliamente referenciada a nivel internacional, pero poco referenciada en el contexto español) es la pedagogía diferenciada, inspirada en una rebelión contra el fracaso escolar y las desigualdades (Perrenoud, 2007b). La diferenciación es tarea tanto del docente como del sistema educativo, y se constituye como una práctica pedagógica lo suficientemente flexible para permitir a todo el alumnado progresar (Tomlinson, 2005; Prud'homme, Dolbec y Guay, 2011).

A partir de este marco, y centrándonos en esta investigación, surge el interés por indagar sobre la manera, y en base a que creencias, actitudes y valores, los maestros articulan sus prácticas didácticas dirigidas a fomentar el aprendizaje de todo el grupo clase y modulando una gestión democrática de sus aulas. Para ello, se aborda el estudio de 4 casos ( 3 españoles y 1 suizo) de aulas enmarcadas en la educación primaria. Así mismo, se pretende establecer un modelo teórico relacional que nos ayude a comprender si existe o no una vinculación entre la diferenciación pedagógica y la participación democrática en el aula inclusiva.

En resumen, la originalidad de este estudio gravita en establecer un modelo teórico sobe los conceptos manejados y en ilustrar y describir cómo se materializan dichos presupuestos teóricos en la realidad del aula. Además, esta investigación contribuye a la esfera internacional enmarcada en el Laboratoire International Sur l'Inclusion Scolaire (LISIS) para una análisis y discusión compartida de las prácticas de diferenciación pedagógica abordadas en los diferentes contextos (Canadá, Suiza y España). Esto es, se pretende realizar una vinculación teórica de los resultados analizados de cada uno de los casos que pertenecen a diferentes realidades contextuales (Rose y Garner, 2010).

\subsection{Preguntas y objetivos de investigación}

Esta tesis doctoral se enmarca en la metodología cualitativa y la investigación se aborda a través del estudio de casos por lo que no se enuncian hipótesis sino preguntas de investigación («issues»). Las preguntas de investigación que respaldan este estudio son las siguientes:

1. ¿Cómo se vincula la diferenciación pedagógica y la participación democrática en el aula inclusiva?

2. ¿Cómo desarrollan los docentes la práctica de la diferenciación pedagógica y la participación democrática en sus aulas? 
3. ¿Por qué los docentes llevan a cabo la diferenciación pedagógica y la participación democrática en sus aulas? ¿Qué creencias, percepciones y experiencias vitales sustentan las propuestas didácticas de los docentes?

El objetivo general de este trabajo es comprender en profundidad y con matices la manera de articular la diferenciación pedagógica y la participación democrática desde la perspectiva de la educación inclusiva en educación primaria. Se trata de indagar sobre la diferenciación pedagógica como herramienta docente para combatir el fracaso escolar y las desigualdades, y de esta manera poder propiciar un aprendizaje óptimo en el alumnado. Este objetivo general se concreta en los siguientes más específicos:

Objetivo 1: Definir la relación entre la diferenciación pedagógica y la participación democrática en el aula inclusiva.

Objetivo 2: Describir y documentar el desarrollo de prácticas guiadas bajo los principios de la diferenciación pedagógica y la participación democrática en el aula inclusiva.

Objetivo 3: Indagar sobre las creencias, percepciones y experiencias vitales de los docentes que sustentan sus propuestas didácticas.

\subsection{Metodología de la investigación: estudio de casos}

Este estudio se enmarca en los parámetros de la investigación cualitativa. Según señala Sandín (2003):

La investigación cualitativa es una actividad sistemática orientada a la comprensión en profundidad de fenómenos educativos y sociales, a la transformación de prácticas y escenarios socioeducativos, a la toma de decisiones y también hacia el descubrimiento y desarrollo de un cuerpo organizado de conocimiento. (p. 123)

Esta misma autora, en lo que respecta a la metodología de investigación cualitativa, distingue entre los métodos orientados a la comprensión y los métodos orientados al cambio y a la toma de decisiones (investigación-acción). Esta tesis doctoral se centra en los métodos orientados a la comprensión, dado que el problema de investigación es abordado mediante el estudio de casos.

Existe una larga tradición en la investigación sobre estudios de casos, la cual se extiende hasta nuestros días (Álvarez y San Fabián, 2012). A pesar de eso, según recoge Simons (2011), existen diferentes connotaciones de lo que se entiende por estudio de caso según diferentes autores y diferentes disciplinas. Lo que sí que parece estar claro es que el estudio de casos se centra en la particularidad, la complejidad, en la singularidad y en la exclusividad (Stake, 1998; Simons, 2011). Esto es, lo que denomina Smith (1978) un sistema delimitado o acotado. Reforzando esta idea, Pérez Serrano (1994: 85) define el estudio de casos como: “una descripción intensiva, holística y un análisis 
de una entidad singular, un fenómeno o unidad social. Los estudios de casos son particularistas, descriptivos y heurísticos y se basan en el razonamiento inductivo al manejar múltiples fuentes de datos". Por su parte Walker (1983), puntualiza que el estudio de casos es:

El examen de un ejemplo en acción. El estudio de unos incidentes y hechos específicos y la recogida selectiva de información de carácter biográfico, de personalidad, intenciones y valores, permite al que lo realiza, captar y reflejar los elementos de una situación que le dan significado. (p.45)

Por otro lado, Yin (1994) concreta este método como:

Una investigación empírica que estudia un fenómeno contemporáneo dentro de su contexto de la vida real, especialmente cuando los límites entre el fenómeno y su contexto no son claramente evidentes. [...] Una investigación de estudio de caso trata exitosamente con una situación técnicamente distintiva en la cual hay muchas más variables de interés que datos observacionales; $y$, como resultado, se basa en múltiples fuentes de evidencia, con datos que deben converger en un estilo de triangulación; $y$, también como resultado, se beneficia del desarrollo previo de proposiciones teóricas que guían la recolección y el análisis de datos. (p.13)

Por lo anteriormente dicho, se infiere también que, existen diferentes tipologías de estudio de casos atendiendo a diferentes autores. Stake (1998) distingue tres tipos de estudio de casos: 1) estudio intrínseco de casos, 2) estudio instrumental de casos y 3) estudio colectivo de casos. El trabajo que aquí se presenta se trata de un estudio instrumental de casos, dado que nos encontramos con una cuestión que interesa investigar, una situación paradójica, una necesidad de comprender cómo se articula la diferenciación pedagógica y la participación democrática en el aula inclusiva y se considera que podemos entender esta cuestión mediante el estudio de una serie de casos en particular. Así pues, también se trata de un estudio colectivo o múltiple de casos. El interés de este trabajo de investigación se centra en indagar en el fenómeno, anteriormente citado, a través del estudio intensivo de varios casos. Habría que decir también que Merriam (1988) y Pérez Serrano (1994) proponen tres tipos de estudios de casos, centrándose en la redacción del informe de la investigación: 1) estudio de caso descriptivo (descripción sin fundamentación teórica), 2) estudio de caso interpretativo (descripción con fundamentación teórica) y 3) estudio de caso evaluativos (descripción y explicación con el fin de emitir juicios sobre la realidad estudiada). En nuestro caso se trata de un estudio de caso interpretativo puesto que contiene descripciones que ilustran los presupuestos teóricos definidos previamente a la recogida de datos. En esta línea, mencionar también los aportes de Bassey (1999), éste diferencia entre los estudios de casos cuya finalidad es buscar la teoría o, por el contrario, aquellos cuyo objetivo es comprobar la teoría.

En suma, este método de investigación nos ayuda a comprender y a indagar sobre el propósito de este estudio. De esta manera, se aumentará el conocimiento en relación a cómo se articula la 
diferenciación pedagógica y la participación democrática en el aula inclusiva. Es por ello que nos interesa comprender los casos, existe un interés en aprender cómo funcionan en sus quehaceres habituales en el contexto educativo del cual forman parte. El interés por los casos radica tanto por lo que tienen de únicos como por lo que tienen de común (Stake, 1998). Con el estudio de casos se pretende:

[...] entrar en la vida de otras personas con el sincero interés por aprender qué y por qué hacen o dejan de hacer ciertas cosas y qué piensan y cómo interpretan el mundo social en el que viven y se desenvuelven (LACE, 1999, p.7).

Siguiendo a Yacuzzi (2005) y prestando atención a la tipología de preguntas planteadas en esta tesis, la investigación con estudio de casos es válida al esbozar preguntas de tipo cómo y porqué, cuando el investigador tiene poco control sobre los acontecimientos y cuando el tema es contemporáneo. Otra razón que justifica la elección de este método reside en que, según introducen Cebreiro y Fernández (2004), son una buena opción cuando la cuestión que se pretende indagar está difusa, es compleja, escurridiza o controvertida y para analizar aquellas situaciones que presentan diversas variables estrechamente vinculadas con el contexto en el que se desarrollan. Tal y como se ha introducido el concepto de diferenciación pedagógica no está consolidado en el contexto español por lo que resulta de vital importancia ver cómo se puede materializar en la vida real del aula y esclarecer su vinculación con la participación democrática. Según introduce Tomlinson (2008) no hay una única forma o camino para crear un aula diferenciada. Así mismo, se cuenta con escasos modelos de aulas que ilustran la diferenciación pedagógica y la participación democrática.

\subsection{Diseño de la investigación}

\subsubsection{Descripción del proceso de la investigación}

La investigación mediante estudios de casos sigue unas fases preestablecidas (Álvarez y San Fabián, 2012), es por ello que se describe el proceso de esta investigación siguiendo las tres fases, preactiva, interactiva y postactiva, propuesta por Martínez Bonafé (1990) y Pérez Serrano (1994).

\section{1) Fase preactiva}

\section{Planificación inicial}

Esta tesis doctoral se empezó a gestar en octubre del 2013. En el comienzo de la misma se definieron los fundamentos epistemológicos que encuadran el problema objeto de estudio, se plantearon las preguntas y los objetivos de investigación, y se estructuraron las principales fases o acciones para ser llevadas a cabo. El 10 de octubre del 2013 fue aprobada por la Comisión de Investigación y Doctorado del Departamento de Educación de la Universitat Jaume I. Posteriormente, se pasó a registrar el tema de este trabajo de investigación. 


\section{$\sim$ Selección de los casos}

Una vez asentadas las bases que sustentan y guían la presente tesis doctoral se procedió con la elección de los casos objeto de estudio. Tal y como se ha explicado anteriormente, en el apartado de metodología, los casos no venían dados (estudio intrínseco de casos). Puesto que, al encontrarse con una cuestión paradójica a indagar se seleccionaron los casos mediante los cuales se pretendía comprender la cuestión objeto de ser abordada (estudio instrumental de casos colectivos o múltiples). Siguiendo a Stake (1995), se seleccionaron aquellos casos que se pensó que ofrecerían las mejores y mayores oportunidades de aprendizaje con respecto a la problemática («issue») objeto de estudio.

Se conocían unas breves pinceladas de la forma de trabajar en el aula de los diferentes casos seleccionados. Respecto al caso 1 y al caso 2 se sabía de algunas experiencias compartidas por los docentes en el seno del Seminario de Ciudadanía Crítica: por una escuela intercultural e inclusiva llevado a cabo en el Departamento de Educación de la Universitat Jaume I. Por lo que respecta al caso 3, se supo de él a través de las Jornadas de Puertas Abiertas del colegio donde está inscrito el caso, dado que el centro ya hace unos años que participa en proyectos de investigación impulsado por el grupo de investigación Mejora Educativa y Ciudadanía Crítica (MEICRI) de la Universitat Jaume I de Castellón.

Conviene destacar que el caso 2 está formado por dos aulas, las maestras de las cuales ya hace muchos años que trabajan conjuntamente y comparten muchos elementos de su filosofía docente. Para empezar con este trabajo se realizó una primera reunión de contacto con los 4 maestros seleccionados para el estudio. En dicha reunión se explicaron los propósitos de la investigación. Esto es, se les presentó de manera generalizada en qué consistía el trabajo que se pretendía realizar y cómo se llevaría a cabo en sus aulas. Todos los docentes aceptaron, voluntariamente, participar en esta investigación. Seguidamente, se pasó a informar a los directores de los respectivos centros para ello se envió una carta informativa (Ver Anexo 1) y se concretó una reunión con los directores que así lo solicitaron. Tras su visto bueno, se pasó a informar a las instituciones educativas pertinentes.

\section{Elaboración y adaptación de los instrumentos de recogida de datos y los documentos de} permiso y acceso al campo

Posteriormente, se procedió a iniciar una revisión bibliográfica (mediante diferentes bases de datos como la del CSIC: ISOC, ERIC, Dialnet y Google Académico) sobre la temática a estudiar para elaborar los instrumentos de recogida de datos y también para la delimitación conceptual del término diferenciación pedagógica y su vinculación con la participación democrática en el aula (primera pregunta de investigación de la tesis). De igual modo, se trabajó sobre la elaboración y redacción del consentimiento informado (Ver Anexo 2) y de las autorizaciones (Ver Anexo 3) a firmar por las familias de los alumnos participantes en el proyecto.

En abril de 2014 se asistió a un encuentro organizado por el Laboratoire international sur l'inclusion scolaire (LISIS) en la Scuola Universitaria Professionale della Svizzera Italiana (SUPSI) Locarno (Suisse) con el 
motivo de la celebración del simposio Implicazioni e sfide dell' inclusione scolastica: pluralità di sguardi sulle pratiche di differenziazione. Una jornada antes del simposio se trabajó sobre l'Étude multicas de pratique de différenciation pédagogique et du savoir professionnel d'enseignants du primaire cuvrant dans une perspective inclusive au Nouveau-Brunswick, au Québec et en Ontario. Concretamente se presentaron y se discutieron los casos de Jacinthe, Michelle y Annie.

Al inicio del curso escolar 2014/2015 se procedió con la firma del consentimiento informado por parte de los 4 docentes (del contexto español) participantes en la investigación y se proporcionaron las hojas de autorización de las familias para permitir la participación del alumnado en la investigación. A petición expresa de un docente, se realizó una reunión informativa con las familias, en la cual se les explicó en qué consistía la investigación y se resolvieron dudas al respecto.

Dentro de los encuentros científicos organizados por el Laboratoire international sur l'inclusion scolaire (LISIS) se participó en el 3ème colloque international « De l'intégration à l'inclusion scolaire: rôles des communautés éducatives " en l'Haute École Pédagogique du Canton de Vaud (HEPL) Lausanne, (Suisse) realizado en abril de 2015. Otro de los espacios en los que se compartieron reflexiones e investigaciones enmarcado en la educación inclusiva, el estudio de casos canadiense y la diferenciación pedagógica.

\section{2) Fase interactiva: trabajo de campo y organización de los datos}

Llegados a este punto, se inició el proceso de recogida de la información. Primeramente, se concretó con los docentes una entrevista inicial (Ver Anexo 4) y se realizó un inventario de prácticas de aula (Ver Anexo 5). Tras ver que las prácticas efectuadas por los maestros se enmarcaban dentro de los parámetros de la diferenciación pedagógica y la participación democrática en el aula inclusiva se procedió con las observaciones y el seguimiento de las situaciones de aula. Para ello, se realizaron fotografías y grabaciones de vídeo en los casos 1 y 3 para ilustrar las prácticas educativas llevadas a cabo. En el caso 2 el director del centro no dio su permiso a realizar grabaciones de vídeo en el aula ni fotografías del alumnado. Ahora bien, sí que contamos con el permiso de las maestras para grabar las sesiones en audio y realizar fotografías del material utilizado o generado. De esta manera, en todos los casos, durante las sesiones observadas, se realizaron fotografías de materiales o documentos utilizados en los quehaceres diarios en el aula y también se recogieron documentos, actividades, producciones del alumnado, etc. Para realizar, después, un análisis del material. Aparte de las notas de campo se utilizó una tabla de apoyo a la observación en el aula (Ver Anexo 6) y la herramienta DCOS (Assessing Classroom Differentiation Protocol - Revised) (Cassady, Speirs Neumeister, Adams, Dixon y Pierce, 2004), para evaluar el nivel de compromiso de los alumnos (Ver Anexo 7).

Una vez realizadas las observaciones se pasó a entrevistar a los sujetos implicados en los diferentes casos. Para ello, se utilizó un guión de entrevista semiestructurado para entrevistar al alumnado seleccionado (Ver Anexo 8), otro para entrevistar a las familias (Ver Anexo 9) en el caso 2 y 3, otro para 
entrevistar a dos estudiantes de magisterio (Ver Anexo 10), cuya estancia de prácticas coincidió con la recogida de la investigación en el caso 1 y 2, otra para entrevistar a la maestra de música del caso 3 (Ver Anexo 11) y, finalmente, se realizó otra entrevista a los 4 maestros después de la observación (Ver Anexo 12). Es necesario destacar que la maestra del caso 3, en la entrevista final, comentó que para el próximo curso escolar iba a implementar, por primera vez en su aula, los rincones de trabajo en primaria. Cómo se consideró que era otra práctica ilustrativa de la diferenciación pedagógica y participación democrática en el aula se concretó una sesión de observación y entrevista en octubre del 2015.

Remarcar que durante los meses de mayo, junio y julio del 2016 se realizó una estancia de investigación a l'Haute École Pédagogique du Canton de Vaud (HEPL) Lausanne (Suisse) con el profesor Serge Ramel (co-director del LISIS). Durante estos meses aparte de conocer y acompañar en las diferentes formaciones y reuniones realizadas por el profesorado de la HEPL en los établissements y participar en la investigación PIDOPÉ- Pratiques inclusives : des orientations de l'établissement au projet de l'élève (Ramel, Zamarra, Sanahuja y Bico, 2016), se realizó un pequeño estudio de caso en un aula Suiza.

El profesor Ramel, fue quien contactó con el director del établissement y con la maestra, la clase de la cual era objeto de estudio, para solicitarles su colaboración en la investigación. Posteriormente, se procedió a traducir al francés y adaptar los instrumentos de recogida de datos que habían sido utilizados en el contexto español. Es necesario destacar que, en este cuarto caso objeto de estudio solamente se entrevistó a la docente y se observaron diferentes situaciones de aula durante una jornada escolar. No se realizaron ni fotografías al alumnado ni se grabaron las sesiones con vídeo, estas fueron registradas mediante una grabadora de audio. Primero, se procedió con la firma del consentimiento informado (Ver Anexo 13). Después, se pasó a realizar la recogida de los datos. Aparte de las notas de campo, los instrumentos para la recogida de los datos que se utilizaron fueron: la hoja de apoyo a la observación (Ver Anexo 14), el inventario de prácticas de aula (Ver Anexo 15) y una selección de preguntas para la entrevista a la maestra (Ver Anexo 16).

Posteriormente, una vez se contó con todos los datos recogidos se realizó la laboriosa tarea de transcripción literal de los datos. Concretamente, se transcribieron las entrevistas efectuadas a los actores intervinientes en cada uno de los casos. Al inicio de las transcripciones se intentó seguir las convenciones de transcripción de Jefferson (2004), pero pronto se detectó que esta cometida no era funcional y práctica para el tipo de análisis que se pretendía hacer, dado que se pretendía realizar un análisis de contenido y la simbología anteriormente citada no enriquecía el proceso de análisis. Es por ello, que se procedió con una transcripción literal identificando los participantes y marcando entre paréntesis si se detectaba algún elemento a tener en cuenta para su posterior interpretación. 


\section{3) Fase postactiva: elaboración del informe y devolución de los datos}

Seguidamente, se procedió con el análisis de contenido (Miles y Huberman, 1994) de los resultados recogidos mediante la herramienta ATLAS.ti. El proceso de análisis se explica detalladamente en el punto 3.4.4. Procesamiento y análisis de los datos de este mismo capítulo.

Mediante el software ATLAS.ti, en herramienta de consulta, se procedió a generar los informes de resultados de cada una de las categorías teóricas categorizadas, pero limitado a cada familia de documentos primarios de cada uno de los casos y a la práctica que ilustra cada cita. Esto es, como posteriormente se explicará en el punto 3.4.4. Procesamiento y análisis de los datos, se hizo una doble codificación, una referente a la categoría teórica (extraídas de los presupuestos teóricos que descansan sobre la diferenciación pedagógica y la participación democrática en el aula) y otra referente a la identificación de la práctica de aula a la que hacía referencia la cita seleccionada (p.ej. proyectos, estaciones, grupos de investigación, puzle de Aronson...).

Cuando se tuvieron todos los informes por prácticas de aula y casos extraídos del ATLAS.ti, se procedió a la redacción de los relatos de cada caso. En la redacción de los casos se ha dado la palabra a los protagonistas de los mismos, esto es, el relato se caracteriza por la diversidad de voces, siendo los diferentes artífices de los casos los que, mayoritariamente (junto a otros datos procedentes de otras fuentes instrumentales), explican y describen su propia práctica escolar.

Una vez se tuvieron los relatos de los casos escritos se procedió a la devolución de los resultados a los docentes, para ello se entregó un borrador avanzado de la redacción de su caso en el cual pudieron hacer los comentarios y sugerencias que consideraron pertinentes.

Mencionar también que en octubre del 2016 se celebró la 3ème biennale du LISIS : «Mobilisation des connaissances issues de la recherche par les acteurs de l'éducation inclusive » en l'Haute École Pédagogique du Canton de Vaud (HEPL) Lausanne (Suisse). Durante el encuentro tuvieron lugar diferentes reuniones del equipo de investigación Diversité et pratiques d'enseignement, en el cual se inscribe esta tesis doctoral y se trazaron las líneas de trabajo del grupo para los dos próximos años.

A continuación, en la Tabla 13, se presenta un resumen de las principales actuaciones y tareas realizadas en el transcurso de esta tesis doctoral. 
Tabla 13

Desarrollo cronológico del trabajo de investigación

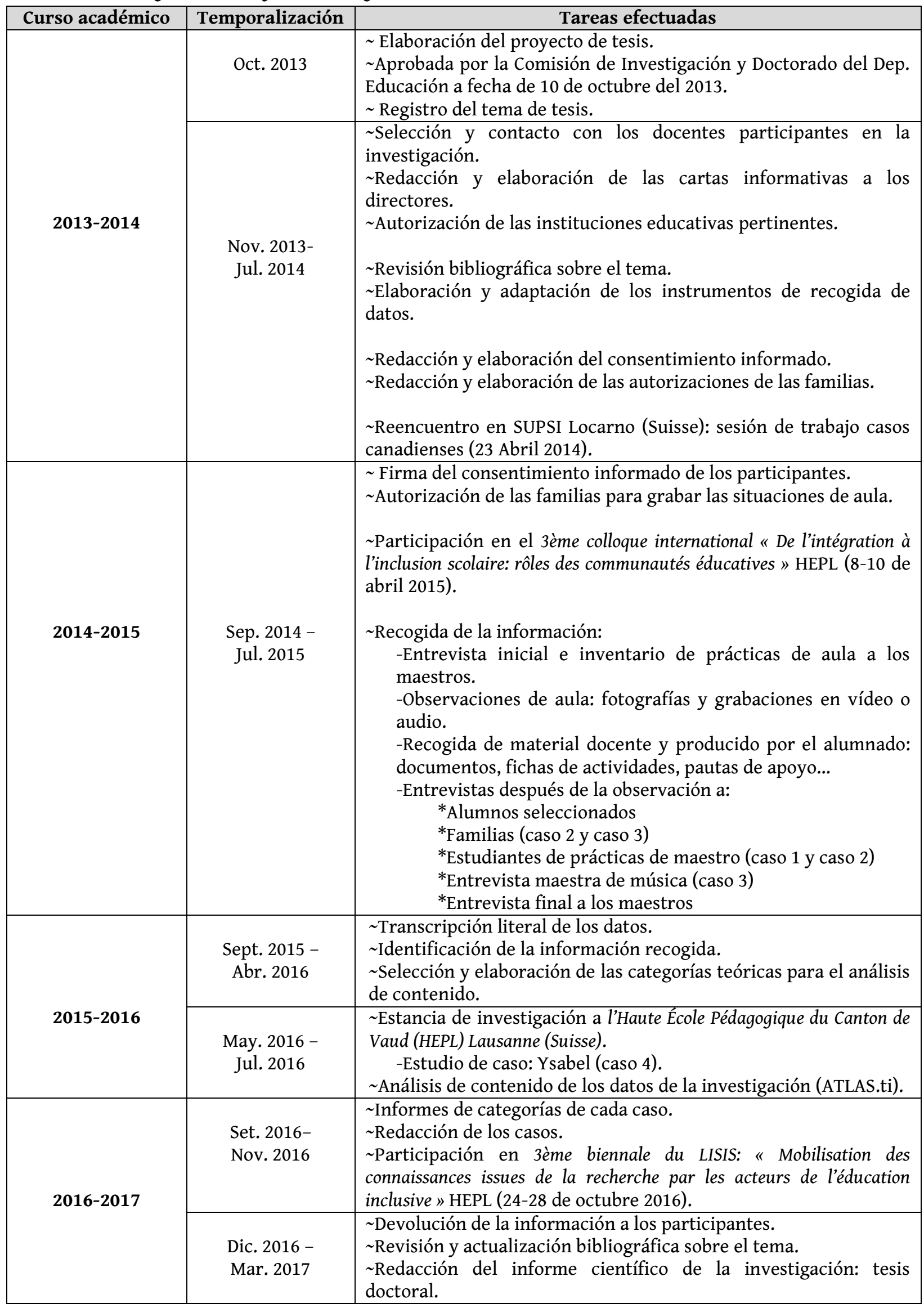




\subsubsection{Descripción de los participantes en el estudio}

Se considera necesario matizar que la investigación mediante el estudio de casos no es una investigación de muestras, visto que el fin del estudio de casos no es la comprensión de otros casos, el principal propósito es comprender el caso o casos seleccionados (Stake, 1998).

La selección de los casos se ha realizado en función de los siguientes parámetros: 1) maestros de primaria, que haya tenido o tenga algún alumno con dificultades de aprendizaje o dictamen (diagnóstico n.e.a.e.), 2) con experiencia, 3) de la provincia de Castellón o de Valencia (casos del contexto español). Siguiendo a Tochon (2004) se ha tenido en cuenta también que lleven implementando la diferenciación pedagógica y la participación democrática en el aula durante al menos dos años; que hayan estado involucrados en procesos de investigación-acción o de innovación educativa, y que sean reconocidos por sus pares (colegas, directores, psicopedagogos...) como expertos.

En el primer caso, el caso de Manolo, se trata de un aula de $5^{\circ}$ de primaria del CEIP Isidoro Andrés Villarroya (Castellón de la Plana) que está conformada por 25 alumnos (de los cuales 8 fueron entrevistados). Durante el periodo de estudio había un estudiante de prácticas de magisterio y el docente.

Tal y como se ha mencionado anteriormente el segundo caso de estudio está formado por dos aulas, la de Mati y Amèlia. Se trata de dos aulas de $2^{\circ}$ de primaria ( $2^{\circ}$ A y $2^{\circ}$ B) del CEIP Cervantes J. Dualde (Betxí), compuestas: una por 28 alumnos (de los cuales 6 fueron entrevistados) y la segunda por 27 alumnos (de los cuales 8 fueron entrevistados). Un total de 8 madres participaron en el estudio, ya que fueron entrevistadas, al igual que 5 abuelos de entre los que intervinieron en uno de los proyectos abordados. También había una estudiante de prácticas de magisterio y ambas docentes mencionadas.

En el tercer caso, el caso de Cristina, se trata de un aula de $5^{\circ}$ y $6^{\circ}$ de primaria del aulario de Quart de les Valls del CRA Benavites- Quart de les Valls que está conformada por 21 alumnos (de los cuales 9 fueron entrevistados). En el estudio ha participado una madre, la docente de música y la maestra tutora.

En el cuarto caso, el caso de Ysabel, solamente se incorpora la voz de la maestra (mediante la entrevista y el inventario de prácticas de aula). Decir también que para la selección de este caso se tuvo en cuenta que la docente llevara implementando la diferenciación pedagógica y la participación democrática en su aula durante al menos dos años; que hubiera participado en proyectos de innovación educativa y que fuera reconocida por sus pares (colegas, directores, psicopedagogos...) como experta.

A continuación, en la Tabla 14, se recogen los participantes distribuidos por casos. 
Tabla 14

Participantes en el estudio distribuidos por casos

\begin{tabular}{|c|c|c|c|c|}
\hline Centro & $\begin{array}{c}\text { CASO } \\
\text { Docentes }\end{array}$ & Alumnado & $\begin{array}{c}\text { Estudiantes de } \\
\text { prácticas }\end{array}$ & Familias \\
\hline $\begin{array}{l}\text { CEIP Isidoro Andrés } \\
\text { Villarroya } \\
\text { (Castellón de la Plana) }\end{array}$ & $\begin{array}{c}\text { Manolo } \\
1\end{array}$ & $\begin{array}{c}25 \text { (total aula) } \\
8 \text { (entrevista) }\end{array}$ & 1 & 0 \\
\hline \multirow{2}{*}{$\begin{array}{l}\text { CEIP Cervantes J. Dualde } \\
\text { (Betxí) }\end{array}$} & $\begin{array}{c}\text { Mati } \\
2.1\end{array}$ & $\begin{array}{c}28 \text { (total aula) } \\
6 \text { (entrevista) }\end{array}$ & 0 & 2 madres \\
\hline & $\begin{array}{c}\text { Amèlia } \\
2.2\end{array}$ & $\begin{array}{c}27 \text { (total aula) } \\
8 \text { (entrevista) }\end{array}$ & 1 & $\begin{array}{l}6 \text { madres } \\
5 \text { abuelos }\end{array}$ \\
\hline $\begin{array}{c}\text { CRA Benavites- Quart de } \\
\text { les Valls } \\
\text { (Quart de les Valls) }\end{array}$ & $\begin{array}{l}\text { Cristina } \\
\text { P. (maestra de } \\
\text { música) } \\
\mathbf{3}\end{array}$ & $\begin{array}{c}21 \text { (total aula) } \\
9 \text { (entrevista) } \\
+ \\
18 \text { (total aula) } \\
2 \text { (entrevista) }\end{array}$ & 0 & 1 madre \\
\hline $\begin{array}{l}\text { L'établissement primaire } \\
\text { de Payerne et environs } \\
\text { (Corcelles, Suisse) }\end{array}$ & $\begin{array}{l}\text { Ysabel } \\
\mathbf{4}\end{array}$ & $\begin{array}{c}19 \text { (total aula) } \\
0 \text { (entrevista) }\end{array}$ & 0 & 0 \\
\hline
\end{tabular}

\subsubsection{Técnicas e instrumentos de recogida de la información}

Con el propósito de abordar los objetivos planteados y acorde con el diseño metodológico expuesto para llevar a cabo esta tesis doctoral se han empleado una serie de técnicas e instrumentos para la recogida de la información. Concretamente las técnicas de recogida de los datos han sido: la entrevista, un inventario de prácticas de aula, la observación no participante y el análisis documental.

\subsubsection{La entrevista: guión de entrevista semiestructurada}

Según Simons (2011), en la entrevista los informantes suelen desvelar más información de la que se puede obtener mediante la observación. Siguiendo con esta misma idea, Stake (1998) afirma que, no todos los integrantes del caso lo ven de la misma manera. De esta forma, esta técnica de recogida de datos permite al investigador descubrir y reflejar las múltiples visiones del caso objeto de estudio. Por tanto, mediante la entrevista, se ha obtenido información de primera mano sobre los hechos o los fenómenos objeto de esta investigación (Taylor y Bogdan 1987; Valles, 1997). Seguidamente, se presentan los instrumentos de recogida de datos empleados, enmarcados en la técnica de la entrevista.

En primer lugar, decir que, en todos los casos se trataba de entrevistas semiestructuradas (Albert, 2007), dado que la investigadora llevaba un guión con algunas cuestiones a abordar, pero estas se iban reestructurando o emprendiendo a medida que los temas iban saliendo y se iban desarrollando. Todas las entrevistas fueron grabadas mediante una grabadora de audio. Aunque los guiones semiestructurados de las entrevistas, presentados en los anexos, son los mismos para todos los casos,

${ }^{8}$ Recogida de datos sobre los rincones de trabajo (octubre 2015). 
es necesario añadir que las preguntas se adaptaban en función de los aspectos más relevantes y característicos de cada uno de los casos observados en las situaciones de aula.

\section{Entrevista a los docentes}

Por lo que respecta a las entrevistas realizadas a los docentes, cabe señalar que se han efectuado en dos momentos clave del proceso. Se ha realizado una entrevista inicial, antes del comienzo de la recogida de datos, la cual se ha complementado con las reflexiones emitidas por los maestros tras completar un inventario de prácticas de aula. También se ha realizado otra entrevista final, al terminar el proceso de observación en el aula y las entrevistas a los otros integrantes del caso con el fin de confrontar toda la información recogida. En el caso 1 y 3, las entrevistas a los maestros se han realizado de manera individual. Por lo que respecta a las maestras del caso 2 ambas entrevistas, la inicial y la final, y las reflexiones extraídas del inventario de prácticas de aula (que se presenta a continuación) se han realizado conjuntamente con las dos docentes. Se trata de entrevistas semiestructuradas y concretamente entrevistas explicación (Vermersch, 2010).

La entrevista inicial (Ver Anexo 4) realizada a los maestros, fue traducida y adaptada de Paré (2011). En ella se plantean aspectos contextuales sobre: años de experiencia docente, formación académica, formación continua, descripción de los integrantes del aula, principales metodologías utilizadas en el aula, el motivo por el cual gestionan su aula de la manera explicada, entre otras cuestiones de este estilo.

Para cerrar la recogida de datos en cada uno de los casos, se realizó una entrevista final (Ver Anexo 12) con los docentes. En ella se plantean aspectos sobre las situaciones de aulas observadas: agrupaciones, objetivos y contenidos curriculares, metodologías cooperativas y diferenciadas, la participación de las familias y otros agentes en el aula, y la evaluación diferenciada. Señalar que, en el caso 3 se realizó una entrevista a la docente de música (Ver Anexo 11) para conocer más sobre una de las prácticas observadas, el proyecto LóvA9 .

Por lo que respecta al caso suizo, se realizó una única entrevista (Ver Anexo 16) tanto de aspectos contextuales como de la propia práctica didáctica.

\section{$\sim$ Entrevista al alumnado seleccionado}

Después de cada una de las sesiones observadas, a un par (o trio -en algún caso) de alumnos se les realizaba una breve entrevista (Ver Anexo 8) sobre sus quehaceres cotidianos en el aula. Los docentes eran los que seleccionaban o proponían al alumnado que sería entrevistado (siguiendo el criterio de heterogeneidad, es decir, alumnos excelentes, alumnos con mayor dificultad hacia las tareas académicas...). Dicha entrevista se estructuró con los mismos elementos que la entrevista final realizada a los docentes, pero con un lenguaje propio del alumnado de dicha edad. Las cuestiones

\footnotetext{
${ }^{9}$ Proyecto educativo a partir del cual se articula la ópera como vehículo de aprendizaje.
} 
giraban en torno a los siguientes componentes: agrupamientos, objetivos, metodologías, actividades de aula, evaluación, gestión del aula, su participación y la de sus familias u otros agentes en el contexto educativo.

\section{$\sim$ Entrevista a estudiantes de prácticas de magisterio (caso 1 y 2.2)}

En el caso 1 y en el caso 2.2, las observaciones de las situaciones de aula analizadas coincidieron con la estancia de prácticas de dos estudiantes del último curso del grado de magisterio de primaria de la Universitat Jaume I. Debido a que el periodo de prácticas en $4^{\circ}$ es extenso y por lo que supone para el estudiantado la vivencia de esta etapa, se consideró oportuno realizarles una entrevista (Ver Anexo 10) al finalizar el proceso de recogida de datos. En dicha entrevista se abordaron los mismos elementos que la entrevista final realizada a los docentes.

\section{Entrevista a madres (caso 2 y 3) y entrevista a los abuelos (caso 2.2)}

En el caso 2 y en el caso 3, se realizaron entrevistas (Ver Anexo 9) a algunas madres partícipes en las actividades del aula. Además, debido al desarrollo de un proyecto de trabajo, en el caso 2.2 se realizó una entrevista a 5 personas mayores participantes en el mismo. Las cuestiones, para las madres, estaban relacionadas con su participación en el aula, los aprendizajes y la participación de sus hijos en relación a la manera de trabajar del docente en el aula. La entrevista realizada a los abuelos se centraba en su participación en el aula y sobre el hecho de que los alumnos estudiaran aspectos sobre su propia localidad.

Para finalizar este epígrafe decir que las entrevistas fueron efectuadas en valenciano, a pesar de que las transcripciones se realizaron en castellano siguiendo el idioma empleado en la redacción del informe de ésta tesis doctoral. En el caso suizo (caso 4), las entrevistas y las trascripciones fueron realizadas en francés.

\subsubsection{Inventario de prácticas de aula}

Al terminar la entrevista inicial realizada a los docentes se comentó, con éstos, un inventario de prácticas de aula (Ver Anexo 5) traducido y adaptado de Heacox (2002). Dicho inventario se compone de 16 presupuestos prácticos en los cuales el docente, a partir de un continuum, tiene que situar su práctica de aula. Se insistió a los maestros en la importancia de su justificación y explicación del porqué de su posicionamiento, en lugar del número en si marcado en el continuum. Por lo que respecta al caso suizo, las reflexiones derivadas de la entrevista también fueron completadas con el inventario de prácticas de aula contestado por la maestra (Ver Anexo 15).

A partir de ambas entrevistas (inicial y final) y el inventario de prácticas de aula se ha recogido el repertorio de prácticas didácticas de los docentes y los valores, creencias y actitudes que subyacen en ellas, incluyendo sus patrones de comportamiento y acción (Malo, 2005). 


\subsubsection{Observación no participante: hoja de apoyo a la observación de aula, notas de campo, fotografías, vídeos y audios}

La observación científica es una técnica que consiste en observar atentamente el fenómeno que se quiere estudiar tomando la información que se crea relevante y registrándola para su posterior análisis (Sabino, 1992; Vázquez, 2004). Se trata de percibir activamente la realidad exterior con el propósito de obtener los datos que previamente han sido definidos de interés para la investigación (Ruiz Olabuénaga, 1996; Alonso, 1998). Consecutivamente, se muestran los instrumentos de recogida de datos empleados y encuadrados en la técnica de la observación.

Hoja de apoyo a la observación de aula

Para las sesiones de observación de las situaciones de aula se utilizó una hoja de observación (Ver Anexo 6). Se trata de un instrumento de trabajo generado por los colegas (Prud'homme, LeBlanc y Paré, 2013) que realizan el estudio de casos múltiples de prácticas de diferenciación pedagógica enmarcado dentro del Laboratoire international sur l'inclusion scolaire (LISIS). Esta hoja de observación pone el foco en 5 elementos generales, que se van concretando en los diferentes ítems a observar. Estos son: 1) rigor y coherencia entre las intenciones, los contenidos y las actividades pedagógicas; 2 ) anticipación (planificación) y toma en consideración de la diversidad; 3) prácticas de enseñanza y de evaluación; 4) gestión y clima del aprendizaje y 5) recursos atribuidos para efectuar adaptaciones, modificaciones y ofrecer un apoyo particular.

Así mismo, esta hoja de observación se completa con la herramienta DCOS- Assessing Classroom Differentiation Protocol - Revised (Ver Anexo 7) (Cassady et al. 2004). Este instrumento permite registrar y codificar la actividad cognitiva y el nivel de compromiso (engagement) del alumnado hacia la tarea.

Notas de campo, fotografías, grabaciones de vídeo y de audio

Durante la observación o inmediatamente después de esta se realizaron registros narrativos (notas de campo) sobre los elementos e impresiones a resaltar de lo acontecido durante la sesión observada. Para ello, y al tratarse de una observación no participante, se utilizó la técnica de la mosca en la pared (Marchena, 2005). En el caso 1 y 3 se realizaron grabaciones de vídeo de las sesiones. En el caso 2 y 4 , las situaciones de aulas observadas se registraron mediante una grabadora de audio.

\subsubsection{Análisis documental o material: generados por los docentes y por el alumnado de la propia práctica de aula}

Durante las sesiones de acceso al campo, se recogieron documentos (o fotografías de éstos) elaborados por los docentes para el desarrollo de su práctica en el aula (guías, apoyos visuales, instrucciones, pautas, normas...) o producidos por el alumnado (actas, dosieres, cuentos, actividades...). Seguidamente, se presenta la Tabla 15 con todos los datos recogidos en la investigación. 
Tabla 15

Datos recogidos distribuidos por casos

\begin{tabular}{|c|c|c|c|c|}
\hline AULA & TÉCNICA/INSTRUMENTO & FUENTE & CONTENIDO & SOPORTE \\
\hline \multirow{15}{*}{ CASO 1} & \multirow{7}{*}{ Entrevista } & \multirow[t]{2}{*}{ Maestro } & Entrevista inicial & Grabación de audio (0:23:25) \\
\hline & & & Entrevista final & Grabación de audio (0:53:34) \\
\hline & & $\begin{array}{l}\text { Estudiante prácticas } \\
\text { magisterio }\end{array}$ & Estancia de prácticas en relación a cómo trabaja el maestro. & Grabación de audio (0:23:37) \\
\hline & & $\begin{array}{l}\text { Alumnado } \\
\text { (A1)- (A2) }\end{array}$ & $\begin{array}{c}\text { Cuentacuentos a infantil y aspectos relacionados en el } \\
\text { funcionamiento del aula. }\end{array}$ & $\begin{array}{l}\text { Grabación de audio (0:07:01) } \\
(0: 24: 16)\end{array}$ \\
\hline & & $\begin{array}{l}\text { Alumnado } \\
\text { (A3)- (A4) }\end{array}$ & $\begin{array}{l}\text { Cultura Valenciana y aspectos relacionados en el } \\
\text { funcionamiento del aula. }\end{array}$ & $\begin{array}{l}\text { Grabación de audio (00:11:23) } \\
\qquad(00: 16: 54)\end{array}$ \\
\hline & & $\begin{array}{l}\text { Alumnado } \\
\text { (A5)- (A6) }\end{array}$ & $\begin{array}{l}\text { Leemos en pareja y aspectos relacionados en el funcionamiento } \\
\text { del aula. }\end{array}$ & $\begin{array}{l}\text { Grabación de audio (0:09:31) } \\
(0: 21: 23)\end{array}$ \\
\hline & & $\begin{array}{l}\text { Alumnado } \\
\text { (A7)- (A8) }\end{array}$ & $\begin{array}{l}\text { Tertulia literaria dialógica y aspectos relacionados en el } \\
\text { funcionamiento del aula. }\end{array}$ & $\begin{array}{l}\text { Grabación de audio (0:17:54) } \\
(0: 22: 37)\end{array}$ \\
\hline & $\begin{array}{c}\text { Inventario de prácticas de } \\
\text { aula }\end{array}$ & Maestro & Práctica docente & $\begin{array}{l}\text { Grabación de audio (0:7:13) } \\
\text { Hoja con respuestas }\end{array}$ \\
\hline & \multirow{7}{*}{$\begin{array}{l}\text { Observación no } \\
\text { participante }\end{array}$} & \multirow{7}{*}{ Situaciones de aula } & Leemos en pareja & $\begin{array}{c}\text { Grabación de vídeo (58:3) } \\
\text { Fotografías-50 } \\
\text { Hoja de registro de la observación }\end{array}$ \\
\hline & & & Tertulia literaria dialógica & $\begin{array}{l}\text { Grabación de vídeo (0:39:67) } \\
(0: 25: 59) \\
\text { Hoja de registro de la observación }\end{array}$ \\
\hline & & & Cuentacuentos a infantil & $\begin{array}{l}\text { Grabación de vídeo (0:5:97) } \\
\text { Fotografías- } 167 \\
\text { Hoja de registro de la observación }\end{array}$ \\
\hline & & & Teatro a infantil & $\begin{array}{l}\text { Grabación de vídeo (0:4:12) } \\
\text { Fotografías-96 } \\
\text { Hoja de registro de la observación }\end{array}$ \\
\hline & & & Exposiciones de libros & $\begin{array}{c}\text { Grabación de vídeo }(0: 34: 79) \\
\text { Fotografías- } 25 \\
\text { Hoja de registro de la observación }\end{array}$ \\
\hline & & & Cultura Valenciana & $\begin{array}{c}\text { Grabación de vídeo (107) } \\
\text { Grabación de audio (0:17:48) } \\
\text { Fotografías-79 } \\
\text { Hoja de registro de la observación }\end{array}$ \\
\hline & & & Naturales - Mates- Experimentos & $\begin{array}{c}\text { Grabación de vídeo }(0: 8: 38) \\
\text { Fotografías-50 } \\
\text { Hoja de registro de la observación }\end{array}$ \\
\hline
\end{tabular}




\begin{tabular}{|c|c|c|c|c|}
\hline \multirow[t]{8}{*}{ Continua caso 1} & \multirow{8}{*}{$\begin{array}{l}\text { Análisis documental o } \\
\text { material }\end{array}$} & \multirow{8}{*}{ Material } & $\begin{array}{l}\text { Proyecto "¿Qué sentido tiene la lengua? El gusto...por la } \\
\text { lengua" sobre las actividades del cuentacuentos a infantil, } \\
\text { cartas a otros centros y la tertulia literaria dialógica }\end{array}$ & Documento de 18 páginas \\
\hline & & & $\begin{array}{c}\text { Hoja de autoevaluación de la lectura en pareja. } \\
\text { Actividades leemos en pareja }\end{array}$ & $\begin{array}{l}246 \text { hojas de autoevaluación por parejas y } \\
\text { sus respectivas actividades (1r, } 2^{\circ} \text { y } 3 \mathrm{r} \\
\text { trimestre). }\end{array}$ \\
\hline & & & Rúbricas de autoevaluación de las libretas & 7 \\
\hline & & & Rúbricas de autocontrol de deberes & 6 \\
\hline & & & Cuentos & 10 \\
\hline & & & Escritos del alumnado valoración actividades & 25 \\
\hline & & & Prácticas material- Naturales & Documento \\
\hline & & & Carteles exposición de libros & Fotografías -90 \\
\hline \multirow{14}{*}{ CASO 2} & \multirow{14}{*}{ Entrevista } & \multirow{2}{*}{$\begin{array}{l}\text { Maestras } \\
\text { (D1) } \\
\text { (D2) }\end{array}$} & Entrevista inicial & Grabación de audio (0:54:20) \\
\hline & & & Entrevista final & Grabación de audio (0:52:42) \\
\hline & & $\begin{array}{l}\text { Estudiante prácticas } \\
\text { magisterio }\end{array}$ & Estancia de prácticas en relación a cómo trabaja la maestra. & Documento escrito \\
\hline & & $\begin{array}{c}\text { Alumnado } \\
\text { (A1.1)- (A2.1) }\end{array}$ & $\begin{array}{l}\text { Proyectos de trabajo y aspectos relacionados en el } \\
\text { funcionamiento del aula. }\end{array}$ & Grabación de audio (0:17:31) (0:21:05) \\
\hline & & $\begin{array}{l}\text { Alumnado } \\
\text { (A3.1)- (A4.1) }\end{array}$ & Talleres 1r ciclo. & $\begin{array}{l}\text { Grabación de audio } \\
(0: 04: 40)\end{array}$ \\
\hline & & $\begin{array}{l}\text { Alumnado } \\
\text { (A5.1)- (A6.1) }\end{array}$ & \multirow{5}{*}{ Aspectos relacionados en el funcionamiento del aula. } & $\begin{array}{l}\text { Grabación de audio } \\
(0: 16: 09)\end{array}$ \\
\hline & & $\begin{array}{l}\text { Alumnado } \\
\text { (A1.2)- (A2.2) }\end{array}$ & & $\begin{array}{l}\text { Grabación de audio } \\
(0: 35: 57)\end{array}$ \\
\hline & & $\begin{array}{l}\text { Alumnado } \\
\text { (A3.2)- (A4.2) }\end{array}$ & & $\begin{array}{l}\text { Grabación de audio } \\
(0: 24: 16)(0: 24: 57)\end{array}$ \\
\hline & & $\begin{array}{l}\text { Alumnado } \\
\text { (A5.2)- (A6.2) }\end{array}$ & & $\begin{array}{c}\text { Grabación de audio } \\
(0: 30: 32)\end{array}$ \\
\hline & & $\begin{array}{l}\text { Alumnado } \\
\text { (A7.2)- (A8.2) }\end{array}$ & & $\begin{array}{c}\text { Grabación de audio } \\
(0: 15: 24)\end{array}$ \\
\hline & & $\begin{array}{l}\text { Familiares } \\
\text { (F1)-(F2) }\end{array}$ & \multirow{3}{*}{$\begin{array}{c}\text { Aspectos relacionados con su participación en el aula y en los } \\
\text { aprendizajes de sus hijos. }\end{array}$} & $\begin{array}{l}\text { Grabación de audio } \\
(0: 21: 22)(0: 26: 00)\end{array}$ \\
\hline & & $\begin{array}{l}\text { Familiares } \\
\text { (F3)-(F4)-(F5) }\end{array}$ & & $\begin{array}{l}\text { Grabación de audio } \\
(0: 16: 20)\end{array}$ \\
\hline & & $\begin{array}{l}\text { Familiares } \\
\text { (F6)-(F7)-(F8) }\end{array}$ & & $\begin{array}{c}\text { Grabación de audio } \\
(0: 18: 07)\end{array}$ \\
\hline & & 5 Abuelos & Su colaboración en el proyecto de Betxí a lo largo del tiempo. & $\begin{array}{c}\text { Grabación de audio } \\
(0: 20: 22)\end{array}$ \\
\hline
\end{tabular}




\begin{tabular}{|c|c|c|c|c|}
\hline \multirow[t]{15}{*}{ Continua caso 2} & $\begin{array}{l}\text { Inventario de prácticas de } \\
\text { aula }\end{array}$ & $\begin{array}{l}\text { Maestras } \\
\text { (D1) - (D2) }\end{array}$ & Práctica docente & $\begin{array}{l}\text { Grabación de audio }(0: 29: 06) \\
\text { Hoja con respuestas }\end{array}$ \\
\hline & \multirow{13}{*}{$\begin{array}{l}\text { Observación no } \\
\text { participante }\end{array}$} & \multirow{6}{*}{$\begin{array}{l}\text { Situaciones de aula } \\
\text { clase } 1\end{array}$} & $\begin{array}{c}\text { Proyecto "La prehistoria"- Asamblea } \\
\text { Escritura del acta }\end{array}$ & $\begin{array}{c}\text { Grabación de audio } \\
(0: 29: 08)(0: 20: 06) \\
\text { Hoja de registro de la observación }\end{array}$ \\
\hline & & & Proyecto "La prehistoria"-¿Qué queremos saber? & $\begin{array}{c}\text { Grabación de audio(0:44:38) } \\
\text { Hoja de registro de la observación }\end{array}$ \\
\hline & & & $\begin{array}{l}\text { Proyecto "La prehistoria"- } \\
\text { Recogida de información }\end{array}$ & $\begin{array}{c}\text { Grabación de audio } \\
(0: 16: 57)(0: 35: 50)(0: 06: 41) \\
\text { Hoja de registro de la observación }\end{array}$ \\
\hline & & & $\begin{array}{l}\text { Proyecto "La prehistoria"- } \\
\text { Lola la historiadora }\end{array}$ & $\begin{array}{c}\text { Grabación de audio (1:11:04) } \\
\text { Hoja de registro de la observación }\end{array}$ \\
\hline & & & $\begin{array}{l}\text { Proyecto "La prehistoria"- } \\
\text { Distribución de los temas por grupos }\end{array}$ & $\begin{array}{c}\text { Grabación de audio } \\
(0: 42: 02)(0: 05: 48) \\
\text { Hoja de registro de la observación }\end{array}$ \\
\hline & & & $\begin{array}{c}\text { Proyecto "La prehistoria"- } \\
\text { Exposición1 } \\
\text { Exposición2 } \\
\text { Eje cronológico }\end{array}$ & $\begin{array}{c}\text { Grabación de audio } \\
(0: 24: 43)(0: 20: 13) \\
(0: 02: 22) \\
\text { Hoja de registro de la observación }\end{array}$ \\
\hline & & \multirow{7}{*}{$\begin{array}{l}\text { Situaciones de aula } \\
\text { clase } 2\end{array}$} & Proyecto Betxi - ¿Qué queremos saber? & $\begin{array}{l}\text { Grabación de audio (1:23:33) } \\
\text { Hoja de registro de la observación }\end{array}$ \\
\hline & & & $\begin{array}{c}\text { Proyecto Betxi- } \\
\text { Sesión abuelos } \\
\text { Después sesión abuelos }\end{array}$ & $\begin{array}{c}\text { Grabación de audio } \\
(1: 26: 30)(0: 22: 34) \\
\text { Hoja de registro de la observación }\end{array}$ \\
\hline & & & $\begin{array}{l}\text { Proyecto Betxi- } \\
\text { Juegos } \\
\text { Tira cronológica }\end{array}$ & $\begin{array}{c}\text { Grabación de audio } \\
(0: 49: 44)(1: 03: 19) \\
\text { Hoja de registro de la observación }\end{array}$ \\
\hline & & & $\begin{array}{l}\text { Proyecto Betxi- } \\
\text { Exposición }\end{array}$ & $\begin{array}{c}\text { Grabación de audio } \\
(0: 29: 55)\end{array}$ \\
\hline & & & Grupos interactivos & $\begin{array}{l}\text { Hoja de registro de la observación (C2.1) y } \\
\text { (C2.2) }\end{array}$ \\
\hline & & & Talleres 1r ciclo & $\begin{array}{c}\text { Grabación de audio (0:24:43) } \\
\text { Hoja de registro de la observación }\end{array}$ \\
\hline & & & Yoga en familia & $\begin{array}{c}\text { Grabación de audio (1:13:26) } \\
\text { Hoja de registro de la observación }\end{array}$ \\
\hline & $\begin{array}{l}\text { Análisis documental o } \\
\text { material }\end{array}$ & Material & $\begin{array}{l}\text { De la propia práctica docente } \\
\text { Elaborados o generados por el alumnado }\end{array}$ & Fotografías-372 \\
\hline
\end{tabular}


CAPÍTULO 3

Metodología y diseño de la investigación

\begin{tabular}{|c|c|c|c|c|}
\hline \multirow{19}{*}{ CASO 3} & \multirow{9}{*}{ Entrevista } & \multirow[b]{2}{*}{ Maestra } & Entrevista inicial & Grabación de audio (0:27:07) \\
\hline & & & Entrevista final & Grabación de audio (1:10:24) \\
\hline & & Maestra de música & Aspectos relacionados con el Proyecto LóVA & Grabación de audio (0:21:55) \\
\hline & & $\begin{array}{l}\text { Alumnado } \\
\text { (A1)- (A2) }\end{array}$ & \multirow{5}{*}{ Aspectos relacionados en el funcionamiento del aula. } & $\begin{array}{c}\text { Grabación de audio } \\
(0: 20: 43)(0: 05: 38)\end{array}$ \\
\hline & & $\begin{array}{l}\text { Alumnado } \\
\text { (A3)- (A4) }\end{array}$ & & $\begin{array}{l}\text { Grabación de audio } \\
(0: 29: 01)\end{array}$ \\
\hline & & $\begin{array}{l}\text { Alumnado } \\
\text { (A5)- (A6) }\end{array}$ & & $\begin{array}{l}\text { Grabación de audio } \\
(0: 31: 40)\end{array}$ \\
\hline & & $\begin{array}{l}\text { Alumnado } \\
\text { (A7)- (A8) - (A9) }\end{array}$ & & $\begin{array}{c}\text { Grabación de audio } \\
(0: 37: 03)\end{array}$ \\
\hline & & $\begin{array}{l}\text { Alumnado } \\
\text { (A10)- (A11) }\end{array}$ & & $\begin{array}{l}\text { Grabación de audio } \\
(0: 33: 14)\end{array}$ \\
\hline & & $\begin{array}{c}\text { Familia } \\
\text { (F1) }\end{array}$ & $\begin{array}{l}\text { Aspectos relacionados con su participación en el aula y en los } \\
\text { aprendizajes de sus hijos. }\end{array}$ & $\begin{array}{c}\text { Grabación de audio } \\
(0: 28: 33)\end{array}$ \\
\hline & $\begin{array}{l}\text { Inventario de prácticas de } \\
\text { aula }\end{array}$ & Maestra & Práctica docente & $\begin{array}{c}\text { Grabación de audio (0:08:52) } \\
\text { Hoja con respuestas }\end{array}$ \\
\hline & \multirow{9}{*}{$\begin{array}{l}\text { Observación no } \\
\text { participante }\end{array}$} & \multirow{9}{*}{ Situaciones de aula } & Puzle de Aronson & $\begin{array}{l}\text { Grabación de vídeo (0:26:48) } \\
\text { Hoja de registro de la observación }\end{array}$ \\
\hline & & & Taller de ciencias: "Los minerales" & $\begin{array}{c}\text { Grabación de vídeo (0:23:54) } \\
\text { Fotografías- } 6 \\
\text { Hoja de registro de la observación }\end{array}$ \\
\hline & & & Estaciones -Matemáticas & $\begin{array}{l}\text { Grabación de vídeo (0:26:95) } \\
\text { Fotografías- } 9 \\
\text { Hoja de registro de la observación }\end{array}$ \\
\hline & & & Lectura por parejas & $\begin{array}{c}\text { Grabación de vídeo (0:27:5) (0:31:81) } \\
\text { Fotografías- } 12 \\
\text { Hoja de registro de la observación }\end{array}$ \\
\hline & & & Proyecto Cortometraje & $\begin{array}{l}\text { Grabación de vídeo }(0: 42: 28) \\
\text { Hoja de registro de la observación }\end{array}$ \\
\hline & & & Estaciones -Lengua castellana & $\begin{array}{l}\text { Grabación de vídeo (0:36:18) } \\
\text { Hoja de registro de la observación }\end{array}$ \\
\hline & & & Dossier & $\begin{array}{c}\text { Grabación de vídeo (0:24:28) } \\
\text { Hoja de registro de la observación }\end{array}$ \\
\hline & & & Plan de trabajo & $\begin{array}{l}\text { Grabación de vídeo }(0: 31: 48) \\
\text { Hoja de registro de la observación }\end{array}$ \\
\hline & & & Proyecto LÓVA- MÚSICA & $\begin{array}{l}\text { Grabación de vídeo }(0: 15: 23) \\
\text { Fotografías- } 16 \\
\text { Hoja de registro de la observación }\end{array}$ \\
\hline
\end{tabular}




\begin{tabular}{|c|c|c|c|c|}
\hline \multirow[t]{11}{*}{ Continua caso 3} & & & Tertulia Literaria & $\begin{array}{l}\text { Grabación de vídeo (0:38:75) } \\
\text { Hoja de registro de la observación }\end{array}$ \\
\hline & & & Ginkama & $\begin{array}{l}\text { Grabación de vídeo }(0: 38: 66) \\
\text { Fotografías- } 11 \\
\text { Hoja de registro de la observación }\end{array}$ \\
\hline & & & Rincones & $\begin{array}{l}\text { Grabación de vídeo }(0: 27: 34) \\
\text { Hoja de registro de la observación }\end{array}$ \\
\hline & \multirow{8}{*}{$\begin{array}{l}\text { Análisis documental o } \\
\text { material }\end{array}$} & \multirow{8}{*}{ Material } & Carteles, murales, documentos ... & Fotografías- 170 \\
\hline & & & Lectura por pareja - castellano & $\begin{array}{c}\text { Tadeo Jons descubre las matemáticas } \\
\text { Lágrimas de Piedra } \\
\text { Las siete maravillas del mundo } \\
\text { Breve historia del dia de la mujer }\end{array}$ \\
\hline & & & Lectura por pareja - valenciano & $\begin{array}{c}\text { Tirant Lo Blanc } \\
\text { Les set meravelles de la natura } \\
\end{array}$ \\
\hline & & & Estaciones matemáticas & 4 documentos \\
\hline & & & Rubrica para evaluar el plan de clase & 1 documento \\
\hline & & & Dosier edad media & Documento 24 páginas \\
\hline & & & Projecte Star Wares Ciencias Sociales & Documento \\
\hline & & & Viaje a Londres & Documento \\
\hline \multirow{4}{*}{ CASO 4} & $\begin{array}{l}\text { Observación no } \\
\text { participante }\end{array}$ & Situaciones de aula & Situación de clase & $\begin{array}{c}\text { Hoja de observación } \\
\text { Audio -01:32:04 } \\
\text { 00:54:13 - 01:19: } 25 \\
\text { Notas de campo } \\
\end{array}$ \\
\hline & Entrevista & \multirow[t]{2}{*}{ Maestra } & \multirow{2}{*}{ Sobre el cómo y el porqué de su práctica docente } & $\begin{array}{c}\text { Entrevista estructurada } \\
\text { Audio - 01:21:21 }\end{array}$ \\
\hline & $\begin{array}{l}\text { Inventario de prácticas de } \\
\text { aula }\end{array}$ & & & $\begin{array}{l}\text { Audio - 00: } 44: 20 \\
\text { Hoja con respuestas }\end{array}$ \\
\hline & $\begin{array}{c}\text { Análisis documental o } \\
\text { material }\end{array}$ & Material & Material o situación de clase & $\begin{array}{c}164 \text { fotos } \\
2 \text { documentos }\end{array}$ \\
\hline
\end{tabular}




\subsubsection{Procesamiento y análisis de los datos}

El análisis de contenido de carácter temático (Paille y Mucchielli, 2003) ha sido la técnica utilizada para llevar a cabo la reducción e interpretación de los datos (Miles y Huberman, 1994). Para el procesamiento y análisis de la información, los datos recogidos han sido tratados mediante el software ATLAS.ti. Para la categorización de los datos se ha seguido una lógica de razonamiento deductivo. Esto es, se partía de unas categorías definidas previamente a partir de las cuales se rastrearon los datos (de enunciados generales a evidencias particulares). Tal y como introduce Yacuzzi (2005):

Un buen diseño incorpora una teoría, que sirve como plano general de la investigación, de la búsqueda de datos y de su interpretación. A medida que el caso se desarrolla, emerge una teoría más madura, que se va cristalizando (aunque no necesariamente con perfección) hasta que el caso concluye. (p.9)

A fin de no tener problemas a la hora de identificar todo el material perteneciente a cada uno de los casos se estableció el siguiente sistema de códigos (Ver Tabla 16). Este sistema de códigos consiste en identificar primeramente el caso al que pertenece el material, la técnica e instrumento utilizado y el informante. Por ejemplo:

\section{CASO_TÉCNICA.INSTRUMENTO_ INFORMANTE \\ Ej: C1_E.F_D \\ CASO1_ENTREVISTA.FINAL_DOCENTE}

A continuación, se presenta la tabla generada con el propósito de codificar e identificar la procedencia del dato. 
Tabla 16

Sistema de códigos para la identificación de la procedencia de los datos ${ }^{10}$

\begin{tabular}{|c|c|c|c|c|c|}
\hline \multirow{4}{*}{ CASO } & CASO 1 -MANOLO & \multicolumn{4}{|c|}{ C1 } \\
\hline & \multirow{2}{*}{$\begin{array}{c}\text { CASO } 2 \\
\text { 2.1- MATI } \\
\text { 2.2- AMÈLIA } \\
\end{array}$} & \multicolumn{4}{|c|}{ C2.1 } \\
\hline & & \multicolumn{4}{|c|}{$\mathrm{C} 2.2$} \\
\hline & CASO 3- CRISTINA & \multicolumn{4}{|c|}{$\mathrm{C} 3$} \\
\hline \multirow{11}{*}{ TÉCNICA } & \multirow[t]{2}{*}{ ENTREVISTA } & \multirow[t]{2}{*}{ E } & \multirow{11}{*}{ INSTRUMENTO } & $\begin{array}{c}\text { Entrevista } \\
\text { Semiestructurada } \\
\text { Inicial } \\
\end{array}$ & I \\
\hline & & & & $\begin{array}{c}\text { Entrevista } \\
\text { Semiestructurada } \\
\text { Final }\end{array}$ & $\mathrm{F}$ \\
\hline & $\begin{array}{c}\text { INVENTARIO } \\
\text { PRÁCTICAS DE AULA }\end{array}$ & IP & & Hoja de registro & $\mathrm{HR}$ \\
\hline & \multirow{6}{*}{ OBSERVACIÓN } & \multirow{6}{*}{$\mathrm{O}$} & & $\begin{array}{c}\text { Hoja de } \\
\text { Observación }\end{array}$ & $\mathrm{HO}$ \\
\hline & & & & Herramienta DCOS & DCOS \\
\hline & & & & Notas de Campo & $\mathrm{NC}$ \\
\hline & & & & Grabación en vídeo & GV \\
\hline & & & & Grabación en audio & GA \\
\hline & & & & Fotos & FO \\
\hline & \multirow[t]{2}{*}{ ANÁLISIS MATERIAL } & \multirow[t]{2}{*}{$\mathrm{AM}$} & & Documentos & DO \\
\hline & & & & Fotos de material & FOM \\
\hline \multirow{5}{*}{ INFORMANTE } & DOCENTES & \multicolumn{4}{|c|}{ D } \\
\hline & $\begin{array}{l}\text { ALUMNADO } \\
\text { PRÁCTICAS }\end{array}$ & \multicolumn{4}{|c|}{$\mathrm{AP}$} \\
\hline & ALUMNADO & \multicolumn{4}{|c|}{$\mathrm{A}$} \\
\hline & MADRES & \multicolumn{4}{|c|}{$\mathrm{M}$} \\
\hline & ABUELOS & \multicolumn{4}{|c|}{$\mathrm{AB}$} \\
\hline
\end{tabular}

Por lo que respecta a las categorías teóricas referentes a la diferenciación pedagógica se extrajeron de la literatura los elementos más importantes a indagar en los datos recogidos. A continuación, en la Tabla 17, se presentan las definiciones de las categorías teóricas que se han tenido en cuenta para el análisis (Tomlinson, 2008; Leroux y Paré, 2016).

${ }^{10}$ El caso 4 no aparece en el sistema de códigos, ya que solamente hay una informante (la docente). 
Tabla 17

Definición de las categorías teóricas: diferenciación pedagógica

\begin{tabular}{|c|c|}
\hline \multicolumn{2}{|c|}{ Diferenciación pedagógica } \\
\hline DIFERENCIACIÓN DE LAS ESTRUCTURAS & DIFERENCIACIÓN DEL CONTENIDO \\
\hline $\begin{array}{l}\text { Aquellos elementos que están directamente } \\
\text { relacionados con la organización del aula (Leroux y } \\
\text { Paré, 2016): } \\
\text { agrupamientos, } \\
\text { modalidades de trabajo, } \\
\text { tiempo, } \\
\text { espacio y } \\
\text { recursos } \\
\text { - recursos o apoyos visuales } \\
\text { recursos o apoyos personales }\end{array}$ & $\begin{array}{l}\text { Variedad de textos, saberes y conocimiento, el } \\
\text { grado de complejidad y los diferentes materiales } \\
\text { didácticos (Leroux y Paré, 2016). } \\
\text { Siguiendo a Tomlinson (2008), el contenido es } \\
\text { aquello que un estudiante debe llegar a conocer } \\
\text { (hechos), comprender (conceptos y principios), y } \\
\text { ser capaces de hacer (habilidades) como resultado } \\
\text { de un segmento concreto de estudio (una lección, } \\
\text { unidad o experiencia de aprendizaje). El contenido } \\
\text { es lo adquirido. Asimismo, engloba todos los medios } \\
\text { que ponen al alumno en contacto con la } \\
\text { información (libros de texto, lecturas } \\
\text { suplementarias, vídeos, excursiones, ponentes, } \\
\text { conferencias, experimentos, programas de } \\
\text { ordenador...). }\end{array}$ \\
\hline DIFERENCIACIÓN DEL PROCESO & DIFERENCIACIÓN DEL PRODUCTO \\
\hline $\begin{array}{l}\text { En palabras de Leroux y Paré (2016) se diferencia el } \\
\text { proceso según el campo de interés del alumnado, } \\
\text { los conocimientos previos y el nivel de } \\
\text { competencias, las retroalimentaciones entre el } \\
\text { alumno y el docente o el alumno y sus pares, } \\
\text { nivel de desarrollo del alumnado (motor, } \\
\text { cognitivo, social...), motivación y compromiso } \\
\text { hacia la tarea y el modo de vida del alumnado. } \\
\text { Siguiendo a Tomlinson (2008), el proceso es la } \\
\text { oportunidad que tienen los alumnos de dar sentido } \\
\text { a los contenidos. Los aprendices deben procesar las } \\
\text { ideas para apropiarse de ellas. }\end{array}$ & $\begin{array}{l}\text { Las diferentes modalidades de expresión, } \\
\text { destinatarios, proyectos o creaciones, modalidades } \\
\text { de evaluación del aprendizaje y criterios y } \\
\text { niveles de aprendizaje (cualitativos o } \\
\text { cuantitativos) (Leroux y Paré, 2016). } \\
\text { Tomlinson (2008), por su parte lo entiende como el } \\
\text { vehículo mediante el cual el alumno muestra (y } \\
\text { amplía) lo que ha llegado a comprender y a saber } \\
\text { hacer como resultado de un segmento de } \\
\text { aprendizaje de cierta magnitud. }\end{array}$ \\
\hline
\end{tabular}

Por otra parte, es necesario destacar que las categorías teóricas referentes a la participación democrática fueron construidas, definidas y discutidas por el grupo de investigación de Mejora Educativa y Ciudadanía Crítica (MEICRI). Enmarcadas dentro de los proyectos: Participación comunitaria y escuela democrática: estrategias para la formación de una ciudadanía crítica (2014-2016, UJI- P1·1B2013-32) y La escuela incluida en el territorio: análisis de las estrategias de participación ciudadana desde la educación intercultural inclusiva (2014-2015, MINECO- EDU2013-46491-R). Desde el grupo de investigación se realizó una validación del contenido de cada constructo por jueces expertos (Escobar-Pérez y CuervoMartínez, 2008). Concretamente se envió a 10 jueces expertos, puesto que Hyrkäs, AppelqvistSchmidlechner y Oksa (2003) consideran que dicho número de jueces ya ofrecen una estimación confiable de la validez de contenido. Se calcularon las medias y las desviaciones típicas de cada una de las categorías y se tomaron en cuenta las anotaciones o sugerencias propuestas por los jueces expertos.

Para este trabajo no se tomaron todas las categorías definidas desde el grupo Mejora Educativa y Ciudadanía Crítica (MEICRI), se seleccionaron aquellas que nos interesaron para responder a las preguntas de investigación 2 y 3 de este trabajo. Las categorías teóricas con sus respectivas $\mathrm{M}$ y 
D.T. ${ }^{11}$ tomadas en el eje de participación democrática han sido: valoración y reconocimiento de la diversidad $(\mathrm{M}=8.10, \mathrm{DT}=2.331)$, valores democráticos $(\mathrm{M}=8.70, \mathrm{DT}=1.567)$, cultura colaborativa $(\mathrm{M}$ $=8.50, \mathrm{DT}=1.434)$, participación democrática $(\mathrm{M}=8.30, \mathrm{DT}=1.636)$, redes de apoyo $(\mathrm{M}=8.10, \mathrm{DT}=$ 1.969), liderazgo compartido $(M=8.00, \mathrm{DT}=1.633)$, sentido de pertenencia $(\mathrm{M}=8.60, \mathrm{DT}=1.647)$, ciudadanía crítica $(\mathrm{M}=8.70, \mathrm{DT}=2.044)$, vinculación con el territorio $(\mathrm{M}=8.30, \mathrm{DT}=1.567) \mathrm{y}$ comunicación intercultural $(\mathrm{M}=8.20$, DT $=2.044)$. En la Tabla 18, que se presenta a continuación, se recogen cada una de las categorías teóricas con sus respectivas definiciones.

Tabla 18

Definición de las categorías teóricas: participación democrática

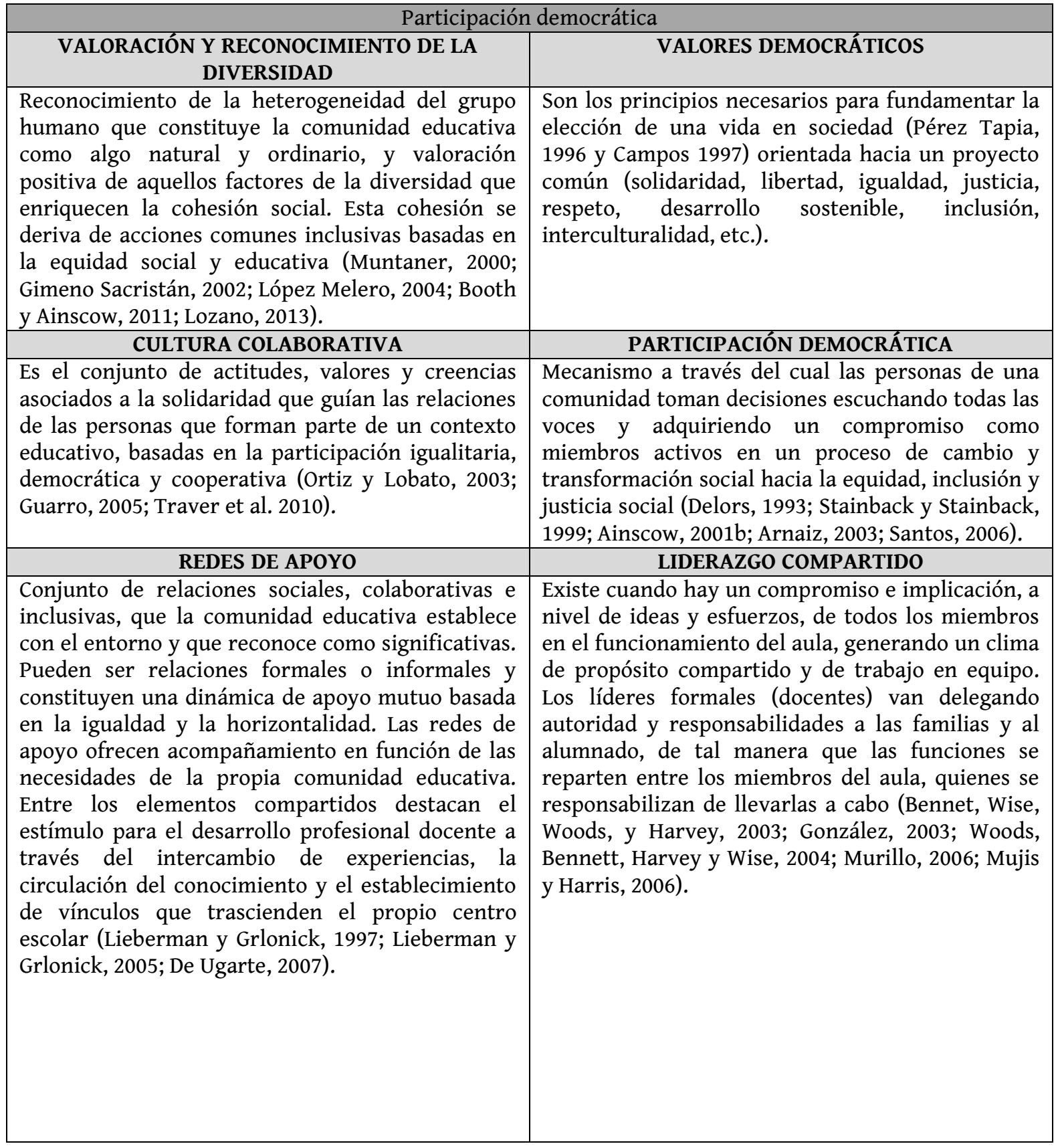

${ }^{11} \mathrm{M}=$ Media / D.T.= Desviación Típica

Los constructos teóricos podían ser valorados por los jueces del 1-10.

A mayor valor de la desviación típica mayor variabilidad entre los sujetos de la muestra lo que indica heterogeneidad en la variable medida. 


\begin{tabular}{|c|c|}
\hline SENTIDO DE PERTENENCIA & CIUDADANÍA CRÍTICA \\
\hline $\begin{array}{l}\text { Consciencia de vinculación emocional, histórica y } \\
\text { cultural con la comunidad escolar y con su } \\
\text { entorno. Reconocimiento positivo y apropiación } \\
\text { de los lazos intra e intercomunitarios que genera } \\
\text { la institución educativa. Sensación de que la } \\
\text { experiencia vivida en la escuela deja una huella } \\
\text { personal que, a su vez, es compartida por otros } \\
\text { miembros del colectivo y es capaz de construir una } \\
\text { identidad colectiva (Muntañola, 1996; Hellinger, } \\
\text { 2001; Ander-Egg, 2005; Carvajal, 2011; Feito, 2010). }\end{array}$ & $\begin{array}{l}\text { Apela al ejercicio de una ciudadanía que } \\
\text { problematiza la realidad, reflexiona } \\
\text { cooperativamente y propone acciones colectivas. } \\
\text { Para ello es necesario un liderazgo compartido, un } \\
\text { compromiso personal y social y una implicación } \\
\text { activa en la planificación, toma de decisiones } \\
\text { democrática y puesta en marcha de la acción } \\
\text { (Benjamin, 2002; Sales, 2012). }\end{array}$ \\
\hline VINCULACIÓN CON EL TERRITORIO & COMUNICACIÓN INTERCULTURAL \\
\hline $\begin{array}{l}\text { La vinculación de la escuela con el territorio se } \\
\text { expresa en el desarrollo de relaciones sostenibles y } \\
\text { de apoyo mutuo, mediante los cuales se percibe un } \\
\text { sentido de pertenencia (aceptación y valoración) e } \\
\text { implicación recíproca entre la comunidad escolar } \\
\text { y su entorno (Anant, 1966; Hagerty, Lynch-Sauer, } \\
\text { Patusky, Bouwsema y Collier, 1992). }\end{array}$ & $\begin{array}{l}\text { Se refiere a aquellas interacciones comunicativas } \\
\text { verbales y no verbales entre personas con } \\
\text { diferentes referentes culturales. Es un proceso de } \\
\text { negociación de significados, prácticas y valores en } \\
\text { el que los participantes relativizan la propia } \\
\text { cultura a la vez que generan comprensión de } \\
\text { valores alternativos. La finalidad de este proceso } \\
\text { es crear un mestizaje de saberes y prácticas } \\
\text { culturales capaz de vincular a los sujetos en una } \\
\text { propuesta de convivencia integradora. Tal objetivo } \\
\text { requiere una competencia comunicativa basada en } \\
\text { la empatía, la eliminación de estereotipos } \\
\text { negativos y la mediación intercultural (Rodrigo, } \\
\text { 1999; Touriñán, 2005; Lozano, Cerezo, Angosto, } \\
\text { Ramón y Alvarez, 2008; Rizo, 2013). }\end{array}$ \\
\hline
\end{tabular}

Una vez definidos los constructos teóricos de partida, se creó la unidad hermenéutica de trabajo en el software ATLAS.ti y se subieron todos los documentos primarios de cada uno de los casos (correctamente identificados siguiendo la Tabla 16). Seguidamente, se inició el proceso de codificación. Concretamente, se realizó una doble codificación de los datos, atendiendo a: 1) la categoría teórica (eje de la diferenciación pedagógica y/o eje de la participación democrática) y 2) la identificación de la metodología de aula a la que hacía alusión el dato. Puesto que, por ejemplo, en una entrevista se abordaban aspectos o elementos referentes a diferentes metodologías de aula. Estas metodologías de aula son: proyectos de trabajo, trabajo de investigación, proyecto LÓVA, leemos en pareja, grupos interactivos, tertulia dialógica, estaciones, exposición de libros, experimentos, rincones, ginkama, plan de trabajo, cartas al censal, puzle de Aronson, cuentacuentos, teatro a infantil, taller de ciencias, talleres y composición de textos en valenciano. Además, durante este proceso de codificación, en el cual se agrupaba la información recogida en las categorías anteriormente citadas se iban generando memos en el software para dejar rastro de aquellas evidencias o comentarios descubiertos por la investigadora a los cuales no se les debía de perder el rastro.

Posteriormente, se pasó a generar los informes de resultados de cada uno de los casos. Para ello, en el ATLAS.ti, se generaron familias de documentos primarios. Esto es, todos los documentos primarios del caso 1 formaban una familia, los del caso 2 formaban otra... Este hecho facilitó enormemente la organización de los datos y la redacción de los casos de cada uno de ellos. Se consideró, que una 
opción para presentar los datos de los casos podía ser por las metodologías de aula empleadas, ya que esta cometida ayudaría a contestar la segunda pregunta de investigación de la tesis. Mientras que, a través de la indagación de las categorías teóricas en los datos se detectaron las creencias, actitudes y valores subyacentes en las prácticas educativas de los docentes (tercera pregunta de investigación de la tesis). En el Anexo 17 se pueden consultar los informes de resultados emitidos en el ATLAS.ti.

Llegados a este punto, se inició el laborioso proceso de redacción de cada uno de los casos. Al mismo tiempo se utilizó la herramienta Manual Thinking (Huber, 2015), para ir plasmando, de forma manual, los mapas de relación de contenido de cada uno de los casos, los cuales fueron posteriormente informatizados con la herramienta CmapTools.

Esta tesis doctoral descansa sobre los criterios de rigor científico propios de la investigación cualitativa propuestos por Guba y Lincoln $(1985$; 1990) y Guba (1989): credibilidad, transferencia, dependencia y confirmabilidad. O lo que es lo mismo en palabras de Miles y Huberman (1994): autenticidad, fittingness, auditability y confirmabilidad.

Con el fin de aumentar la calidad en el proceso de investigación y garantizar la validez interna, credibilidad y rigor del estudio se realizó la triangulación como estrategia en la investigación educativa (Okuda y Gómez-Restrepo, 2005; Aguilar y Barroso, 2015). Cisterna (2005, p.68) define el proceso de triangulación hermenéutica como "la acción de reunión y cruce dialéctico de toda la información pertinente al objeto de estudio surgida en una investigación por medio de los instrumentos correspondientes, y que en esencia constituye el corpus de resultados de la investigación". Concretamente, de los diferentes tipos de triangulación propuestos por Denzin y Lincoln (1998) en este estudio se ha realizado la triangulación de datos. En palabras de Aguilar y Barroso (2015), este tipo de triangulación se refiere al uso de diferentes fuentes de información. Además, en el caso de los docentes dicha triangulación ha sido temporal (entrevista inicial-centrada en aspectos más generales y determinantes para la selección de los casos y entrevista final- centrada en lo observado) y personal: se ha preguntado a diferentes sujetos integrantes de cada uno de los casos. También se ha llevado a cabo una triangulación metodológica, puesto que se han utilizado diferentes métodos en la recogida de la información: entrevista, inventario de prácticas de aula, observación y análisis de documentos o materiales. Por último, decir que para evitar interpretaciones erróneas se les devolvió un borrador avanzado, del relato del caso, a los docentes para que pudieran comentar o sugerir lo que consideraron oportuno.

Por lo que respecta a la validez externa o generalización (transferencia o fittingness) hay que matizar que como señala Stake (1998), parece que el estudio de casos es una base pobre para poder generalizar, dado que se toman unos pocos casos. Pero como ya se ha introducido, el estudio de casos se basa en el detalle, en la unicidad, y esto implica el conocimiento de los otros casos de los que el caso en cuestión se diferencia, pero la finalidad última de este tipo de estudio es la comprensión del caso en sí mismo. 
En cuanto a la consistencia o fiabilidad del estudio (dependencia o auditability), esto es, el grado de reproducibilidad del estudio, este trabajo puede ser replicado por otros investigadores en otros contextos o etapas educativas.

Por último, el grado de objetividad o confirmabilidad del estudio se detecta en la coherencia de los datos, puesto que a partir de ellos se relatan los casos presentados.

\subsubsection{La investigación educativa: cuestiones éticas y profesionales}

La actividad de investigación en el campo educativo suscita algunas preocupaciones o dilemas a los investigadores, tanto en referencia al propio rol de investigador como a su relación con los agentes investigados (Moliner y St-Vicent, 2014). Las diferentes disciplinas han ido redactando sus propios códigos deontológicos o éticos a medida que se ha suscitado dicha necesidad en sus diferentes ámbitos profesionales (Tójar y Serrano, 2000). En nuestra rama de conocimiento destacar el Code of Ethics American Educational Research Association (AERA, 2011), el cual recoge los siguientes principios: a) competencia profesional, b) integridad, c) responsabilidad profesional, científica y académica, d) respeto a los derechos de los pueblos, dignidad y diversidad y e) responsabilidad social.

Para realizar esta investigación se han seguido los principios, criterios y compromisos que se desprenden del Código de Buenas Prácticas (CBP) de la Escuela de Doctorado de la Universitat Jaume I (2015) y del código ético de la investigación de l' Hautes Écoles Pédagogiques en Suisse romande et du Tessin (2002). Las cuestiones éticas y profesionales que han regido esta investigación educativa han sido:

Consentimiento libre y aceptado por parte de los sujetos objeto de ser investigados. Según Sandín (2003), el consentimiento informado es un código ético que permite informar, acerca del propio estudio que se va a llevar a cabo, a los sujetos objeto de ser investigados. Los docentes de cada uno de los casos, anteriormente al inicio de la investigación, firmaron el consentimiento informado (Ver Anexo 2 y 13), siendo conocedores de las principales acciones del estudio y aceptando, voluntariamente, su participación en el mismo. De la misma forma, tratándose de una investigación efectuada en el contexto escolar, con menores de edad, se informó y se solicitó las autorizaciones (Ver Anexo 3) pertinentes a los tutores legales de los alumnos, para poder realizar filmaciones o fotografías en el aula. En el caso de no contar con dichas autorizaciones, no se efectuaron. Igualmente, antes de empezar con la recogida de los datos se informó a los directores del centro y a las instituciones pertinentes para poder acceder al campo. Cabe señalar también, que, en el caso de los menores entrevistados, se les comunicó brevemente en qué consistía la investigación y manifestaron verbalmente su consentimiento a responder libremente a las preguntas que se les iban a realizar.

$\sim$ Respeto de los derechos fundamentales de la persona. Este principio hace alusión a salvaguardar la dignidad y el valor del ser humano, preservando ante todo el bienestar de las personas objeto de 
estudio (Tuckman, 1990). En este trabajo se han cumplido los principios rectores de la Universitat Jaume I establecidos en sus Estatutos, como son: la libertad, la democracia, la justicia, la igualdad, la independencia, la pluralidad, la integración de colectivos desfavorecidos, la paz y la solidaridad (CBP, 2015, p.3).

$\sim$ Respeto a la esfera privada: privacidad y confidencialidad. En esta investigación, no se revela ninguna información de la esfera privada de los participantes. A cada uno de los maestros, se les ha proporcionado el relato de su caso y han tenido la oportunidad de modificar o sugerir lo que han considerado oportuno. Se ha utilizado un sistema de códigos para no revelar nombres de los participantes. En lo que atañe al nombre de los docentes identificativos de cada uno de los casos, tal y como se aprecia en el consentimiento informado (Ver Anexo 2 y 13), éstos han podido utilizar libremente un pseudónimo.

Devolución de los resultados de la investigación. La investigadora envió a cada uno de los docentes los relatos de sus casos para que pudieran modificar posibles interpretaciones erróneas o generalizaciones abusivas. Además, al finalizar la tesis doctoral se les proporcionará a los maestros el informe de tesis completo.

$\sim$ Uso de la información recogida. Los datos recogidos en esta tesis doctoral, serán custodiados por la doctoranda, teniendo exclusivamente fines científicos y formativos. Se ha velado por el rigor científico a la hora de desarrollar la investigación, efectuando un proceso cuidadoso de descubrimiento y de interpretación de los resultados de la misma.

Responsabilidad personal y solidaridad colectiva. La difusión de los resultados también es una obligación ética del personal investigador. La investigadora en formación es responsable de su trabajo en el campo, de los datos recogidos y de los textos publicados y derivados de los mismos. La transmisión y explotación de los resultados derivados de este estudio se realizará una vez terminada la lectura pública de la presente tesis doctoral. Se velará por que los resultados de la investigación se difundan, se aprovechen y se trasfieran a la sociedad.

Así pues, bajo estas premisas se ha efectuado el trabajo de investigación que aquí se presenta. 


\section{CAPÍTULO 4}

\section{$\sim$ Resultados de la investigación}

4.1. Diferenciación pedagógica y participación democrática: modelo teórico relacional

4.2. Estudio de casos múltiples ..................................................................119

4.2.1. Caso 1: Manolo ..................................................................................119

4.2.1.1. Desarrollo de prácticas diferenciadas y democráticas .................119

4.2.1.2. Creencias, actitudes y valores que sustentan la práctica ..............154

4.2.2. Caso 2: Mati y Amèlia ...................................................................167

4.2.2.1. Desarrollo de prácticas diferenciadas y democráticas .................167

4.2.2.2. Creencias, actitudes y valores que sustentan la práctica ..............213

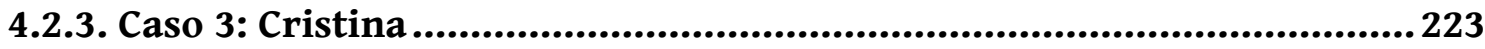

4.2.3.1. Desarrollo de prácticas diferenciadas y democráticas ..................223

4.2.3.2. Creencias, actitudes y valores que sustentan la práctica ..............267

4.2.4. Cas 4 : Ysabel ..................................................................... 277

4.2.4.1. La Suisse : contexte général de l'éducation ............................ 277

4.2.4.2. Cadre des pratiques de différenciation et participation ...............281

4.2.4.3. Croyances, attitudes et valeurs de l'enseignante .......................... 300 


n este capítulo se presentan los resultados obtenidos en esta tesis doctoral. Concretamente, para completar y dar respuesta a la primera pregunta de investigación, se construye un modelo teórico relacional (que se apoya tanto en la revisión teórica sobre los elementos que caracterizan la diferenciación pedagógica y la participación democrática como en los datos empíricos del trabajo realizado). En segundo lugar, se presentan cada uno de los casos abordados focalizando en dos aspectos: a) describir e ilustrar pormenorizadamente cada caso estudiado en este trabajo (segunda pregunta de investigación) y b) presentar los resultados referentes a las creencias, actitudes y valores que sustentan las prácticas educativas de cada uno de los casos examinados (tercera pregunta de investigación).

\subsection{Diferenciación pedagógica y participación democrática: modelo teórico relacional}

Trazar el camino de las prácticas de diferenciación pedagógica no resulta una tarea sencilla, ya que emergen perspectivas asociadas y contribuyentes que se nutren entre sí, como son la individualización, la personalización de la enseñanza, enseñanza multinivel o el diseño universal del aprendizaje (DUA). La investigación realizada desde este trabajo se focaliza en el enfoque de la diferenciación pedagógica, entendida esta como una filosofía docente centrada en dar respuesta educativa al conjunto del colectivo del grupo clase.

Articular el aula desde la diferenciación pedagógica emanada en una perspectiva inclusiva se basa en la valoración y el reconocimiento positivo de la diversidad y en los valores democráticos del docente. En ambos bloques de valores subyace el propósito de perseguir una educación justa y equitativa, es decir, se pretenden eliminar todas aquellas barreras o elementos que dificultan el aprendizaje y la participación de los alumnos.

La diferenciación pedagógica combinada con los principios que sostiene el diseño universal del aprendizaje (DUA), proporcionan a los docentes instrumentos teórico-prácticos que les ayudan a gestionar el desafío que supone atender al alumnado en un aula diversa y al mismo tiempo. Y es que, esta perspectiva depende de cómo el maestro concibe la heterogeneidad de los alumnos que conforman su aula y en cómo éste articula su acción docente para hacer frente a las diversas necesidades, ritmos, estilos o perfiles de aprendizaje, intereses y motivaciones de los sujetos que la componen. Se parte de unos objetivos de aprendizaje comunes o prácticamente comunes para todos 
los alumnos, pero para adquirirlos el docente proporciona diferentes vías. De esta manera en el transcurso del proceso de enseñanza- aprendizaje se presentan diferentes medios, métodos, dispositivos, procedimientos o acciones permitiendo que todos los alumnos puedan progresar.

Así pues, para articular la enseñanza diferenciada desde la práctica, el maestro es el principal agente que puede realizarlo a través de la diferenciación de las estructuras (agrupamiento y modalidades de trabajo, tiempo, espacio y recursos), el contenido (contenidos a adquirir, currículum democrático), el proceso (procedimientos más óptimos para el aprendiz) y el producto (modalidades de proyección de lo que se ha adquirido), a partir de una evaluación inclusiva y democrática. Esto es, los docentes y los alumnos colaboran para determinar una evaluación auténtica de sus producciones. La enseñanza parte del punto en el que están los alumnos, proporcionando retroalimentación a lo largo del proceso para seguir creciendo y desarrollándose. A partir de estos elementos se hace efectiva la diferenciación pedagógica y la participación democrática del alumnado en el aula.

Desde esta postura, se vislumbra un cambio de roles, fomentando un alumno activo y participativo (alumno protagonista) y un docente que facilita, guía, media y coordina en el proceso de enseñanza aprendizaje. Se precisa que el maestro fomente un liderazgo compartido en su aula, de esta manera comparte las responsabilidades, escucha los puntos de vista y los deseos de todo su alumnado en relación al aprendizaje. El docente muestra a los alumnos que sus pensamientos son respetados y tomados en cuenta, entre todos planifican e implementan decisiones en torno al currículum. Se realiza un aprendizaje integrado, globalizador, funcional y significativo.

Se fomenta la autonomía de los aprendices y la cultura colaborativa a partir de la ayuda mutua entre los iguales, quienes reconocen su propia diversidad y la de sus compañeros. Se promueve la convivencia, se aprende a vivir juntos y en sociedad, se desarrollan habilidades sociales y comunicativas, adquiriendo de forma natural la tolerancia y el respeto hacia la diferencia. Se promueve la reflexión y el pensamiento crítico. En definitiva, se crea en el aula una comunidad de aprendizaje y se promueve una gestión participativa originando tanto la intercomprensión como la interdependencia entre el alumnado. Generando, de este modo, el sentido de pertenencia al grupo aula puesto que los alumnos pueden participar, pueden aprender, en definitiva, se sienten parte, valorados y tomados en consideración.

Para que la educación sea verdaderamente inclusiva y se propicie una participación democrática, en el sentido amplio, es necesario que el docente extienda la cultura de colaboración (construyendo redes de apoyo), el liderazgo compartido y la participación democrática a las familias y otros agentes comunitarios, propiciando, además una vinculación con el territorio, es decir, con el entorno inmediato en el cual se inscribe el centro educativo.

A continuación, en la Figura 5, se presenta un modelo relacional entre los elementos que componen la diferenciación pedagógica desde una perspectiva inclusiva. 


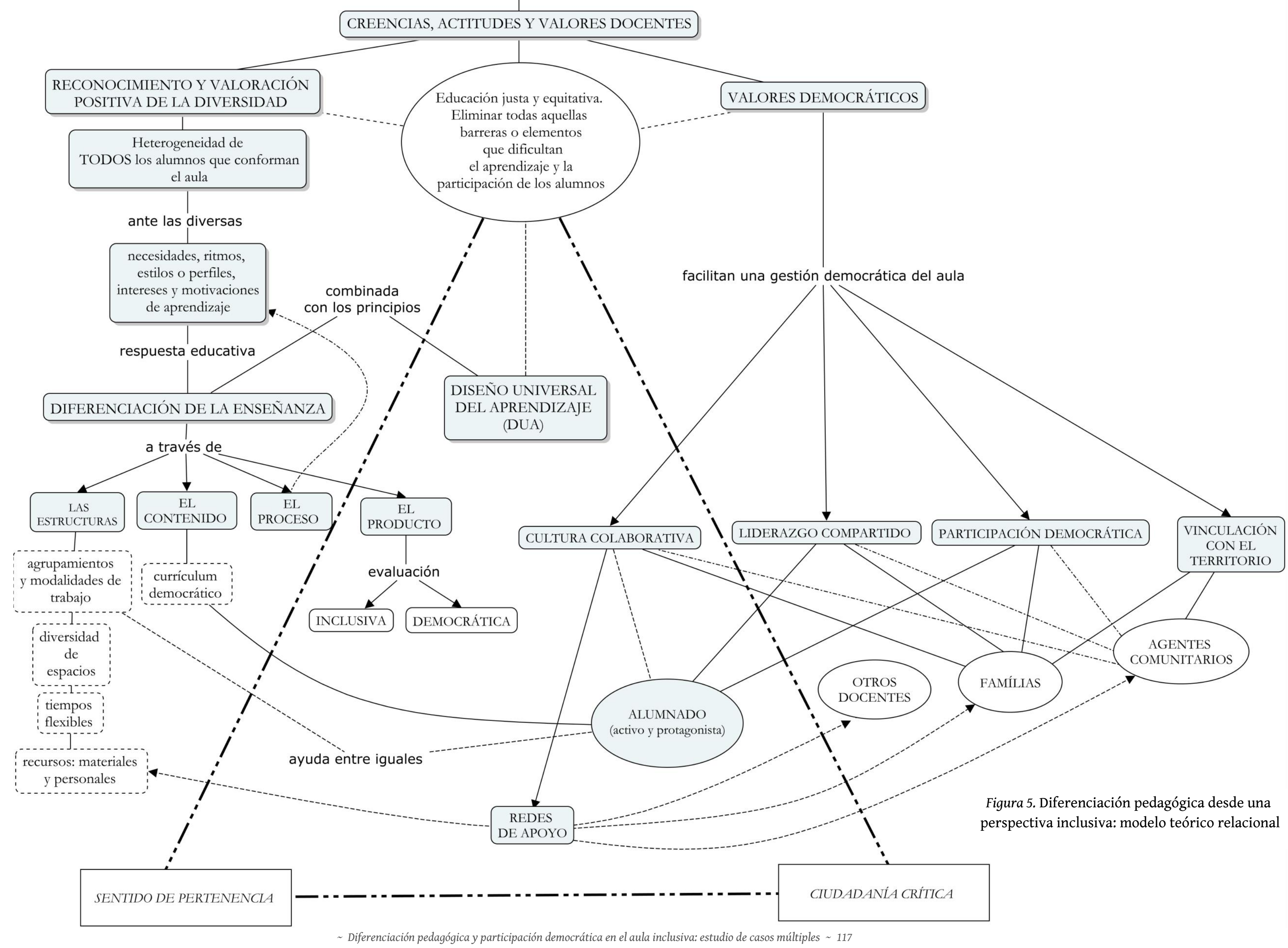





\title{
4.2. Estudio de casos múltiples
}

Una vez trazados los vínculos entre la diferenciación pedagógica y la participación democrática en el aula inclusiva se van a proceder a presentar los diferentes casos analizados en este trabajo. Seguidamente, se presentan cada uno de los relatos de los casos abordados. Se describe e ilustra pormenorizadamente cada uno de ellos siguiendo un criterio temático (prácticas didácticas), lo cual nos ayuda a responder a la segunda pregunta de investigación y, después, se presentan los resultados referentes a las creencias, actitudes y valores que sustentan las prácticas educativas de cada uno de los casos examinados con el propósito de contestar a la tercera pregunta de investigación.

\subsubsection{Caso 1: Manolo}

A continuación, se va a abordar el caso 1, el de Manolo. Primeramente, se hace una descripción de las prácticas didácticas y después se comentan las creencias, actitudes y valores que subyacen en su forma de trabajar en el aula.

\subsubsection{Desarrollo de prácticas diferenciadas y democráticas}

\author{
“[...] cal anar fent-los més crítics. M'agrada que diguen la seua, que no peguen 'cabotà' $i$ ja \\ està, perquè ho diu el mestre. Vull que siguen ells i elles els que s'adonen del que cal fer, per què \\ i com, i això requerix de reflexió, diàleg, debats".
}

(Blog "El raconet de Manolo", 8 setembre del 2014)

\subsection{Contexto general: localidad y centro educativo ${ }^{12}$}

La población de Castellón de la Plana, situada en la comarca de la Plana Alta, es la capital de la provincia de Castellón. El municipio cuenta con un total de $171.669^{13}$ habitantes.

El CEIP Isidoro Andrés Villarroya, está situado en la zona sur-este de la ciudad de Castellón. La zona de influencia se extiende entre la Avenida Valencia al oeste, la Avenida Borriana al norte, el límite sudeste de la ciudad y el nuevo eje de circunvalación al este, en gran parte en proceso de urbanización.

La familia nuclear es el tipo de estructura familiar predominante en el centro, pues las familias tienen pocos hijos, 1 o 2 y mayoritariamente en edad escolar. Remarcar que el $90 \%$ de las familias están formadas por madre, padre e hijo/s, siendo el 10\% familias monoparentales. Existe un 30\% de paro de las madres y un $20 \%$ de paro de los padres. El 32\% de los padres y madres tienen estudios primarios, el $47 \%$ tienen estudios secundarios y el $21 \%$ tienen estudios superiores. Mencionar que el 
55\% de las familias son de Castellón y provincia, el 7\% de otras zonas de la Comunidad Valenciana, el $21 \%$ del resto del Estado Español y el 17\% de otros estados. Las lenguas vehiculares familiares son el castellano (66\%), el valenciano (21\%) y otras lenguas (13\%).

El centro educativo cuenta con un total de 9 unidades de $2^{\circ}$ ciclo de educación infantil, 18 unidades de educación primaria y 1 aula habilitada de comunicación y lenguaje. El colegio dispone de un total de 43 docentes y 1 educador para el aula de Comunicación y Lenguaje (CyL).

\subsection{Los miembros de la clase: el maestro y su alumnado}

Con respecto a la experiencia docente, Manolo lleva trabajando en educación primaria 5 años. No obstante, es necesario subrayar que éste ha trabajado en otras etapas educativas. "En todos los niveles llevo 20 años. Estuve en educación secundaria y en educación primaria. No he estado en otros sitios" [C1_E.I_D]. Por lo que respecta a su formación académica, Manolo es maestro y psicólogo. "Soy maestro, diplomado en la titulación antigua de educación general básica y después soy licenciado en psicología" [C1_E.I_D]. Durante los últimos cinco años, ha participado como colaborador y ponente en cursos de formación complementaria para exponer o presentar dinámicas que lleva a cabo en su aula.

El maestro, durante el curso académico 2014/2015 es tutor de un aula de $5^{\circ}$ de primaria. Tiene un total de 25 alumnos: 11 chicas y 14 chicos, aunque hay que decir que a mitad de curso se incorporó un alumno nuevo. El docente reconoce la diversidad presente en su aula.

"En principio no hay ningún niño que esté diagnosticado, ni que requiera una adaptación curricular significativa, ni que tenga un dictamen. Lógicamente, como en todos los grupos hay niños que van más atrasados o que les cuesta un poco más, pero bueno, está todo dentro de lo que hay en un grupo de clase normal y corriente. Hay niños más adelantados y otros que les cuesta más, pero sin ninguna diferenciación grave" [C1_E.I_D].

La clase se denomina El Planeta de $5^{\circ} \mathrm{A}$. Es necesario decir, que en el aula objeto de estudio también encontramos a un estudiante de prácticas de magisterio. Hay que destacar también que Manolo es el secretario del CEIP Isidoro Andrés Villarroya.

Por lo que respecta a la participación de las familias, en $5^{\frac{0}{}}$ de primaria, ésta queda relegada principalmente a su colaboración, en casa, en la "lectura por parejas".

"Les he invitado de una manera informal, pero no de una manera concreta. Una madre sí que dijo que quería estar en una 'tertulia', al final pues no le dije: 'ven este día a la tertulia'. Pero sé que quiere venir. Más que nada ha sido como un abrir y decirles, que bueno, que el aula está abierta a su intervención y a su participación. También ha sido el primer año, yo pienso que el año que viene se hace más real esta participación en el aula, cuando los invito a ver las 'exposiciones' de los hijos, cuando les invito a hacer los 'grupos interactivos', cuando los invito a que participen en las 'tertulias' o que si algún padre quiere venir en algún momento por su trabajo o tarea que hace a contar alguna cosa" [C1_E.F_D]. 
Por tanto, en el segundo año que están con el docente, en $6^{\circ}$ de primaria, las familias son más partícipes dentro del aula. "Es así cómo lo suelo hacer, que lo hago más en el segundo año que estoy con ellos" [C1_E.F_D].

\subsection{La gestión general del aula}

El maestro usa varios formatos de agrupación del alumnado (por ejemplo, grupo clase, pequeños grupos, parejas, individual). "Utilizo todas las formas posibles que hay" [C1_IP.HR_D].

"[...] son diferentes agrupaciones que van respondiendo a diferentes maneras de trabajar, porque no es lo mismo trabajar con una persona, que con una pareja. Que es más fácil de coordinarse, que a la hora de trabajar en grupo que a lo mejor pueden haber dos o tres opiniones y ya a partir de ahí tienen que resolver sus problemas para poder llegar a una conclusión" [C1_E.F_AP].

Al hilo de lo anterior, uno de los muchos propósitos de Manolo es enseñar a su alumnado a saber ser competentes en los diferentes espacios y en los diferentes grupos. "Concretamente en el proyecto que presento habrá actividades donde el trabajo es individual, por ejemplo, en la de cartearnos con compañeros de otras escuelas, a pesar de que en el pequeño grupo se mantienen las ayudas, correcciones y colaboraciones entre los diferentes miembros cuando se les intercambian para recibir la opinión de sus compañeros" [C1_AM_DO]. Así pues, el alumnado trabaja mediante diferentes agrupaciones según la metodología requerida.

"Depende de la actividad. Lógicamente, pues el 'leemos en pareja' es una actividad de dos. Lo que hacemos es trabajar en dos, cuando hacemos un trabajo..., ahí depende del trabajo. Los dejo hacer... Igual se me hace un grupo de cinco que se me hace un grupo de dos, los respeto. Y después lo que sí que es un trabajo más cotidiano y más diario... Eso sí que son los grupos de clase, porque son grupos de cuatro o de tres, que es con el que más interacciones y más horas pasan juntos" [C1_E.F_D].

En referencia a las agrupaciones, el estudiante de prácticum destaca las diferentes relaciones que se generan entre los alumnos y que propician la búsqueda de la resolución de conflictos y el consenso en el aula.

"Hay como diferentes relaciones. Está la hora de planteárselo individualmente que también se hace el trabajo. Está la hora de planificarse en pareja, que es un pequeño grupo, que es más fácil de coordinar y también a la hora de hacer pequeños grupos, se tienen que coordinar con más compañeros y lo que tienen que hacer es llegar a unos acuerdos. ¿Qué pasa ahí? Que a veces aparecen conflictos y esos conflictos son buenos a la hora de resolver problemas [...]" [C1_E.F_AP].

En cuanto a los criterios de formación de los grupos remarcar que se realizan grupos heterogéneos. "Agrupamos a los niños en mesas, en grupos de alumnos diversos, heterogéneos y con diferentes capacidades, con diferentes aptitudes [...]" [C1_E.I_D]. Los miembros de los grupos cambian cada mes, esto es, cada 4 semanas.

El maestro propone desde un primer momento que sea el alumnado quien gestione su aula y su grupo. "Desde que recibo un grupo nuevo, pues por ejemplo, este año que he recibido los niños de 5 o de primaria, siempre 
mi propuesta va dirigida a que sean ellos los que vayan gestionando y organizándose el aula" [C1_E.I_D]. Por consiguiente, encontramos una doble gestión y organización por parte del alumnado: una a nivel de aula y otra a nivel de grupo. "El docente solicita la participación de todos los alumnos tanto en la gestión del aula como en la organización" [C1_O_HO].

\section{Gestión y organización del aula: encargados}

En el aula encontramos seis grupos, formados por 4 o 3 alumnos. Cada grupo tiene asignado un rol o una función que repercute en el buen funcionamiento, o no, del aula. "Porque así la clase funciona un poco más arreglada" [C1_E.F_A6]. Cada mesa desempeña un rol, éstos son: 1) encargados de la decoración, 2) encargados de la agenda, 3) encargados del blog, 4) encargados de la pizarra y el corcho informativo, 5) encargados de la biblioteca, 6) encargados de la mascota, la planta, las ventanas y la puerta.

\section{1) Encargados de la decoración}

La clase o el propio grupo de decoración pueden aportar ideas para decorar el aula y los encargados de esta tarea la llevan a cabo (Ver Imagen 1). "Por ejemplo, si eres el grupo de decoración puedes aportar cosas, pero ya no las hace toda la clase las hace tu grupo, para decorar la clase [...]" [C1_E.F_A6]. "[...] si queremos poner un cartel, por ejemplo, de que llega la primavera él le dice al grupo de decoración que entre todos hagan un cartel [...]" [C1_E.F_A4]. De esta manera crean un ambiente agradable a sus gustos o preferencias. "Así nuestra clase estará más ordenada y nosotros participaremos más en la decoración de

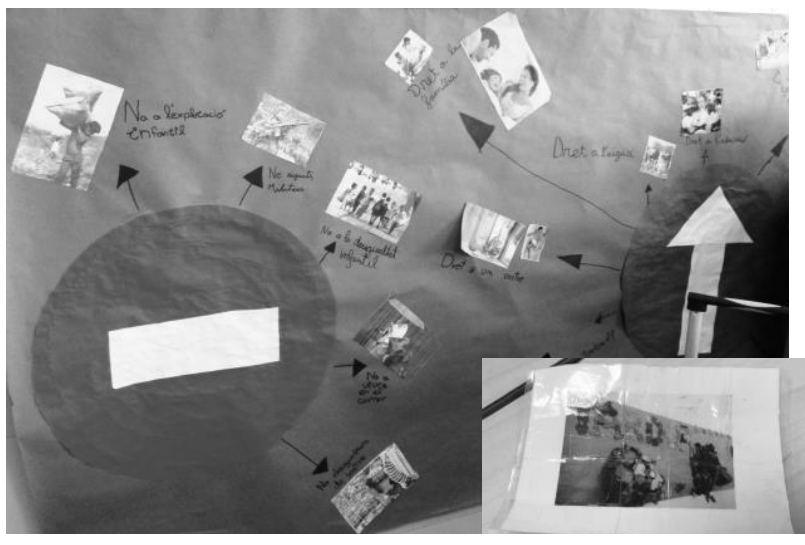

Imagen 1. Mural decorativo en el aula. [C1_O_FO]. nuestra clase y la cuidamos más" [C1_E.F_A7].

\section{2) Encargados de la agenda}

Otro grupo se encarga de actualizar la agenda de clase (Ver Imagen 2) y la agenda online del blog (Ver Imagen 3). "Pues que el grupo de las agendas, que actualiza las agendas" [C1_E.F_A6].

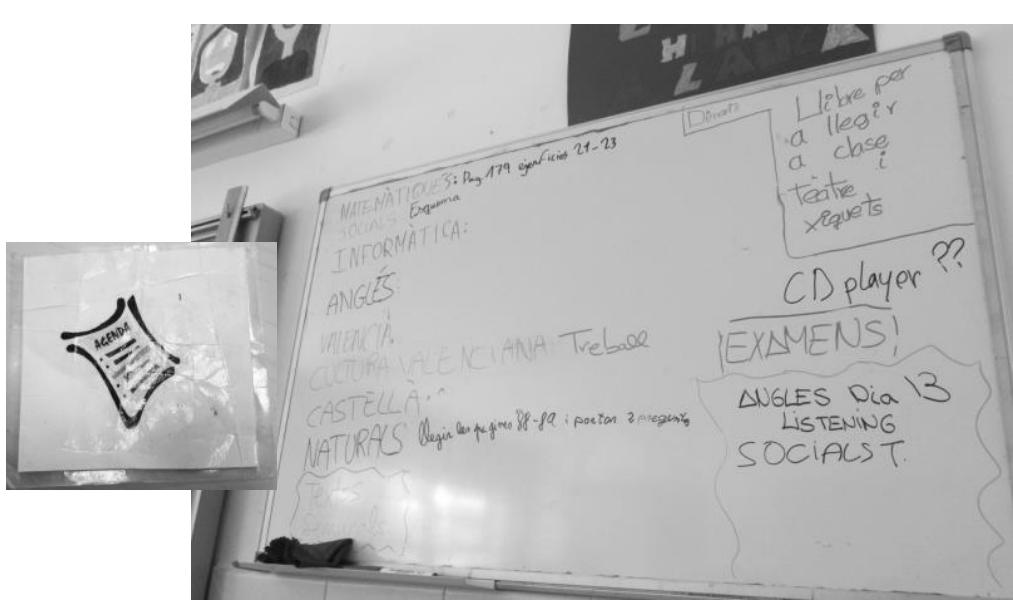

Imagen 2. Pizarrón de la agenda [C1_O_FO].

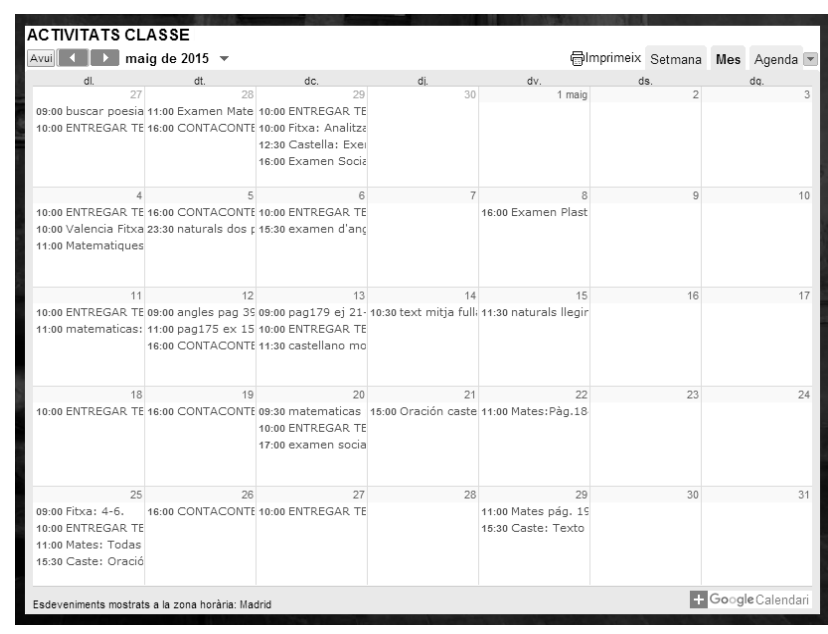

Imagen 3. Agenda online del blog de aula [C1_AM_FOM]. 


\section{3) Encargados del blog}

Otro grupo se encarga del mantenimiento del blog del aula, según las diferentes actividades que van realizando en clase. El blog lo utilizan tanto cuando el alumno cursa $5^{\text {o }}$ como cuando estos están en $6^{-}$de educación primaria. Hay grupos que no realizan correctamente esta función y son objeto de crítica por parte de sus compañeros. "Y que el grupo del blog, que si hace mucho tiempo, que creo que un mes... Porque nosotros lo hicimos cuando nos tocó, [...] bueno cada semana una entrada al blog y ahora se ha quedado muy pobre el blog porque nadie hace nada" [C1_E.F_A5].

\section{4) Encargados de la pizarra y el corcho informativo}

Este rol consiste en mantener y actualizar el corcho del aula. Para ello, los encargados cuelgan algunas noticias o informaciones que son de la incumbencia o del interés de los compañeros del aula. Otra de las tareas que debe realizar este grupo son: escribir la fecha del día en la pizarra y mantenerla limpia (Ver Imagen 5).

\section{5) Encargados de la biblioteca}

Otra de las tareas a desempeñar es la gestión de la biblioteca. "Atender la biblioteca: orden, préstamo, control..." [C1_O_NC]. Además, este grupo se encarga de la gestión de las exposiciones de los libros de lecturas voluntarios. Esto es, cuando algún miembro de la clase ha leído algún libro y quiere exponerlo a sus compañeros debe informar al grupo de la Biblioteca y en algún hueco o al final de alguna clase se procede a la exposición (esto se explicará más detalladamente en un apartado posterior). Para ello, utilizan diferentes registros de las lecturas (Ver Imagen 6).
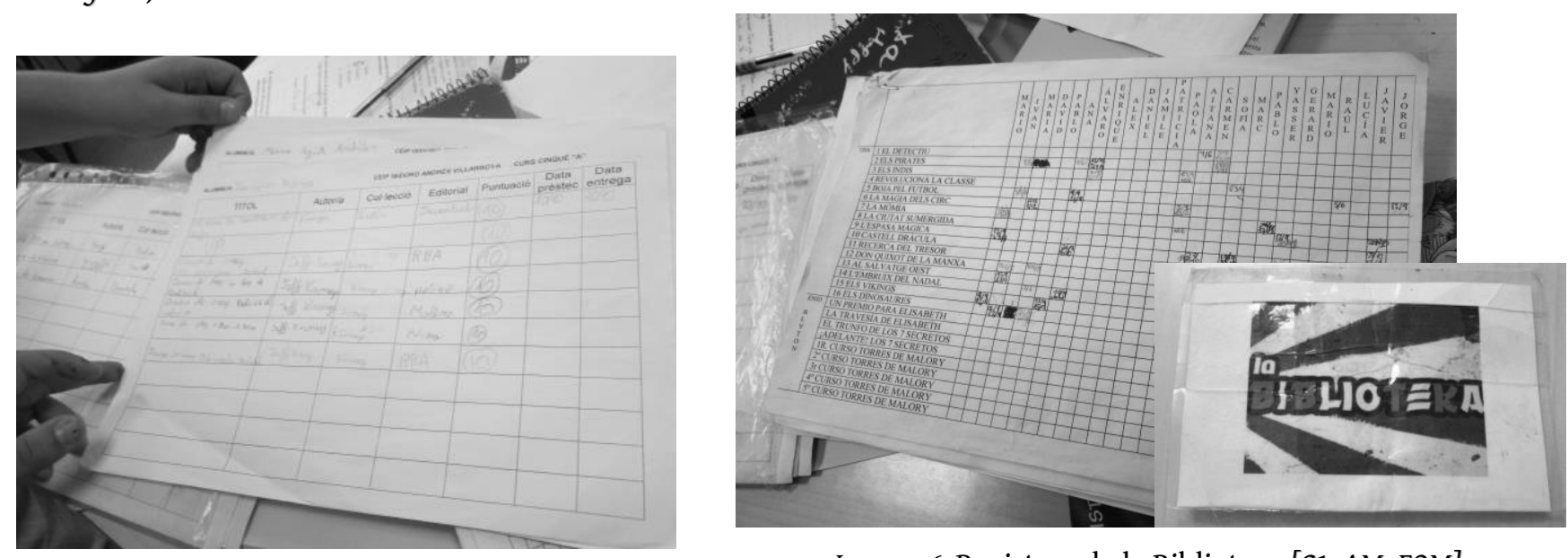

Imagen 6. Registros de la Biblioteca [C1_AM_FOM]. 


\section{6) Encargados de la mascota, la planta, las ventanas y la puerta}

Las últimas funciones de grupo que quedan por mencionar son: "levantar y bajar persianas y cerrar la puerta. Cerrar y encender las luces. Tener cuidado de la mascota y la planta" [C1_O_NC]. Como curiosidad, decir que tienen un hámster como mascota de la clase, la cual se llama Mossets (Ver Imagen 7).

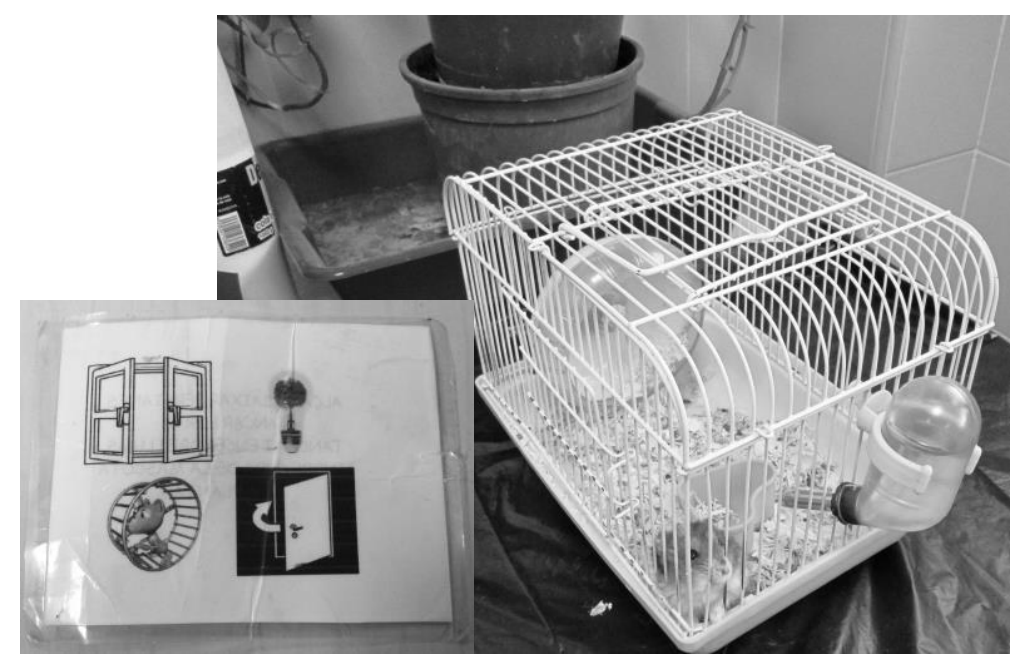

Imagen 7. La mascota de la clase [C1_O_FO].

Así pues, estas tareas corresponden a los diferentes grupos, y si éstos no las hacen los propios compañeros son los que se encargan de recordarlo, ya que el funcionamiento del aula se ve entorpecido.

"Tenemos una organización a nivel de gran grupo o cada grupo y cada uno tiene unas responsabilidades dentro del aula. Todo eso va rotando y cambiando, semanalmente, según lo que les toca. Empiezo esa dinámica ya un poco más participativa de ellos, las cosas se hacen si ellos las hacen, si no las hacen no las llevan a cabo. Tenemos biblioteca, si la biblioteca no funciona es porque el grupo de biblioteca es quien se encarga o si el blog que tenemos de aula funciona o no funciona es porque a quien le toca hacer el blog o atender el blog es el que está pendiente del blog o no. Y se van dando cuenta, y se van quejando entre ellos que eso no funciona y les digo: 'no me lo digas a mí, decirlo al grupo correspondiente'. $O$ 'alli no han puesto en la agenda los deberes'. 'Pues dilo al grupo'. Entonces ellos mismos se van apoyando, se van reforzando y se van pinchando también para darse cuenta de que las cosas se han de ir haciendo. Si no se han levantado las persianas y estamos a oscuras pues es porque hay un grupo que no ha funcionado. Y un poco pues esa sería la dinámica a nivel general" [C1_E.I_D].

Vemos cómo la gestión de la organización del aula no depende del docente, sino que depende del alumnado. "Es una forma de que ellos se cojan una responsabilidad y que vean que, si esa responsabilidad no la asumen, toda la clase se ve perjudicada. Y yo creo que organizar la clase por cargos es una forma de repartir las tareas bien organizadas y de que la clase funcione si todo el mundo colabora. Claro, porque si uno deja de colaborar la clase se viene abajo" [C1_E.F_AP]. 
Los alumnos también son conscientes de la importancia de esta distribución de los roles para que todos puedan participar y colaborar en el funcionamiento de su aula. "Porque si hacemos todos el mismo cargo, ahí la mayoría se quedarían sin hacer nada y los mismos lo harían todo" [C1_E.F_A8].

Destacar que en cada mesa hay un cartel que indica el rol de esa semana del grupo (Ver Imagen 8). En el reverso se señalan brevemente las tareas que se deben realizar en cada cargo.

\section{Gestión y organización del grupo: roles en el grupo cooperativo}

Hay que subrayar por otro lado, los roles o funciones

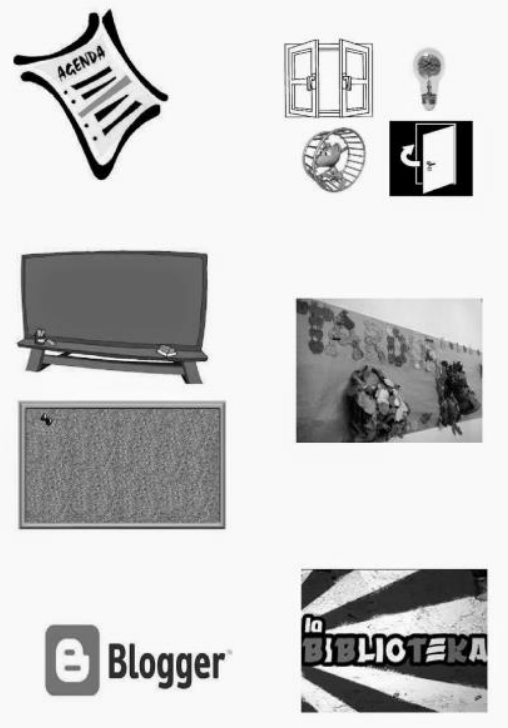

Imagen 8. Carteles con los roles de grupo. [C1_AM_FOM]. a nivel interno de cada grupo. Esto es, cada miembro del grupo ejerce un rol que repercute en el buen funcionamiento o no de su grupo. Los diferentes roles a desempeñar son: delegado, subdelegado, encargado del material y secretario. "Nosotros en el grupo somos un secretario, un subdelegado, un delegado, y todo eso [...] Hay un secretario, que es el que apunta [...] el que guarda todo y apunta la opinión del grupo. El delegado que es el portavoz del equipo, el encargado que es para no hacer mucho escándalo, es el único del grupo que se puede levantar, y el subdelegado es el que hace que el grupo se tranquilice, calle y todo eso" [C1_E.F_A8].

Con esta distribución de tareas el maestro pretende que cada persona sepa estar en los diferentes lugares que le toca.

"[...] el que los compañeros sepan respetar. Saber atender a las demandas del grupo. Pues cuando les digan 'tienes que ser tú portavoz o tienes que ser secretario', lo que el grupo les pida que digan, que hagan, que... 'Bueno pues ahora soy yo', pues en cada momento saber estar en ese lugar, saber ocupar ese espacio, esa silla... de alguna manera y llevarla adelante o resolver los problemas en los que se encuentran" [C1_E.F_D].

Los alumnos, por su parte, también son conscientes de la tarea que tienen que realizar. "Porque así como que somos más responsables y aprendemos a... cosas" [C1_E.F_A4]. Los cargos son rotativos de manera que todos desempeñan todas las funciones. "Siempre, cada semana cambiamos. Si por ejemplo en una yo soy secretaria en la siguiente me toca ser encargada y vamos dando vueltas y hacemos todos todo" [C1_E.F_A8]. Asimismo, el hecho de tener roles asignados ayuda a que todos puedan participar y colaborar en la ejecución de las mismas. Transcurridas cuatro semanas, todos han desempeñado todos los roles y se procede al cambio de integrantes de cada grupo. "Bien, porque siempre en el grupo hay una persona o dos... A mí también me pasa sobre todo si soy yo en mi grupo que me gusta hacerlo todo, entonces los otros, yo no me doy cuenta, pero cuando me lo hacen a mí no me gusta, entonces como somos los 4 hacemos todo, todo" [C1_E.F_A8]. 
En esta ocasión vemos nuevamente, cómo la gestión de la organización del grupo no depende del adulto, depende de los alumnos integrantes de cada grupo.

"Y había niños que se quejaban, decían 'éste no ha hecho nada'. Digo: 'bueno pues habrá sido que la organización no habrá sido la correcta', porque si un niño no ha hecho nada es porque no le habrán dado la tarea y la tarea la marca el grupo, no la marca un niño. Pues son cosas que iremos hablando para ir mejorando y que son totalmente normales y habituales. Pero que yo pienso que irán mejorando" [C1_E.I_D].

Otra gestión a desempeñar por el alumnado, a nivel de grupo, es el control de los deberes. Para ello tienen unas hojas de registro semanales (Ver Imagen 9), de cada una de las asignaturas. "Tenemos, en todos los grupos, tablas donde hacen control de deberes. Por ejemplo, si han traído el material que es una cosa que ellos se van anotando y después me lo pasan a mî" [C1_E.I_D]. "Y también los deberes, y cuando en el grupo, si cada uno ha hecho los deberes de una asignatura lo anotamos en una ficha y así Manolo también puede tener un poco de referencia de eso [C1_E.F_A4].

\section{NATURALS I SOCIALS}

\begin{tabular}{|c|c|c|c|c|c|c|c|c|c|c|c|c|}
\hline \multicolumn{4}{|c|}{ RESPONSABLE: } & \multicolumn{3}{|c|}{ SETMANA DEL } & \multicolumn{6}{|c|}{ DE } \\
\hline & \multicolumn{3}{|c|}{ DILLUNS } & \multicolumn{3}{|c|}{ DIMARTS } & \multicolumn{3}{|c|}{ DIMECRES } & \multicolumn{3}{|c|}{ DIJOUS } \\
\hline $\begin{array}{l}\text { MEMBRES DE } \\
\text { L'EQUIP }\end{array}$ & 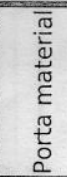 & 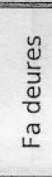 & 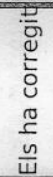 & 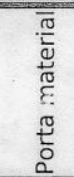 & 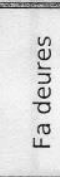 & $\begin{array}{l}\overline{5} \\
\bar{u} \\
\frac{0}{0} \\
0 \\
\frac{0}{4} \\
\frac{n}{4}\end{array}$ & 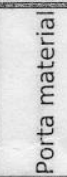 & 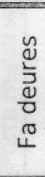 & 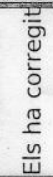 & 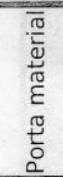 & 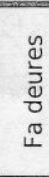 & 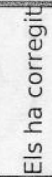 \\
\hline & $x$ & & & $x$ & & & $x$ & & & $x$ & & \\
\hline & $x$ & & & $x$ & $x$ & $x$ & $x$ & & & $x$ & $\alpha$ & \\
\hline & $x$ & & & $x$ & $x$ & $\alpha$ & $x$ & & & $x$ & & \\
\hline & $x$ & & & & $x$ & $x$ & $x$ & & & $x$ & & \\
\hline
\end{tabular}

Imagen 9. Registro de los deberes o tareas [C1_AM_FOM].

El hecho de que el alumnado auto-gestione el control de deberes hace que haya una mayor implicación, en la mayoría de los casos, a la hora de realizarlos.

"Eso sobre todo también, en un principio, me sirve a mí para ver quien hace los deberes o no. Pero eso lo sabes enseguida. Pero sobre todo sirve para ellos ¿no? El hecho de que los compañeros estén controlando los deberes, hace que de alguna forma estén más pendientes de los deberes. jAlgunos! A otros les da igual que les controle el compañero, que les controle yo. Que lo controle quien lo controle, le da igual. Pero bueno, ahí está" [C1_E.F_D]. 


\subsection{Metodologías de trabajo: diferenciación pedagógica}

Se procede a relatar una muestra de cómo trabaja Manolo con su alumnado. Primeramente, se explica de qué manera abordan, en la asignatura de cultura valenciana, los grupos de investigación. Posteriormente, se habla de las diferentes dinámicas que el docente utiliza para trabajar la asignatura de valenciano, como son: "leemos en pareja", tertulia literaria dialógica, exposición de libros, cuentacuentos y teatro a infantil, las cartas al Censal y otras producciones escritas. Es necesario destacar que la asignatura de castellano no la realiza Manolo, la imparte el director del colegio. Se ilustra cómo trabajan, en las asignaturas de matemáticas, ciencias sociales y ciencias naturales, mediante el aprendizaje cooperativo y el libro de texto. Además, se presenta una sesión de experimentos, llevada a cabo en la asignatura de ciencias naturales. Se termina aportando aspectos que atañen a la evaluación del alumnado.

\subsection{Los grupos de investigación: descubriendo la cultura valenciana}

En la asignatura de cultura valenciana no tienen libro de texto, para abordar la temática a estudiar lo hacen mediante los grupos de investigación. Las principales fases o etapas que suelen realizar las podemos resumir en las siguientes:

$\sim$ Bloque general de contenidos a trabajar: escoger el tema y formación de grupos de trabajo.

$\sim$ Sesiones de trabajo e indagación sobre los contenidos a estudiar.

Exposición de los contenidos: acuerdos sobre los criterios de evaluación y evaluación del trabajo de los compañeros.

$\sim$ Bloque general de contenidos a trabajar: escoger el tema y formación de grupos de trabajo

Habitualmente, el docente les presenta un bloque de contenidos general de la asignatura, y a partir de una lluvia de ideas extraen lo que pueden estudiar en relación a dicha temática. "Yo lanzo un poco el bloque general de contenidos y ellos escogen" [C1_E.F_D]. "Por ejemplo, en Cultura Valenciana, ellos escogen el tema, los niños, y a partir de ahí, a partir de sus necesidades, les va creando el trabajo" [C1_E.F_AP].

Por ejemplo, en el primer trimestre estudiaron aspectos relacionados con la geografía de la Comunidad Valenciana. "A lo largo del curso, en el primer trimestre nos dedicamos al tema de geografía y hablamos de ver que cuestiones geográficas de la comunidad podían hablar y [...] lluvia de ideas y empezaron a decir cosas que si cabos, que si lagos, que si ríos, que si montañas, que... y anotamos, escogieron e hicieron el trabajo sobre eso" [C1_E.F_D]. "Al principio de curso, en Cultura Valenciana, Manolo nos dio unas fichas que hablaban sobre el terreno y todo eso, la zona montañosa y todo eso de la comunidad" [C1_E.F_A4].

Posteriormente, escogen los subtemas que estudiará cada uno de los grupos. "El otro día en Cultura estábamos pensando qué trabajar y cada uno hacía una propuesta y Manolo iba apuntándolo en la pizarra y al final 
hicimos grupos para que cada uno trabajara lo que... " [C1_E.F_A4]. "Que cada uno da ideas y escogemos cuál queremos hacer" [C1_E.F_A7]. Así pues, en la mayoría de casos, se forman los grupos según los intereses temáticos de los alumnos en estudiar cada uno de los subtemas que conforman la temática general. "Pues elegimos las fiestas y después con votaciones de lo que cada uno quería, pues hicimos los grupos" [C1_E.F_A4].

"Concretamente, en cultura lo que hemos hecho ha sido por preferencias de temas. Que escogiesen el tema que les gustara, hicimos lluvia de ideas sobre diferentes temas que podrían hacer los trabajos y una vez habían visto todas las posibilidades escogían los temas que más les llamaba la atención y ellos mismos se juntaban. Es cierto, que hay niños que se han juntado porque el tema les gustaba y, es cierto, que hay niños que se han juntado por quién escogía el tema, no por el tema, pero bueno eso son cosas que ellos tienen que ir valorando y madurando" [C1_E.F_D].

Por tanto, en la asignatura de cultura valenciana abordan diferentes temáticas mediante esta metodología de trabajo.

"De las fiestas [...] Fiestas de la comunidad que eran significativas y tal. Y en el tercer trimestre ha sido un poco similar. Bueno, hemos visto fiestas, hemos visto geografía y ahora '¿qué otras cuestiones o aspectos de la comunidad, de nuestra cultura, pensáis que sería interesante conocer?' y es pues cuando ellos también hicieron la lluvia y escogieron desde animales y plantas, a personajes famosos de la comunidad. Bueno lo que hemos visto hoy: la tomatina, els Pelegrins de les Useres, fiestas de Segorbe y otro grupo que también tenía personajes famosos. Gente de la farándula que son conocidos: Carlos Latre, el piloto de la fórmula 1 este... Roberto Merhi, bueno gente que es de aquí de la comunidad" [C1_E.F_D].

\section{Sesiones de trabajo e indagación sobre los contenidos a estudiar}

Una vez el tema de estudio está seleccionado dedican unas sesiones a indagar sobre el mismo. "Después ibamos a la biblioteca y buscábamos en libros la información" [C1_E.F_A4]. "Bueno pues hemos buscado información en grupos y después hemos puesto lo más importante y lo hemos expuesto" [C1_E.F_A3]. Para trabajar más cómodamente, los alumnos utilizan diferentes espacios, tanto dentro como fuera del aula. "Dos grupos de alumnos trabajan en la biblioteca, otros en otra sala y otros en clase. Se favorece la elección de espacios para trabajar, para que el alumnado esté a gusto" [C1_O_NC]. El número de sesiones dedicadas oscila entre las 3 o 4, aunque a medida que van terminando los grupos se establece el orden de las exposiciones, de esta manera se favorece que, mientras, vaya terminando el resto de grupos. "Me parece que tres. Si hicimos tres, dos en la biblioteca y después la última fuimos aquí a hacerlo en el papel. Para exponerlo" [C1_E.F_A4]. "[...] y nos da un apartado a cada grupo y cada grupo, en clase, nos da por ejemplo tres clases $y$ en tres clases tenemos que hacer un resumen en un cartel y con el cartel exponerlo delante de toda la clase" [C1_E.F_A8].

Exposición de los contenidos: acuerdos sobre los criterios de evaluación y evaluación del trabajo de los compañeros

Una vez el alumnado ha terminado de investigar sobre su tema, se realiza una exposición a toda la clase. De esta manera los niños explican a sus compañeros aspectos sobre el tema que han trabajado. "[...] Para ver cómo lo planteaban o cómo lo desarrollaban, que vuelve a ser una actividad donde todos participan [...]" [C1_E.I_D]. La exposición la realizan en una sala del centro educativo, en la cual hay una tarima y un 
proyector. Antes de iniciar las exposiciones, el alumnado y el docente establecen los criterios de evaluación.

"En los proyectos de trabajo hacen la exposición y después diré, a los compañeros, que pongan nota cuantitativa [...]. También para que vayan viendo qué es lo que va bien. Cosas que han hecho bien y cosas que hay que mejorar cuando tengan que hacer otro proyecto de trabajo,... Un poco pues el funcionamiento es ese" [C1_E.I_D].

"El último trabajo que hicimos de cultura, estuvimos hablando antes de hacer la exposición cómo evaluaríamos los compañeros o cómo quieren que se evalúen a ellos mismo realmente. $Y$ es una forma fácil de que ellos lo entiendan y puedan poner unos ítems al compañero. Entre todo lo que se está haciendo realmente es ver cómo quieres que evaluemos a los compañeros, pero realmente estás diciendo cómo quieres que te evalúen a ti" [C1_E.F_AP].

El docente, en este caso, es quien dirige la sesión, da los turnos de palabra procurando que no sólo participen los alumnos que lo solicitan, sino que también participe el resto. Va reforzando las ideas y va recapitulando todo lo que se va diciendo. Se van negociando los diferentes ítems a valorar en la exposición. El maestro remarca que cada uno puede presentar el trabajo en el formato que quiera. Entre todos acuerdan que los criterios que van a valorar son: la presentación, la participación, la claridad en la exposición y el dominio de los contenidos. Además, el docente también promueve que el alumno razone, consensue y decida la forma de valorarlo: De 0 a 10; de 0 a 5 ; de 0 a 3; muy bien, bien, regular, mal; guay, genial, estupendo. Los alumnos valoran y se posicionan para ver cuál es la manera más factible de hacer la valoración de cada uno de los ítems acordados. Entre las dos o tres formas que les parecen más óptimas hacen una votación. "Valoran cada uno de los apartados de 0 a 10. El maestro les dice que se apunten individualmente la nota, para posteriormente en el grupo clase proponer una nota de grupo. Así, cada grupo tiene 5 notas de cada uno de los grupos de clase" [C1_O_NC].

Una vez ya han acordado los criterios de evaluación y cómo valorarlos, pasan a realizar las exposiciones. Un alumno comenta que el hecho de exponer genera un poco de nerviosismo. "Al principio como que da un poco de vergüenza ¿no? Pero después ya te vas acostumbrando" [C1_E.F_A4].

La producción del trabajo a exponer se puede hacer cómo cada grupo decida. "Me parece bien porque cada uno no tiene... porque como casi todos hacen 'power point', tú no tienes porque hacer un 'power point'. Si quieres puedes hacer una cartulina o no tiene que ser siempre..." [C1_E.F_A4]. "Hay una cosa que se llama, que hay que hacerlo por el ordenador, que se llama un 'power point' que todavía no lo he hecho. Todos los grupos con los que he estado yo lo hemos hecho en un cartel pero... [...] para mí el 'power point' mejor, porque así ven algunas imágenes y si no se han enterado nosotros diciéndolo, tienen una imagen detrás de nosotros para verla [...] no queda tan espectacular como el 'power point' " [C1_E.F_A1].

Los niños son quienes explican los conocimientos que han aprendido a sus iguales. "Si lo expone otro, nos damos más cuenta que leyéndolo. Porque leyéndolo después no nos damos cuenta, porque algunos están muy despistados, pero si después estamos ahí con el trabajo..." [C1_E.F_A8]. "[...] cuando lo están exponiendo Manolo nos dice que tenemos que escribirlo para que no se nos olvide" [C1_E.F_A7]. "Hacemos un esquema para estudiarlo después, porque 
después de eso nos pone el examen [...] como lo explica el otro, para ti es mucho más fácil. Porque te lo explica otro compañero. El compañero, dice Manolo: 'que de un compañero se puede aprender mucho' " [C1_E.F_A8].

Realizadas las exposiciones el alumnado procede con la evaluación de sus compañeros. Cada alumno valora individualmente el grupo que ha expuesto siguiendo los criterios establecidos previamente por el grupo clase. Posteriormente, cuando vuelven al aula, comenta con su grupo base la nota que le dan a cada uno de los grupos que ha expuesto y entre todos acuerdan una nota de grupo que es la que le comunican al maestro, para que la contemple en su evaluación. Finalmente, éste hace la media aportada por los demás grupos y la tiene en cuenta junto a su valoración. "Me parece que de todos los grupos que han valorado el tema que nosotros hemos dado hace una nota media y Manolo me parece que la evalúa así [...]. Pues que, por ejemplo, tú no sólo valoras el trabajo en sí, también puedes valorar diferentes puntos" [C1_E.F_A4].

"Cada grupo expone, e individualmente ponemos 4 notas y hacemos más o menos lo que a nosotros nos parece la media. Después vamos a clase, y el grupo de 4 deciden una misma nota y se lo dicen a Manolo y hacen la media [...]. La mayoría de veces nos dice que tenemos que participar en grupo [...]. Cada grupo [...] decimos una, nuestra opinión y lo hacemos así general de todos. Y después lo decimos en voz alta y él, pues, ya ve las notas" [C1_E.F_A8].

Los alumnos conocen, porque los han consensuado, los criterios de evaluación, lo cual les ayuda a aprender de sus compañeros. De hecho valoran positivamente que su voz sea escuchada en la evaluación: "A veces haces una exposiciones que tú crees que Manolo te pone, por ejemplo, un 7 y tú crees que, por ejemplo, no se lo sabe bien, porque la exposición no ha estado clara, entonces como lo hacen tus compañeros te das cuenta y aprendes..." [C1_E.F_A8].

Por lo que respecta a los aprendizajes los alumnos comentan que han aprendido sobre ríos y montañas y otros aspectos de su comunidad. "Pues aprendemos más sobre nuestra comunidad y las tradiciones que hay" [C1_E.F_A4]. "Pues por ejemplo, tú a lo mejor cuando vas a una fiesta de esas tú ya sabes porqué se celebra y todas las tradiciones que se hacen en esa fiesta y todo eso" [C1_E.F_A4].

El maestro valora esta práctica muy positivamente.

"En cultura valenciana yo encuentro que ha sido genial ¿no? Ha sido una manera de trabajar que me ha servido el área, que son unos contenidos así bastante generales y que tampoco puedes ir a cosas demasiado concretas. Pues pienso que, precisamente, cultura es una asignatura que se da mucho para este tipo de trabajo ¿no? En otras también, naturales, en sociales. Pero lo que pasa es que como te lo marca el currículum un contenido tan amplio y tan concreto a veces tienes que ir a morir a esos... a esos contenidos ¿no? Si quieres, la verdad es que, si quieres, pero que está mucho más cerrado. Aquí en cambio en cultura ha sido pues trabajar cosas súper interesantes dentro de la cultura valenciana pero que ha dado pie a hacer trabajos chulos" [C1_E.F_D].

La participación y el compromiso del alumnado en los grupos de investigación son altos a lo largo de todo el proceso. El ritmo de la enseñanza es correcto ${ }^{14}$, el transcurso del trabajo de cada grupo va

${ }^{14}$ Según los parámetros establecidos en la herramienta DCOS- Assessing Classroom Differentiation Protocol - Revised (Cassady et al. 2004) (Ver Anexo 7). 
marcando los tiempos y las exposiciones. "El docente va viendo la marcha de trabajo de cada grupo y a medida que van terminando van proponiendo las sesiones de exposición. Normalmente, realizan unas dos sesiones de evaluación. Para hacer las exposiciones van al aula multiusos donde hay tarima y proyector" [C1_O_DCOS]. A lo largo de las sesiones se realizan diferentes actividades cognitivas. "Recordar (la información que se ha buscado), entender (para poderla explicar), analizar (seleccionar la información que se considera principal y más pertinente), evaluar (todos evalúan a todas las exposiciones), crear (power point, mural...). Destacar que el docente deja plena libertad para que el alumno escoja el soporte de presentación del trabajo" [C1_O_DCOS]. El estudiante dirige todo el aprendizaje. La labor del docente consiste en intervenir y hacer preguntas, para potenciar las reflexiones grupales. Los alumnos tienen claro, en todo momento, que es lo que tienen que hacer. El tiempo, aunque es flexible, está estipulado. Éste se aprovecha al máximo a lo largo de todo el transcurso del trabajo de investigación.

\subsection{Leemos en pareja: la diferenciación de la práctica}

Esta dinámica la llevan a cabo en la asignatura de valenciano.

“El 'leemos en pareja', es el programa de David Duran, lo que pretende es la tutorización entre iguales. [...] Y ahora hemos empezado ya la actividad con los alumnos, todavía les falta un poco de rutina y de funcionamiento, fue el primer día, coger esas dinámicas, esas rutinas, ese hábito, ese orden en la sesión. [...] sé por la experiencia que tengo que es una actividad que triunfa siempre. Normalmente, no tiene nunca ningún problema. Les hace crecer mucho y aprender mucho. Al principio les gusta mucho, después poco a poco les va resultando un poco más pesada porque es trabajo que tienen que realizar, pero que me permite ir trabajando esa ayuda entre iguales, ese aprendizaje cooperativo. Donde los dos que participan, mejoran y avanzan con sus objetivos" [C1_E.I_D].

Por lo que respecta a la agrupación en esta práctica, decir que, el "leemos en pareja" como su nombre indica es un trabajo de dos. Las parejas cambian cada mes, coincidiendo con el compañero que tienen sentado al lado en el grupo. "Según el que coincide en el grupo, cada mes cambiamos de grupo, entonces según los que coinciden cada mes se van haciendo las diferentes parejas, por tanto cada mes están con una pareja diferente" [C1_E.I_D]. Los niños son conscientes de la ayuda que se da entre ellos y sus iguales. "Por ejemplo, yo ahora estoy con M. pero si por ejemplo después de Magdalena me toca con P. lo conoceré mejor porque será el tutorado o el tutor" [C1_E.F_A6]. "Y también P. le puede enseñar cosas que yo no le he enseñado" [C1_E.F_A6]. "A mí me parece mejor el tutor porque les puedes enseñar a los otros" [C1_E.F_A5].

En esta actividad se informa e implica a las familias. "Tuvimos una reunión con los padres y tuvo muy buena acogida" [C1_E.I_D]. "Les hice una reunión adrede únicamente para la dinámica esta" [C1_E.F_D]. El alumno tutor tiene que preparar la actividad en casa junto con la supervisión de un adulto (madre, padre, familiar...). "Hay algunos que lo hacen solos" [C1_E.F_A8]. "Con nuestros padres o con los hermanos. Normalmente, casi todos con sus padres porque en nuestra clase hay más que son los mayores (se refiere a hermanos) y entonces si lo hacen con los pequeños no lo sabrían" [C1_E.F_A5]. "Pues por ejemplo, la primera semana me toca a mí hacer el 'leemos en pareja' y en mi casa tengo que preparar un texto con preguntas, y después el lunes, después de vacaciones mi compañero que tengo 
al lado sentado del grupo le hago el 'leemos en pareja' [...]" [C1_E.F_A1]. Para su preparación, en el hogar, la persona adulta hace de tutor.

Con esta actividad, se implica a la familia, se intercambian roles y la responsabilidad que ello conlleva, se va fomentando la autonomía, la creatividad y la capacidad de pensar en el compañero con quién voy a hacer la actividad.

"El implicar a la familia, la responsabilidad de ser el tutor o responsable de un compañero, el saber estar como alumno y dejarse ayudar por otro compañero, el saber intercambiar esos roles, una vez soy profe y la otra vez soy alumno, tutor y tutorado. Va por ahí también esa autonomía, el desarrollar la creatividad y el pensar, el ser capaz de pensar en el otro, para ver como lo ayudo" [C1_E.F_D].

Esta actividad se realiza semanalmente, cada semana los roles se intercambian, un alumno es el tutor y el otro el tutorado. La actividad consiste en realizar una lectura compartida. "El tutor lee primero, después leemos tutor y tutorado a la vez, que eso es un poco lio, y después lee el tutorado y hacemos las preguntas. Y después se valora" [C1_E.F_A6]. La manera de ejecutar esta actividad se adapta a las necesidades de los alumnos. "Porque, por ejemplo, hay una vez en que tú tienes que leer con el compañero, pero como haciendo el eco y ellos como eso es muy complicado no lo hacen" [C1_E.F_A4].

El alumnado tiene una guía con pasos que han de realizar en cada sesión (Ver Imagen 10). Éstos son: 1) antes de leer, 2) lectura, 3) comprensión lectora, 4) gramática /ortografía, 5) expresión escrita y 6) evaluación. Aunque a medida que va avanzando el curso y van interiorizando los pasos no la utilizan. "Sí que la tenemos lo que pasa es que ahora ya no la utilizamos" [C1_E.F_A4]. Además, tienen una hoja con frases para dar ánimo a su compañero a lo largo de la lectura. Cuándo el que hace de tutor detecta un error tiene que avisar a su compañero. Por tanto, si un alumno comete un error el tutor le para con la mano y el tutorado tiene que reflexionar sobre el error que ha hecho y corregirlo. "Tocarle con la mano al

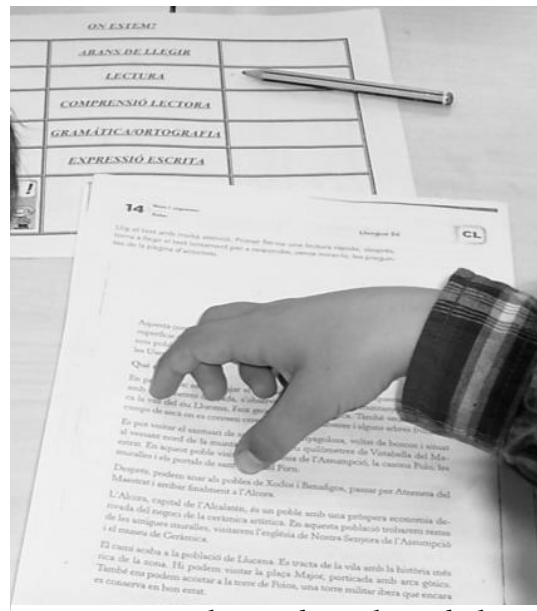

Imagen 10. Alumnado realizando la actividad de leemos en pareja (1r trimestre) [C1_O_FO]. brazo" [C1_E.F_A5]. "Y el tutorado tiene que reflexionar y cuando lo acierta el tutor tiene que animarlo" [C1_E.F_A6]. Esto es, previamente, el docente proporcionó a sus alumnos una hoja con algunas frases que podían utilizar para animar a su compañero. "Manolo nos dio un folio que tenemos lo que le podemos decir" [C1_E.F_A6].

Si algún tutor no efectúa la tarea causa un problema a su compañero. "Lo que pasa es que a veces a tus compañeros se les olvida y como que tú tienes un poco de rabia porque tú sí que se lo has hecho a él y él no te lo ha hecho a ti" [C1_E.F_A4]. Antes esta situación, buscan alternativas de trabajo. "Pues si ha faltado alguien y es al que le hace el 'leemos en pareja' lo tiene, pues hacemos otras parejas [...]. Hacemos otra cosa" [C1_E.F_A4].

Esta práctica varía a lo largo del curso escolar. En el primer trimestre, el maestro proporciona una hoja con un texto y actividades. En el segundo trimestre, el maestro proporciona una hoja con un texto y el alumnado debe proponer preguntas y actividades. $\mathrm{Y}$ en el tercer trimestre el maestro no 
proporciona nada, es decir, cada alumno debe elegir un texto y proponer libremente las actividades que cree oportunas. "Ahora tenemos que hacer las preguntas nosotros. Antes nos las daba Manolo" [C1_E.F_A5]. "Ahora tenemos que escoger una... fotocopiar un texto que lo hemos sacado del ordenador y hacer preguntas sobre él" [C1_E.F_A6].

"Manolo lo que hace es... Por ejemplo, hacemos el 'leemos en pareja' y él cada trimestre va haciendo una cosa para que sea más divertida. Porque al principio [...] el 'leemos en pareja' por ejemplo, nos ponía él las actividades y [...] el texto y después nosotros hacíamos las actividades y ahora hacemos las dos cosas [...] Cada vez lo va haciendo para que sea más divertido y que nosotros aprendamos más" [C1_E.F_A8].

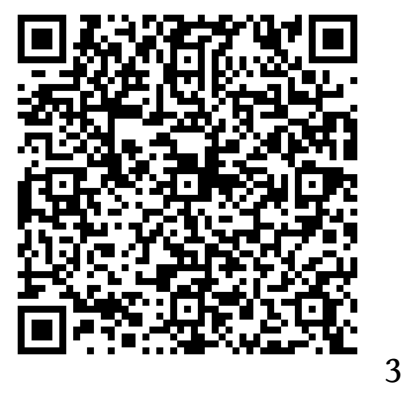

Ejemplos de hojas de lecturas y actividades [C1_AM_DO].

En general, al alumnado le gusta más realizar esta actividad de la manera que se lleva a cabo en el tercer trimestre (Ver Imagen 11). "A mí eso me parece bien porque puedes escoger tú el tema que te parece interesante para tu compañero" [C1_E.F_A5]. "Me parece más interesante que nosotros busquemos el texto porque así aprendemos más de lo que nosotros queremos saber" [C1_E.F_A1]. "Ahora a mí me gusta más, porque casi aprendemos más sobre lo que buscamos que nos lo busque Manolo" [C1_E.F_A7].

Para escoger los textos, en el tercer trimestre, el alumnado suele tener presentes los gustos $o$ preferencias de su compañero. "A mí, si me toca con alguien le preguntaré que le gusta y seguramente de lo que me diga intentaré sacarlo" [C1_E.F_A6]. "Yo le pregunto a mi compañero cual le gusta y cuando me lo dice yo decido si me gusta también y lo hago [...]. Me dijo que le gustaba la moda y a mí también me parecía curioso y lo hice de la moda" [C1_E.F_A2]. No todos trabajan los mismos contenidos. "Cada uno hace un texto diferente [...] Por tanto, por ejemplo, yo lo hago de la Moto GP y el otro lo puede hacer de..." [C1_E.F_A1]. "Pues yo cuando ya dicen fecha de examen [...] pues cojo una página del libro, la imprimo, la fotocopio y después hago las preguntas y así mi compañero y yo aprendemos un poco más en el 'leemos en pareja'

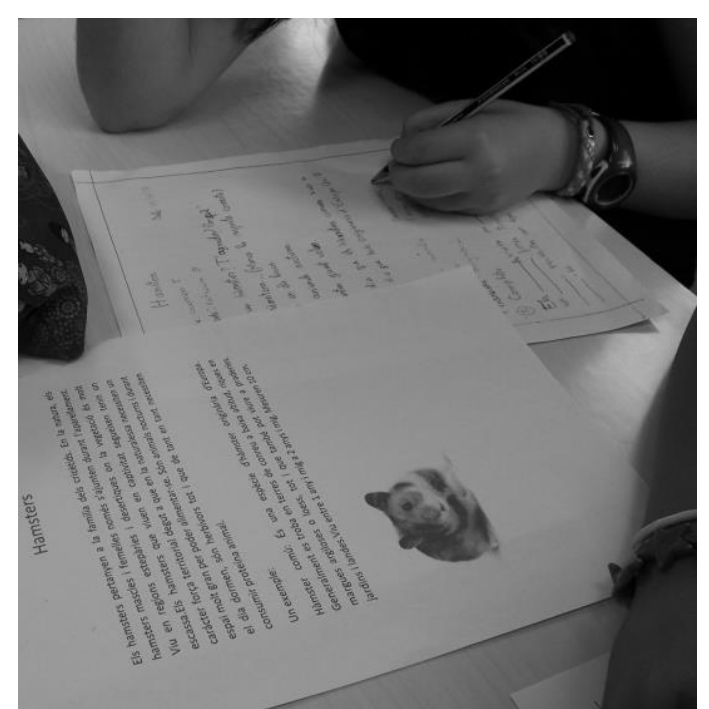

Imagen 11. Alumnado realizando la actividad de leemos en pareja (3r trimestre) [C1_O_FO]. [...] pero cuando no nos dicen nada del examen, pues ya cojo un texto por internet que me guste y ya..." [C1_E.F_A1]. El alumnado, mientras busca el texto y prepara las actividades, aprende más sobre el contenido 
escogido. "En el 'leemos en pareja' cuando sacamos información de internet o enciclopedia, aprendemos también nosotros más cosas sobre lo que estamos buscando, porque no sabíamos tanta cosa y por eso lo buscábamos en ordenador o enciclopedia" [C1_E.F_A7]. "Y hay veces que, por ejemplo, nos gusta mucho Vicent Marzà (escritor valenciano), y sabemos muchas cosas de él, pero después buscamos información y nos damos cuenta de muchas cosas que te aparecen, muy chulas y no las sabías" [C1_E.F_A8]. "Si porque, por ejemplo, ahora que están los compañeros haciendo el texto y todo para hacer preguntas aprendemos temas que no sabíamos" [C1_E.F_A3].

Así pues, en este tercer trimestre se permite al alumnado escoger el texto y pensar en su pareja para realizar la actividad. "Escoger los textos, es pensar en la temática, en tu pareja, ¿Qué le va a gustar?, ¿Qué no le va a gustar? Es ponerte un poco en la piel del otro ¿Qué le va a gustar?, ¿Eso le gustará o no? voy a hacerlo lo mejor que pueda para que esté contento, los felicitan cuando leen. Se crean ahí vínculos [....]" [C1_E.F_AP]. Los alumnos son conscientes del grado de implicación en esta actividad, hay quién escoge el primer texto que ve, mientras que otros reflexionan y preparan conscientemente la actividad. "Y a aparte él (se refiere al maestro) ve que nos esforzamos, sabe si cogemos el primer texto y ya está o si miramos a ver cuál es el más correcto" [C1_E.F_A8].

"Me doy cuenta en fichas que hay veces [...] que preparan la ficha que a él se le ha ocurrido y la ha hecho y punto, pero hay muchos niños que hacen la ficha según el compañero que tienen y yo pienso que eso es muy grande, que tengan en cuenta quien es su compañero y que según quien es, hacen la ficha y ves cómo hay unas que son mucho más complejas, porque su compañero es un tío potente y hay veces que son fichas sencillitas, porque saben que su compañero no puede. Están trabajando eso que me preguntabas antes de la diversidad esa del niño, la capacidad, ellos la están teniendo en cuenta a la hora de preparar" [C1_E.F_D].

En cuanto a la confección de las actividades, señalar que, suelen tener presentes contenidos referentes a gramática y ortografía. "Pues de gramática, de encontrar cosas en los textos, sopas de letras..." [C1_E.F_A5]. "Si es verdad o no" [C1_E.F_A6]. "A veces también pones una descripción o de un lugar del que habla el texto y dice Manolo que ahora tenemos que introducir cosas de ortografía" [C1_E.F_A4]. El hecho de que el alumno prepare las actividades les parece muy interesante. "Porque claro te tienes que leer bien el texto para hacer las actividades correctas" [C1_E.F_A8].

Al terminar la sesión, el alumnado procede con la evaluación. "Y después de las actividades puntuales pues, por ejemplo, el 'leer en pareja' cada sesión hacen su autovaloración" [C1_E.I_D]. "Y después en el 'leemos en pareja' también nos ponen una hoja para ver qué es lo que hacemos bien" [C1_E.F_A8]. La primera pareja que termina coge las hojas de la autoevaluación y las reparte a sus compañeros. "Es de marcar. Pone tres cuadrados y hay que marcar nunca, a veces o siempre. Pone frases para que nosotros podamos saber si lo hemos hecho bien o lo hemos hecho mal" [C1_E.F_A5]. "Lo que es leer bien con buena entonación. Y el tutor da un tiempo para corregirlo, si se ha equivocado. Y después si ha leído bien si ha respetado los puntos y las comas..." [C1_E.F_A5]. "No sólo leemos, yo creo que leyendo, él evalúa nuestra comprensión, comprensión lectora para poner nota" [C1_E.F_A7]. 


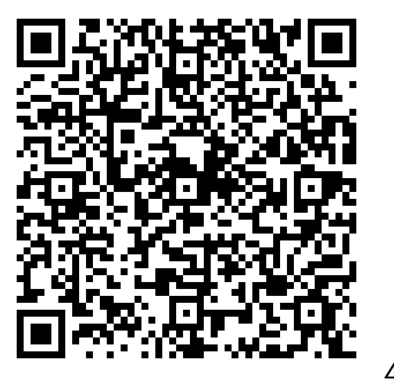

Pautas de autoevaluación de "leemos en pareja" [C1_AM_FO].

La participación y el compromiso del alumno son altos. "Tanto el tutor como el tutorado tienen unas funciones claramente definidas. A lo largo de la actividad vemos como las pautas con los pasos para desempeñar la actividad ya no son necesarias, puesto que los alumnos van interiorizando los pasos. La participación del alumno va in crescendo. En el primer trimestre el docente proporciona el texto y las preguntas, en el segundo trimestre el docente proporciona el texto y el alumno es quien plantea las preguntas o actividades. En el tercer trimestre el alumno escoge el texto, y las preguntas" [C1_O_DCOS]. El ritmo de la enseñanza es correcto. "El tiempo de ejecución de la tarea lo marca el propio alumnado. Tienen 45 minutos para realizar la actividad. La primera pareja que termina reparte las hojas de autoevaluación. A medida que van terminando los alumnos realizan otras actividades o tareas" [C1_O_DCOS]. Las actividades cognitivas son variadas. "Recordar (el alumno tutorado tiene que recordar las ideas principales del texto), entender (ambos, tutor y tutorado tienen que entender el texto -comprensión lectora- el tutor para poder corregir -1r trimestre-para poder efectuar las preguntas $-2^{0}$ y 3 r trimestre), aplicar y crear (el alumno tutor tiene que realizar las actividades el segundo y tercer trimestre), evaluar (tanto el alumno tutor como el alumno tutorado)" [C1_O_DCOS]. El estudiante dirige todo el aprendizaje. Los alumnos tienen claro en todo momento qué es lo que tienen que hacer. "En el primer trimestre se van apoyando en la hoja guía con los pasos de la actividad y con el listado de palabras para reforzar a los compañeros cuando lo hacen bien" [C1_O_DCOS].

\subsection{Tertulia literaria dialógica: El geperut $i$ altes contes de}

\section{les mil i una nit}

Se trata de una actividad que se lleva a cabo los jueves a las 9:00 horas. La clase se desdobla, una mitad hace informática y la otra mitad hace valenciano. Así pues, cada grupo hace la tertulia literaria dialógica cada 15 días. Están leyendo el libro "El geperut $i$ altes contes de les mil $i$ una nit" de la editorial Vicens Vives. Los alumnos están sentados en círculo. "La tertulia, nos ponemos en círculo con las sillas nuestras, nos ponemos en círculo y cogemos unos libros de la tertulia y empezamos a leer" [C1_E.F_A1]. "A mí me gusta en círculo porque también así no nos despistamos, porque si Manolo tiene que estar ahí donde está la pizarra y cada uno por un lugar de la clase no se podría ver como si estamos en círculo. Y nos vemos todos a todos" [C1_E.F_A8]. Destacar también que el docente se sienta en el círculo, cosa que es del agrado de su alumnado. "Y también lo que nos gusta mucho es que Manolo se pone como si fuera un alumno [...]" [C1_E.F_A8].

"[...] en lugar de hacer una clase tradicional que diríamos o normal de contenidos o de repaso de algún contenido, lo que hacemos es una tertulia dialógica, nos sentamos y hablamos y leemos un libro. Con la 
particularidad, que tiene el hacer una tertulia, que es que no hay uno más listo que otro, o no hay uno más importante que otro ni yo tan sólo. Sencillamente, lo que hacemos de una manera voluntaria... se habla, se charla, se lee, se comenta y se expone y expresa aquello que me ha aportado la lectura, o aquello que me ha recordado, o aquello que me ha dicho a partir de las experiencias propias y eso es algo que cada uno tiene, que nadie puede tenerlas si no ha sido uno mismo. Todo eso también les hace sentirse bien, porque ya no es el más listo y el que no es tan listo, todos son iguales y todos pueden contar cosas. Y se puede ir haciendo y rompiendo esa idea de que yo no sé tanto como mi compañero de al lado. Pues no, en esta actividad sabes tanto como tu compañero de al lado. Porque nadie ha vivido lo que tú has vivido y a partir de lo que leemos pues comentamos" [C1_E.I_D].

En cada sesión hay un moderador que se encarga de repartir los libros y de leer lo que se realizó en la sesión anterior. Para ello, tienen una libreta donde cada moderador al finalizar escribe lo que se ha tratado durante la sesión. "El moderador coge la libreta y lee lo que ha sido la última vez" [C1_E.F_A8]. "Antes de leer, leemos un texto que ha hecho uno de los compañeros que ha sido el [...] moderador" [C1_E.F_A1]. "Leemos entre todos y después hacemos un resumen de lo que hemos leído" [C1_E.F_A3]. "El moderador dice quien lee y explica y después en su casa hace un resumen de todo lo que hemos leído" [C1_E.F_A4].

Por tanto, el moderador tiene unas tareas y funciones marcadas. "Reparte los libros y dice la página en la que nos hemos quedado y empezamos a leer y dice: ‘Quién quiere leer?' y de ese niño hacemos la rueda hasta que termina otra vez el que ha empezado a leer y después el moderador elige a uno para que explique lo que hemos leído" [C1_E.F_A8]. Así pues, un niño voluntario lee un fragmento. Al finalizar el moderador pregunta: ¿Quién quiere explicar lo que ha pasado? Los alumnos comentan si han detectado algún error sobre la lectura. Posteriormente, hacen un breve comentario de lo que han leído. El maestro interviene preguntándoles que quieren decir algunas palabras, expresiones y dichos o refranes que han aparecido durante la lectura. "Pues por ejemplo, las palabras que salen que no sabemos, las hablamos todos y si alguien la sabe, la dice y ya los demás ya saben las cosas. Y también aprendemos, porque cada cuento..., todos los cuentos, y no hay ninguno que no tenga..., tienen cosas para que nosotros aprendamos. Entonces siempre aprendemos de cada cuento alguna cosa" [C1_E.F_A8].

A continuación, siguiendo el mismo esquema, se procede a leer y comentar otros fragmentos. El moderador consulta en la libreta si queda algún alumno por leer para, de este modo, promover la participación de todos. Quien quiere hacer alguna intervención levanta la mano y el moderador les da el turno de palabra. "Y también hacemos para leer todos, porque a veces si me toca a mí ser moderadora a veces hay que sólo eligen a sus amigos, pues hacemos eso y entonces leemos todos. Hacemos un punto aparte cada uno y leemos todos" [C1_E.F_A8].

Los alumnos valoran positivamente esta actividad. "Yo creo que está bien porque así todos podemos opinar de como leen nuestros compañeros y podemos escribir en la libreta como ha ido la tertulia ese día" [C1_E.F_A4]. "Si, porque hablamos y a veces en el libro que leemos hay cosas muy interesantes que hablamos con Manolo" [C1_E.F_A8]. "Divertido y también aprendemos con él, porque salen palabras que no conocemos y vamos aprendiéndolas" [C1_E.F_A7]. El estudiante de prácticum también considera la actividad de manera positiva. 
"La tertulia me parece... yo creo que de las mejores actividades que se hacen en clase, más que nada porque puede salir cualquier tema realmente y todos pueden participar libremente y con lo que quieran $y$ es un momento de comentar con tus compañeros y con tus iguales, porque en ese momento todos son iguales, de comentar aquellas cosas que nos pasan en la vida cotidiana ¿no? Hablamos de los abuelos, todo el mundo puede hablar de los abuelos. Hablamos de qué tipo de casa tengo, todo el mundo puede hablar. Es un debate en que todo el mundo participa y en el que todo el mundo, yo creo que hace la tertulia como suya, es decir, es un punto de reunión que además de hacer grupo, hace también que los alumnos aprendan. Aprendan con eso que están haciendo" [C1_E.F_AP].

El docente por su parte destaca el hecho de poder compartir, a partir de una relación de horizontalidad, entre los diferentes integrantes que asisten a la tertulia.

"Lo que pretendemos es el saber estar en un grupo, saber pedir el turno de palabra, saber dar la opinión, saber respetar a los compañeros, saber escuchar. Un poco lo que se pretende serían esos otros aspectos ¿no?, lo que se trabaja en el diseño de un grupo mediano que estamos leyendo y que estamos compartiendo. La idea esa a mí me gusta mucho, esa idea de que en ese momento todos somos iguales de que no hay uno que sabe más que otro. Sí que hay uno que sabe más que otro en muchas cosas, pero siempre desde su experiencia. Entonces claro el poder compartir esas experiencias es lo que da ese equilibrio y esa igualdad en el grupo. Es una actividad también bonita ¿no?” [C1_E.F_D].

La participación y el compromiso del alumno son altos. El ritmo de enseñanza es correcto. "Básicamente, lo marca el grupo. De hecho, al ser un grupo reducido (media clase), los dos grupos no van al mismo ritmo" [C1_O_DCOS]. "No, porque a lo mejor ellos van más atrasados, entonces nosotros ya lo sabemos" [C1_E.F_A8]. Las actividades cognitivas son variadas. "Resaltar principalmente el recordar, entender y analizar (en ocasiones analizan el contenido de alguna frase hecha, para ver el significado)" [C1_O_DCOS]. En este caso el moderador, es quien gestiona los tiempos e intervenciones. "Vemos como el maestro se sitúa como uno más en el aula, se establece una relación horizontal" [C1_O_DCOS]. Los alumnos tienen clara la estructura y los momentos de la tertulia.

\subsection{Exposiciones de libros: anuncio propagandístico de las lecturas}

En la asignatura de valenciano, voluntariamente, el alumnado lee y presenta libros a sus compañeros. “[...] cuando se ha leído un libro se hace un cartel y lo presentamos a la clase [...] Y lo presentamos delante de toda la clase y Manolo apunta los libros que nos hemos leído y así sube la nota de valenciano o la baja" [C1_E.F_A4]. En el aula tienen un cuadro de registro para anotar los libros que va leyendo cada alumno (Ver Imagen 12). "Es muy visual para que vean quien ha leído y quién no" [C1_E.F_D].

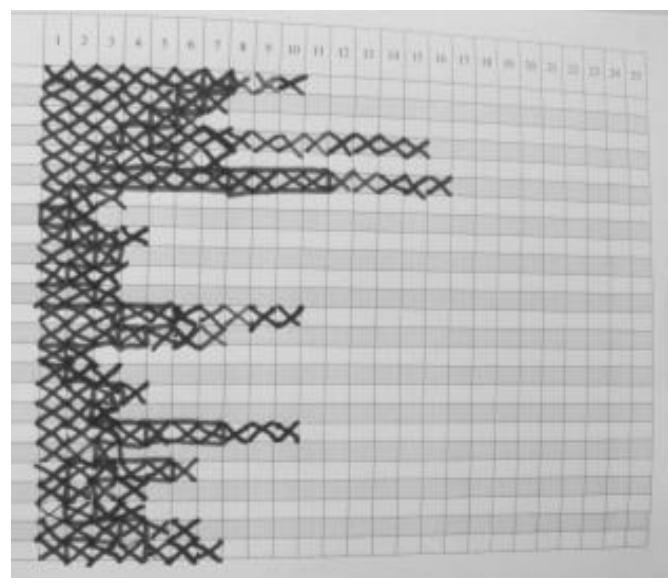

Imagen 12. Registro de lecturas presentadas [C1_O_FO]. 
Para hacer las exposiciones aprovechan algunos momentos, por ejemplo, al terminar el cuentacuentos a infantil o la actividad de "leemos en pareja". El alumnado aparte de leer el libro, tiene que hacer un cartel publicitario para convencer a sus compañeros de que merece la pena la lectura de dicho libro. "Hacemos como un anuncio, para que los demás lo lean y lo exponemos en clase [...]" [C1_E.F_A7]. El alumnado puede escoger los libros que prefiera.

"Ellos leen lo que quieren. Les hago algún toque de atención cuando cogen libros muy infantiles, pero respeto. $O$ cuando no leen, no es una obligación, pero si, por lo menos un libro al trimestre. Pero no lo marco como una obligación: 'os tenéis que leer un libro al trimestre', espero que lo hagan. Cuando no lo hago, entonces les pego la bronca ¿no? pero sino les voy dejando un poco de libertad en ese sentido también" [C1_E.F_D].

Los alumnos son conscientes de que, a través de la actividad de la tertulia literaria dialógica, el docente puede comprobar si la lectura de los alumnos es fluida y va en consonancia con los libros que el alumnado dice leer. "[...] si Manolo ve que yo me he leído 20 libros y después en la tertulia yo leo muy mal, él se dará cuenta que no es verdad. Yo creo que también lo hace por eso" [C1_E.F_A8].

"En la exposición van adquiriendo y van mejorando mucho, sobre todo por el refuerzo y el feedback de los compañeros, que siempre les hacen preguntas y les dicen: 'me gusta mucho lo que has hecho' y 'esto no lo has hecho bien' y 'a míno me ha gustado'. Pues todo esto les [...] como son tantos, al final va calando, va calando, va calando ¿no? El otro día, [...] discutían con un niño, que es el que más ha leído, se ha leído 14 o 15 o 16 libros, no sé cuántos. Pero le reñi y le dije: 'Me parece estupendo que leas mucho y que nos cuentes los libros pero estás pasando absolutamente de todo lo que están diciendo los compañeros todos los días, porque has leído mucho, los compañeros todos los días te han dicho lo mismo y tú estás haciendo lo mismo, cambia, no pases, cambia, es muy bueno leer pero si todo lo que te estamos diciendo no te sirve para nada, no nos sirve, no estamos avanzando, nos estamos quedando estancados' "[C1_E.F_D].
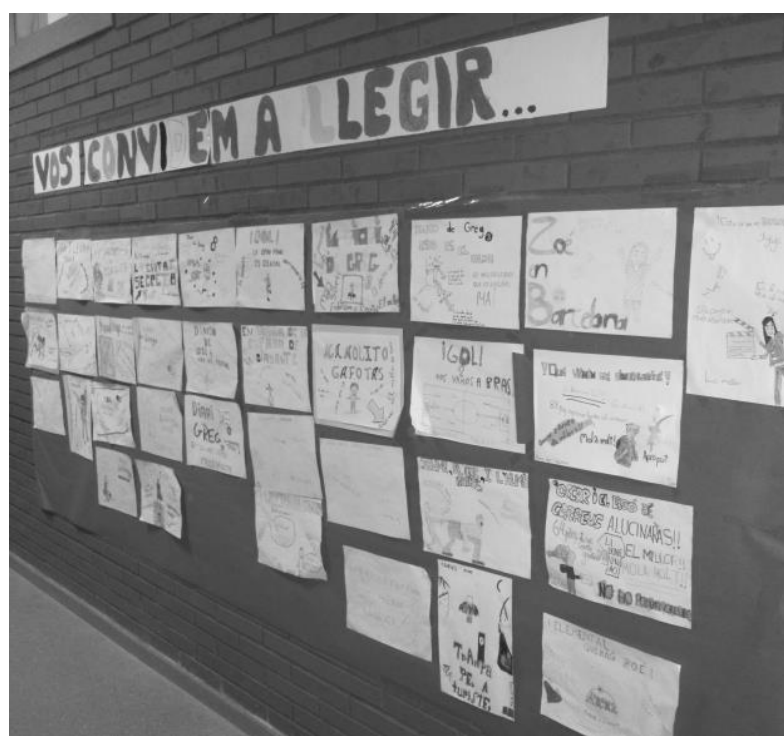

Imagen 13. Exposición de las lecturas en el pasillo [C1_O_FO].
Así pues, el alumnado voluntariamente realiza una lectura de un libro y prepara una hoja como si de un anuncio publicitario se tratara. En clase lo expone y posteriormente los compañeros le hacen preguntas, sugerencias y valoraciones. Finalmente, los carteles que hacen los cuelgan fuera, en el pasillo, para animar a los compañeros de clase o los de otros cursos a que lean el libro (Ver Imagen 13). 
La participación y el compromiso del alumno se sitúan entre moderada - alta. "En este caso el alumno expone el libro que se ha leído al resto de sus compañeros. El resto de alumnos escuchan y al finalizar hacen preguntas, felicitan, proponen sugerencias de mejora... En general, el compromiso del alumno, tanto el que expone, como el que presenta el libro es alto. No obstante, esta actividad la realizan en huecos libres que tienen entre asignatura y asignatura, al volver de la actividad del cuentacuentos,... si se exponen muchos libros seguidos vemos como la atención del público decae" [C1_O_DCOS]. El ritmo de la enseñanza es correcto. "El alumno que expone es quien marca el ritmo de su presentación del libro y es quien da los turnos de palabra a sus compañeros al finalizar la exposición de los libros. Además, no hay horarios fijos de exposición, sino que los van haciendo a medida que los alumnos lo van solicitando" [C1_O_DCOS]. Las actividades cognitivas presentes en esta actividad son variadas. "Recordar (preparar la exposición), entender (comprensión lectora), aplicar y crear (confeccionar el cartel para la exposición y después colgarlo al pasillo), evaluar (reflexionar conjuntamente sobre cómo se ha realizado la exposición junto al grupo clase, con las preguntas sobre el libro, sugerencias de mejora, felicitaciones...)" [C1_O_DCOS]. El estudiante dirige todo el aprendizaje. "En algunos casos el docente interviene para realizar alguna corrección muy grave (ej: estave - ESTAVA). En otras ocasiones el maestro también hace preguntas (ej: Què vol dir bajoca?, es una frase feta?, Per què creus que li han ficat eixe nom?...)" [C1_O_DCOS]. En cuanto a la gestión de la clase, los alumnos tienen claro el funcionamiento.

\subsection{Cuentacuentos y teatro a infantil}

La actividad del cuentacuentos y teatro a infantil también la realizan en la asignatura de valenciano. "Contar cuentos, que es una actividad de participación cooperativa con el alumnado de educación infantil, inter nivel, de tal manera que los niños de mi aula se hacen responsables de un niño de infantil y semanalmente todos los martes a las 16:15h. bajamos a su aula e individualmente les cuentan un cuento [...]" [C1_E.I_D]. Los niños de 5o de primaria se preparan el cuento en sus casas.

Esta actividad también varía a lo largo del curso. En el primer trimestre, de manera individual, cogen cuentos del aula de infantil y se lo preparan para contárselo al niño de 4 años. En el segundo trimestre, de manera individual, escriben y elaboran los cuentos y los preparan para contarlos. En el tercer trimestre, por grupos, preparan una pequeña representación teatral.

Durante el primer trimestre, los cuentos van rodando dentro de cada grupo de $5^{\circ}$ de primaria, se los cambian al finalizar la sesión. Cada semana, los alumnos de $5^{\circ}$ de primaria tienen que preparar y ensayar esta actividad en casa. "Al principio nos daban unos cuentos y nosotros lo preparábamos en nuestra casa, pero después ya hacíamos nosotros los cuentos" [C1_E.F_A1]. "El cuentacuentos, por ejemplo, participan ellos en un primer momento. Se les daba el cuento para que ellos lo leyeran, ¿no? para coger la mecánica [...]" [C1_E.F_AP].

El segundo trimestre, cada alumno elabora el cuento cómo quiere. "Hay algunos que lo hacemos en una

hoja [...], hay otros que lo hacen en una hoja de ordenador, pero yo lo hago en forma de cuento" [C1_E.F_A1]. Por tanto, el alumno escoge tanto el formato del cuento como su temática. "Pues yo el de un animal que se hace amigo de otro" [C1_E.F_A1]. "De una casa que se puede transportar" [C1_E.F_A2]. Esto es, el propio alumnado, es quien escribe y prepara en casa el cuento que van a contar a los niños de infantil. "El cuentacuentos es una tarea que se hace en principio individual, para después hacerla en pareja" [C1_E.F_AP]. Manolo les da plena libertad en la 
escritura y elaboración de los cuentos. "Pues, por ejemplo, los cuentos, yo no me he parado a ver si los cuentos que hacían eran buenos, eran malos, eran mejores, o... los he dejado hacer. Sí que me gusta leerlos, sí que me gusta decirlos alguna cosa, sobre todo según el tema que tratábamos o que contenidos habían puesto, para hacerlos reflexiones, pues les he dado libertad" [C1_E.F_D].

El alumno de prácticas comenta que, al dar la libertad al alumnado, a la hora de confeccionar la actividad, ves el grado de implicación en la misma.

"Eso lo que dice mucho también del niño, es una forma de ver. Cuando tú dejas hacer, lo que ves es: éste se lo curra y éste no se lo curra. Porque si tú dices, no es que quiero que me lo traigas con una cartulina, pegado en súper glue y que me hagas el título así. Te lo van a hacer todos igual. Pero cuando tú dices tú traes un cuento y lo traes cómo quieres. Y ahí te das cuenta de cuál es el niño que más se lo curra y cuál es el que menos y es una forma de ver y de evaluar también realmente. Tú después le puedes decir esto, puedes ir dándoles ítems, puedes ir currándotelo más o menos. Es una forma de tu ver cómo ha trabajado cada niño" [C1_E.F_AP].

Las parejas entre el alumno de $5^{\circ}$ y el alumno de infantil (4 años) las hace Manolo. Las parejas son las mismas en el primer y el segundo trimestre. Como son impares algún niño de infantil escucha dos cuentos. Al preguntarles a los alumnos si les gustaría cambiar de niño de infantil para hacer la actividad con otro niño, responden que no. Se crean unos vínculos fuertes entre ambos.

"Tienen la responsabilidad de, semanalmente, prepararse ese cuento y cuando van a infantil pues contarlo. Es un momento que estamos con los de infantil y es un momento que ellos se sienten bien. Tienen la autoestima subida, les resulta agradable porque ellos son los mayores, ellos son los importantes, ellos son los que saben y ellos son los responsables de otra personita más pequeñita. Normalmente, el niño pequeño pues también se siente muy agradecido de que uno vaya a contarle un cuento, que le haga caso y que le preste atención. Pienso que es una actividad muy interesante y que refuerza mucho a mis alumnos. No tan sólo, el tema de la responsabilidad individual, sino que también a nivel de competencias y a nivel de lengua porque les hace mejorar mucho el tema de la expresión oral y de creatividad, a la hora de contar el cuento, que precisamente este grupo es un grave hándicap que tienen, un grave problema que tienen, mucho, la expresión oral muy flojita. Pues pienso que esta actividad les puede ayudar" [C1_E.I_D].

Dicha actividad la hacen en el patio de los pequeños o si hace frío en el pasillo. Para hacer la representación teatral, lo escenifican en el aula de infantil. "Nada más entrar en el aula cada alumno de $5^{\circ}$ coge al alumno de infantil asignado y salen al patio para proceder con la actividad. Al terminar los niños entran en clase y el alumnado de infantil hace un dibujo del cuento que les han contado" [C1_O_NC].

El tercer trimestre se lleva a cabo en la misma clase, la actividad de teatro a infantil. "Estudian cuentos, ahora, tradicionales y nosotros les queremos ayudar a aprendérselos mejor y enseñándoles en un teatro" [C1_E.F_A7]. La maestra de infantil, aprovechando que están trabajando algunos clásicos, es la que les propone los cuentos a representar teatralmente a la clase de 5을 de primaria. "La elige el profesor, bueno la profesora de infantil y la profesora de infantil se lo dice a Manolo y Manolo nos lo dice a nosotros [...] Normalmente, nos dice dos y nosotros tenemos que elegir una de esas dos" [C1_E.F_A1]. Habitualmente, el maestro les da a escoger el 
clásico a trabajar y tienen una semana o dos para preparárselo. Una vez el grupo ya sabe que cuento debe representar pasan a organizarlo y a ensayarlo. "Pues nosotros quedamos en una casa de alguien o el profesor en clase nos deja salir del aula y nos ponemos en una como esta [...] Y después, en nuestras casas buscamos más información para que el teatro quede mejor" [C1_E.F_A1]. "Y lo que tengamos que hacer, y ensayamos. Y después ya todos los martes vamos a hacerlo" [C1_E.F_A4]. "Lo trabajamos, nos aprendimos el guión y nos hicimos unas máscaras e hicimos el teatro" [C1_E.F_A1]. En este tercer trimestre para hacer el teatro sólo participa el grupo que lo representa esa semana, el resto de compañeros de $5^{\circ}$ son espectadores como los alumnos de infantil 4 años. "Ahora con el teatro no participamos nada, bueno sólo los que hacen el teatro [...] Sólo participan ellos y los niños" [C1_E.F_A6]. Las familias no ayudan al alumnado a preparar el teatro, estos tienen plena autonomía. "En mi grupo lo hice, lo hicimos nosotros. Los familiares no nos ayudaron" [C1_E.F_A1]. Las obras representadas son: El Gato con Botas, Peter Pan, Los tres Cerditos, Hansel y Gretel, entre otras. A veces, para sorprender a los niños de infantil cambian o adaptan el final de la historia.

"Y hay veces que para hacerles la gracia y eso [...] cambiamos el final, para hacerlo gracioso. Por ejemplo, el de los 'Tres cerditos' que hicimos nosotros dos, cambiamos el final. En vez de que el lobo se los comía, pues se hacía bueno... y sólo quería comer con ellos. Entonces a los niños les hace gracia y aprenden más y luego la profesora para que estén atentos les pregunta que ha pasado en el cuento y todo. Y hay veces que hasta, por ejemplo, un grupo llevaron una tarta, porque estaban haciendo Hansel y Gretel y la compartimos entre todos, entre todos los niños" [C1_E.F_A8].

Al terminar de contar el cuento o representar el teatro los niños de $5^{\circ}$ vuelven a su aula y realizan una pequeña reflexión al respecto. "El cuentacuentos suele tener una pequeña autoevaluación grupal de cómo ha funcionado, de qué hay que ir mejorando y de qué no, cómo se han sentido. Ya se trata de una valoración más cualitativa, no tanto, cuantitativa, de qué nota te pondrías, sino de: ¿qué ha ido bien?, ¿qué no ha ido bien?, ¿qué hay que mejorar?" [C1_E.I_D].

Tal y como reflexiona el docente en su blog, con esta actividad se trabaja: la autoestima, la responsabilidad individual, la expresión oral, la expresión corporal, la comprensión lectora, la autorealización personal, la creatividad, la reflexión... (Blog "El raconet de Manolo"). "El cuentacuentos, pues es que quiero la responsabilidad, la autoestima. El sentirse mayores, el trabajo curricular como es el de escribir, el mejorar su expresión oral, el mejorar su expresión escrita, el interactuar con personas más pequeñas y la responsabilidad individual que eso supone, todo eso que se me ocurre ahora. Reflexionado lo tengo en el blog ${ }^{15}$ "[C1_E.F_D].

Esta actividad crea lazos fuertes entre ambas aulas. "Una vez hicimos una comida con los niños, pero sólo una vez [...] Hicimos nosotros, cogimos comida de nuestra casa y cada uno teníamos una comida que traer a infantil... yo por ejemplo traje unos zumos de naranja" [C1_E.F_A1].

El docente ya había llevado a cabo esta actividad en cursos anteriores y solicitó el proyecto titulado Quins sentit té la llengua? El gust... per la llengua a Conselleria de Educación ${ }^{16}$, para el curso

15 http://elraconetdemanolo.blogspot.com.es/

16 La Conselleria de Educación de la Generalidad Valenciana promueve convocatorias en las cuales los maestros pueden solicitar proyectos educativos. 
académico 2013/2014, del cual extraemos otra variedad de esta dinámica, el Kamishibai.

"[...] el alumnado de $5^{\circ}$ le contaba un cuento que nos había dejado la maestra de infantil y que se había preparado en casa y en clase. Cuando terminábamos (10-15 minutos) nos encontrábamos al aula, comentábamos como había ido y hacíamos intercambio de cuentos para la semana siguiente. En el segundo trimestre, recogí los cuentos y la actividad siguió la misma dinámica, pero los cuentos eran escritos por el alumnado de 50. Tuvieron que escribir un total de once cuentos y muchos de ellos se animaron a acompañarlos de ilustraciones o a hacer cuentos donde los protagonistas eran el alumnado de 5 años. Los resultados superaron los objetivos iniciales que me había marcado. En el tercer trimestre la dinámica fue que el alumnado de 5 años escribía su cuento con la ayuda, orientación, guía y correcciones de su compañero de $5^{\circ}$ [...]. El alumnado quiere seguir en esta actividad porque le gusta mucho, se siente bien, mayor, responsable, la actividad to hace madurar, auto-realizarse, mejorar sus competencias lingüísticas, su creatividad, imaginación...y una nueva manera de hacerlo es cambiando nuevamente de estrategia para tratar de evitar caer siempre en lo mismo. Me enteré que un compañero de Benlloch, que había realizado esta actividad del Kamishibai y me pareció muy interesante. La idea es que el alumnado a lo largo de un mes (4 o 5 sesiones) prepare por grupos (4 cada mes) un cuento con formato del Kamishibai. 1) Inventar y escribir el cuento entre todo el grupo (4 personas); 2) Esquematizarlo y reducirlo a viñetas, escenas que tendrán que dibujar y pintar; 3) Pensar que elementos hay en cada escena y como está organizada; 4) Concretar la frase o frases que irán en cada escena; 5) Ensayar la puesta en escena; 6) Un día al mes ir al aula de infantil a contar los 3 Kamishibai creados; 7) Escribir y publicar al blog la experiencia con su valoración y opinión personal" [C1_AM_DO].

La participación y el compromiso del alumno son altos en el primer y segundo trimestre y moderado en el tercer trimestre. "Esta participación es mayor en el primer trimestre y en el segundo. En el tercer trimestre sólo hace la representación teatral el grupo que le toca esa semana, el resto son espectadores al igual que el alumnado de infantil" [C1_O_DCOS]. El ritmo de enseñanza es correcto. "Cada alumno marca el tiempo, no se corta ni se interrumpe la actividad. Los niños de $5^{\circ}$, a medida que van llegando van cogiendo a su alumno de infantil y escogen un lugar donde están cómodos para proceder con la actividad. Cuando terminan vuelven a clase de infantil donde sigue la interacción entre ambos, en ocasiones los niños de infantil hacen algún dibujo en relación al cuento. Hasta que todos terminan y vuelven a clase. Después en el aula de 5o, reflexionan al respecto o intercambian libros de lectura para la otra semana, en el caso del primer trimestre." [C1_O_DCOS]. Las actividades cognitivas son variadas. "Recordar (los alumnos de $5^{\circ}$ previamente ensayan y preparan el cuento o el teatro), entender (tienen que entender lo que quieren contar), aplicar (el alumnado en la redacción del cuento en valenciano tiene que aplicar los conocimientos que van adquiriendo tanto en la lengua escrita como en la lengua oral- como contar un cuento, lectura de los signos de interrogación...), crear (confeccionan ellos el cuento, no sólo en la redacción del mismo sino también vemos como a lo largo que va avanzando el curso el formato del cuento va mejorando considerablemente: cuentos en 3D...)" [C1_O_DCOS]. El estudiante dirige todo el aprendizaje. "El docente les acompaña e interactúa con ellos para la mejora de la actividad. Los alumnos tienen claras las directrices de la actividad del cuentacuentos, la hacen todos los martes por la tarde, trabajan tanto en casa como en la sesión con el niño de infantil" [C1_O_DCOS]. 


\subsection{Las cartas a la escuela Censal y otras producciones} escritas

En la asignatura de valenciano también escriben cartas a los compañeros del Censal (Ver Imagen 14) y realizan todas las semanas producciones escritas. Aparte, el docente va proporcionando algunas fichas de contenidos lingüísticos a trabajar. "Voy haciendo fichas de algunos contenidos concretos. Y después de los textos que se van produciendo, las conversaciones que se van generando..." [C1_E.F_D].

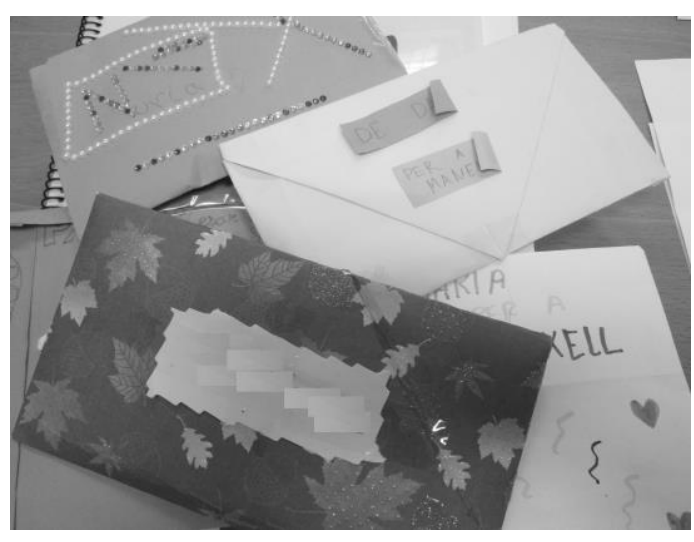

Imagen 14. Cartas para el Censal [C1_AM_FOM].

En dicha asignatura llevan a cabo, a lo largo de todo el curso, la actividad de cartearse con una escuela del municipio. Tal y como recoge el docente en el proyecto presentado a Conselleria de Educación, anteriormente mencionado.

"A lo largo del curso 2012/2013 nos hemos carteado con dos escuelas y ha sido una manera de saber cómo se hace una carta, para que sirve y cuáles son sus elementos. Alrededor de 506 cartas se han escrito con diferentes compañeros, unos de la escuela Censal de Castellón y otra de la escuela de San Joan de Moró. Después organizamos una jornada de encuentro con cada escuela para poder conocernos en persona. Ha habido de todo, desde compañeros que han llegado a un alto grado de complicidad y se han hecho amigos entrañables a los que no se han llegado a entender (yo siempre les digo: como la vida misma), pero en general el alumnado está muy contento de esta actividad y siempre esperaban el día de recibir las cartas como un día especial para ver que les contaban o que les regalaban (ya que incluso empezaban a poner en los sobres regalitos: pulseras, bolígrafos, pins...) así que quieren seguir haciendo la actividad. Con la escuela Censal ya he hablado con la tutora y compañera, R., y les propondremos escribirse cartas formales ocupando diferentes roles de tal manera que también puedan atender a este tipo de correspondencia (solicitar visitas, presentar currículums, solicitar trabajo, hacer una reclamación, realizar una denuncia...). Respecto a Moró aún no tengo claro si continuaremos dado que mi contacto y amigo que era tutor de 5, el próximo año no estará en esa escuela [...]. También es entrañable el encuentro. Con los compañeros del Censal fuimos juntos al Desierto de las Palmas a replantar árboles y después a hacer una excursión que recuerdan con mucho cariño y en el mes de junio nos encontramos en las pistas que hay entre las dos escuelas en un parque (estamos cerca una escuela de la otra) y almorzamos juntos e hicimos juegos cooperativos. Con los compañeros de Moró fuimos un día a su pueblo y nos enseñaron todo lo más importante: la plaza donde hacen toros, la iglesia, el ayuntamiento, el supermercado, la presa o el pinar. También fue un día muy bonito hasta nos costó separar a dos compañeras a la hora de irse. Para el curso 2013/2014 seguiremos con esta dinámica [...]" [C1_AM_DO].

El maestro explica que, a través de esta actividad, aparte de trabajar el contenido de la carta, comparten y conocen a otros niños de otra escuela. 
“Ahí más que nada, pues es el compartir ¿no? con otra escuela, con otros niños. Esta por un lado el contenido curricular que es el saber hacer una carta, el formato que tiene y la estructuración que tiene, pero después el poder conocer a los niños de otra escuela que trabajan de otra manera que es necesario respetar, con los que puedo hacerme o no amigo de él. Hay parejas que tienen feeling y después se encuentran o se hablan o se hacen amigos. Hay otros que no, que se escriben porque se lo mandamos yo o la maestra del Censal y chim pum, pero bueno, pienso que también es más chulo ¿no? el conocer o ser capaz de conocer a alguien que no conozco a través de una carta" [C1_E.F_D].

Aparte de las cartas, cada semana el alumnado debe de entregar un texto en valenciano (Ver Imagen 15).

"Les pido un texto y lo que siempre les pedía era tema libre. Años atrás, [...] me escribían un texto y ya está. Entonces dado que también siempre se repetían, habían que no salían del tema que...Decidí darles unas pautas a la hora de hacer el texto, son bastante generales, pero sí que marcaba ya un... Les marcaba yo un listado en cada día, porque en principio es cada lunes cuando presentan el texto, sobre que tenía que ser cada uno [...]" [C1_E.F_D].

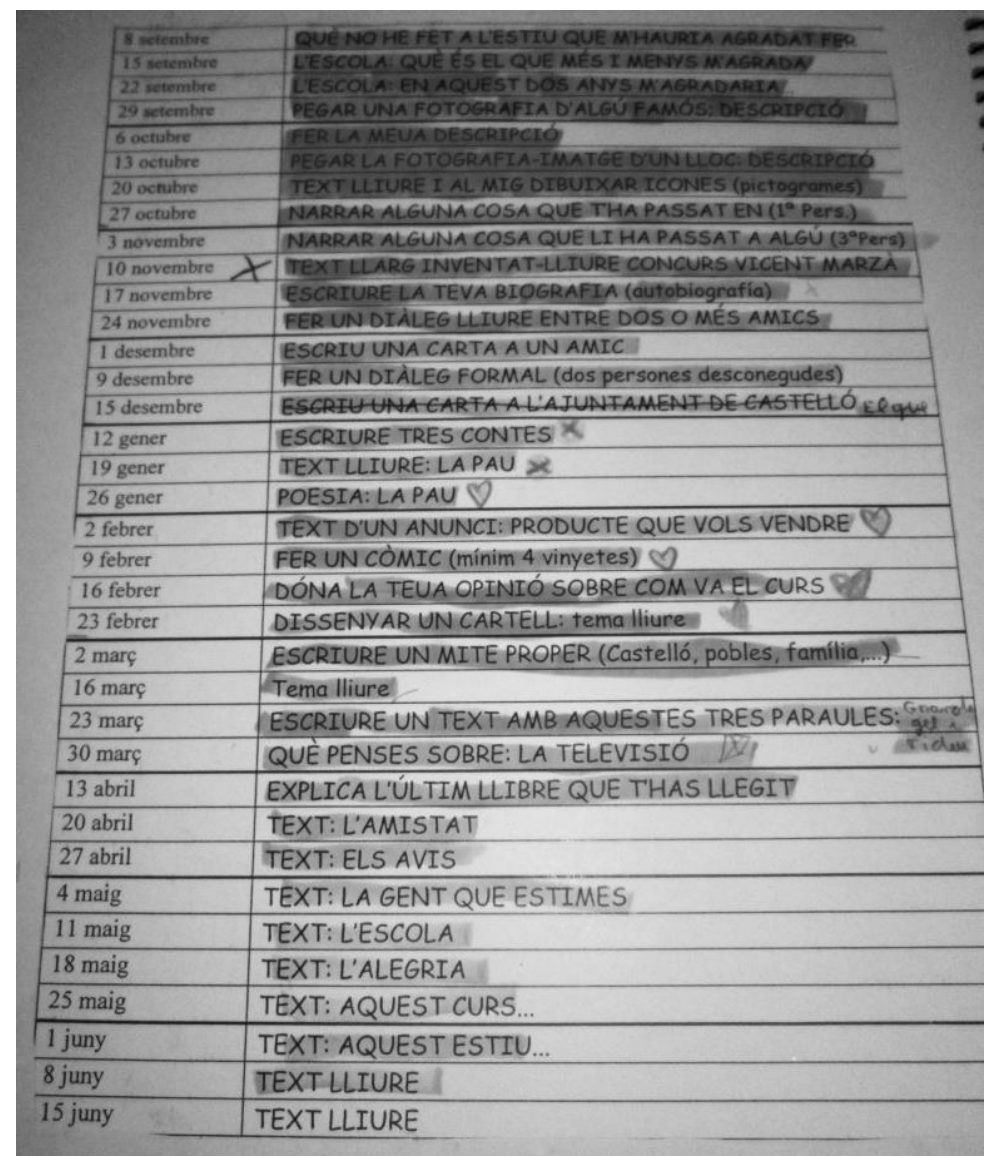

Imagen 15. Relación de textos [C1_AM_FOM].

En la Imagen 15, se observa el listado de textos con las temáticas a entregar cada semana. “[...] en valenciano pero los textos en general de todas las semanas nos han dado una ficha que tenemos que hacer esos temas [...] pone por ejemplo, en el de la semana pasada pone 'Texto: la escuela' que era el que teníamos que entregar hoy y podemos hacer de lo que sea de la escuela" [C1_E.F_A6]. 
El maestro reconoce que esta actividad es más aburrida para el alumnado que la del cuentacuentos a infantil o las cartas al Censal, por ejemplo.

"Sobre todo que hagan una producción con sentido, porque a veces el decir de que escriban un texto 'vaya rollo' o haz una redacción 'vaya rollo'. De hecho, hay niños que les resulta un rollo, ¿Por qué? Porque es uno cada semana, es un deber, es un deber rutinario. Preséntame un texto que... cada lunes. En cambio, por ejemplo, el del cuentacuentos o el de las cartas, tienen un significado muy inmediato ¿no? muy cercano. Y eso no les cuesta tanto de hacer. Porque ven la utilidad. A éste utilidad no le dan" [C1_E.F_D].

Para el curso próximo, el docente pretende realizar mejoras en cuanto a la producción de textos.

"Y de hecho para el año que viene, ya tengo preparado otro listado y quiero que se convierta el año que viene en que..., no lo he hecho, será la primera vez que lo haga. Lo hago porque me lo comentó una maestra del Censal que lo había hecho, y es interesante. Es una libreta con mis textos. En los textos que cuentan de mí o de mi vida cuando hacia $6^{\circ}$. Son textos que buscan un poco la intimidad, buscan un poco el diario, la expresión de sentimientos. Son textos muy sugerentes ¿no? Pues, lo que más me gusta de mí, lo que más aprecio de mi familia, lo que me gustaría para un futuro para el mundo,... No sé... son textos un poco más íntimos y si que quiero que lo hagan bien, se lo pediré en una hoja, se lo corregiré y les pediré que lo vuelvan a escribir a limpio en una libreta para que cuando termine el curso, pues 30 textos uno de cada semana, que se lo pueden llevar y guardar como un recuerdo. Ese es el objetivo" [C1_E.F_D].

Todas estas actividades de producción escrita tienen su efecto. El docente en los primeros días de clase hace la actividad de La Hoja en Blanco.

"En setiembre, [...] Les pongo una 'hoja en blanco' en la pizarra y les digo que hagan una redacción, el primer día de clase o el segundo. Aún ni nos conocíamos. Hacer una redacción sobre título 'la hoja en blanco'. ¡Qué! Lo que queráis. Apañaros, poner lo que queráis. Haced una redacción. La hacen y la recojo ni la corrijo ni nada, la recojo y las leo, bueno y ahora en mayo o en junio les pongo 'la hoja en blanco'. Haced una redacción 'hoja en blanco'. jAy! Lo que queráis, hay alguno que dice: ‘Eso no lo hicimos?. 'No lo sé no me acuerdo'. Y entonces cuando van terminando de escribir ahora les doy la de septiembre. Y entonces, pues se encuentran en que esta es la que han hecho ahora y esta es la que hicieron en septiembre y normalmente no falla. Hay alguien que, si que la ha hecho más o menos similar, pero el contenido o las faltas se nota mucho. Entonces se lo das y ves como 'AAlaaaa! y eso lo hice yo'. 'Madre, no sé qué...' Y hay algunos que es espectacular el cambio" [C1_E.F_D].

Vemos en la Imagen 16, como a simple vista se nota el cambio en cuanto a la escritura de textos. 


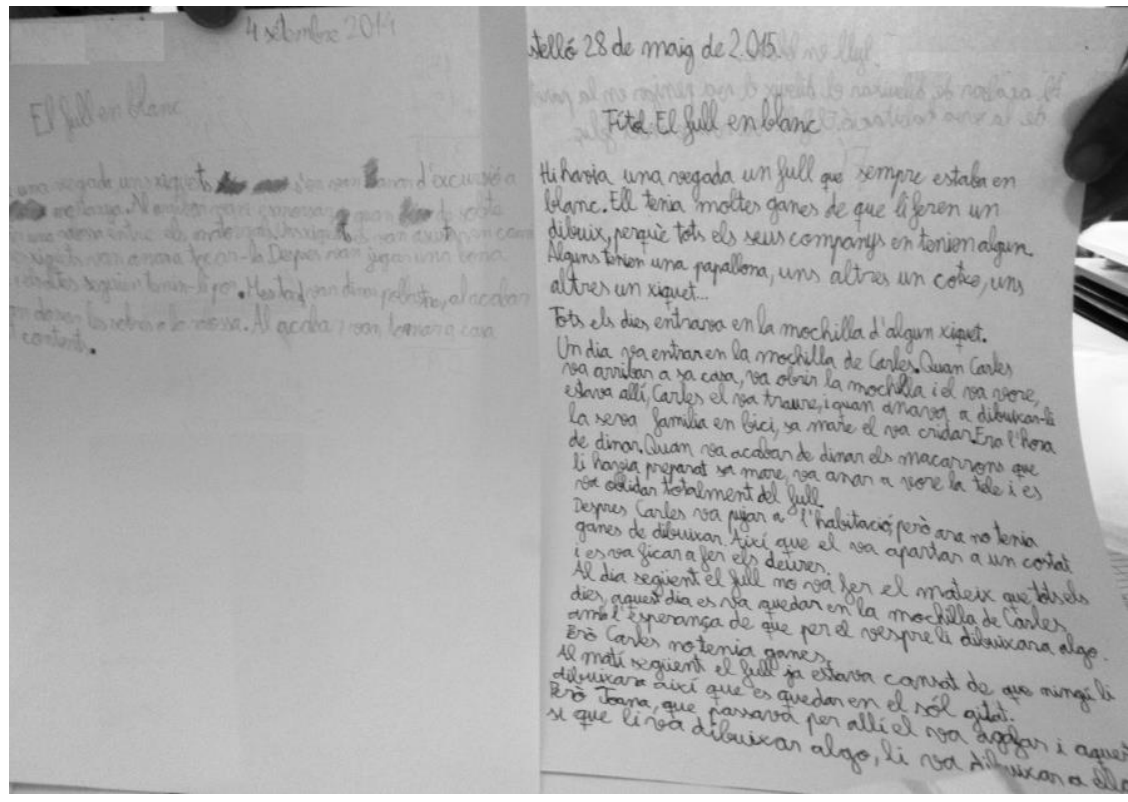

Imagen 16. Resultado de la actividad del folio en blanco. [C1_AM_FOM]
“QQué cambio! ¿no?, y sobre todo ellos lo ven. No es ninguna cosa extraña ni... Es algo muy visual ¿no? para ellos, porque es lo que ellos han hecho, lo que ellos hicieron y lo que ellos han hecho sin ningún tipo de intervención, ni... Sencillamente, lo que están haciendo es plasmar lo que durante todo el año han estado haciendo" [C1_E.F_D].

\subsection{Experimentando: trabajando ciencias naturales}

En ciencias sociales, matemáticas y ciencias naturales los alumnos trabajan mediante el libro de texto y el aprendizaje cooperativo. "Puntualmente, lo que hacemos después ya son dinámicas cooperativas o estructuras simples que trabajamos diariamente en el aula pues ya sea en matemáticas, en valenciano o ya sea en naturales" [C1_E.F_D].

En ciencias naturales y en ciencias sociales suelen trabajar en grupo a partir del libro de texto, bien sea explicando ellos los contenidos o extrayendo preguntas sobre los temas y trabajándolas en grupo para posteriormente hacerlas a los otros grupos mediante la adaptación de la técnica 1-2-4.

"Hemos hecho una actividad, no el 1-2-4, nos hemos saltado y hemos hecho el 1-4, en la actividad de naturales y una actividad en la que participan bastante y que yo creo que el aprendizaje lo consolidan mejor. Porque es una forma de que todos participan, están cooperando. Y es una forma de aprender con los demás. No es una forma sólo de aprender nada más tú. Porque yo creo que a todas las personas eso de estudiar individualmente al final cansa. 0 de aprender individualmente cansa. Pero cuando tu estás aprendiendo una cosa, con tus compañeros y ves que tus compañeros se interesan en el mismo tema que tu, es una forma... además de hacer grupo, una forma de interiorizar los aprendizajes y los contenidos" [C1_E.F_AP].

Por lo que respecta a la asignatura de matemáticas, también resuelven problemas matemáticos mediante el aprendizaje cooperativo. "En mate solemos trabajar en grupo" [C1_E.F_A5]. "Los problemas en grupo" [C1_E.F_A7]. Concretamente, con la técnica simple de lápices al centro. "Por ejemplo, todos dejábamos los lápices en el medio de la mesa y entonces [...] habían problemas de matemáticas y todo el grupo los solucionaba juntos y después cuando ya lo teníamos lo escribíamos y todo" [C1_E.F_A5]. "[...] la técnica, se dice lápices al centro. Pues leemos los problemas y no podemos coger nada para escribir, lo ponemos, los lápices y todo eso lo ponemos en el centro. Entonces ahí uno lee [...] y el otro explica. Y después cuando el que explica todos tenemos que tenerlo bien claro. Sino no podemos escribir 
antes" [C1_E.F_A8]. "Por ejemplo, en matemáticas hicimos al principio una cosa que se llamaba lapiceras al centro, lápices al centro, que podíamos participar todos los grupos y si lo hacíamos individualmente ya no podemos hacer eso, porque somos uno solo" [C1_E.F_A6].

Al hilo de lo anterior, el maestro también explica que, aparte de la técnica de lápices al centro, utilizan otras técnicas simples como el folio giratorio o el 1-2-4.

“En matemáticas lo de las técnicas simples, en el 'lápices al centro'. Y en valenciano, solemos gastar mucho la de '1- 2- 4' o 'el folio rotatorio' y cosas de estas que suponen actividades en las que van participando los 4 o entre ellos se van corrigiendo, entre ellos se van apoyando. Uno pone un nombre, el otro copia el otro nombre y después los cuatro copian los nombres o los verbos ¿sabes? Estas técnicas simples es lo que más gasto" [C1_E.F_D].

Los alumnos como presentan problemas de atención realizan unos 5 minutos de actividades matemáticas. "También como Don E. (el director y maestro de castellano) y Manolo ven que nosotros nos falta un poco de atención. Manolo nos hace una hoja de matemáticas, sobre todo lo hacemos en matemáticas. Que dice 5 minutos eso...y tenemos que estar 5 minutos centrados en una hoja haciéndola" [C1_E.F_A8].

En ciencias naturales, en una sesión, han realizado una serie de 6 experimentos. "Por ejemplo, el último día de naturales hicimos experimentos" [C1_E.F_A6]. "El otro día hicimos un laboratorio" [C1_E.F_A8]. Cada grupo hacía un experimento y después iban rodando. Los experimentos que han realizado han sido: 1) Volumen; 2) Calcular la densidad; 3) Densidad con líquidos; 4) Flotabilidad; 5) Flotabilidad de un huevo y 6) Cambios en la materia.

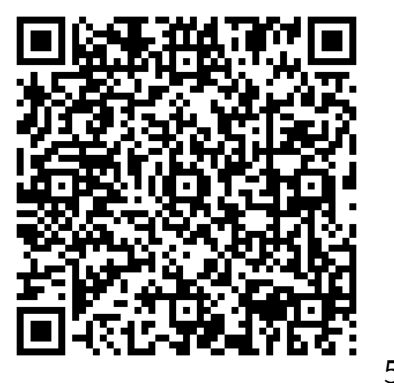

Hoja de experimentos [C1_AM_DO].

\section{1) Volumen}

Una de las actividades consistía en calcular el volumen de algunos objetos (Ver Imagen 17). Para ello, debían de rellenar con agua una probeta y medir la cantidad de agua que cabía en la misma. Posteriormente, depositaban un objeto para que éste se sumergiera. El objeto iba atado en un hilo. De esta manera, aumentaba el nivel de líquido y permitía, Imagen 17. Experimento volumen. [C1_O_FO] realizando una resta, determinar el volumen del objeto. "Mirabas en un recipiente que medía el volumen [...] y 
te fijabas en cuanto medía y después ponías, por ejemplo, una pieza de $500 \mathrm{~g}$ y veías el volumen con lo que subía el agua de donde estaba y así medías el volumen" [C1_E.F_A4]

\section{2) Calcular la densidad}

Para este experimento se necesitaban balanzas, para poder calcular la densidad, los alumnos

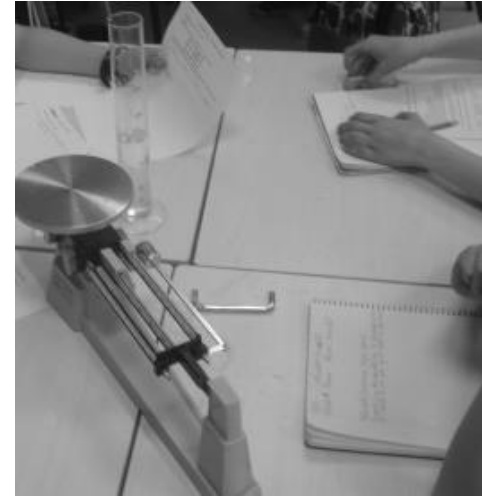

Imagen 18. Experimento densidad [C1_O_FO]. debían realizar la división entre la masa de un cuerpo y el volumen que ocupa (Ver Imagen 18). "Consistía en [...] el recipiente de agua para medirlo y después con unas balanzas ponías también el objeto y también lo medías y así sabías el volumen y cuando pesaba" [C1_E.F_A4]. "Después unas balanzas que tenías que pesar un metal y después ponerlo en una probeta de agua" [C1_E.F_A6]. "Una probeta de ciencias y ponías como pesas pequeñitas y el agua iba subiendo y después también el de la miel y el del alcohol y todo esto" [C1_E.F_A5].

\section{3) Densidad con líquidos}

En un recipiente el alumnado ponía agua con aceite y observaban su posición. Las sustancias se ordenaban en función de su densidad. Con otro recipiente se mezclaba agua con colorante y alcohol y observaban que es lo que pasaba, lo efectuaban con diferentes líquidos. "Había uno que era de miel, y alcohol y colorante y muchas cosas ¿no? Que ese era el más chulo para mí, porque combinabas cosas y después si ibas a tirarlo al wáter, bueno al grifo hacías así (lo simula con los brazos), caía primero la miel, después el alcohol, después el colorante...asi" [C1_E.F_A5]. "Según la densidad, bueno el que eso poníamos, por ejemplo a bajo también había aceite según la... eso se ponía, más arriba estaba el alcohol y el colorante, a bajo el fairy y ese y abajo el agua, el aceite y abajo la miel y..." [C1_E.F_A8]. "La densidad de los líquidos. Porque tu vas poniendo los líquidos y se ordenan de mayor densidad a menor. Los que tienen más densidad se quedan abajo y los que tienen menos arriba y no se mezclan se quedan" [C1_E.F_A4].

\section{4) Flotabilidad}

Para este experimento el alumnado debía de rellenar un recipiente con agua e introducían diferentes objetos como un trozo de corcho, de madera o metal y observaban que ocurría. La flotabilidad de los objetos dependía de su densidad respecto de los líquidos (Ver Imagen 19). "Era que en un recipiente grande ponías objetos y por ejemplo el hierro como tiene más densidad se hundía y el corcho como tiene menos flotaba y la madera como está en medio se quedaba como por el medio [...." [C1_E.F_A4]. "Era corcho, que teníamos que... era una valsa de agua y con agua... y era corcho, metal y madera. Y mi grupo cuando lo teníamos hicimos un tanque de agua. Porque pusimos el corcho, después la madera y después el metal [...] y nos gustó mucho.

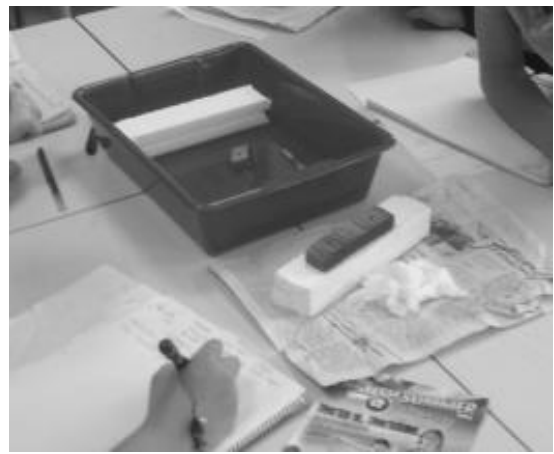

Imagen 19. Experimento flotabilidad [C1_O_FO].

Lo tiramos todo de golpe y nos salpicó" [C1_E.F_A5]. "Y luego según la densidad se hundía o flotaba y también ponías corcho, madera,..." [C1_E.F_A8]. 


\section{5) Flotabilidad de un huevo}

Otro experimento consistía en utilizar una probeta, agua, sal y una cuchara para ver la flotabilidad de un huevo (Ver Imagen 20). El alumnado debía de rellenar un recipiente de agua e introducir un huevo, para observar lo que ocurre. Posteriormente, debían de echar un poco de sal y menar el agua hasta que se disolviera. "También había uno que era un huevo que lo ponías en agua..." [C1_E.F_A8]. "[...] ponías un recipiente de agua, agua y después ponías el huevo y ponías..." [C1_E.F_A4]. "Sal" [C1_E.F_A3]. "Claro y como la sal se mezclaba con el agua, el agua tenía más densidad que el huevo,

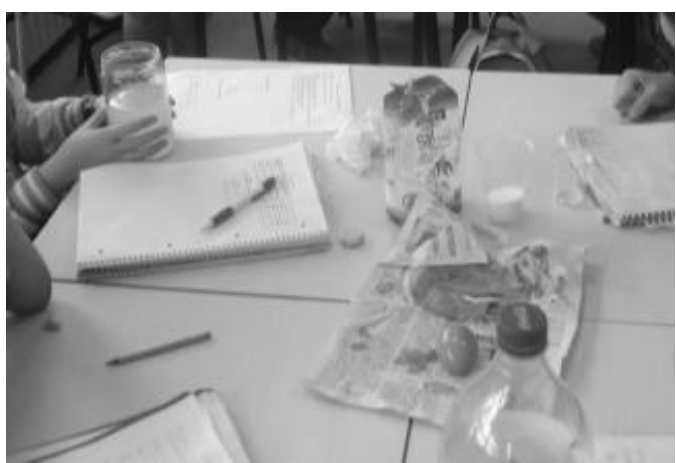

Imagen 20. Experimento flotabilidad de un huevo [C1_O_FO]. entonces el huevo subía" [C1_E.F_A4].

\section{6) Cambios en la materia}

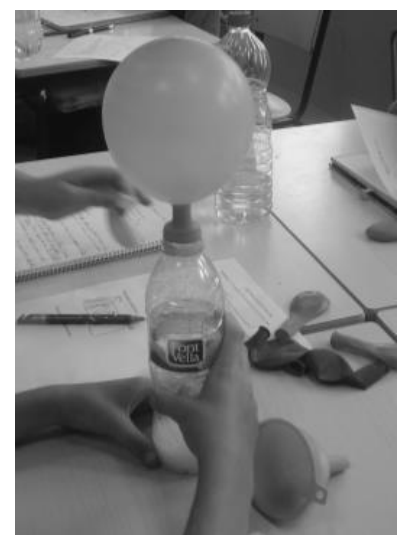

Imagen 21. Experimento sobre la materia [C1_O_FO]

Otro experimento consistía en rellenar, menos de la mitad, una botella de plástico con vinagre y rellenar un globo de agua y bicarbonato. Los niños debían colocar el cuello del globo en el cuello de la botella intentando que no se derramase el bicarbonato en la botella (Ver Imagen 21). Posteriormente, el alumnado derramaba el bicarbonato en la botella y aumentaba el cuello del globo. "Poner bicarbonato, en un globo poner una botella un poco de vinagre y después poner globos en la botella y ponerlo, entonces el globo se infla" [C1_E.F_A3]. "Pero antes de ponerle la embocadura tienes que poner..., no puedes dejar que caiga el bicarbonato primero lo pones $y$ después levantas el globo para que caiga eso y se infle" [C1_E.F_A4]. "A mí el que más me gustó, fue el grupo que me tocó a mí el primero fue... el vinagre, si juntas... ponías un globo lleno de vinagre... ¡Ay! De bicarbonato a la boca de la botella y la botella estaba un poco llena de vinagre y se hinchaba el globo...” [C1_E.F_A6]. "En uno había vinagre, globos, una botella de agua [...] y bicarbonato y globos. Ponías el vinagre en la botella, y el bicarbonato en el globo y luego lo ponías el globo en la botella y el bicarbonato, luego tiras el bicarbonato que hay en el globo a la botella y luego se hincha..." [C1_E.F_A7].

La participación y el compromiso del alumno son altos. "Los alumnos por grupo van cambiando de actividad de manera que en una sesión hacen las diferentes actividades propuestas. Esta forma favorece a la atención hacia la actividad ya que en una sesión se hacen 6 actividades diferentes en 6 mesas" [C1_O_DCos]. El ritmo de la enseñanza está entre correcto- rápido. "Los alumnos tienen que ir haciendo las actividades dentro de un ritmo considerable puesto que el cambio de actividad supone que toda la clase cambie de mesa y de experimento" [C1_O_DCOS]. Respecto a las actividades cognitiva estas son variadas. "Recordar, entender, aplicar (manipulativo), analizar" [C1_O_DCOS]. El estudiante dirige la mayor parte del aprendizaje. "El alumno de prácticas introduce en que va a consistir la actividad y posteriormente se procede a la ejecución de cada uno de los experimentos por parte de los grupos. El alumno de 
prácticas y el docente facilitan, guían, ayudan a quien lo necesita. Los alumnos conocen el funcionamiento de la actividad, si tienen alguna duda se dirigen al alumno de prácticas y al docente" [C1_O_DCOS]. No desaprovechan el tiempo, todo lo contrario, se promueve que en la sesión trabajen 6 conceptos diferentes.

\subsection{La evaluación: rúbricas y voz del alumnado}

Tal y como se ha explicado anteriormente, el alumnado tiene un papel importante en la evaluación en lo que respecta a los grupos de investigación en la asignatura de cultura valenciana. "Porque ellos hacen el trabajo, nosotros lo escuchamos, ponemos las notas y [...] a mi sinceramente me gusta porque me siento como un profesor [...] A míme parece bien, porque así sé que mis compañeros han entendido bien el trabajo y que saben lo que hemos trabajado" [C1_E.F_A1]. "Pues primero después de que expusiéramos, cada uno puso las notas y después en grupo hablamos y llegamos a un acuerdo de que nota poner" [C1_E.F_A4]. Hay que recordar también las evaluaciones que hacen al terminar la actividad del "leemos en pareja" y las reflexiones para mejorar el cuentacuentos o el teatro a infantil. Como ya se ha explicado, anteriormente, el alumnado también se gestiona y supervisa los deberes.

Otro elemento a destacar dentro de la evaluación es la valoración de la libreta por parte de los compañeros.

"Tenemos también la evaluación de las libretas que es importante porque hacen muchas tareas en la libreta y esa evaluación la hacen ellos, la valoran ellos a partir de una rúbrica que hemos creado en el aula, en una sesión en la que vimos las cosas que teníamos que valorar y como las teníamos que valorar y son ellos los que van puntuándose. Ahora, al finalizar el trimestre se puntuarán la libreta o el trabajo que han hecho" [C1_E.I_D].

Así pues, el alumnado para la evaluación de las libretas, de todas las asignaturas, de los compañeros cuenta con una rúbrica (Ver Imagen 22) los ítems de la cual fueron acordados al inicio del curso por el alumnado. "Pues que nos valoramos las libretas [...] y tenemos una ficha y se la damos al compañero y así el compañero pone lo que piensa de nuestra libreta y así nosotros podemos saber qué opina el compañero y lo que podemos mejorar" [C1_E.F_A4]. Este hecho sirve para motivar y mejorar la presentación individual de las libretas. "Porque vemos lo que hacen los compañeros y a veces queremos hacer lo mismo" [C1_E.F_A3].

Al alumnado le gusta este sistema de evaluación de las libretas, porque al ver marcada la valoración de sus compañeros en la casilla de la rúbrica ven si tienen que mejorar o no algunos aspectos.

"Nos parece bien que lo haga de esta forma, porque a lo mejor Manolo lo ve de una forma y los compañeros de otra y tú piensas que al hacerlo Manolo no sabes en que te ha valorado, no sabes que tienes mal. Pero si a los compañeros les pones una cruz en una cosa que... la libreta está con buena letra y limpia, si te ponen una cruz sabes que tú tienes buena letra y todo eso. Pero si no te la ponen sabes que tienes que mejorar la letra y la presentación" [C1_E.F_A8]. 
Els companys i companyes de grup posaran nota de la meua llibreta. Això em permetrà vore si pensen com jo o no a l'hora de valorar la llibreta.

M'ajudarà a corregir errades i a seguir fent bé

allò que faig bé.

\section{Per obtenir la nota:}

Primer sumaré les creuetes de cada apartat i les dividiré entre 4.

Després els quatre resultats els tornaré a sumar i els tornaré a dividir entre quatre.

Ha d'eixir una nota entre 0 i 3 punts.

NOTA LLIBRETA:

SOCIALS:

\section{CULTURA VALENCIANA:}

VALENCIÀ: ?

MATEMÀTIQUES: 275

NATURALS: $2^{i} 75$

LLIBRES LLEGITS: 3
SOCIALS

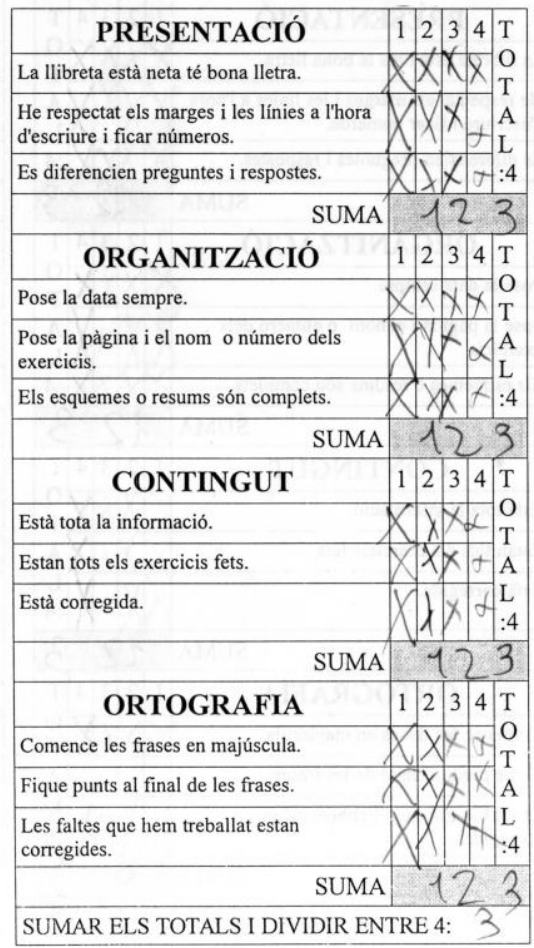

NATURALS

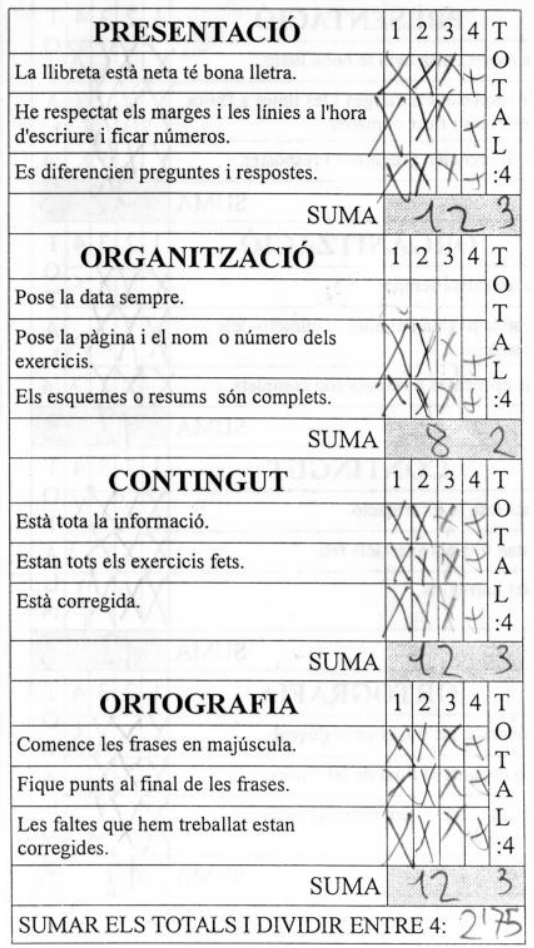

Imagen 22. Rúbrica evaluación de las libretas [C1_AM_FOM].

El docente interviene en el caso que algunas notas no se adecúen a la realidad de la libreta presentada.

"Después tenemos que hacer la media y después Manolo nos dice pues si, por ejemplo, un niño de nuestra clase que el otro día sacó 2,8 porque es entre 3. Sacó un 2,8 [...] Que un 3 es un 10. Pero él dice 2,8, y él en verdad como sabe qué $P$. no lo hace tan bien, entonces él dice: pues $P$. después me das la libreta. Para ver yo si de verdad te mereces este 2,8 y la mira y si ve que es mentira le baja la nota, por intentar engañar a Manolo [...] después Manolo nos dice ‘que habéis aprendido?' y decimos pues yo que se...que yo creo que no he hecho buena letra, que es lo que comenté yo, que no hacía buena letra, me parece buena la presentación, pero todos los que me valoraron la libreta me dicen que sí que lo hago bien y me ponen cruces. Y yo claro, yo como ellos no saben la letra que yo hago normalmente saben que esa letra está buena pero yo me pongo que no, porque yo sé que la puedo mejorar" [C1_E.F_A8].

Los alumnos son conscientes que el docente tiene en cuenta su voz a la hora de incorporar la nota de la libreta a la nota final de cada asignatura. "Así tiene en cuenta nuestra opinión y por ejemplo si él cree que la libreta no tiene las cosas muy bien y algún compañero cree que si, te dice lo que tienes" [C1_E.F_A3].

El hecho que el alumnado intervenga en la evaluación completa su proceso de aprendizaje, ya que le permite reflexionar y conocer sobre el mismo.

"Que los alumnos se evalúen es una forma de que ellos mismos se den cuenta de lo que ellos han conseguido y de lo que no han conseguido. Y aparte, el profesor se da cuenta de si ellos realmente llegan a lo que se habían propuesto ellos mismos también. Porque yo creo que cuando tu evalúas a un compañero tú te pones más en la piel del compañero que si lo hace el profesor. Porque es una persona que no 
comparten a lo mejor los mismos gustos, no comparten la misma edad, pero cuando evalúan los compañeros, se ponen en el lugar y dicen 'yo sé que es difícil estar ahí exponiendo' o 'yo sé que difícil es hacer ese trabajo'. Yo creo que a veces puede ser una evaluación más justa que la propia que hace el maestro [...] Y a veces, también hay que decir que son más críticos que el propio profesor. 0 que el propio docente, porque ellos se están mirando se están comparando. [...] Es una forma de darse cuenta o aquí tengo que mejorar y aquí no. Porque no es lo mismo que llegue el profesor y que ponga un 8 y tu ese 8 de ¿dónde lo has sacado? Que tú compares a los compañeros y que te des cuenta" [C1_E.F_AP].

Otra herramienta de evaluación es el examen. "Nosotros hacemos el examen y cuando terminamos se lo damos a Manolo y nos pone la nota" [C1_E.F_A1]. "Utiliza la estrategia del examen, por así decirlo, para avaluar los contenidos y las competencias" [C1_E.F_AP].

"Bueno, pues es lo que pasa, pues yo utilizo exámenes tradicionales de los que son los contenidos de las diferentes áreas. Trabajamos a partir de ver si los contenidos que hemos estudiado o que hemos trabajado en la clase se han aprendido $y$, pues, hacemos exámenes que me da la editorial y que la verdad que este año me están gustando, el nuevo planteamiento de la editorial [...]. Porque son muy dirigidos a los niveles competenciales, que la verdad que son interesantes. Ya no es la típica pregunta- respuesta sino que supone un ejercicio de reflexión [...]" [C1_E.I_D].

Los exámenes, son los mismos para todos los alumnos de la clase. En ellos se aborda lo fundamental que se ha trabajado, aquellos objetivos mínimos que todo el alumnado del ciclo debe de adquirir.

"El hecho de tener que hacer exámenes, pues ¿qué es lo que pongo en el examen? Pues normalmente pongo lo que es fundamental, podríamos llamar 'objetivos mínimos' que están marcados a nivel de nivel o a nivel de ciclo y lo que intentamos es que los niños logren esos mínimos [...] Son generales para toda la clase, son generales a nivel de curso. Lo que sí que es cierto es que cuando yo valoro o evalúo, puede ser evalúo diferente a un niño que a otro. Según sus competencias o sus capacidades" [C1_E.F_D].

Así mismo, el docente utiliza diferentes herramientas para la evaluación y tiene en cuenta las capacidades o competencias de cada alumno. "Utilizo diferentes instrumentos de evaluación, pero para todos el mismo" [C1_IP.HR_D]. Por tanto, el maestro realiza una evaluación continua, y para ello utiliza la observación, la intuición, los exámenes y los controles de deberes y evaluaciones de las libretas valoradas por los niños. "Pues utilizo la observación, la intuición, los exámenes, la libreta, el control diario de deberes, de faena, las técnicas que utilizo de evaluación. Serían esas, después las tablas o registros de los compañeros que me dan y que me permite todo pues ir estudiándolo" [C1_E.F_D]. "Es evaluación continua. Hay actividades puntuales después de un tema pero continuamente estamos evaluando, mirando lo que saben, lo que no saben, lo que es necesario reforzar" [C1_IP.HR_D].

Vemos cómo el docente tiene presente la voz del alumnado en el proceso de evaluación. "En algunas áreas más que en otras o es más fácil de hacerlo, pero si en principio sí” [C1_E.F_D].

"Pero bueno la evaluación parte de ahí del examen, parte del trabajo en el aula por supuesto [...] Está la parte mía, por decirlo de alguna manera, que yo les pongo la nota, pues al corregir el examen porqué bueno es tan sólo es un medio. No soy yo el que marco la nota es lo que ellos han hecho o lo que ellos han 
aprendido. De hecho, el examen se lo doy siempre a ellos para que vean que es lo que han hecho bien o que han hecho mal y a los padres, para que lo vean. Y después la otra parte de la nota que es propia de ellos, que ellos mismos son los que se valoran y eso pues es lo que juntamos y sacamos la nota trimestral" [C1_E.I_D].

En definitiva, el docente con este tipo de evaluación persigue, además de la responsabilidad y autonomía de su alumnado, que a éste le sirva la evaluación para seguir aprendiendo y mejorando.

"Que aprendan a valorar, que aprendan a ver lo que está bien y lo que no está bien, que aprendan lo que hay que mejorar y que aprendan a ver lo que mi compañero hace bien y yo quiero hacerlo como él. Aprender a ver: 'eso lo he hecho mal', lo tengo que hacer bien, porque mi compañero me lo ha hecho así o porque... Ese sentido, una vez más, de responsabilidad ¿no? y de autonomía, de ser consciente de que lo que hago si lo hago bien o no lo hago bien. Y a partir de esa autoevaluación o evaluación del compañero estoy aprendiendo. Cada niño, está aprendiendo eso ¿no? A que estoy haciendo bien y a que no estoy haciendo bien. Hay quien se lo toma seriamente, hay quien no hace ni caso, como en todos los sitios" [C1_E.F_D].

En el Anexo 18 se recoge una muestra de material ilustrativo de este caso. 


\subsubsection{Creencias, actitudes y valores que sustentan la práctica}

$\mathrm{Al}$ preguntarle al docente por sus creencias, percepciones y experiencias vitales que subyacen a su forma de trabajar éste explica que es una cuestión que, en muchas ocasiones, él también se la plantea.

"Eso me lo he planteado yo también, muchas veces. Porque así, porque yo,... Todos hemos crecido y hemos aprendido en el aprendizaje tradicional o más frecuente. El de que el maestro explica y los alumnos toman nota, prestan atención y hacen. Y todos hemos llegado donde estamos, ¿no? Yo pienso que, pues... yo soy muy feliz donde estoy, soy maestro y tengo una plaza. Digo pues no lo habrán hecho tan mal cuando yo he sido capaz de llegar aquí, ¿no? Una persona como yo, de lo más normal. ¿Y por qué lo he de hacer de otra manera? Yo pienso que el razonamiento o la justificación más coherente que tiene el cambio es para hacer una educación más justa, más solidaria y más participativa, más creativa, más abierta que esto sí que no lo tenía la otra educación. La otra educación recuerdo yo, ¿no? cuando iba a clase... Yo siempre busco el ejemplo de cuando yo iba a clase. Era difícil participar o proponer cosas para que se hiciesen en el aula y que te hiciesen caso. A lo mejor sí que podías proponerlo, pero que te hiciesen caso era más complicado. 0 que en el aula se hablara y que los niños pudiesen hablar, era complicado, el tema del trabajo en grupo era muy puntual, pero lo hacías en tu casa no se hacía en el aula y son cosas que yo pienso que son muy buenas. Bueno dicen los que saben ¿no? o los que lo estudian que está demostrado que es una manera de aprender y que se aprende más y mejor. Entonces, ¿si se aprende más y mejor? ¿por qué no hay que hacerlo? Y desde ese punto de vista, de lo que me dicen los especialistas y desde el punto de vista del sentido común que ves que es más justo que ellos pueden ser participes y protagonistas de su aprendizaje. Pues pienso que es necesario tomar otras maneras de enseñar" [C1_E.I_D].

\subsection{El sentido del aprendizaje: gramos de entusiasmo, quilos de emociones y metros de vivencias}

El docente pretende crear y fomentar una clase agradable para sus alumnos, de tal manera que éstos disfruten en su propio proceso de aprendizaje. "Desde una asamblea inicial, el primer día de clase, donde comentamos y hablamos de qué queremos en nuestra aula para que sea un lugar de acogida y un lugar, pues interesante que haga que vengamos a gusto a la escuela" [C1_E.I_D]. Para lograr la implicación de los alumnos en su aprendizaje es muy importante que éstos encuentren el sentido y la utilidad a lo que trabajan, además de otorgarles el protagonismo de su propio aprendizaje.

"Soy de los docentes que piensan que para que el alumnado se implique y se esfuerce en la tarea de aprender es necesario que encuentre 'sentido' a lo que hace y que le vea una 'utilidad', un significado próximo. Es necesario conseguir resultados tangibles, transformadores del entorno y que tengan una repercusión a su alrededor. Es la manera en que la cantidad de tiempo y el trabajo deja de contarse en números y se empiece a contarse en calidades, en competencias, en gramos de entusiasmo, en quilos de emociones y en metros de vivencias. La experiencia me lo ha demostrado repetidamente y por este motivo, en mi tarea cotidiana de cada año, intento ir proponiendo dinámicas, actividades y experiencias donde el protagonista es el alumnado. Ellos y ellas se hacen cargo de organizar, de programar, de elaborar y de obtener resultados llenos de sentimientos y emociones que tan sólo ellos son capaces de evaluar, ya que los 
productos dejan de valorarse de manera cuantitativa para dar paso a la calidad, al compartir experiencias, al hablar de que ha ido bien y que es necesario mejorar" [C1_AM_DO].

Hay que destacar la importancia de la motivación del alumnado en el proceso de aprendizaje. Para ello el docente propone diferentes estrategias de aprendizaje, así como diferentes agrupaciones que promueven la variedad de formas de abordar el conocimiento.

"[...] todo cambio, a los niños hay que cambiarlos de manera de trabajar. Pienso que tan sólo por hacer el cambio ya les supone una motivación, un saber estar, una manera diferente. Aparte de eso pues al estar de diferentes formas, con diferentes agrupaciones les hace saber manipular o resolver esa situación de diferente manera. Es diferente trabajar con uno, ya puede ser que con ese me lleve bien o no, a cuando trabajo con cuatro, ya puede ser que me lleve bien o no con uno de esos o cuando trabajo con medio grupo ¿no? Un grupo de 10, 12 o 15 cuando hacemos la tertulia. Son diferentes formas de estar y todo eso, pues son competencias [...]" [C1_E.F_D].

Los niños valoran positivamente esta forma de trabajar, ya que para ellos el aprendizaje parece un juego, aunque son conscientes de que aprenden.

"Muchas veces, por ejemplo, en $3^{\circ}$ o en $4^{\circ}$ hacíamos cosas que no nos gustaban nada y haciendo Manolo lo que hace, hace cosas que aprendemos un montón pero a nosotros nos parecen como juegos. $Y$ en verdad, estamos aprendiendo un montón [...]. Me parece que Manolo hace una forma muy divertida de hacer las clases y aprendemos un montón. Porque claro si hacemos todo normal nos aburrimos un poco todos, unos no están pendientes y no hacen caso. [...] también, me parece que como el curso es muy largo si hacemos todo el rato lo mismo es un poco aburrido, pero Manolo va haciendo cada vez un poco más divertido y también lo que hace es para que nosotros aprendamos también a leer, a leer y a escribir" [C1_E.F_A8].

El docente es consciente de lo que agrada o no a su alumnado y por esa razón realiza las diferentes propuestas metodológicas intentando huir lo máximo que sea posible del tipo de enseñanza en la cual los alumnos adoptan un rol más pasivo. No obstante, se mantiene la necesidad de realizar actividades que los niños deben aprender a hacer, ya que no todo es lúdico en el aula, ni mucho menos.

"Que lo que no les gusta son los deberes, es la faena y son los exámenes, y lo que les gusta pues es un poco lo que sale un poco de lo que se considera una clase normal. Eso pues te da pie a intentar realmente hacer cosas que no sean una clase normal pero también mueres en ella, algunas veces, porque es preciso 0 también han de saber estar ahí, porque les va a tocar estar ahí y tienen que saber estar. Y quitar lo que no les gusta, pues hasta cierto punto también, porque los deberes son deberes y la faena es la faena y los exámenes son los exámenes [...]. Entonces sí que los escuchas, sí que los atiendes en lo que puedes, intervienes o intentas evitar caer en estas rutinas a veces intentando hacer cositas diferentes, pero ya está ¿no? El ritmo lo mantienes" [C1_E.F_D]. 


\subsection{Una educación más justa para todos: reconocimiento y valoración de la diversidad}

Tal y como se ha recogido en la descripción del aula, el docente comentaba que no había ningún niño diagnosticado con dificultades de aprendizaje, necesidades específicas de apoyo educativo (n.e.a.e.) o con dictamen pero que, lógicamente, como en todos los grupos hay niños que van más atrasados o a los que les cuesta un poco más. Es por ello que éste reconoce la diversidad del alumno presente en su aula, y esto es lo que le lleva a gestionarla y proponer las metodologías que lleva a cabo. Remarcar que en otras ocasiones el docente sí que ha trabajado con alumnos diagnosticados.

"En otros años, sí que en la clase, he tenido alumnos del aula CyL, que eran alumnos asperger, o he tenido algún alumno con adaptación curricular significativa. En estos grupos atrás sí que he tenido algún alumno así [...]. Siempre mi filosofía de trabajo con niños de educación especial o niños que tenían dificultades era que estuvieran dentro del aula y que si venía el compañero de pedagogía terapéutica, o el que lo atendía, que fuese siempre la atención dentro de mi aula. Siempre que fuera posible. Había horas puntuales de logopedia que entonces se iban pero en general eran dentro del aula [...]. Cuando he tenido alumnos de educación especial, han formado parte de estos grupos y han aportado lo que han podido desde sus capacidades y desde sus habilidades, siendo uno más en el aula" [C1_E.I_D].

Esta evidencia se refuerza con un comentario extraído del proyecto Quin sentit té la llengua? El gust... per la llengua presentado, por el maestro, a Conselleria de Educación.

"En el aula tengo alumnado de diferentes niveles (como en todos los grupos) y particularmente tengo un alumno con síndrome de Asperger. Aunque no escribe le gusta mucho recibir cartas y que los compañeros se las lean y él, en cambio, les envía un dibujo. En el cuentacuentos le gusta escuchar las historias preparadas por sus compañeros o ser el reportero gráfico de la sesión y este año en el nuevo proyecto puede formar parte perfectamente del grupo, dando ideas, pintando o contando parte del Kamishibai. Igual que él, los otros alumnos a los que les cuesta más tanto la expresión como la creación o la organización, gracias a la ayuda del grupo pueden ir haciendo sus aportaciones y aprendiendo a un ritmo diferente" [C1_AM_DO].

El docente siente que está capacitado para hacer frente a la diversidad de su aula. "Dentro de mis limitaciones yo pienso que puedo ayudar a los niños a ir hacia delante, que pienso que es mi misión" [C1_E.I_D]. Además, añade que todas sus actividades planteadas en el aula se enmarcan en una filosofía inclusiva. "Es una propuesta que tiene en cuenta a toda la clase de manera grupal y de manera individual" [C1_E.F_AP].

"[...] yo pienso que en todas porque en todas lo que busco es que el alumno se desarrolle el máximo posible según sus capacidades y siempre intento tratar a los alumnos de una manera positiva. Eh, que vea pues sus posibilidades y sus capacidades y lo que puede hacer las cosas bien dentro de sus posibilidades $y$ capacidades, está claro. Pues yo pienso que tanto las dinámicas puntuales o los proyectos puntuales que llevamos a cabo, como las sesiones de aula diarias que pueden ser las rutinarias y las aburridas, [...] siguen un poco esa filosofía" [C1_E.I_D]. 
Así pues, la manera de trabajar del docente se adapta a los estilos y capacidades de sus alumnos.

"Se adapta mucho más a los estilos y a las capacidades de cada niño, porque no les estás marcando que tienen que hacer todos lo mismo. Sí que tienen que hacer la misma actividad, pero cada uno desde sus posibilidades. No será lo mismo, la carta que haga un niño con muchas capacidades que otro, pero los dos hacen la carta. No será el mismo cuento que hace un niño muy creativo y muy entusiasmado en la actividad que otro, pero los dos hacen el cuento. Claro, ahí se atiende mucho a ese estilo de aprendizaje y a esa diversidad" [C1_E.F_D].

Otras reflexiones del maestro relacionadas con las necesidades del alumnado apuntan a que se plantea unas exigencias mínimas que deben alcanzar todos los alumnos.

"Lógicamente, si tenemos que atender a las necesidades de un estudiante, yo no le puedo pedir lo mismo a un alumno que a otro. Aunque le he de exigir unos mínimos que se irán ajustando [...] Una cosa es lo que yo quiero, que todos aprendan al mismo ritmo. Pero la realidad es que los alumnos, cada uno tienen su ritmo. Hay algunos a los que les cuesta más y tienen que preguntar las cosas más veces, tienen que hacer más ejercicios [...]. Yo quiero que los alumnos se impliquen al máximo en todas las actividades, lo que pasa que no todos se pueden implicar de la misma manera, pero sí, sí que exijo la misma implicación de los alumnos" [C1_IP.HR_D].

Destacar también que este reconocimiento de la diversidad está presente en el alumnado hacia sus compañeros. Por ejemplo, a la hora de preparar la actividad de "leemos en pareja" en el tercer trimestre, tanto a la hora de plantear la dificultad de las actividades como la temática según los gustos o preferencias del compañero. "Porque puedes escoger una cosa que piensas que le puede gustar a tu compañero y Manolo a lo mejor como es un texto para toda la clase, bueno para media clase que a lo mejor no lo acierta" [C1_E.F_A6]. Al preguntarle al docente por la diferenciación que realiza en la práctica de "leemos en pareja" a lo largo del curso, éste explica que a medida que transcurre el curso se le va dotando al alumnado de mayor autonomía.

"Es como el ejemplo que siempre pone Joan Traver de la bicicleta. El niño primero sabe ir en bicicleta con las 4 ruedecitas, con el casco, las protecciones en los codos y en las rodillas y con el padre que le aguanta la sillita por detrás la bicicleta, y poquito a poco le vas quitando ayudas, le vas quitando ayudas hasta que el solo es el que va con la bicicleta ¿no? Siempre sabe ir en bicicleta. Esto es lo mismo, siempre es capaz de hacer el niño el 'leemos en pareja', con la ayuda de los padres, con mi ayuda, con lo que yo les doy y poco a poco les vas quitando. Los padres poco a poco se van cansando, sé que al final hay muy pocos que siguen a su lado, yo les daba la ficha, después no les daba la ficha. Les daba el texto y después no les doy el texto y poco a poco ellos van haciendo el 'leemos en pareja' y ahora lo hacen ellos solos" [C1_E.F_D].

Así pues, según explica, esta autonomía se ve latente en los comentarios que le realizan los familiares al respecto.

"Claro, es uno de los objetivos que se consiguen en esta manera de hacer. Yo no sé si los de sociales o los de naturales lo conseguirán o los de mates o aprenderán polígonos o no, eso tengo claro que no lo sé, habrá que sí y habrá que no, pero lo que sí que está claro en todo es que van asumiendo autonomía, eso no 
hay ninguna duda y no porque lo diga yo, porque me lo dicen las familias, los padres ¿no? y por otros cursos que los niños se van haciendo más autónomos y van aprendiendo a trabajar. Te lo expresan también los padres, que te dicen: 'lo he dejado solo y es que no ha pegado chapa' y es cierto. Hay niños que necesitan una ayuda y un apoyo al lado, pero hay que ir haciendo las pruebas, hay que ir haciendo la prueba de que sea él el que vaya. En las edades que tienen, hay muchas cosas que pueden hacer solos, que no tienen por qué estar de la manita" [C1_E.F_D].

En relación al ideario de cómo el docente entiende y concibe la educación, éste le da más valor al proceso que al producto.

"Sobre todo me interesa el proceso, el producto, pues bueno, es como es. Puede ser mejor o puede ser peor a veces te sabe mal lo que han terminado. Por ejemplo, exposiciones ¿no? de cultura, lo que terminan sacando o que terminan presentando te sabe mal, no han ido a lo mejor a lo que tú pensabas que hubieran tenido que hacer o lo que pensabas que tenías que haber obtenido. Y les puedes llamar la atención o hacerles alguna recomendación o decirles que no está o no han hecho lo que tocaba. Pero después cuando te pones a reflexionar dices, tampoco es tan importante, lo importante ha sido el ejercicio de esfuerzo que han hecho y el trabajo que han hecho" [C1_E.F_D].

\subsection{Una educación más solidaria: cultura colaborativa y liderazgo compartido}

La práctica educativa del maestro se basa en una educación más solidaria, en la cual prima la ayuda de los compañeros y la distribución de responsabilidades y tareas dentro de los grupos. "Mi práctica diaria se basa en el aprendizaje cooperativo y es a partir de la distribución en grupos del alumnado desde donde empezamos el trabajo" [C1_AM_DO]. "La propuesta que siempre intento ir encaminando a los niños es el organizar de manera grupal para poder ir haciendo técnicas de aprendizaje cooperativo, dinámicas de aprendizaje cooperativo, enseñanza cooperativa en el aula a lo largo de todas las sesiones" [C1_E.I_D]. La ayuda entre iguales, es una de las estrategias utilizada para atender a la diversidad de su aula.

"Yo lo que marco o lo que lanzo es la propuesta de hacer unas actividades y entonces los niños se ponen a hacerlas, según las competencias que cada uno tiene lo hacen o no lo hacen,...cuando no lo hacen es cuando interviene el grupo y entonces es cuando entre todos han de conseguir que el grupo lleve a delante la actividad o tenga hechas las actividades. Hay niños que a lo mejor no son capaces de hacer los ejercicios, el problema o esa actividad y los compañeros del grupo son los que lo tienen que ayudar a que la lleve a adelante. Esa sería la atención a la diversidad o la atención a las diferencias. Lógicamente, hay niños que la actividad que haces enseguida la tienen hecha y 'chin pum'. Yo lo que estoy viendo también es la diferencia del comportamiento de los niños ¿no? En cuanto a ayudas, hay quien es muy capaz, lo hace, termina y ya estoy. Y hay quien hace, lo termina, lo tiene bien y se preocupa por el compañero. Y se pone a ayudarle y a explicarle cosas. Esas actitudes también voy viendo cómo a lo largo del año van cambiando y van madurando" [C1_E.F_D]. 
Asimismo, el docente piensa que esta forma de trabajar, aparte de la autonomía mencionada anteriormente, ofrece un aprendizaje más solidario y justo, primando la ayuda entre los compañeros del aula.

"Sobre todo por la autonomía, la solidaridad, las ayudas entre ellos. Porque es un aprendizaje más justo. Aprender los niños aprenden siempre, les enseñes cómo les enseñes ¿no? Utilizando la técnica, la metodología, la filosofía de aprendizaje que haces da lo mismo, siempre aprenderán. El tema es que lo que consiguen en una manera de hacer $u$ otra es diferente. Yo pienso que lo más significativo, ¿no? la diferencia entre un aprendizaje que consideramos tradicional: más expositivo, más explicativo, más de maestro, más magistral y la cooperativa, pues sobre todo es ese aprender a compartir, aprender a estar en grupo, aprender a ser solidario, aprender a ayudar, eso en la otra clase no lo pueden tener, no lo consiguen. Lo conseguirán en los momentos de patio o lo conseguirán en los momentos de educación física o de estar todo el día trabajando de esta otra forma, pues da pie a todos estos valores que yo considero que son valores muy importantes para la vida, pues pueden ir desarrollándolos día a día, hora a hora y en cada asignatura. Y eso es lo rico del aprendizaje cooperativo. Ya no tanto los contenidos, [...] sino todo lo otro" [C1_E.F_D].

Esta cultura colaborativa también está latente en los comentarios de los niños, ya que éstos son conscientes tanto de la ayuda que reciben de sus compañeros como de la ayuda que ellos brindan a sus iguales. "En grupo aprendes más que si estás solo, porque si tienes dudas puedes preguntárselo al grupo y que te las resuelvan [...]. Y tú también les puedes ayudar, si ellos tienen dudas" [C1_E.F_A7]. "Pero hay algunos a los que les cuesta más, pero claro el grupo les ayuda a que lo entiendan" [C1_E.F_A8]. "Si, para aprender de los compañeros" [C1_E.F_A3]. Además, al alumnado también le gusta escuchar las opiniones de sus compañeros. "A mí me gusta trabajar en grupo [...]. Porqué así puedes saber lo que opinan tus compañeros" [C1_E.F_A4]. El estudiante de prácticum también comenta esta relación mutua de ayuda entre iguales, además de remarcar la importancia de las relaciones que se generan con esta manera de trabajar.

"[...] el que menos puede recibe la ayuda de los otros [...]. Se crean vínculos, empatías y eso hace que todos los niños se relacionen ¿no? por así decirlo, que puede haber conflictos, sí. Pero se crea un buen ambiente [...]. Yo creo que es una muy buena forma de trabajar. Porque siempre se ha visto el trabajo de la escuela como un trabajo individual, pero el trabajo en grupo y en parejas lo que hace también es socializar. Te ayuda a interactuar, te ayuda a comprender el compañero. Aporta tus ideas, saber escuchar ¿no? Yo creo que es un poco lo que realmente pasa fuera de la escuela, que fuera de la escuela no estás tú solo y no eres tú solo y el mundo que te rodea sino que es todo, ¿no? es un conjunto que tienes que saber coordinarte para aprender a trabajar creo yo" [C1_E.F_AP].

Resaltar también el liderazgo compartido presente en la organización y la gestión del aula por parte del alumnado. "[...] a partir de ahí es con su organización, primero interna del grupo, mediante diferentes roles $y$ diferentes cargos empiezo a trabajar lo que es en pequeño grupo" [C1_E.I_D]. 


\subsection{Una educación más participativa y abierta: valores democráticos y ciudadanía crítica}

A nivel organizativo del espacio en el aula, destacar que el docente no tiene una mesa para él. "No hay una barrera tan grande entre el docente y los niños, sino que hay una barrera más cercana que se supera, de esa forma $y$ en la que todos hacen que los contenidos lleguen a todos" [C1_E.F_AP]. Este aspecto es un elemento que nos permite ver la posición de horizontalidad entre el educador y el educando.

"No tengo mesa en la clase y no tengo una mesa delante de mis alumnos desde donde hablo y les corrijo los exámenes. Siempre estoy de pie en el aula y siempre estoy con ellos. O puede ser delante explicando cosas, o puede ser paseando y mirando lo que hacen. Si que pienso que a nivel organizativo es algo importante ¿no? que los alumnos ven que el maestro no está sentado en una mesa" [C1_E.I_D].

Así, adopta un papel de acompañante o facilitador en el proceso de aprendizaje de su alumnado, promoviendo en todo momento la participación, el diálogo y la reflexión en su aula. "Procuro que sea el alumnado quien proponga, desarrolle y concrete el trabajo a realizar desde el diálogo y la argumentación de tal manera que yo me voy convirtiendo en un acompañante, facilitador, reforzador, del propio aprendizaje del alumnado" [C1_AM_DO].

La participación y cooperación de los alumnos en el aula es un aspecto difícil de conseguir en un principio. Progresivamente, se les debe ir dotando de confianza y herramientas específicas para que sean más participativos y cooperativos. Así lo manifiesta el maestro:

"Las dinámicas que son cooperativas y que también lo que pretenden es la máxima participación del alumnado y su autonomía poco a poco [...]. Siempre les cuesta porque no están acostumbrados a eso. Así pues, les tienes que ir sacando un poco lo que quieren o los tienes que ir poco a poco dándoles libertad y dándoles confianza para que vean que sí, que lo que ellos dicen o lo que ellos piensan pues se lleva a delante. Si tiene sentido y una argumentación correcta. Y así lo vamos haciendo. Pero cuesta. Y ahora, por ejemplo, en este grupo ya llevo 2 meses y noto los cambios que ha habido, noto las mejoras que ha habido, noto que empiezan a participar muy poco todavía, pero ya empiezan a participar y dar ideas para el grupo y para llevar a cabo cositas" [C1_E.I_D].

Los niños, con sus comentarios, manifiestan cómo está presente su voz y se incrementa su participación en las diferentes propuestas planteadas por el docente. "En muchas cosas como las actividades podemos proponer y el profesor nos dice si podemos hacerla o no, pero tenemos bastante libertad" [C1_E.F_A1]. "Sobre todo los lunes decimos lo que queremos cambiar de la clase y todo [...] Sí, pero luego las opiniones entre todos decimos si nos parecen bien o mal" [C1_E.F_A8]. "El lunes dice: ¿qué cosas pensáis para mejorar la clase?' y le vamos diciendo" [C1_E.F_A6]. "Y te dice que es una semana muy maravillosa porque no la tendemos nunca más" [C1_E.F_A5]. "Opinar y hacer lo que queramos en clase" [C1_E.F_A7]. El alumno de prácticas también constata que el docente tiene en cuenta la voz de su alumnado.

"Los niños tienen voz, tienen voto en la clase y es una forma de acercar los conocimientos a los niños [...]. Sí, es que la tiene en cuenta sí o sí. Porque cada lunes les pregunta a primera hora: ‘¿Qué os gustaría hacer?, ¿Qué no os gustaría hacer?, ¿Hay algo que queréis cambiar?, ¿Algo que no queréis cambiar?’ Y 
realmente yo a principio de curso no estaba, no sé cómo lo planteó pero por lo que me ha contado sí que sé que les hace como un debate y a partir de ahí se decide cómo va a funcionar la clase y después cada cosa que se hace se pregunta, si les ha gustado, si no" [C1_E.F_AP].

El primer día de clase el docente siempre presenta su forma de trabajar al alumnado y se decide de forma conjunta el funcionamiento general de la clase.

"El primer día que entramos en clase para comenzar el curso nos sentamos así en un círculo. Más o menos dijo: 'que quede claro que aquí mandáis vosotros, porque es vuestra opinión y tenéis que decir vosotros que queréis, que no queréis, si queréis que hagamos un ejercicio u otros, si no queréis, mandáis también vosotros, porque la decisión tiene que ser vuestra'. Entonces nosotros opinamos lo que..." [C1_E.F_A8].

Los alumnos comentan que en otras ocasiones hay maestros que no les dejan expresar sus opiniones, como lo hace Manolo. "A veces los otros profesores no nos dejaban hablar de nuestras opiniones mucho y Manolo sí que nos deja [...]. Porque, por ejemplo, J. el año pasado él casi siempre, casi siempre ponía la fecha de los exámenes y nosotros no podíamos opinar. Ahora nosotros la ponemos" [C1_E.F_A5].

Mediante asamblea se promueve que el alumnado dé su opinión. "Hacemos una pequeña asamblea y vamos escogiendo ideas" [C1_E.F_A4]. "Hay veces hasta que nos obliga a que digamos nosotros lo que queremos cambiar de la clase y todo [...]. Bueno no nos obliga, no dice 'ese punto lo tenéis que decidir vosotros' "[C1_E.F_A8].

"Manolo también muchas veces lo dice: 'eso lo hacemos si vosotros queréis, si no queréis no se hace. Pero claro, si os comprometéis vamos a hacerlo. Y eso si queréis que dejamos de hacerlo no lo hacemos'. Y yo creo que a la hora de proponer lo que los alumnos quieren en consenso, la participación es mayor. Es una participación libre, pero eficiente" [C1_E.F_AP].

Otro elemento a destacar es el propósito que tiene el maestro de hacer a sus alumnos más críticos. "Porque tengo en cuenta los contenidos, para que los niños aprendan. Pero desde un punto de vista abierto, donde los niños pueden ser críticos y puedan aportar" [C1_IP.HR_D]. Retomamos la cita extraída de su blog: "[...] es necesario hacerles más críticos. Me gusta que digan la suya, que no asientan y ya está, porque lo dice el maestro. Quiero que sean ellos y ellas las que se den cuenta de lo que tienen que hacer, por qué y cómo, y eso requiere de reflexión, diálogo, debate" (Manolo, 8 de setiembre del 2014). El docente comenta que desde el momento que se les da a los niños la opción de escoger, de valorar, de aportar y de decidir se les está haciendo más críticos.

"[...] desde el momento que les das opción de escoger. Pues desde la fecha del examen que normalmente siempre les digo '¿Cuándo queréis hacer el examen?' $Y$ entre ellos van proponiendo fechas $y$ van dando argumentos y escogen qué día hacen el examen. Pues siempre que les das opción a escoger, a poder decidir o dar alguna cuestión, les estas ayudando a ser más críticos ¿no? y a saber optar y tener que tomar una decisión, todo eso es hacerles críticos, claro que sí" [C1_E.F_D].

Este rasgo también se ve presente en la evaluación, ya que los niños deciden que ítems evaluar y que calificación otorgar. "A ver, estamos tomando nota de todo lo que estamos diciendo. Si hay algún compañero que no está de acuerdo con lo que sus compañeros dicen, por favor que lo diga: 'yo pienso que eso no hay que valorarlo. Yo 
pienso que eso deberíamos hacerlo así. Decidlo ¿eh?” [C1_O_NC]. También en la manera de resolver los conflictos dentro del grupo para llegar al consenso. "[...] Pero si hay un conflicto, como por ejemplo del grupo que no se entienden o uno quiere decir una cosa y el otro no. Trata de decir, apañaros que sois un grupo, apañaros. La propuesta que tenéis que hacer es de grupo" [C1_E.F_AP].

En cuanto a la participación de la familia en el aula, hay que destacar que no se materializa prácticamente hasta que los niños cursan el segundo año con el maestro, es decir, hasta $6^{\circ}$ de primaria.

"Me ha explicado lo de las exposiciones de los libros. Quiere hacer que participen las familias, que vengan a ver como los niños lo hacen. También me ha dicho que le gustaría que si en algún tema algún abuelo, por ejemplo, o alguna madre o algún padre pueden venir a explicar su experiencia o a ver de qué manera podrían hacer una charla sobre aquello que están tratando. Le gustaría que participaran, pero sabe que tampoco es fácil, sabe que todos no pueden venir. Le gustaría que viniesen todos. Pero sí que me ha comentado aquellas cosas que si que querría hacer. Por ejemplo, me ha comentado que vino un abuelo a hablar de cómo se hacían las películas antiguamente, cómo se rodaban, cómo se proyectaban. Y que es una cosa que les gustó y que si hubiera otra situación parecida de que una persona de la familia pudiera aportar algo, le gustaría traerla al aula. Pero que no se ha dado tampoco el caso" [C1_E.F_AP].

Por otro lado, los niños manifiestan que les gustaría que las familias participaran en el aula. "[...] me gustaría que en una 'tertulia' viniesen nuestros padres y pudiesen hacer la 'tertulia' con nosotros" [C1_E.F_A1]. "Porque, por ejemplo, en el 'teatro' de los niños ha dicho Manolo, que si queríamos, que un día podía venir nuestro abuelo a contar, por ejemplo, un cuento tradicional o eso" [C1_E.F_A4]. "Porque comentamos en Manolo que los abuelos son los que mejor lo hacen" [C1_E.F_A8].

Al hilo de lo anterior, el docente explica que cuando el alumnado está en $5^{\circ}$ invita a las familias de una manera más informal.

"Es una toma de contacto, que a lo mejor me debería abrir ya, si me debería abrir ya en $5^{\circ}$ y que empezaran a participar, pero tampoco quiero hacerme pesado. Porque yo también soy padre y cuando en la escuela te invitan pues está muy guay, pero si tienes que ir por obligación. ¡Buff! dices: 'vaya, ¿eso no es faena del maestro? A mí que no me llamen' ¿no?” [C1_E.F_D].

Por tanto, el docente suele invitar a las familias de manera más explícita en 6o de primaria. "Les invitaré de una forma más explícita y más concreta [...]. Sí, es así cómo lo suelo hacer, que lo hago más en el segundo año que estoy con ellos [...]. Les propongo que vengan a la 'tertulia', les propongo que vengan a los 'grupos interactivos', a las 'exposiciones' de los alumnos" [C1_E.F_D].

Por la información disponible, sabemos que otros años atrás las familias ya han participado en la clase de Manolo.

"En los 'grupos interactivos', estuvimos un par de meses con padres y bien, pero también se cansan [...]. En matemáticas, los 'grupos interactivos' lo hago en matemáticas. Pero se cansan. De hecho, hubo una madre que me dijo 'Manolo, las semana que viene yo no vendré'. Y estuvieron 7 o 8 semanas viniendo. En 'exposiciones de libros', hubo mucha participación, muy bien porque al principio venían los padres de los 
niños que exponían, pero después quedaban o venían, hasta cuando no le tocaba a su hijo porque le gustaba. Y hubo algunas semanas con 10 o 12 familias o padres de diferentes niños, veían las exposiciones. Y en la tertulia, ahí siempre me ha venido poca gente, son horarios complicados por las mañanas, ha de ser gente que no trabaje, que le guste leer, porque sino pues ya no vienes. Entonces pues sí, he tenido 2 madres que recuerdo yo que vinieron un año" [C1_E.F_D].

El maestro plantea estos aspectos relacionados con la participación familiar en la reunión inicial. "Ellos desde principio de curso lo saben, lo que vamos a hacer, les digo las actividades que haremos y les invito" [C1_E.F_D]. Al preguntar al docente si las familias pueden proponer proyectos o actividades para que se realicen en el aula este dice que sí. "Sí, lo que pasa es que no lo han hecho hasta ahora" [C1_E.F_D]. Por lo que respecta a su valoración en cuanto a la implicación de las familias, explica que suele ser muy positiva, aunque siempre vienen las familias de los niños que menos lo necesitan.

"Pues pasa lo mismo que suele pasar en todos los sitios y en todas las escuelas. Normalmente, en general, hay casos que cambian ¿no? Pero en general las familias más implicadas suelen ser las de los alumnos que tienen menos necesidad y de las que deberían tener más necesidad o que estaría chulo que los acompañaran más, no suele haber tanta participación. Pero hay casos concretos de...estoy pensando en niños y niñas. Qué niños y niñas que realmente necesitaban el acompañamiento de la familia que se sentían reforzados, vinieron ¿no? y eso les hace sentir muy bien" [C1_E.F_D].

\subsection{Reflexión continúa sobre su propia práctica docente}

El docente continuamente reflexiona sobre su práctica cotidiana en el aula, y plantea propuestas de mejora para llevarlas a cabo en los futuros cursos.

"Pienso que todos los años voy aprendiendo cosas [...] año a año me voy dando cuenta de qué he hecho bien de que no. Pues hay veces que veo que soy demasiado exigente y me olvido un poco de que son niños de 10 años. Pienso que podrían hacer las cosas mejor y no las hacen. $Y$ otras veces que tengo comportamientos míos, particulares con ellos, que yo pienso que son buenos y me doy cuenta que tampoco he de ser tan estricto [...]. Por ejemplo, a mi no me gusta hacerlos caso ni contestarles, cuando me preguntan cosas que pienso que ellos saben o que ellos son capaces de resolver. Y a veces soy demasiado cerrado en ese sentido de decir: 'pues no le voy a contestar, no le voy ni hacer caso'. Y el niño pues incluso a veces se siente como desorientado ¿no? '¿Y ahora qué hago? ¡Manolo está enfadado! No está enfadado,...' ¿Se lo vuelvo a preguntar, no se lo vuelvo a preguntar?' Se queda como ahí...y a veces veo yo que soy demasiado estricto que debería... y que son niños de 10 años y que tampoco hay que pasarse. Pero pienso que les va bien ${ }_{j} E h !$, que les va bien porque suelen ser niños o en este grupo particularmente, que están muy acompañados, les hace falta también un poco de ser capaces de ir funcionando ellos solos dentro de sus limitaciones, ¿no? y dentro de la edad que tienen. Pero sí, claro que sí, que hay cosas que se pueden mejorar siempre. jPor supuesto!" [C1_E.I_D].

Además, el docente piensa que es demasiado crítico consigo mismo.

"La verdad es que soy demasiado crítico conmigo mismo. Tengo los dos extremos yo me doy cuenta. Un extremo es de decir: 'Va eso ya está bien, seguimos por aquí. ¿Para qué voy a cambiar nada?' y el otro 
extremo de decir 'Buff, eso no me gusta nada a ver cómo lo hago, me disgusto, me despago porque veo que no ha salido como tenía que salir, y a ver si...' A lo mejor ni una cosa es así ni la otra cosa es esa. Pero me veo yo que tengo estos dos extremos. Y una cosa que si, una propuesta de mejora a nivel personal que tengo que hacer es a nivel de programación, respetar mucho más el tema de programación del curso, porque hay veces, en alguna área voy muy a lo que va surgiendo y cosas que a lo mejor, no sé si serán o no importantes pues o me las salto, o me las dejo o me las olvido o no las hago o no las tengo programadas y esto no está bien" [C1_E.F_D].

Seguidamente en la Figura 6, se presenta un esquema relacional de las creencias, actitudes y valores que sustentan la acción docente del primer caso objeto de estudio. 


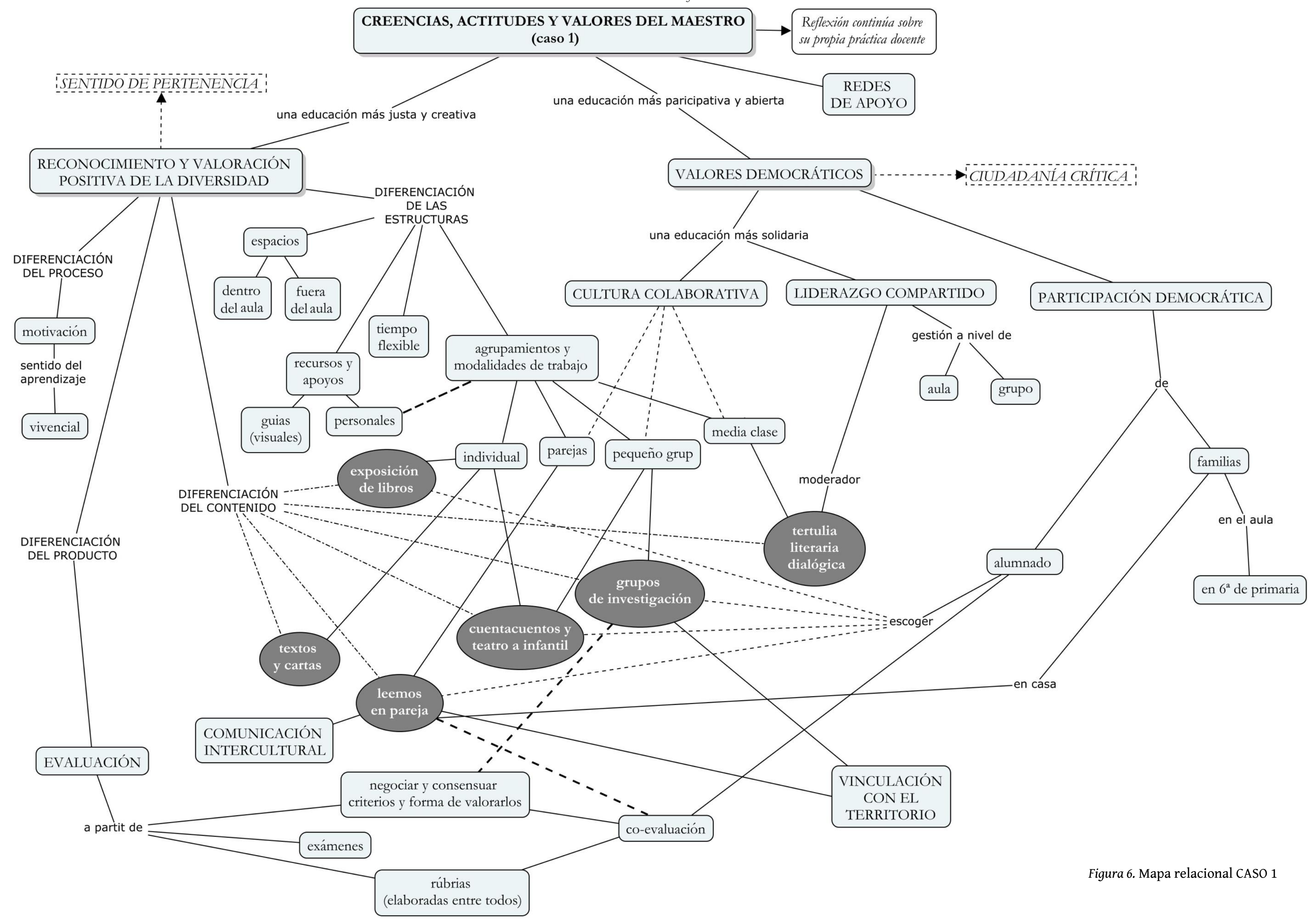

$\sim$ Diferenciación pedagógica y participación democrática en el aula inclusiva: estudio de casos múltiples 165 



\subsubsection{Caso 2: Mati y Amèlia}

A continuación, se va a abordar el caso 2, el de Mati y Amèlia. Primeramente, se hace una descripción de las prácticas didácticas y después se comentan las creencias, actitudes y valores que subyacen en su forma de trabajar en el aula.

\subsubsection{Desarrollo de prácticas diferenciadas y democráticas}

\subsection{Contexto general: localidad y centro educativo}

El municipio de Betxí está situado al pie de la Sierra de Espadán y forma parte de la comarca de la Plana Baixa (Castellón). La localidad cuenta con una población de $5.770^{17}$ habitantes, procediendo aproximadamente una quinta parte de ésta de movimientos migratorios de los años 60 y 70 . Además, la zona ha recibido inmigración procedente de Rumanía y Marruecos, tal como se refleja en las aulas del centro educativo.

El municipio cuenta con diferentes servicios y asociaciones que están presentes en la vida del centro, destacando: la Escuela de Personas Adultas (E.P.A.) de Betxí, la Biblioteca Municipal, la Escuela de Música, el Ayuntamiento, centro cultural, entre otras.

Hay que remarcar también que, a causa de la crisis económica, se ha incrementado notablemente el paro, debido al cierre de algunas fábricas de azulejos y almacenes de naranjas. Esto ha tenido repercusiones en el incremento de la participación de los padres en el centro educativo pudiendo implicarse en las diferentes propuestas que se llevan a cabo. No obstante, como algunas familias trabajan en la recolección de cítricos, tratándose de empleos temporales, la participación no es constante a lo largo de todo el curso académico.

El CEIP Cervantes Dualde es el único centro público de educación infantil y primaria de la localidad. El centro cuenta con 6 unidades de $2^{\circ}$ ciclo de educación infantil y 14 de educación primaria con un total de 463 alumnos, aproximadamente un 15\% son de origen inmigrante. Todas las líneas son en valenciano.

A pesar de que se presenta como un solo caso, éste está constituido por dos aulas de educación primaria: la clase de Mati $\left(2^{\circ} « A »\right)$ y la clase de Amèlia $\left(2^{\circ} \ll B »\right)$. Es importante señalar que, ya hace más de 23 años que ambas trabajan de manera conjunta, compartiendo y reflexionando sobre una misma filosofía educativa y siguiendo una línea de trabajo común.

\subsection{Los miembros de la clase: las maestras y su alumnado}

En cuanto a la experiencia docente remarcar que Mati hace 31 años que trabaja como maestra y concretamente 14 en la etapa de educación primaria, habiendo trabajado anteriormente en educación

17 Según datos del 2014 del Instituto Nacional de Estadística. 
infantil. Por su parte, Amèlia tiene un año más de experiencia, es decir, ha trabajado 32 años como docente y de éstos 15 los ha dedicado a educación primaria y el resto a infantil. Por lo que refiere a la titulación académica, Amèlia explica: "Cuando yo hice magisterio había tres ramas: ciencias, filología y humanidades. Yo hice ciencias, pero después hice la especialidad de educación infantil" [C2.2_E.I_D2]. Mati añade: "Yo hice la de filología inglesa, hice la especialidad de infantil y ahora estoy trabajando en primaria" [C2.1_E.IDD1]. Además, ambas continúan realizando diferentes cursos de formación continua, por ejemplo, la última formación realizada versa sobre la educación emocional en el aula, tema por el que actualmente las maestras están muy interesadas. Además, las dos docentes tienen una participación regular y desde sus orígenes en el Seminario de Ciudadanía Crítica: por una escuela intercultural e inclusiva ${ }^{18}$, que se desarrolla des de hace 10 años en el Departamento de Educación de la Universidad Jaume I de Castellón. Dicho seminario surgió a raíz de que un grupo de docentes de diferentes niveles educativos coincidieran en los cursos Prácticas inclusivas: más allá de la integración (2005) y Estrategias didácticas, organizativas y sociocomunitarias para una ciudadanía crítica (2006) organizado por la Consellería, el CEFIRE y la Universitat Jaume I. A lo largo del curso académico se realizan unas 5 o 6 sesiones, en las cuales los diferentes integrantes que asistimos al seminario compartimos experiencias y los trabajos que llevamos a cabo durante cada curso escolar.

En el aula de $2^{\circ}$ «A», hay un total de 28 alumnos (15 niñas y 13 niños). La maestra reconoce la diversidad de su alumnado.

"Este año tengo un alumno recién llegado de Marruecos que no entiende el castellano ni el valenciano. A este niño le correspondería estar en tercero [...]. Hay otro niño recién llegado, es rumano. Entiende el castellano, el valenciano lo entiende, pero no lo habla. Le cuesta más la lectura y la escritura en valenciano, porque me dice que hay letras que no las conoce, y claro también tiene un poco de retraso [...]. Después, hay tres niños que van a atención educativa, que son retrasos madurativos (presentan problemas de memoria y atención). Hay un cuarto que también va que ya es un tema un poco más grave, muy bien todavía no sabemos qué problema tiene" [C2.1_E.I_D1].

Además, hay 9 niños cuyos padres se han divorciado, lo que hace que algunos tengan unas condiciones familiares problemáticas o difíciles. Esto repercute gravemente en su mal comportamiento en el aula, ya que buscan constantemente llamar la atención. En suma, nos encontramos con un aula formada por 11 niños con excelentes resultados académicos y el resto de los alumnos presentan diferente nivel de dificultad de aprendizaje.

En el aula de $2^{\circ}$ «B», hay un total de 27 alumnos (16 niñas y 11 niños). Amèlia, por su parte, también reconoce la diversidad presente en su aula.

"Hay dos alumnos que asisten a atención educativa, uno de ellos este año estoy viendo que está evolucionando bastante bien, estoy contenta. A lo mejor sería necesario mirar y hablar con la psicopedagoga. La otra niña sí que está diagnosticada, no tiene ninguna etiqueta, pero es una niña que de

\footnotetext{
${ }^{18}$ Web del Seminario de Ciudadanía Crítica http://ciutadaniacritica.blogspot.com/
} 
razonamiento está muy bajita y le cuesta. Esa es la única niña que se queda un poco más descolgada. Después hay, pues, las diferencias que hay en todas las aulas, los que no necesitan mucho para avanzar y otros que necesitan una segunda explicación o una segunda ayuda" [C2.2_E.I_D2].

La alumna que presenta un nivel de razonamiento bajo, tiene problemas de espalda por lo que lleva un corsé y tiene una adaptación de madera para la mesa. Es una niña que se esfuerza mucho y la familia está muy implicada.

Es importante mencionar que no es extraño encontrar, en ambas aulas que conforman este caso, otras personas o agentes comunitarios implicados en los quehaceres del aula, muy especialmente en los proyectos de trabajo, en los cuales siempre acude un entendido en la materia. En los proyectos de trabajo, la colaboración y participación, en el aula, de las familias es mayor en primero de primaria que en segundo. "En primero tienes que ayudar mucho más y no llegas a todos, alguna tarde vinieron algunas madres" [C2.2_E.F_D2]. Además, las familias también tienen un papel muy destacado en las otras metodologías que proponen las maestras. Ya hace 8 años que las maestras promueven la participación de las familias, de manera regular, en su aula. Aunque en los proyectos de trabajo prácticamente siempre han recurrido a algún familiar o experto en la materia. "Cuando yo pasé aquí a primaria, ya recuerdo que nos salió el de la electricidad y ya vino un padre" [C2.2_E.F_D1].

\subsection{La gestión general del aula}

En el aula utilizan diferentes formas de agrupamiento, lo que permite variar la manera de abordar los conocimientos.

"A veces haces el grupo clase, otras veces hacemos el trabajo por parejas, trabajo individual también hacemos y en pequeños grupos también. No sé si lo hacemos en más o menos intensidad, porque depende de qué actividad pero sí que vemos que cuando trabajamos por parejas, se ayudan, intercambian, interactúan porque aprenden. Les haces ayudarse entre ellos y eso sí que lo utilizamos bastante. La clase expositiva como tal no la utilizamos, pero trabajar en gran grupo lo hacemos muchas veces. Procuro partir siempre de lo que ellos saben y cuando vas a explicar un contenido no te pones tú a explicarlo, sino que les haces preguntas: ‘¿Alguien ha escuchado hablar de...? ¿Alguien sabe lo que es eso?’ Y ellos cuentan si lo han escuchado, su experiencia, en qué momento y de ahí tú vas sacando para que puedan llegar a comprenderlo. No haces la explicación desde tu punto de vista, vas sacando de ellos, procuras. La mayoría de veces lo hacemos asi" [C2.2_IP.HR_D2].

El hecho de trabajar en pareja o pequeño grupo genera un ambiente sonoro de aula que va in crescendo.

"Están sentados por equipos. Porque claro, ellos se ayudan, interactúan, lo que no dice uno lo dice el otro, él me ha dado una pista, y tal. Entonces esa interacción te gusta y no te sabe mal de que estén... pero que pasa que a veces eso también crea un,... que dices a ver, y no sabes cómo crear un trabajo más tranquilo y a veces gastas la autoridad [...]. Otras veces, les pones un poco de música, les dices vamos a relajarnos un poco [...]. Quiero decir que tampoco hacemos nada que habitualmente pienso que la 
mayoría no haga. Pero va bien, a mí me gusta que estén en grupo, comparten el material, tienen la bandeja y se hacen cargo de todos, cada uno sí que tiene su lápiz en particular para que controlen un poco y no se pierda, que lo tienen que cuidar y tal. Lo que hacemos es que cada tres semanas cambios (de grupo). Ellos cogen un papelito y donde les toca para que estén sentados con todos, para que sea con quien me ha tocado [...] y así de cada tres semanas hacemos cambio de mesas y según el número que les ha tocado van situándose, a veces van bien porque ha tocado un grupo tranquilo y otras veces el grupo llega un momento que dices no...[...] Pero bueno normalmente no, normalmente conforme se sientan están. Si no hay ningún conflicto muy,..." [C2.2_E.I_D2].

Hay que resaltar que en ambas aulas, cada día, hay dos encargados diferentes que se encargan de gestionar las tareas que precisa el grupo (repartir libretas, colores, anotar el resultado de una votación,...). En el aula hay un listado con el nombre de los alumnos, en la cual van poniendo diferentes gomets para marcar a quienes les toca ser los encargados del día.

\subsection{Metodologías de trabajo: diferenciación pedagógica}

La principal metodología que utilizan son los proyectos de trabajo. Con esta metodología se abordan de manera significativa todas las áreas instrumentales del currículum, además de la educación artística. Es necesario remarcar que en ambas clases no trabajan con libros de texto, pero sí que tienen unos cuadernos de matemáticas y lengua, la ejecución de los cuales se va alternando con las diferentes propuestas metodológicas. Éstas son: los grupos interactivos, el cuentacuentos a infantil y los talleres internivel.

Seguidamente, se presentan de manera pormenorizada dos proyectos: el de la Prehistoria llevado a cabo en el $2^{\circ}$ trimestre del curso académico 2014/2015 en el aula de $2^{\circ}$ «A» y el proyecto de ¿Cómo pasa el tiempo? Betxí, nuestro pueblo, realizado en el $3 \mathrm{r}$ trimestre, de dicho curso, en el aula de $2^{\circ}$ «B». Posteriormente, se pasa a describir de manera conjunta, esto es, sin hacer distinciones entre ambas aulas, pero indicando en todo momento la procedencia de la fuente de información, las prácticas educativas referentes a los grupos interactivos, el cuentacuentos a infantil y los talleres interciclo.

\subsection{Proyectos de trabajo}

Normalmente, se realizan tres proyectos a lo largo del curso académico, uno por trimestre. Durante el curso académico 2014/2015, el alumnado de $2^{\circ}$ "A» ha estudiado: los egipcios, la prehistoria y los insectos. Por su parte, el alumnado de $2^{\circ}$ «B» ha trabajado: los minerales, los egipcios

y Betxí. Éste método da la oportunidad de centrarse en las destrezas o habilidades de cada uno de los alumnos, lo que permite dar respuesta a sus necesidades y motivaciones.

"El proyecto gira alrededor del tema que ellos eligen en asamblea. Ese tema es lo que diríamos el hilo conductor: la motivación. Hay varias fases en el proyecto y la primera es buscar información y eso les motiva mucho. Cuando traen información, la explican a los demás, a su manera, tú también les ayudas. Porque ellos, muchas veces esa información no saben transmitirla, [...] hay mucha información que ellos 
no pueden asimilar todavía. Pues vas extrayendo un poco esa información que traen, les vas tirando un poco del hilo o vas concretando toda esa información que puede servir, que es una idea sobre... Y eso les motiva y alrededor de ese proyecto vamos trabajando otras cosas. Digamos que es la excusa, a través de las ganas de aprender sobre esa cosa hacemos un proceso un poco de investigación. En la excusa del proyecto necesitamos que venga gente a explicarnos, y tenemos que escribir textos para invitar a ver si esa gente puede venir. Y entra alguien en el aula y eso a ellos les gusta mucho. Y siempre procuras que vengan, alguien, algún padre, algún conocido que sabe sobre ese tema. $Y$ eso es otra forma, porque cuando viene el padre, el entendido o viene el experto ya no eres tú la que explica, ya es otra persona que dice otras cosas y ellos preguntan y ellos introducen otras formas de que el conocimiento llegue al aula, no sólo porque lo dice el maestro" [C2.2_E.I_D2].

Después de esta clara y concisa explicación que nos enmarca, de forma general, la manera en que llevan a cabo los proyectos de trabajo, se hace un recorrido deteniéndonos en cada una de las principales etapas de ambos proyectos desarrollados.

\subsection{La prehistoria: el origen del ser humano}

Antes de empezar cada sesión se suelen hacer algunos ejercicios de relajación. La maestra les dice a los alumnos: "Espalda recta, mano en la barriga y cerramos los ojos. Cogemos aire y notamos como nos llega a la barriga y expulsamos. Lo repetimos 3 veces" [C2.1_O_NC]. Seguidamente, hacen el masaje de la concentración, el cual consiste en masajearse las cejas con un dedo repitiendo: "ponemos intención en aprender mucho, estar atentos en clase y ser felices" [C2.1_O_NC]. Estos ejercicios se efectúan con el objetivo de mejorar el clima del aula.

Las principales fases o etapas del proyecto de «la prehistoria» por las cuales se hace un recorrido para explicar cómo lo han realizado son:

$\sim$ Elección de la temática a trabajar: asamblea de clase y escritura del acta

¿Qué sabemos y qué queremos saber?

$\sim$ ¿Qué tenemos que hacer?: Planificación del trabajo

$\sim$ La mesa de la información: búsqueda y exposición de los contenidos encontrados

$\sim$ La experta en paleontología: Lola la historiadora

$\sim$ Distribución de las tareas: trabajo en equipo para la elaboración del dosier

$\sim$ Escritura de notas para solicitar ayuda y colaboración en el proyecto

$\sim$ Reseña para la revista del centro

$\sim$ Preparación y exposición de lo aprendido a las familias y compañeros

$\sim$ Evaluación del trabajo realizado

\section{Elección de la temática a trabajar: asamblea de clase y escritura del acta}

En asamblea el alumnado decide la temática que va a trabajar en el siguiente proyecto. Previamente a esta sesión, la maestra les indica que deben pensar y reflexionar sobre qué es lo que les interesaría aprender. Cada alumno lleva su propuesta escrita, los que improvisan en la sesión son los 
menos, de esta manera se favorece la reflexión. Los alumnos ven la asamblea como un órgano de decisión colectiva y de consenso. "Hacemos la asamblea para ver lo que queremos estudiar [...] podemos escoger y después votar" [C2.1_E.F_A4]. "Porque si no, no sabemos ni que estudiar" [C2.1_E.F_A5]. "Para la asamblea nos cogemos nuestras sillas y nos ponemos en un círculo muy grande y después nosotros decimos: yo quiero estudiar, por ejemplo, la prehistoria" [C2.1_E.F_A6].

El hecho que los alumnos puedan elegir la temática sobre aquello que quieren estudiar y que adopten un papel activo en todo el proceso les despierta la curiosidad y el interés. "El interés, de ellos mismos de decir: 'Yo voy a investigarlo, yo voy a averiguarlo'. Claro, de la otra manera dirían léete eso y sabrás muchas cosas" [C2.1_E.F_M2].

Los dos encargados, de ese día, dan los turnos de palabra y anotan en una hoja las diferentes temáticas que proponen sus compañeros. Además, cada alumno debe explicar o justificar el motivo de su elección. En el Cuadro 1, se recogen algunos de los temas que propusieron en la asamblea.

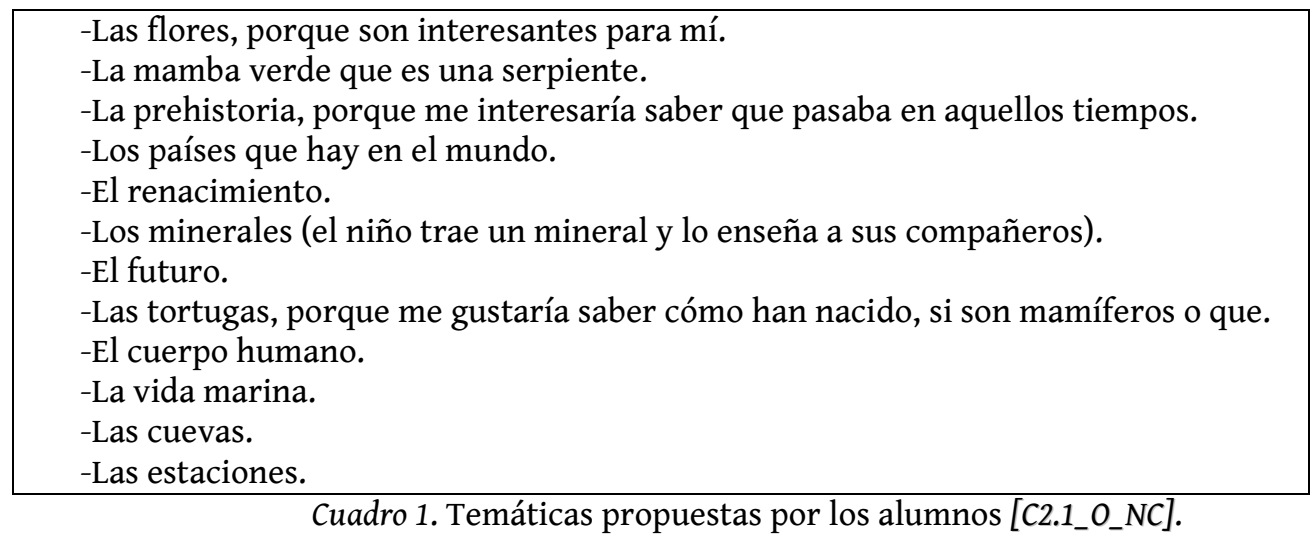

Es importante remarcar que en algunas ocasiones la temática es propuesta por la maestra, como por ejemplo el proyecto de los insectos del 3r trimestre del curso 2014/2015. "Este tema no lo hemos escogido nosotros, lo ha dicho Mati, es una propuesta porque el abuelo de I. vino a enseñarnos una colmena de cristal" [C2.1_E.F_A7]. Esto es, un abuelo de un alumno había fabricado una colmena de cristal para ver como las abejas fabrican la miel, por esa razón la maestra les propuso ese tema para estudiarlo e invitar al abuelo en cuestión. "Íbamos a hacer las abejas, pero como había gente que no quería. Por mayoría, escogimos los insectos" [C2.1_E.F_A2]. "Teníamos que votar entre no estudiar los insectos o estudiarlos. Y al final fue más estudiarlos que no estudiarlos" [C2.1_E.F_A1].

Los alumnos prefieren proponer ellos los temas a estudiar y entre todos escoger uno. "A mí me gusta más decirlo yo, porque por ejemplo a muchos de la clase esa propuesta no les gustaba mucho, pero ha tenido buen resultado. Al principio no te gusta y dices: 'A mí no me gustan los insectos'. Pero después cuando terminas de estudiarlos ya te gusta más, jcomo ya sabes más cosas!" [C2.1_E.F_A7]. "A mí me gusta cuando lo dice cada niño [...]. Pero aun así, el de los insectos me ha gustado" [C2.1_E.F_A2].

Una vez todos los alumnos han propuesto las temáticas que quieren estudiar, los encargados las anotan en la pizarra y se someten a votación. "Mati les dice a los niños que tienen que escoger cada uno una propuesta, aquella que piensan que van a aprovechar más" [C2.1_O_NC]. A la asamblea asisten 25 alumnos. "A. el 
alumno inmigrante no vota. Mati les dice que no pasa nada, que todavía no los entiende muy bien. Por tanto, en la clase, en esta sesión hay 25 alumnos, pero como A. no vota hay un total de 24 votos" [C2.1_O_NC]. La opción más votada es «la prehistoria» con 11 votos, seguida de la vida marina (4 votos), los minerales y el renacimiento (ambos temas con 3 votos) y la mamba verde, el futuro y los países (1 voto cada uno).

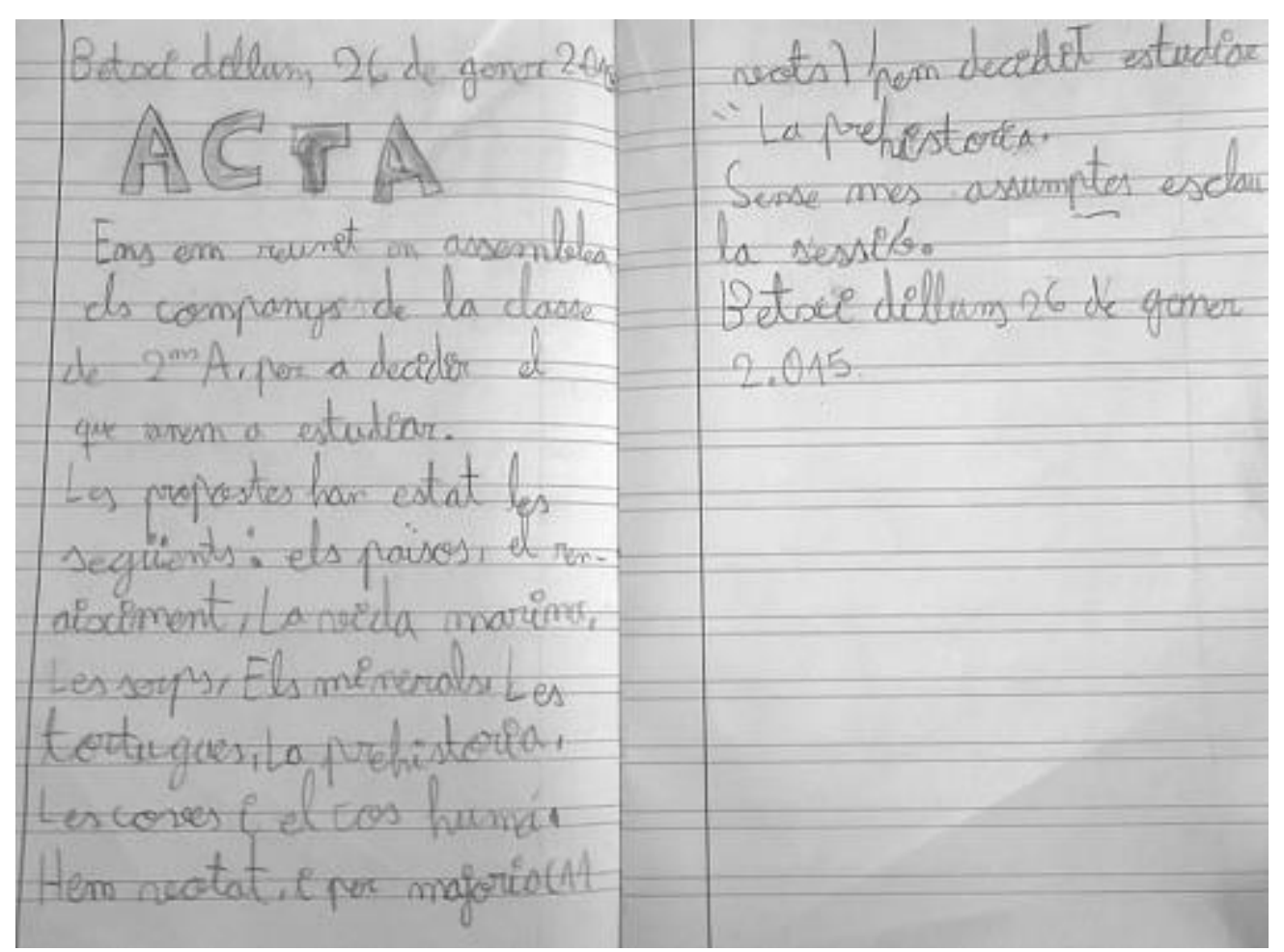

Imagen 23. Acta de la asamblea [C2.1_AM_FOM].
Al terminar la asamblea, entre todos escriben el acta de la sesión (Ver Imagen 23). La maestra va escribiendo en la pizarra lo que van acordando y cada alumno lo copia en su libreta. Lo van escribiendo al dictado, ya que esto da la oportunidad de revisar $y$ corregir las faltas antes de escribirlas.

"La maestra va borrando las primeras líneas de la pizarra, deja las últimas para los alumnos que van más retrasados. Entra la maestra de pedagogía terapéutica, ayuda al niño inmigrante y a dos o tres más a escribir el acta" [C2.1_O_NC]. Cabe subrayar que a lo largo de las diferentes sesiones del proyecto las maestras de pedagogía terapéutica y audición y lenguaje, a veces, no se llevan al niño a la clase de apoyo, otras veces sí. Depende de la actividad que están haciendo. En otras ocasiones la maestra de audición y lenguaje al ver que los niños están trabajando en el proyecto se marcha dejando al alumno participar del mismo.

Para solicitar la ayuda y colaboración de las familias en el proyecto, una vez conocen la temática a trabajar, el alumnado les escribe una nota informativa en la agenda. En el Cuadro 2. se presenta un ejemplo de nota.

Padre y madre:

Vamos a estudiar «la prehistoria», por favor ¿nos podéis ayudar a buscar información? Gracias.

Cuadro 2. Nota para las familias [C2.1_O_NC].

De esta manera, las familias quedan informadas sobre la temática que van a estudiar sus hijos. "Los padres en todo lo que podemos pues ayudamos; primero en aportar información sobre el tema que nos dice la maestra" 
[C2.1_E.F_M2]. "Sobre todo en aportar información, por casa buscarla: libros, cuentos... todo lo que encontramos por Internet también, para que los niños se involucren un poco a la hora de saber dónde tienen que buscar y de donde tienen que sacar la información" [C2.1_E.F_M1].

\section{¿Qué sabemos y qué queremos saber?}

Previamente, en una primera sesión, el alumnado reflexiona sobre todos los conocimientos previos que tienen sobre la temática escogida para trabajar, es decir, «la prehistoria». Los encargados reparten las cajas del material (cada caja está identificada en un color, el cual coincide con el color de cada una de las mesas) y las libretas a cada uno de sus compañeros para proceder con la escritura, al dictado, de todo aquello que ya saben sobre dicha temática. Los alumnos van proponiendo sus ideas acerca de lo que saben y la maestra lo va anotando en la pizarra (Ver Imagen 24).

"La maestra se va dirigiendo a los alumnos que van más lentos y les cuesta más

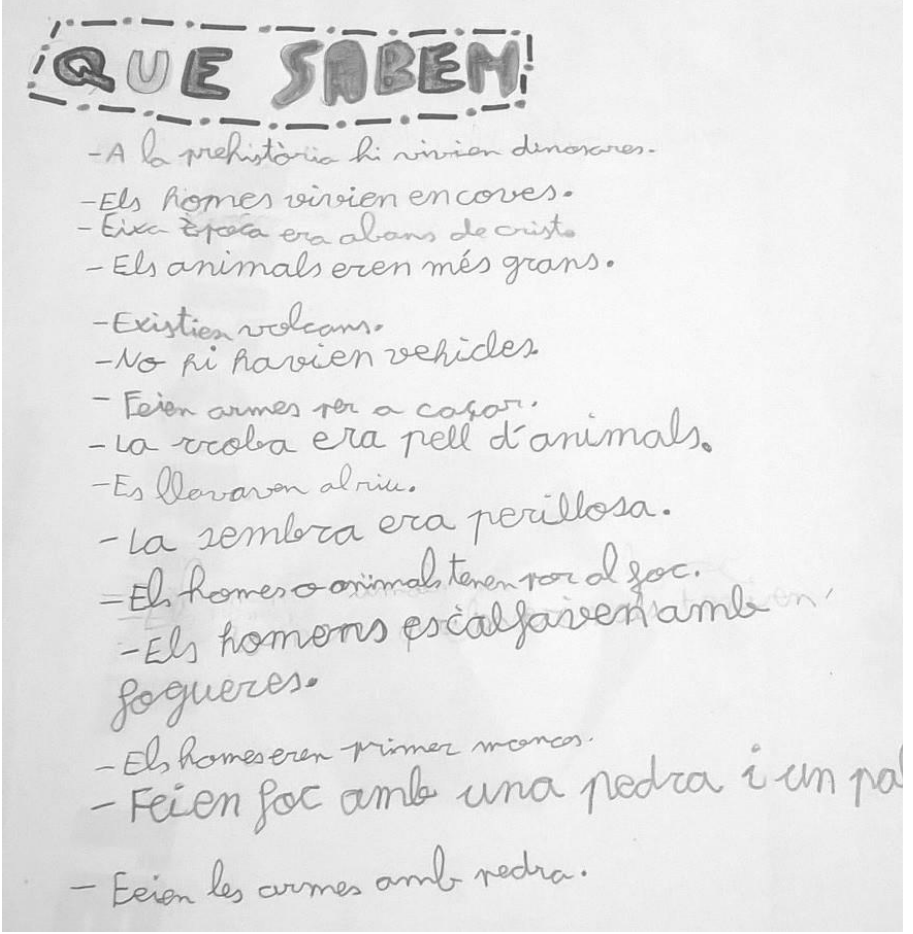

Imagen 24. ¿Qué sabemos de «la prehistoria»? [C2.1_AM_FOM]. para ver por dónde van. '¿I. tú has escrito la fecha cariño?' La docente va borrando las primeras líneas de la pizarra, deja las últimas para los alumnos que van más retrasados. Van comentando como se escriben algunas palabras. Por ejemplo, les sale la palabra volcán. La maestra dice que no hace falta recordar cómo se escribe, porque el curso pasado hicieron un proyecto sobre los volcanes. Regresan 3 alumnos que estaban en el aula de apoyo con la maestra de pedagogía terapéutica. Ahora sale I. y se va con la maestra de pedagogía terapéutica" [C2.1_O_NC].

Con el trabajo por proyectos se parte de los conocimientos previos del alumnado. Asimismo, al terminar el proyecto se vuelve a las afirmaciones emitidas por el alumnado para comprobar si las hipótesis que dijeron eran o no correctas.

"La maestra les dice que ya tienen muchas ideas, quien termina colorea el título y coge el cuaderno de matemáticas. Trabaja cada uno a su ritmo. Los alumnos que terminan las hojas del cuadernillo de matemáticas hacen unas multiplicaciones que Mati ha escrito en la pizarra, estas multiplicaciones no las harán todos los alumnos de la clase, sólo unos pocos, los que van más rápido. Al terminar la sesión la maestra felicita a dos mesas por lo bien que han trabajado, estas son las primeras en bajar al patio" [C2.1_O_NC]. 
En otra sesión, el alumnado reflexiona sobre aquello que quiere aprender de la temática escogida. La maestra va escribiendo en la pizarra las preguntas planteadas por el alumnado. Cada alumno escribe en su libreta las preguntas formuladas. Siguen la misma dinámica explicada en el ¿Qué sabemos? A continuación, en la Imagen 25, se presentan los interrogantes que quieren responder los alumnos de $2^{\circ}$ «A» en relación a «la prehistoria».

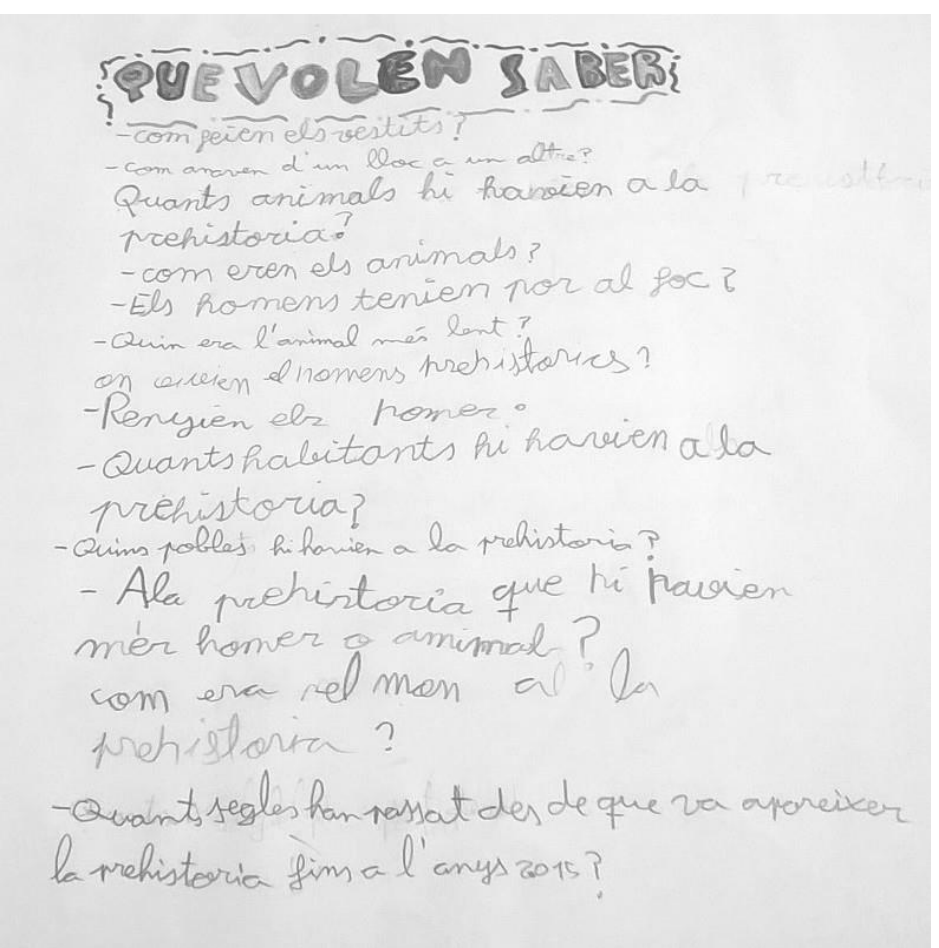

Imagen 25. ¿Qué queremos saber? [C2.1_AM_FOM]

\section{$\sim$ ¿Qué tenemos que hacer?: Planificación del trabajo}

En esta fase se reflexiona sobre la planificación, esto implica una organización del trabajo en el tiempo. Entre todos comentan que es aquello que necesitan hacer para llevar a cabo el proyecto, es decir, determinan las principales tareas. Van explicando entre todos y la maestra lo anota en la pizarra, cada alumno lo copia en su libreta. A lo largo del trabajo, el alumnado, recurre a la planificación para ver que han hecho y que tienen pendiente. A continuación, en la Imagen 26, se muestra un ejemplo de planificación.

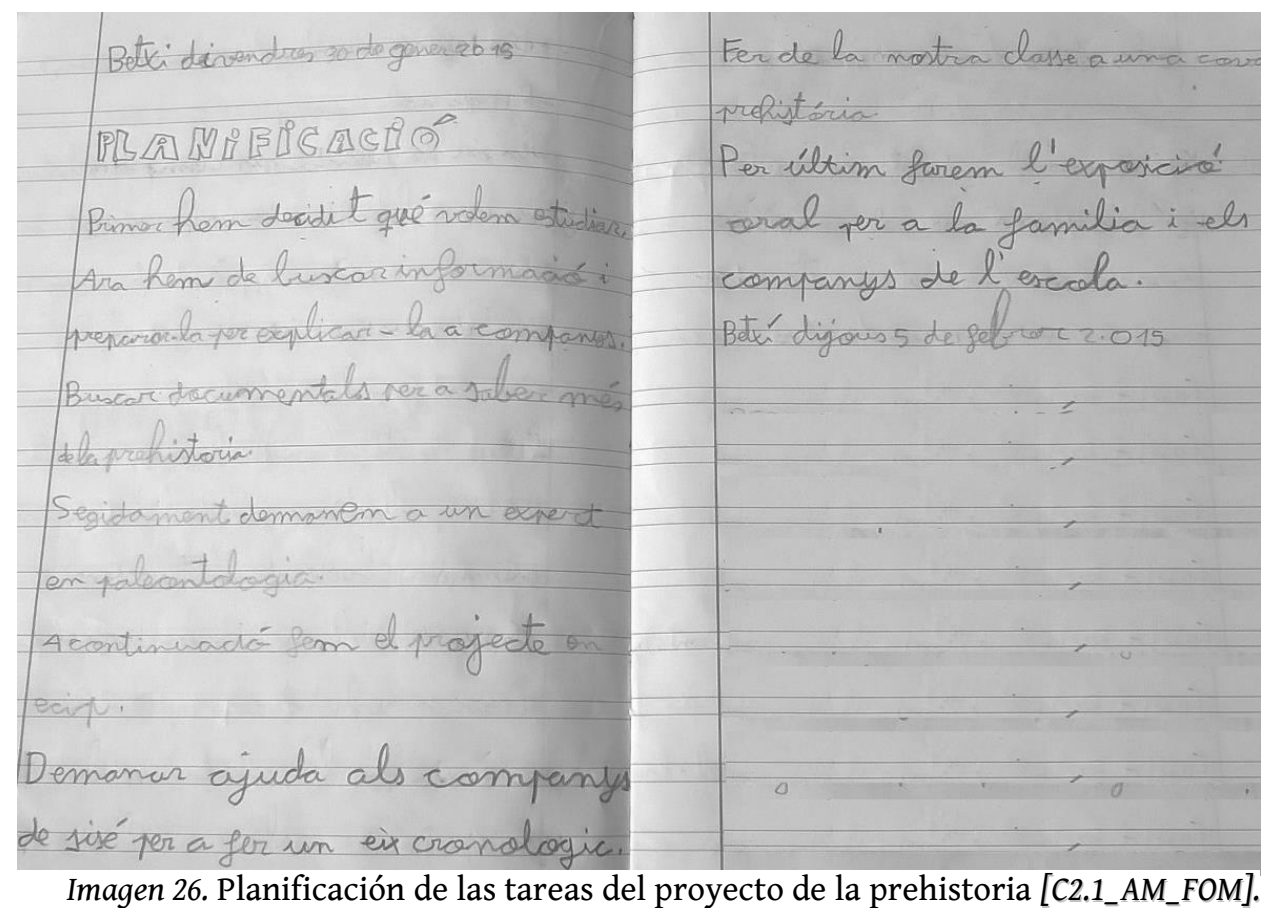




\section{La mesa de la información: búsqueda y exposición de los contenidos encontrados}

Esta fase del proyecto tiene una duración de entre dos a tres semanas, dependiendo de la información que los alumnos van trayendo. El alumnado, en casa y con la ayuda de las familias, va buscando libros, materiales, páginas web, etc. donde encontrar las respuestas a las preguntas previamente planteadas. "Los niños van sacando la documentación. Mati comenta que para que no les pase como en el proyecto de Egipto, van a dejar sobre la mesa un folio para ir recogiendo la bibliografía del material que van utilizando, sino después no se acuerdan" [C2.1_O_NC]. Los alumnos a medida que van trayendo la información al aula la van explicando a sus compañeros, de esta manera van teniendo un primer contacto sobre el contenido a estudiar.

"La prehistoria estudia al hombre des del principio [...], explica un alumno. Los niños tienen que preparar en casa un poco la información que traen a clase. Les surge la duda de cómo escribir la cifra de 2 mil millones de años. Los alumnos hacen varios intentos y solicitan ayuda a un alumno de 3o para que se lo escriba a la pizarra. Durante la exposición también surgen algunos vocablos nuevos que los alumnos no conocen y anotan como son, por ejemplo: nómada o clan" [C2.1_O_NC].

Posteriormente, depositan en una mesa la información que van trayendo. "Hay una mesa donde está toda la información [...] esa mesa es donde está la información que vamos trayendo. Nosotros de momento (hace referencia a su grupo de trabajo) no tenemos mucha, pero bueno." [C2.1_E.F_A2]. En la Imagen 27, se presenta alguna de la información que el alumnado trajo para el proyecto de «la prehistoria».

Por tanto, el alumnado va escuchando las

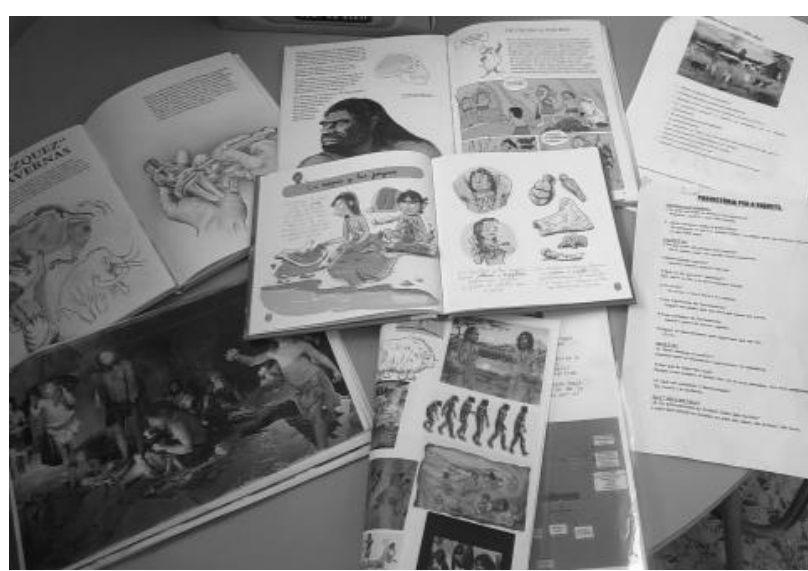

Imagen 27. Información que el alumnado trajo para el proyecto [C2.1_AM_FOM] explicaciones de sus compañeros en referencia a la temática estudiada. "Mientras que íbamos trayendo información íbamos estudiando y poco a poco sacábamos la libreta e íbamos escribiéndolo" [C2.1_E.F_A2]. "Y cada vez aprendíamos más" [C2.1_E.F_A1]. Por ende, el alumnado aprende del material y las explicaciones de sus iguales. "A la hora de hacerlo como que cada uno va aportando una cosita, se aprenden la que ha dicho aquello, la que ha traído el otro y encima tienen que buscarlo y tienen que preocuparse" [C2.1_E.F_M1].

\section{$\sim$ La experta en paleontología: Lola la historiadora}

En cada proyecto siempre se invita a algún especialista o experto en la temática estudiada. En este caso se invitó a una experta en paleontología que les explicó a los alumnos la evolución de la especie humana y el caso de Atapuerca donde ella había estado trabajando. "Aprendimos aún más sobre las excavaciones de Atapuerca [...] un día sobre las excavaciones de Atapuerca escribimos lo que no sabíamos y claro..." [C2.1_E.F_A2]. 
Previamente, a la exposición de la paleontóloga, los alumnos dedicaron una sesión en la que confeccionaron un listado con preguntas que querían plantearle a la especialista invitada (Ver Imagen 28).

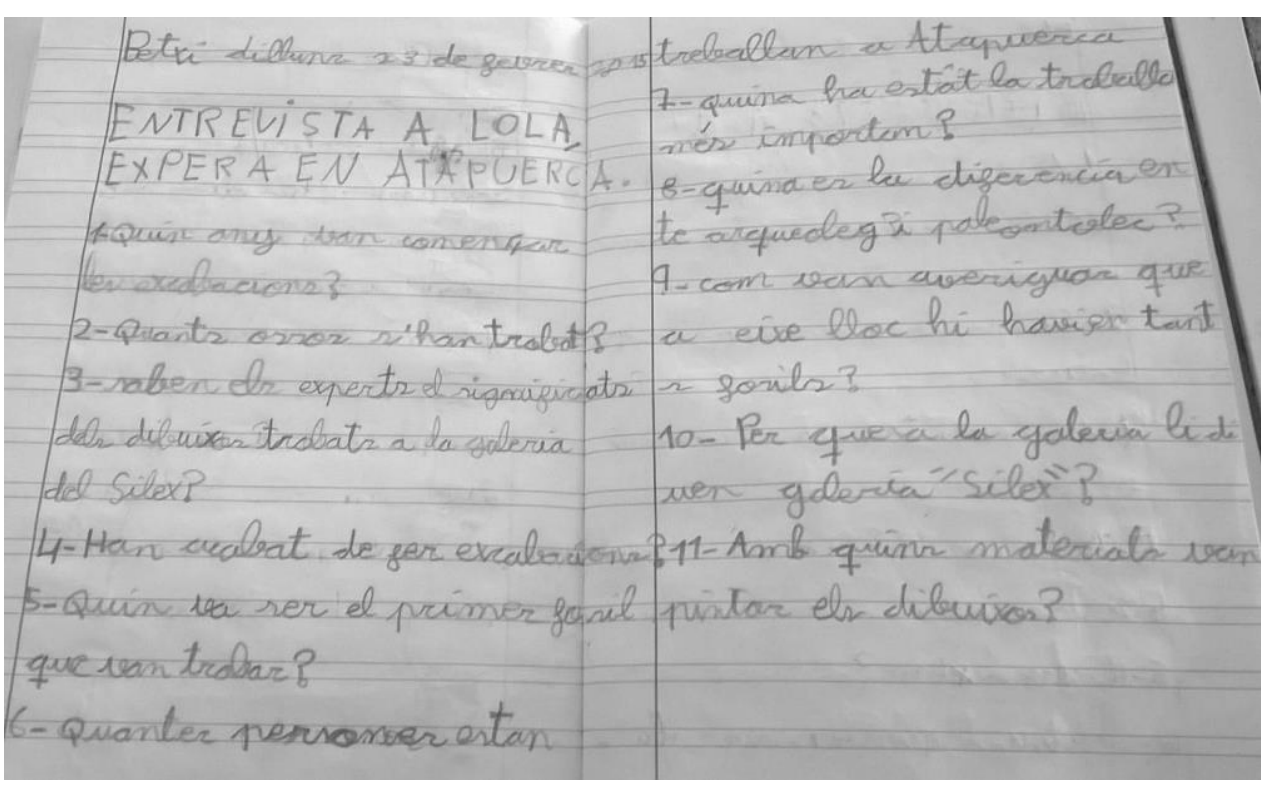

Imagen 28. Entrevista a la experta en paleontología [C2.1_O_FOM].

Antes de efectuarle las cuestiones planteadas para la paleontóloga, ésta les explica aspectos sobre Atapuerca. "Lola ha preparado una presentación con varias imágenes, la cual la proyectan en el proyector, los alumnos están sentados en el suelo mirando $y$ escuchando muy atentos" [C2.1_O_NC]. Dos alumnos fueron los encargados de realizar las preguntas al terminar la exposición de Lola. Se dedicó otra sesión para escribir en las libretas las respuestas que había dado la experta (Ver Imagen 29).

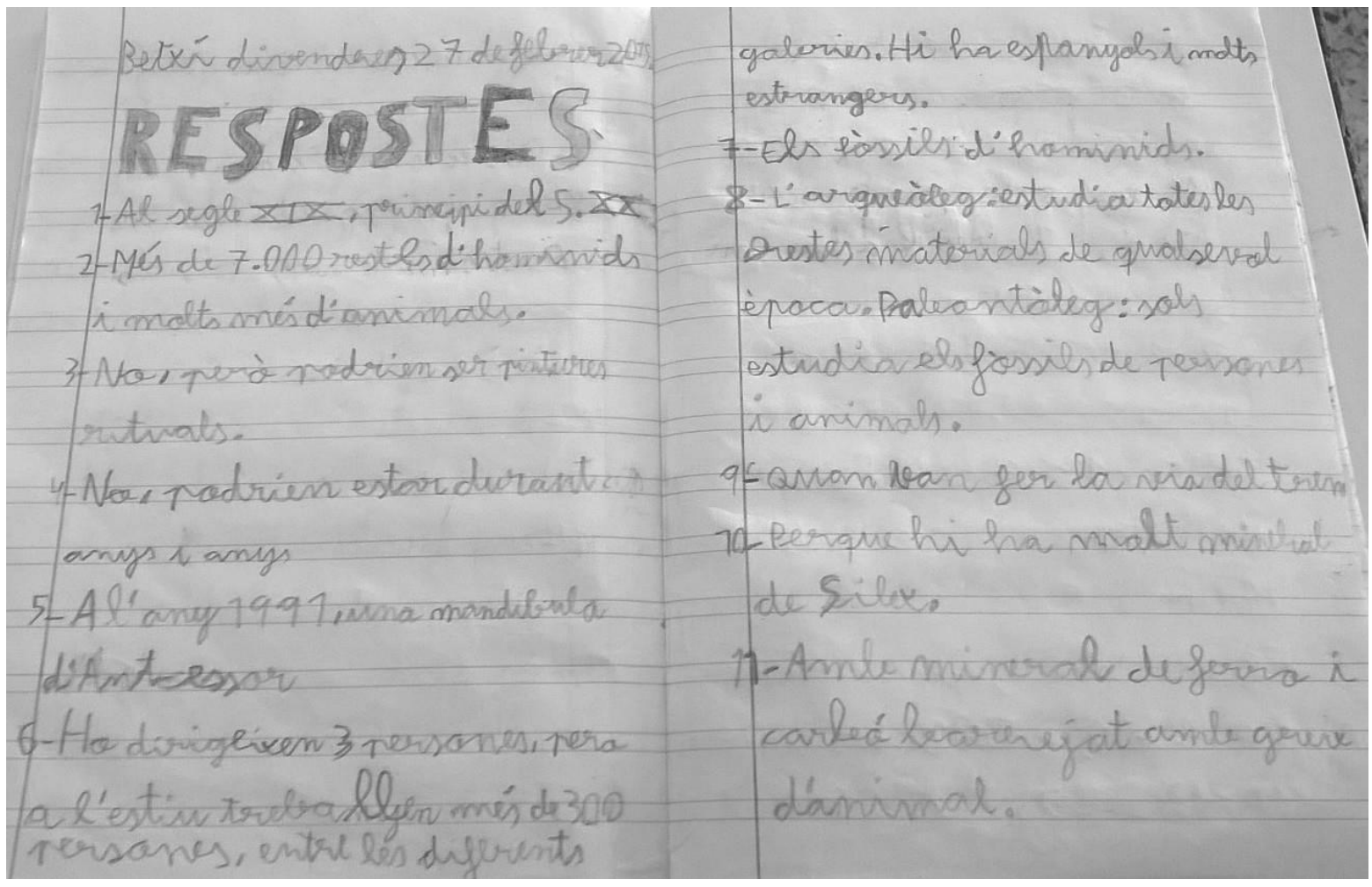

Imagen 29. Respuestas de la experta en paleontología [C2.1_O_FOM]. 


\section{$\sim$ Distribución de las tareas: trabajo en equipo para la elaboración del dosier}

Una vez el alumnado ha terminado de traer y exponer la información relativa a la temática planteada se realiza otra asamblea a través de la cual se dividen entre los diferentes equipos los subtemas que van a trabajar cada uno de ellos. "Pues hoy hemos empezado a escoger lo que tiene que estudiar cada uno" [C2.1_E.F_A2]. El aula está formada por 7 equipos de 4 alumnos heterogéneos. Cada equipo tiene asignado un color. A partir de la información encontrada y sin perder de vista las preguntas planteadas (¿Qué queremos saber?) los alumnos van proponiendo los diferentes subtemas, la maestra los va escribiendo en la pizarra y los encargados recogen por escrito lo que cada equipo escoge para trabajar (Ver Cuadro 3).

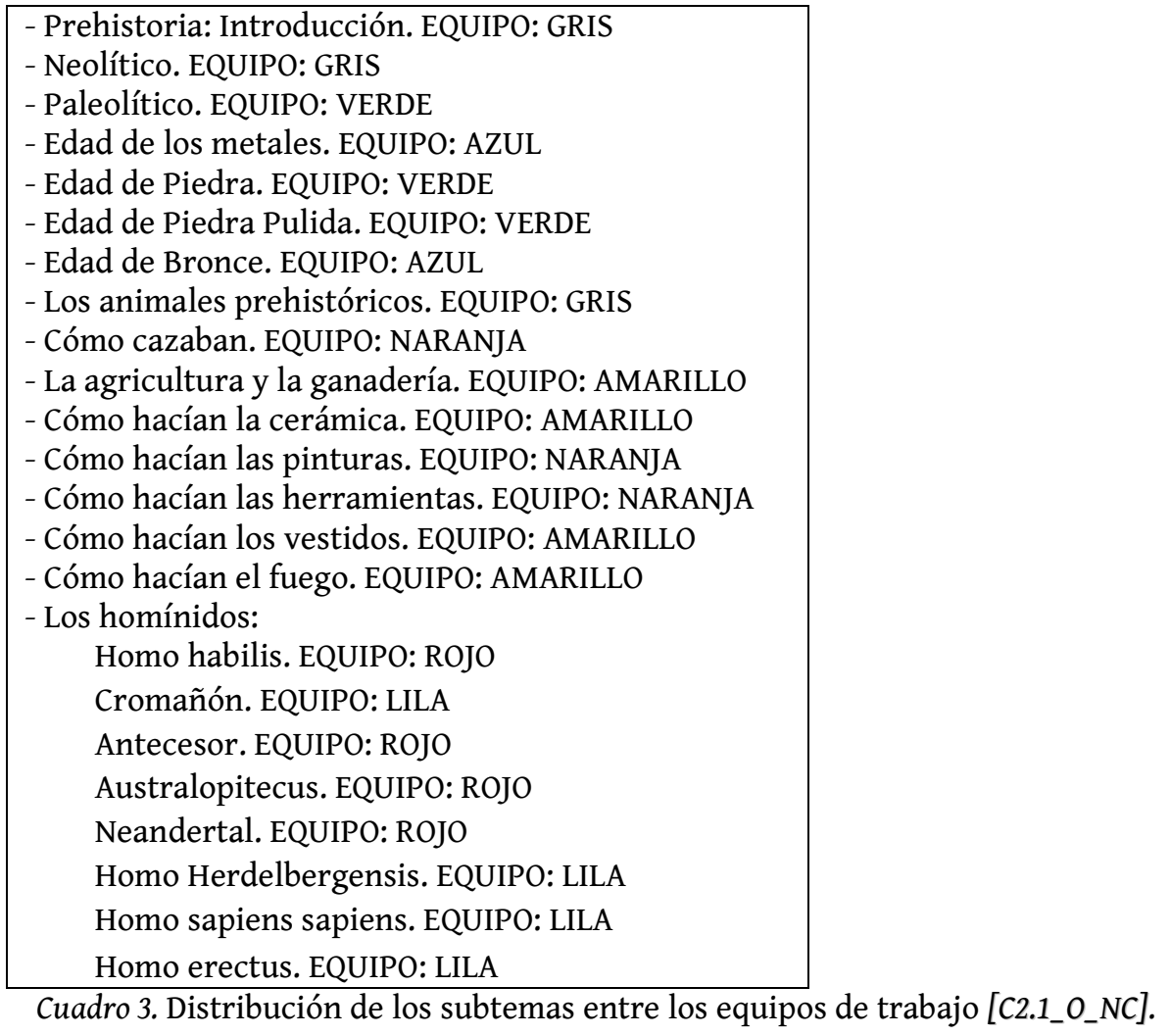

En esta sesión los alumnos deben llegar a un acuerdo sobre los subtemas que abordará cada una de las mesas. "Pues, por ejemplo, Mati apunta unos en la pizarra y si alguien quiere y toda la mesa quiere pues votamos ese. $Y$ sino tenemos que convencer a los otros. Por ejemplo, si dos votan una cosa que les gusta pero no mucho y los otros dos votan una cosa que está más chula pues entonces nosotros nos convencemos y votamos eso" [C2.1_E.F_A5]. No obstante, en caso de que más de un equipo quiera estudiar el mismo tema y si no llegan a un acuerdo, se hace por sorteo. "Pues cogemos ese bote, ponen estos dos colores en la mano de un niño que no sea de ninguna de esas dos mesas, entonces lo meneamos el niño coge uno [...]" [C2.1_E.F_A1]. Una vez ya tienen claro que grupo estudia cada subtema, los encargados pintan el color del equipo para identificarlo. "Porque cada mesa tiene un adhesivo de un color" [C2.1_E.F_A2].

Consecutivamente, se va identificando y asignando todo el material depositado en la mesa de la información con las temáticas acordadas a trabajar por cada grupo. “[...] vamos, la cogemos [...] lo que 
tengamos que hacer nosotros, cogemos la información de eso y después vamos mirando para escribirlo en una hoja, para después pasarlo a la hoja grande" [C2.1_E.F_A2]. Los alumnos van trabajando la información que han traído. "Cuando nos reparten mucha información que han traído los niños, pues de cada cosa lo llevan a la mesa y nosotros subrayamos lo que es más importante y lo ponemos ya en el proyecto en limpio, para el dosier" [C2.1_E.F_A5]. Para ordenar y clasificar el material por temáticas, cada mesa tiene una carpeta. "Está muy bien porque, [...] cuando de momento les aparece en esa información algo de uno de los temas que están trabajando los otros equipos, ellos ya lo miran y dicen 'esto les va bien a tal equipo'. Van a dárselo: 'Mirad que hemos encontrado' " [C2.1_E.F_D1].

Llegados a este punto, los alumnos empiezan a
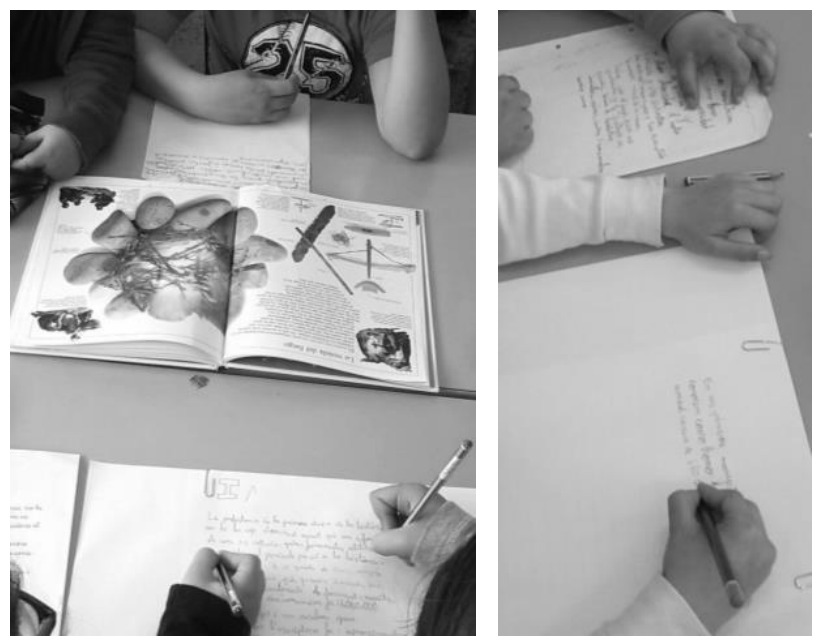

Imagen 30. Alumnos trabajando en equipo [C2.1_O_FO_A]. trabajar en grupos cooperativos para confeccionar el dosier del proyecto (Ver Imagen 30). "Pues en la mesa pensamos en grupo que es lo que queremos y como lo repartimos" [C2.1_E.F_A7]. Cada equipo se organiza el trabajo. "Pues trayendo la información, decidir cómo escribimos, escribirlo y dictar para que lo escriban. [...] Pues unos van buscando la información juntos y otros, según los que les dicen, eso en nuestra mesa, uno va dictando y otro va escribiéndolo y vamos cambiando" [C2.1_E.F_A2]. En otra mesa se organizan de otra manera. "En la mía, si no hay suficiente información, pues el que sobra se queda quieto y los otros van leyendo. Pero ahora como hay bastante información uno escribe y los otros 3 leen y después cambiamos" [C2.1_E.F_A1]. Concretamente, se utiliza la técnica del folio giratorio. Esta consiste en que un miembro del equipo empieza a escribir su parte o su aportación en el “folio giratorio". Mientras los demás se fijan como lo hace, le ayudan si hace falta, le corrigen, le animan, le dictan... A continuación, pasa el folio al compañero del lado, siguiendo la dirección de las agujas del reloj para que escriba su parte de la tarea en el folio, y así sucesivamente hasta que todos los miembros del equipo han participado en la resolución de la tarea.

El propósito de este trabajo es realizar un dosier del proyecto. "Porque vamos a hacer en esa hoja en sucio que nos daba [...] lo escribiremos en una hoja y haremos un libro" [C2.1_E.F_A2]. Tal y como ya se ha introducido, cada mesa trabaja un subtema y, a veces, dentro de cada equipo cada miembro se encarga más de una parte. "Por ejemplo C. y C. estudiaron el homo sapiens sapiens, porque había una mesa en la prehistoria que estudió los homos" [C2.1_E.F_A5]. "Yo era el australopitecos con D." [C2.1_E.F_A4]. "Mira yo estaba en un grupo y nos organizamos. Unos hacían lo del fuego mientras otras dos... mira R. y D. hicieron lo del fuego y yo y P. nos dijo Mati: 'Hacer lo de la introducción'" [C2.1_E.F_A6].

Durante el proceso de elaboración del dosier, si es necesario, se sigue negociando las tareas que van haciendo cada equipo a medida que se van trabajando los contenidos. "Un grupo tenía que estudiar una mitad de homínidos y el otro grupo la otra mitad" [C2.1_E.F_A1]. "Ya, eso me pasó a mí. Yo estaba en una de esas mesas. 
Había 8 homínidos, 4 para cada mesa, pero al final decidimos que como ellos ya tenían otra cosa. Lo que hicimos fue que nosotros todos los homínidos y ellos hicieron el fuego y las herramientas" [C2.1_E.F_A2]. Los alumnos adoptan un rol de investigadores en el transcurso del proyecto de trabajo. "Como que están explorando y están averiguando cosas que tú no sabes y te lo digo yo. Es como buscar un tesoro, que es más sorprendente, cada uno te dice una cosa y puede ser sorprendente de decir: 'Si, eso, pues mira yo lo otro...' "[C2.1_E.F_M1].

Al finalizar cada sesión de trabajo el grupo reflexiona y hace una pequeña evaluación sobre cómo han trabajado. El grupo que ha trabajado correctamente obtiene una estrella, la cual se pega en un papel colgado en el aula con el color de cada grupo. "Mati hizo una hoja en cada color de la mesa y cuando trabajábamos mucho, mucho, mucho, pues después nos ponía una estrella. A mí, V. y A. nos pusieron, me parece que, 2 estrellas. Porque hicimos 3 páginas" [C2.1_E.F_A5]. Además, los alumnos también van reflexionando sobre su trabajo y lo anotan en una libreta que guardan en la carpeta del equipo. Entre algunas valoraciones de grupo destacar las siguientes: "4/3/15: Valoración, hemos participado todos de la clase de $2^{\circ}$ A. Hemos decidido estudiar los animales (en la prehistoria) en la mesa plateada" [C2.1_O_FOM]. "Hemos trabajado mucho, pero a mí me ha costado mucho buscar un dinosaurio. Yo he trabajado mucho y $E$. ha hecho un minuto de tonterías. No hemos discutido. No nos hemos levantado de la silla, sólo para buscar información" [C2.1_O_FOM]. "Hemos trabajado un montón y hemos adelantado faena, y nos hemos levantado de la silla para cosas importantes, y no hemos molestado a la mesa de al lado y no hemos reñido nada" [C2.1_O_FOM].

Una vez finalizado el proyecto los niños se llevan el dossier para enseñárselo a sus familias. "Siempre cuando terminamos de hacerlo poco a poco hacemos un sorteo cada uno coge un número y según esos números nos lo llevamos a casa para verlo con los padres" [C2.1_E.F_A2]. Los familiares escriben comentarios que cada niño comparte posteriormente con sus compañeros al devolver el dossier al aula.

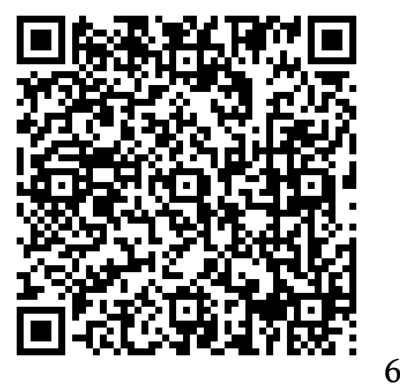

Dosier de la prehistoria elaborado por el alumnado [C2.1_AM_FO].

Además, a partir de la información que el alumnado va aportando, la maestra, aparte del dosier que elaboran de manera colaborativa el alumnado, prepara lecturas que ayudan a la consolidación del conocimiento. Las lecturas se van trabajando a lo largo del proyecto. "Tenemos que hacer esquemas de todo eso" [C2.1_E.F_A5]. "Porque además nos hace un libro para estudiárnoslo y para casa" [C2.1_E.F_A2]. 


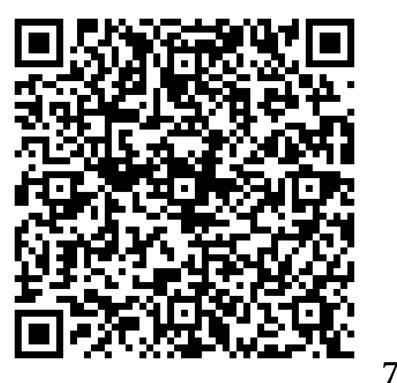

Lecturas suplementarias proporcionadas por la maestra [C2.1_AM_DO].

\section{$\sim$ Escritura de notas para solicitar ayuda y colaboración en el proyecto}

En cada proyecto, según su temática o características, siempre se suele recurrir a la implicación de la comunidad educativa o del entorno social inmediato. En esta ocasión, se solicitó ayuda a los compañeros de $6^{\circ}$ de primaria para representar en el pasillo un eje cronológico (Ver Imagen 31). "NOTA PARA LOS DE SEXTO. Hola somos los compañeros de $2^{\circ} \mathrm{A}$, estamos estudiando la prehistoria y queremos hacer un eje cronológico. Por favor, ¿nos podéis ayudar? Necesitamos situar los años des de 2,5 millones de años a.C. hasta el año 2015 d.C. Lo hemos representado al pasillo, que mide 41 metros. Gracias por vuestra atención. Fdo. Compañeros de $2^{\circ} A^{\prime \prime}$ [C2.1_O_FOM].

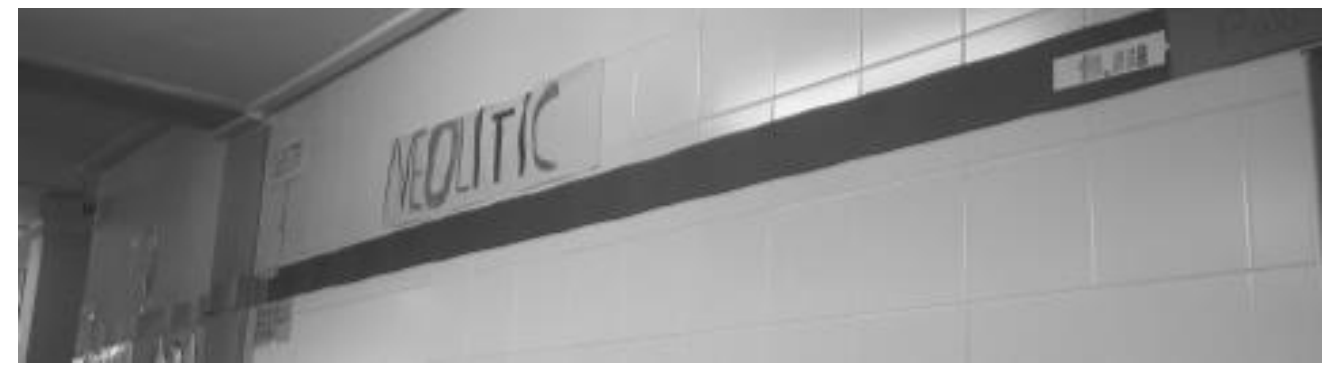

Imagen 31. Parte del eje cronológico [C2.1_O_FO].

A lo largo de algunas sesión trabajaron la confección del eje cronológico. "En la prehistoria toda la información, que era muy interesante, la pusimos en el pasillo" [C2.1_E.F_A5]. Para ello, 3 representantes de $6^{\circ}$ ayudaron a situar los años correspondientes a cada período histórico. "Vinieron los de sexto a ayudarnos, bueno en realidad no vinieron toda la clase de sexto porque claro, ya eran muchos en nuestra clase y lo hicieron todos los de sexto y vinieron 3 a explicarlo" [C2.1_E.F_A2].

Aprovechando que los compañeros de la clase de $2^{\circ}$ «B» estaban estudiando Los Egipcios también localizaron temporalmente la época de mayor esplendor de los faraones en el eje cronológico confeccionado por el alumnado de $2^{\circ}$ "A». "Hicieron una tira cronológica desde hombre antiguo hasta el hombre primitivo, que somos nosotros ahora [...] Investigamos mucho eso y [...] pusimos, una cosa y la otra cosa" [C2.2_E.F_A1].

También reprodujeron a tamaño real un australopitecos, un homo habilis y el homo sapiens sapiens, con la ayuda de un chico de prácticas (Ver Imagen 32). "Y esos chicos [...] en el papel blanco eso habíamos hecho un sorteo y habíamos puesto los números del 1 al 28 y a quien le tocara se pondría con A. el tío de V." [C2.1_E.F_A1]. "Y tenían que calcarlo" [C2.1_E.F_A2]. Esto es, un estudiante del prácticum de magisterio sirvió 
de modelo para representar, a tamaño real, un homo sapiens sapiens. Mientras que por sorteo un compañero de clase representó al homo habilis. "Era para diferenciar la altura en uno pequeño y uno grande, era porque en la prehistoria los homínidos eran más pequeñitos que nosotros" [C2.1_E.F_A2]. "Por ejemplo, un homo hábiles era como P." [C2.1_E.F_A1].

Esta forma de trabajar ayuda al alumnado a asimilar los conceptos trabajados de una forma más amena y divertida. "En esta forma como trabajan jugando, yo creo que lo asimilan mejor y que se les queda más bien, se les queda mejor. Porque es una forma de aprender. Coger el libro y ya está ya sabemos todos que es poco atractivo y de esta manera yo creo que ellos lo entienden de otra forma. Al tener que dibujar el muñeco, ahora se ríen, ahora lo comentan. La verdad que es como un juego y se les queda mejor. [...] Yo creo que de esta forma lo cogen con más interés, con más gana y se les queda mejor" [C2.1_E.F_M1].
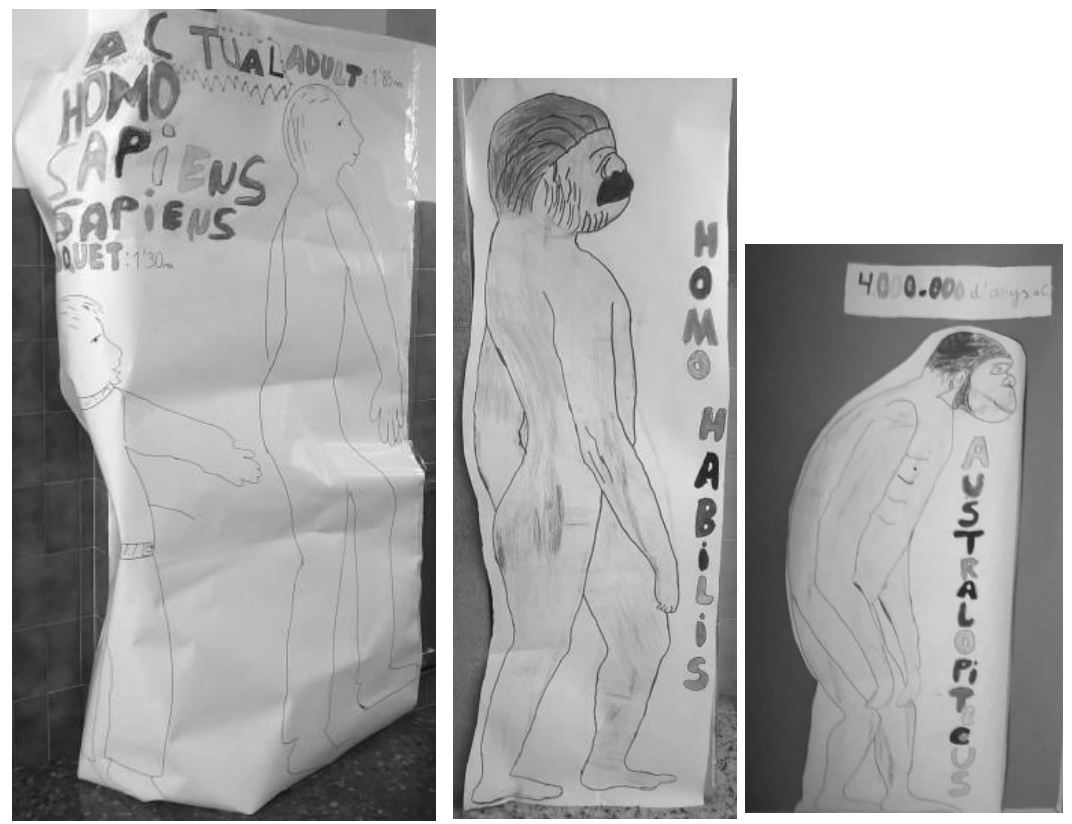

Imagen 32. Representaciones a tamaño real de los homos y australopitecos [C2.1_O_FO].

Vemos como a partir de estas actividades se introducen conceptos numéricos. "Incluso en la parte del cálculo y numeración vamos trabajando. No es tanto: 'han trabajado hasta el 300 y ahora recordemos el 300'. No, porque la numeración vamos trabajándola a lo largo del curso, como va apareciendo [...] cuando lo miras en el currículum siempre

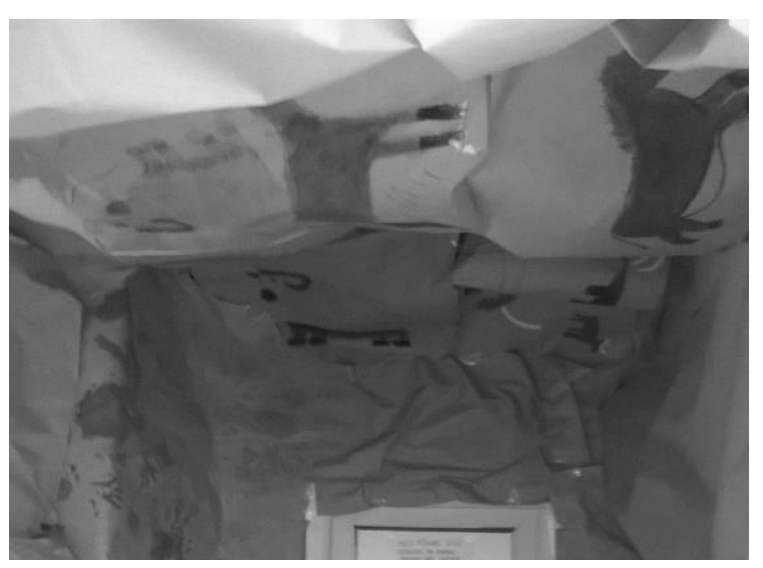

Imagen 33. Reproducción de la cueva de Altamira [C2.1_O_FO]. hay objetivos del currículum que se corresponde con lo que estás trabajando" [C2.1_IP.HR_D1].

En este proyecto, sobre «la prehistoria», se realizó una reproducción de la cueva de Altamira con pinturas rupestres (Ver Imagen 33). Primeramente, cada alumno, con la ayuda de la maestra escribió en su libreta todo el material que necesitaban para la cueva y posteriormente entre todos la confeccionaron. "Betxí, lunes 9 de febrero del 
2015. Hacemos una cueva. Material: metros de papel continuo, tijeras, colores, lápices, goma y pinturas. Para sujetarla utilizaremos celo y grapas" [C2.1_O_FOM]. "Arriba de la cueva hicimos uno cada uno (hacer referencia a las representaciones rupestres). Después unos a los lados los hicimos también entre todos. Y otros los hice yo" [C2.1_E.F_A2].

Este tipo de propuestas surgen a veces del alumnado o a veces de la maestra. "Pues unas ideas eran de Mati y como a nosotros nos gustaban decíamos que sí. Un ejemplo, fue cuando nos dijo de hacer la cueva" [C2.1_E.F_A2]. Así pues, la docente lanza la propuesta y los alumnos en consenso deciden si quieren o no llevarla a cabo. "Pero a veces cuando una propuesta es buena y nos gusta la votamos" [C2.1_E.F_A7]. Esta representación de la cueva de Altamira es del agrado de las familias, tanto por el trabajo de los alumnos como de las docentes.

"A mí la cueva me ha parecido una monada. Me he quedado alucinada de todo lo que han hecho [...] lo han pintado muy bien a los animalitos, la verdad que se esmeran, se esmeran mucho [...]. Eso ha llevado una faena y mira la maestra todo lo que habrá trabajado. $Y$ aun así les gusta y quieren hacerlo cuando más veces mejor [...]. Eso que tienen que tocar, palpar, jugar, buscar y trabajarlo y que ellos mismos se crean que son los descubridores de lo que se ha hecho o de lo que se ha dicho" [C2.1_E.F_M1].

\section{$\sim$ Reseña para la revista del centro}

Cada año el centro edita una revista y es el alumnado de cada aula quien propone y decide que trabajo quiere aportar. Los alumnos de $2^{\circ}$ «A», mediante asamblea, decidieron hacer una reseña de la temática que estaban trabajando. Primeramente, entre todos decidieron lo que iban a poner, la maestra lo escribió en la pizarra y los niños lo iban escribiendo en sus libretas. Después lo escribieron en la plantilla para la revista, cada uno escribió una frase. Seguidamente en la Imagen 34. se muestra la reseña para la revista.
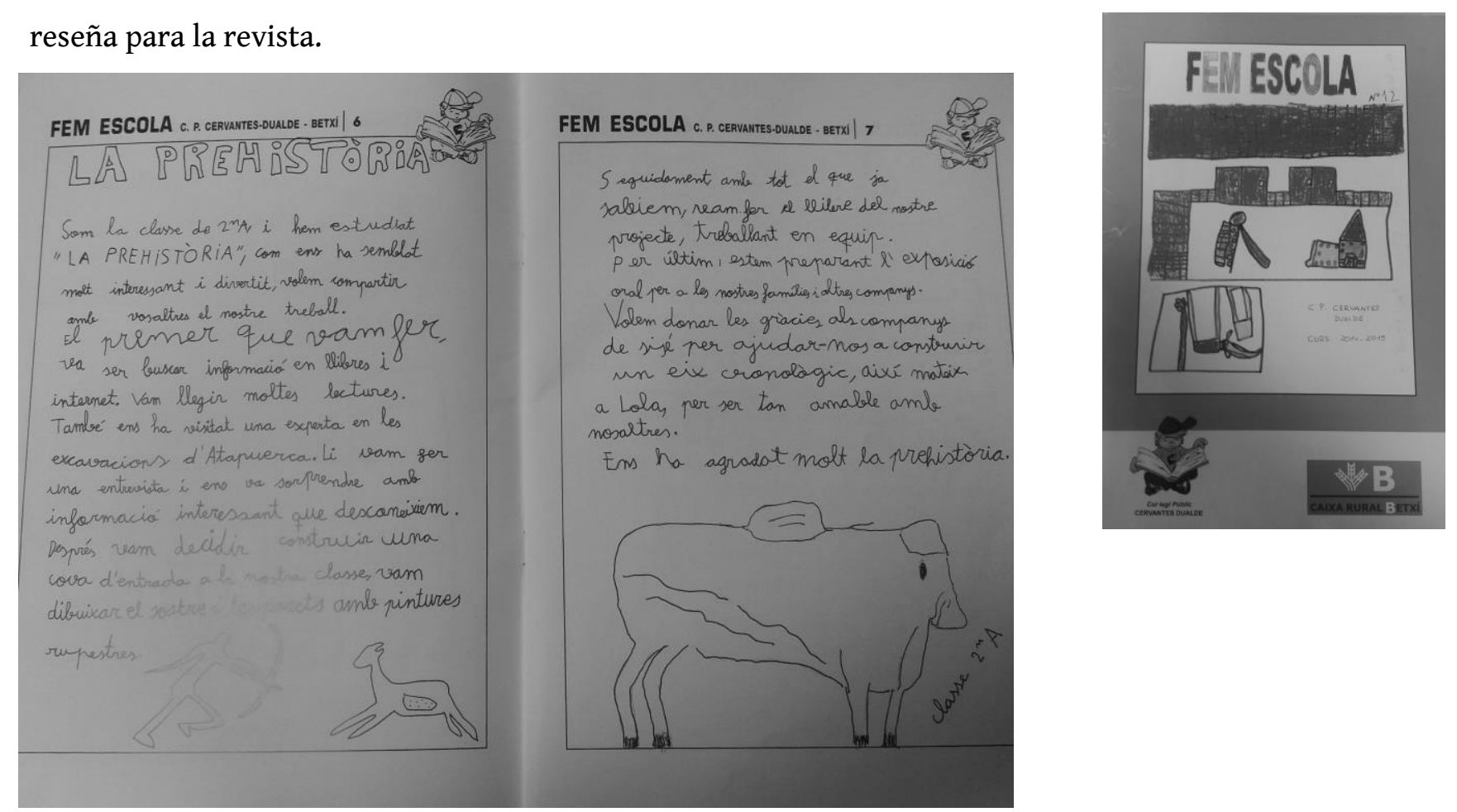

Imagen 34. Reseña para la revista del centro [C2.1_O_FOM]. 


\section{Preparación y exposición de lo aprendido a las familias y compañeros}

Para cerrar todo el proceso del proyecto el alumnado realiza una exposición de todo lo que han aprendido. Así pues, dedican unos días previos a la exposición para prepararla y ensayarla. "Pues a una mesa el tema o los temas que está estudiando, Mati le da un trocito que está en un papelito, entonces tiene que llevárselo a casa y aprendérselo" [C2.1_E.F_A1]. "Antes hacen unas fotocopias y van recortando, tenemos que escoger entre la mesa quien es el que presenta" [C2.1_E.F_A2]. "[...] nos llevamos las lecturas a casa y de allí nos lo aprendemos todo" [C2.1_E.F_A4].

A lo largo de un día los alumnos hacen 3 o 4 exposiciones, en las cuales muestran todo lo que han abordado y aprendido a lo largo de todo el proyecto. Previamente a esta sesión los alumnos confeccionan invitaciones para sus compañeros y familiares (Ver Imagen 35). Para la sesión invitan a los familiares y compañeros de otros cursos. "Bueno, vienen los padres, la tenemos que hacer varias veces porque vienen varias personas" [C2.1_E.F_A2]. El hecho de realizar diferentes exposiciones en diferentes franjas horarias tiene el objetivo de favorecer y facilitar la mayor asistencia posible de los diferentes públicos.

Cada equipo expone la parte que ha trabajado.

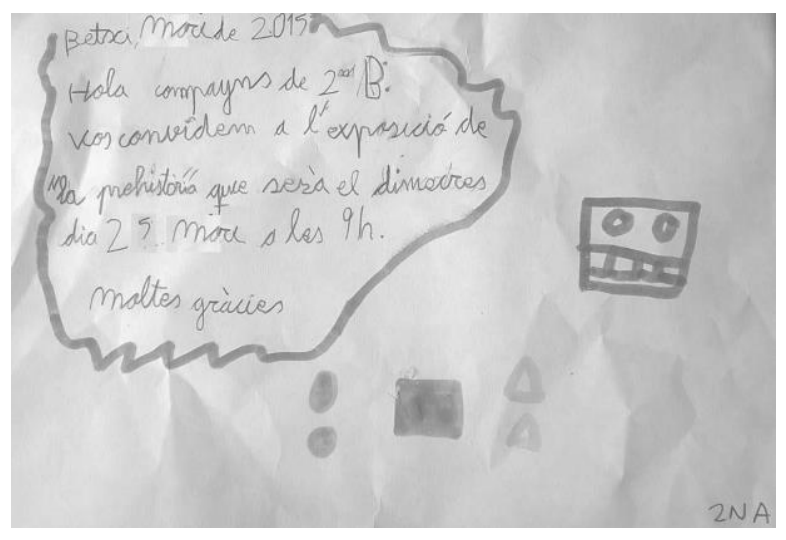

Imagen 35. Invitación para la exposición [C2.1_0_FOM].

En este proyecto hubo un niño que no quiso realizar la exposición oral. "Pues eso se tiene que respetar [...]. A él le cuesta mucho memorizar, y yo también pienso que el terminar en la exposición oral, me gusta, es conveniente y es otro tipo de aprendizaje, pero si eso emocionalmente les supone.......]" [C2.1_E.F_D1]. "Si algún niño no quiere leer o dos, pues si la lectura esa o va para un niño o va para otro. Por ejemplo, yo la otra de la prehistoria tenía un papel, pero un niño tenía que leer una parte y esa no quería participar, entonces yo decidí que también iba a leer la otra parte de la hoja" [C2.1_E.F_A1]. Aunque, rara vez algún alumno no quiere exponer."No es lo habitual. Porque aunque tengan un poco de vergüenza, les gusta mucho. $Y$ hacen un esfuerzo, pero siempre puede haber algún caso pues... Además, se comprende el caso en particular" [C2.1_E.F_D2]. Generalmente, existe un alto grado de implicación y preparación de la exposición. "Mi niña iba por casa en el folio ese...jtodos claro!" [C2.1_E.F_M1].

Para el día de la exposición muestran todos los murales y esquemas que han ido confeccionando (Ver Imagen 36). Además, a mediados del curso escolar les instalaron una pizarra digital en el aula, la cual también utilizaron en las exposiciones. "También para que lo vean los padres hay un proyector, donde están todas las páginas del libro" [C2.1_E.F_A1]. 

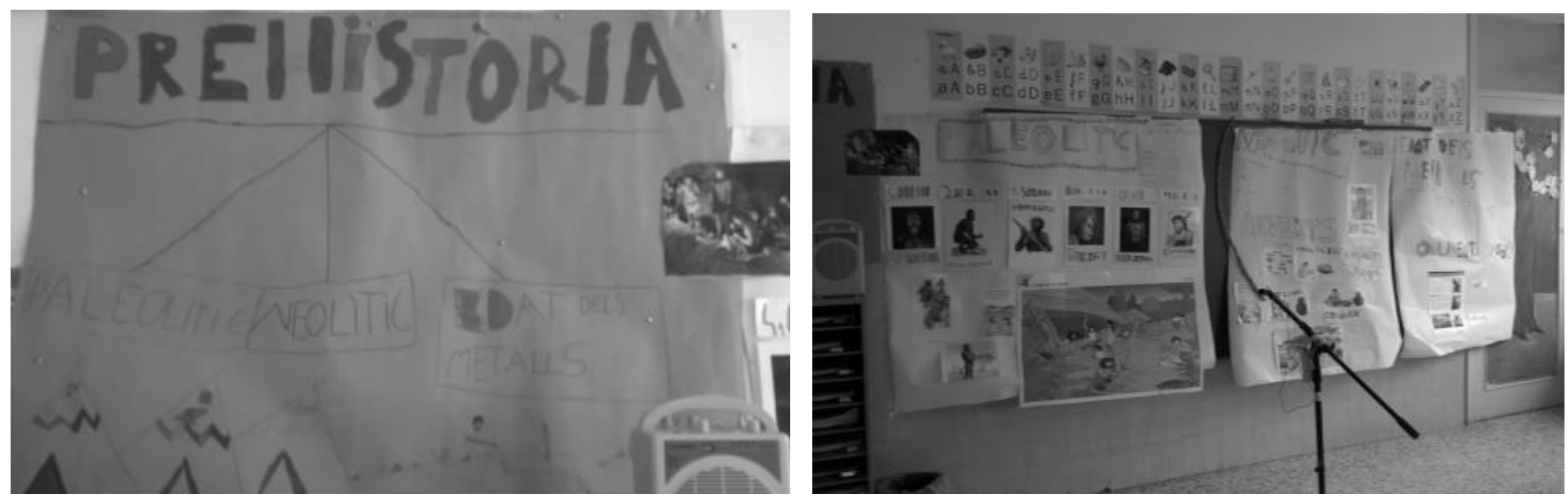

Imagen 36. Murales generados a lo largo del proyecto [C2.1_O_FOM].

Un alumno hace de presentador de la exposición. "Uno dice: Hola buenos días, soy -quien sea - y mis compañeros son tal, tal y tal". [C2.1_E.F_A1]. Las madres están contentas con la exposición, aunque en algunos casos los niños tienen un poco de vergüenza. "Los niños muy bien, siempre hay alguno que se pone un poco nervioso al ver a la gente..." [C2.1_E.F_M1]. "Pero es normal, yo soy la primera que: jterror escénico! " [C2.1_E.F_M2].

Al terminar la exposición, la maestra siempre les congratula por el trabajo realizado. "Y después Mati nos felicitaba" [C2.1_E.F_A5].

\section{$\sim$ Evaluación del trabajo realizado}

Al terminar el proyecto se hace una evaluación escrita sobre los contenidos más importantes trabajados a lo largo del proyecto. "De lo que aprendemos hacemos un examen y nosotros tenemos que escribir las respuestas pero yo tengo una que no sé si me sabré muy bien" [C2.1_E.F_A2]. Es necesario destacar que los 5 alumnos que presentan un retraso madurativo esta prueba la hacen de manera oral. Además, la maestra hace una evaluación continua del trabajo diario de los alumnos. Hay que remarcar que ningún alumno ha suspendido la evaluación del proyecto de «la prehistoria».

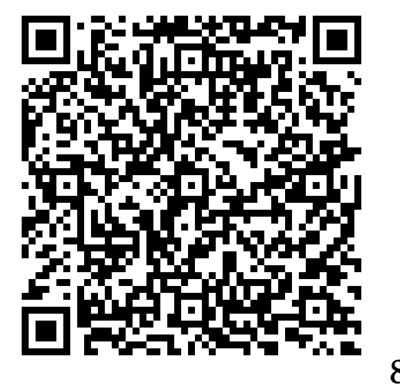

Preguntas de evaluación del proyecto [C2.1_AM_DO].

En la entrevista los alumnos explican cosas curiosas que han averiguado $u$ otras curiosidades que les han surgido. "Había un mineral, que sé que es la limonita, que si lo tocas te ensucias todo de amarillo [...] Y había unas cosas que hacian en forma de espada y eso." [C2.1_E.F_A1]. "En 'Erase una vez el hombre' te acuerdas que ya había un 
tipo de flauta [...] También sé que solían gastar minerales para hacer algunas cosas. Por ejemplo, la pirita [...] Una cosa que aún no sé es: que si ya de mayores son como nosotros ¿Cómo serán de pequeños?" [C2.1_E.F_A2].

Con motivo de la excursión final de curso van a Valltorta para visitar la cueva y el museo. Esta actividad completó y cerró todo el trabajo realizado en el proyecto de «la prehistoria». "Hace poco se fueron de excursión y también pintaron pinturas rupestres y les llevaron a ver una cueva" [C2.1_E.F_M1].

Las madres están muy satisfechas por los aprendizajes de sus hijos y por las metodologías utilizadas.

"O lo que es Egipto, o lo que es la arqueología o... Cosas que han dado ellos a esta edad tú no puedes ponerlo si no es de esta manera. [...] Cosas que en un libro no aprenderían así las aprenden. Yo creo que sí. Y se acuerdan, pero ¿por qué? Porque lo tienen súper machacado, lo han estado buscando y lo han estado eso..." [C2.1_E.F_M2].

"O sea, que yo creo que todo eso se les queda mucho más grabado y de esa manera les gusta más estudiar y hacer cosas. Como les ponen en situación y les ponen a que ese momento están allí en la cueva como si estuvieran viviéndolo yo creo que les gusta más. Están más predispuestos a aprender a saber la historia [...]A los padres, desde luego, nos gusta a todos y siempre decimos: 'ojala sigan trabajando asi' [...]. Les despiertas la chispita esa yo creo que cuando enlazan $3^{\circ}$ y $4^{\circ}$ ya van más predispuestos a aprender. Es muy buena la idea, a mí me gusta mucho "[C2.1_E.F_M1].

\subsection{2. ¿Cómo pasa el tiempo? Betxí, nuestro pueblo.}

A continuación, se desarrolla de manera puntualizada los principales pasos y actividades que caracterizan el proyecto que se presenta. Éstos son:

$\sim$ Asamblea y acta: comenzamos un nuevo proyecto de trabajo

$\sim$ Evaluación inicial: ¿Qué sabemos?

$\sim$ ¿Qué queremos saber?

$\sim$ Proceso de investigación y organización de la información

$\sim$ Escribimos la carta para invitar a los abuelos y realizamos un guión de preguntas

$\sim$ Los abuelos nos visitan: recuperación de la historia oral del municipio de Betxí

$\sim$ Carta y visita del historiador

$\sim$ Visitamos el Barranquet y el casco antiguo de Betxí

$\sim$ Trabajamos con mapas y recorremos el municipio en Google Maps

$\sim$ Recapitulación por escrito del proceso de investigación: elaboración del dossier

$\sim$ El juego del paso del tiempo en Betxí y confección del eje cronológico

$\sim$ Exposición oral

$\sim$ ¿Qué hemos aprendido?: la evaluación final

\section{$\sim$ Asamblea y acta: comenzamos un nuevo proyecto de trabajo}

Para poder iniciar el proyecto, todo el alumnado se reúne en asamblea. De esta manera escogen el tema que quieren estudiar. "Hacemos la asamblea y cada uno dice un tema y el que tenga más votaciones de ese tema lo hacemos" [C2.2_E.F_A1]. "Cuando hacen las asambleas para decidir el tema que van a hablar, son ellos los que lo deciden entre ellos" [C2.2_E.F_M3]. "Al elegir la temática del proyecto, cada uno comunica aquello que quiere aprender, y entre todos se realiza una votación" [C2.2_E.F_AP]. 
En el caso del proyecto ¿Cómo pasa el tiempo? Betxí, nuestro pueblo fue la alumna de prácticas quien propuso el tema para realizar su Trabajo Final de Grado (TFG). “A. (se refiere a la alumna de prácticas) quería que la ayudáramos, entonces no podíamos hacer otro tema. Teníamos que ayudarla" [C2.2_E.F_A1]. Pero el alumnado prefiere proponer los temas y entre todos escoger. "A nosotros nos gusta más escoger" [C2.2_E.F_A1]. "Porque así proponemos más ideas y votamos lo que a nosotros nos parezca bien" [C2.2_E.F_A6].

Aun así, la temática propuesta es bien acogida por el alumnado. "A mí me ha interesado mucho porque como mis abuelos no son de Betxí, mi abuela es de otro lugar y mi abuelo es de Asturias" [C2.2_E.F_A4]. "Bueno no está mal, aunque yo no vivo aquí. Me interesa, está bien saberlo" [C2.2_E.F_A5]. Y también por los abuelos. "Lo primero que se tiene que conocer es eso" [C2.2_E.F_AB2]. "Tienen que conocer sus antepasados. Lo que ha sido el pueblo, lo que ha sido sus familias y lo que ha sido [...]. Hay familias que les preguntas como se llamaba el bisabuelo y ya no lo saben. Los niños de esta forma se van enterando de todo eso y siempre cuando preguntarás algo se acordarán [...] Los niños de estas edades tienen memoria y tienen mucho conocimiento y entienden todo lo que les dices" [C2.2_E.F_AB1].

Una vez ya está decidida la temática que abordarán a lo largo del proyecto pasan a realizar el acta de la sesión. "Para estudiar, Amèlia dice que hay que hacer actas. Porque así sabemos lo que hemos hecho y cuando seremos mayores podremos leerlas y saber todo lo que hicimos" [C2.2_E.F_A6]. "Siempre son ellos los que hacen una asamblea, porque además cuando nos pasan los proyectos hay un acta en la que ellos presentan varios proyectos y votan el proyecto que más les gusta para poderlo desarrollar" [C2.2_E.F_M5].

Además también se reflexiona sobre qué tipo de información necesitan para poder ver cómo el pueblo ha evolucionado. Entre todos llegan a la conclusión que quienes más saben sobre las cosas del pasado son los abuelos y las abuelas, los tíos y las tías, etc. Después, entre todos y todas, aportan ideas sobre cómo elaborar el acta. Por turnos, dicen que es lo qué se tiene que escribir mientras se redacta a la pizarra y cada niño lo copia al dictado en su libreta. En el acta se puede leer que la temática del nuevo proyecto de estudio no fue impuesta. Se planteó la propuesta y la mayoría estuvieron de acuerdo en trabajarla.

\section{Evaluación inicial: ¿Qué sabemos?}

Para comprobar qué conocen sobre el tema, sus capacidades y poder iniciar el proyecto, se realiza una evaluación inicial, para extraer lo que el alumnado sabe. Para ello, la alumna de prácticas prepara una ficha, para que cada alumno la realice de manera individual.

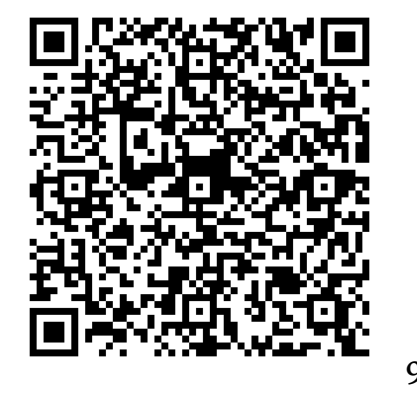

Preguntas de evaluación inicial del proyecto [C2.2_AM_FO]. 
Se pregunta sobre la percepción del pueblo, en cuanto a la cantidad de población y su extensión. También tienen que hacer memoria de los lugares de Betxí y otras cosas más generales que ven diariamente, sabiendo qué se han quedado atrás en el tiempo, qué han perdurado hasta ahora y qué han aparecido recientemente. Así, se observa si son conscientes que el paso del tiempo ha sido el responsable de estos cambios. Además, hay una parte con imágenes, donde tienen que saber qué es de ahora y qué era de antes. A partir de esta actividad, y tras la puesta en común, se va determinando que es lo que sabe el alumnado en referencia a su localidad.

En otros proyectos, una vez escogida la temática, el alumnado va diciendo aquello que conocen en relación al contenido objeto de estudio. La maestra lo va anotando en la pizarra, al mismo tiempo que el alumnado lo va copiando en sus respectivas libretas al dictado. "[...] hacemos 2 hojas que pone ¿Qué sabemos? y ¿Qué queremos saber? Y después buscamos información" [C2.2_E.F_A3].

\section{¿Qué queremos saber?}

A continuación, se extrae aquello que quieren saber sobre la temática. "La alumna de prácticas reparte las libretas y ponen el título. Amèlia pregunta al alumnado el tema del proyecto que van a estudiar para ver si todos lo tienen claro" [C2.2_O_NC]. Por turnos, aportan sus intereses y aquello que les gustaría aprender, la maestra lo apunta en la pizarra y el alumnado lo va copiando en su cuaderno. "Hacen hincapié en la escritura de algunas palabras (por ejemplo: esta palabra va con $b$ o con v). Amèlia dice que algunos niños están haciendo un esfuerzo por mejorar la letra" [C2.2_O_NC]. Recuerdan las tres principales fuentes de información para este proyecto: los abuelos, Internet y fotografías.

\section{$\sim$ Proceso de investigación y organización}

\section{de la información}

El alumnado mediante una nota informa a las familias, sobre la temática que van a trabajar, les solicitan su ayuda en la búsqueda de información o material sobre la temática. "Hacemos una carta a los padres, para buscar información" [C2.2_E.F_A3]. Es necesario remarcar que éste es el segundo año que los alumnos trabajan mediante los proyectos. En primero de primaria los alumnos tienen unas ayudas que poco a poco se les van retirando. Tal y como se puede ver en la Imagen 37, la nota a los padres está muy pautada, corresponde a la nota realizada en $1^{\circ}$ de primaria.

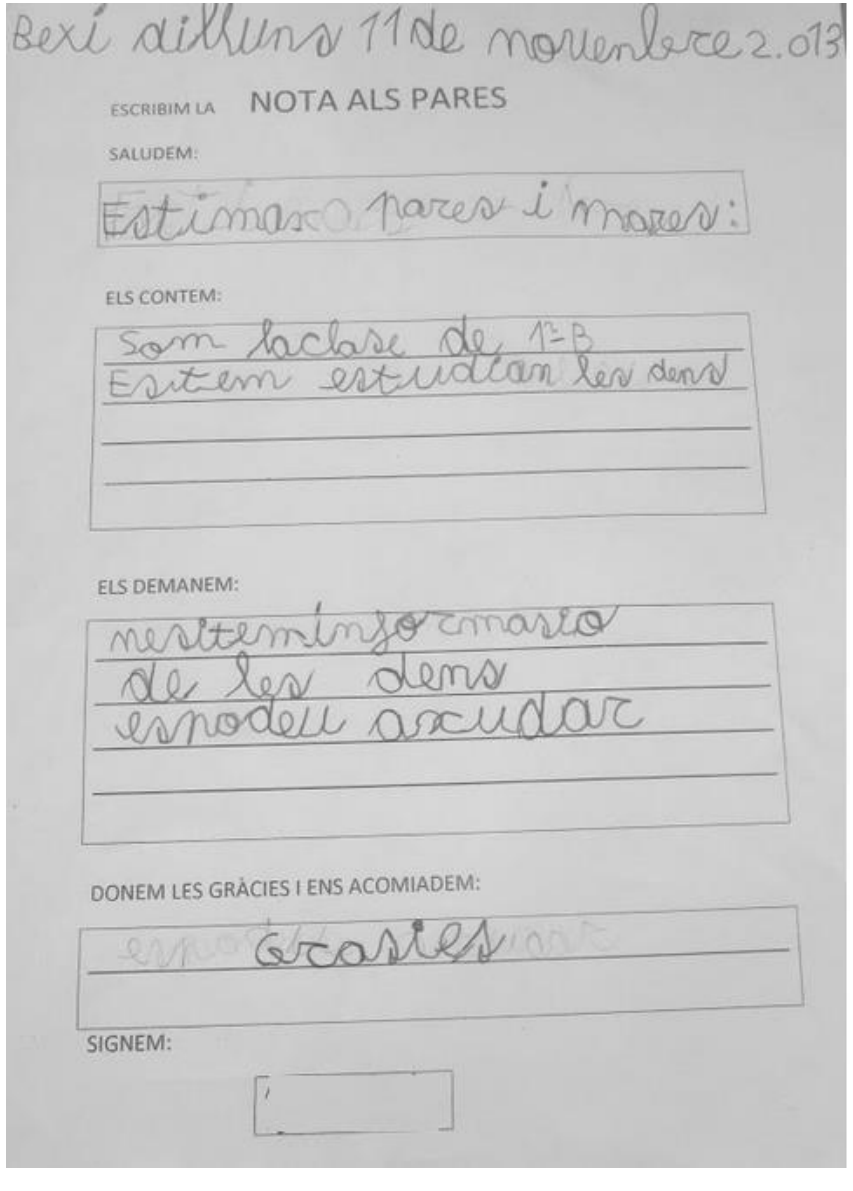

Imagen 37. Nota: pauta de escritura (1ํㅡㅁ primaria) [C2.2_O_FOM]. 
Dedican un tiempo a la búsqueda de información y material sobre el tema que van a estudiar. "Buscamos información en el ordenador o en la biblioteca o donde sea" [C2.2_E.F_A3]. La colaboración de las familias es clave en este momento.

"Según lo que los niños nos piden [...] depende del proyecto que sea, pues en este vinieron los abuelos y las abuelas y buscamos fotos y demás, en los otros nos han pedido más información [...] libros de casa o internet y demás. Depende de cada proyecto cómo sea pues nos piden unas cosas u otras, a las madres y a los padres y por tanto vamos dándoles información para que puedan hacer un cribado en clase y puedan coger lo que más les interese del proyecto..." [C2.2_E.F_M6].

El proyecto depende en gran medida de este paso, esto es, de la capacidad de investigación que adquiere el alumnado, puesto que condiciona la realización de las actividades siguientes. El alumnado investiga con las familias buscando información de Betxí. Se les concreta que tienen que aportar fotografías antiguas, éstas pueden ser de tradiciones, oficios, edificios, lugares, personas, etc.

Posteriormente, se dedica alguna sesión para tratar la información. De esta manera cada alumno muestra y explica a sus compañeros sus aportaciones. Con el objetivo de que las fotografías no se estropeen, la maestra las fotocopia o las escanea.

\section{$\sim$ Escribimos la carta para invitar a los abuelos y realizamos un guión de preguntas}

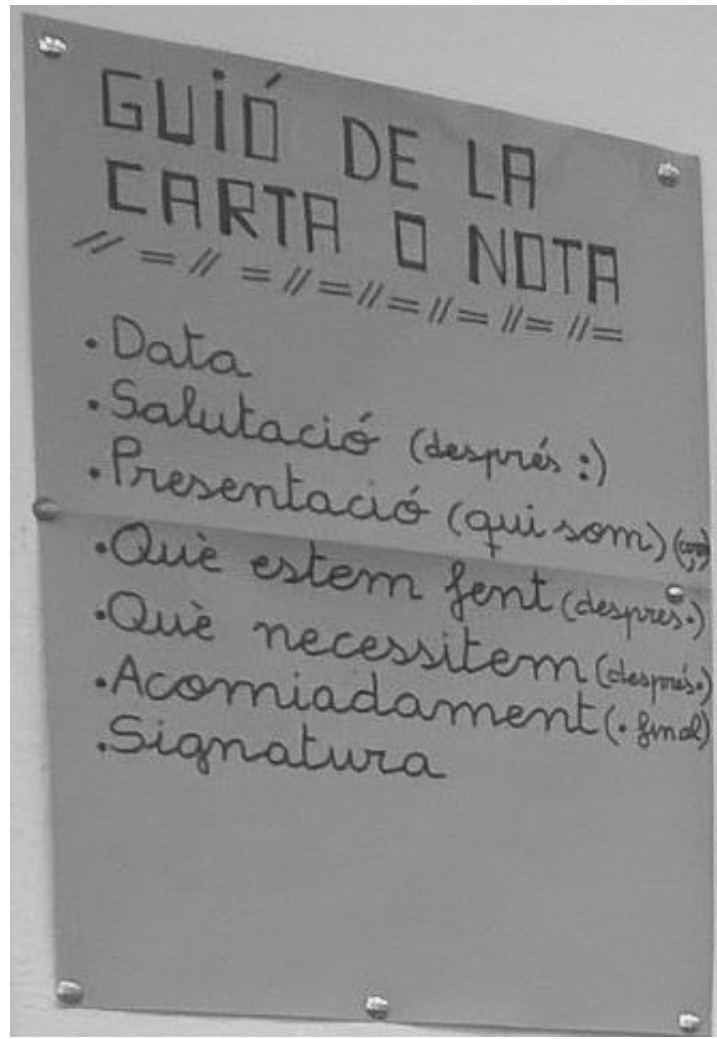

Imagen 38. Guión para escribir la carta o la nota [C2.2_O_FOM].
Los alumnos escriben una carta invitando a los abuelos al aula. Para ello, tienen un guión que les sirve de pauta para recordar las partes de la carta (Ver Imagen 38). La carta es un elemento que suele estar presente en la mayoría de los proyectos de trabajo. Además, la escritura es muy funcional, surge por necesidad. "Tú tienes la necesidad de escribir, tienes una finalidad $y$ es un texto que sirve para algo y todos nos ponemos a la tarea de preparar ese texto, entonces es ahí donde decimos que el trabajo es por parejas o en grupo para ir ayudando a los que están un poquito en otro nivel, que vayan avanzando" [C2.2_E.F_D2]. "Vamos viendo que cada vez que lo van utilizando pues van mejorando. [...] Vas utilizando los conceptos que necesitas para seguir avanzando" [C2.2_IP.HR_D2].

A medida que se va avanzando la forma de realizarla varía. Por ejemplo, en $1^{\circ}$ de primaria la escritura de la carta es mucho más dirigida. Esto es, entre todos van comentando los puntos de la carta, la maestra lo escribe en la pizarra y los alumnos la van copiando al dictado en su cuaderno. Además, el alumnado cuenta con una hoja auto correctiva 
(Ver Imagen 39), para que los propios alumnos reflexionen sobre su carta y se den cuenta si les falta algún elemento indispensable en ésta.

\begin{tabular}{|l|l|l|}
\hline He posat la data? & \multicolumn{1}{|c|}{ Ni No } \\
\hline He escrit la salutació? & & \\
\hline He dit qui som? & & \\
\hline He explicat el que volem? & & \\
\hline He posat la data que ho farem? & & \\
\hline He dit el lloc i l'hora? & & \\
\hline & & \\
\hline M'he acomiadat? & \\
\hline
\end{tabular}

Imagen 39. Hoja auto correctiva para escribir la carta [C2.2_O_FOM].

En esta ocasión, al tratarse del $3 r$ trimestre la maestra le da al alumnado la consigna de hacer un borrador de la carta a los abuelos de manera individual. Para después, comentarla y mejorarla entre toda la clase. "[...] primero lo hicimos cada uno solo. Amèlia vio que faltaban algunas cositas y entonces lo hicimos todos juntos en la clase" [C2.2_E.F_A3]. "Si, después lo escribimos todos a la pizarra y nos salió muy bien y los abuelos se alegraron" [C2.2_E.F_A4].

Se hace especial hincapié en la escritura de dicha carta, ya que es importante que lo hagan muy bien para que los abuelos les entiendan. "Cuando hacemos un borrador o eso, cuando hacemos la carta a los abuelos, hay que hacerlo con mucho cuidado para que lo entiendan bien" [C2.2_E.F_A1].

"Amèlia les dice a los alumnos que hay muchos abuelos que no saben leer si no está muy bien hecha la carta. Amèlia pone música para ir trabajando. Hace punta al lápiz de Pinocho (un lápiz que ha traído À. la alumna de prácticas). Amèlia deja escribir un trozo de la carta con el lápiz de Pinocho sólo a aquellos alumnos que están trabajando. Es un elemento que funciona, el alumnado se centra en la tarea y les gusta escribir con dicho lápiz" [C2.2_O_NC].

Entre todos y todas escriben una carta a partir de la cual se dirigen a los mayores para invitarlos.

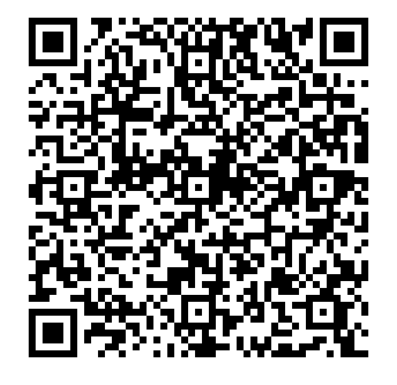

Ejemplos de cartas para invitar a los abuelos [C2.2_AM_FO].

Antes de la sesión con las personas mayores, el alumnado prepara un guión de preguntas para hacer una pequeña entrevista a los abuelos. "PREGUNTAS A LOS ABUELOS: ¿Cómo os llamáis?, ¿Cuántos años hace 
que vivís en vuestro pueblo?, ¿Nacisteis en nuestro pueblo?, Si no, ¿cuándo vinisteis?, ¿Cuándo erais pequeños el pueblo era igual?, ¿A quéjuegos jugabais? y ¿Cómo vestíais?”[C2.2_O_FOM].

\section{$\sim$ Los abuelos nos visitan: recuperación de la historia oral del municipio de Betxí}

Concretamente, se dedican tres sesiones donde diferentes abuelos asisten al aula y les cuentan o comentan aspectos relacionados en el transcurso del tiempo en su municipio. "Los abuelos que también vinieron, dijeron cosas que no sabíamos y preguntamos. Y preguntamos cómo era la Navidad entonces [...]" [C2.2_E.F_A6].

La dinámica de las tres sesiones es similar, se proyectan las fotografías antiguas escaneadas y se da la voz a los abuelos, ellos son la principal fuente de información oral. A lo largo de estas sesiones se va confeccionando La galería de Betxí (Ver Imagen 40), puesto que al mismo tiempo que se trata cada fotografía, se va conociendo que hay en ella y su año aproximado, cada alumno, después de ser comentadas, coge una,

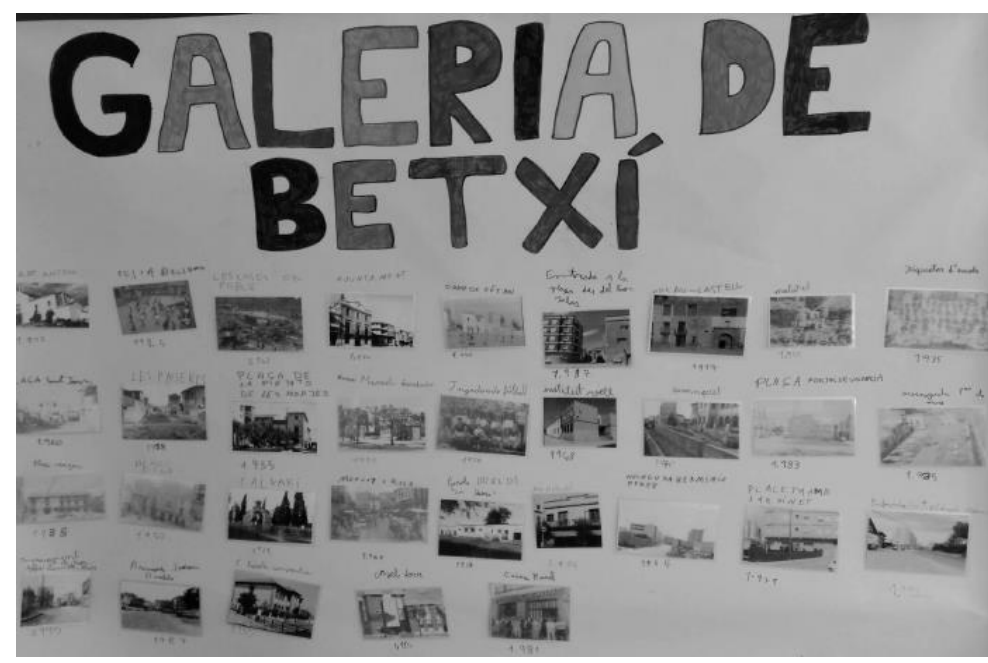

Imagen 40. Galería de Betxí [C2.2_O_FOM]. la pega al mural y escribe arriba el nombre que le corresponde y a bajo el año. "Un abuelo comenta que una foto debe de ser de hace 70 años. Los alumnos calculan el año aproximado para ello se sitúan en el año actual, el 2015, y tienen que contar hacia atrás 70 años, hacen la resta y datan la fotografía del año 1945" [C2.2_O_NC].

En la primera sesión, se cuenta con la presencia de dos abuelos y cuatro abuelas. La gente mayor, junto a los alumnos y las maestras se sientan formando un gran círculo. Se da el turno de palabra a los alumnos para hacer algunas de las preguntas que habían preparado. Posteriormente, se proyectan algunas imágenes en el proyector, lanzando preguntas como ¿Qué es esto?, ¿Alguien conoce este lugar?, ¿Dónde está?, etc. [C2.2_O_NC]. Se proyecta también la imagen actual del lugar, de forma que, al alumnado, les queda claro como era antes y cómo es ahora. Al terminar esta sesión entre todos comentan los principales aspectos que les han contado los abuelos del municipio. "Amèlia les pregunta que han aprendido. Después, D. una alumna de Rumanía ha traído unas fotografías antiguas de su familia, la alumna las enseña a sus compañeros y comentan algunos aspectos, se centran especialmente en vestimenta, entre otros aspectos. Amèlia le da las gracias por traer esa información" [C2.2_O_NC].

La segunda sesión siguió la misma dinámica. En esta ocasión, asistieron tres abuelas y tres abuelos. También explicaron sobre los antiguos oficios que han desaparecido, con qué y cómo jugaban cuando eran pequeños y que hacían en su tiempo libre. Una abuela cantó algunas canciones y todos las bailaron. 
En la tercera sesión, acudieron doce mayores, alumnos de la Escuela de Personas Adultas (E.P.A.) de Betxí. Se empezó con una presentación de los asistentes y se continuó con el mismo procedimiento que se había realizado en las dos anteriores sesiones.

Los alumnos valoran muy positivamente la ayuda ofrecida por los abuelos y los alumnos de la Escuela de Personas Adultas (E.P.A.) de Betxí. "Nos ha parecido bien porque estaban interesados por ayudarnos y hemos aprendido más con los abuelos" [C2.2_E.F_A6]. "Vino mi abuela a explicarnos el bar S. Y lo que más me gusta de ese tema fue los 'mantecaos' "[C2.2_E.F_A3]. "Además, nos hicieron uno" [C2.2_E.F_A4].

Para las personas mayores también es muy gratificante poder ayudar en el aula en el transcurso del proyecto de Betxí. "Es muy bonito saber cómo ellos cogen o enfocan la enseñanza" [C2.2_E.F_AB1].

"Yo había venido varias veces con las nietas que tengo más grandes. Siempre que me lo han pedido. A hacer trabajos, incluso a ayudarles a hacer disfraces cuando ha sido carnaval y a todo lo que me han pedido, a verlos cuando hacen los exámenes orales (se refiere a las exposiciones orales de los proyectos) [...]Me encanta colaborar y venir siempre que me lo pidan. ¡Es magnifico! He venido también a hacer examen... digamos pruebas de matemáticas para colaborar con ellos. Colaborar en grupos (se refiere que ha participado también en los grupos interactivos), también he venido a los grupos con ellos, con los niños y me gusta" [C2.2_E.F_AB4].

$\mathrm{Al}$ asistir al aula y aportar su conocimiento sobre el proyecto demuestran que tienen interés por lo que realizan sus nietos. "Con estas cosas podemos dar testimonio, y les demostramos que tenemos interés por lo que ellos están haciendo al venir a la escuela" [C2.2_E.F_AB2]. Asimismo, el grado de implicación de los mayores es muy elevado.

"A mí me dijo mi hija, porque yo traía también documentación, además traía canciones apuntadas de cómo lo hacíamos [...] Un libro que son las primeras escuelas que se hicieron aquí. Entonces... por si acaso me preparo de alguna canción que cantábamos antes o de conforme jugábamos. También me había hecho dos hojas y también me había preparado más o menos unas canciones. Hablé con una amiga que aquella aún tiene más memoria y lo tengo ahí anotado. Por si no eran todo fotografías y era una base de como jugábamos. Todo eso lo tenía yo preparado por si querían hacer alguna cosa (la mujer enseña una bolsa llena de fotos, papeles con canciones, juegos...)" [C2.2_E.F_AB5].

Igualmente, su aportación en el aula la conciben como una responsabilidad. "Yo en un principio hasta tenía miedo y todo [...] por si me ponían en un compromiso. Porque es que en casa te hacen unas preguntas que dices: 'Éste niño de donde ha sacado esto'. Te ponen... ya no la tuya, sino los otros. Y cuando ya vine y me dijo Amèlia: 'No es que vienen más abuelos'. 'A tranquila pues...' " [C2.2_E.F_AB2].

Los mayores valoran muy positivamente la participación de las familias en el aula. "Yo pienso que repercute mucho, muy favorable. Todo esto que vengan las familias" [C2.2_E.F_AB4]. "Porque saben cosas de antes que ahora ya no se hacen" [C2.2_E.F_AB5]. Se trata de un aprendizaje más humano y cercano. "Aunque hoy tienen todo esto de los ordenadores" [C2.2_E.F_AB3]. "Información y todo, pero a ellos les estimula mucho que vengan los abuelos y los padres. Les da alegría [...] ]esto es más humano" [C2.2_E.F_D2]. 


\section{$\sim$ Carta y visita del historiador}

Se comenta al alumnado la idea de solicitar ayuda a un historiador. Por eso, se les pregunta: “¿Cómo podríamos saber cosas de nuestro pueblo de hace muchos años antes de que los abuelos habían nacido? ¿Quién nos podría contar cosas que los abuelos no conocen?" [C2.2_O_NC]. Se dialoga al respecto y se llega a la conclusión que un experto en historia les podría ayudar. Más tarde, escriben una carta para invitarlo.

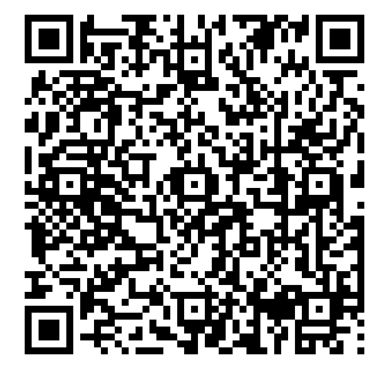

Ejemplo de carta al historiador [C2.2_AM_FO].

En cuanto a la visita, el historiador mostró un mapa de la localidad en el proyector donde se podía observar cómo se había ampliado el municipio desde el siglo XIV hasta el siglo XXI. El historiador, comentó cómo era el pueblo en aquellos años, qué había, cómo estaba formado y cuáles eran sus límites. A continuación, se siguió con la misma dinámica que la realizada en las sesiones con los mayores, para datar algunas fotografías. El experto les enseñó algunas técnicas para datar aproximadamente las fotografías, observando la calidad de la fotografía, si hay vehículos, los tipos de casas, calles, etc.

\section{$\sim$ Visitamos el Barranquet y el casco antiguo de Betxí}

Toda la clase fueron a visitar el comienzo del Barranquet, e hicieron el recorrido por donde iba el agua. "El Barranquet nos pareció muy chuli y nos dijo Amèlia que si el Barranquet lo hubieran tapado se habría inundado todo Betxi" [C2.2_E.F_A1]. "Fuimos al Barranquet para ver de dónde empezaba y después cuando llegamos a clase, pues nos hicieron preguntas" [C2.2_E.F_A3]. "Salimos al pueblo y nos situamos porque claro, ellos no sabían que había habido un "Barranquet", que estaba tapado, les resultó súper curioso. Fuimos a ver de dónde comenzaba el "Barranquet" que estaba tapado y que iba hasta el rio [...." [C2.2_E.F_D2].

Otro lugar del municipio que se visitó fue por donde limitaba la localidad antiguamente, es decir, por donde estaban situadas las paredes de la muralla. Se paseó por distintas calles. Vieron una placa en la cual había inscrito "siglo XVI". Se observaron detenidamente algunas casas antiguas que todavía se conservan, viendo sus características y comparándolas con las actuales. Por último, se visitó la Plaza Mayor y el Palau-Castell. Dónde se les explicó la fachada y vieron los restos de las antiguas columnas y el foso. Se prestó atención, también a un plano antiguo donde se podía ver el casco antiguo rodeado por la muralla. 


\section{$\sim$ Trabajamos con mapas y recorremos el municipio en Google Maps}

Se proporcionó un mapa del municipio de Betxí a cada niño y se realizó un trazo en el mismo marcando el recorrido del Barranquet.

"Después teníamos un mapa, un plano del pueblo de Betxí. [...] Ellos se fueron situando donde vivían, en ese plano, e hicieron el recorrido. Eso les gustó mucho y se lo llevaron para ellos. Estuvo muy bien porque comparando cómo era Betxí antes, conocieron cómo es Betxí ahora también porque se situaron en el plano y donde vivía cada uno, si era la parte antigua del pueblo o si era la parte nueva. Las calles de la parte nueva que eran mucho más... y ellos iban distinguiéndolo todo. Quiero decir que estuvo muy bien" [C2.2_E.F_D2].

Así pues, aparte de la visita por los diferentes lugares del municipio, después se proyectó, en el proyector, el mapa de la localidad mediante Google Maps. "Pusieron el mapa en la pantalla del pueblo y todas las casas. Y se veía todo" [C2.2_E.F_A3]. Y se hizo el mismo recorrido de manera virtual desde el principio del Barranquet, hasta su desembocadura. Mientras se hizo el recorrido, se pausó en algunos lugares para comentarlos y explicaron cómo eran antes y algunas cosas que ya no están en la actualidad. Para finalizar, se buscaron las casas del alumnado, para verlas proyectadas.

"En la pizarra digital, en el Google Maps, fuimos recorriendo todo el pueblo, el lugar por donde pasaba el "Barranquet" y diferentes lugares del pueblo [...] también salimos para ver lo que era lo más antiguo del pueblo, los tipos de calles, calles estrechas, calles que no eran rectas, [...]. Vino el historiador y nos habló de cómo se inició el pueblo, pues fuimos a esas calles donde el principio, el pueblo era pequeñito y comenzó... hicimos diferentes salidas y en el Google Maps aprovechamos mucho..." [C2.2_E.F_D2].

\section{$\sim$ Recapitulación por escrito del proceso de investigación: elaboración del dossier}

Cabe señalar que durante este proceso de confección del dosier una alumna trae una poesía a clase (Ver Cuadro 4). "En una cosa que dice uno aprenden todos los otros, como la información. Por ejemplo, un tío mío me ha dado una poesía que yo no me sabía nada y ya me la he aprendido" [C2.2_E.F_A4].

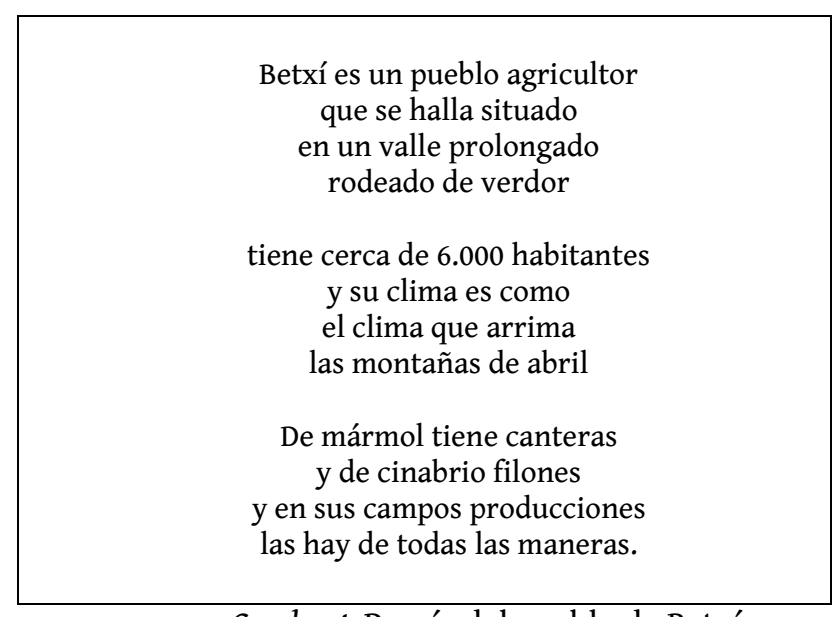

Cuadro 4. Poesía del pueblo de Betxí.

Después de ser leída en clase, centran su atención en la estrofa "tiene cerca de 6.000 habitantes". Entonces, entre todos reflexionan sobre qué quiere decir. Después, realizan una lista de números que 
están cerca del 6.000. Con la excusa de la poesía se han trabajado las aproximaciones numéricas y el cálculo mental.

Mediante asamblea, se van recordando y recogiendo las temáticas que han ido emergiendo a lo largo del proceso de investigación sobre ¿Cómo pasa el tiempo? Betxí, nuestro pueblo. El alumnado va diciendo aquellos subtemas que han ido interiorizando a lo largo de todas las sesiones. La alumna de prácticas anota en la pizarra las ideas que van surgiendo, de esta manera se recogen un total de veintiséis temas. A continuación, se presentan los temas a trabajar que han surgido en asamblea (Ver Cuadro 5).

1. Barranquet (Les passeres)

2. El mercado en la plaza

3. El sereno

4. La vaquería

5. La acequia (¿Cómo se lavaba la ropa?)

6. El afilador

7. San Antonio

8. El pozo y las fuentes

9. El matalasser

10. Los cadafals y las barreras

11. El bar Salas

12. El ayuntamiento y el alguacil

13. El zapatero
14. El trabajo al campo
15. Bebederos
16. La panderola y los carros de caballos
17. La escuela Dualde y la de monjas
18. Los corrales
19. El campo de fútbol
20. El instituto
21. El cochero y el cartero
22. El taxista
23. Los juegos
24. El llanterner
25. El trapero
26. El herrero

Cuadro 5. Listado de subtemas del proyecto [C2.2_O_NC].

En otra asamblea se reparten los temas por parejas. Habitualmente, la confección del dosier lo trabajan en el equipo con el que están sentados. "Cuando son los proyectos cada 'mesa' hace un tema. Y como cada 'mesa' hace un tema y no se deciden mucho, hacemos un sorteo a veces" [C2.2_E.F_A6]. En esta ocasión, lo realizan por parejas. "El último proyecto que hicimos era de dos parejas no de cuatro personas, era de dos personas" [C2.2_E.F_A6]. Una vez están claras las parejas, se reparten las temáticas a trabajar cada una de ellas. "Pues algunos hacen una cosa y otros hacen otra. Por ejemplo, una pareja hace dos hojas o una" [C2.2_E.F_A5]. "Bueno, escogimos dos [...] como había tantos temas en parejas terminamos antes" [C2.2_E.F_A6]. "En los temas que estamos haciendo el libro para enseñarles a los padres pues cada uno trabaja de una cosa" [C2.2_E.F_A3].

Una vez distribuidas las temáticas que conforman el proyecto de Betxí se dedican unas sesiones a la redacción y descripción de cada uno de los subtemas. "Mira cuando hacemos el proyecto cada uno no escribe lo mismo, cada uno hace su cosa. A mí me parece muy chulo porque yo no sé lo que están haciendo y les pregunto ¿vosotros que estáis haciendo? Y me parece muy interesante y a nosotros nos lo preguntan y a ellos también les parece muy interesante" [C2.2_E.F_A1]. Como ya se encuentran en el 3r trimestre, en una hoja ponen el título del tema y los alumnos por parejas realizan un breve texto con las explicaciones de lo que saben sobre los asuntos en cuestión. "Nos da la hoja que tenemos que escribir y todo y nos lo da en nuestra mesa y nuestros compañeros y ya está" [C2.2_E.F_A2]. Posteriormente, se lo corrigen ellos mismos (Ver Imagen 41). Para ello, la maestra pasa los escritos a ordenador y los imprime sin ningún tipo de corrección, tal y como lo redactan. "Primero hacemos un borrador y después lo pasamos todo a limpio" [C2.2_E.F_A1]. Seguidamente, se 
subrayan las palabras a corregir y entre comillas alguna frase o fragmento que puede ser que no tenga sentido, y el alumnado reescribe el texto ya corregido. De este modo el alumnado tiene la posibilidad de detectar sus propios errores y aprender a corregirlos. La maestra realiza una segunda corrección y se procede a la confección del dossier. "Amèlia nos da una hoja grande, así muy grande y escribimos lo que sabemos [...] y algunas veces pegábamos fotos. Al final Amèlia hace unas fotocopias recorta un trozo y cada uno se lleva uno para estudiarlo. $Y$ aún tengo el de Egipto" [C2.2_E.F_A3]. Cada pareja pasa a limpio sus escritos en unas hojas DIN A3. Después, de todas las fotografías sobre las que han estado trabajando eligen la correspondiente a su tema y la pegan en el dossier. Cuando lo terminan, lo

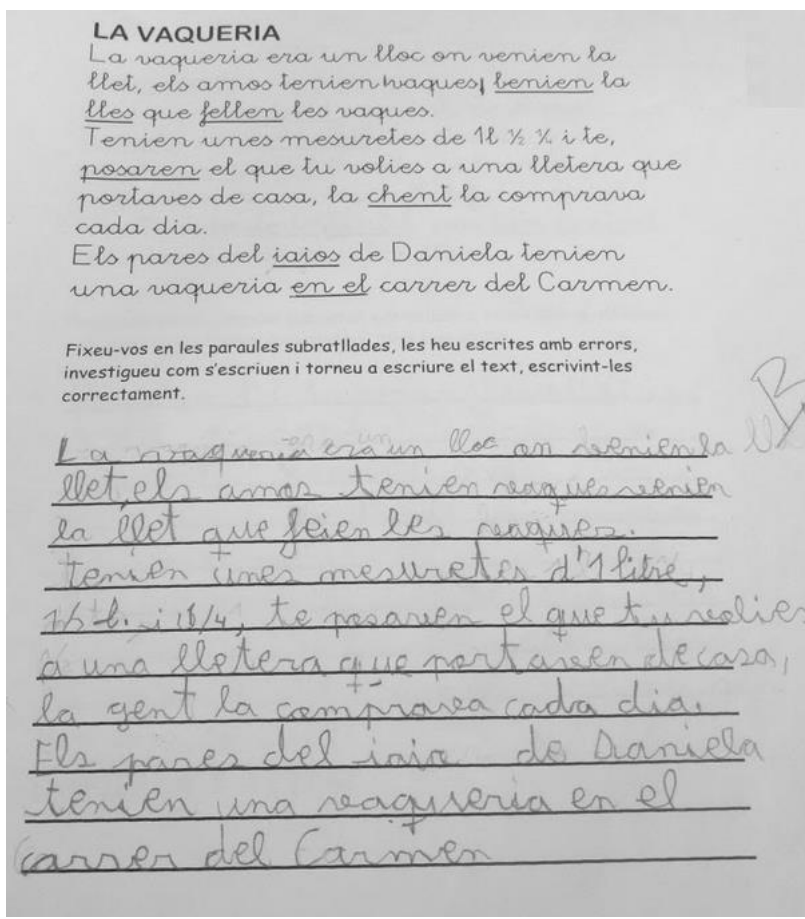

Imagen 41. Elaboración del texto [C2.2_O_FOM]. decoran y hacen la portada y algunas hojas de manera conjunta, por ejemplo, el índice o la bibliografía.

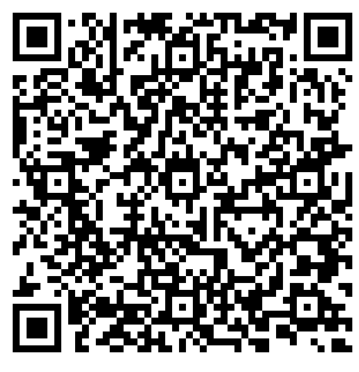

Dosier de ¿Cómo pasa el tiempo? Betxí, nuestro pueblo elaborado por el alumnado [C2.2_AM_DO].

\section{El juego del paso del tiempo en Betxí y confección del eje cronológico}

Se realiza un juego, a través del cual se pone en práctica todo lo aprendido de una manera lúdica. Los materiales se confeccionan con las fotografías trabajadas en la galería de Betxí y las fotografías actuales referentes a estas, proporcionadas por la docente. Además, todas las fotografías, en el dorso, presentan escrito el año aproximado de su fecha, también se hacen unos carteles con el nombre del lugar que representan las fotografías.

El juego se compone de tres actividades diferentes, pero encaminadas hacia unos objetivos comunes. La maestra y la alumna de prácticas organizan todas las fotografías por parejas, es decir, la antigua con la actual y se reparten equitativamente en tres grupos para realizar cada actividad. 
"Todo el alumnado se distribuye en 3 grupos de 9 alumnos cada uno, ya que falta una alumna, para realizar cada uno una de las actividades. En el aula se habilitan 3 espacios, de manera que en cada uno de éstos se realiza una actividad y a la señal de la docente, transcurridos unos 15 minutos aproximadamente, los grupos cambian de actividad. La maestra y la alumna de prácticas van pasando por las mesas y ayudan a quien lo necesita" [C2.2_O_NC].

Seguidamente, se describen las tres actividades realizadas simultáneamente.

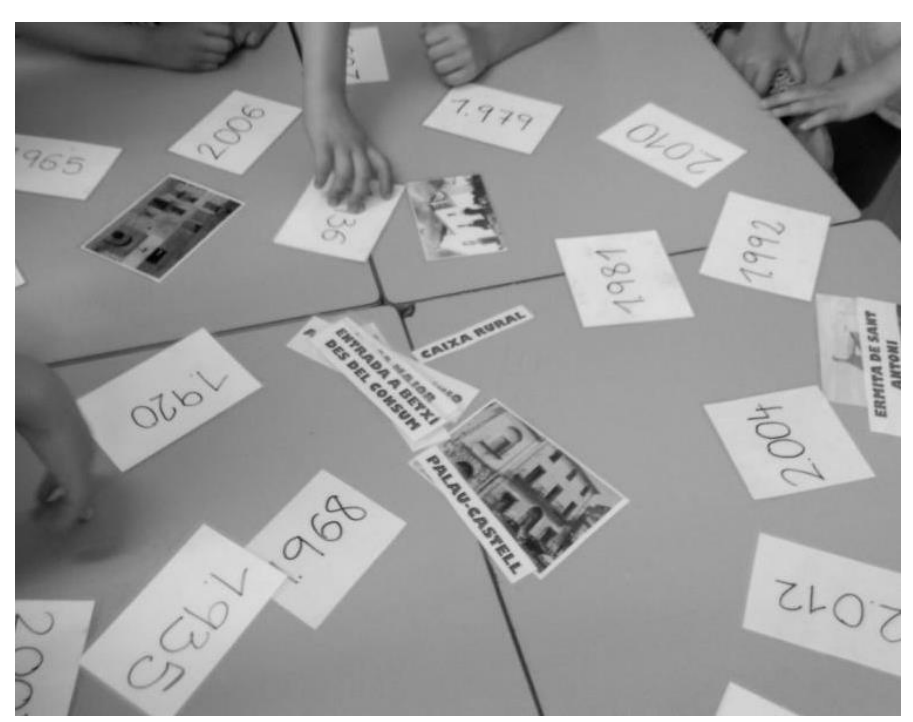

Imagen 42. Actividad 'encuentra la pareja' [C2.2_O_FOM].

1) Encuentra a la pareja: esta actividad consiste en emparejar las dos fotografías, la antigua y la actual (Ver Imagen 42). "[...] era de hacer parejas y un número (se refiere al año de datación de cada fotografía), tenías que hacer a ver cuál estaba más cerquita porque a lo mejor esa era la pareja de ese ¿sabes? De antiguo y más nuevo" [C2.2_E.F_A2]. Todas las fotografías están depositadas boca abajo de manera que solamente se puede ver el año referenciado. El alumnado debe ir levantando cada una de las fotografías y emparejarlas con su pareja. Por turnos, los alumnos van descubriendo dos fotografías si son parejas se las guardan y si no lo son las vuelven a poner boca abajo. El juego termina cuando están todas las fotografías emparejadas. "Los alumnos tienen como pista que si una foto es del año 1965, saben que la otra será hacia el año 2000. La participación es muy alta, los alumnos están de pie impacientes esperan su turno" [C2.2_O_NC].

2) Organizamos por parejas: cada cual dispone de una ficha (Ver Imagen 43) con unos vacíos que tienen que llenar con fotografías y tarjetas de los años y los nombres de los lugares, que se encuentran mezcladas encima de la mesa. "Y aquí estaba yo con I. Me veo una cosa que...cogí una cosa que era del antiguo, antiguo...Por ejemplo, yo cojo y pongo..." [C2.2_E.F_A1]. "Casal joven ¿no? Y pongo casal joven antiguo y casal joven nuevo, y aquí ponía los años que tenía el casal joven y el antiguo y aquí

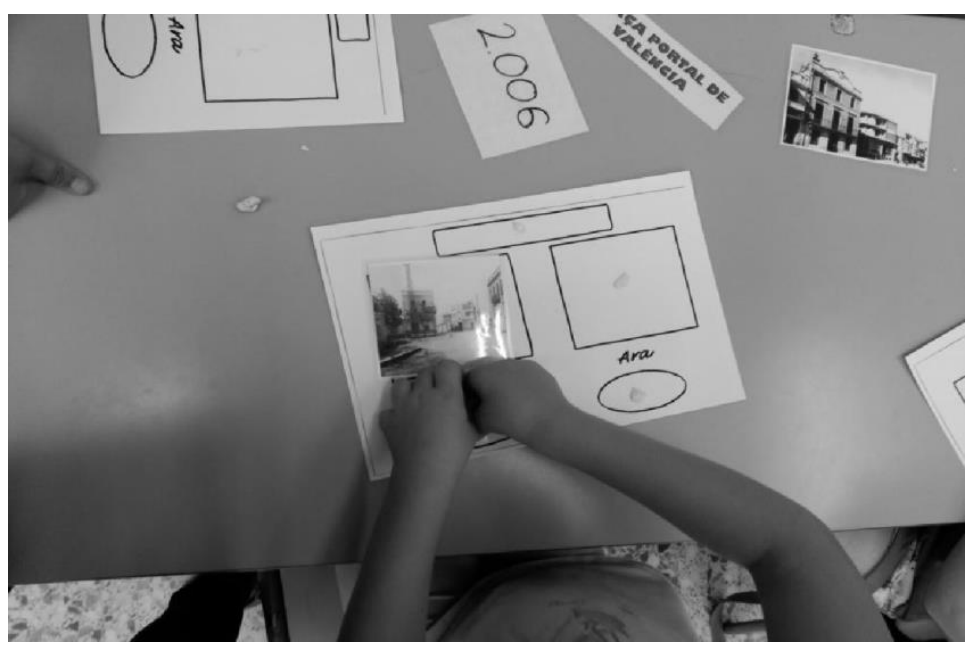

Imagen 43. Actividad 'organizamos por parejas' [C2.2_O_FOM]. los años que tiene esa foto de ahora" [C2.2_E.F_A2]. Las fotografías, los años y los nombres se tenían que pegar con Blu-Tack. 
3) Buscamos las diferencias: cada cual dispone de una ficha (Ver Imagen 44) con unos vacíos que tienen que llenar con fotografías y los datos que se indican. Cada cual tiene que elegir una fotografía, buscar la pareja y pegarlas con Blu-Tack en la hoja. También tiene que buscar la tarjeta del nombre y escribirla en el lugar correspondiente de la ficha y lo mismo con los años. Hay cuatro líneas donde tienen que escribir cuatro diferencias que encuentran entre la fotografía más reciente y la fotografía más antigua. "Colocan el adaptador a M. porque en esta actividad tiene que escribir" [C2.2_O_NC].
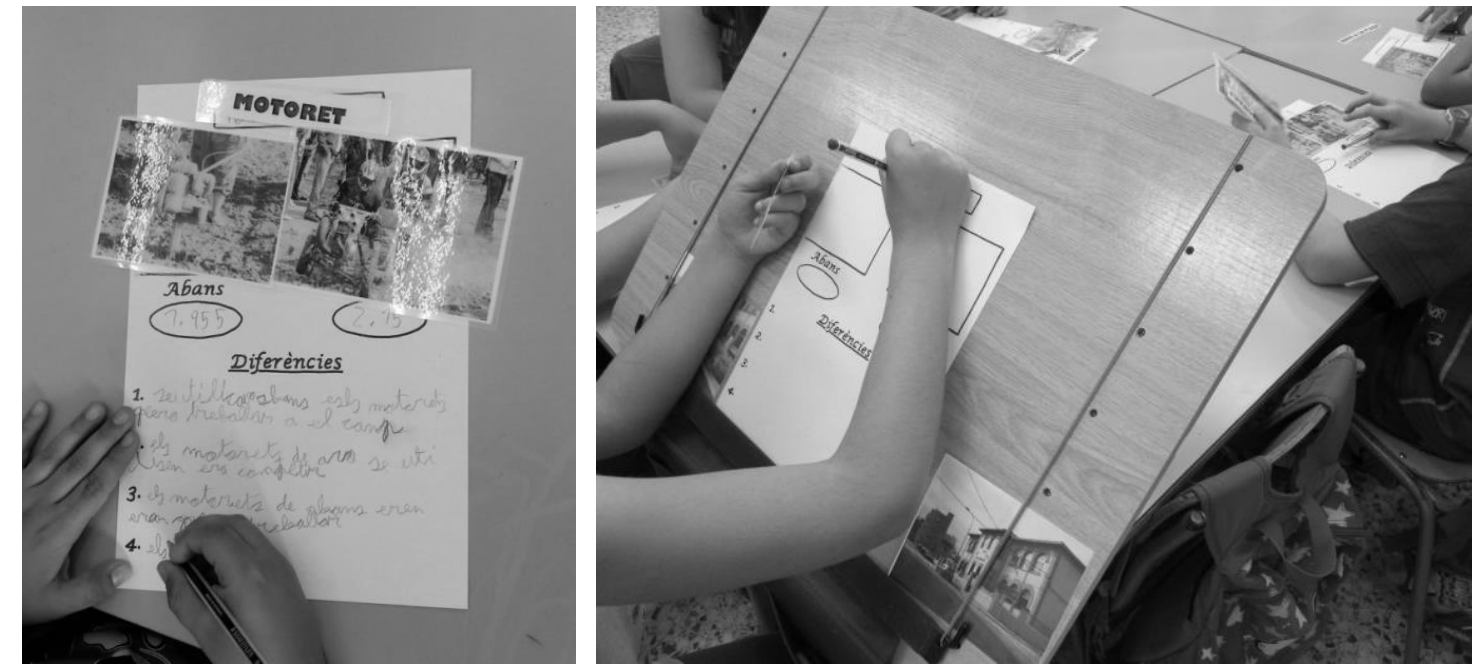

Imagen 44. Actividad 'buscamos las diferencias' [C2.2_O_FOM].

"Entra la maestra de audición y lenguaje, 2 alumnos tienen que salir con ella, pero no lo hacen. La misma maestra de audición y lenguaje habla con Amèlia y como están haciendo un juego del proyecto, los alumnos no salen del aula. Amèlia me comenta que esto lo suelen hacer más veces dependiendo de la actividad que están haciendo en ese momento. Hay veces que la maestra de audición y lenguaje se queda en el aula otras veces no" [C2.2_O_NC].

Posteriormente, el juego cuenta con una actividad final que la realiza de manera colectiva todo el grupo clase. Consiste en organizar todas las fotografías desde la más antigua hasta la más reciente. Se juntan todas las fotografías del juego y se mezclan. Se cuelga en el aula un cordel largo atravesándola diagonalmente, a la altura del alumnado. "À. la alumna de prácticas pregunta al alumnado si saben que es un eje cronológico. Los alumnos están sorprendidos porque hay una gran cinta colgado de punta a punta del aula. Tienen que ordenar las fotografías de más antiguo a más reciente en el tiempo, por eso escriben a la pizarra los símbolos de > y<" [C2.2_O_NC]. Como ayuda cuelgan la foto más antigua, la cual está datada de 1917 y la más reciente de 2013. Los alumnos van saliendo por parejas, se les da una fotografía al azar y entre ambos la localizan en el eje cronológico (Ver Imagen 45). Se les pregunta: “¿Qué es? y ¿De qué año es?" [C2.2_O_NC]. Seguidamente, razonan y

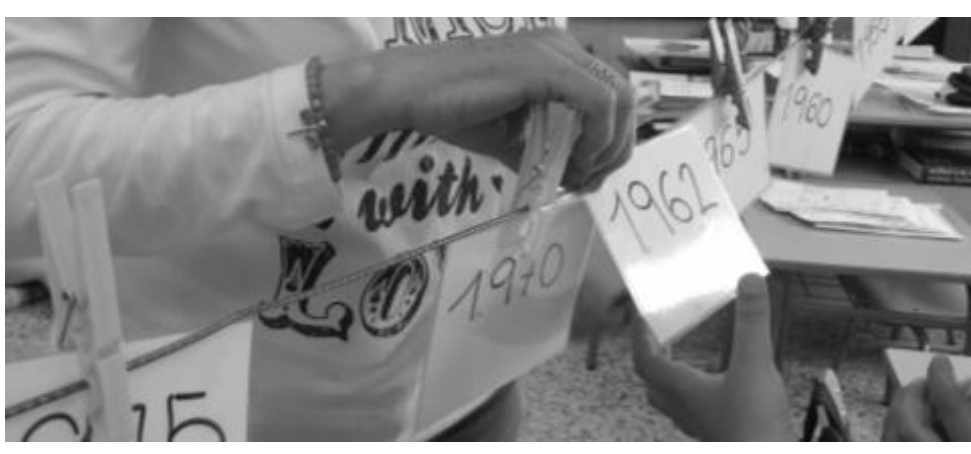

Imagen 45. Confeccionando el eje cronológico [C2.2_O_FOM]. 
deciden donde las tienen que colgar, de más antigua a más actual, fijándose en el año escrito al dorso y construyendo así una tira cronológica.

Después de colocarlas, se pregunta a los demás si está bien y, si es necesario, se corrige.

"Amèlia va anotando a la pizarra los niños que se están portando bien y les dice que esos serán los próximos en salir. Llama a la puerta una alumna de prácticas que está en una clase de 3․ Viene a solicitar ayuda a la clase de $2^{\circ}$ «B» puesto que les ha aparecido una fotografía antigua y una actual en el libro. A la tarde vendrán a que les expliquen qué es lo que están haciendo. Amèlia les comenta que es una suerte que alumnos más mayores vengan a solicitarles ayuda, se están convirtiendo en unos expertos sobre el paso del tiempo" [C2.2_O_NC].

Se van trabajando las aproximaciones numéricas y los números más grandes que y más pequeños que. Transcurridos los 45 minutos llega Mati porque tiene desdoble, pero los alumnos continúan con la actividad. Los alumnos continúan saliendo de dos en dos, ahora se les da dos fotos. A continuación, en la Imagen 46 se presenta una perspectiva del eje completo.

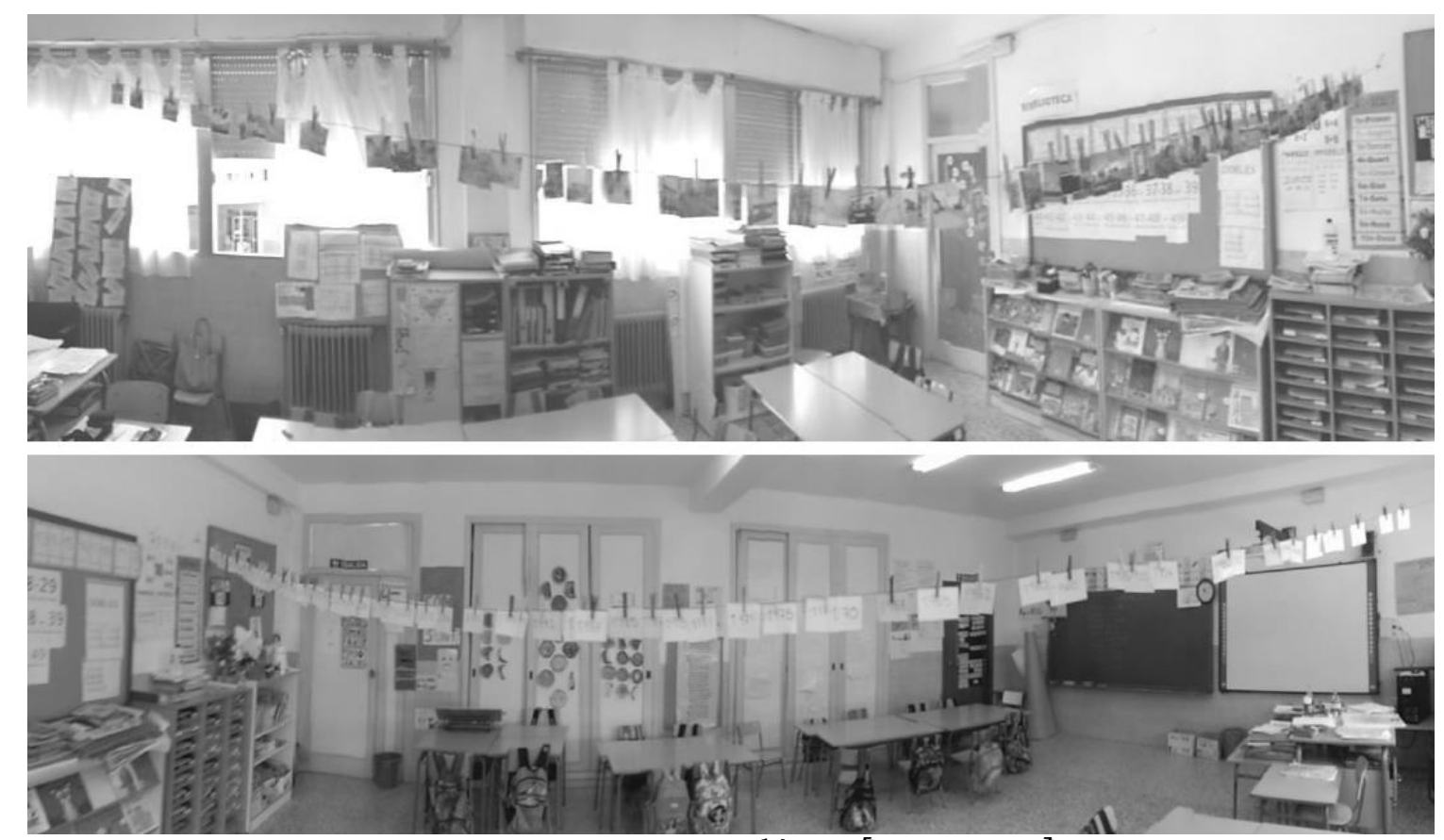

Imagen 46. Eje cronológico [C2.2_O_FOM].

\section{$\sim$ Exposición oral}

Una vez ya se ha finalizado la elaboración del dossier, se dedican algunas sesiones para preparar la exposición oral a la cual asisten familiares, estudiantes de la Escuela de Personas Adultas (E.P.A.) de Betxí y compañeros de diferentes cursos del CEIP Cervantes Dualde de Betxí. Para facilitar la asistencia, los alumnos realizan dos días de exposiciones orales, en un día hacen una sesión a la cual acude el alumnado de la E.P.A. y en otro día realizan dos exposiciones en diferente franja horaria a las que acuden familiares y compañeros del centro escolar según su disponibilidad. "Cuando te presentan un 
trabajo que han hecho te hacen por la mañana, te lo hacen por la tarde, porque como los padres ya te están diciendo que la mayoría trabajan pues a lo mejor uno trabaja por la mañana y otro trabaja por la tarde..." [C2.1_E.F_AB2].

Anteriormente, a estas sesiones, se distribuyen la información para exponer y se realizan diferentes ensayos. "Cuando ya tenemos todo preparado del proyecto que tenemos que hacer entonces Amèlia coge y hace las fotocopias [...] y prepara el proyector y todo, nos hace fotocopias y recorta a cada uno lo que presenta. Por ejemplo, yo soy del equipo de I. ¿no? Y coge y me dice Amèlia '¿Tú quieres ser el primero en presentar?' y yo digo 'si' pues I. entonces dice 'yo quiero ser el segundo' y C...." [C2.1_E.F_A1].

Los alumnos, generalmente, exponen el fragmento escrito que han trabajado a lo largo de la confección del dosier. "Yo el taxista de mi familia. Es que era el padre de mi abuela" [C2.1_E.F_A4]. "Yo el bar Salas de mi familia" [C2.1_E.F_A3]. No obstante, también ayudan en la exposición a algún compañero si éste lo necesita. "A veces ayudamos en los temas, pero si no hay que ayudar a nadie pues nos da lo que hemos escrito cada uno de nuestro equipo y lo recorta y ya está" [C2.1_E.F_A2]. "Claro, y en la exposición oral también nos ayudamos todos. Porque no puede hacerlo uno solo" [C2.1_E.F_A7]. "Por ejemplo, una cosa que es muy cortita y otra cosa es larga le ayudamos otro compañero. Como hicimos en Betxí, porque el 'Bar Salas.' era muy largo y teníamos una cosa del cochero y el carretero que lo decía N. y yo le decía lo del matalaser que estábamos juntos" [C2.1_E.F_A1].

En relación a la distribución de contenidos, a una madre le parece bien. "Si tuvieran que hacer todo entre todos, sería un cacao, entonces se lo dividen, a mí me parece bien que cada uno trabaje su tema" [C2.1_E.F_M5]. Además, explican que este hecho no dificulta a los alumnos a la hora de conocer sobre los temas que estudian sus compañeros. "Mira, mi hijo como no era lo que tenía que estudiar, lo ha sacado a la exposición (faltaba una compañera) y él sabía que de memoria no se lo sabía pero ha cogido un poco el hilo. Sabía lo que era, lo que significaba y lo ha explicado" [C2.1_E.F_M4]. "Yo pienso que es otra manera de que se te queden las cosas, o sea no es lo mismo que te toque hacer una exposición que tienes que saber y que te están todos mirando que te tienes que aprender algo escrito en un papel. Como que parece que ellos quieran implicarse más en el tema" [C2.1_E.F_M5].

Las familias también les ayudan a preparar la exposición en el hogar. "N. es mi madre y me ayuda a ensayar para la exposición oral" [C2.1_E.F_A3]. La exposición es una oportunidad para compartir los conocimientos que han aprendido. "Conociendo qué saben sobre el tema, sus inquietudes día a día al mismo tiempo que se va formando su conocimiento y dando la oportunidad de explicar todo lo que han aprendido" [C2.2_E.F_AP].

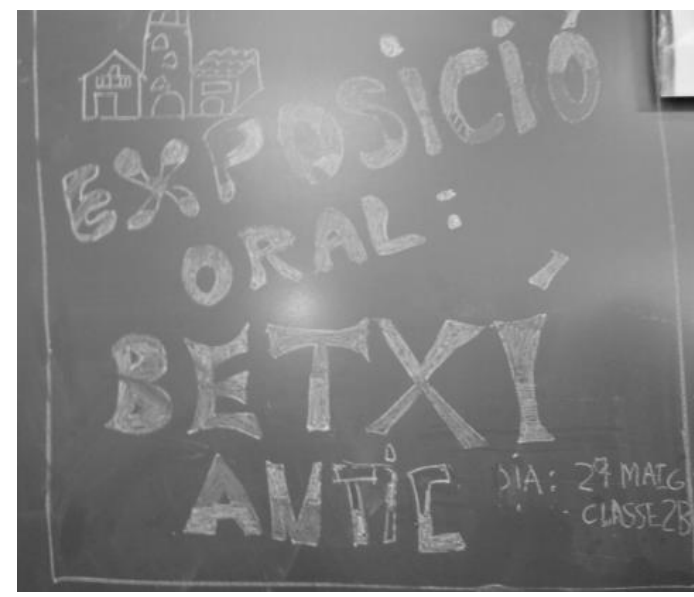

Imagen 47. Cartel exposición oral [C2.2_O_FOM].

Varios alumnos comentan que el día de la exposición tienen algunos nervios y un poco de vergüenza. "Pues muy nerviosos [...]. Cuando hacemos la exposición, porque hay mucha gente y mi madre quiere que la haga bien, me da un poco de vergüenza, pero después ya se me pasa la vergüenza" [C2.1_E.F_A1]. "Yo me puse nerviosa porque empezamos el lunes a ensayar y el día que hicimos la exposición del 
miércoles (se refiere a la primera exposición que hicieron a las personas adultas de la E.P.A. de Betxí) era muy pocos días para estudiarlo y estaba muy nerviosa y después el viernes teníamos más días" [C2.1_E.F_A6].

La maestra, al terminar la exposición, felicita al alumnado si lo han realizado satisfactoriamente. "Pero lo que pasa que nosotros pensamos que si lo hacemos bien Amèlia nos felicita y todo. Y cuando la hacemos bien nos felicita, pero si no lo hacemos bien no nos felicita" [C2.1_E.F_A1].

\section{¿Qué hemos aprendido?: la evaluación final}

Para acabar el proyecto, se evalúa todo aquello que han aprendido a lo largo de todo el proceso. Además, para comprobarlo, se realiza la misma actividad que se llevó a cabo en la evaluación inicial, pero ahora denominada ¿Qué hemos aprendido? "Hacemos un control para ver que sabemos y uno al final para ver lo que hemos aprendido" [C2.1_E.F_A4].

Para completar la actividad escrita, se ha considerado oportuno realizar una evaluación oral, para que los alumnos lo explicaran con sus propias palabras. Para ello, se les hicieron algunas preguntas individualmente, en parejas o en tríos. “¿Por qué ahora el pueblo es más grande?, ¿Por qué ahora han construido más casas?, ¿Por qué crees que lo que hay ahora es diferente?, ¿Por qué crees que ha venido más gente al pueblo?, etc.” [C2.2_O_NC].

Los alumnos son conscientes de que toda la clase aprende, incluido la maestra. "Aprendemos mucho. Porque Amèlia también aprende. Porque miramos información y aprende cosas que no sabía" [C2.2_E.F_A3]."Hemos aprendido mucho [...]. Hemos aprendido que había pozos y ahora no hay [...] Que había muchas cosas diferentes como una plaza, un jardinito a la plaza de San Juan. ¡Eso no lo sabíamos!". [C2.2_E.F_A4]. "Que habían barreras para los toros diferentes" [C2.2_E.F_A3].

Todas las madres entrevistadas coinciden que sus hijos aprenden más trabajando por proyectos que mediante un libro de texto. "Los niños, pienso... que aprenden más" [C2.2_E.F_M1]. "Ahora de Betxí también me está diciendo cosas que a lo mejor yo digo ' ‘madre y tu eso!'. A la mía se le queda más. Y después cuando te traen el proyecto a casa, para verlo y tu detrás tienes que poner lo que... a eso a la mía le encanta" [C2.2_E.F_M3].

Al finalizar el proyecto y con éste la exposición oral, el dosier se lo van llevando todos los alumnos a sus casas para compartir todo lo que han realizado y aprendido con sus familias. "Pues lo de los proyectos, pues aprenden los padres, pero nosotros escribimos lo que sabemos y los padres lo aprenden porque cada día un niño se lo lleva" [C2.2_E.F_A1]. Las últimas hojas del dossier, están reservadas para que los familiares escriban algún comentario. "Pone 'OPINAR' y ahí ponen todo lo que les gusta. Y la madre de E. puso una rima que estaba muy chuli" [C2.2_E.F_A1]. "Nos escriben, opinan en una hoja" [C2.2_E.F_A2]. Al devolver el dosier al aula y entregarlo al siguiente compañero, el alumno comparte con toda la clase el comentario que les ha realizado su familia.

Todas las madres coinciden en que el proyecto de Betxí es uno de los que más les ha gustado. "Si, porque han aprendido muchas cosas que a lo mejor si hubieran tenido un libro de texto puro y duro no hubieran aprendido" [C2.2_E.F_M6]. "A mí de todos los proyectos que han hecho es el que más me ha gustado, pero por eso porque claro a todos nos gusta recordar cómo eran las calles, cómo se salía" [C2.2_E.F_M5]."A mí también me ha gustado. Es una manera de que 
los niños vean que es lo que ha pasado para que vean que el futuro está ahí y que es interesante [...] Yo considero que es muy interesante conocer el pasado" [C2.2_E.F_M6].

La participación y el compromiso del alumno en esta actividad es alta. Aunque varía según la fase del proyecto.

"En el caso del aula de Amèlia es mayor la participación y compromiso del alumnado. En el caso del aula de Mati le cuesta más trabajo captar la atención de determinados alumnos en algunos momentos. Esta participación no es constante a lo largo de todo el proyecto, hay ocasiones de mayor y menor participación y varía según la tarea requerida. Por ejemplo, en el caso de que el alumno adopte un rol más pasivo, en las exposiciones de los compañeros, la participación y el compromiso va decreciendo, frente a un mayor compromiso en el momento de trabajo en equipo" [C2_O_DCOS].

\section{El ritmo de la enseñanza es correcto.}

"Lo van marcando los niños y el funcionamiento de los distintos equipos. Mati comentó que otros años ya han hecho con otros cursos el proyecto de la prehistoria, pero que nunca hay dos proyectos iguales, el transcurso de los proyectos lo marca la clase, según los niños la información que traen, lo que proponen..." [C2.1_O_DCOS].

Las actividades a realizar son muy variadas.

"En el transcurso del proyecto se detectan diferentes actividades cognitivas. recordar (ej.: exposición...), entender (la información que traen los alumnos, a las maestras...es importante que lo entiendan para que después puedan explicarlo), aplicar (actividades: la cueva, eje cronológico, juegos Betxí a lo largo del tiempo,...), crear (dossier, eje cronológico, homínidos tamaño real...). Los alumnos no se evalúan y no son consciente de ello, en muchas ocasiones, cuando las maestras lo realizan" [C2.2_O_ DCOS].

Destacar que los principales directores del aprendizaje son los propios alumnos.

"Las maestras están muy implicadas en todo el proceso, el alumnado poco a poco va adquiriendo mayor autonomía. El alumnado dirige la mayor parte del aprendizaje (elección del tema, ¿qué sabemos?, ¿qué queremos saber?) siempre con la supervisión de la maestra quien va reconduciendo lo que va surgiendo" [C2_O_DCOS].

Por lo que respecta a la gestión del aula destacar que: "Los alumnos tienen claro los diferentes momentos de la tarea y en cada momento precisan de unas actividades diferentes. Además, está la figura de los encargados, quienes tienen unos roles o unas tareas determinadas a desempeñar" [C2_O_DCOS]. 


\subsection{Grupos interactivos: trabajando contenidos matemáticos y lingüísticos con las familias}

Algunos miércoles por la tarde, de $15.30 \mathrm{~h}$ a $17.00 \mathrm{~h}$, la clase de $2^{\circ}$ «A» y $2^{\circ}$ «B» realizan la actividad de los grupos interactivos, para ello precisan de la participación de las familias. "Pues las familias, a los grupos interactivos vienen para ayudarnos que con dos maestras (Amèlia y la alumna de prácticas) no hay suficiente una para cada mesa" [C2.2_E.F_A5]. "Porque necesitaríamos 5 personas más. Pero si es una maestra necesitaríamos 6, porque una maestra no puede estar en todas las mesas, necesitamos padres y madres" [C2.2_E.F_A6]. "Es muy divertido conocer las madres de tus amigos" [C2.1_E.F_A7].

Ambas clases utilizan la misma dinámica y las mismas actividades. "Pues nos explica todas las hojas antes de irnos a las 12 a comer y después cuando vamos por la tarde ya sabemos hacerlo o si no nos aclaramos o no nos acordamos las madres que están allí de los compañeros nos lo explican" [C2.1_E.F_A5]. Esto es, antes de terminar la mañana la maestra explica brevemente que por la tarde realizarán los grupos interactivos y en qué consistirán las actividades. Por la tarde, explica más detalladamente que realizarán en cada una de las mesas.

"Te dicen, pues mira nos tenéis que ayudar en esto o en el caso de los grupos interactivos, yo lo sé por lo que me cuenta mi marido, pues a lo mejor vais a hacer esto o tú te encargas de... Por ejemplo, si hacen un sudoku o lo que sea, de la manera que los tenemos que ayudar, como se tiene que hacer e informados están" [C2.1_E.F_M2].

Las sesiones son muy dinámicas y amenas. "Es variado. Lo que te pasa la 1.30h que no te enteras" [C2.2_E.F_M2]. El cambio de actividades, de mesas y la presencia de las familias en el aula son elementos motivadores que ayudan en la adquisición o repaso de los conocimientos trabajados.

"Organizábamos 7 equipos, pues en cada equipo una actividad de unos 10 minutos y cada padre estaba gestionando un equipo. Y ellos hacían la actividad durante esos 10 minutos que habíamos preparado y a los 10 minutos se iban a otra mesa. Y eso era muy dinámico, ellos estaban muy motivados. Hacíamos en esa tarde en un grupo una actividad de cálculo, en otro una actividad de escribir, en otro una actividad de leer, en otro una actividad de un juego, en otro una actividad de pues, por ejemplo, el tangram de orientación espacial. Y eso era muy dinámico, les gustaba mucho. Los padres veían como trabajaban los niños y ellos también tenían esa motivación de que venían" [C2.2_E.I_D2].

Asimismo, antes de empezar, la maestra explica brevemente todas las actividades y reparte el material de cada mesa. Transcurridos los 10 minutos pone música para indicar el cambio de la actividad, los alumnos cambian de mesa. "Cada grupo hace una cosa... te hace una actividad y los niños van pasando por tu mesa a hacer la actividad que tú estás haciendo. Te lo explica ese día" [C2.2_E.F_M3]. "Vamos de mesa en mesa y pasamos por todos los padres y vamos haciendo las diferentes actividades" [C2.1_E.F_A2]. De esta manera en cada una de las mesas siempre se realiza la misma actividad, la cual es dinamizada por el adulto que se encuentra en ella. Si transcurridos los 10 minutos los alumnos no han terminado la actividad, la tienen que terminar en casa como deber. "Vamos por cada mesa y pasamos por cada actividad y también si no nos da tiempo nos lo llevamos de deberes" [C2.2_E.F_A6]. "Estas haciendo ahí mucho trabajo y cuando te dicen 'cambio' 
entonces te pones muy nervioso porque casi lo terminas" [C2.2_E.F_A1]. "Y lo puedes hacer todo rápido y bien para que no nos lo manden de deberes" [C2.2_E.F_A2].

En una de las sesiones observadas las actividades que se realizaron en cada una de las mesas fueron las siguientes: "1) crucigrama (valenciano), 2) el juego de las frases y la palabra intrusa (valenciano), 3) Tangram (matemáticas), 4) Sudoku (matemáticas), 5) Situarse en el espacio (valenciano), 6) veo, veo (valenciano) y 7) Contar de 4 en 4 desde el número 0 al 100 (matemáticas)" [C2.1_O_NC].

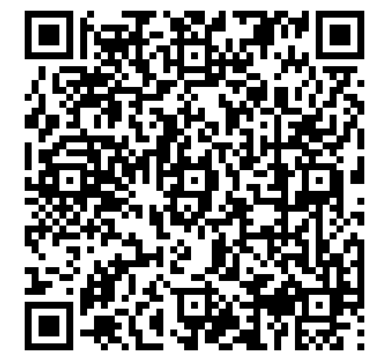

Ejemplos de hojas de actividades [C2.2_AM_DO].

En $1^{\circ}$ de primaria ya hacían los grupos interactivos.

"El año pasado también utilizábamos un recurso que era que vinieran los padres al aula, hacíamos grupos interactivos. Nos gustó que los padres vinieran al aula. Pensamos que sería un poco de caos, de que ellos al ver los padres aquí, y no, estuvo muy bien [...]. Este año a lo mejor no los podemos hacer hasta después de navidad. Otros años teníamos a los padres disponibles, ahora han empezado a trabajar en el almacén de naranjas [...]. Pues lo dejaremos después de navidad. Quiero decir, no todos los años repetimos lo mismo, nos acoplamos un poco a las circunstancias" [C2.2_E.I_D2].

La tipología de actividades propuestas en los grupos interactivos varía de $1^{\circ}$ a $2^{\circ}$ de primaria. "Es que la última vez que hicimos grupos interactivos era casi todo fichas, en primero eran más juegos" [C2.2_E.F_A3]."Pero hacemos más fichas. Pero a veces sólo hacemos fichas, a veces no hacemos juegos [C2.1_E.F_A6]. "Venir aquí interactuar con los niños en fichas, juegos, tanto como hacer mentalmente ejercicios como físicamente de juegos, de jugar con las manos" [C2.1_E.F_M1].

Durante el curso escolar 2014/2015 hicieron pocas sesiones de grupos interactivos. "Bueno este curso hemos hecho muy poquitos [...] estaban trabajando y todo eso" [C2.2_E.F_A2]. "Este curso hemos hecho poquitos, porque teníamos menos participación de los padres que tenían más trabajo" [C2.2_E.F_D2]. Además, no hay que olvidar que las familias también tienen una participación activa en otras de las actividades propuestas por las maestras. Y en la sesión de los grupos interactivos les ha coincidido con otras actividades como la del huerto escolar, el proyecto de trabajo de Betxí y el yoga en familia. Realizaron una sesión de 'yoga en familia' dinamizada por la fundación cívica Novessendes ${ }^{19}$ de Betxí.

"Pasa una cosa, que a lo largo del curso escolar hay tantas cosas a hacer que a veces unas actividades te quedan más cortas que otras porque yo este año tenía problema de personal en plena campaña de la

\footnotetext{
${ }^{19}$ Fundación cívica Novessendes: http://www.novessendes.org/
} 
naranja, porque estaban trabajando casi todos, de la cual cosa me alegro. Pero que estos años atrás que eso no ocurría y claro entre que nos han coincidido estas cosas y que también teníamos poca gente pues no lo hemos hecho al 100\%, tanto como el año pasado. Lo hicimos más el año pasado, era más sistemático. Pero todo y eso es igual, las veces que lo hemos hecho, a los niños les ha gustado mucho, que vengan los padres al aula. Y yo creo que si no abusamos, porque si no los padres también,... también les gusta. Yo creo que el próximo año lo continuaremos también" [C2.2_E.F_D2].

La participación y el compromiso del alumno en esta actividad son altas, prácticamente del $100 \%$. "La dinámica generada en los grupos interactivos es muy buena" [C2_O_DCOS]. "La maestra comenta que le gusta esta actividad porque los niños hacen hasta 7 actividades diferentes con la ayuda de 7 adultos. Explica que la dinámica es muy buena para que los alumnos estén activos. Si no fuera así habría niños que podrían pasarse toda la hora para hacer 1 ficha" [C2.1_O_NC].

El ritmo de la enseñanza está entre correcto y rápido para algunos alumnos. "La actividad en si crea una dinámica activa de trabajo. Cada 10 minutos aproximadamente se cambia de mesa, es por lo que aquellos que no han terminado la actividad la tienen que terminar como deberes" [C2_O_DCOS].

A lo largo de la sesión las actividades cognitivas son diferentes, varían según el tipo de actividad propuesta en cada mesa.

"En cada mesa los alumnos tienen que hacer diferentes actividades: de lengua valenciana o de matemáticas. Entender (lo que se debe hacer en la actividad, una persona adulta es encargada de dinamizarla), aplicar (el alumno tiene que hacer), analizar (el alumno tiene que canalizar lo que se pide en cada una de las tareas)" [C2_O_DCOS].

Los principales protagonistas del aprendizaje son los alumnos. “ La actividad está dinamizada por un adulto, el estudiante realiza las actividades y la docente marca los tiempos (pone música para indicar el cambio de mesa)" [C2_O_DCOS].

\subsection{Cuentacuentos a infantil: vamos a contar un cuento}

La actividad del cuentacuentos a infantil empezaron a realizarla al segundo trimestre. No obstante, se trata de una actividad que ya realizaron durante el curso pasado cuando ambas clases cursaban $1^{\circ}$ de educación primaria. En el curso pasado la realizaban de diferente manera. "En primero venían los padres, que junto al niño se preparaban un cuento [...]. Venían padre o madre y se sentaban junto a su hijo o hija, todos estaban escuchando y entre la madre o el padre y el hijo o la hija pues les leían el cuento a los compañeros. Se preparaban el cuento que ellos querían, los que a ellos les gustaban y que tuvieran en casa y querían leerlo a los compañeros" [C2.2_E.F_D2].

En esta ocasión, cursando $2^{\circ}$ curso de educación primaria, el alumnado va por parejas a leer un cuento a una clase de infantil. Cada semana va la pareja designada, esto es, solamente los niños que lo cuentan, el resto de compañeros continúan en el aula con lo que están trabajando. "Porque cada cuento es una pareja, por semana" [C2.1_E.F_D1]. 
La pareja, antes de ir a la clase de infantil, realizan un ensayo general a sus compañeros de clase. "Entonces esa pareja durante esa semana se prepara, hacen diferentes ensayos y después lo ensayan delante de la clase y cuando están preparados van" [C2.2_E.F_D2]. "Tenemos que ir a infantil, porque a los niños les gusta cómo leemos nosotros, les gusta saber" [C2.2_E.F_A4].

Por lo que respecta a la asignación de las parejas, en ambas aulas, las escogieron los alumnos. No obstante, el procedimiento de elección de las mismas fue diferente entre las dos clases. "Las parejas se las escogían ellos libremente. En mi caso como fue de manera voluntaria cada uno era el que se escogía la pareja, nadie protestó, todos les gustaron, no tuve ningún problema" [C2.1_E.F_D1].

"Yo lo propuse este año diferente, porque como eso de escogerse levantando el brazo y cuando ya han escogido a Fulanito, resulta que Fulanito no quería a ese que lo ha escogido y quería ir con otro, pues [...].Y también un poquito para romper esas tonterías de, esos conflictos de sólo puedo ir con este y si no es con este ya me enfado. La mayoría no se enfadan pero hay alguno que digo va hagamos y resultó, me gustó [...].Yo les dije que pusieran en un papel por prioridades, que pusieran a 4 personas con las que les gustaría ir del 1al 4, y que no era garantía de que el primero que pusieran sería con el que irían, porque tendrían que respetar la voluntad de lo que habían puesto, porque a lo mejor a quién habían puesto no les había puesto a ellos como primera opción. Pero que lo hicieran así e intentarían que fuera de su agrado pero que a lo mejor pues que tampoco era la primera opción, a lo mejor era la $4^{a}$ que habían escogido, $y$ bien a mí me gustó. Ellos tuvieron la posibilidad de pensar y poner y después fui yo, [...] 'pues haber, pues mira este ha escogido a este, a este no lo ha escogido pero el segundo sí que lo ha...' e hicimos las parejas y ellos no protestaron, les pareció bien. Me ayudó a ver cuáles eran los más valorados de la clase para escogerlos y que había dos niñas que no las había escogido nadie y entonces ahí yo también pues un poquito de, pues 'mira a Fulanito a este le irá bien porque lo ha escogido en $3 r$ lugar, pero este...' También un poco tú los conoces y fue el resultado que quedó, nadie protestó, todos intuyeron que ellos habian podido hacer una elección y todos eran conscientes de que a lo mejor la primera opción no eran pero todos habian tenido la oportunidad de escoger a quien le había tocado, porque si no estaba el 1ํ estaba el $3^{\circ}$, el $4^{\circ}$ o el $2^{\circ "}[$ [C2.2_E.F_D2].

Los cuentos son escogidos por la pareja de alumnos encargados de ir esa semana a leer el cuento a infantil. "Pues, escogemos el libro y vamos a leerlo" [C2.2_E.F_A6]. Se negocia con la pareja cuales son los cuentos más pertinentes para infantil.

"La actividad de leer el cuento a infantil hubiese sido, a lo mejor, más fácil decir: 'pues mirad como son niños pequeños las actividades que tenéis que preparar son este, este y este'. ¿No? Y tener ya los cuentos escogidos. Pero, lo planteamos a ellos y les pedimos que piensen que cuentos son convenientes o les gustarán y vemos los criterios con las aportaciones que ellos dicen. Nosotras ahí sí que intentamos ir coordinando las respuestas que ellos van dando pero son ellos los que aportan la soluciones" [C2.1_IP.HR_D1].

"Si esa reflexión la hacemos, antes de comenzar porque los tienes que situar en la actividad que vamos a hacer, $y$ es verdad que ellos son los que aportan toda la información de los cuentos y si alguno te 
propone algún cuento que te parece demasiado..., pues le vuelves a recordar "pensad que son compañeros que...' Pues un poco para situarlos" [C2.1_E.F_D1].

"Lo escogen ellos pero sí que hacemos, yo hice al principio un listado. Les dije 'pensad, situaros en cuando vosotros erais pequeños que tipo de cuentos os gustaban porque los pequeñitos han de ser cuentos que a ellos les gusten o que conocen, porque si no igual no os escuchan mucho, pensad...' y fueron diciendo... y casi todos los cuentos que dijeron fueron los clásicos que en infantil son también muy trabajados [...]. Si de esa lista ellos van escogiendo aunque repitan, como van a diferentes clases" [C2.2_E.F_D2].

Algunos de los cuentos seleccionados por el alumnado fueron: Hansel y Gretel, Sal del cascarón pollito, Blancanieves, Pulgarcito, Los 7 cabritos y el lobo, entre otros. También se prepararon una frase para terminar el cuento. "El final nuestro era 'Vet ací un gos, vet ací un gat aquest conte ja s'ha acabat' " [C2.2_E.F_A1]. "El nuestro era 'Conte contat, conte acabat estira la cua del gat' $"$ [C2.2_E.F_A2].

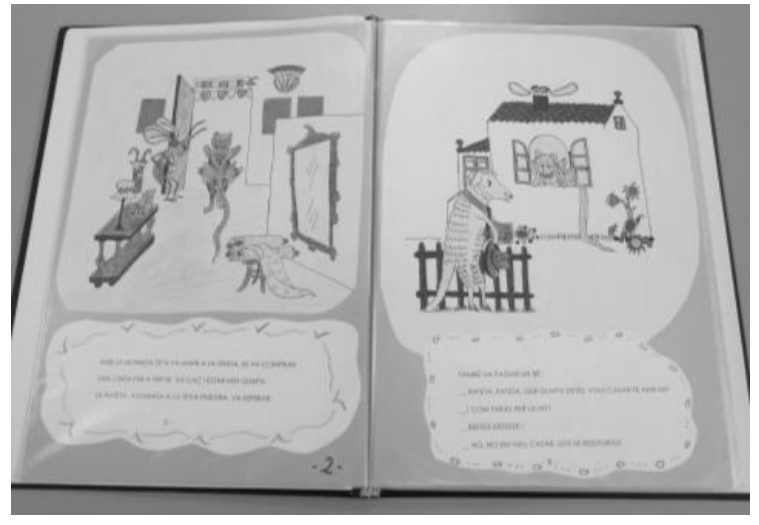

Una vez terminada la lectura es comentada por el Imagen 48. Cuento [C2.2_AM_FO]. alumnado. "Al finalizar la lectura, el alumnado explica el contenido de la historia ayudándose unos a otros. Además, también dan su opinión sobre la historia, comparten experiencias relacionadas y llegan a conclusiones convenientes sobre el tema tratado" [C2.2_E.F_AP].

Además, en $2^{\circ}$ de primaria las familias también son partícipes de esta actividad. "En el caso de los cuentos de este año venía un padre a hacer los ensayos. En la pareja antes de pasar a leerlo a infantil, pues venía un padre y hacia los ensayos" [C2.1_E.F_D1]. "Yo es que tenía a la alumna de prácticas y entonces nos lo apañábamos las dos, pero claro si no tienes ayuda... lo que dice Mati, otras veces yo también lo he hecho pero este año como estaba À., pues nos hemos apañado las dos" [C2.2_E.F_D2]. Las familias si no pueden asistir al aula, les ayudan a ensayar y preparar el cuento en casa.

"Bueno la mía por lo menos traía un cuento a casa y estuvo días leyéndolo y preparándolo [...] Yo no he venido a hacer lectura. Yo sé que algunos padres han venido a leer algún cuento, pero yo por el trabajo que he tenido no he podido venir [...]. En casa sí que lo preparábamos. Leíamos mucho y lo que hacíamos a veces memorizaba o me contaba y yo le decía 'Pues muy bien, pero aquí en esta frase tienes que hacerla más de exclamación, o de la pregunta tienes que darle el tono'. Sí que se lo preparaba, la verdad que sí, pero no he tenido la oportunidad de venir" [C2.1_E.F_M1].

Como se ha mencionado esta actividad la realizan en diferentes aulas de educación infantil. La realización en una u otra clase depende de diferentes variables. "Si vas en una pareja que tiene una hermana en una clase y tú tienes primos en otra clase. Pues vamos a las 2 clases. Porque como hay tantas clases" [C2.2_E.F_A6]. "Por ejemplo, yo tengo una hermana en infantil y entonces fui a su clase" [C2.2_E.F_A2]. "Hombre mis hermanas se pusieron muy nerviosas, muy nerviosas porque entré, me vieron y se pusieron muy contentas" [C2.2_E.F_A1]. 
"Bueno, ellos escogen si tienen algún hermanito. 'Es que ahí está mi hermanito, es que ahí está mi prima'. Bueno pues lo escogemos así un poquito y después también te acoplas a las necesidades porque cuando hablas con las maestras de infantil, por ejemplo la semana cultural M. me dijo ¿¿Por qué no contáis el de la Casita de Chocolate? Lo estamos trabajando en la semana cultural'. Pues ella nos lo propuso, lo propuse yo y como era un cuento como que hablaban los personajes, como de dramatización, lo que hicimos fue en lugar de 2 alumnos fueron 4, cada uno tenía un personaje e iba leyendo según le tocaba intervenir al personaje y también estuvo bien, otra forma..." [C2.2_E.F_D2].

Esta actividad también es muy motivadora para el alumnado.

“Todas las situaciones que puedan ser lo más reales posibles a ellos les motivan. El hecho de ir a infantil que tienen a los hermanos y prepararse para ir... jles hace mucha ilusión! Yo un caso concreto que más ilusión ha puesto, porque todos ponen, pero éste D., pues tiene dos hermanas gemelas que van allí y a D. no le gusta leer. Es que estamos todo el año detrás de él y no hay manera y cuando le tocó el momento de ir a leer a sus hermanos ¡Uyyy! El interés que puso y la preparación que puso porque iba a leer a las hermanitas, quiero decir que todo eso son actividades que dentro del aula a un niño no le gusta leer mucho, tú quieres entrarle y no puedes y si propones una actividad diferente, se engancha por ahí, no quiere decir que a partir de ahora se hará un lector, pero en otros momentos comprende que esa actividad de leer es importante y hace el trabajo mejor" [C2.2_E.F_D2].

Las madres perciben que esta actividad es motivadora y del agrado de sus hijos. "M. está encantada con esto" [C2.2_E.F_M3]. "Porque parecía que era la mayor [...]. Por tanto, que ella fuera la que iba a contar el cuento a los niños pequeños o a otra aula, que tenía que ser como aquel que dice la protagonista, aunque fuera el cuento, porque como ella lo estaba contando. Se hacía grande, se hacía mayor. A ella le gustaba mucho, le gustaba, si” [C2.1_E.F_M1]. "Hay muchos niños a los que conocen en los cursos inferiores, entonces se motivan un poco más vamos a leerles a mis hermanos, a los primos..." [C2.2_E.F_M6]. "Yo por ejemplo la mía pequeña ha venido la teta a leer, no sé qué y claro pues a ellos es la teta grande..." [C2.2_E.F_M5].

Además, comentan que el curso anterior hicieron entre todos un cuento inventado. "Se prepara entre toda la clase y después ya lo pasamos a limpio" [C2.1_E.F_D1]. "Es un cuento que se inventan entre todos y que entre todos lo escribimos, por parejas y ellos después también hacen los dibujos, lo pasan a limpio y lo hacemos en formato grande para que se vea el dibujo mientras ellos leen por detrás y los de infantil lo puedan ver, eso les hace mucha ilusión" [C2.2_E.F_D2].

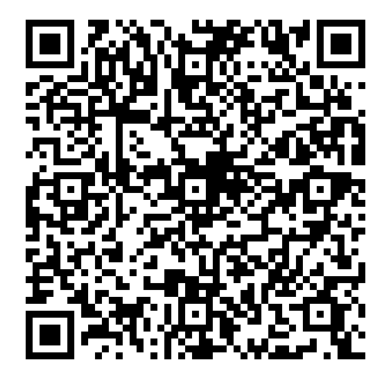

14

Cuento inventado: La aventura de Meteo [C2.2_AM_DO]. 
Para la elaboración del cuento aprovecharon el proyecto sobre el universo que estudiaron en $1^{\circ}$ de primaria. "Hicimos un cuento muy chulo de METEO que era un marciano" [C2.2_E.F_A1]. También aprovecharon esta temática para su aportación en la revista del centro. "Además en dos ocasiones ha sido porque también habían leído en la revista escolar un cuento que querían inventarse. Lo aprovechamos y dijimos, ya que lo hacemos para la revista después lo haremos en grande para ir a leerlo a los de infantil y lo haces para dos motivos" [C2.2_E.F_D2]. Algunas veces regalan el libro confeccionado, entre todos, a alguna clase de infantil.

La participación y el compromiso del alumno en esta actividad son altos. "Esta actividad la hacen los alumnos una vez al curso. La participación en el momento de desempeñar la actividad es muy elevada, existe un gran compromiso por parte del alumnado por asistir a la clase de los más pequeños a leer un cuento, incluso el compromiso es elevado en aquellos alumnos que no son muy buenos lectores" [C2_O_DCOS]. En cuanto al ritmo de la enseñanza es correcto. "Lo marca cada pareja o trío. Ensayan durante la semana, van a contarlo a la clase que tienen algún parentesco (hermanas, primas,...)" [C2_O_ DCOS]. A lo largo de la sesión la actividad cognitiva es diferente. "Recordar (los alumnos previamente ensayan cómo contar el cuento), entender (es necesario realizar una buena comprensión lectora del cuento para posteriormente poder contarlo a los alumnos más pequeños)" [C2_O_ DCOS]. Notemos como el alumno es quien dirige la mayor parte del aprendizaje.

\subsection{Talleres interciclo}

Los talleres interciclo se realizan algunos viernes. A éstos asisten alumnos de todo el primer ciclo de educación primaria, cada grupo se identifica con un color. Los grupos se realizan al inicio del curso. "Hacemos 6 talleres al año, juntamente con el otro nivel de ciclo que es 1‥ Mezclábamos los niños de todas las aulas $y$ hay varios talleres, normalmente son lúdicos: cocina, collage, dibujo, pintura, experimentos y cada año lo variamos..." [C2.1_E.F_D1].
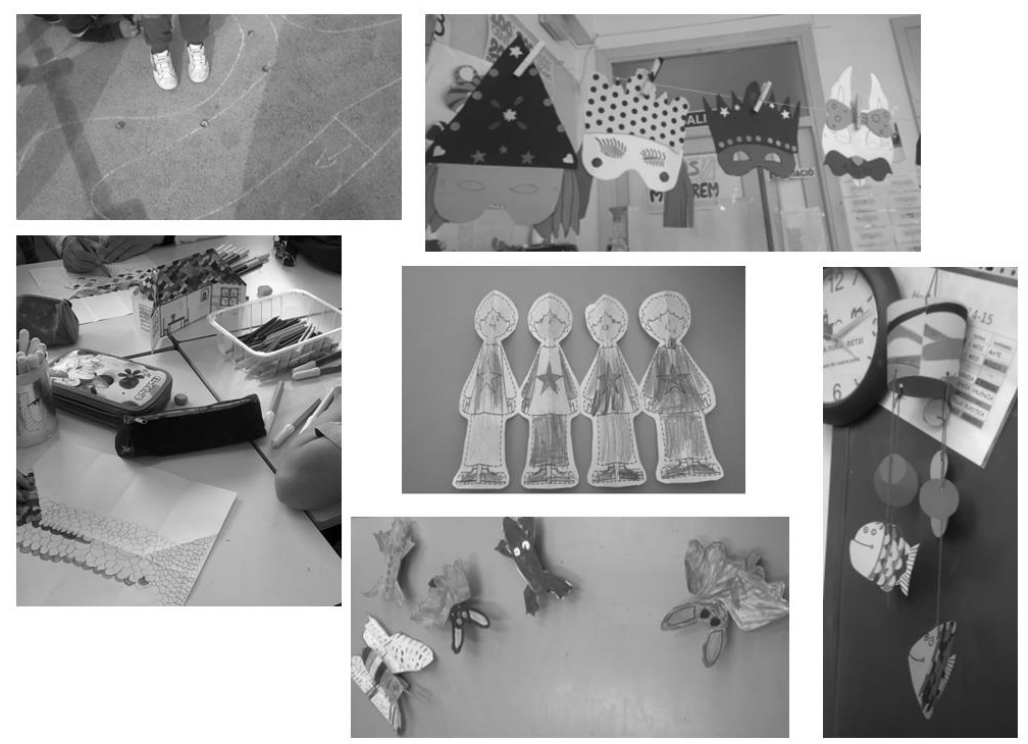

Imagen 49. Los talleres [C2.2_O_FO].
Los talleres que se realizaron durante el curso escolar 2014/2015 han sido: "1) Paz y relajación (Mati), 2) Manualidades fondo del mar (Amèlia), 3) Máscaras, 4) Imanes, 5) Chapas (patio, maestro ed. física) y 6) Casa (inglés)" $\left[C 2{ }_{-} O_{-} N C\right]$.

Concretamente los talleres consistían: "De hacer muñequitos de imanes, de hacer máscaras, el de inglés que es de hacer casas. A veces nos hacen preguntas y cosas así..." [C2.1_E.F_A3]. “Chapas, las chapas de P. (maestro de educación física). Ponías en plastilina y recortabas, podías poner el nombre tuyo..." [C2.2_E.F_A1]. El taller que realiza Amèlia es la manualidad del fondo del 
mar. "Los alumnos están sentados en 7 mesas de unos 4 o 5 alumnos cada una, hay varias personas adultas en el aula" [C2.2_O_NC].

"En Mati hacemos unos papelitos que se abren" [C2.1_E.F_A5]. El taller que realiza Mati consiste en: "Relajarse. Primero meneamos las manos. Cada dedo, rodamos las manos. Cerramos los puños, el puño de arriba lo ponemos debajo, rodamos, meneamos los brazos. Por parejas, vamos a hacer una pizza en la espalda del compañero. Después cambian. Una delante y otra detrás. Escribimos a la espalda dos palabras y que el otro lo adivine. La segunda parte del taller consiste en hacer una ficha, pintar, recortar" [C2.1_O_NC].

En los talleres también participan las familias. "Pues en esta escuela hacen talleres que participamos los padres” [C2.1_E.F_M2]. “Además en los talleres también vienen padres por si nos equivocamos en algo. Volver a hacerlo y ellos nos ayudan" [C2.2_E.F_A6].

"Tienes que ayudarles mucho a hacer el trabajo. [...] Claro es un trabajo, pero al mismo tiempo es una diversión. Por tanto, de vez en cuando se despistan y tienes que decirles 'siéntate, sigue, continúa que se tiene que terminar. Hay que terminarlo, el tiempo se termina'. Pero la verdad es que muy bien, porque como son talleres también que en parte se tienen que divertir y tienen que pasarlo bien. Les gusta mucho, bueno yo la verdad al que estuve sí que les gustó" [C2.1_E.F_M1].

Además, a través de esta actividad se fomentan las relaciones entre compañeros de otros cursos del primer ciclo de educación primaria. "Yo también tengo una amiga que es amiga de D. que se llama L. en primero y que siempre me toca con ella en los talleres y disfrutamos mucho estando con los otros compañeros porque nos conocemos mejor" [C2.2_E.F_A6]. "Además, a ellos les gusta la forma de ir a mezclarse con los otros compañeros del ciclo, ellos se lo pasan bien" [C2.2_E.F_D2]. "Los talleres son muy chulos" [C2.1_E.F_A6]. "Si, son muy divertidos" [C2.1_E.F_A7].

La participación y el compromiso del alumno en esta actividad son altos. El ritmo de los talleres es correcto. "Son actividades lúdicas y se realizan algunos viernes por la tarde de 15.30-17.00h." [C2_O_ DCOS]. La principal actividad cognitiva es crear. Los principales protagonistas son los alumnos con la participación de las familias y la guía de las docentes. Se utilizan diferentes espacios en diferentes aulas, además la actividad de las chapas se realiza en el patio.

\subsection{Evaluación: dilemas y dificultades suscitadas}

Los estudiantes realizan diferentes producciones o presentaciones de aquello que han aprendido en función de sus necesidades o preferencias de aprendizajes "Esa es nuestra intención, no sé si lo conseguimos" [C2.1_IP.HR_D1]. "Aunque todos hacen la misma actividad, no la hacen todos igual, porque al final el resultado es diferente. Ahí sí que entra la permisividad de respetar el ritmo de cada uno. Hay actividades que las hacen por equipos diferentes, parejas diferentes. De rutinas, de numeración o de cálculo vienen a ser el mismo, pero aun así atendemos la diversidad" [C2.1_IP.HR_D1].

Las docentes conciben la evaluación como una dificultad.

"La evaluación es un problema porque no te gusta, o sea lo que no me gusta es dar un número a los padres porque está claro que les tienes que informar cómo van avanzando y ellos tienen que saber más o menos en qué momento se encuentran los hijos y tal" [C2.2_E.I_D2]. 
"Es que cuantificar a un niño y ponerle, eso que dice Amèlia, un número. ¿Qué diferencia hay entre un 7 y un 8? ¿O un 6 y un 7? Es que las personas no somos una hoja de operaciones, quiero decir, entonces nosotras sí que nos basamos mucho en la observación pero claro después tienes que tener un poquito algo que constate lo que tú crees" [C2.1_E.I_D1].

Las maestras no suelen hacer controles, se guían principalmente por las observaciones y el trabajo del alumnado en el día a día en el aula.

"No les decimos a los niños 'Mañana control'. Porque a mí eso de que les ponen las notas y el niño va con la nota que tiene ya empiezas a detectar que no puedo llegar a la nota que tiene Fulanito y ya empieza a pensar [...] Y que pasa, que a veces sí que les pasas una prueba, pero ellos no saben ni que es una prueba. Es para decir, a ver objetivamente que tenemos. [...] Continuamente tú observas y tienes la devolución. Pero claro que les dices a ese padre que tú ves que el niño es muy trabajador, que la familia se preocupa, que todo va bien y después el niño tiene sus limitaciones [...] pues uno llega aquí y el otro aquí. Parece como un castigo, tu hijo ya te puedes preocupar tú o se puede preocupar el niño pero ahí no llega y eso muchas veces da una sensación que te sabe mal" [C2.2_E.I_D2].

En la evaluación del primer trimestre las maestras ponen a la mayoría de la clase la misma nota, ya que consideran un período de adaptación del alumnado en el que todos se esfuerzan. También intentan transmitir en la reunión inicial con los padres que para ellas no tiene importancia la calificación numérica.

"Lo que si podemos comentar es que en primero sí que ponemos la misma nota a todos [...] En el primer trimestre, excepto de esas diferencias que son mucha diferencia. Entonces eso lo tenemos que hacer, quiero decir tampoco puedes crear unas falsas ilusiones respecto de donde se sitúan los niños y eso lo explicamos a los padres en la reunión. Entonces les decimos que por favor no se fijen en la nota, que la nota es un trámite que tenemos que hacer pero que, el primer trimestre es un trimestre de adaptación. Quiero decir, los niños vienen muchos de infantil que todavía no saben ni leer ni escribir y que en ese proceso todos están esforzándose. Yo creo que los padres lo entienden perfectamente y ya no entra la cosa esa de darle valor a esa nota que sacan en la evaluación" [C2.1_E.I_D1].

Las docentes comentan que lo que vale es el comentario sobre los progresos de sus hijos en lugar de la nota.

"Antes era más fácil, porque ponías 'necesita mejorar o progresa adecuadamente' y sobre todo ahí tu ponías un comentario al padre. El comentario es lo que vale, es tu niño se está esforzando y con esto ha avanzado mucho, en aquello está un poco más flojo, ves con cuidado, ayúdale. Eso es lo que vale, como evoluciona el niño. Más que tu hijo es un excelente y si es un excelente porque tiene una suerte de ser excelente y otro que a lo mejor tiene más implicación y hay más trabajo que no puede llegar. Pero es que ahora con esto del programa este de Ítaca, le tienes que poner una nota y después vas a las sesiones de evaluación y [...] No es que no lo apruebes porque si lo apruebas el año que viene no puede estar en atención educativa y este niño tiene que seguir en atención educativa. Entonces que es que el formalismo me dice que no lo apruebe porque si lo apruebo me lo quitarás de atención educativa y necesita la 
atención educativa. Entonces ¿lo tengo que suspender por narices porque me lo manda el programa? ¿El niño se tiene que ir con un suspenso a casa? a un niño que está haciendo un esfuerzo colosal y jeso te da rabia! La psicopedagoga te dice 'si me lo apruebas en todo no lo puedo poner en atención educativa, el año que viene se la quito', si no puede estar en refuerzo si tiene esa materia aprobada... y tú dices 'ipero si tenemos que ayudarle!' "[C2.2_E.I_D2].

No obstante, las maestras piensan que esta forma de trabajar es la mejor. "Estamos convencidas de que es la mejor, porque integra" [C2.1_E.I_D1]. "Integra, eso no quiere decir que las capacidades de cada uno son las que son y qué primero y segundo son dos cursos en los que hacemos un aprendizaje de procedimientos" [C2.2_E.I_D2]. 


\subsubsection{Creencias, actitudes y valores que sustentan la práctica}

\subsubsection{Dar valor a la persona, a lo humano}

La práctica educativa de Mati y Amèlia se basa principalmente en dar valor a la persona, a lo humano.

"Lo que damos es valor a la persona. Entendemos que antes de aprender a leer, de aprender a escribir, de saber contar, de saber la numeración, está la persona. Y tú a lo primero que tienes que llegar es a aprender y respetar a la persona, entonces lo que te preocupa es cada uno de los niños por todo el bagaje que trae de casa y por todo lo que el estar aquí en la clase tiene que representar después en su manera de ser" [C2.1_E.I_D1].

"Cuando te vas a casa nunca se te ocurre pensar 'a Fulanito es que se lo he explicado tres veces y no'. A mí eso no se me ocurre pensarlo. Cuando me voy a casa se me ocurre pensar 'que me he alterado y no les he contestado bien o que le pasa a Sotanito que todos los días problemas, tengo que hablar con su madre, tengo que hablar con el niño [...]. Cuando me ha dicho eso que quería decir, no le he hecho caso. Mañana se lo tengo que preguntar. No lo he atendido correctamente'. Eso sí que me lo llevo a casa. El que no llega a hacer este concepto por si es complicado o..., lo consideras normal. Todo el mundo cuando aprende no lo sabe todo. Y a uno le cuesta más que a otro" [C2.2_E.I_D2].

Esta concepción de "lo humano" ya ha aparecido en los dilemas que les suscita, a las maestras, la evaluación.

\subsubsection{Las clases no son nunca homogéneas: reconocimiento y valoración positiva de la diversidad}

Tal y como se desprende de la última cita aportada por la maestra, en el apartado anterior, es normal que haya alumnos que les cueste más que a otros en el proceso de aprendizaje.

"Las clases no son nunca homogéneas, la diversidad ha estado siempre. Entonces qué haces, pues adaptarte un poco a esas necesidades, que te surge algo, pues enseguida buscas a ver cómo lo puedes solucionar. Entonces tampoco es, o al menos yo tampoco la entiendo, que la clase sea un trabajo constante, igual cada día, sino que va variando, va cambiando y tú lo que tienes que hacer es eso, es ir adaptándote. Porque estamos hablando de niños con necesidades educativas pero hay otros niños que tienen necesidades emocionales" [C2.1_E.I_D1].

Ya se ha comentado en la descripción de los diferentes miembros que integran este caso, que no hay ningún niño con un diagnóstico o discapacidad grave. Pero las maestras, en su transcurso como docentes, han trabajado con algunos alumnos que requerían un mayor grado de atención.

"Yo en el grupo anterior a éste, tenía un TEL, y tenía un caso de hiperactividad, que también era un poco especial. Es que en realidad lo de los retrasos madurativos, decimos retrasos madurativos y eso engloba mucho, pero después cada niño es diferente, quiero decir que no porque tenga ese 
nombre... Igual que el TDAH pues bueno si sabes que ahí hay unas necesidades y al final pues algún nombre hay que poner. Pero que después también hay diferentes grados y no se ciñe todo a un mismo patrón, ¡ni pensarlo! [...] Hace unos años también tuve un asperger" [C2.1_E.I_D1].

El alumno asperger era partícipe como un miembro más del aula. "El niño no estaba diagnosticado cuando empezamos primero, se lo diagnosticamos, estando aquí en la clase y fue un poco un aprendizaje de toda la clase junto a él, quiero decir que pasa muchas otras veces en otros compañeros" [C2.1_E.I_D1]. "Yo también los últimos años, sí, en algunos retrasos madurativos que después han derivado en un ACI, tiene atención educativa desde que entro, ya tenía un retraso madurativo desde infantil" [C2.2_E.I_D2].

Las maestras basan su manera de enseñar en las necesidades de aprendizaje de los estudiantes, tanto educativas como emocionales, y en los contenidos que por ley hay que trabajar en el 1r ciclo de educación primaria. "No es sólo la prioridad o las necesidades, no dejas que sean ellos tampoco los que te dirijan todo. Pero que el currículum, es más orientativo. Tú ya tienes la idea de cuáles son esos objetivos y contenidos que se han de dar en el primer ciclo y sobre eso sin necesidad de estar atados al currículum vas haciendo el trabajo de cada día" [C2.1_IP.HR_D1]. "Y a veces no atiendes todas las necesidades, porque ni las puedes captar todas. Una mirada o atención para 27, vas observando e intuyendo cosas y procuras que las necesidades de ellos y de aprendizaje sean más orientativas que el currículum" [C2.2_IP.HR_D2]. La alumna de prácticas añade al respecto: "Han ido evolucionando progresivamente. Siempre se ha intentado integrar al alumnado en el aprendizaje, considerando sus necesidades y actuando sobre ellas en caso de que no eran capaces de seguir el trabajo de la clase" [C2.2_E.F_AP].

Los objetivos son los mismos para todos los alumnos de la clase. "Tú sabes lo que tienes que trabajar en segundo, pero todos no llegan ahí y algunos niños necesitas que les adaptes un poco" [C2.1_IP.HR_D1]. "Algunos niños necesitan una adaptación más diferenciada que el resto, pero cada uno también llega donde llega. Las respuestas son diferentes y particulares de cada niño, nunca le pides que la respuesta sea igual a la de todos. Por ejemplo, las actividades que hacemos no son igual para todos. Porque uno puede dar una respuesta supongamos de 30 palabras, otra de 15, de 4,..." [C2.2_IP.HR_D2]. Las maestras establecen unos objetivos mínimos. “[...] ya estás pensando que esos mínimos los tienen que conseguir todos los alumnos. Después pues están las particularidades y hay quien puede conseguir esos y muchos más y por nuestra forma de trabajar eso no es problema porque el que es capaz de avanzar puede avanzar perfectamente, yo creo que intentamos plantear siempre las actividades desde ese punto" [C2.1_E.F_D1].

Las docentes intentan proporcionar diferentes caminos de aprendizajes en función de las necesidades de aprendizaje y habilidades del alumnado. "Sabes que no todos aprenden de la misma forma ni les llega todo por la misma fuente. Lo que intentas es que cada uno encuentre por donde puede ir interiorizando todo lo que trabajamos" [C2.1_IP.HR_D1].

Habitualmente, todos realizan todas las actividades.

"En la mayoría todos hacen todas las actividades, es cuando tienes a niños que les cuesta mucho más. Tú llevas la clase al unísono aunque intentas que los niños que más les cuesta tengan más ayuda, pero sí que quieres que todos vayan, a no ser que tienes algunos niños, que son los menos en la clase, que no pueden seguir totalmente ese ritmo y los tienes que adaptar un poco" [C2.2_IP.HR_D2]. 
"Sí, porque los niños también son espabilados, está claro que los que no pueden seguir que ya tienen el material más adaptado para él, pues con ellos tienes otras consideraciones. Pero cuando consideramos el grupo clase en general si tú o ellos van viendo que... 'No pasa nada pues tú esa no la hagas' la primera semana serán una o dos, después ya serán tres o cuatro. Ellos también tienen que entender que se tiene que terminar la tarea que hay" [C2.1_IP.HR_D1].

"Un ejemplo que se me ocurre, cuando vienen a primero cada uno está en un nivel de escritura, de lectura y, tal pues, si estás haciendo una actividad de escribir y la estás haciendo a la pizarra y la tienen que copiar y todavía no se aclaran hacerlo con la letra cogida, pues tú sí que permites que lo hagan en mayúsculas, que cada uno lo escriba según el nivel donde está y eres consciente de que cuando te lo traerá Fulanito lo habrá escrito con todas las letras y otro te lo dará,... Respuestas hay muchas, pero todos hacemos la actividad" [C2.2_IP.HR_D2].

Ante este panorama, usan una variedad de estrategias educativas.

"Son ofertas diferentes. Es la manera de trabajar vamos a trabajar la escritura pues unas veces hacemos una carta al alcalde otras veces otra para los padres o una invitación a otros compañeros o...procuramos que ahí entre la variedad y que esa variedad sea siempre de manera significativa. ¿Qué es lo que necesitamos?, esto pues vamos a hacer esto o lo otro. Eso todo es aprendizaje" [C2.1_IP.HR_D1].

Además, exigen diferentes grados de implicación. "Siempre procuras que vayan a más e implicar a toda la clase, pero si no puedes algunas cosas tienes que ir adaptando. Si no es inútil" [C2.2_IP.HR_D2].

Remarcar también que tanto los alumnos como la madre entrevistada son conscientes de las diversidades presentes en sus aulas. Por lo que respecta al alumnado destacar: "Porque aprendemos cada uno de una forma" [C2.2_E.F_A1]. "Hay niños que les cuesta más aprender y hay niños que no" [C2.2_E.F_A6]. "Pues cada vez van aprendiendo un poco más" [C2.1_E.F_A5]. "No todos lo hacen diferente, pero no todos lo hacen igual" [C2.1_E.F_A7]. "De diferente manera, pero algunos lo hacen de la misma manera" [C2.1_E.F_A6].

Destacar al respecto la siguiente reflexión de una de las madres:

“Cada niño necesita, el desarrollo que hace él en el juego o en la actividad, un tiempo y tú tenías que estar muchas veces, cuando iban cambiando de grupos o de niño, te dabas cuenta enseguida quien tenías que estar más encima o quien lo hacía más ligero, porque decías 'A este casi no le hace falta ni que le diga...' Se nota, la verdad que se nota, que sí que se puede tomar atención, porque Mati lo hace de una manera que implica a bastantes padres, entonces tenemos a 4 o 5 niños solo en la mesa o 3 o 4 depende del taller que hacemos y la verdad que..., si que puedes presentarle la atención que necesita a cada niño a su medida, porque claro tampoco en una hora o poco más, pues tampoco te da mucho tiempo, pero vamos yo creo que sí que se atendía bastante bien a los niños. Y ellos mismos también había muchos que te decían 'Ayúdame, es que no sé, es que no me sale' Claro, les decías 'Venga que se termina el tiempo'. 'Hay que no llego'. Ellos mismos también te lo piden. Entonces, además de darte cuenta, como te lo dicen tú puedes ir a cada niño. Además, al que veías que iba así un poco más apañado, ibas dejándolo 'muy bien, muy bien...' y seguías en el otro para ayudarle más. 
Además, Mati ya lo hace de manera que cuando vienen los padres cada grupo de niños si hace falta de que tengan un poco más de atención pone a uno sobre el resto, que ya van más sueltos ¿sabes?” [C2.1_E.F_M1].

\subsection{Una escuela agradable: en busca de la motivación y el interés}

Las maestras, con su forma de trabajar en el aula, pretenden hacer una escuela más atractiva e interesante al alumnado.

"Y después otra cosa que también nos preocupa es el hacerle la escuela agradable. En el sentido en que en la escuela te bombardean de tal manera que al final lo importante son los conocimientos, te bombardean las pruebas diagnósticas, te bombardea la sesión de evaluación, te bombardea el inspector para ver la ratio, te bombardea todo el mundo de tal manera en los conocimientos que parece lo más importante y la escuela nunca se plantea, en el sentido de que es una escuela aburrida, repetitiva y poco atractiva" [C2.2_E.I_D2].

"Y que sólo da valor a los conocimientos y al éxito académico en el sentido... Pero esos niños que no son tan brillantes también se tienen que sentir a gusto y que son brillantes dentro de la clase, como sus compañeros" [C2.1_E.I_D1].

En cuanto a la motivación y el interés hacen referencia muy especialmente a la metodología de los proyectos de trabajo.

"Te das cuenta, cuando estás trabajando algún proyecto de trabajo, de la ilusión que ponen en ese tema y te das cuenta que a quien hace los currículums para la escuela no sabe que les puede interesar a esos niños. En su clase están estudiando Egipto (2$« \mathrm{~A} »)$ y en la mía los minerales $\left(2^{\circ} « \mathrm{~B} »\right)$, eso no está en ningún currículum. Que en primero o en segundo tengan que estudiar esos temas, son temas que ellos... Entonces cuando ves que esos niños vienen y están motivados y todas las historias alrededor de Egipto, éstos los minerales...que yo cuando escogieron los minerales pensé ¡ $i$ Dios mio! ¡Que tenemos que dar de los minerales!' $Y$ después te quedas asombrada del interés que muestran en eso y dices pues eso es más motivador que toca el tema no sé qué porque lo dice en el currículum porque el libro de texto que han comprado dice eso o dice... Entonces intentas eso quitártelo de encima. jNi libros de texto, ni currículum! A estos niños les interesa las cosas que les interesan, y lo que se intenta es que aprendan a manejarse, a leer y a escribir para manejarse en su vida y eso igual lo aprendan estudiando unas cosas u otras. En ese sentido estas más tranquila porque no sabes si es lo correcto o lo incorrecto, seguramente habrá prácticas educativas pedagógicas mucho más interesantes y [...] pero tú ves que los niños en eso están motivados y en eso van aprendiendo. En cambio, lo otro siempre está más cojo, en cuanto a eso que estamos diciendo, la convivencia, la participación, la parte emocional, la parte como personas todo eso está más cojo. Y lo otro no sé si lo hacemos mal o bien pero yo estoy tranquila yo sé que trabajando así ellos están motivados" [C2.2_E.I_D2]. "Y lo que no aprendan hoy lo aprenderán la semana que viene y sino a la otra, eso no es problema" [C2.1_E.I_D1]. 


\subsection{Ayuda entre iguales: cultura colaborativa}

Vemos cómo la cultura colaborativa subyace en los trabajos en pareja o en pequeño grupo. Mientras que la asamblea, se concibe como un espacio de consenso o decisión colectiva. Hay que destacar también la idea de que se parte de los conocimientos previos del alumnado.

Los propios compañeros del aula son los que ayudan, en muchas ocasiones, a aquellos que lo necesitan.

"Yo en el caso de mi aula como somos tantos en el aula, porque con 28 alumnos en el aula la verdad es que cuesta hacerlo muy personalizado. Pues, los que se ayudan son los mismos compañeros. Quiero decir, que en esta diversidad hay unos que son muy rápidos, que terminan pronto y que tenemos una forma de trabajar, ya desde que empezamos en primero que la ayuda de los compañeros es muy valorada. Entonces siempre que hacemos un trabajo entre todos ellos ya saben que estos compañeros no son tan rápidos y no pueden ir a ese ritmo y ellos ya se ofrecen. Ya no soy yo la que digo, quieres ayudar a...pues ya son ellos mismos los que ya dicen 'puedo ir y ayudar a...'. Quiero decir que la ayuda es de los mismos compañeros" [C2.1_E.I_D1].

Los comentarios de la estudiante de prácticas, refuerzan la misma idea de que los propios alumnos ayudan a quien lo necesita en el aula. Además, añade que el hecho de trabajar en grupo supone una motivación extra al alumnado

"Agrupando al alumnado de esta manera, creo que la maestra pretende promover un aprendizaje muy eficaz potenciando un intercambio de información entre cada uno de los miembros $y$, por tanto, todos puedan beneficiarse de todos. Así pues, tiene en cuenta el sentido más positivo de la heterogeneidad, en que las capacidades más altas pueden aportar un gran apoyo y ayuda a las más bajas. Además, también produce en el alumnado un alto nivel de motivación el hecho de trabajar en equipo, dando lugar a un nivel de trabajo más elevado. Un aspecto positivo de este hecho es que todos trabajan por igual, dentro de sus capacidades, pero el esfuerzo y la dedicación están muy presentes" [C2.2_E.F_AP].

Esta cultura colaborativa también subyace en los comentarios emitidos por el alumnado de ambas aulas que conforman el caso. "Estamos en grupo y si no sabemos algo los otros nos pueden ayudar" [C2.1_E.F_A3]. "Si lo haces en grupo te ayudas más, si por ejemplo yo no sé una palabra alguien la sabe y nos ayudamos entre todos y en pareja lo mismo que si yo no sé una palabra a lo mejor ella puede... Pero en individual no me gusta mucho porque si alguna cosa no se o algo, nadie me ayuda" [C2.1_E.F_A6]. "Porque así nos ayudamos todos y nos lo pasamos bien" [C2.2_E.F_A2]. "Pues, porque cada uno tiene una idea y así podemos estar mezclados y así podemos tener más ideas" [C2.2_E.F_A2].

Esta filosofía colaborativa también la vemos presente en los comentarios de las madres.

"Es lo ideal trabajar en equipo y cuando antes aprendan a trabajar en equipo es más fácil después, en el mercado laboral digamos, eso es súper importante. Lo que no aporta uno lo aporta el otro, se complementan, aprenden también a saber escuchar las opiniones de los demás a respetarlas o a poder 
discutirlas" [C2.1_E.F_M2].

"[...] la paciencia, un poco la convivencia también del equipo, que tengan paciencia que sepan esperar a escuchar, porque muchas veces como soy yo, yo, yo cuando hacen equipos saben que cada uno tiene también su tiempo y tiene su voz y eso se hace... la verdad que sí y además para que no sean retraídos o yo que sé, que no se queden en solitario. Siempre va muy bien lo del equipo además se nota. Porque después los niños son más participativos" [C2.1_E.F_M1].

"Y aprenden a trabajar en común con compañeros y no solo. Es su opinión, no es su palabra la que consta al final, sino que tienen que llegar a un acuerdo con los compañeros de la mesa y cuando son pequeños funcionan así, están con mesas de 4 o 5 personas, de 405 alumnos y yo creo que es una forma de poder compartir las cosas y poder llegar a acuerdos que en el futuro les irá muy bien" [C2.2_E.F_M6].

"En el caso de la mía (la niña que tiene la mesa adaptada y lleva corsé) sola, por ejemplo, le cuesta más, en grupo unos y otros ayudan" [C2.2_E.F_M3].

\subsection{Participación del alumnado y de las familias: valores democráticos}

Uno de los principales elementos que hace que la participación del alumnado sea democrática en el aula, es que éstos tienen voz a la hora de escoger aspectos importantes como: qué tema general les interesa estudiar en el proyecto, qué subtema va a abordar cada equipo, qué cuento contar. Éstos aspectos vienen guiados principalmente por el interés y la motivación del alumnado.

"Vamos todos a una en ese sentido. Depende a veces damos a elegir entre varias, pero normalmente vamos todos a una. Ahora según como, por ejemplo, cuando nos ponemos con lo del proyecto y dividimos por grupo y tal, a veces lo hacemos por mesas, a veces les dejas a ellos que escojan en que grupo les gustaría estar o en qué tema les gustaría más ... depende, sí que les vas dando oportunidad, ahora todos los días no" [C2.2_IP.HR_D2].

Para las madres, la forma de trabajar en el aula propicia que el alumno adopte un rol activo en su propio proceso de aprendizaje, esto es, los alumnos son los protagonistas. "Participan y yo en la mía veo que participa más, colabora más y se le queda más" [C2.1_E.F_M1]. Éstas comparan la forma de trabajar en el aula de sus hijos y el trabajo mediante el libro de texto, en esta segunda opción el alumno tiene un papel pasivo en el proceso de asimilación del conocimiento. "El libro es..., lo leen una vez y ya se han aburrido. De la otra manera no te dirán estoy aburrida" [C2.1_E.F_M2].

“A M. (la niña que tiene la mesa adaptada y lleva corsé) por ejemplo le cuesta mucho y yo en los proyectos y eso ella lo coge más. Yo nada más con eso ya... A ella le pones un libro de texto delante y a lo mejor se pone a leerlo y no lo entiende. Y de esta manera sí. [...] Porque a ella le cuesta mucho y en un libro de texto te puedes estar mucho rato explicándole las cosas y no... Y así en el caso de la mía le va mejor." [C2.2_E.F_M3].

"Buscarse la vida ellos, intentar averiguarse las cosas. Porque yo, por ejemplo, a la mía le encanta entrar en Internet, buscarse no sé qué,... a ella le gusta. Le gusta el tema de 'vamos a hacer este tema, 
vamos a ver que encontramos'. Los animales y todo me acuerdo que era todo el día, buscamos y buscamos y buscamos y a ella le gusta" [C2.1_E.F_M5].

Por lo que respecta a la gran participación de las familias en el aula, se ha visto como éste es un elemento a destacar del caso. "Las familias yo creo que vienen a gusto y participan a gusto [...]. Unas más que otras porque cada uno tiene una disponibilidad" [C2.2_E.F_D2].

Para las madres, básicamente, el aspecto que facilita su participación en el aula recae en el ideario de las docentes. "No sé lo que lo facilita yo supongo que será ideas de las maestras, que irán viendo que así es mejor" [C2.2_E.F_M2]. "Hay profesores que creen más que son ellos los que tienen que hacer las actividades en los alumnos y hay otros que si se abre la escuela y los padres interactúan con ellos siempre es mejor la formación para los alumnos de esos cursos" [C2.2_E.F_M3]. Otra madre señala la importancia de la formación de las maestras como otro elemento facilitador de que se dé la participación familiar en el aula. "[...] Supongo también que dependerá del tipo de formación de la maestra. Yo sé que por ejemplo; Mati y Amèlia sobre los grupos interactivos han hecho muchos cursos y mucha cosa entonces si el maestro no domina...yo creo que el maestro también tiene que dominar el trabajo en grupos interactivos si el maestro ve que eso se le escapa de las manos y no puede hacerlo no lo hará porque no está formado en eso" [C2.1_E.F_M2].

Seguidamente en la Figura 7, se presenta un esquema relacional de las creencias, actitudes y valores que sustentan la acción docente del segundo caso objeto de estudio. 

Resultados de la investigación

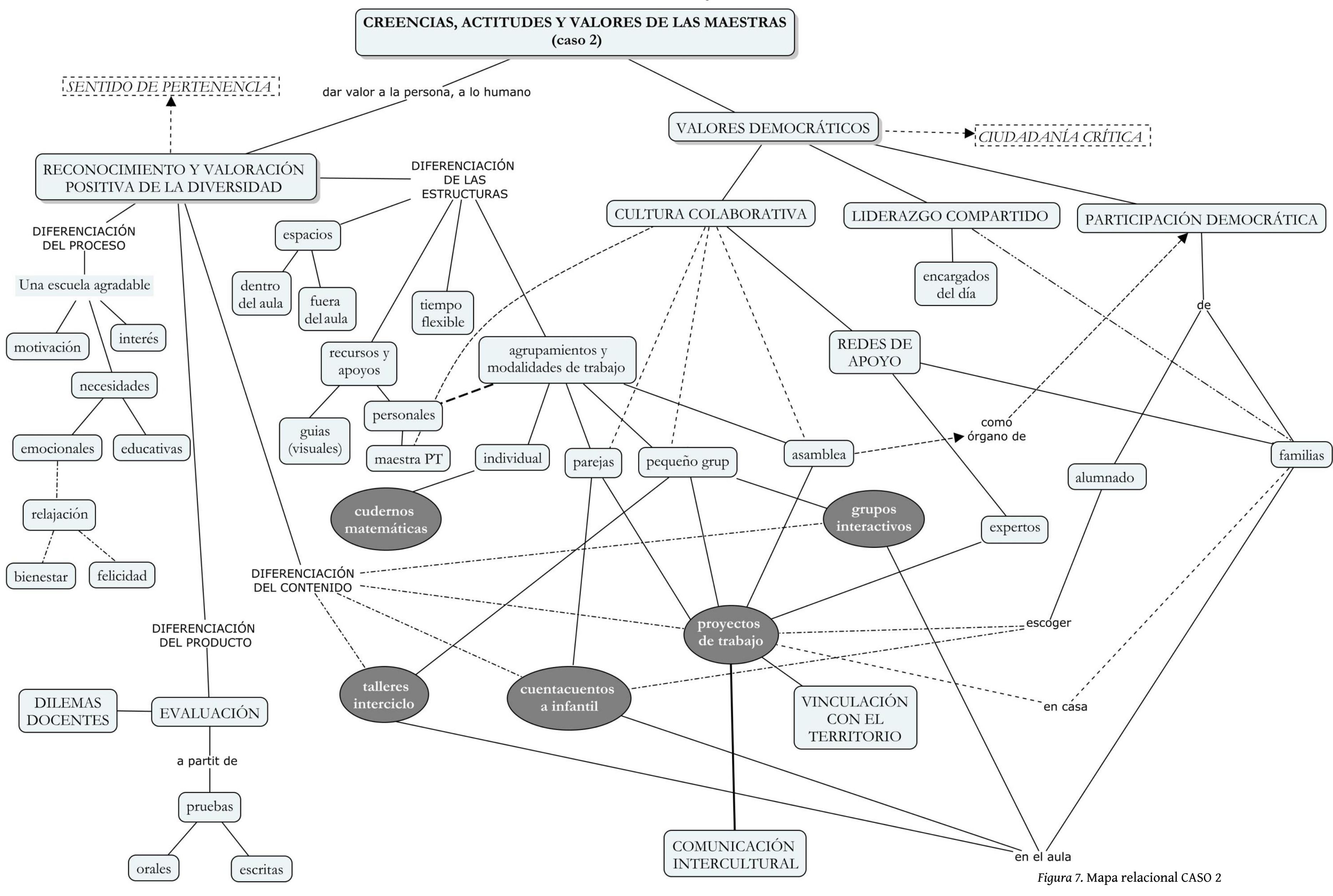

Diferenciación pedagógica y participación democrática en el aula inclusiva: estudio de casos múltiples 221 



\subsubsection{Caso 3: Cristina}

A continuación, se va a abordar el caso 3, el de Cristina. Primeramente, se hace una descripción de las prácticas didácticas y después se comentan las creencias, actitudes y valores que subyacen en su forma de trabajar en el aula.

\subsubsection{Desarrollo de prácticas diferenciadas y democráticas}

\subsection{Contexto general: localidad y centro educativo ${ }^{20}$}

El CRA Benavites-Quart de les Valls es un Colegio Rural Agrupado formado por dos aularios; uno situado en el municipio de Benavites (626 habitantes) y otro en el municipio de Quart de les Valls. En esta última localidad nombrada se sitúa el caso objeto de nuestro estudio. El centro se constituyó como CRA en el curso académico 2005/2006, con el objetivo de maximizar los recursos procedentes de ambas localidades.

La población de Quart de les Valls está situada en la comarca del Camp de Morvedre, en la provincia de Valencia, formando parte de La Vall de Segó. La localidad cuenta con una población de $1.056^{21}$ habitantes. La mayoría de la

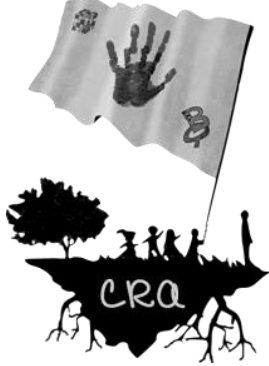

Imagen 50. Logo CRA.

Extraida de: http://crabenavitesquartdelesvalls .edu.gva.es/wp/ población es originaria de las localidades vecinas, aunque en los últimos años ha habido casos de inmigración (2\%). Existe un predominio lingüístico del valenciano. Las principales actividades económicas del municipio son la agricultura (cítricos) y los servicios.

En el CRA, hay un total de 130 alumnos y 15 maestros (algunos definitivos). Además, el colegio dispone de maestra de pedagogía terapéutica, de audición y lenguaje y psicopedagoga, siendo sobresaliente la dotación y utilización de recursos informáticos en el centro.

Ya hace unos años que el CRA Benavites-Quart de les Valls participa y trabaja muy estrechamente con diferentes proyectos de investigación impulsados des del Grupo de investigación MEICRI ${ }^{22}$, para la construcción de la escuela intercultural e inclusiva. Concretamente, los proyectos abordados han sido: Participación comunitaria y escuela democrática: estrategias para la formación de una ciudadanía crítica (2014-2016, UJI- P1·1B2013-32) y La escuela incluida en el territorio: análisis de las estrategias de participación ciudadana desde la educación intercultural inclusiva (2014-2016, MINECO- EDU2013-46491-R). De esta manera se han desarrollado, en el CRA, diversas estrategias participativas y democráticas. Más específicamente, se han impulsado las metodologías participativas en el aula, Jornadas de Puertas Abiertas y de Convivencia (tanto en los propios centros escolares como en lugares emblemáticos de

20 Extraído del proyecto de dirección (Benet, Ferrer, Gimeno y Cayuela, 2014): https://sites.google.com/site/crabqportal/noticies/projecte-de-direccio

21 Según datos del 2015 del Instituto Nacional de Estadística.

22 Grupo de investigación Mejora Educativa y Ciudadanía Crítica de la Universitat Jaume I de Castellón http://meicri.uji.es/ 
ambas localidades), trabajo por comisiones mixtas, consejo escolar ampliado (órgano de toma de decisiones colectivas, el cual cuenta con la representación de diferentes colectivos: maestros, alumnos, familias y agentes comunitarios). Estas innovaciones han convertido a la escuela en un colegio de referencia, ya que reciben visitas de otras escuelas propiciadas por el centro de formación del profesorado (CEFIRE).

\subsubsection{Los miembros de la clase: la maestra y su alumnado}

Por lo que respecta a la experiencia de la docente, remarcar que, esta lleva trabajando desde hace 8 años en educación primaria. Anteriormente, había trabajado en el sector privado, pero en deporte, visto que la maestra es diplomada en magisterio especialidad de educación física. "Soy de educación física $y$ he aprobado las oposiciones por primaria" [C3_E.I_D].

En cuanto a cursos o seminarios realizados en los últimos 5 años, la docente se ha centrado en aspectos relacionados con la dirección de centros educativos y la competencia digital.

"Pues los últimos años había cogido más de dirección, porque yo antes sí que estaba de directora. Así que, toda la formación que realicé era de gestión, organización,... De cursos enfocados a eso. Y la formación ahora, que estoy de tutora, de los cursos de este colegio pues he cogido de cosas de nuevas tecnologías. Como en el aula trabajamos lo que son las Tablets, pues he cogido de nuevas tecnologías" [C3_E.I_D].

Además, la psicopedagoga del centro realiza formaciones según demandas específicas del profesorado del CRA. "Sí que es verdad que nuestra psicopedagoga, sí que ha dado un pequeño curso por demanda. Porque habíamos comentado que a K. (niño hiperactivo) [...], no sólo era para mí, sino que también para los maestros que entran en el aula. Y hemos hecho durante 3-4 semanas un pequeño curso de ella" [C3_E.I_D]. Por lo que respecta a las formaciones impartidas por la psicopedagoga, añadir que ésta también ha realizado formación referente a mindfulness o concentración plena, así como aspectos relacionados con la educación emocional.

Antes de pasar a presentar al alumnado, decir que la clase objeto de nuestro estudio se denomina Auladino (Ver Imagen 51). Esto es, porque son los alumnos más mayores del CRA. "Los dinosaurios también eran muy antiguos [...] entonces Cristina nos dijo que nos diríamos AULADINO, por lo de los dinosaurios" [C3_E.F_A5].

Cristina es la tutora de tercer ciclo. En total hay 21 alumnos, 7 de $5^{\circ}$ de primaria y 14 de $6^{\circ}$. Al preguntarle por las necesidades específicas de apoyo educativo presentes en su aula, la maestra comenta que la especialista de pedagogía terapéutica $\mathrm{u}$ otros docentes de apoyo le ayudan con el alumnado que más lo necesita.

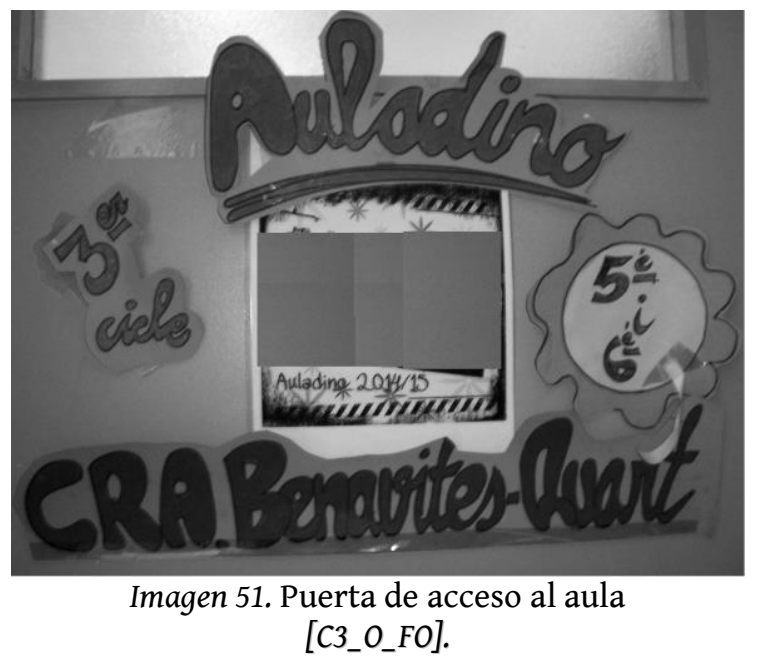


“M. ha repetido un curso. Presenta necesidades educativas especiales, tanto por el contexto familiar como por sus capacidades, no llega a la media. Y después también tenemos a H. y a K. H., es una alumna de Marruecos, que no comprende la lengua y K. es un niño hiperactivo. Pues la maestra de pedagogía terapéutica se dedica más a esos alumnos dentro del aula o fuera según la actividad [...]. Hacemos apoyo también dentro del aula con otros maestros. Por tanto, estos maestros sí que hacen refuerzo dentro del aula de forma general [...]. La verdad es que el niño hiperactivo no necesita lo que es un apoyo dentro del aula. Simplemente planificar bien la tarea y repetirla después individualmente con él, porque el niño lleva muy bien los contenidos. Así pues, simplemente planificar y tranquilizarlo un poco, darle otra tarea o actividad y ya está [...]. M. sí que es verdad que algunas horas hace refuerzo fuera porque no llega a los contenidos mínimos, ya es el último año, está en $6^{\circ}$, y parece que no da tiempo y hay cosas que sí que hay que..." [C3_E.I_D].

Por lo que respecta a la alumna marroquí la docente añade que ésta, debido a que se marcha a Marruecos con su familia, pierde meses de clase.

“H. es una niña que se incorpora a finales de octubre- noviembre, que es de aquí del pueblo desde que nació. Pero ella siempre se incorpora a finales de octubre- noviembre, claro si llegas a esta clase en noviembre no te enteras de cómo va la clase, porque tú ya has dado [...] este primer mes es tan importante en la clase, pero bueno se va a intentar. Es también una niña que en su casa no hablan ni castellano ni valenciano. La familia no viene aquí nunca. Mira este año he conseguido que venga el hermano. Después desapareció a final del tercer trimestre, se marcharon otra vez a su país, entonces estas cosas..." [C3_E.F_D].

En muchos momentos de la jornada lectiva hay dos maestros en el aula. Este hecho lo tienen instaurado en todo el centro, ya que en numerosas ocasiones entra un maestro de apoyo al aula. Este maestro de apoyo no es ni el de pedagogía terapéutica ni el de audición y lenguaje, se trata de otro tutor de otra clase que entra a ayudar en el aula. Aludir también a la maestra de música como principal actora en el diseño, elaboración y puesta en práctica del proyecto LÓVA.

Además, tanto en el aula objeto de nuestro estudio como en el CRA en su conjunto, existe una apertura del centro a la comunidad propiciando la participación de los familiares, así como de otros agentes comunitarios. Los canales, para la maestra, de difusión de información a las familias más destacados son el WhatsApp. "La vía WhatsApp me ha ido muy bien y la vía reunión también [...]. Aunque sea una reunión de padres y madres, hay personas muy tímidas. Pues a lo mejor después contigo sí que te dicen mira esto" [C3_E.F_D]. Los alumnos también tienen un grupo de WhatsApp. “AULADINO, y los niños AULADINO JUNIOR [...] Si tenemos dudas lo ponemos ahi" [C3_E.F_A6]. Asimismo, el centro da una hoja a las familias para que anoten propuestas o aspectos a mejorar. "Yo la doy [...]. Aunque nadie da la hoja o no llega a casa. Yo creo que se da la opción por si acaso alguna persona quiere. Pero me resulta más enriquecedor la otra forma" [C3_E.F_D]. Esto es, la maestra suele escuchar las propuestas o aspectos de mejora sugeridas por parte de las familias en las reuniones. 


\subsection{La gestión general del aula}

La maestra, combinado a sus explicaciones, utiliza varios formatos de agrupación del alumnado (grupo clase, pequeños grupos, parejas, individual). "Primero expongo, pero luego ya trabajo real. Sí que hay una parte de explicación de la actividad para que sepan lo que tienen que hacer" [C3_IP.HR_D]. Las agrupaciones varían según la actividad propuesta y van evolucionando a lo largo del curso escolar según las necesidades del grupo. Esto es, la agrupación al inicio del curso escolar dista de las realizadas al finalizar el curso.

En el 1r y $2^{\circ}$ trimestre los alumnos están sentados en clase mediante diferentes agrupaciones que cambian cada mes. "Estos grupos cambian cada mes e intento que sean mixtos en todos los aspectos: género, comportamiento, disciplina y contenido. Que sean un poco heterogéneos" [C3_E.I_D]. Por tanto, hay unos alumnos que trabajan en grupos de 4 , otros en pareja y otros, los sabios, de manera individual (Ver Imagen $52^{23}$ ). Esto es, mientras que los que están sentados en grupo o por pareja hacen la actividad interactuando con sus compañeros. Los sabios deben realizarla de manera individual y, si lo necesitan, solicitan ayuda a los docentes. "Algunas veces trabajan más de forma individual para poder solucionar los problemas de forma individual, $y$ hacer nosotros el refuerzo que sea

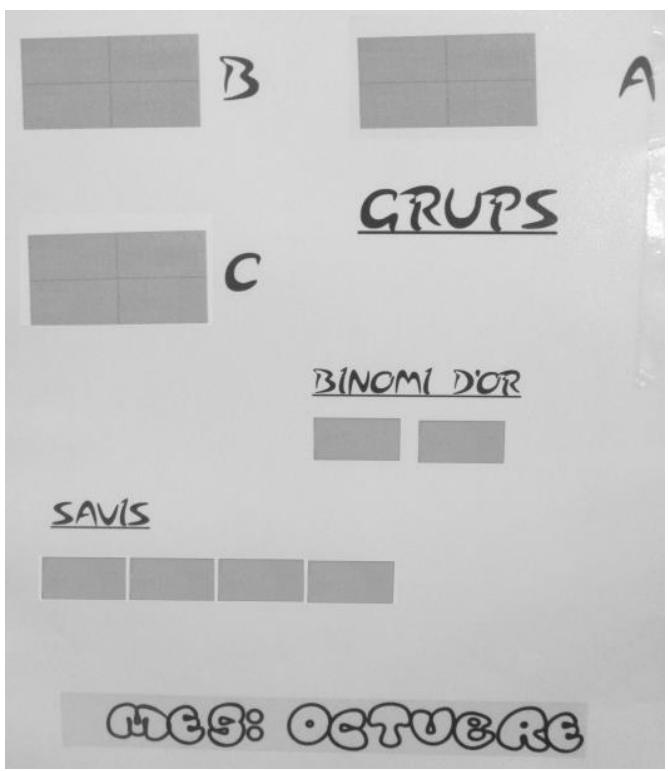

Imagen 52. Agrupaciones [C3_AM_FO]. necesario" [C3_E.I_D].

"Por ejemplo, estamos haciendo geometría los jueves, un ejercicio que tenemos que hacer aquí en clase, lo hacemos y dice que es en pareja $u$ os tenéis que ayudar en el grupo, pero los sabios lo tienen que hacer individual. Yo creo que lo hacen porque cada mes se cambia de grupo y los sabios para que sepan trabajar solos sin ayuda de los otros, pero vamos... que todos vamos a pasar por los grupos, por sabios, por parejas" [C3_E.F_A11].

Así pues, los alumnos cuando son sabios hacen el trabajo de manera individual. "Esta tarea la hacéis vosotros, no como grupo, sino de forma individual [...]. Pero los demás siempre trabajan en grupo y van rodando lo que es su responsabilidad cada semana. Si yo soy encargada, tengo la responsabilidad no de la tarea final, sino de organizar, es decir, planificar" [C3_E.I_D].

En el 3r trimestre, terminan trabajando con lo que denominan macro-grupos o mesa redonda, es decir, grupos formados por 7 alumnos (Ver Imagen 53).

"Se introdujo la idea de trabajar en la mesa redonda [...] ahora en este tercer trimestre [...]. Casi todos los productos, los proyectos finales, los hacen en mesa redonda. Pero, por ejemplo, hay diferentes agrupaciones también dentro del grupo: para la corrección del plan de trabajo, es mejor hacer primero

${ }^{23}$ Hay que señalar que esta agrupación corresponde con el mes de octubre del 2015, es por ello que el sumatorio del número de alumnos no coinciden con el de 21, ya que nos encontramos en otro curso escolar, el 2015/2016. 
una parejita, si son 4 que no en el grupo total. Vale, pero sí que es verdad que después en cuanto a las estaciones son demasiada gente para hacer una estación, 7 personas para una estación y más las propuestas que hay no daría tiempo. Vale, entonces se coge otro grupo para dispersar un poco más" [C3_E.F_D].

En los grupos hay alumnos de ambos niveles, de $5^{\circ}$ y $6^{\circ}$ de primaria. Los grupos los organiza Cristina e intenta que sean heterogéneos pero homogéneos entre si.

"Dentro del grupo tienen un número y más o menos intento entre comillas que tengan las mismas características, es decir, por ejemplo, el número 1 de aquí (señalando el no1 de cada mesa), pues es una persona que se le da bien estas cosas, pues a lo mejor según la semana el director según si está más organizado o menos organizado pues esta semana serán mejor o peor porque más o menos tienen unas características comunes [...]. Entonces, también cuando trabajo "el número", que es para que se preparen un tema

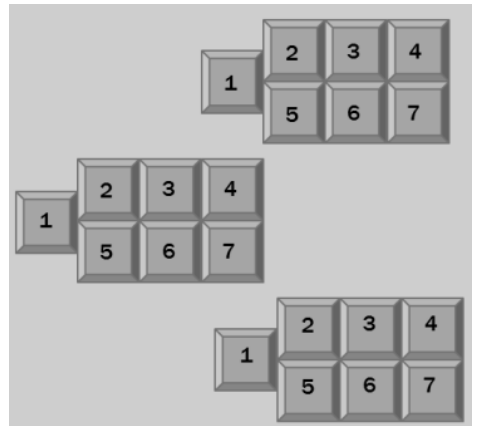

Imagen 53. Macro-grupos o mesa redonda entre todos, cojo el número y al que le toca pues más o menos están equilibrados, no pueden destacar uno sobre el otro" [C3_E.F_D].

Conviene subrayar que los integrantes de cada mesa redonda no cambian de grupo, pero sí que cambia cada semana de lugar. Los alumnos que se sientan en la mesa $\mathrm{n}^{\mathrm{0}} \mathbf{1}$ hacen de director o coordinador. "Entonces son 7 semanas y esto está pensado para terminar el curso. Cuando terminen la rueda, terminarán y ya será primero de junio. $Y$ cuando lo terminemos se pondrá ya la "U" para terminar el curso" [C3_E.F_D]. Esta variación en la forma de agrupamiento se debe a una evolución. "De trabajar en subgrupos, unos grupos más reducidos y sabios y después hacer la finalización del segundo trimestre para hacer los maxi-grupos y ya este trimestre de la mesa redonda. Hemos introducido también nuevas técnicas, la mesa redonda no se trabajaba" [C3_E.F_D].

Como se ha mencionado antes, los alumnos, dentro del grupo tienen roles o cargos a desempeñar. Esto es, en los grupos hay un miembro que es el director o el encargado o el coordinador. "Entonces él se encarga sobre todo de ayudar a los que necesitan ayuda y de controlar que todos hagan su faena" [C3_E.F_A1].

"Pues el coordinador como su nombre indica coordina el equipo, no es mandar: 'tú haz esto, tú haz lo otro', 'o me haces caso a mí o no sé qué...'. Cuando vamos a hacer trabajos que es de búsqueda de información, por ejemplo, en ciencias estamos dando el cuerpo humano que es cada pareja el apartado digestivo y todo eso... que ya hemos hecho la presentación, pero cuando empezamos era yo el coordinador y dijimos que primero hay que planificarse, hay que poner la planificación, la búsqueda de la información y después ya sería plasmarlo en la presentación" [C3_E.F_A11].

Los roles no son fijos, van rodando según los distribuye en cada tarea el director o coordinador de la semana. "Cuando trabajamos algún proyecto nos tenemos que dividir los roles, para saber a cada uno lo que le toca hacer" [C3_E.F_A6]. "Van rodando. Bueno, el director reparte los roles y a lo mejor a la semana que viene no eres el mismo o si" [C3_E.F_A5]. Aunque el director suele preguntar qué roles prefiere hacer cada compañero. "Por 
ejemplo, ahora en el proyecto, el director a nuestro grupo le ha preguntado quien quería ser cada cosa" [C3_E.F_A6]. "El nuestro también ha hecho eso" [C3_E.F_A5].

Los roles o funciones son: el buscador de la información, el secretario, el director, el regulador de la voz, el regulador del tiempo, el encargado del material y el corrector. "Por ejemplo, el buscador busca la información que haga falta en el trabajo, el secretario apunta toda la información, el director va mandando y va ayudando, apoyando a los que lo van haciendo" [C3_E.F_A8]. "El regulador de voz, por ejemplo, si tu grupo está chillando mucho y dicen bajad la voz, el regulador del tiempo dice: 'faltan 5 minutos para presentar o para terminar' " [C3_E.F_A9]. "Pero, por ejemplo, el del material a veces no se hace porque es un trabajo con el ordenador y no hace falta traer los colores, tráeme las tijeras,... no hace falta" [C3_E.F_A8]. También hay un corrector, que se ocupa de supervisar y corregir las producciones. Esto supone una responsabilidad para cada alumno, el buen funcionamiento o no de su rol o función tendrá repercusiones en el trabajo del grupo. "Es que el fallo... Si estás en un macro-grupo que son de 7 personas. Si, por ejemplo, no funcionan los buscadores. No tenemos información. Nos retrasamos toda una sesión. Y ya la hemos fastidiado" [C3_E.F_A8].

El tener estas diferentes responsabilidades es del agrado del alumnado. "Bien porque así puedes experimentar diferentes cosas, buscar...y así lo pruebas todo y la próxima haces lo que más te gusta de esas cosas" [C3_E.F_A2].

Además, respecto a los roles o funciones, remarcar que, cada semana hay un encargado que tiene que desempeñar tareas que competen a la organización y al buen funcionamiento del aula (Ver Imagen $54)$.
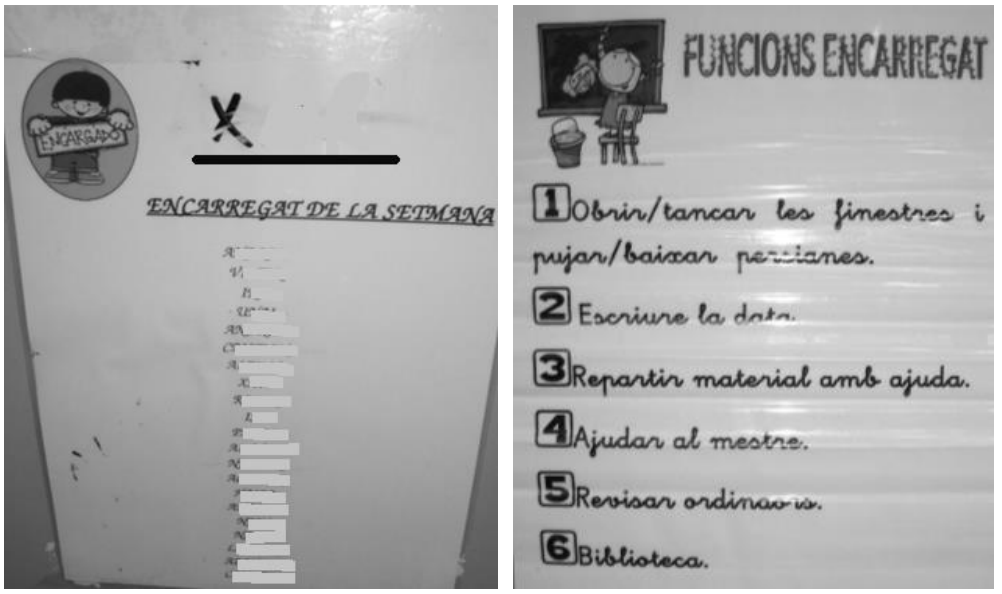

Imagen 54. Listado de encargados y funciones [C3_AM_FO].

Los alumnos resuelven las diferentes actividades a partir de la utilización de diferentes técnicas cooperativas. "Cuando hacemos trabajos en grupo utilizamos diferentes técnicas como por ejemplo, lápices al centro [...] y técnicas que utilizamos sobre todo en las estaciones" [C3_E.F_A1]. Otras técnicas que utilizan son el folio giratorio o la del Rompecabezas. Tal y como podemos ver en la Imagen 55 en un rincón de la clase tienen el nombre de las diferentes técnicas Kagan que van utilizando. Como posteriormente

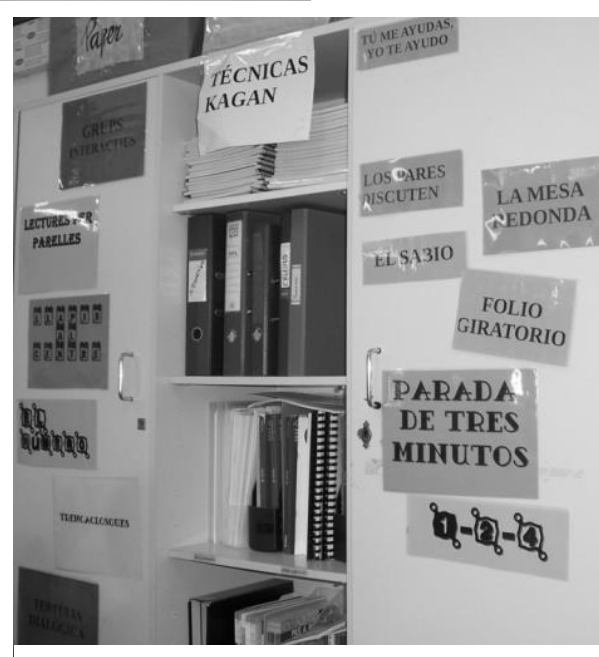

Imagen 55. Carteles técnicas Kagan [C3_O_FO]. 
veremos, la maestra deposita esos carteles en las diferentes mesas para que el alumno sepa en todo momento mediante que técnica tienen que resolver la actividad propuesta.

\subsection{Metodologías de trabajo: diferenciación pedagógica}

Hay que remarcar que en este tercer caso objeto de nuestro estudio no utilizan libro de texto.

"En cuanto a recursos materiales, lo que es la clase de $3 r$ ciclo trabajan en lo que es la Tablet, no tienen libro de texto. Por tanto, nosotros lo que hacemos es hacer el tema, yo como maestra, o coger temas por internet, coger uno de aquí, otro de allá y hacer nuestro tema. Eso lo subimos al Dropbox y es el material que el alumno puede estudiar o trabajar. No se trata de subir el trabajo y hacer como si fuera un libro de texto, no. Pues cogen y van trabajando a partir de las diferentes técnicas cooperativas [...] Pues a lo mejor un día trabajamos lápices al centro, otro día folio giratorio y las diferentes técnicas que las tenemos colgadas y según la actividad yo cojo la hoja y la pongo en la pizarra explico lo que es la actividad y después pues vale esta actividad la vamos a hacer de esta forma y ellos ya tienen consolidadas todas las técnicas" [C3_E.F_D].

Seguidamente, se presentan las diferentes metodologías activas y participativas que se llevan a cabo en este caso. Se aborda la descripción del plan de trabajo semanal de las tareas y su corrección mediante la técnica cooperativa del 1-2-4. Se presenta cómo integran las temáticas de los proyectos de centro a las actividades de aula. Se expone cómo trabajan mediante algunas técnicas de aprendizaje cooperativo. Concretamente, se ilustra la técnica de leemos en pareja y la técnica del Puzle de Aronson o Rompecabezas. Se explica cómo desarrollan las estaciones, una metodología utilizada para trabajar, mediante técnicas cooperativas o de manera individual, conceptos matemáticos y lingüísticos, tanto de lengua castellana como de lengua valenciana. Después, se procede a explicar el taller de ciencias a través de un trabajo sobre los minerales. Se presenta cómo trabajan a lo largo del curso académico en la tertulia literaria dialógica y la exposición voluntaria de libros. Posteriormente, se explica el proyecto LÓVA, diseñado, elaborado y ejecutado por la maestra de música con la ayuda y coordinación de la tutora del aula objeto de nuestro análisis. Después, se procede con la explicación de los talleres de los jueves (en los cuales participan las familias) y de las ginkamas, una actividad realizada con el objetivo de desarrollar la cohesión grupal. Se finaliza con la erudición de los rincones de trabajo y aspectos relacionados con la evaluación. 


\subsection{El plan de trabajo: organización y planificación semanal de las tareas}

El plan de trabajo se realiza todas las semanas. "De lunes a lunes tenemos que hacer el plan de trabajo para corregirlo con los compañeros. O sea, tenemos que hacer las fichas que nos ha dicho" [C3_E.F_A6]. "Nos lo dan los lunes y [...]. Pues el plan de trabajo son unas hojas, unos ejercicios" [C3_E.F_A11]. "[...] en la Tablet" [C3_E.F_A10]. La maestra es la que se encarga de subir a la nube los ejercicios que tienen que realizar. "El plan de trabajo o estas faenas nos las suben. 'Lo hemos subido al Dropbox en tal carpeta o en el Classroom' ${ }^{24}$. En el Classroom puedes enviar tu faena desde el ordenador directo a la maestra, como si se la dieses a ella. En el Dropbox, lo podemos mirar todos" [C3_E.F_A2]. Además, la docente comenta cada lunes las tareas que conforman el plan de trabajo de la semana en curso. "Tenemos que apuntárnoslo en la agenda cuando ella (se refiere a la maestra) lo dice [...]. Esta faena, para tal día la tenéis que entregar por el Classroom o si no me la tenéis que entregar y se la damos" [C3_E.F_A2]. Esto es, algunas veces se entrega el plan de trabajo u otros deberes de manera on-line y otras en formato papel. "Tienes que copiarlo a la libreta y tienes que hacer los ejercicios" [C3_E.F_A10].

Las actividades del plan de trabajo refuerzan los contenidos trabajados mediante las otras técnicas de aprendizaje cooperativo. "Ella (se refiere a la maestra) la sube al Dropbox, antes los sube al Dropbox y el viernes que toca, bueno matemáticas o lengua, pone media hoja porque se supone que ya lo has hecho, pero ella da media hoja" [C3_E.F_A3]. La otra media hoja se trata de un ejercicio con los mismos contenidos pero que se realiza mediante otros métodos, como por ejemplo a través de las estaciones que a continuación se explican.

Los niños deben organizarse las tareas del plan de trabajo. "El plan de trabajo, Cristina nos lo da para que hagamos un poco cada día, tenemos una semana, pero el fin de semana hay gente que lo hace el fin de semana y el fin de semana se supone que no hay que hacerlo. Hay que hacerlo entre semana, cada día un poco" [C3_E.F_A4]. La maestra pretende, con el plan de trabajo, que el alumnado se gestione y planifique el tiempo. "Yo, por ejemplo, Cristina no va a decirme ¿Qué has hecho? ¿Qué has hecho ayer? ¿Qué has hecho hoy? [...] yo depende de cómo me viene la semana, por ejemplo, mañana no tengo clase de música, por tanto, digo: 'Ostras, pues mañana puedo hacer un poquito y después de mañana otro'. Pero si veo que en toda la semana voy a ir muy agobiada, pues hago el plan de trabajo en dos días" [C3_E.F_A3]. La madre entrevistada destaca la autonomía y la responsabilidad individual del niño, ya que después comparte su trabajo con sus compañeros.

"A ver la forma de trabajar,... el niño tiene que ser autónomo total, porque se tiene que organizar el trabajo, se la tiene que buscar y después la tiene que compartir, lo que ha buscado tiene que compartirlo con sus compañeros. Entonces si no lo haces bien o no lo has hecho... Pues tus compañeros te van a decir, esto no está bien. Claro. Entonces los niños tienen que organizarse y hacerlo como toca porque después se lo van a decir" [C3_E.F_M1].

\footnotetext{
${ }^{24} \mathrm{https} / / /$ classroom.google.com/welcome
} 
Transcurrida la semana se procede, en el aula, a la corrección del plan de trabajo. Para ello, utilizan la técnica del 1- 2- 4 (Ver Imagen 56). "Cuando hacemos el plan de trabajo utilizamos la técnica 1- 2- 4 que es: el 1 lo hacemos en casa que hacemos el plan de trabajo, el 2 lo hacemos aquí en clase compartido (se refiere en pareja) [...] y si tenemos alguna duda lo hacemos con los de delante (4)" [C3_E.F_A2]. Hay que mencionar, además que los sabios (los niños que están sentados en la fila y suelen trabajar de manera individual) en esta ocasión, se

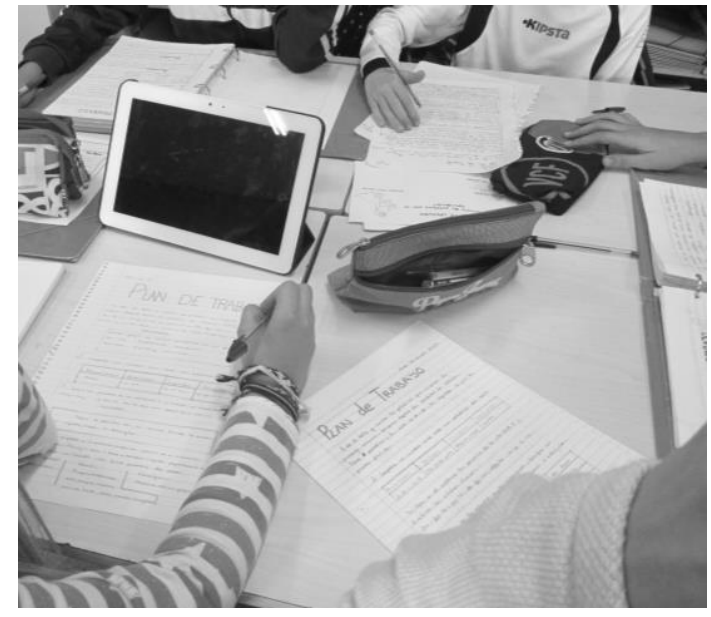

Imagen 56. Alumnado corrigiendo el plan de trabajo [C3_O_FO]. distribuyen y van a una mesa libre. De esta manera corrigen el plan de trabajo utilizando la misma técnica que sus compañeros, la técnica del 1-2-4. Al terminar, las correcciones, las parejas se hacen preguntas sobre los contenidos abordados en el plan de trabajo.

"También hay una cosa que es cuando terminamos las dos parejas del grupo se hacen primero preguntas la pareja. Por ejemplo, imagina que yo tengo una pareja al lado. Yo le tengo que hacer una pregunta sobre el plan de trabajo y ella a mí y después le tenemos que hacer una pregunta a la pareja y esa pareja a nosotros. Para ver si hemos entendido algo y al final ya Cristina nos pregunta aleatorio, pregunta a ver si hemos entendido el plan de trabajo" [C3_E.F_A11].

Además, en la corrección de trabajo vemos una flexibilidad en cuanto al tiempo. Para terminar la sesión de corrección y mientras que un grupo termina la maestra realiza preguntas sobre el contenido trabajado. "El grupo que todavía no ha terminado sigue corrigiendo. La maestra junto al resto de la clase comenta y reflexiona sobre lo que han trabajado a lo largo de la semana: sinónimos y antónimos (ponen ejemplos), las palabras agudas, planas y esdrújulas" [C3_O_NC].

La participación y el compromiso del alumnado son moderado- alto. "Algunos alumnos no traen el plan de trabajo hecho o terminado" [C3_O_DCOS]. El ritmo de enseñanza es correcto y negociado con el alumnado. "El alumno de manera individual realiza la tarea, las parejas lo corrigen y después pasan a comentarlo o a hacerse preguntas en grupo. Mientras que un grupo termina la maestra interactúa con otros haciendo preguntas y comentando sobre las actividades trabajadas" [C3_O_DCOS]. Son diferentes las actividades cognitivas requeridas en esta actividad. "Recordar (conceptos trabajados), entender (las actividades), aplicar (conocimientos en la resolución de las tareas), analizar (en las actividades) y evaluar (corregir el trabajo)" [C3_O_DCOS]. El estudiantado dirige la mayor parte del aprendizaje. 


\subsection{Del proyecto de centro "EL CINE" a las actividades de aula}

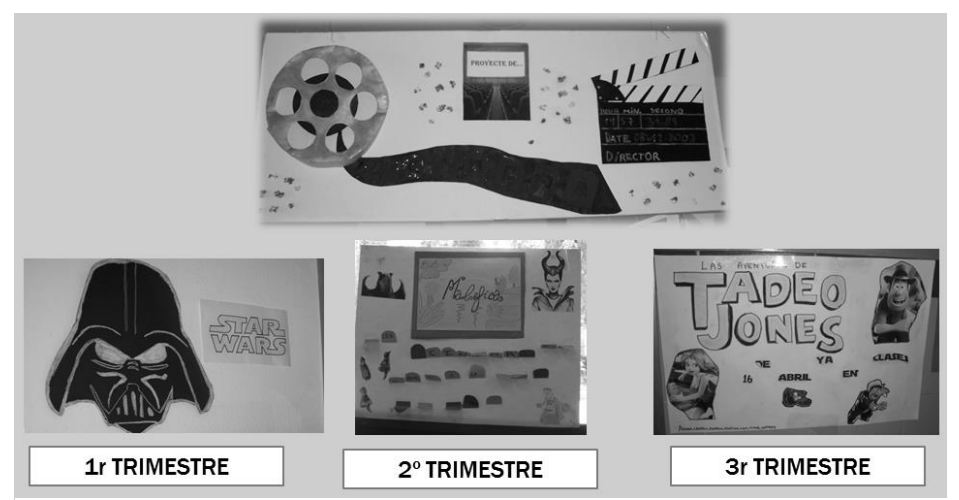

Imagen 57. Carteles proyecto de cine [C3_AM_FO].

En el CRA realizan una serie de proyectos a nivel de centro. El curso escolar 2014/2015 el proyecto de centro era sobre el cine (Ver Imagen 57), y en cada uno de los trimestres trabajaron 3 películas diferentes (Star Wars, Maléfica y Tadeo Jones). "El eje central es el cine que es de todo el centro. Cada trimestre es una película designada. Dentro del aula trabajamos un proyecto, ahora estamos con lo que es la imagen que deriva ya en el cine. El primer trimestre fueron las sombras chinescas, la cámara oscura como el origen, pero llevamos ese eje todo el curso" [C3_E.I_D]. La propuesta fue realizada por el director del CRA al claustro de profesores.

"Fue una propuesta de A. (el director del CRA) el tema del cine un poco entre todos escogimos las películas y a partir de las películas pues coges el contenido por ley y adaptas, que no es necesario que sea el orden que te pone. Coges te planificas y programas. Por ejemplo, ahora 'Star Wars' esta película te da para sociales y naturales, todo. Porque te da el sistema solar, las galaxias, todo. Los contenidos y después en naturales te da la luna, el sol, las máquinas. Y después la lengua, tanto castellano como valenciano. ¡Está chulísimo!" [C3_E.I_D].

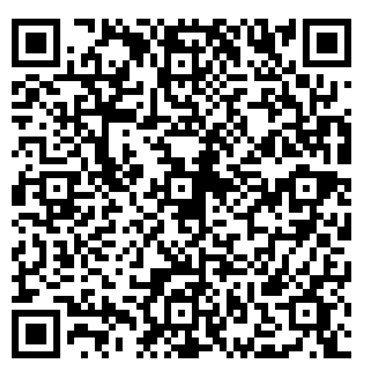

Ejemplos de materiales del proyecto de cine trabajado en el aula [C3_AM_DO].

Todo el alumnado del centro, de manera conjunta, realiza el visionado de las películas. Destacar que las actividades propuestas a nivel de aula giran en torno a las temáticas de las películas. Por ejemplo, como es el caso de algunas lecturas en pareja o también en actividades a realizar en el dosier individual o en murales realizados de manera grupal.

Por lo que respecta a los murales (Ver Imagen 58), enmarcados dentro de la película de Tadeo Jones se trabajaron contenidos relacionados con la prehistoria. "Como el mural de la prehistoria que hemos hecho un grupo tenía artesanía, el arte, otros la evolución y el otro monumentos" [C3_E.F_A7]. "Por ejemplo, en la prehistoria ahora 
estamos dando 'Tadeo Jones y las 7 maravillas del mundo' que es de arqueología y todo eso" [C3_E.F_A8]. El alumnado tiene que realizar colaborativamente un mural. Para ello, deben llegar a un acuerdo para ver que apartado del tema desarrolla cada uno de los grupos.

"El escoger el tema [...] los intereses son diferentes dentro del grupo. Por tanto, es un poco de democracia, son 7 personas que, si no escogen lo mismo, evidentemente no van a escoger lo mismo, si no tienen las mismas curiosidades o necesidades, tienen que hablar, dialogar y si no llegan a un acuerdo pues votar y ya está. Y claro que pasa que después se dan cuenta que otros grupos han escogido lo mismo, pues miran a ver si llegan a un acuerdo o la suerte o lo que sea. Después en cuanto a motivación yo creo que la forma de hacer un mural entre todos, porque era el tema de la prehistoria y cada grupo hacía un subtema y a partir de ahí todo el conjunto de la clase hacía un mismo mural, no hacían varios. Era una tarea difícil. Los encargados tenían que plasmar el espacio que era, cómo lo querían, 'a ver yo quiero este espacio, yo quiero este espacio' un poco de dialogar los directores, la forma de motivación ¿no? también. Era diferente" [C3_E.F_D].
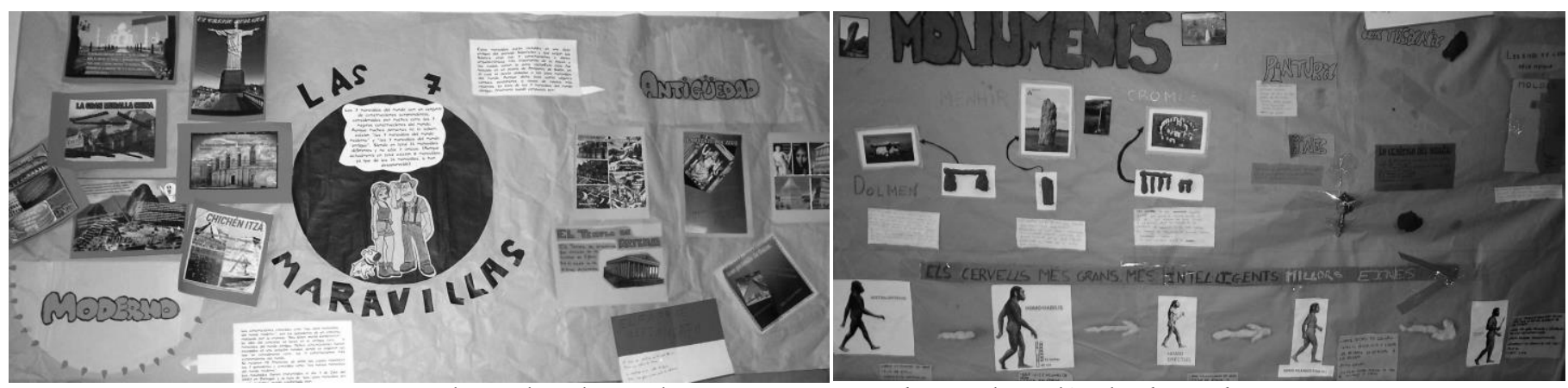

Imagen 58. Murales sobre la prehistoria enmarcados en la película de Tadeo Jones

[C3_AM_FO].

La participación y el compromiso del alumnado son altos. "Implicación del alumnado para el desarrollo de la tarea de manera colaborativa" [C3_O_DCOS]. El ritmo de enseñanza es correcto y negociado con el alumnado. "Se pauta el tiempo, pero se va viendo cómo van evolucionando y trabajando los grupos" [C3_O_DCOS]. Son diferentes las actividades cognitivas requeridas en esta actividad. "Recordar (conceptos trabajados), entender (las actividades), aplicar (conocimientos en la resolución de las tareas), analizar (en las actividades) y evaluar (corregir el trabajo)" [C3_O_DCOS]. El estudiantado dirige la mayor parte del aprendizaje. El director o coordinador gestiona y organiza el trabajo de su grupo. 


\subsection{Leemos en pareja}

La actividad de leemos en pareja se realiza todas las semanas. "Cada semana va cambiando la persona que lo hace y el tema también" [C3_E.F_A11]. Esto es, cada semana un alumno hace de tutor y el otro de tutorado. Hay alumnos que prefieren ser tutores, mientras que otros prefieren ser tutorados. "A mí me gusta tutor [...]. No sé, porque le explicas al otro lo que se tiene que hacer y me gusta" [C3_E.F_A5]. "A ayudar a los compañeros, porque si eres tutor tienes que ayudar a tu tutorado a entender la lectura. Y si eres tutorado puedes aprender del tutor" [C3_E.F_A6]. "Tutorados [...]. Porque así no nos preparamos la lectura en casa" [C3_E.F_A8].

En el 1r y $2^{\circ}$ trimestre las parejas las hace la maestra. "Nos lo dice la maestra o lo elegimos nosotros como ha sido en esta ocasión" [C3_E.F_A8]. Aunque en el último trimestre la maestra deja que sea el propio alumnado quien escoja con quien quiere realizar la actividad, pero teniendo ambos un nivel de comprensión y velocidad lectora similar. "Pero el último trimestre ha sido que teníamos que pensar quien tenía los mismos fallos que nosotros y que era más compatible con nosotros y escoger una pareja" [C3_E.F_A7]. Las parejas cambian cada trimestre, es por ello que a lo largo de todo el curso el alumnado hace esta actividad con tres compañeros diferentes.

"Cada trimestre cambian. Sí que es verdad que habíamos comentado que esta técnica era mucho de intentar tener una homogeneidad o una atadura en cuanto a la velocidad lectora o comprensión lectora, entonces es ese el criterio. Velocidad lectora o comprensión lectora un mismo nivel. Claro, que pasa si tienes ese criterio a lo mejor el carácter puede chocar. $Y$ después tampoco somos tantos para no cambiar y sobre todo el criterio más fuerte es el nivel. Porque si no imagina un niño que lee muy rápido y otro que tenga problemas en velocidad lectora ¿Cómo harán la segunda lectura? Costaría mucho, por tanto si tienes ese criterio consolidado es más fácil" [C3_E.F_D].

En la lectura por parejas las familias juegan un papel muy importante. "Primero está el tutor que es el que se prepara la lectura en casa [...] y la lee con su padre o con su madre o alguna persona mayor de su familia que le ayuda, después viene aquí a la escuela y hace lo mismo pero con su tutorizado que es otro alumno" [C3_E.F_A8]. Los alumnos, en casa, realizan los mismos pasos que en clase, pero el adulto es quien hace de tutor. "Pues la lectura te la mandan a casa y el padre hace de tutor y te va haciendo los ejercicios. Hacemos la primera lectura, la segunda lectura y la tercera lectura [...] Todos los pasos igual que aquí en clase" [C3_E.F_A7]. La maestra explica que generalmente los alumnos preparan esta actividad con sus familias, aunque no siempre.

"Hay una niña que no ¡Eh! Hay una niña que es H. (alumna inmigrante) [...] La niña no trae muchas veces la lectura, se queda a la hora del patio. Tiene que pasar por mí muchas veces la lectura. Claro, ese es un caso muy especifico. Después te das cuenta que muchas veces la ha hecho con su hermano mayor. A veces, al principio de curso, sí que te das cuenta de que la prepara con ellos. Entonces eso sí que se les marca al principio de curso mucho, en todas las reuniones se marca, que la lectura por parejas es la única que yo pido que estén los padres [...]. Los errores de ortografía y gramaticales y todo eso también pasa, la búsqueda de información, el alumno no tiene que tenerlo bien, a lo mejor ha de tener ahí una persona que es la tutora, que marca. De enseñarles cómo tiene que ser el tutor [...]." [C3_E.F_D]. 
El alumnado cuenta con una hoja con instrucciones para preparar, en casa, junto a un adulto la actividad de leemos en pareja. Además, el alumnado también cuenta con una hoja con instrucciones para seguir la lectura en pareja en clase.

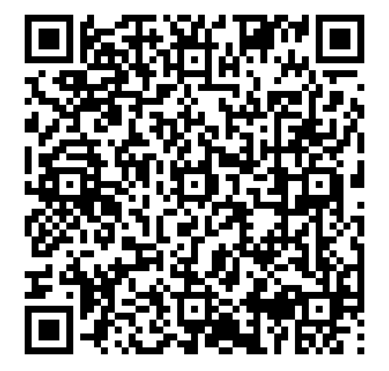

16

Hoja con instrucciones para seguir la lectura en pareja en casa y en clase [C3_AM_FO].

La madre entrevistada comenta como la preparan en el hogar. "Pues primero lee él (hace referencia a su hijo), después lo leemos nosotros, yo o mi marido y después lo leemos entre los dos. Después él hace las preguntas y si tiene alguna duda o alguna cosa pues me lo pregunta o nos lo dice" [C3_E.F_M1]. Asimismo, la madre opina que el alumnado se cansa al tener que leer tantas veces el texto. "Bien porque tiene que leer y tiene que comprender lo que está leyendo, pero después se cansan cuando lo tienen que leer tantas veces, ya lo leen porque me lo tengo que leer y cuando antes me lo quite de encima mejor" [C3_E.F_M1].

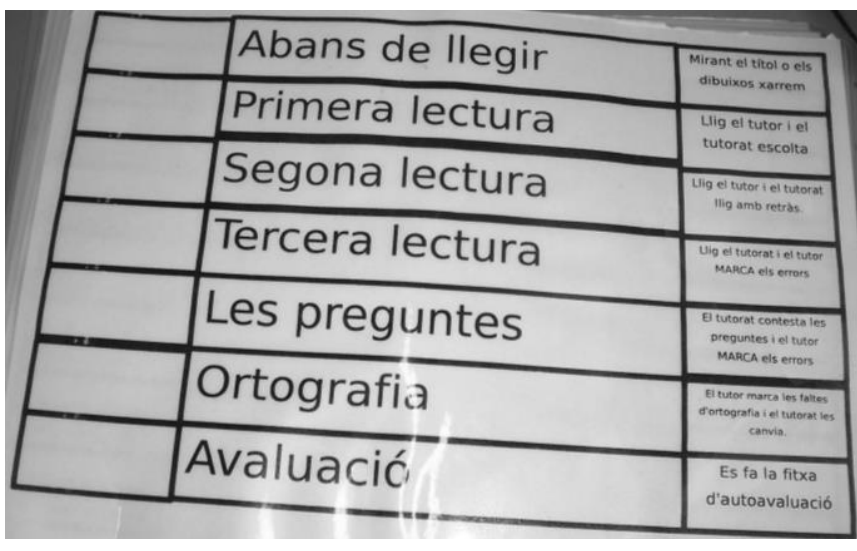

Imagen 59. Pautas actividad leemos en pareja [C3_AM_FO].

Los alumnos tienen una hoja guía con los diferentes momentos de la actividad del leemos en pareja (Ver Imagen 59), cada momento lo van marcando. 1) Antes de leer (mirar y comentar el título o los dibujos), 2) Primera lectura (lee el tutor y el tutorado escucha), 3) Segunda lectura (lee el tutor y el tutorado lee en retraso), 4) Tercera lectura (lee el tutorado y el tutor marca los errores), 5) Las preguntas (el tutor contesta las preguntas y el tutor marca los errores), 6) Ortografía (El tutor marca las faltas de ortografía y el tutorado las corrige), 7) Evaluación (ficha de autoevaluación).

Asimismo, el alumno tutor cuando detecta un error de su tutorado le avisa que ha cometido un error. El tutor también anima a su tutorado. "Le pone la mano encima de su tutorado y el tutorado se para [...] y si no sabe que error ha hecho el tutor le dice que error" [C3_E.F_A8]. "Y tiene que buscar el error [...] y también los tutores dan ánimos a los tutorados" [C3_E.F_A9].

Las lecturas las proporciona la maestra, cada semana. "Cada una con un tema y después cuando llegamos a clase el lunes o el viernes, hacemos lectura por parejas y es que el tutor coja la hoja, o sea, la lectura para el tutorado. Una cartulina en la que tenemos que ir marcando lo que vamos haciendo y empezamos a leer, después hacemos las preguntas y

Diferenciación pedagógica y participación democrática en el aula inclusiva: estudio de casos múltiples 235 
después viene la evaluación. Al finalizar el mes" [C3_E.F_A6]. Las temáticas de la lectura varían a lo largo de todo el curso, a menudo están relacionadas con los proyectos de centro u otras temáticas que están trabajando en otras asignaturas. "Pero es de diferentes temas, a veces va relacionado con algo que estamos dando" [C3_E.F_A7]. "En la lectura por pareja, por ejemplo, en este tercer trimestre estamos dando la película de Tadeo Jones entonces también va un poco alrededor de eso" [C3_E.F_A4].

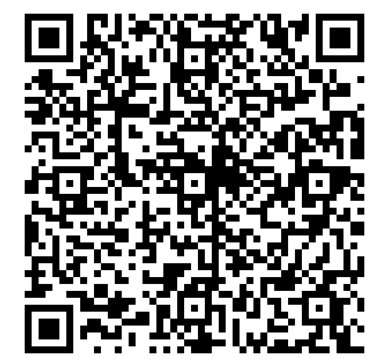

17

Ejemplos de lecturas y actividades del leemos en pareja [C3_AM_FO].

Los alumnos no pueden escoger la temática de las lecturas, aunque sí que les gustaría. “A mí me gustaría escogerlos, porque hay algunos que se te hacen muy pesados porque no entiendes varias palabras y como después tienes que hacer todas las preguntas" [C3_E.F_A6]. Al plantearles la posibilidad de que ellos propusieran los textos y las actividades hay diversidad de opiniones. "A mí me daría igual" [C3_E.F_A5]. "Estaría bien porque así cada uno puede proponer lo que le gusta y no siempre tenemos que estar haciendo lo que trabajamos. Porque aparte de lo que trabajamos en clase tenemos que trabajarlo también en la lectura" [C3_E.F_A6]. A la madre entrevistada también le gusta la idea.

"Yo pienso que leen cosas que no saben lo que están leyendo o son lecturas un poco complicadas [...] o son muy complicadas o son muy fáciles [...]. A mí eso me parecería a lo mejor bien, porque a lo mejor si se tiene que hacer él las preguntas, a lo mejor lee más interesante, lo lee más centrado porque tiene que después hacer preguntas. Después que hacen, a lo mejor se leen las preguntas antes, van buscándose la respuesta..." [C3_E.F_M1].

El alumnado, para responder a las actividades puede utilizar diferentes materiales para la búsqueda de información. Por ejemplo, tal y como se puede ver en la Imagen 60, el alumno puede buscar información en el ordenador, en un mapa, en un atlas,...
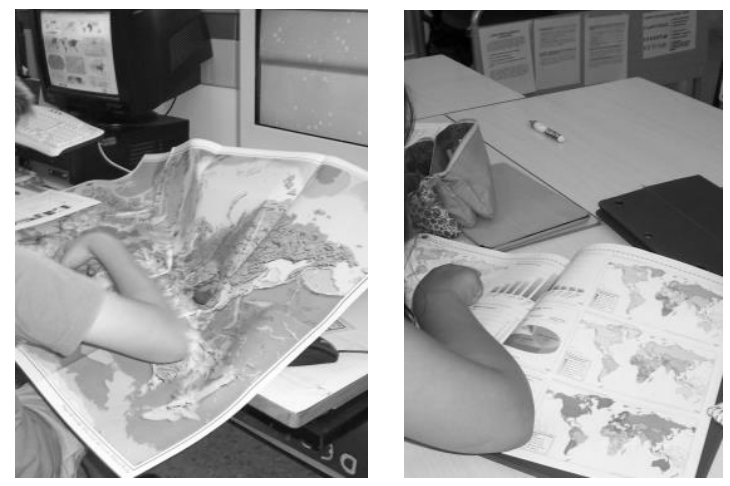

Imagen 60. Alumnado consultando a diferentes fuentes [C3_O_FO]. 
Para finalizar, los alumnos realizan la evaluación de la actividad de leemos en pareja. El curso anterior hacían la evaluación al finalizar cada sesión. "Antes, pero ahora ya no. Ahora la hacemos cada mes" [C3_E.F_A5]. Esto se debe al cambio de horarios. "Porque era de 1 hora, pero ahora como es de 45 minutos, lo hacemos cada mes la ficha. Y lo hacemos en general de todo" [C3_E.F_A8]. Esto es, el curso anterior las clases eran de 1 hora, pero en el presente curso son de 45 minutos. Así pues, al finalizar el mes la maestra proporciona una hoja de evaluación. "Pues a final de mes Cristina nos da una hoja que es una evaluación y tenemos que poner, por ejemplo: Lee bien. Tenemos que poner nuestra opinión" [C3_E.F_A6].

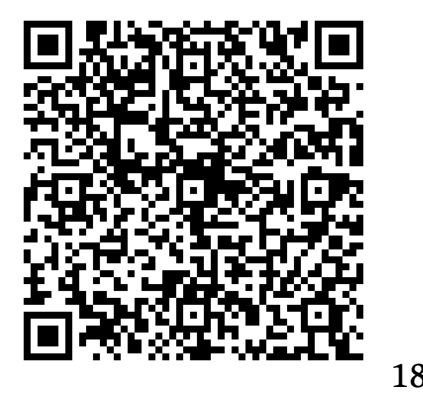

Hoja de autoevaluación leemos en pareja [C3_AM_FO].

El alumnado evalúa diferentes ítems en relación a la comprensión lectora, ortografía y gramática. Concretamente estos marcan si necesita mejorar o lo hace bien. Posteriormente, hay un apartado que solamente lo contesta el tutorado y otro que lo contesta el tutor. La maestra tiene en cuenta las evaluaciones de cada pareja. "Lectura por parejas, que también lo hacemos con la ficha, la evaluación la hacemos cada mes, cojo las observaciones, hablo con la pareja. Para ver el feedback que le puedo dar, a ver si este mes... [...] Bueno va esto lo tenéis que mejorar" [C3_E.F_D].

La maestra destaca, de esta actividad, el rol activo del alumnado y la proximidad de las parejas.

"A ver, en esta yo creo que eso es bastante fácil. Lo que es la voz. Porque estás en parejas, son grupos reducidos. Estás en tu pareja que estás trabajando todo el trimestre. Por tanto, hay una proximidad con tu pareja, para bien o para mal. Porque hay parejas que a lo mejor pues chocan y tienes que estar más como moderadora. ¿Cómo lo sabes?, por la ficha de observación. Yo no lo hago cada semana, porque si no es una pérdida de tiempo. Pero sí que es verdad que me quitaba tiempo a lo que era la actividad propia, entonces la hacemos lo que es a final de mes. Entonces ellos tampoco se cansan. Y ahí se explayan más. Yo me he dado cuenta que me ponen más observaciones y piensan. Y por tanto a final de mes antes de que tú también observas, te das cuenta, pues tienes que ponerte más en las parejas que chocan. La voz, siempre está porque una persona es tutor y otra persona es tutorada. Por tanto, a la hora de escuchar, de hablar y escuchar eso también toca, ahí yo pienso que es más fácil" [C3_E.F_D].

La participación y el compromiso del alumnado son moderado- alto. "Se ha visto como en algunas sesiones no todos traen preparada la lectura en parejas de clase, pero por lo general los alumnos tienen consolidada la dinámica" [C3_O_DCOS]. El ritmo de enseñanza es correcto y negociado con el alumnado. "Como no da tiempo a terminar, la maestra les propone para la próxima sesión continuar con la lectura o introducir otra. Entre todos acuerdan terminar la que no les ha dado tiempo" [C3_O_NC]. "Asimismo, pasan de realizar la evaluación al finalizar cada sesión a 
realizarla una vez al mes" [C3_O_DCOS]. Son diferentes las actividades cognitivas requeridas en esta actividad. "Recordar (comprensión lectora), entender (el texto y las actividades), aplicar (conocimientos en la resolución de las tareas), analizar (en las actividades) y evaluar (al tutor, tutorado,... Lo hacen 1 vez al mes por problemas de tiempo: 45 minutos)" [C3_O_DCOS]. El estudiantado dirige la mayor parte del aprendizaje.

\subsection{Puzzle de Aronson o rompecabezas: resolviendo problemas matemáticos}

Para la resolución de problemas matemáticos suelen utilizar la técnica del Puzzle de Aronson o rompecabezas. En esta ocasión vemos a dos maestras en el aula, Cristina la tutora y P. la maestra de música que ha entrado para reforzar en la actividad. Cristina reparte las hojas con los problemas matemáticos.

"Ordenan las hojas que Cristina ha repartido. [...] Vemos como la maestra se sitúa delante de K. (niño hiperactivo) tiene dificultad en ordenar las hojas. Le ayuda tanto la maestra como la compañera que tiene al lado [...]. La maestra explica cómo hacer los problemas. Tienen que centrarse en los problemas que tienen su número. Cada miembro del grupo tiene un número asignado del 1 al 7 (según la mesa en la que están sentados). Recuerdan los pasos de resolución de problemas. Técnica: subrayo los datos, subrayo la pregunta en rojo, etc. La han utilizado a lo largo de todo el curso. La maestra les dice que quien quiera puede no utilizar los pasos, da la opción. Les dice que la utilicen aquellos que lo necesiten. Recuerda que pronto, algunos, ya pasarán al Instituto" [C3_O_NC].

Posteriormente, la maestra, deja un tiempo para que cada alumno, individualmente, trabaje sobre los problemas de su número. Pero antes la maestra verbaliza brevemente las principales acciones en las que se divide la sesión.

"La maestra dice: 'Nos centramos en nuestro bloque de problemas. Se dejarán unos 10 minutitos de trabajo y después haremos la técnica del rompecabezas. Cada grupo de expertos, esto es, los niños con el mismo número, comentarán los problemas que les ha dado tiempo a resolver cada uno de manera individual y los hayan hecho todos. Los que han hecho de más no, eso ya los comentarán. Luego se dará tiempo y nos pondremos con nuestro grupo inicial A-B-C (macro-grupo). Y comentarán sus problemas de forma oral'. Cristina pregunta si tienen alguna duda [...] Y que si alguien necesita ayuda que se la pida a ella o a P. (maestra de música). Añade que lo importante no es la cantidad, tienen tiempo de hacer más o menos 3 o 4 problemas. Cada alumno hace los que les da tiempo" [C3_O_NC].

Los problemas están agrupados bajo los siguientes contenidos: 1) Datos de la misma naturaleza, 2) Escalares, 3) Producto cartesiano, 4) Problemas a los que les falta un dato o la pregunta, 5) Problemas con datos de más, 6) Problemas a los que le falta un dato que debo conocer, 7) Dada una pregunta formular un problema, 8) Sistema métrico decimal, 9) Unidades de tiempo y dinero, 10) Razonamiento lógico, 11) Texto sobre el entorno social que contenga datos y sobre el que hay que responder a varias preguntas. En esta sesión se centran en los 7 primeros grupos de problemas. 


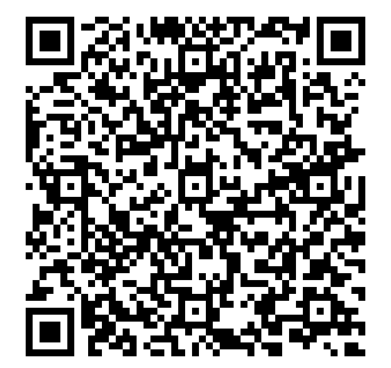

Hoja de problemas matemáticos [C3_AM_FO].

En cuanto a la distribución de problemas, la maestra comenta que esta actividad depende mucho de la técnica del rompecabezas.

"Tienes que cuadrar muy bien los problemas, las personas. Por ejemplo, más fácil para las personas que tal... porque si no se enganchan y cuando están en la reunión de expertos no les ha dado tiempo. Son cosas que hay muchos errores al día a día, ¿eh? [...]. Entonces hay días que tienes que hacer uno y ya está. Entonces claro dependiendo de la característica y lo que es el problema, tienes que saber muy bien a quien le va a tocar hacer ese problema ¿eh? Entonces, si no lo tienes en cuenta te das cuenta en un momento. A veces dices, ostras que le ha tocado este problema a este y ya nos miramos $P$. (la maestra de música, que entra de apoyo) y la única forma de rectificar es darle un poco más de refuerzo en la parte individual e intentar solventar el error" [C3_E.F_D].

Una vez transcurrido el tiempo los alumnos realizan la reunión de los grupos de expertos. "Cristina va organizando el espacio, ubicando a cada rincón del aula a un grupo de expertos. Hablan todos mientras se cambian de sitio y Cristina levanta la mano, los alumnos van levantando la mano a medida que van callando. Es una técnica que utiliza la maestra para recuperar la atención del aula, funciona muy bien" [C3_O_NC]. Se forman un total de 7 grupos (7 grupos de problemas diferentes) de 3 personas (una de cada grupo de origen). Como falta un alumno, un grupo de expertos está formado solamente por dos personas. "Ahora la clase está más viva respecto a antes, cada grupo de expertos comenta y corrigen los ejercicios que han hecho [...]. Cristina comenta que si terminan de corregir una 'ronda de ejercicios', esto es que cada experto comparte con su grupo un ejercicio de lo que ha hecho pueden hacer otra ronda de corrección de ejercicios. Las maestras pasan por las mesas. Los niños que requieren de ayuda levantan el brazo" [C3_O_NC].

Transcurrido el tiempo, los alumnos regresan al grupo de origen, a los grupos A-B-C, Cristina les dice que lo hagan todo de forma oral y que comenten cada uno un ejercicio. Ambas maestras pasan por la mesa. Los niños "expertos" leen el ejercicio de su número que han realizado y todos los comentan. Los tres grupos comentan. "K. (alumno TDAH), cuando le toca a la alumna inmigrante va a su lado y le ayuda, le supervisa" [C3_O_NC]. En esta actividad vemos como hay mucha flexibilidad en los tres principales momentos, esto es, tanto en la cantidad de ejercicios que hace cada alumno individualmente, como en la cantidad de rondas de corrección realizada por cada grupo de expertos, como en la cantidad de problemas explicados a los grupos originales o grupos puzle. Antes de 
finalizar la sesión, y para concluirla Cristina les hace algunos comentarios para mejorar el trabajo y cómo lo tienen que realizarlo las próximas veces.

"Como hay un grupo que no le ha dado tiempo, la maestra les deja más tiempo [...]. Mientras Cristina escribe los deberes en la pizarra que tienen colgada en la ventana (Ver Imagen 61). Cristina le pregunta al grupo si han terminado. Como deber cada uno tiene que hacer dos problemas de cada bloque de las hojas que ha repartido previamente la maestra. Sólo los problemas del 1-7 de lo que han trabajado" [C3_O_NC].

La participación y el compromiso del alumno en esta actividad es elevada. "La participación en la tarea es muy elevada, todos están centrados en la tarea. Las maestras siguen pasando por las mesas y recuerdan que quedan 2 minutos" [C3_O_DCOS]. "Primero trabajan de manera individual, después en el grupo de expertos y después en macro-grupo" [C3_O_HO]. El ritmo

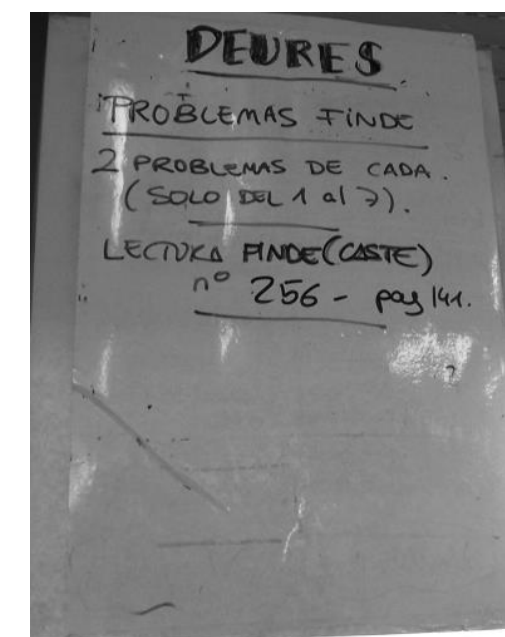

Imagen 61. Pizarra de deberes [C3_AM_FO]. de enseñanza es correcto. "La maestra va viendo el ritmo de trabajo y va recordando 'venga dos minutos más de trabajo individual y pasamos...'. Además, al terminar la clase a un grupo no le da tiempo a compartir como mínimo una ronda de ejercicios realizados, es por eso que la maestra otorga unos minutos para que como mínimo todos los alumnos del grupo comenten un ejercicio de los que han trabajado con su grupo de expertos" [C3_O_DCOS]. Las actividades cognitivas son variadas. "Aplicar (los conocimientos que han aprendido para la resolución de problemas), entender (los problemas), analizar (los que utilizan la técnica de resolución de problemasPASOS- subrayar las preguntas, datos...es opcional), recordar (los procedimientos de resolución de problemas para explicarlo a sus compañeros- vuelta al macro-grupo)" [C3_O_DCOS]. Vemos como a lo largo de toda la actividad el que dirige la mayor parte del aprendizaje es el alumnado. Las maestras resuelven dudas y Cristina marca los tiempos según la necesidad de los grupos.

\subsection{Estaciones: trabajando matemáticas y lengua castellana y valenciana}

A partir de las estaciones se trabajan y refuerzan contenidos lingüísticos y matemáticos, para ello la maestra divide la clase en grupos de 4 personas. Los grupos no son los mismos que los grupos de base de clase. "No somos los grupos en los que estamos" [C3_E.F_A6]. "A veces coge a dos de ahí que sobren y hace el grupo de 5" [C3_E.F_A5].

Las estaciones las realizan dos veces por semana, en una sesión trabajan diferentes contenidos matemáticos y en la otra sesión trabajan diferentes contenidos lingüísticos (valenciano o castellano). "Matemáticas es el viernes y lengua es el lunes, si no pasa nada. Si no cambia o algo" [C3_E.F_A3]. "Los viernes hacemos en matemáticas, los lunes hacemos una semana en valenciano y otra en castellano" [C3_E.F_D]. 
En alguna ocasión, asisten algunos padres a ayudar en alguna estación. A menudo, durante estas sesiones vienen algunos maestros a reforzar en la actividad. "A veces viene M. la de refuerzo o A. $y$ algunas veces viene P. la de música y echa una mano a Cristina para organizar todos los grupos" [C3_E.F_A1]. La maestra valora la presencia de un maestro de apoyo en algunas sesiones. Le ayuda a atender las necesidades surgidas en alguna estación.

"Es difícil la observación de la participación dentro del grupo. Porque tienes que pasar y no hay una persona en cada grupo. Aprovechaba el refuerzo de A. para que estuviera en una estación y yo estuviera en dos, porque se hacían 3 o 4 grupos, ahí más fácil cuando tienes el refuerzo y escuchas quien participa, quien no participa [...]. También se intentaba que fuera heterogéneo cada grupo, pero también homogéneos entre ellos. Es decir, siempre había una persona que nunca habla, que nunca tal, se intentaba siempre dar un poco... [...] Sí que se intenta parar al que habla demasiado e intentar que se escuche la voz del que nunca habla. Pero es difícil la observación si no tienes el refuerzo de un maestro o una persona o un padre" [C3_E.F_D].

El funcionamiento de las estaciones suele ser siempre el mismo, lo que cambia es la actividad a realizar y la técnica de aprendizaje cooperativo mediante la cual se debe resolver. "Cada grupo tiene una técnica, un grupo hace el folio giratorio, en otro es individual, en otro lápices al centro" [C3_E.F_A2]. Además de actividades de lápiz y papel también suelen haber una o dos estaciones para trabajar mediante las Tablets. "Normalmente pone dos de aplicaciones, dos grupos aplicaciones a veces es el tangram, las otras el Rey de las mates sobre todo las aplicaciones son de matemáticas, una de mate y otra de lengua" [C3_E.F_A1]. "De sopa de letras, adivinanzas,... cosas de esas" [C3_E.F_A2].

La maestra una vez distribuidos los alumnos en mesas explica que se tiene que realizar en cada una de ellas. "La maestra va diciendo: 'en esta mesa vais a hacer fotocopias de ortografía, alli el Rey de las mates, que es una aplicación de hacer operaciones y en cada mesa una cosa'. Y vamos rodando y vamos haciéndolo todos, cada vez que suena la música cambiamos de sitio" [C3_E.F_A8]. "Son formas de aprender pero no es siempre de copiar y..." [C3_E.F_A9]. En relación a la utilización de las técnicas de aprendizaje cooperativo, los alumnos comentan que a veces les cuesta. "Hay veces que, aunque esté el cartel (se refiere al cartel con el nombre de la técnica a utilizar en esa estación) nos cuesta hacer esa técnica. Por ejemplo, lápices en el centro nos cuesta hacerla, porque mientras que está el lápiz en la mesa puedes hablar y cuando coges el lápiz ya no puedes hablar y hay gente que no hace caso a esa técnica" [C3_E.F_A4]. "O no habla y tiene todo el rato el lápiz en la mano, puedes tener el lápiz en la mano pero claro no puedes hablar, pero tampoco tienes que tener el lápiz en la mano sin hablar en ningún momento" [C3_E.F_A3].

En la sesión observada de las estaciones de matemáticas, la clase está dividida en 4 grupos de 5 personas. "Hay cuatro estaciones: 1) resolución de una ficha a partir de la técnica 1-2-4,2) programación, esta estación está dinamizada por A. (el maestro que ha entrado de apoyo, no es de Pedagogía Terapéutica ni de Audición y Lenguaje), 3) aplicación de cálculo matemático y 4) resolución de una ficha a partir de la técnica lápices al centro" [C3_O_NC]. 


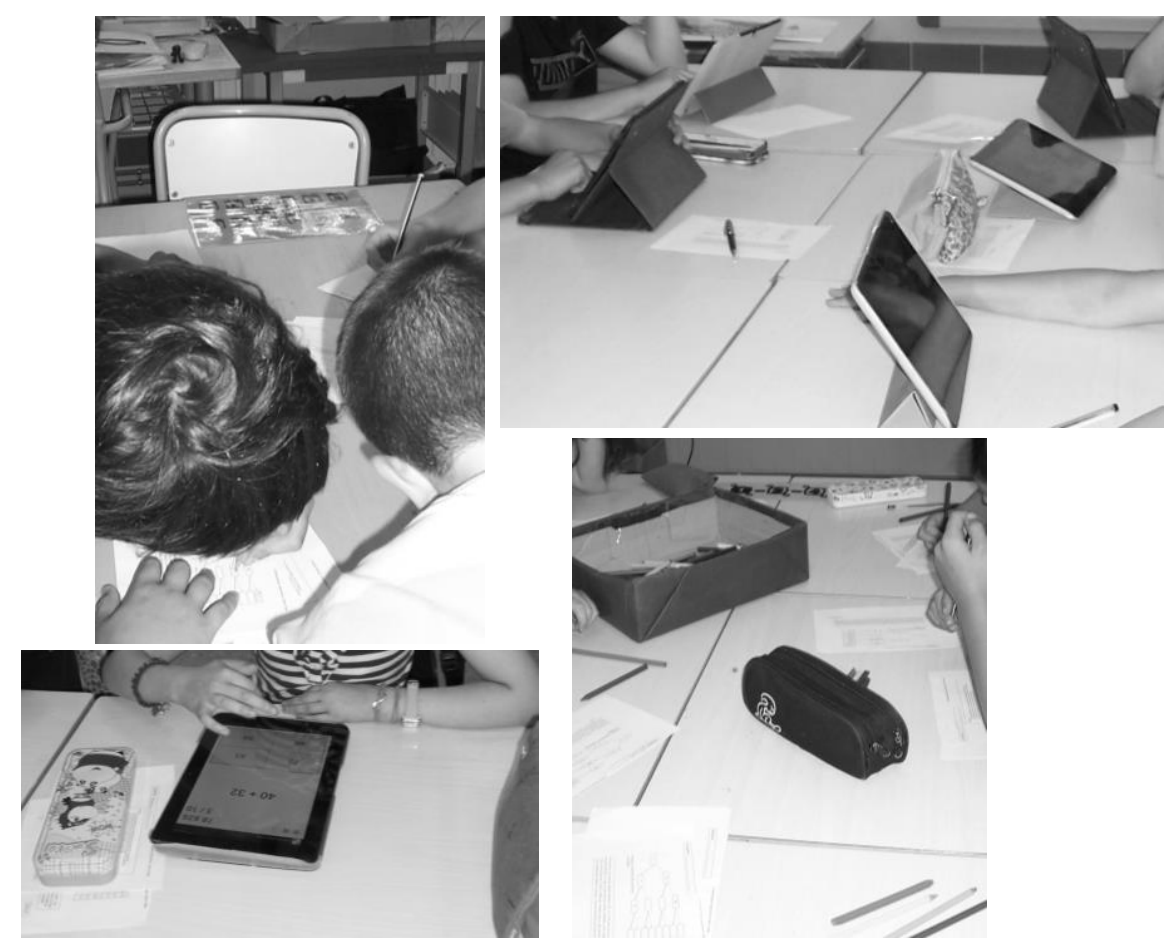

Imagen 62. Alumnado realizando estaciones de matemáticas [C3_O_FO].

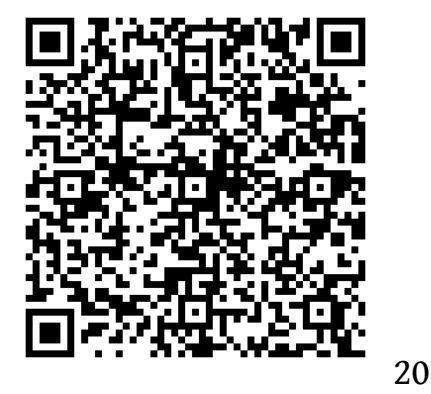

Ejemplos de actividades para las estaciones de matemáticas [C3_AM_FOM].

En la sesión observada de las estaciones de lengua las actividades a realizar en cada estación son las siguientes: 1) la Tablet giratoria, en esta estación los alumnos deben de resolver una sopa de letras entre todos, un alumno marca una palabra y pasa la Tablet a su compañero, 2) resolver mediante una aplicación, de manera individual, una serie de adivinanzas. Se puede utilizar la técnica tú me ayudas yo te ayudo, 3) resolución de una ficha sobre tabús y eufemismo mediante la técnica del folio giratorio y 4) resolución de una ficha de completar oraciones según el tiempo verbal que corresponda mediante la técnica de lápices al centro.

Generalmente, al alumnado le gusta esta dinámica. "Me gusta así, así haces diversas cosas y te diviertes" [C3_E.F_A2]. "Divierte mucho ir cambiando de lugar, ir cambiando de faena. No estar toda la sesión en un mismo lugar. Normalmente, cambiamos en 6-7 minutos" [C3_E.F_A1]. Otros alumnos, valoran el cambio de actividad en poco tiempo. "Y tampoco en mucho tiempo porque si no te aburres [...]. A veces falta un poco para hacer cosas, pero es según el ritmo que tengas" [C3_E.F_A7]. "Y se pasa rápido" [C3_E.F_A9]. Sin embargo, otros alumnos opinan que tienen 
poco tiempo para realizar la actividad. "Hay veces que se nos queda muy corto y claro lo que no terminamos aquí nos lo tenemos que llevar a casa y claro, es muy agobiante" [C3_E.F_A4]. "Es muy agobiante porque tú no te centras, hay algunos que están ahí molestando y no te centras. Por ejemplo, en la Tablet que están todos concentrados se te hace más corto" [C3_E.F_A3]. "Es que hay actividades que son muy rápidas de hacer y hay otras que cuestan" [C3_E.F_A5].

Además, la maestra utiliza muchos recursos visuales para esta actividad. A veces, es la maestra la que anota en la pizarra que es lo que se debe hacer en cada estación, otras veces lo escribe el alumno encargado. "Eso es por si a alguien se le olvida pues mira a la pizarra y no tiene que estar preguntando" [C3_E.F_A5]. También hay en cada mesa un cartel con el nombre de la técnica a partir de la cual tienen que resolver este ejercicio. "[...] eso también ayuda por si alguien se pierde [...] Y claro si tú sin querer, tú sabes y sin querer te vas y claro tú ves la mesa y ves algo que brilla o que da la sensación que es brillante y pues lo ves. Pues es como un jostras que se me ha olvidado la técnica!" [C3_E.F_A3].

Las estaciones facilitan y propician una participación y un compromiso elevado por parte del alumnado hacia la tarea. El ritmo de la actividad tiende a ser correcto o rápido para algunos alumnos. "Puesto que quien no termina la actividad al sonido de la música, que indica cambio de estación, debe de terminar la actividad como deber" [C3_O_DCOS]. Las actividades cognitivas de esta actividad son diferentes y varían según la tarea concreta que deben de realizar en cada estación. "Destacando principalmente entender (lo que se tienen que realizar en cada una de las actividades propuestas), aplicar (resolución de tareas)" [C3_O_DCOS]. Se ha visto que el rol de los docentes presentes en el aula recae en la ayuda de quien lo necesita, Cristina marca los tiempos de la actividad y el rol más activo recae en el alumnado, todos trabajan en la ejecución de la tarea.

\subsection{El taller de ciencias: los minerales}

Otra actividad que tienen sistematizada en el aula son los talleres. En biología, aprovechan el tema de las rocas minerales para hacer el taller de ciencias. "La maestra hace explícito el objetivo de la actividad, consiste en hacer cada uno, en su hoja, un listado de los minerales que les ha tocado a cada grupo. Los minerales están en una caja y el alumnado no sabe el nombre. Por eso tienen una hoja a color con todos los nombres de los minerales de la caja" [C3_O_NC]. La hoja con el nombre de los minerales y gemas del mundo se presenta en la Imagen 63.

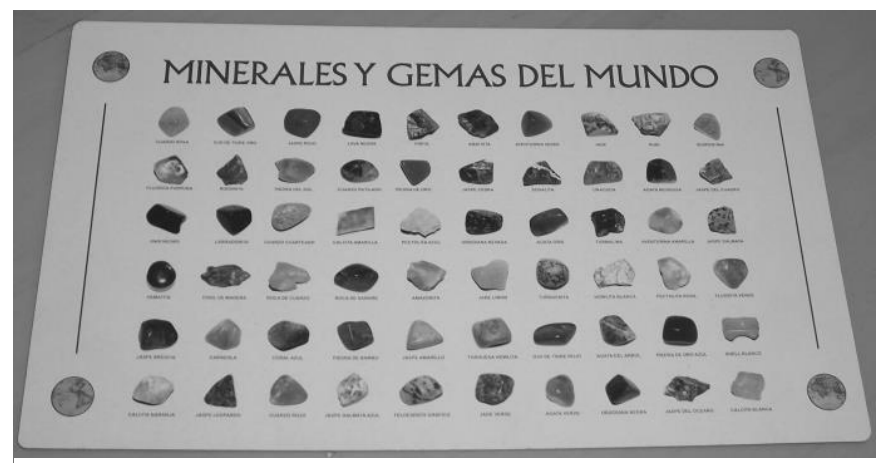

Imagen 63. Hoja con el nombre de los minerales y gemas del mundo [C3_AM_FOM]. 
Esta actividad la hacen por grupo, cada grupo está formado por 7 alumnos. El alumno que tiene asignado esa semana el rol de director, es quien hace las parejas para trabajar, reparte los minerales a estudiar. Hay algunos que dan la opción de que cada alumno escoja el mineral que quiere estudiar. El director está fuera de esas parejas, su función es la de dirigir y ayudar a todas las parejas de su grupo. Éste puede mirar, puede coger el material y también puede colaborar en la pareja. También tiene que supervisar que las 3 parejas de su grupo funcionen bien. "Como en una mesa falta el alumno que tiene el cargo de director, otro niño asume el rol y, en dicho grupo, en algún momento la pareja del director trabaja de manera individual" [C3_O_NC].

Cristina escribe en la pizarra los pasos que tienen que hacer para el taller de ciencias (Ver Imagen 64). Esto ayuda al alumnado a recordar que es lo que debe realizar para la ejecución de la tarea. "Eso es por si a alguien se le olvida pues mira a la pizarra y no tiene que estar preguntando" [C3_E.F_A5].

Concretamente, la actividad consiste en que la maestra reparte diferentes minerales

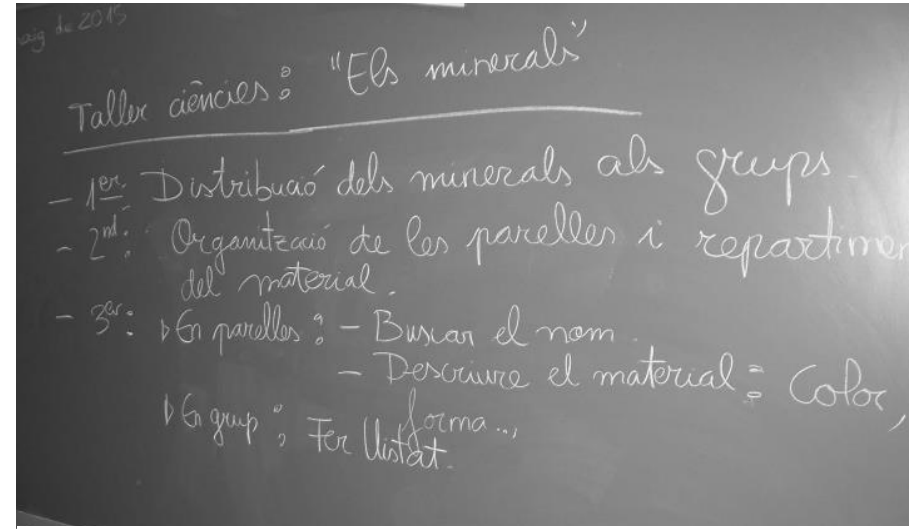

Imagen 64. Pasos a realizar en el taller de ciencias [C3_O_FO]. a los 3 directores. Los 3 directores los distribuyen entre las parejas integrantes de su grupo. Reparten un folio para cada uno. De forma individual se tiene que hacer un listado. Posteriormente, hacen una puesta en común, ésta consiste en enseñar los minerales y el nombre. Después en la hoja tienen que anotar las características observables, es decir, el color, el peso, la forma, la textura,... a simple vista. "Cada uno tenía unos pero después hemos visto los que tenían nuestros compañeros" [C3_E.F_A2]. "Los directores del grupo están de pie, van supervisando el trabajo de los compañeros" [C3_O_NC]. Además, en el aula hay otra maestra de refuerzo, aunque esta se va antes de terminar la clase. "Ahora la otra maestra se ha marchado, solamente está Cristina. Quien quiere alguna cosa levanta el brazo y Cristina le da la palabra, la maestra pasa por las mesas. Además, la maestra recuerda a ciertos alumnos que les queda un minuto para hacer la comprobación del grupo" [C3_O_NC].

"Todos trabajan. Cuando van terminando, Cristina levanta la mano y todos la van levantando hasta que hay silencio" [C3_O_NC]. Esta técnica para captar la atención de todo el alumnado y silenciar la clase es muy recurrida por la docente y resulta eficaz. La maestra vuelve a recalcar el objetivo de manera explícita de la actividad.

"12 minerales por cada equipo, 4 por pareja, hay que hacer la lista con el nombre. Puede que algunas parejas se hayan equivocado en el nombre del mineral. El viernes próximo haremos la comprobación de todo. Repartiré los mismos minerales a otro director, y lo que vais a hacer será hacer una presentación (power point) y comprobar los datos de esos minerales en investigación, vais a comparar si os habéis equivocado o no. Lo vais a investigar en la Tablet o en el ordenador que sea y ya pondremos los datos que 
encontréis sobre vuestros minerales y después a partir de ahí montaréis vuestro power point. Importante cuidar el material" [C3_O_NC].

En algunos talleres también participan las familias. "En el taller de ciencias, hay veces, hace un tiempo vino el padre de un alumno que nos trajo telescopios e hicimos un taller en el taller de ciencias [...] en naturales dimos los animales, las plantas, las células y trajo un telescopio con virus donde estaban las células" [C3_E.F_A1]. "Mirando las moléculas y todo [...]. Como conocía mucho sobre eso vino" [C3_E.F_A2].

Destacar en el taller de ciencias el alto grado de participación y compromiso que presenta el alumnado hacia la tarea. "Dado que todo el alumnado muestra interés hacia la tarea y todos participan" [C3_O_DCOS]. El ritmo de la enseñanza es correcto. A lo largo de la ejecución de la actividad vemos como hay

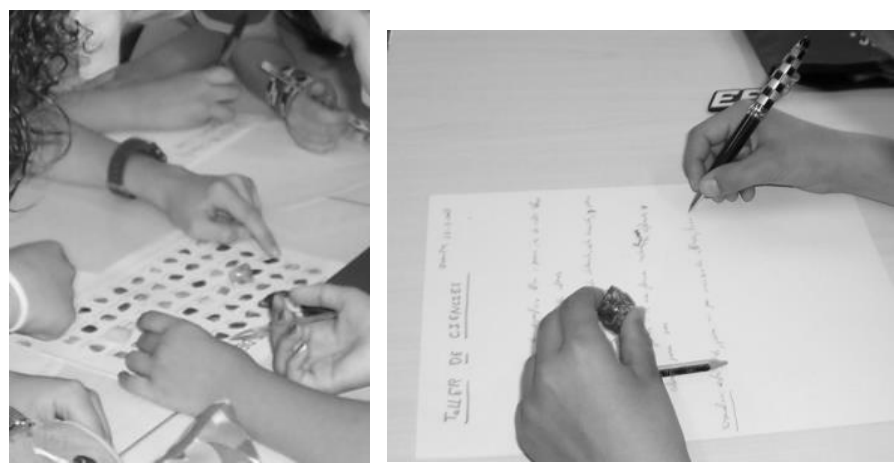
diferentes actividades cognitivas. "analizar

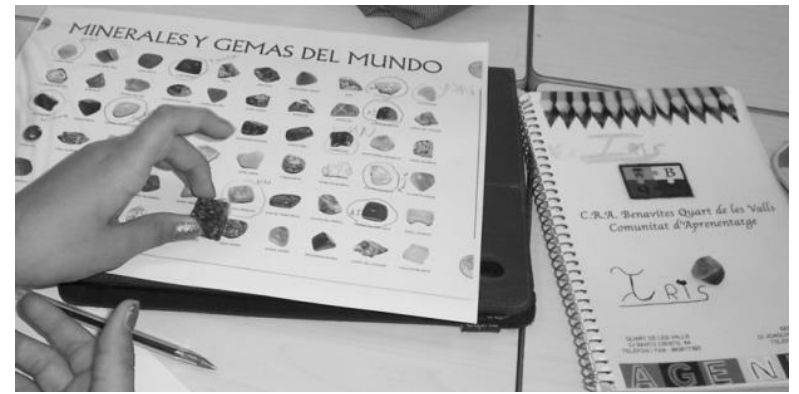

Imagen 65. Grupos trabajando en el taller de ciencias [C3_O_FO]. (detectar las características visuales de los minerales: color, tamaño, peso,...) crear (power point: investigar más a fondo los minerales) explicar (presentar a los compañeros)" [C3_O_DCOS]. Mencionar también que el estudiante dirige la mayor parte del aprendizaje. "Concretamente el alumno que tiene el rol de director es el principal conductor de la actividad, quien hace las parejas, distribuye los minerales, supervisa el trabajo de cada pareja, colabora, ..." [C3_O_DCOS].

\subsection{Tertulia literaria dialógica y exposición de libros}

La tertulia literaria dialógica es otra de las actividades que llevan a cabo en el aula objeto de nuestro estudio. "Lo hacemos los viernes, este trimestre la hacemos en castellano, el trimestre pasado lo hicimos en valenciano. El trimestre pasado fue un libro en concreto y este trimestre hemos cogido pequeños cuentos en castellano para pensar" [C3_E.I_D]. Esta actividad varía a lo largo del curso escolar, estos cambios se deben principalmente a la necesidad del grupo. "El primer trimestre fue un libro, el segundo trimestre "Cuentos para pensar' de Jorge Bucay, que eran cortos y se lo leían aquí y el tercer trimestre un fragmento leído previamente en casa y preparado en casa y después ya para comentar aqui" [C3_E.F_D]. Destacar que en la tertulia literaria dialógica existe el rol del moderador. "El primer trimestre fui yo la moderadora y el segundo trimestre pues cada día uno" [C3_E.F_D].

En el primer trimestre, la dinámica de la tertulia literaria dialógica consistía en que un grupo leía durante la sesión. "Escoge Cristina un grupo que todavía no ha leído. Empieza una persona del equipo, y así hasta que damos la vuelta. Cuando leen 3 personas, cada persona resume y después de resumirlo, se hacen preguntas a los demás y respondemos y damos nuestra opinión que nos ha parecido y cosas así" [C3_E.F_A2]. Esto es, cada alumno lee un 
trocito y le pasa el libro a su compañero. "Teníamos un libro que era de diferentes capítulos, no tenían nada que ver" [C3_E.F_A4]. "Cada dos o tres puntos tenías que pasar el libro al compañero" [C3_E.F_A6]. Y posteriormente explicaban lo que habían leído. "Lo que habíamos leído, si lo habíamos entendido y todo eso" [C3_E.F_A5]. Cada sesión leía un grupo. "Los otros escuchan, a la sesión siguiente lo hace otro grupo y los otros escuchan y así..." [C3_E.F_A3]. Esta dinámica se les hacía un poco pesada al alumnado de los grupos que no tenían que leer. "Los otros se supone que tienen que escuchar. Pero hay gente que se...claro" [C3_E.F_A4]. "Pero se nos hacía más aburrido y ahora hacemos Lecturas para pensar" [C3_E.F_A3].

En el segundo trimestre se cambió la lectura puesto que no captaba la atención del alumnado. "Yo creo que el trimestre pasado [...] era un poco como si se nos hiciera aburrido porque a lo mejor ese mismo día hacías dos capitulos y esos dos capitulos no tenía nada que ver. Entonces te mareabas y desconectabas" [C3_E.F_A4]. "Como era un libro, pues cada semana igual leíamos un capítulo y todo, entonces como pasaba una semana pues había gente que no se acordaba entonces era un mareo" [C3_E.F_A3]. Con las lecturas de este segundo trimestre la tertulia literaria dialógica funciona mejor. "Son lecturas para pensar y como se terminan en una sesión pues entonces sí que tiene..." [C3_E.F_A3]. "Cristina piensa que sí que llega a lo que queremos" [C3_E.F_A4]. Asimismo, durante la sesión de la tertulia literaria dialógica también hacen atención plena. "Pero hacemos atención plena que tenemos que estar muy bien sentados [...] para poder escuchar mejor" [C3_E.F_A4].

En el tercer trimestre, la tertulia dialógica continúa con variaciones. Una de las novedades introducidas consiste en que el alumno que hace esa semana de director o coordinador, se tiene que preparar un libro para exponerlo a sus compañeros. "Se tiene que preparar lo que más le ha gustado, el autor, la editorial. Todo. [...] lo que nos había interesado más y que nos había parecido el texto y se puso en común en la clase." [C3_E.F_A7]. "Dice su opinión sobre el libro, sobre porque lo recomendaría leer, que es lo que más le ha gustado y ya le hacemos nosotras preguntas por si no nos hemos enterado [...] Y nosotros le preguntamos, por ejemplo, cuál es el escritor, la editorial y eso y... por si no nos hemos enterado, básicamente." [C3_E.F_A8]. Por tanto, en este tercer trimestre podían escoger los libros de texto, aspecto que les gusta más al alumnado. La otra tarea que hacían en este tercer trimestre era que la maestra proporcionaba un texto y el alumnado lo leía en clase o en casa y después lo comentaban. "Cristina nos dio un texto de Williams Shakespeare y teníamos que escoger una frase [...]" [C3_E.F_A6].

Por lo que respecta a la evaluación en esta actividad intervenía tanto el alumnado como la docente. "Y empezaban a leer entre ellos, haciendo un capítulo y después al que leía mejor le ponían un positivo" [C3_E.F_A7]. "Bueno nosotros, como lee un grupo, nosotros valoramos lo que más nos ha gustado: como ha leído, y [...] nos pone un positivo. Pero su voto también cuenta. A la persona que más le ha gustado le pone un positivo" [C3_E.F_A4].

Hemos visto como a lo largo del curso se presentan diferentes formas de hacer la tertulia. Existe una negociación entre la maestra y el alumnado sobre la mejora de la práctica educativa. "El trimestre pasado preguntándolo a todos" [C3_E.F_A4].

"Para ver yo y valorar cual es la que mejor me parece. Y voy un poco también a lo que me dicen ellos. A ver, cada grupo es una cosa. Yo propongo el primer libro gustó, pero no... 'Cuentos para pensar' por ejemplo, les gustó mucho. Y después la tercera se propuso hacer eso y querían hacerlo. A ver qué queréis 
continuar con un libro, continuar con cuentos cortos o queréis eso.... U otra forma. Vamos a probar esa" [C3_E.F_D].

La maestra comenta que la tertulia literaria dialógica es una actividad que fomenta la participación de todo el alumnado.

“[...] la participación de todos los miembros para decir que persona había dado la entonación, el ritmo de la lectura. Todos hablaban, tenían su opción [...]. Después en cuanto a la colaboración, en cuanto a la opinión, también estaba muy marcada en cuanto a eso. No era obligatorio, porque si te tocaba y no querías hablar, pues no pasa nada. Pero si una persona no habla nunca, pues sí que intento [...] motivarlo para que hable" [C3_E.F_D].

En cuanto a la exposición de libros remarcar que, a lo largo del curso escolar hay lecturas obligatorias y lecturas optativas.

“Tienen la biblioteca de aula y después sí que es verdad que no les marco mucho de coger libros de la biblioteca y es más libre ¿no? Esos libros que salen ahora de Geronimo Stilton o de...bueno. Sí que hay uno obligatorio que es el de valenciano y después ellos hablaban de lo que querían. De lo que se habían leído en valenciano o en castellano. Después hay exposiciones de intentar vender ese libro [...]. El propósito es el hábito lector, sî" [C3_E.F_D].

En valenciano hay unas lecturas marcadas y obligatorias cada mes.

"Son obligatorios [...] Es una ficha, no me gustan las fichas ¿Vale? Pero claro es un 5y un $6^{\circ}$ y se tienen que acostumbrarse a lo que les piden en la ESO y en la ESO es verdad que se les pide una ficha y tienes que estar acostumbrados a otras cosas y no se le da tanta importancia, pero es una forma de saber que se lo han leído, ¿no? Te la pueden colar, pero bueno. Sí que es verdad que de la forma que hablan y todo eso si que vas comprobando que se lo han leído. Al final en literatura valenciana de los libros que habrán leído tendrán que hacer un trabajo, que ellos no lo saben. En cuanto a la lectura no me gusta mucho jeh! Pero bueno" [C3_E.F_D].

No todos los alumnos leen el mismo libro, a cada uno se le asigna uno referente a la colección de libros que tienen para trabajar literatura valenciana. Señalar también que la ficha de la lectura varía entre los alumnos de $5^{\circ}$ y los alumnos de $6^{\circ}$ (Ver Imagen 66).
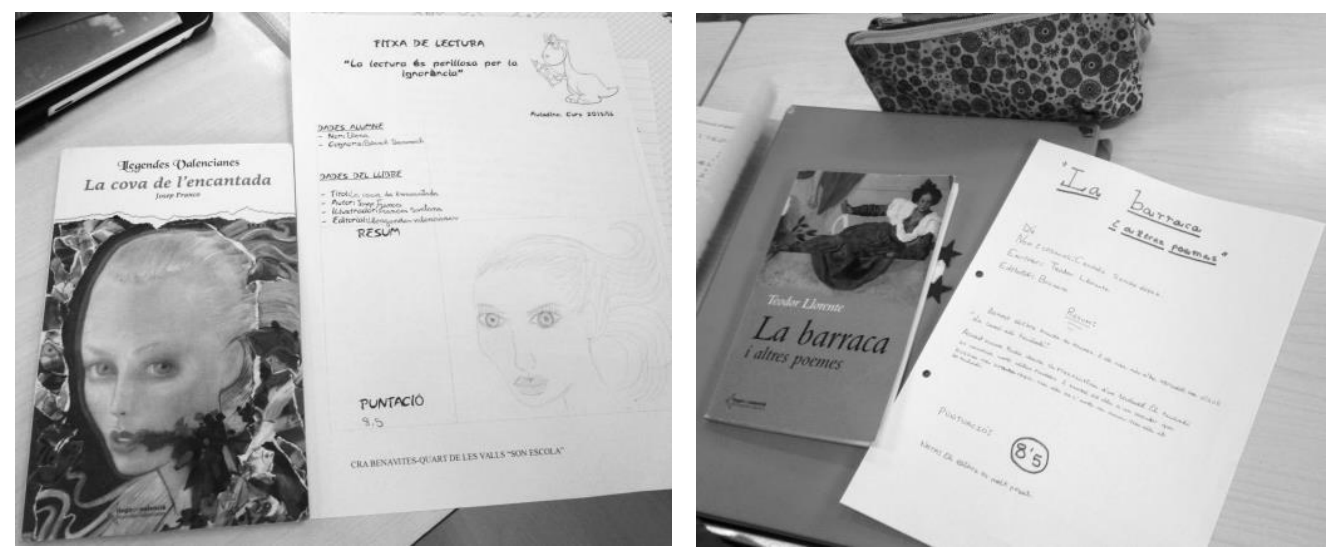

Imagen 66. Libros de lectura: literatura valenciana [C3_O_FO]. 
Por otra parte, los alumnos pueden leer libros de manera voluntaria y exponerlos a sus compañeros. Esto se realiza durante todo el curso escolar y coincide con la primera parte realizada en la tertulia dialógica del $3 \mathrm{r}$ trimestre. "Pero el libro de castellano de cada mes es libre y podemos escoger nosotros de casa, de clase, de un amigo" [C3_E.F_A2]. "Esos de la biblioteca te lo lees tú si quieres en casa" [C3_E.F_A5].

"Castellano o valenciano me da igual [...]. Yo les dije, simplemente vamos a trabajar, como no tenemos educación artística- la plástica, bueno pues a cualquier niño le gusta dibujar, pues bueno simplemente tenéis que traer portadas. ¿En la portada que está? Pues los datos más importantes, me hacéis las portadas y una puntuación ¿para qué? Para hacer una recogida de libros que recomendáis y así pues si alguien quiere leer alguna cosa y no tiene idea pues ; a ver este libro quien lo tiene? Pues lo puedes pedir o lo que sea o si queréis cogerlo de aquí también. Claro no venían portadas, pues que los niños leían en su casa, pero no hacían la portada. Porque yo les decía 'para apuntarse aquí tenéis que traer la portada', 'es que yo sí que he leído, pero no lo anoto porque no he hecho la portada'. Al principio no leían, pues os daré un poco más de puntuación en la nota al final de trimestre [...]" [C3_E.F_D].

En el aula tienen una hoja registro para anotar el número de páginas leídas cada mes (Ver Imagen 67). La lectura repercute en la nota final del alumnado. "Los colgamos, ponemos la nota y por cada 100 páginas Cristina nos sube 0.01" [C3_E.F_A6]. "Cada 100 páginas tienes una décima más en la nota” [C3_E.F_A7].

A lo largo del curso, tal y como se ha relatado, la participación y el compromiso del alumnado varió. "La atención del alumnado decrece cuando este debe de adoptar un papel o un rol más pasivo en el proceso de aprendizaje. En el momento de que el director expone su libro, son bastantes los alumnos que hacen preguntas e interactúan con el alumno que ha presentado el libro. Asimismo, en el momento de leer y compartir los comentarios sobre el texto de Williams Shakespeare el alumnado también presenta un rol activo" [C3_O_DCOS]. El ritmo de la enseñanza es correcto, lo va marcando el moderador. La actividad cognitiva de la persona que expone el libro es variada. "Recordar, entender y analizar en cuanto a la persona que expone el libro. Posteriormente, todos tienen la oportunidad de levantar la mano $y$ participar. En el texto de Williams Shakespeare cada uno lee la frase, explica porque la ha escogido (recordar), que significa (entender y analizar)" [C3_O_DCOS]. A lo largo de esta actividad vemos como el estudiantado dirige todo el aprendizaje. La moderadora establece el
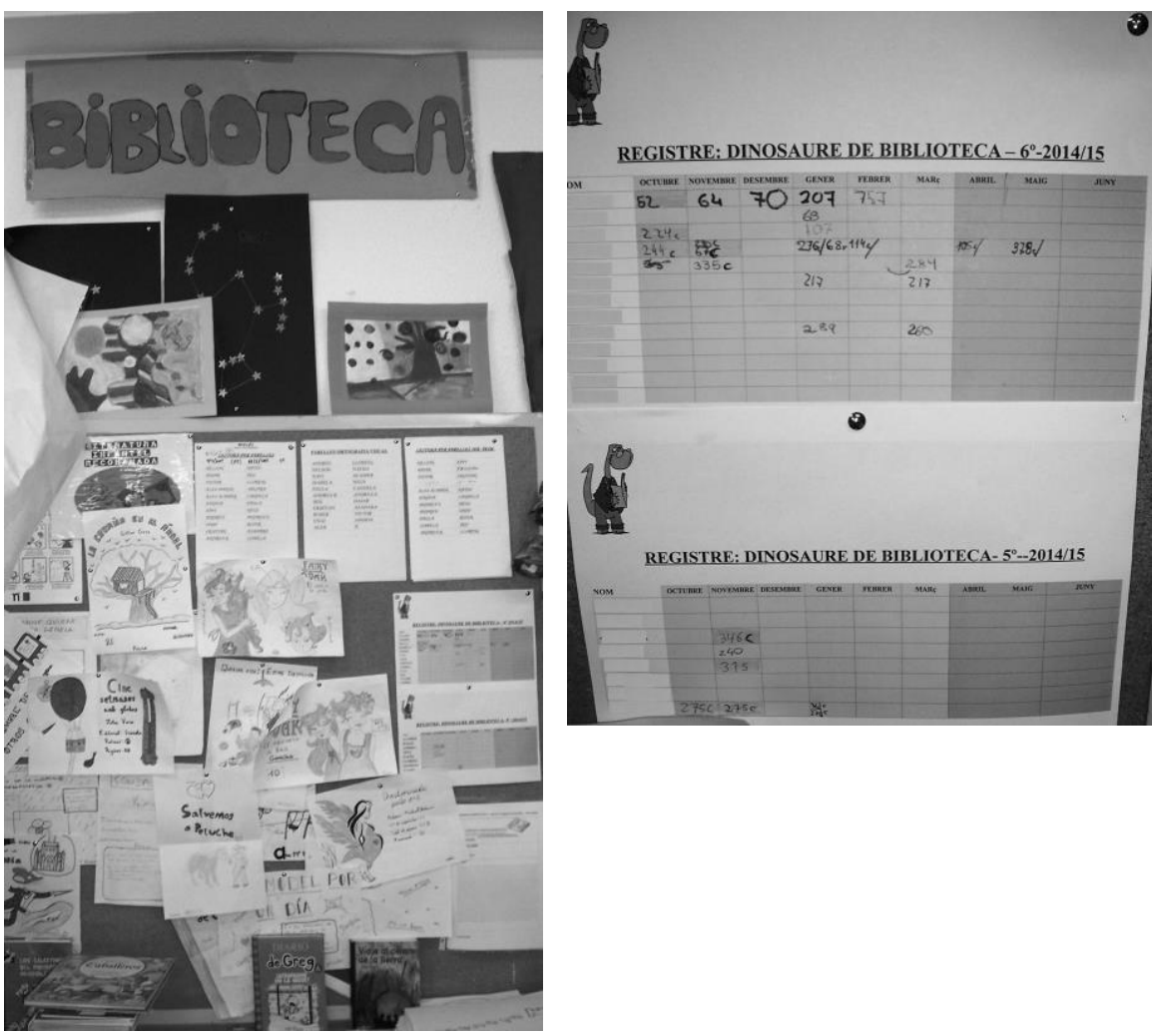

Imagen 67. Rincón biblioteca y hoja de registro [C3_O_FO]. 
turno de palabra. La maestra hace algunas preguntas. Todos participan, algunos son más pasivos, pero la maestra intenta potenciar y promover la participación de todos.

\subsection{Proyecto LóVA: la ópera infantil como vehículo de aprendizaje}

El Proyecto LÓVA ${ }^{25}$ se lleva a cabo por iniciativa de la maestra de música. "El proyecto LóVA estaba dirigido por ella (hace referencia a la maestra de música), ella es la que daba las instrucciones a principio de curso [...], yo estaba más en la sombra" [C3_E.F_D].

La maestra de música comenta los orígenes del Proyecto LóVA.

"Esto nació de una chica americana [...] y lo llevaron al teatro Real de Madrid, Pedro Sarmiento. Entonces a Pedro Sarmiento le encantó este proyecto y empezó a promocionar cursos de LÓVA, que es la ópera como proyecto, como vehículo de aprendizaje. Entonces yo tengo un compañero, que conocí y que hice cursos de danza con él, [...]. Y lo hizo en Castellón y estuve el verano pasado, este verano no, el anterior (hace referencia al verano del 2014), en Castellón haciendo el curso con él. Y me gustó mucho. Tenía mucho miedo a hacerlo porque claro, nosotros hicimos un curso muy express, de 4 o 5 días. Nada más, y este curso pienso que necesita al menos un par de semanas más. Para ya consolidar más aspectos. Entonces lo hice con él" [C3_E.F_Dm].

El proyecto radica en crear una ópera infantil. "Hemos empezado de 0 una ópera" [C3_E.F_A1].

"El proyecto LÓVA consiste en formar una compañía de ópera y que los niños aprendan que van a trabajar para conseguir un objetivo, pero es un objetivo compartido. Entonces dentro de las profesiones de la ópera cada una de las profesiones es muy importante para el objetivo final que es la producción final de esa ópera, desde el director hasta el técnico de luces, hasta el vestuario, maquillaje, documentalista,... cualquiera de las profesiones es súper importante" [C3_E.F_Dm].

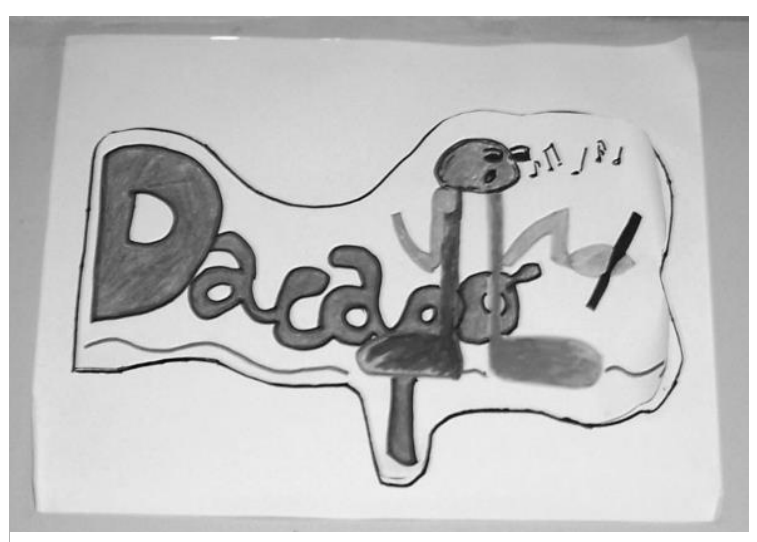

Imagen 68. Logo compañía DACAPO [C3_AM_FOM].

Así pues, los alumnos al inicio de curso crearon la compañía de ópera. "[...] hemos creado la compañía que se llama DACAPO" [C3_E.F_A1]. En la Imagen 68, se presenta el logo de la compañía. Ese compromiso de crear la ópera se hace por escrito. "Porque ellos firman también como un contrato ¿no? de que están de acuerdo. De que quieren formar una compañía de ópera" [C3_E.F_Dm]. La ópera la realiza el aula objeto de nuestro estudio. Aunque en ella también participan algunos extras. "Lo que

\footnotetext{
${ }^{25}$ http://proyectoLóvA.es/
} 
pasa es que necesitamos personas de $3^{\circ}$ y $4^{\circ}$ sólo van a salir pero de relleno" [C3_E.F_A5]. "Como de extras" [C3_E.F_A5].

Temporalmente, este proyecto se realiza durante todo el curso escolar, principalmente en la asignatura de música. Aunque también se trabaja en la asignatura de plástica y la tutora integra algunos contenidos en otras asignaturas.

"Es que esta todo ligado en este proyecto. Entra el lenguaje, entra la música, entran las matemáticas, entra la plástica, entra todo. Lo que pasa es que por currículum pues a veces no puedes coger todas las sesiones que quieres. Entonces dijimos, pues bueno cogemos tres que son las 2 de música y la de plástica y después me vas ayudando tú (hace referencia a Cristina) de manera puntual en el resto de asignaturas. Y así íbamos trabajando" [C3_E.F_Dm].

Así pues, Cristina también tiene un papel activo en el proyecto LóVA.

"Está muy bien que estés dentro del aula, porque después ella (hace referencia a la maestra de música) pide ayuda en cuanto a otras áreas. Pues, por ejemplo, ella quiere trabajar la descripción de los personajes, por tanto, tú ya sabes que en castellano en la descripción, aprovecho lo que este proyecto te está pidiendo. Por tanto, se hizo la descripción de personajes (del proyecto LÓVA) y se trabajó la descripción de los personajes de Malefica (del proyecto de centro sobre el cine). Después en el segundo trimestre yo ya participé más dentro de la clase en cuanto a grupos que se hicieron. Se hizo una pequeña ópera [...]. Y en el tercer trimestre, sí que es verdad que ya, se estaba trabajando mogollón. Los niños tenían un grupo y ya pues..., no decisiones porque yo no quería tomar decisiones, las decisiones debían tomarlas los alumnos, pero sí que la hojeada de 'Mira P.' yo le contaba las cosas. 'P. pasa eso...', porque P. no podía estar en todos los grupos, unos trabajaban allá otros aquí. Entonces era un poco de ahí los ojos ahí donde no estaba P. Evidentemente P. tampoco tomaba la decisión de autoridad, porque el proyecto es eso: el alumno piensa eso y tienes que hablar con ellos, pero las decisiones son de ellos" [C3_E.F_D].

Por tanto, es un trabajo en equipo y es un trabajo de todo el curso.

"Lo que hacemos es todo el primer trimestre trabajamos a nivel de grupo. Entonces trabajamos mucho los sentimientos, trabajar sus relaciones, ¿Qué sienten?, ¿Quéles pasa?, ¿Qué les preocupa?, a nivel emocional. Entonces a partir de esas emociones se hacen ciertas preguntas que son las que les conducirán al tema de la ópera. Por ejemplo, habían preguntas de que cosas nos hacen felices, que nos da miedo, que nos preocupa, que nos hace estar tristes, entonces a partir de ahí, de esas preguntas que van surgiendo durante todo el primer trimestre que trabajamos más los

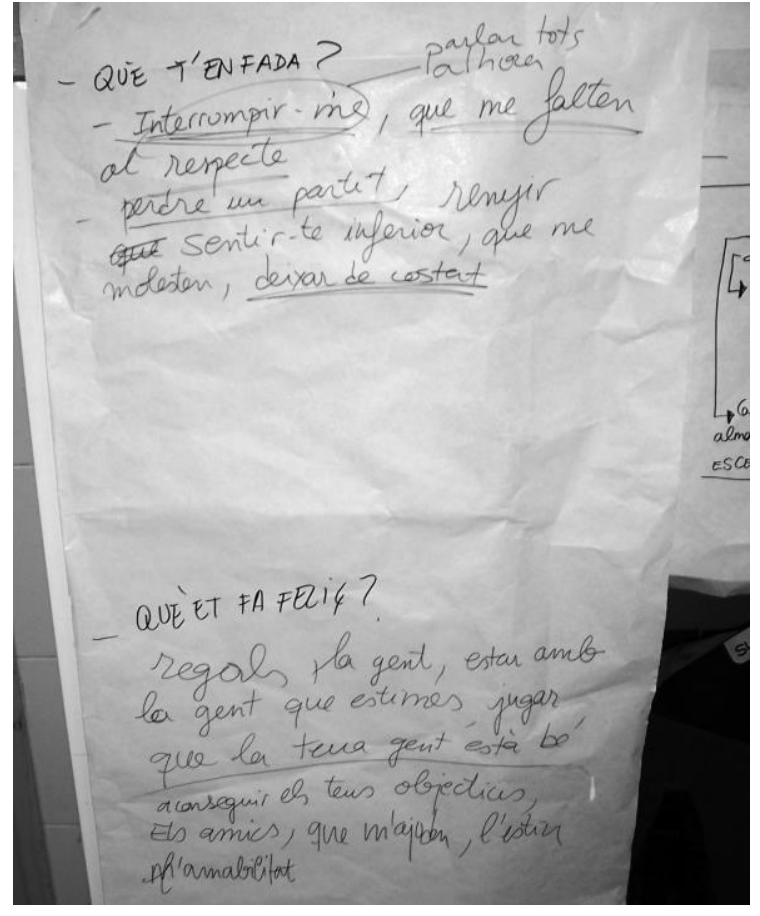

Imagen 69. Trabajando los sentimientos [C3_AM_FOM]. 
sentimientos, nace el tema de la ópera (Ver Imagen 69). Durante todo el primer trimestre también vamos aprendiendo que objetivo tiene cada profesión" [C3_E.F_Dm].

Así pues, una vez ya se ha trabajado con todo el grupo los sentimientos, se ha sacado el tema de la ópera, se ha creado el logotipo de la compañía,... se pasa a trabajar por profesiones.

En un primer momento, el alumnado va conociendo acerca de las profesiones de la ópera.

“[...] durante todo el primer trimestre que ellos investigan las profesiones, que viene gente a contarles. Yo les paso dijéramos como unos documentos. Y ellos van recopilando información. El objetivo del escritor ¿Cuál es? ¿Te gustaría ser escritor? Y hay varias preguntitas. A ver escribe el principio de un cuento en el que aparece una bruja. Son pequeñas actividades, preguntas personales para yo saber hacia dónde van orientados sus gustos y así después cuando termina, dijéramos, antes de Navidad que es cuando dimos las profesiones, de cada una les damos a escoger tres. Y ellos ponen por orden de preferencia, la que más les gusta la $1^{a}$, después la $2^{a}$ y después la $3^{a}$. Para intentar dar la que ellos más les gusta y más cómodos se puedan sentir. Sí que hay veces que hay alguna profesión que no tenía tantos niños y otros tenían demasiadas. [...] Por ejemplo, hubo una niña que no le había tocado la que ella se esperaba y al principio fue 'Documentalista, no me gusta'. Claro le dijimos, vamos a hacer una cosa, prueba, empieza a trabajar documentalista, prueba a ver cómo se trabaja en documentalista...si no te gusta vamos a ver qué es lo que hacemos. Claro, ella dijo que no le gustaba porque resulta que cuando habían estado investigando y cuando habían venido tenían una idea diferente a lo que era un documentalista, una vez se puso a hacer entrevistas a sus compañeros, escribir al blog, escribieron una noticia para un periódico,... Se sintió, vamos... 'es que estaba totalmente equivocada P. Es que pensaba que era otra cosa'. Entonces menos ese caso que después estaba encantada, les gustó a todos" [C3_E.F_Dm].

Por ende, el alumnado, según sus gustos escoge el rol o profesión que más le interesa. "Hemos aprendido, primero nos enseñaron en qué consisten las diferentes faenas y después ya hemos escogido [...] las que más nos gustaban y las maestras nos han dado las tareas que pensaban que..." [C3_E.F_A2]. "Y nosotros teníamos que marcar 3 y ella intentaría que uno de esos tres se cumpliera" [C3_E.F_A8]. En cada una de las profesiones hay 2 o 3 alumnos.

Para llevar a cabo el proyecto LóVA, se informó a

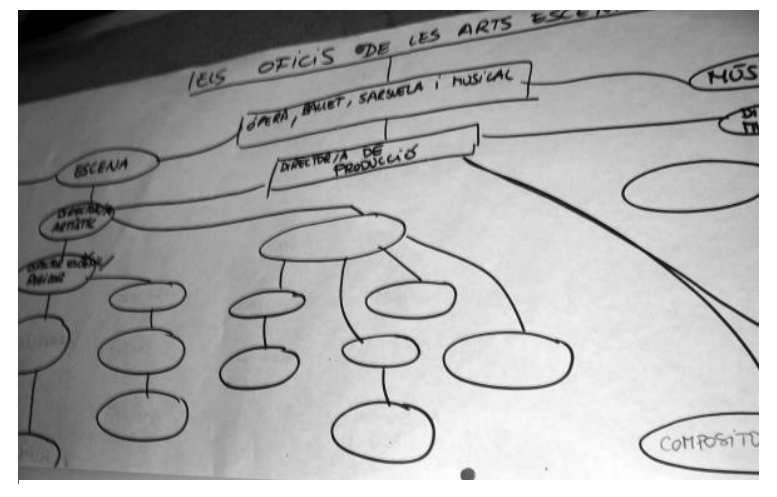

Imagen 70. Trabajando los oficios de las artes escénicas [C3_AM_FOM]. las familias.

"Pues al principio de curso nos hicieron una explicación de que la maestra de música llevaba a adelante todo un proyecto que se llamaba LóVA, entonces teníamos que hacer plástica y música, iba a consistir en llevar a cabo ese proyecto, que es un proyecto de ópera. Entonces, durante el curso irían trabajando las diferentes partes de la ópera y después cada niño conforme iría pasando el trimestre cogería un personaje de la ópera o un personaje que tiene que trabajar en la ópera, que igual puede ser el 
actor, que el guionista, el encargado de las luces, el del sonido,...entonces cada uno va haciéndose su faena, su trabajo" [C3_E.F_M1].

Los roles a desempeñar son: director, regidor, documentalista, relaciones públicas, escritor, músicos, actores, escenografía, vestuario y maquillaje.

El director y el regidor iban separados, pero debían de ayudarse para coordinarse.

"El regidor, se encargaba de que todo estuviera organizado, cada uno de los trabajos y sobre todo se encargaba de ensayar con los intérpretes. Se iba dando trucos, consejos de cómo tenían que hacer las cosas. El director, que era el que tenía que hacer las instancias, pedir permiso al auditorio, tenía que animar a los compañeros y por ejemplo al director le costó mucho hacer el papel de director" [C3_E.F_A6].

Documentalista y relaciones públicas trabajaban más acorde, más juntos. "Yo tengo que hacer entrevistas a cada miembro de la compañía y colgar las entrevistas y lo que está pasando cada día en el blog de la clase ${ }^{26}$ "[C3_E.F_A6].

"Uno se encargaba más de hacer los carteles, tickets, dípticos, o trípticos, diseñar el logotipo, ya finalmente como quedaría. Documentalista se encargaba más de hacer las entrevistas a sus compañeros, de hacer noticias, de ir escribiendo en el blog de la clase, en qué momento se encontraban, que estaban haciendo, buscar periódicos que les publicaran o llamar a la radio" [C3_E.F_Dm].

La alumna perteneciente al grupo de los escritores explica que tuvieron que escribir el guión de la ópera. "Pues yo lo que hago es primero escribimos en un papel el guión de la ópera, después lo revisamos, lo pasamos al ordenador, lo volvimos a revisar, lo imprimimos y ahora estamos con los intérpretes para ayudarles a cómo hacer los gestos $y$ todo eso" [C3_E.F_A5]. Los escritores tuvieron que trabajar duro para poder terminar la ópera antes de pascua. "Los escritores, que eran los que más en contra reloj iban porque el regidor y el director les dijeron que la obra tenía que estar escrita antes de pascua. Que después tenían que ensayar, entonces en pascua por ejemplo quedaron conmigo algunos días de fiesta de ellos para que les ayudara en alguna cosita. Y los guionistas tuvieron también que aceptar críticas ¿no? Porque ellos escribieron un texto, decían los compañeros, es que eso, es que lo otro" [C3_E.F_Dm].

Los músicos compusieron e interpretaron la música de todos los actos de la ópera (Ver Imagen 71). "Los músicos que eran los compositores. Durante todo el curso han hecho de compositores y el día de la obra hicieron de músicos, que hacen las propias canciones y ellos decidían si lo tocaban en el clarinete, si lo tocaban en el teclado, si cogían la flauta, si la persona que sabía tocar la trompa, tocaba la trompa. Ellos se habían dividido" [C3_E.F_Dm].
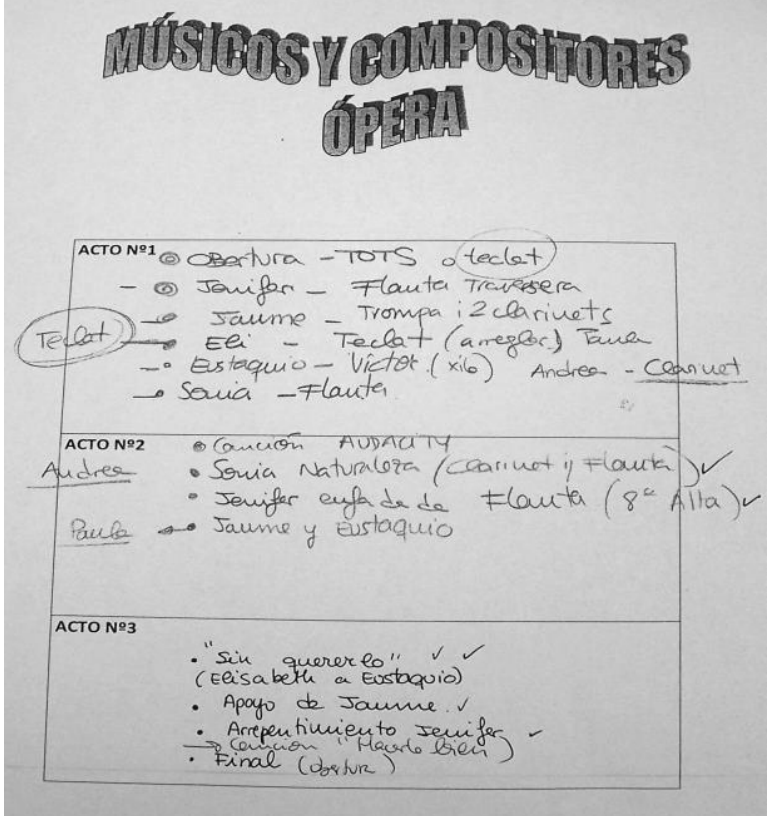

Imagen 71.Estructura de la ópera [C3_AM_FOM].

${ }^{26}$ http://crabenavitesquartdelesvalls.edu.gva.es/wp/cristina/ 
Había 5 actores que representaron y cantaron la ópera. "Después teníamos los intérpretes, teníamos 5 intérpretes que tenían que cantar e interpretar" [C3_E.F_A6].

Técnicos de luces y escenografía trabajaron colaborativamente.

"Técnicos de luces y sonido, que eran dos niños que trabajaban conjuntamente. Porque claro, el técnico de luces y de sonido hasta la semana o dos semanas antes que no podían ir a probar el sonido ni nada no podíamos trabajar. Por tanto, técnicos de luces y sonido han trabajado durante todo el primer y segundo trimestre con los escenógrafos, que solamente eran dos y necesitaban mucha ayuda. Entonces dijéramos que hemos tenido 4 en escenografía, pero de esos 4, pues dos se han encargado de técnico de luces y de sonido" [C3_E.F_Dm].

Por último, destacar, que había niños encargados del maquillaje y el vestuario. "Después teníamos maquillaje y vestuario, teníamos uno de maquillaje y uno de vestuario, pero trabajaban paralelos" [C3_E.F_Dm]. Así pues, cada grupo trabajaba sobre sus quehaceres para lograr un objetivo compartido (Ver Imagen 72).
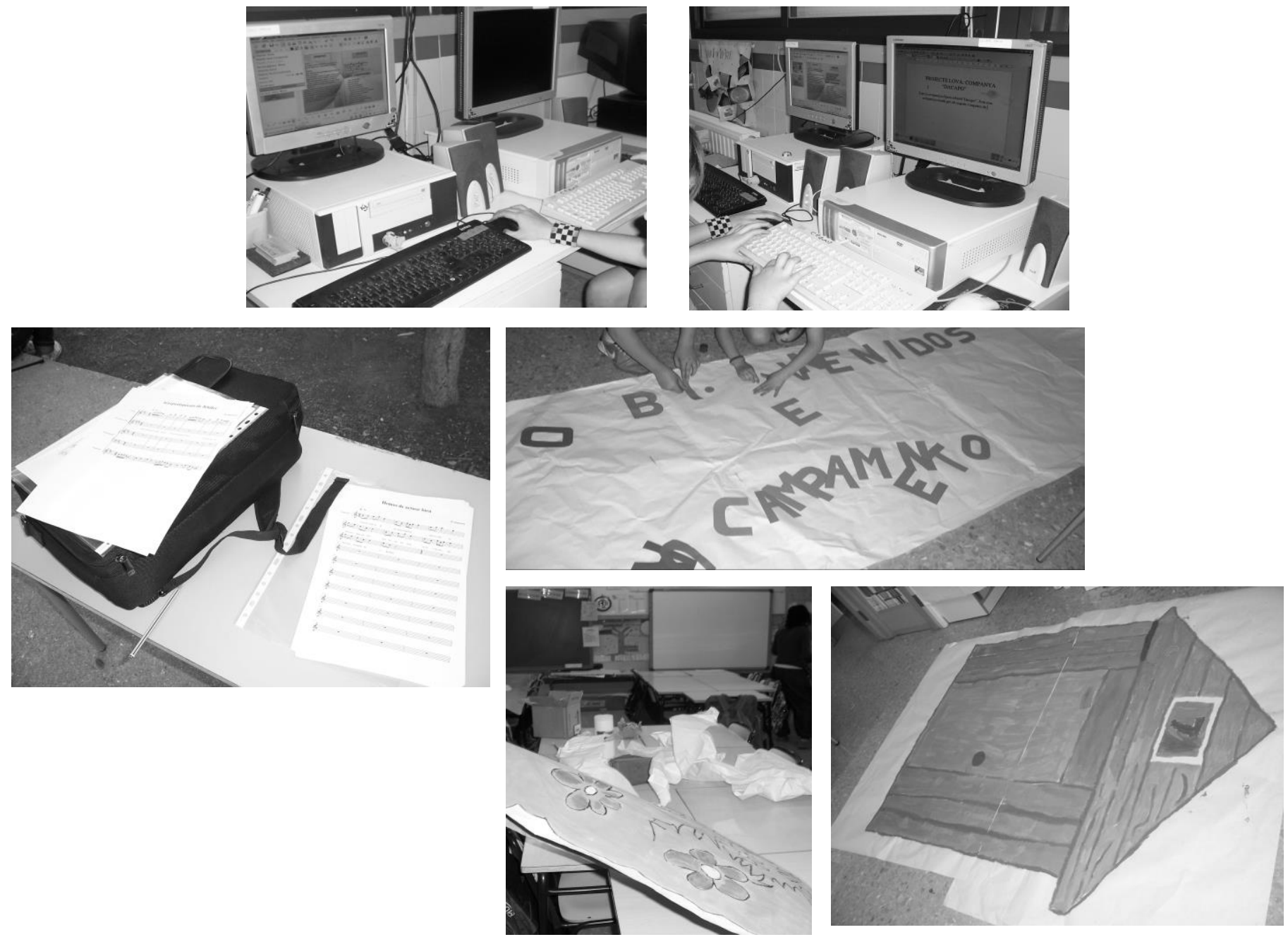

Imagen 72. Trabajando en la preparación de la ópera [C3_O_FO]. 
El alumnado tenía muy marcada la distribución y organización del espacio para que cada profesión pudiera trabajar (Ver Imagen 73). Esto les ayuda notablemente a optimizar el tiempo y el espacio. Ya que cada rol o profesión debe desempeñar unas tareas diferentes. "N. está trabajando en un ordenador, está preparando un díptico. Los escenógrafos también están trabajando, unos trabajan sobre el cartel en el pasillo y otros trabajan en el decorado en clase. Los músicos están ensayando en el patio junto a los actores" [C3_O_NC].

M., el alumno que faltaba bastante a clase y había repetido un curso, le dieron un rol manipulativo para que pudiese ser partícipe de la actividad.

"Técnico de luz y se sintió bastante realizado. Porque se dio cuenta que si no ponía él las luces que no lucía. [...] él tuvo que aprenderse el cuadro de luz. Después sí que le pusimos una persona. Es que necesito a alguien que me ayude. Por ejemplo, el escritor ese día, el día de la

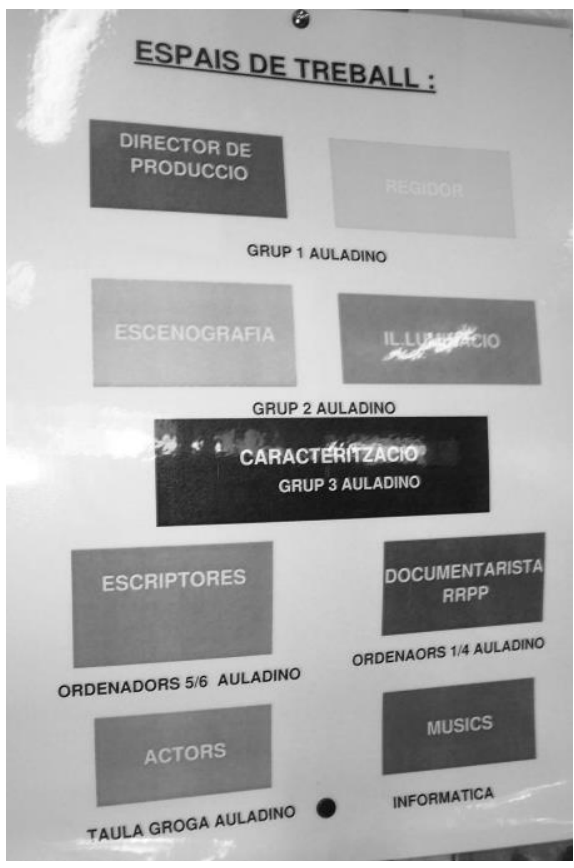

Imagen 73. Espacios de trabajo LÓVA [C3_AM_FOM]. función estaba ayudando también un poco para que esa persona estuviera también reforzándole y no se sintiera solo. Pero bueno, el técnico de luces es él, tú le vas a ayudar. Entonces sí que se buscan dependiendo de sus habilidades y para que ellos se sientan mejor, no más pequeños, sino más grandes, más reforzados" [C3_E.F_Dm].

Las familias también tuvieron un papel importante en el proyecto LóVA. "A mí personalmente me gusta mucho que puedan interactuar los padres a la clase. Que por ejemplo en el proyecto de la ópera que estamos haciendo en música que los padres puedan venir a ayudar a lo que haga falta" [C3_E.F_A1].

"Podían venir a enseñárnoslo los padres, pero cuando ya lo teníamos todo ya consolidado ¿sabes? Al principio no podían venir porque hasta que no tuvieran todo medio terminado [...] Sí, porque éramos nosotros los que teníamos que crear sin ayuda de los padres, sólo nosotros, después cuando ya sabíamos lo que íbamos a hacer ya nos ayudaron, por ejemplo en escenografía" [C3_E.F_A2].

"Estuvo súper bien porque ellas mismas dijeron: ¿bueno necesitáis ayuda? y escenografía, 'si, nosotros si'. A escenografía les costó bastante porque tuvieron que hacer un autobús gigante y la escenografía implica mucho trabajo y ellos hasta que arrancan les cuesta arrancar, pero les cuesta arrancar. Y dibujar en grandes dimensiones, están acostumbrados a dibujar en pequeñas dimensiones. $Y$ vinieron bastantes padres a ayudar en la parte de escenografía y en escenografía echaron una mano muy grande. Porque ¡A Ah!, pues vamos a poner para el autobús, para que los niños puedan cogerlo. Vamos a poner esto’. El padre de una niña que es obrero y tenía material. Pues en este pegamento que es más duro eso lo pondré yo por la tarde y... Y muy bien, estuvieron ayudando todas las tardes que pudieron, sobre todo eso fue más en escenografía" [C3_E.F_Dm].

Tal y como se ha comentado previamente Cristina, la maestra, también ayudó notablemente en el proyecto LóVA. 
"Cristina me ayudaba mucho también en la parte del documentalista y el relaciones públicas. A la hora de utilizar el blog, eso se encargaba Cristina, de controlar un poco. A la hora de utilizar programas para maquetar. Todo esto Cristina, y yo me encargaba más de los compositores. Entre las dos nos encargábamos un poco de corregir los textos de los guionistas. Y después sí que es de verdad, que es importante la coordinación con el tutor porque yo al tutor le dije, pues mira ahora vamos a hacer los personajes, trabaja los adjetivos. Ahora vamos a trabajar la descripción del lugar. Por si puedes trabajar la descripción de un paisaje es... Nos vamos coordinando para que ella también en lenguaje vaya trabajando esas cosas. 0 después por ejemplo las matemáticas a la hora de dibujar utilizar la escala. Pues en matemáticas trabaja un poquito lo que es la escala. Para hacer ampliación de... o a la hora de medir, trabajamos los metros, los decímetros, los centímetros... Como tienen que medir el espacio, que tipo de material necesitarían. Tuvieron que ir un día los escenógrafos a medir cual era el espacio donde tenían que colocar todo el material" [C3_E.F_Dm].

La maestra de música también se apoyó y reforzó con los compañeros que hicieron el curso de formación sobre el proyecto LóvA.

"Se comprometió a llevar un seguimiento con nosotros. Nosotros a lo mejor quincenalmente, mensualmente los que habíamos decidido que íbamos a hacer el proyecto LóVA nos reuníamos. Y a lo mejor éramos 4 personas que habíamos hecho el curso en Castellón, nos reuníamos en Castellón pues una vez al mes y íbamos hablando, tú por dónde vas, yo voy por aquí...Creamos un grupo de WhatsApp, que todavía continúa. ‘'Ay!, es que necesito que venga un documentalista. ¿Conocéis a alguno periodista?’ $Y$ eso se iba reforzando, se iba creando una ayuda. Eso vino muy bien, porque era el primer año" [C3_E.F_Dm].

La noticia de la representación salto a los medios locales.

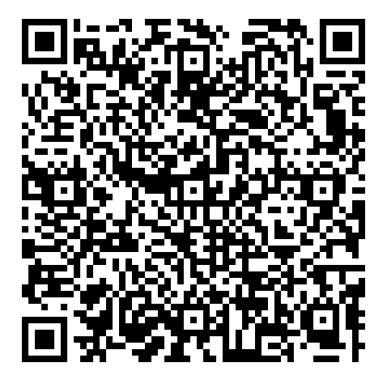

21

Noticia sobre el proyecto LóVA.

La ópera la representarán al final de curso en el Auditorio de la localidad. "El día 12 de junio me parece en el Auditorio de Quart" [C3_E.F_A2]. Pero antes hacen un ensayo general. "Aquía a la escuela lo hacemos el día 26" [C3_E.F_A1]. "El 26, una ópera sólo para que la vean los alumnos y otra para todos" [C3_E.F_A2].

Los últimos meses fueron muy intensos.

"Se dan cuenta que la improvisación no es buena, que tienen que prepararse las cosas, aprendieron todo esto. Al final de curso se dieron cuenta que ese tiempo que faltaba era porque había tiempo que no se había aprovechado...entonces claro...salen las cosas pero podrían salir mejor si la cosa no va tan ahíal 
final, sino que todo el curso se aprovecha ¿no? Son reflexiones que se dan cuenta al final del proyecto" [C3_E.F_D].

"Bien, pero a lo mejor se sienten un poco estresados. Porque claro es una responsabilidad [...] Tienen un poco de miedo de ver a ver cómo les sale, porque claro ahora estamos al final de curso y estamos ahí en la recta final y es eso...yo pienso que un poco nerviositos, para ver cómo les sale. Sí, porque mientras lo ven lejos pues bien yo pienso que están así un poco..." [C3_E.F_M1].

El proyecto fue un éxito. "El proyecto puede salir o no salir. La finalidad es que, si todos han trabajado en equipo, todos han trabajado juntos, han sabido compartir, han sabido decirse las cosas, han sabido organizarse, quererse, al final el trabajo sale. Y salió" [C3_E.F_Dm].

"El proyecto final fue extraordinario. Ves los nervios del día anterior que parece que no iba a salir nada de lo que... y dices 'madre pobres, que mal, que mal que lo pasaron'. [...] y después ellos lo hacen perfecto. Pues muy enriquecedor. Porque ves las cosas, incluso les dices a los niños, 'mira esto deberías...' y 'porque no...'. 'No, me gusta asi'. Pues ya está para que vas a cambiar una cosa que...” [C3_E.F_D].

"Y cuando terminaron el abrazo que se hicieron entre ellos, como lo disfrutaron, organizaron una cena todos juntos. Yo creo que sí, que unió mucho al grupo, que es un poco la finalidad. De que sean compañeros, de saber trabajar todos juntos. Cosa que a los adultos también nos falta" [C3_E.F_Dm].

Además, finalizado el proyecto LóVA, unos alumnos fueron junto a la maestra de música al Palacio de las Artes y las Ciencias de Valencia a contar su experiencia a unos docentes que estaban realizando el curso de formación para llevar a cabo el proyecto LóVA en sus aulas.

"Fuimos 3 niños porque era en julio y allí disfrutaron mucho y si, les cantaron las canciones, todo. Y se sintieron como muy premiados, estuvo bien. Y en este caso el palacio de las artes en Valencia también hizo una visita solamente para los que hacían el proyecto LóVA, que les enseñó todas las profesiones y todos los espacios donde trabajaban realmente en una ópera" [C3_E.F_Dm].

La participación y el compromiso del alumnado son muy altos. "Se trata de una actividad motivadora para el alumnado" [C3_O_DCOS]. El ritmo de enseñanza es negociado, pero tiende a ser acelerado ya que tienen que representar la ópera en el Auditorio a finales de curso. Son diferentes las actividades cognitivas requeridas en esta actividad, según los roles o funciones de cada una de las profesiones. Las maestras van dirigiendo y guiando el proceso de aprendizaje. 


\subsection{Talleres de los jueves: interactuando con compañeros del centro y las familias}

Cada jueves por la tarde todos los alumnos del CRA realizan diferentes talleres en sus respectivos aularios. Los grupos de cada taller están formados por alumnos que pertenecen a diferentes clases y por tanto a diferentes niveles. Los talleres son los siguientes: básquet, experimentos y ajedrez, robótica y revista y radio. Los diferentes talleres los proponen los maestros. No obstante, en estos talleres pueden participar las familias. "Y los padres también vienen a hacer el taller" [C3_E.F_A5]. "Esos talleres los hacen los maestros pero los padres también vienen a ayudar y todo" [C3_E.F_A3].

Además, los padres proponen y hacen talleres impartidos por ellos, para ello sustituyen a los propuestos por los maestros. "Pero si alguna madre quiere hacer un taller pues se quita el taller que menos prefieran" [C3_E.F_A3]. "Por ejemplo, hay madres que proponen hacer cosas y por ejemplo en educación física el otro día hicimos una clase de zumba que propusieron dos madres. Podían venir todas las madres y quien quisiera y sí que vinieron" [C3_E.F_A4]. "Por ejemplo, mi madre quiere venir a preparar un taller de cocina. Entonces mi madre se lo dijo a la maestra 'A mí me gustaría hacer un taller de cocina'. Entonces se quita uno para..." [C3_E.F_A3]. "Pues yo me acuerdo de dos que hizo mi madre y su compañera, que uno fue de subir a una montaña y bajar. Y nos explicaron porque estaban muriendo tantos pinos y el otro fue de zumba" [C3_E.F_A6]. La madre entrevistada también ha sido partícipe en los talleres. "Ellas lo propusieron y se hizo, después también hicimos una actividad de ir al camino del Codoval también, pues fuimos al camino del Codoval" [C3_E.F_M1].

Además, si algún alumno quiere proponer algún taller se lo tiene que decir a sus padres. "Cada alumno si quiere propone el taller a los padres y los padres le ayudan a decir que si o a alguna cosa..." [C3_E.F_A6].

Generalmente, al alumnado le agrada que participen las familias en los talleres. "Mayoritariamente a toda la clase nos aporta ilusión" [C3_E.F_A3]. La participación de las familias no es constante a lo largo de todo el curso.

"Sí que es verdad que ha menguado la participación en cuanto a talleres al principio, a final de curso sí que ha mejorado esta participación. No sabemos si fue por un pequeño problema que hubo en cuanto a los horarios a principio de curso. Pues bueno se solucionó en poco ¿no? al final y si que se notó. Participación en cuanto al aula directamente yo ya te digo que a partir del segundo trimestre que se comentó lo de intentar participar, porque a lo mejor dentro del aula es más cerrado el horario yo les dije que tampoco deberían centrar la participación conmigo, pues en P. (maestra de música) era prioritario LÓVA, en E. (maestro de educación física) también les dije. Entonces a partir de ahí 'Ostras, pues mira porque no una Batukada...' 'porque no caminar'. Porque a lo mejor piensan que proponer un taller o una actividad dentro del aula iyo sabré? [...] A otras cositas sí, yo creo que el miedo es en la obligatoriedad. Pero buenos si se les da libertad" [C3_E.F_D].

La participación y el compromiso del alumnado son altos. "Se trata de una actividad lúdica en la que participan diferentes compañeros de diferentes niveles" [C3_O_DCOS]. El ritmo de enseñanza es correcto. "Básicamente se trata de actividades manipulativas" [C3_O_DCOS]. Son diferentes las actividades cognitivas 
requeridas en cada taller. "Entender (las actividades), aplicar (conocimientos en la resolución de las tareas) y analizar (en las actividades)" [C3_O_DCOS]. El estudiantado dirige la mayor parte del aprendizaje.

\subsection{Ginkama: cohesión grupal}

A lo largo del curso, algunos viernes, realizan algunas ginkamas. Las ginkamas siempre suelen estar contextualizadas con alguna de las temáticas que están trabajando.

"Porque es una cosa chula, yo me lo paso muy bien. Y es divertido y estás dando un contenido, se tienen que reorganizar, va por tiempo. Porque el tiempo es un problema en esta vida ¿vale? Entonces tienen que saber, pues el tiempo, planificarse, trabajar de manera cooperativa, no por grupos, sino cooperativa y ayudarse, hay riñas, pues si no gano el punto y no lo hago contigo... pero bueno son cosas que..." [C3_E.F_D].

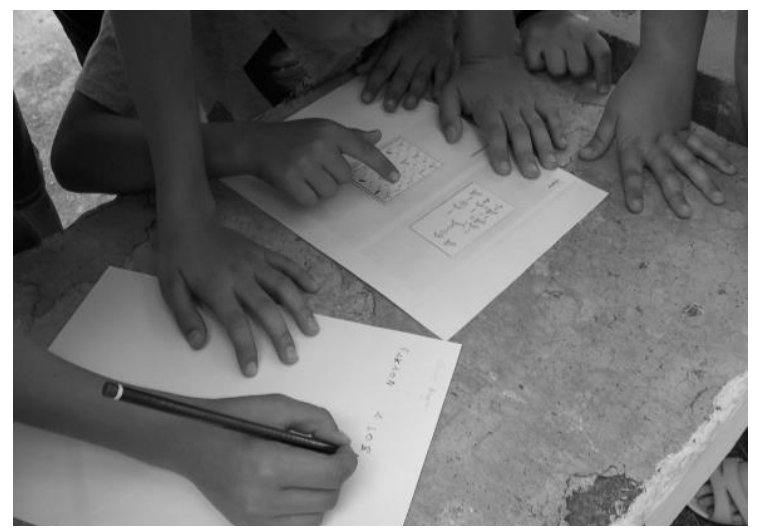

Imagen 74. Alumnado realizando actividades de cohesión grupal [C3_O_FO].

Se trata de una actividad más lúdica que fomenta la cohesión de grupo. En esta actividad también está A. (maestro de apoyo). La participación y el compromiso del alumnado en la actividad son altos, puesto que todos participan. El ritmo es adecuado ya que van completando una serie de actividades contextualizadas en la temática del proyecto de cine trabajadas en el tercer trimestre. Las actividades consisten en descifrar, crear, entender y completar. Los maestros son los que dan las consignas y el alumnado las realiza.

\subsection{Rincones de trabajo ${ }^{27}$ : el proyecto de nuestro pueblo}

En el curso escolar 2015/2016, es la primera vez que la maestra utiliza los rincones en su aula. Esto se debe a que ésta ha realizado un curso de formación impartido por la psicopedagoga del centro.

"He estado ahí mirando y observando, porque se hizo formación con nosotros, una interna y claro de infantil fue. Yo recogí información, pero claro de cómo se hace en infantil no sirve para primaria. Por tanto, tienes que reflexionar y a ver y habrá cambios jeh! Yo voy a proponer hacerlo de una forma $y$ seguro que no será así. Y me dan la vuelta estos niños (tono de risa). Pero bueno" [C3_E.F_D].

\footnotetext{
${ }^{27}$ Hay que recordar que las observaciones y la entrevista al alumnado sobre esta práctica educativa se realizan en octubre del 2015, por lo cual los integrantes de la clase han cambiado. En ese momento en el aula hay un total de 18 alumnos de ambos cursos de procedencia ( $5^{\circ}$ y $\left.6^{\circ}\right)$, concretamente 9 niñas y 9 niños. Los alumnos que este año cursan $6^{\circ}$ de primaria, ya es el segundo curso que trabajan con Cristina.
} 
Por lo que respecta a la metodología, la maestra mediante esta propuesta trabaja y refuerza el contenido abordado en las diferentes asignaturas.

"Es diferente de un rincón infantil, he intentado adaptarlo también al rincón de primaria, que sea manipulativo, pero es diferente la actividad. Y aprovecharé para, también, reforzar cosas que se den. Por ejemplo, si en mates estamos dando a lo mejor los números romanos, pues a lo mejor ese día toca pues hacer una actividad en una página web o en un rincón de mates, que esté relacionado y es también para consolidar" [C3_E.F_D].

Los rincones se realizan todos los jueves y cada 15 días cambia la actividad a realizar en cada rincón. "Tú escoges el que quieres, no es por grupos, es individual. Pero claro, por ejemplo, el de ciencias, como necesitas ayuda de otra persona, si está ahí te puedes ayudar en él. Y son diferentes sitios y tienes que intentar completarlos todos hasta llegar a hacer los 6 que hay" [C3_E.F_A11]. Esto es, el alumnado individualmente se gestiona el tiempo y escoge que rincones realiza en cada sesión, puede realizar un máximo de 6 rincones en dos sesiones. "Los que te da tiempo, Cristina siempre nos dice que normalmente cada rincón dura un cuarto de hora como máximo" [C3_E.F_A10]. La maestra comenta que el alumnado se tiene que acostumbrar a la técnica. "Es de forma individual. Por ahora en el primer trimestre sí. Nos tenemos que acostumbrar a la técnica, no la hemos hecho. Por tanto, será un poco de trabajo, eso no quiere decir que estés ahí en un rincón y te aproveches del trabajo de grupo" [C3_E.F_D].

"En el primer trimestre habrá experimento cada 15 días [...] para ligarlo a lo que son los Juegos Olímpicos" [C3_E.F_D]. La temática de los Juegos Olímpicos, se trata de otro de los proyectos de centro del curso escolar (2015/2016). En el curso escolar 2015/2016, además del proyecto de los Juegos Olímpicos, hay otro proyecto de centro el cual consiste en la elaboración de un libro de ambos municipios que conforman el CRA. Cada clase decide cómo abordar este propósito para la elaboración conjunta del material. La docente objeto de nuestro estudio decide trabajarlo mediante la metodología de rincones. Esto es, dedica un rincón para abordar las aportaciones de la clase al proyecto de centro "nuestro pueblo".

Antes de empezar a trabajar en los rincones, realizarán un trabajo previo de identificación de cada rincón y las normas de funcionamiento (Ver Imagen 75).

“[...] en septiembre. Todo eso, el inicio del proyecto de los Juegos Olímpicos, en cuanto a ambientación y en cuanto a los carteles ¿no? de saber dónde está cada cosa, y eso lo harán ellos. Las normas también las harán ellos y todo eso. Por tanto, en octubre empezaremos todo eso. [...] el espacio, saber dónde está. Por tanto, tendremos que preparar estas primeras semanas los carteles de saber dónde están... los carteles diferenciados" [C3_E.F_D]. 

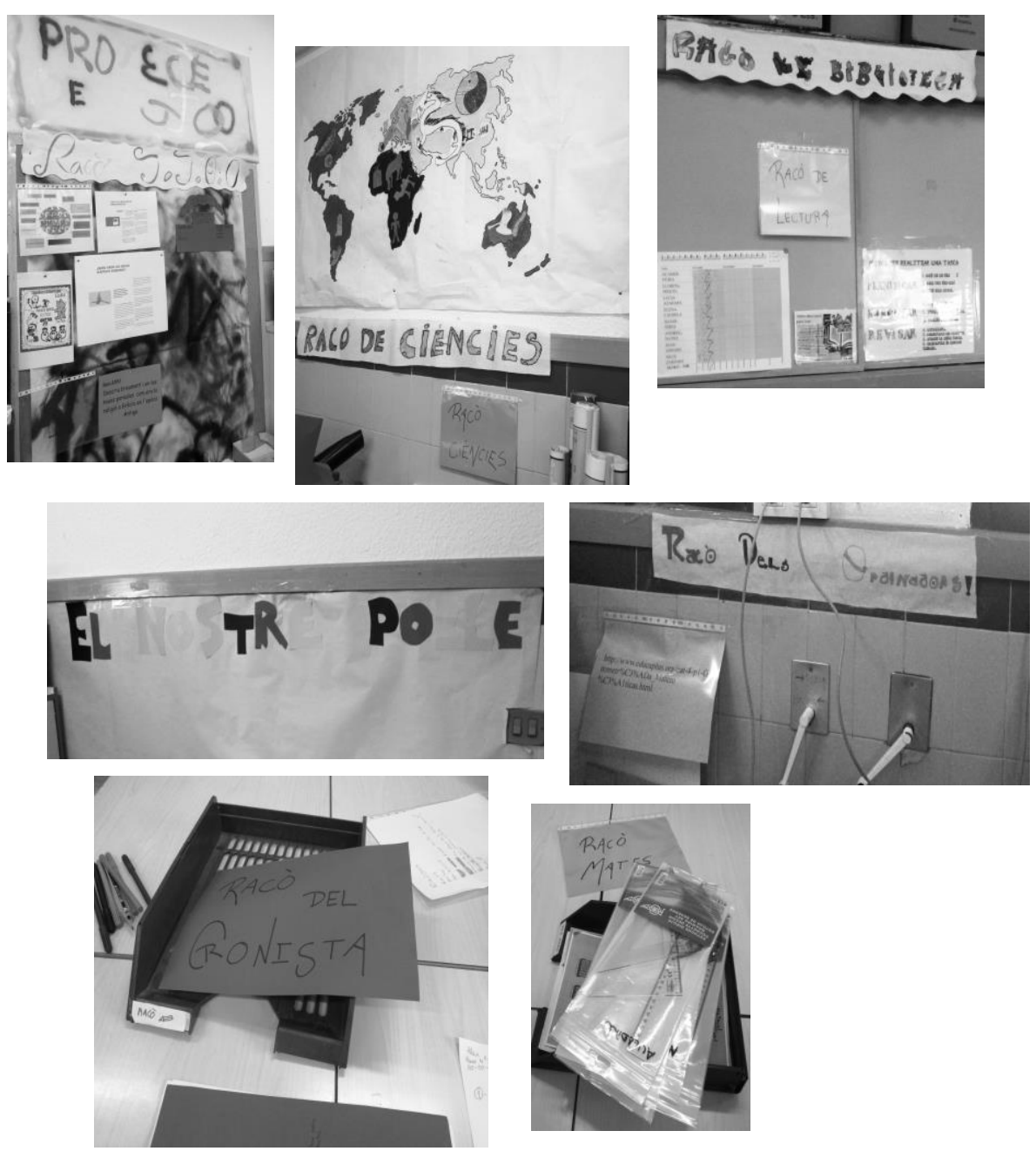

Imagen 75. Carteles identificativos de los rincones [C3_O_FO].

Por lo que respecta a la planificación la maestra comenta que tienen una hoja registro del control de los rincones (Ver Imagen 76).

"Y después estarán ahí 5y 6 6o su planning, para saber si han hecho los rincones [...]. Va a ser difícil porque ten en cuenta que el rincón se tiene que planificar y cuando llegan al tercer ciclo tú te das cuenta que no saben planificarse, el primer trimestre es sobre todo la adaptación de ir dando una rúbrica de estas de planning del mes, porque no saben planificarse los deberes, el trabajo. Es muy complicado eso de la planificación [...]" [C3_E.F_D].

Según el número de rincones realizados, en cada quincena, el alumnado anota en la hoja registro el número de rincones efectuados. "Después tienes que hacer los que tú puedas en una semana y en la otra semana otros. Si haces de 1 -2 son rojo, te tienes que marcar en una

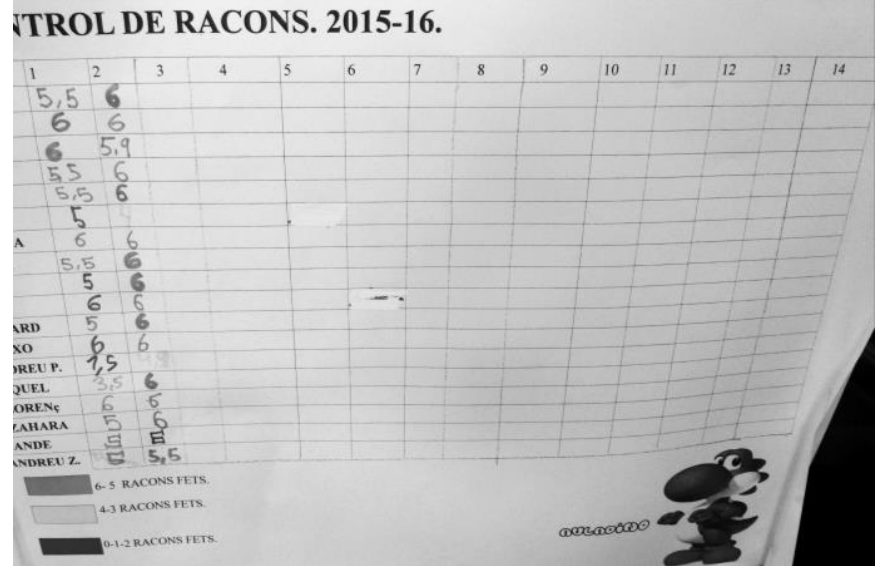

Imagen 76. Hoja control de los rincones [C3_AM_FOM]. 
tabla que tenemos en clase en rojo, si haces 3-4 es amarillo y si haces 5-6 es verde" [C3_E.F_A10]. "Si lo has hecho verde, si no lo has hecho un amarillo, como que está ahí pendiente. Que a lo mejor no llega, pues bueno a ver cómo sale, a ver qué pasa y en las asambleas pues comentaremos" [C]_E.F_D].

Concretamente, hay un total de 6 rincones: el rincón de ciencias, el rincón de lectura, el rincón de matemáticas, el rincón de ordenadores, el rincón de los Juegos Olímpicos y el rincón de escritura: el cronista (proyecto nuestro pueblo).

1) Rincón de ciencias: en el cual se realiza algún experimento (Ver Imagen 77). En el caso de la sesión observada, el experimento que se realizó consistía en generar electricidad con frotamiento y ver cómo la regla atraía los trozos de papel que previamente habían cortado. "El rincón de ciencias [...] que a lo mejor será un experimento muy corto que estará ahí el material de hacerlo ellos mismos. El de salud también será aquí, será el rincón de ciencias" [C3_E.F_D]. Los alumnos comentan algunos de los diferentes experimentos: "De la botella y una caja y dos cirios"

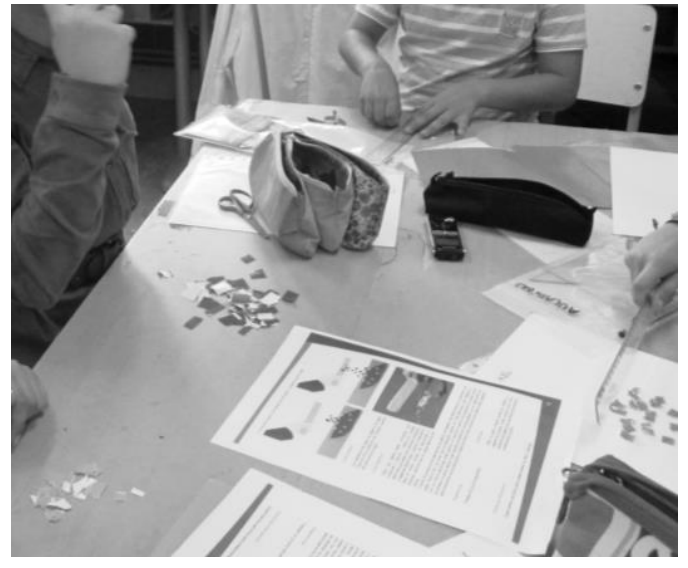

Imagen 77. Rincón de ciencias [C3_O_FO]. [C3_E.F_A10]. "De apagar un cirio" [C3_E.F_A11]. "Pues nos dan una hoja y mira, el primer día hicimos como si fuera un experimento [...]" [C3_E.F_A10]. "Si, la semana pasada nos dio un folio. Lo que ha dicho ella que eran las enfermedades, la gripe o embarazo, y ponía alimentos que hay que evitar y alimentos que segregan, se pueden comer para esas enfermedades o para eso" [C3_E.F_A11].

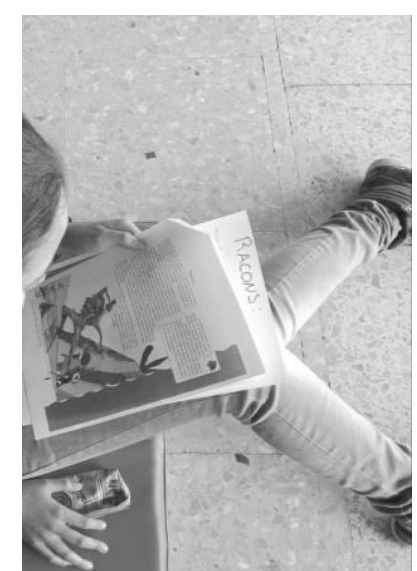

Imagen 78. Rincón de lectura [C3_O_FO].

2) Rincón de lectura: en el cual se proporcionan diferentes lecturas relacionadas con el proyecto o temática que estén trabajando (Ver Imagen 78). "Tenías que ir leyendo una lectura y después hacer los ejercicios que te ponían. En la hoja. Y el de lectura te ponen una lectura y las últimas semanas nos han dado de los Dioses Griegos y cogemos una colchoneta y vamos fuera a leer" [C3_E.F_A10]. "Uno de leer que están las colchonetas ahí para que cojan el libro y se vayan fuera, si quieren irse fuera, más cómodos y tal" [C3_E.F_D].

3) Rincón de matemáticas: "Ejercicios de matemáticas" [C3_E.F_A11]. En el cual se deben resolver algunos problemas matemáticos (Ver Imagen 79).

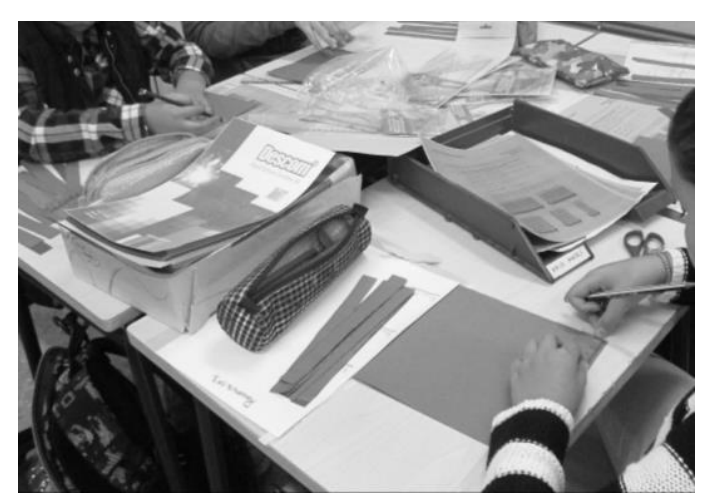

Imagen 79. Rincón de matemáticas [C3_O_FO]. 
4) Rincón de los ordenadores: en el cual hay disponible diferentes páginas web seleccionadas por la maestra para reforzar ejercicios trabajados en el aula (Ver Imagen 80). "El de los ordenadores de la página web. Que será de TIC, que tendremos que tener un registro. Esta página estos ejercicios y tienes que hacer eso, o incluso también tengo ahí un programita de TIC que son para trabajar diferentes programas, actividades muy cortitas" [C3_E.F_D]. "En los ordenadores la página web también es la misma"

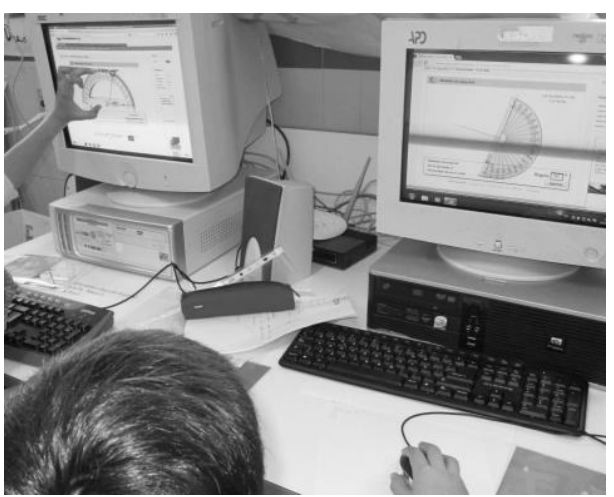

Imagen 80. Rincón de los ordenadores [C3_O_FO]. [C3_E.F_A11]. "Pero después ya la semana pasada nos dio Cristina una hoja y con el ordenador teníamos que ir investigando lo que te ponía en la hoja" [C3_E.F_A10].

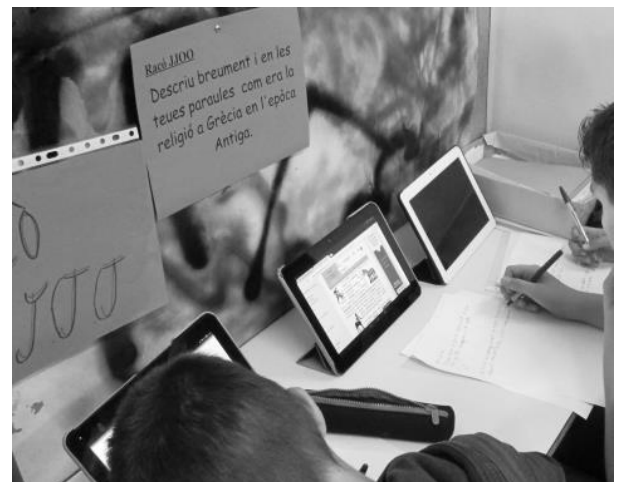

Imagen 81. Rincón de los Juegos Olímpicos [C3_O_FO].

5) Rincón de los Juegos Olímpicos: en el cual, mediante el Ipad, se debe de dar respuesta a una pregunta planteada. Por ejemplo: Describe brevemente y con tus palabras como era la religión en Grecia en la época Antigua (Ver Imagen 81). "Antes estábamos dando los Juegos Olímpicos en la antigüedad y ahora el moderno. Y la semana pasada por ejemplo nos preguntaron de la sociedad en que se dividía, por ejemplo, se dividía en las mujeres... no les dejaban participar en los Juegos Olímpicos, las mujeres casadas" [C3_E.F_A11]. "Bueno y después el de los Juegos Olímpicos es que nosotros el tema principal que estamos dando ahora son los Juegos Olímpicos. Y Cristina pues cada día nos dice: 'Tenéis que buscar esto'. Normalmente, es en castellano" [C3_E.F_A10].

6) El Rincón de escritura: el cronista: éste es el rincón destinado al proyecto de centro "Nuestro pueblo". El objetivo del cual es confeccionar un libro elaborado por todas las clases que conforman el CRA. "Uno de escritura que será éste, el rincón y hay uno que será el de cronista que será simplemente el primer trimestre. Cronista porque aparte del proyecto de los Juegos Olímpicos, hay uno que es del pueblo de Quart, para hacer el producto final que es un libro. Por tanto, como yo hablé con V. (el maestro de $6^{\circ}$ del aulario de Benavites) que él quería ya toda la información en el primer trimestre, pues yo digo mira un rincón aquí en el rincón de escritura por ejemplo y que sean los cronistas. Que vayan cogiendo información" [C3_E.F_D]. La primera actividad a realizar durante la primera quincena consistía en escribir un listado de los lugares, monumentos o aspectos de su localidad que querían investigar. "Tienes que escoger una, lo que tú quieres investigar del pueblo" [C3_E.F_A10]. "De nuestro pueblo, de un monumento o algo que te interesaba y después a la otra semana tenías que decir lo que querías investigar de esa cosa [...] Detrás de la hoja pone por ejemplo: 'Font de Quart', 'La casa de la cultura' " [C3_E.F_A11]. 


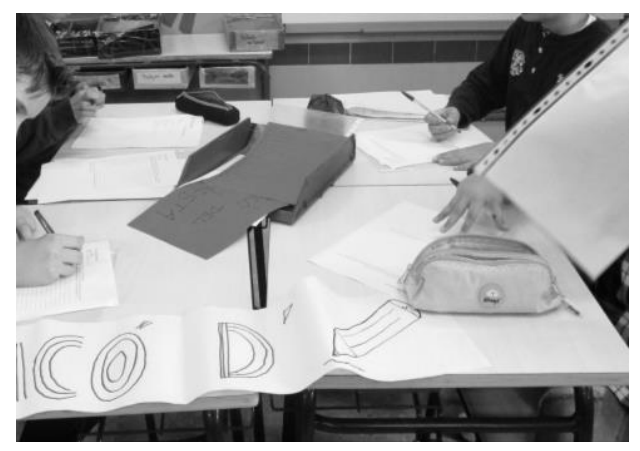

Imagen 82. Rincón del cronista [C3_O_FO].
La segunda actividad propuesta trataba en escoger un aspecto de la lista y escribir preguntas para indagar al respecto (Ver Imagen 82). Para ello contaban con la colaboración de los abuelos. "Si, vendrán a participar [...] Pues está claro que los abuelos que viven aquí en Quart, han vivido más tiempo y pueden saber más cosas importantes de Quart que nosotros, porque tienen más experiencia. Por eso nos pueden aportar más experiencia para hacer mejor un ejercicio o un rincón. Sobre todo vienen para lo de los cronistas" [C3_E.F_A11]. "Yo creo que bien por ayudarnos" [C3_E.F_A10]. "Es diferente porque cada uno escoge un monumento, bueno un monumento una cosa importante, que cree que es importante del pueblo" [C3_E.F_A11]. "Ahora después vendrán, después del patio, vendrán personas mayores del pueblo que sabían cosas y vendrán a los rincones para que les preguntemos" [C3_E.F_A10]. "Para explicarnos, como tienen más experiencia, que han vivido más, para explicarnos algunos monumentos o cosas interesantes de cada cosa del pueblo [C3_E.F_A11]. "Pues Cristina nos dijo que si teníamos algún abuelo o familiar que supiese algo del pueblo [...] pues que le dijéramos: 'mira que vamos a hacer los rincones, si quieres venir' " [C3_E.F_A10].

Por tanto, en otra sesión del rincón, el alumnado iba al bar de los jubilados y pensionistas, el cual está al lado de la puerta del colegio, dónde había personas mayores (con los cuales ya habían quedado previamente) y les realizaban las preguntas y el alumnado anotaban las respuestas y explicaciones realizadas por los mayores. "Pero dijo que sobre todo en el bar, en el bar este de los jubilados, este que está a la plaza esta de al lado. Como a veces hay abuelos, ibamos a ir a ver si habian para poder preguntar, no hace falta que sean familiares" [C3_E.F_A11]. A lo largo del curso y mediante este rincón se realizó la propuesta del aula de $5^{\circ}$ y $6^{\circ}$ para el libro del municipio.

Las fuentes de información de cada semana cambian. "Dijo que cada semana cambian de fuentes de información está internet, pero ha dicho que vamos a empezar la experiencia de los abuelos después pasaremos a otra cosa, cada vez tendremos que buscar una fuente de cada..." [C3_E.F_A11]. Como ya se ha dicho el objetivo es confeccionar un libro con las aportaciones de las distintas clases de los dos aularios que conforman el CRA.

"Donde está la mesa de la maestra, la de Cristina detrás de la mesa hay una cartulina muy grande que pone 'EL NOSTRE POBLE', que yo creo que se supone que lo que estamos dando de cronistas, también dijo algo de eso que lo haríamos, que lo que hemos cogido las cosas importantes que hemos escogido nosotros, haremos como un mini trabajo de coger información y de lo que hemos querido buscar, los buscaremos y después lo colgaremos ahí fotos e información de cada cosa que hemos elegido" [C3_E.F_A11].

En el primer trimestre cada aula hace la recogida de la información, en el caso de la clase estudiada lo trabajan mediante los rincones, el resto cada uno de una forma, en el segundo trimestre redactarán y editarán el libro y en el tercer trimestre se publicará.

Cada alumno mientras va realizando las diferentes actividades de cada uno de los rincones que va completando, va anotando lo que realiza en una hoja (Ver Imagen 83). "A ver, tenemos una hoja que es para 
apuntar si lo hemos hecho o no, ponemos el nombre del rincón y ponemos si lo hemos hecho o no y lo que nos dice que tenemos que poner en cada rincón" [C3_E.F_A11].

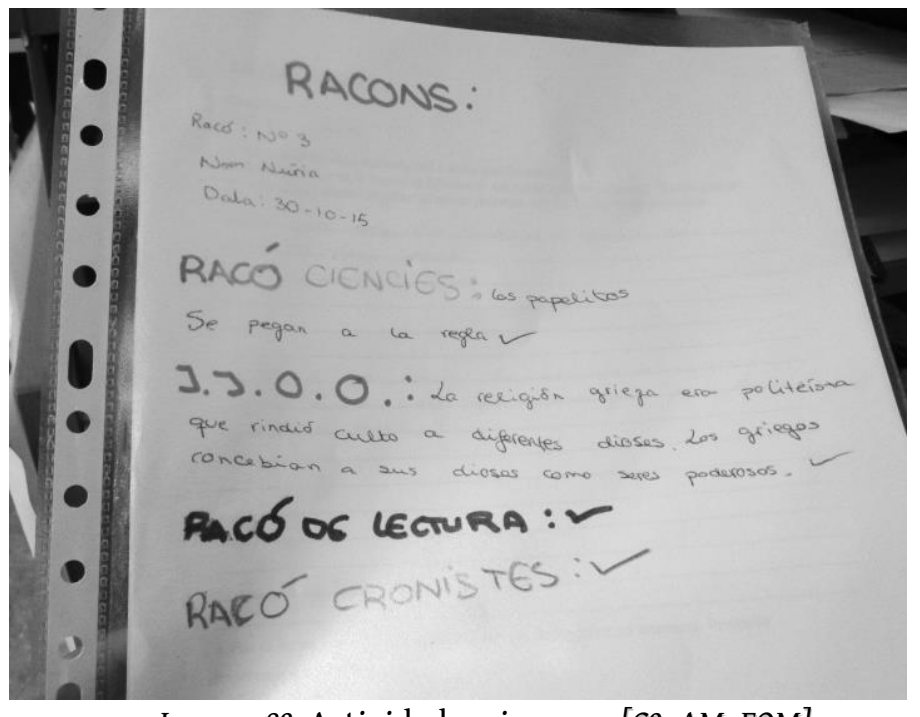

Imagen 83. Actividades rincones [C3_AM_FOM].

Así pues, transcurridos los 15 días los alumnos junto con la maestra comentan que tal van las actividades de cada rincón, el tiempo,... esto permite a la maestra reflexionar sobre su propia práctica, ver que funciona y que no y modificar si se da el caso. "Después cuando ya terminamos todos los rincones que vamos a corregir todo, Cristina por ejemplo dice 'ciencias...' porque cuando empezamos cogemos un folio...cuando empezamos los rincones tenemos un folio y ponemos $n^{\circ} 1$ por ejemplo, si hemos ido primero al rincón de los ordenadores, ponemos ordenadores que, si hay varios niveles en ese juego o de cálculo o de lo que sea, nivel 1 el tiempo que has tenido... hasta el tres, por ejemplo. Y por ejemplo, el tema de ciencias pues ciencias, si lo tienes hecho pues pones un tic o...tienes que ir completándolos todos" [C3_E.F_A11].

La participación y el compromiso del alumnado en los diferentes rincones son altos. El ritmo de la enseñanza es correcto. "El alumnado se registra en la tabla los rincones que hace. Hay un máximo de 6 rincones y cada uno los realiza a lo largo de 2 sesiones" [C3_O_DCOS]. Vemos como la actividad cognitiva varía según las actividades propuestas en cada rincón. El estudiante dirige todo el aprendizaje. 


\subsection{Evaluación de los aprendizajes}

Antes de iniciar una unidad, la maestra utiliza estrategias de evaluación previas para determinar lo que los estudiantes ya saben. "Lluvia de ideas, no lo doy por hecho incluso pueden saber más que yo. Tengo que saber lo que ellos saben para a partir de ahígenerar el proyecto" [C3_IP.HR_D].

La maestra realiza una evaluación tradicional. "Lo hago de manera tradicional con mi cuaderno, cojo nota, observaciones $y$ de todas las tareas que hacemos pues a ver" [C3_E.I_D]. Por tanto, la docente utiliza una evaluación continua para comprobar el aprendizaje de los estudiantes a lo largo de una secuencia de enseñanza. "La continua, tengo una final, pero el día a día se evalúa. Ellos me preguntan ¿esto va para examen? Todos los días desde que entran aquí yo evalúo" [C3_IP.HR_D].

La maestra valora las actitudes del alumnado hacia la tarea, el orden, el cuidado de su material y la participación. "Se valora tanto cuidar el material, su libreta, la Tablet, su organización espacio- temporal, es decir, cajón, mochila, de todo eso yo también voy tomando anotaciones. Si lo cuida o no. Después la participación si es activa o pasiva, si la activa es demasiado activa. Si la pasiva, es porque ¿Por qué? Porque pasas o porque no puedes. Disciplina también pues si es una actitud del niño pues que tiene problemas en cuanto...pues también se valora. La participación colaborativa. ¿Qué más...? libreta, participación, examen y proyectos" [C3_E.F_D]. "Si todo. Te puede ayudar o no te puede ayudar el trabajo del día a día y [...] La libreta es fundamental, y eso también se valora, no es nota numérica, pero eso te puede subir o bajar o lo que sea" [C3_E.I_D].

Utiliza la misma herramienta de evaluación para todos. "Tengo la misma herramienta de evaluación, el examen, pero el alumnado que necesita que le de la información poco a poco, por ejemplo K. (alumno hiperactivo) o M. (alumno absentista) que necesita que les de ese chispazo, la prueba sería la misma pero la forma de evaluar no. La herramienta, la actividad es la misma, pero depende de cómo la muestres" [C3_IP.HR_D].

Los alumnos conocen los porcentajes en torno a los cuales se articula su evaluación. "Y después también nos dio, ya hace, donde ponía la nota final el por cien de lo que vale esa nota. Por ejemplo $50 \%$ examen, el 10\% en material, 10\% trabajo en casa, 10\% trabajo aquí en el colegio, participación y etc." [C3_E.F_A8]. La docente así lo corrobora.

"Era un 50\% lo que era la prueba de examen individual y un 50\% el trabajo que era tanto de casa como de aquí de la clase. El trabajo de casa era individual y el trabajo de aquí se trabajaba de forma individual y grupal, casi todo grupal. Entonces después de forma grupal pues actividades, participación, también su actitud en la clase, y todo eso eran ítems en la tabla del profesor ¿no? Lo único que pienso es que se le da demasiada importancia al examen de texto con un 50\%" [C3_E.F_D].

Por tanto, no solamente se tiene en cuenta el producto final. "El producto final se evalúa pero evidentemente todo lo demás también porque la actitud es fundamental y cómo lo haces también es importante y eso lo hacen ellos también" [C3_E.F_D]. Los alumnos también tienen voz en su evaluación. "Porque así también sabe que creemos nosotros de nuestro trabajo, si lo hemos hecho bien decimos la nota que nos ponderamos nosotros a nosotros para que ella sepa, como creemos nosotros que lo hemos hecho" [C3_E.F_A2]. Una herramienta que utilizan, a veces, es la rúbrica (Ver Imagen 84). 
“A ver, muchas veces cojo una webquest de estas o como se dice... una 'casilla del tesoro', entonces allí hay ya rúbricas de forma bolativa y si no está la rúbrica pues le doy yo una general y si no la hacen de forma oral. Es una forma de agilizar también. [...]Y la verdad que la forma oral a mí me gusta mucho, porque me quita autoevaluación de ellos y veo que si que hacen la reflexión y mira simplemente es que la han hecho" [C3_E.F_D].

\begin{tabular}{|c|c|c|c|c|}
\hline \multicolumn{5}{|c|}{$\begin{array}{l}\text { RUBRICA PARA EVALUAR EL PLAN DE CLASE } \\
\text { Jaime Gerardo Méndez Barrientos }\end{array}$} \\
\hline \multirow{2}{*}{ CRITERIOS } & \multicolumn{3}{|c|}{$\begin{array}{l}\text { ESCALA } \\
\end{array}$} & \multirow{2}{*}{ PUNTAJE } \\
\hline & BIEN (3) & REGULAR (2) & INSUFICIENTE (1) & \\
\hline $\begin{array}{c}\text { Competencias } \\
\text { (Puntaje máximo 3) }\end{array}$ & $\begin{array}{l}\text { Todas las competencias } \\
\text { genéricas y los atributos } \\
\text { elegidos son congruentes y se } \\
\text { relacionan con la } \\
\text { competencia disciplinar y } \\
\text { particular, contenidos y } \\
\text { actividades }\end{array}$ & $\begin{array}{l}\text { La mayoría de competencias } \\
\text { genéricas y los atributos } \\
\text { elegidos son congruentes y se } \\
\text { relacionan con la competencia } \\
\text { disciplinar y particular, } \\
\text { contenidos y actividades }\end{array}$ & $\begin{array}{l}\text { La relación entre } \\
\text { competencias genéricas y } \\
\text { los atributos elegidos con } \\
\text { la competencia disciplinar } \\
\text { y particular, contenidos y } \\
\text { actividades, son confusos } \\
\text { e insuficientes }\end{array}$ & \\
\hline $\begin{array}{c}\text { Contenido } \\
\text { (Puntaje máximo 3) }\end{array}$ & $\begin{array}{l}\text { Todos los contenidos son } \\
\text { congruentes para lograr la } \\
\text { competencia disciplinar y } \\
\text { particular }\end{array}$ & $\begin{array}{l}\text { La mayoría de contenidos } \\
\text { permiten el logro de la } \\
\text { competencia disciplinar y } \\
\text { particular }\end{array}$ & $\begin{array}{l}\text { Los contenidos son } \\
\text { insuficientes para el } \\
\text { logro de la competencia } \\
\text { disciplinar y particular }\end{array}$ & \\
\hline $\begin{array}{c}\text { Actividades de la fase de } \\
\text { apertura } \\
\text { (Puntaje máximo 3) }\end{array}$ & $\begin{array}{l}\text { Las actividades de apertura, } \\
\text { permiten identificar los } \\
\text { saberes previos del estudiante } \\
\text { para relacionar sus } \\
\text { experiencias con los } \\
\text { contenidos }\end{array}$ & $\begin{array}{l}\text { La mayoría de las actividades } \\
\text { de apertura, permiten } \\
\text { identificar los saberes previos } \\
\text { del estudiante para relacionar } \\
\text { sus experiencias con los } \\
\text { contenidos }\end{array}$ & $\begin{array}{l}\text { Las actividades de } \\
\text { apertura no permiten } \\
\text { identificar los saberes } \\
\text { previos del estudiante } \\
\text { para relacionar sus } \\
\text { experiencias con los } \\
\text { contenidos }\end{array}$ & \\
\hline $\begin{array}{c}\text { Actividades de la fase de } \\
\text { desarrollo } \\
\text { (Puntaje máximo 3) }\end{array}$ & $\begin{array}{l}\text { Las actividades de desarrollo } \\
\text { permiten la ejercitación y } \\
\text { fortalecimiento de } \\
\text { habilidades para adquirir } \\
\text { conocimientos en forma } \\
\text { sistematizada y aplicarlos en } \\
\text { diferentes contextos }\end{array}$ & $\begin{array}{l}\text { La mayoría de las actividades } \\
\text { de desarrollo permiten la } \\
\text { ejercitación de habilidades } \\
\text { para adquirir conocimientos en } \\
\text { forma sistematizada y } \\
\text { aplicarlos en diferentes } \\
\text { contextos }\end{array}$ & $\begin{array}{l}\text { Las actividades de } \\
\text { desarrollo no permiten la } \\
\text { ejercitación para adquirir } \\
\text { conocimientos y aplicarlos } \\
\text { en contextos } \\
\text { determinados }\end{array}$ & \\
\hline
\end{tabular}

Imagen 84. Ejemplo de rúbrica para evaluar el plan de clase [C3_AM_DO].

Así pues, la rúbrica a veces la hacen por escrito y otras veces de manera oral. "Pero lo asimilan, porque al menos ellos yo se que han hecho la reflexión. No lo tienen escrito, pero yo sé que ellos reflexionan de hacer un trabajo, has hecho una reflexión, perfecto. Eso es lo que importa" [C3_E.F_D].

También evalúan las exposiciones que realizan. "Se valora la exposición de todos los miembros, se valora lo que yo veo durante el trabajo [...]. Primero cuando la hace que es en la clase. Después como la exponen, y en la exposición no sólo es el contenido, sino que también valoración y después el producto final que es lo que yo tengo. 0 en la mano o en el Dropbox o...en lo que sea" [C3_E.F_D].

Las familias están informadas sobre la evaluación de sus hijos. "De todas maneras sí que es verdad que dan su opinión en cuanto al tipo de evaluación, ¿vale? por ejemplo, a principio de curso se hizo este porcentaje [...] no hay ningún problema" [C3_E.F_D].

En el Anexo 19 se recoge una muestra de material ilustrativo de este caso. 


\subsubsection{Creencias, actitudes y valores que sustentan la práctica}

\subsection{Reflexión colectiva sobre la propia práctica docente}

La maestra comenta que su forma de trabajar se debe principalmente a sus creencias, valores y opiniones. Además, subraya que en el CRA todos sus compañeros docentes llevan una misma línea de trabajo, lo que les permite realizar reflexiones colectivas sobre sus propias prácticas educativas.

"Pues yo creo que mis creencias, mi opinión y mis valores. Por ejemplo, yo estaba en otro cole, hicimos esto de las comunidades de aprendizaje, fui a diferentes cursos me gustó la idea y en el cole que yo estaba era un poco difícil, era un poco más de hacerlo dentro del aula y la verdad es que he encontrado este colegio y es una maravilla, porque es todo el cole. Son todos los compañeros que tienen la misma línea de trabajo y estás más cómoda porque no has de estar en tu aula ahí como si fuese una cueva, vas haciendo las reflexiones. Pues si ves que otros utilizan la técnica de otra forma, pues mira eso es... Yo creo que es un poco de todo. Como uno piensa y el llegar a un colegio que trabaja de la misma forma que a ti te gusta y te motiva más. Y los compañeros no tan sólo del centro sino los compañeros. Y sobre todo este año es muy positivo. Si tienes dudas, si han salido más hablas del tema y como a todos nos gusta lo mismo de hablar las cosas, evaluarnos [...]. Yo me siento muy cómoda, si tuviera que coger un libro me estresaría, yo mi trabajo me gusta es como si fuera un hobby, coger un libro tenerlo todo tan marcado, el de intentar llevar los contenidos al día porque no...y mira tengo que dar esta sesión, esta unidad y si no se llega lo siento mucho tengo que dar otro contenido. Me sabría mal por los niños, porque no, de esta forma tengo ese margen de decir eso yo pensaba que estaba bien dado y no lo vamos a trabajar de otra forma. Hay un margen y estoy más cómoda. Das el contenido, pero no es tan cerrado. La programación pues has programado, pero si no es a esta fecha,... los contenidos pienso yo que están más consolidados. Hay un margen de error para adaptarme mejor" [C3_E.I_D].

Vemos como la docente reflexiona constantemente sobre su práctica educativa, lo que le permite ir introduciendo cambios en su aula. "Yo por ejemplo, estoy abierta, yo trabajo de una forma, pero yo hice un curso y otro y las cosas que me gustan las añado. Lo que me gusta si hago la reflexión y si pienso que va a ir bien pues venga y sino pues lo quitas y ya está" [C3_E.I_D].

\subsubsection{Escapar del aburrimiento: en busca de la motivación}

La maestra con las diferentes metodologías de trabajo pretende despertar la motivación del alumnado y huir de una escuela aburrida y monótona.

"Porque yo creo que una escuela, no me desagrada la escuela tradicional, pero creo que le falta un poco de motivación. Escapar un poco del aburrimiento. Sí, ser un poco diferente. En las técnicas cooperativas, el dejar que te ayuden. Muchas veces eso cuando uno crece no, no deja, ¿no? Tienen su compartimiento y ya está y tienen que saber pedir ayuda cuando la necesitan, si no la necesitan no [...]. Porque imagina que todos los trimestres libro cerrado, tú haces. Yo creo que hacer una forma diferente cada año o cada trimestre. Incluso después, es lo que yo te decía, cada curso intento dar una cosa diferente, una técnica diferente o acoplarme o darle más importancia, para que no se cansen [...]. 
Entonces se van dando unas nuevas, porque este curso también añadiremos más nuevas, porque si son siempre las mismas técnicas ¡Buff! Pues añadiremos cada año, dejaremos a lo mejor algunas a un lado o cogeremos otras nuevas, en más variedad, mejor. En cuanto a metodologías sí que los niños se las conocen. Los padres, eh... yo creo que también. A ver, yo a principio de curso hice un power point, eso está en el Dropbox de las técnicas que utilizamos, la metodología, se explicó todo lo de los talleres,...en power point. Los padres que no saben es porque no quieren" [C3_E.F_D].

\subsection{Atendiendo a la heterogeneidad del aula: reconocimiento y valoración positiva de la diversidad}

La maestra ante el reto que supone la enseñanza en un aula heterogénea, busca ayuda, cuando la necesita, en la psicopedagoga del centro. Ésta la dota de herramientas para mejorar su trabajo dentro del aula.

"Algunas veces, piensas que no llegas, pero bueno, te pones las pilas ¿no? Y si necesito ayuda pues le pido, sobre todo a C. (la psicopedagoga del CRA), si pienso que no estoy capacitada para cualquier cosa le pido ayuda. No en coger al niño, sino que me dé a mí la información que tengo que tener para resolver el problema dentro del aula, que yo creo que es el primer paso. C. es nuestra ayuda" [C3_E.I_D].

La docente piensa que con las diferentes actividades y técnicas que propone respeta los diferentes estilos y ritmos de aprendizaje de cada alumno.

"Es más difícil creo, yo creo que es más difícil jeh! Porque en la forma tradicional te das cuenta de que hay una persona que no llega. Pero yo creo que incluso en una cultura tradicional no le das ese refuerzo. Por tanto, es más difícil aquí, pero yo creo que sí que se da, te interesas más por estos tipos de ritmo [...]. Yo creo que si, a su ritmo jeh! A su ritmo unas personas te hacen una subida increíble y otras son más constantes y están ahí y van subiendo, otras personas arriba-abajo, pero bueno yo creo que sí. Pero se tiene que respetar también, cada uno tiene un ritmo de aprendizaje. Pues bueno es un niño que va despuntando pues aprovechas cuando está ahí. En esta forma de trabajar se respetan más los ritmos. Por ejemplo, había un niño que despuntaba con su ritmo de trabajo y con los deberes, en el trabajo de casa, en el trabajo de aquí, se tenía en cuenta, en el examen, se tenía en cuenta la cantidad de trabajo que sea menor" [C3_E.F_D].

La maestra tiene en cuenta las necesidades de aprendizaje de su alumnado. "Basa su manera de enseñar en las necesidades de aprendizaje de los estudiantes, así como en el currículum" [C3_IP.HR_D]. "Los objetivos se ajustan a los estudiantes en función de sus necesidades" [C3_IP.HR_D]. "El ritmo de enseñanza puede variar, en función de las necesidades de aprendizaje de los estudiantes" [C3_IP.HR_D].

Asimismo, decir que, el alumnado realiza diferente número de actividades en función de sus necesidades o preferencias de aprendizaje. "Si, porque hay algunos que van más deprisa y les tienes que ampliar y otros no llegan" [C3_IP.HR_D]. "Hay actividades que son cerradas, pero hay otros proyectos que yo les doy diferentes recursos o si ellos me proponen diferentes formas de hacerlo pues tú mismo cambias lo que necesitas" [C3_IP.HR_D]. "La tablet tampoco es la libreta. Yo creo que no es aburrido y son diferentes proyectos dentro de uno que es el eje vertebral" [C3_E.I_D]. 
En cuanto a los deberes de fin de semana, explica que no les pone un negativo si lo han hecho mal. "Por ejemplo, los deberes de fin de semana, si una persona lo ha hecho mal no le voy a poner un negativo o ponerle peor nota por haberlo hecho mal. Después pues evalúo en un examen y la nota media son los exámenes y después sube o baja según su trabajo de cada día y de las anotaciones que voy realizando" [C3_E.F_D].

Continuando con la evaluación del alumnado, la maestra tiene en cuenta la diversidad de ritmos y estilos de aprendizaje.

"Hay unos criterios de puntuación y de evaluación. Pero también no es lo mismo evaluar a una persona que sabes que puede llegar a una persona pues que bueno, has de ver también la evolución [...]. En cuanto al nivel sí que se tiene en cuenta y dentro del nivel sí que, a ver no es lo mismo una persona que tiene un nivel más... pues que no llega a los contenidos. Pues miras a la hora de evaluar, por su evolución. Ves y comparas, mira pues en el anterior trimestre o en el anterior trabajo pues ha hecho lo que le había comentado" [C3_E.F_D].

Los alumnos también son conscientes de la diversidad en el aula. "Hay personas que no captan bien la idea y Cristina tiene que estar [...] explicándoselo mejor para que ellos puedan..." [C3_E.F_A1]. "Diciéndolo de otra forma" [C3_E.F_A2]. La madre entrevistada también reconoce la diversidad del aula.

"Yo pienso que va bien, yo lo veo positivo y lo veo bien. Porque claro si un niño necesita más y su información enseguida lo coge, ese niño irá a más. Pero si un niño le va a costar menos se va a coger lo que necesita. El mínimo que la maestra exige. ¿Qué pasa? que si tú coges un libro y a todos les pides lo mismo a lo mejor el que necesita más, podemos decir que le sabe a poco y el que no llega es una montaña. Entonces cada uno se acopla al mínimo que la clase exige, porque siempre tiene que saber el mínimo de la clase. Que quien no llegará al mínimo, el que necesita un poco más, pues ese niño cogerá más" [C3_E.F_M1].

\subsection{Tú me ayudas yo te ayudo: Cultura colaborativa y liderazgo compartido}

La maestra pretende formar a su alumnado para vivir en sociedad. "Yo creo que la educación en la escuela es preparar para la sociedad. Así pues, vivimos en una sociedad y los tienes que preparar. No somos ahí un cajón cerrado y ya está. Tiene que saber trabajar en grupo porque después su trabajo, casi siempre es trabajar con otras personas $y$ tienen que adaptarse" [C3_E.F_D]. Tal y como se ha visto, se promueven diferentes agrupaciones y formas de trabajar en el aula. "La docente favorece el aprendizaje cooperativo para fomentar el apoyo mutuo, la interdependencia y la comprensión mutua y para asegurar que los alumnos estén cómodos, trabajando con alumnos de diferentes características" [C3_O_HO].

Como podemos ver en la Imagen 85, se representa un cartel con el espíritu del aula. La maestra la concibe como un espacio dinámico, en el que fomenta las interacciones entre iguales y el trabajo colaborativo. 


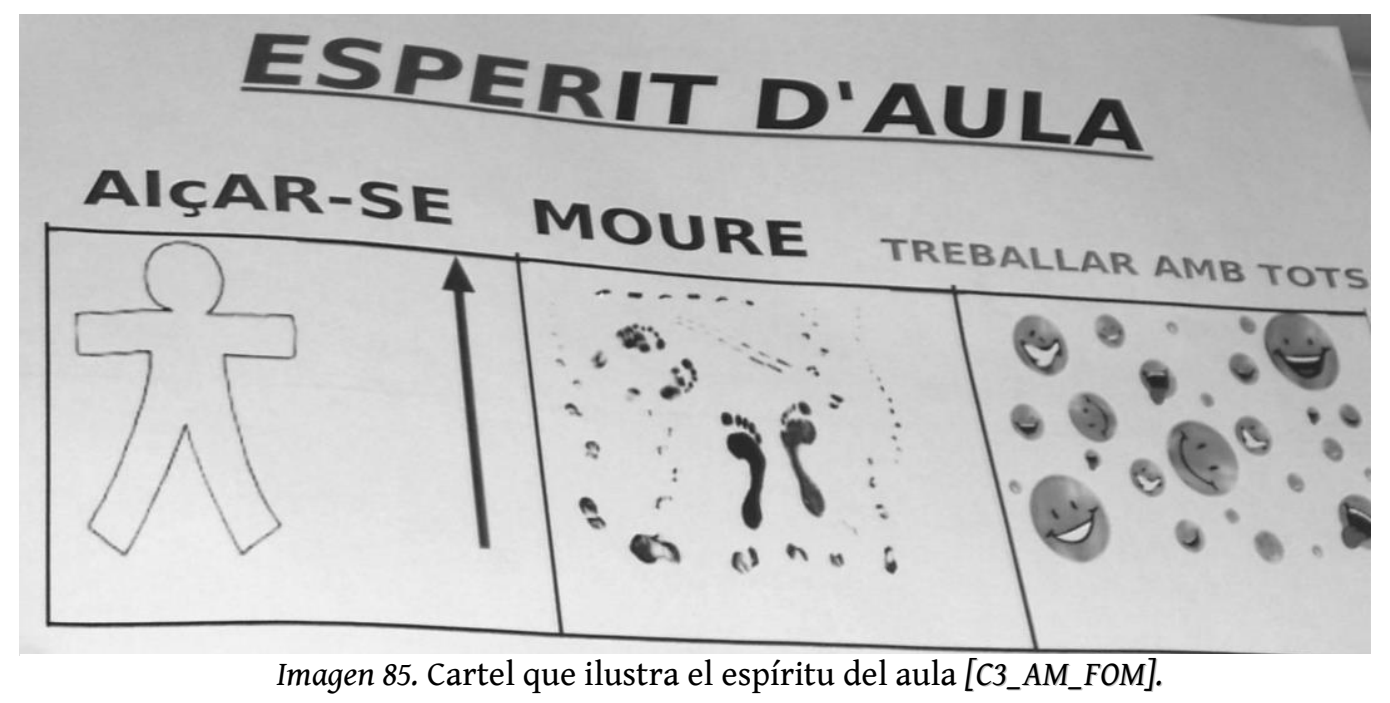

Generalmente, al alumnado le gusta trabajar en grupo. "Porque si no sabes algo pues te pueden ayudar" [C3_E.F_A10]. "No sé cual me gusta más, porque hombre a mi sabio... A mí siempre me ha gustado hacerlo en grupo, en parejas también estará bien. Pero los sabios también el año pasado lo hicimos y no es que me gusta mucho, porque individual [...] te las tienes que apañar tu solo. Pero bueno, lo hace para que sepamos trabajar nosotros solos" [C3_E.F_A11]. "Una mejora de trabajo en equipo, aprendemos a trabajar mejor en equipo e individualmente" [C3_E.F_A2]. "Porque en grupo puedes hacer un trabajo más extenso en menos tiempo y claro todos podemos hacer la faena" [C3_E.F_A7]. No obstante, el hecho de trabajar en grupo genera algún conflicto. “A mí también me gusta en grupo, pero es que claro, hay veces que no nos ponemos de acuerdo" [C3_E.F_A5]. "Bueno, yo hoy he trabajado con mi amiga R. y con un niño que se llama K. (niño hiperactivo) y he trabajado muy bien con ellos. Porque son unos niños que sí que debaten, pero dicen: ostras es verdad. No son unas personas cabezotas y tenemos que hacer eso... Yo he trabajado muy a gusto con ellas. Trio, pareja, individual. Individual, no me gusta mucho porque claro, eso que sin querer te pasas" [C3_E.F_A3].

Además, en este caso la cultura de la colaboración y la ayuda mutua se extiende entre la plantilla docente. Recordemos que en muchas ocasiones otros docentes entran a ayudar en el aula, este sistema está instaurado en todo el CRA. Asimismo, como se ha introducido anteriormente, Cristina también solicita ayuda a la psicopedagoga del centro. Hay que mencionar también, la ayuda existente entre la tutora y la maestra de música tal y como se ha visto en el Proyecto LóvA.

"Lo que pasa es que por eso es muy importante la acción y que se involucre mucho el tutor. Porque por ejemplo, Cristina trabaja mucho el grupo, entonces a mí me ayudaba mucho Cristina, la capacidad de trabajar los sentimientos, dentro del grupo, las relaciones entre ellos, ella me iba ayudando un poco en esa parte, porque ibamos muy cortos de tiempo [...]Cristina me ayudaba mucho también en la parte del documentalista y el relaciones públicas" [C3_E.F_Dm].

Igualmente, esta cultura colaborativa, se extiende entre el centro y las familias. Si lo necesitan, solicitan ayuda a las familias, tal y como se ha visto en el Proyecto LÓVA. "Estuvo súper bien porque ellas mismas dijeron ‘¿bueno necesitáis ayuda?’ y escenografía, 'si nosotros si” " [C3_E.F_Dm]. El alumnado valora positivamente la ayuda prestada por las familias en dicho proyecto LÓVA. "Como si nos apoyaran y nos ayudan más" [C3_E.F_A8]. 
Vemos también un liderazgo compartido tanto en los encargados de la semana, en los diferentes roles o cargos que desempeña el alumnado a nivel de aula, como en los oficios o profesiones del proyecto LÓVA. Existe un compromiso e implicación del alumnado para llevar a cabo las diferentes funciones o actividades.

\subsection{Participación del alumnado y de las familias: valores democráticos}

La docente cree que su forma de trabajar repercute en la formación del alumnado como ciudadanos críticos, ya que en algunas ocasiones el alumnado escoge y tiene que llegar a acuerdos. "Hace hincapié en el pensamiento crítico y creativo y la aplicación del aprendizaje" [C3_IP.HR_D]. Aunque no es una tarea fácil. "Tú te imaginas que va a ser de una forma y después dices: 'ostras' no sale la actividad de la forma que tú te pensabas. Pensabas más utópico ¿no? Pero bueno si se coge una cosita, pues una cosita" [C3_E.F_D].

Los alumnos se sienten escuchados y piensan que tienen en cuenta su voz y opinión. "Porque ellos (se refiere a los maestros) quieren mejorar y saber nuestra opinión y lo hacen mucho, Cristina y los otros maestros" [C3_E.F_A2]. "El año pasado nos hicieron una pared de deseos de cada uno lo que quería (JORNADA DE PUERTAS ABIERTAS -2014). La mayoría ponía renovar los baños y este año los han renovado" [C3_E.F_A1].

Ya hace unos años que el aula está abierta a la participación de las familias. "Tres años llevaremos o cuatro" [C3_E.F_M1]. "cuatro o cinco años. Cinco años que participan las familias" [C3_E.F_D]. "Es participar los padres, decir lo que pensamos. A lo mejor ellos se piensan que están haciendo una cosa bien y pues mira, 'yo pienso esto', y a lo mejor ellos no lo habían pensado. Y es otro punto de vista que tenemos" [C3_E.F_M1].

La maestra, mediante una reunión inicial, explica a las familias la forma de trabajar en el aula. “[...] en el Dropbox un power point, en cuanto a las metodologías explicando un poquito los proyectos. [...] Y después también las puertas están abiertas, si tú quieres venir puedes venir. Es verdad que está el tema del horario, pero bueno. Igual que a lo mejor coges un día para otra cosa o tienes un día libre pues puedes aprovechar para venir" [C3_E.F_D]. Para informar a las familias se realizan asambleas.

"Las asambleas se hacen a final de trimestre, al inicio de curso para la asamblea informativa. Hay una participación no casi del 100\%, pero si faltas a la reunión después quedamos en otro momento. Entonces sí que esa información está [...], y de darte su opinión o de darte ideas pues sí que la dan. También se facilita porque todas las asambleas se hacen por la tarde. En el grupo de WhatsApp se da 'A ver qué día de esta semana y a qué hora' pues se da libertad" [C3_E.F_D].

Por lo que respecta a las jornadas informativas, una de ellas se realiza al inicio de curso. En ella asisten todas las familias del centro.

"Salió lo de la jornada esta de convivencia a principio de curso. Porque se hacía una asamblea vale, una asamblea era más una reunión de inicio de curso y que estaban los miembros del claustro y A. (director del CRA) explicaba un poco ¿no? pues lo que era el centro y presentaba al equipo docente. Eso es como se hacía antes. Pero surgió lo que es esta jornada para informar un poco y vender el producto 
¿no? Hacemos esto y porqué lo hacemos y a que podemos llegar. Entonces pues bueno [...]. Que el objetivo es intentar aproximar a las familias, eso es lo que hacemos y como lo hacemos. Información va haber. Y después también, por ejemplo, en talleres se va a explicar lo que se hace y porque se hace, después habrá una tabla para que te anotes para las propuestas. A final de curso también se va a hacer, por ejemplo, en tercer ciclo se van a aprovechar las reuniones finales para coger las propuestas tanto de excursiones, de salidas y de taller. Entonces pues hay unas propuestas ya cogidas también de las familias" [C3_E.F_D].

Al alumnado le gusta esta participación de sus familiares, aunque hay veces que por cuestiones laborales no pueden asistir con regularidad. "Como que nos gusta más que los padres participen [...] y que vean cómo lo hacemos nosotros [...]. A mi madre, por ejemplo, a mi madre le encanta venir para ver como trabajamos, pero como tiene su trabajo no puede venir mucho, pero cuando viene se lo pasa muy bien" [C3_E.F_A2]. "Interactúan con nosotros" [C3_E.F_A1]. "Pues hay algunos que si pueden sí que vienen a participar y hay otros que como no pueden intentan venir" [C3_E.F_A6].

La docente también es consciente de que por motivos laborales se hace complicada la participación regular de las familias en el aula. “A ver, ¿qué es lo que empeora la participación de la clase? El horario lectivo. ¿Por qué hay más participación en la asamblea o reunión? Porque está fuera del horario lectivo a las 19:00h de la tarde. Entonces yo creo que el problema es el horario, porque son gente que sí que trabaja jeh! Y aun gracias, pero si la mayoría trabajan, tienen turnos de trabajo" [C3_E.F_D].

Debido a que un gran número de familias trabajan en almacenes de naranjas, la participación no es constante a lo largo de todo el curso escolar. Además, durante el curso académico 2014/2015 las familias jugaron un papel importante en su implicación y ayuda para llevar a cabo el proyecto LóvA.

"El primer trimestre es imposible. El segundo trimestre, aquí, por ejemplo, la naranja se quedó ahí en febrero o marzo. Claro ahí depende. Y después si están haciendo el proyecto LóVA y quieres que vayan ahí, pues lo prefería ¿no? Porque lo otro, pues te acostumbras, o coges el refuerzo de un compañero [...] Por eso yo no insisto tanto en la participación instaurada de todas las formas y el objetivo que sí que marqué a principio de curso de decir: 'es proponer una actividad o participar en un taller o en una tertulia lo que queráis, algo..." " [C3_E.F_D].

La maestra, por su parte, desearía que la participación de las familias se diese de manera regular. Aunque, se conforma con que las familias participen, como mínimo, una vez al año.

"A mí me vendría mejor que vinieran, pues todos los viernes, venga va, siempre una madre o un padre. Pero es muy difícil, porque el grupo es más numeroso que en otra clase y después los horarios de trabajo. Por tanto, les va mejor proponer. Sí que lo del objetivo de intervenir o proponer una vez al año, ya está. Si yo tengo este curso 18, pues yo ya tengo 18 personas que van a venir una vez al año. Simplemente, pues para empezar bueno, no está mal. Estaría muy bien ¿no? de decir: 'yo todos los viernes o todos los jueves en la tertulia..." " [C3_E.F_D].

La madre comenta que, las familias, sí que participan en el contexto escolar. "Siempre que en la escuela hay alguna actividad, nos invitan. O pues, participamos en las clases, en la escuela" [C3_E.F_M1]. 
La madre cree que la participación de las familias se debe, especialmente, a la iniciativa de los docentes del centro.

"Principalmente, porque los maestros quieren. Porque los maestros abren la escuela a todo el mundo. Si los maestros no quisieran no entraríamos. Yo tengo una hija de 15 años, antes no entrábamos para nada los padres aquí y hoy en día sí, tienes la oportunidad de entrar cuando quieras y para lo que quieras sin ningún problema [...]. Facilita que estés viendo lo que los niños están dando. Entonces, después en casa puedes explicarles si tienen alguna duda o alguna cosita. Si después no vienes o no participas en clase, a lo mejor si los niños tienen alguna duda no puedes explicarles cómo lo tienen que hacer o qué hay que hacer" [C3_E.F_M1].

Con esta forma de trabajar, la madre entrevistada piensa que requieren de una mayor implicación de los padres.

"Mi otra hija también era autónoma pero claro era su libro, su libreta y sus cositas y aquí en este sistema a lo mejor van un poco más perdidos los padres, en el sentido de que tú no llevas una guía en un libro y claro si tú no te implicas un poco en el niño, lo que está dando... no es coger el libro y decir hijo estás por la página 40, ideal, y la semana que viene estarás por la 45 [...] Entonces aquí te tienes que involucrar un poco y mirar a ver el niño que es lo que está haciendo y lo que está mirando. Porque a lo mejor te dice 'estoy haciendo los deberes' ahí con la Tablet" [C3_E.F_M1].

La docente comenta, que algunos padres están un poco a la expectativa en relación al cambio en la metodología de trabajo en el aula.

"A ver están un poco a la expectativa. A ver yo creo que un poco el problema es que nosotros hemos recibido una educación muy tradicional en cuanto a libro de texto ¿vale? Entonces para nosotros como padres nos resulta muy fácil pensar cómo lo hacíamos antes y entonces hacer lo mismo que hacían nuestros padres, hay una guía. Pero claro, nosotros mismos no hemos recibido una educación así. Ahora, nosotros no sabemos cómo funciona como padres y ayudar a nuestros hijos. No hay una guía. Entonces sí que hay, tenemos que cambiar como padres la mentalidad. Yo como madre sí que me sentaba y venga vamos a hacer los deberes, o a lo mejor mi madre no se sentaba conmigo. Simplemente, eso, eso y eso. Ahora a estudiar. Vale, perfecto yo lo he hecho, lo he visto en mi madre. Voy a hacer lo mismo. Ahora, cambia la metodología. 'Ostras y como le puedo ayudar a mi hijo'. Es diferente, por ejemplo [...] le digo: 'no es el libro, ves a su libreta y verás lo que está trabajando. Su material es la libreta, ve al Dropbox y verás, ve a su agenda, en su planning y veras en su planning, los deberes y la planificación'. Es cambiar de chip. Pero tal vez, ahí sí que nosotros como maestros sí que tienes que intentar darles el cambio de chip. Pero es difícil" [C3_E.F_D].

La madre entrevistada valora positivamente el cambio metodológico en el aula.

"A ver, yo valoro mejor esto que lo de antes. Antes era pues eso la escuela de toda la vida, los niños entran y tú ya no te implicas en la educación de tu hijo. Ahora no, ahora tienes unas oportunidades de ver lo que tu hijo está aprendiendo y el proceso que va llevando. Y después también por ejemplo muchas cositas. Pues la cosa tonta de que yo, por ejemplo, llevaba a mi hija de 3 años y me decían: 'de la puerta ya 
no puedes pasar'. Ahora no, si el niño está llorando pues entra a clase, te esperas un poquito y cuando más o menos termina de llorar, pues ya te vas. Eso al principio de curso, antes no. Antes de la puerta ya no pasabas" [C3_E.F_M1].

La madre concibe la educación de los hijos como una cosa tanto de las familias como de los docentes.

"Yo lo veo muy positivamente, porque al fin y al cabo es la educación de los hijos. No es tan sólo de los maestros, los maestros te pueden ir enseñando, pero creo que es una cosa de los dos, es una cosa que el niño está en el medio y tiene que tener el apoyo de los maestros y el apoyo de los padres, entonces si nos juntamos los tres el niño en lugar de ir hacia un lado o hacia otro en su educación pues irá más rectito e irá mejor [...]. Yo veo que sí, pero porque también entro, que aquí hay un problema, que hay mucha gente que habla, pero no entra, entonces 'hablan con desconocimiento de causa' que se dice, entonces hablar es muy fácil hablar, pero si tienes alguna duda, algún problema,... Si tienes una escuela ideal, entra $y$ pregunta y se solucionan las cosas. Y a lo mejor si lo que tu hoy, por ejemplo, ves mal, si entras, explicas tu problema a lo mejor cambias completamente de vista" [C3_E.F_M1].

La madre anima a todos los padres a entrar en el colegio, ya que la educación de sus hijos es de su incumbencia, en todos los aspectos.

"Yo animo a la gente que entren, lo que pasa es que no quieren y al final quien lo paga es sus hijos, no es ni el hijo de la maestra, ni el hijo del maestro. Es tu hijo y si tú estás pensando en su futuro tienes que estar a su lado y si a ti te están diciendo desde el cole 'ven y mira que estamos haciendo',... pues no cojas la posición cómoda de coger y quedarte en casa, entra y ten un poco de interés porque es tu hijo. Y tu hijo realmente te interesa. Su educación en todos sus aspectos" [C3_E.F_M1].

Seguidamente, en la Figura 8, se presenta un esquema relacional de las creencias, actitudes y valores que sustentan la acción docente del tercer caso objeto de estudio. 
CAPÍTULO 4

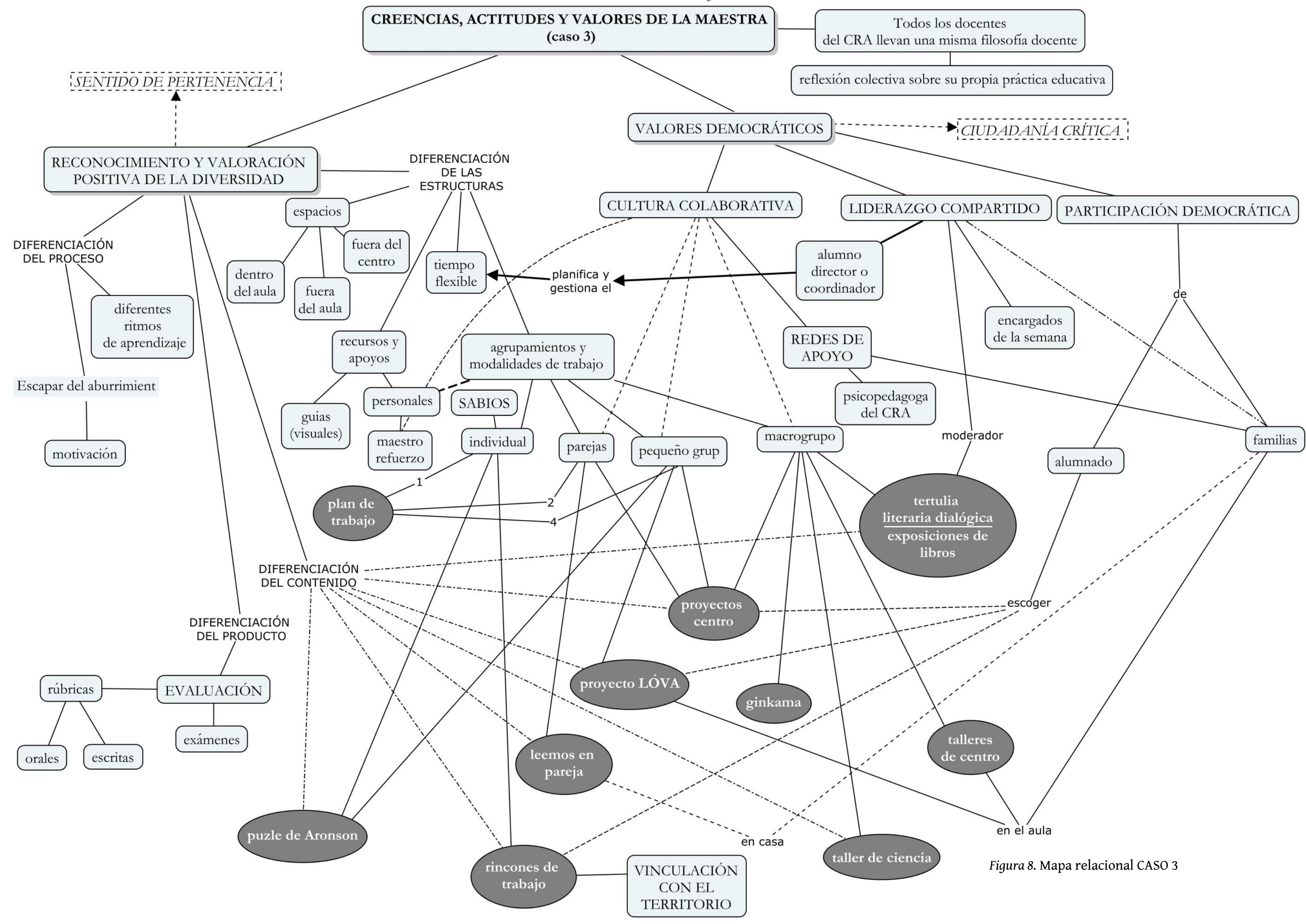

$\sim$ Diferenciación pedagógica y participación democrática en el aula inclusiva: estudio de casos múltiples 275 



\subsubsection{Cas 4 : Ysabel}

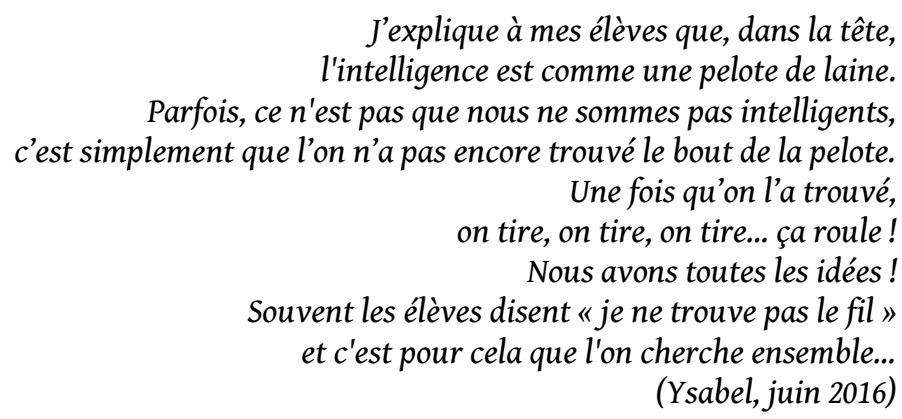

Le but d'une étude de cas, ici le cas Suisse, est de mieux comprendre les différentes manières de travailler en fonction des paramètres de différenciation pédagogique et de participation démocratique. Cette étude a été effectué auprès des membres du Laboratoire international sur l'inclusion scolaire (LISIS) de la Haute école pédagogique du Canton de Vaud (Lausanne, Suisse).

Avant d'aborder le récit du cas d'Ysabel, sera présenté le contexte général de l'éducation en Suisse, ainsi que ses principales lois et ses principaux accords.

\subsubsection{La Suisse : contexte général de l'éducation ${ }^{28}$}

Le Département de la Formation, de la Jeunesse et de la Culture (DFJC) est chargé de la formation d'enfants, jeunes et adultes, dans les domaines de l'enseignement obligatoire, post-obligatoire et supérieur, ainsi que dans celui de l'enseignement spécialisé. Nous nous attacherons surtout à l'enseignement obligatoire et l'enseignement spécialisé.

La direction générale de l'enseignement obligatoire (DGEO) : assure la gestion de l'école obligatoire du Canton de Vaud et assume la scolarisation des élèves de 4 à 15 ans. Selon la Loi sur l'enseignement obligatoire (LEO, 2011), celle-ci comprend le degré primaire et le degré secondaire I. Le degré primaire d'une durée de huit années comprend deux cycles : $1^{\circ}$ ) années $1 \mathrm{P}$ à $2 \mathrm{P}$ et années $3 \mathrm{P}$ et $4 \mathrm{P}, 4$ ans au total $; 2^{\circ}$ ) années 5P à 8P, 4 ans également. A la fin de la huitième année, l'enfant est orienté.

Le temps de fréquentation scolaire varie selon les années d'étude; par exemple, dans le cas recruté pour notre étude (cinquième/sixième année), le temps hebdomadaire d'enseignement est de 28 périodes. La durée de la période est fixée à 45 minutes. Les épreuves cantonales de référence (ECR) ont lieu au mois de mai pour les élèves de 4ème, 6ème, 8ème et 10ème (concordat HarmoS).

Il convient, par ailleurs, de relever que le Service de l'Enseignement Spécialisé et de l'Appui à la Formation (SESAF) né en 2002, est basé sur l'ancien Service de l'Enseignement Spécialisé (SES). Le SESAF regroupe différentes mesures applicables dans le secteur de l'appui à l'insertion professionnelle et le secteur de l'appui à la scolarisation. Quant à l'appui à la scolarisation, il est

28 Information tirées de différents sites internet et de documents officiels (voir références bibliographiques). 
important de souligner que l'enseignement spécialisé propose plusieurs types de mesures destinées aux enfants en situation de handicap et en appui aux enseignants :

- le Service Éducatif Itinérant (SEI) offre une aide à domicile aux enfants d'âge préscolaire qui présentent des difficultés dans leur développement ou un handicap.

- le Renfort pédagogique (RP) permet à l'enseignant titulaire de leur apporter de meilleures réponses pédagogiques, dans le cadre de la classe. Cette mesure est dispensée par un enseignant spécialisé ou non spécialisé.

- Les classes de développement sont destinées aux élèves qui ne peuvent pas tirer profit de l'enseignement d'une classe primaire ou secondaire pour lesquelles un enseignement et un programme individualisés sont nécessaires mais dont des mesures d'encadrement plus spécifiques de type enseignement spécialisé ne sont pas requises. La prise en charge des enfants décrits ci-dessus peut se faire sous différentes formes :

Classes de développement "traditionnelles", avec un effectif de 10 à 12 élèves.

$\sim$ Classes-ressources : les enfants fréquentent partiellement la classe pour faire des activités spécifiques (français, maths). Le reste du temps, ils sont intégrés dans des classes de l'enseignement ordinaire.

MCDI (maître de classe de développement itinérant). L'élève ayant des difficultés reste intégré dans la classe ordinaire. Le maître de classe D intervient auprès de lui chaque semaine dans la classe ou dans un local annexe, en collaboration avec le titulaire de la classe.

Toutes ces prises en charge visent une meilleure intégration scolaire, sociale et professionnelle. Les classes sont intégrées dans les établissements scolaires et gérés par les Directions d'écoles.

- le Soutien pédagogique spécialisé (SPS) est une prestation d'enseignement spécialisé destinée aux élèves relevant de la Loi sur l'Enseignement Spécialisé (LES) qui fréquentent l'école ordinaire. Elle est fournie par des enseignants spécialisés qui apportent une aide spécifique à l'enfant et collaborent avec l'enseignant titulaire de la classe. Ses missions principales portent sur l'enseignement individualisé, l'adaptation des méthodes pédagogiques, l'adaptation des programmes, les liens avec les divers intervenants auprès de l'enfant et l'évaluation régulière de l'intégration.

- Les classes d'enseignement spécialisé (COES) sont des classes relevant de l'enseignement spécialisé et intégré dans des Établissements scolaires.

- L'aide à l'enseignant est une mesure destinée à des élèves relevant de l'art. 1 de la LES, qui leur permet de poursuivre leur formation au sein de l'école régulière, par une aide non spécialisée destinée à augmenter leur autonomie ou à leur permettre une meilleure participation. 


\subsection{Principales lois et des principaux accords ${ }^{28}$}

Le 4 septembre 2011, les vaudois ont accepté en votation populaire la loi sur l'enseignement obligatoire (LEO). Elle remplace la Loi Scolaire du 14 juin 1984. La nouvelle loi est entrée en vigueur le $1^{\mathrm{er}}$ août 2013 et s'applique à tous les élèves, tous niveaux confondus. L'école obligatoire dans le canton de Vaud fait progressivement face à quelques changements d'organisation et de structure liés à l'Accord Intercantonal HarmoS et à la loi LEO.

Nous ne retrouvons pas mention du terme d'inclusion dans les législations cantonales ou fédérales (Ramel, 2015b). Le terme utilisé est : intégration.

L'Accord Intercantonal sur la collaboration dans le domaine de la pédagogie spécialisée (AICPS) entré en vigueur le $1^{\mathrm{er}}$ janvier 2011, pose comme principe :

"Les cantons concordataires travaillent ensemble dans le domaine de la pédagogie spécialisée dans le but de respecter les obligations découlant de la Constitution fédérale de la Confédération suisse de l'Accord intercantonal sur l'harmonisation de la scolarité obligatoire et de la loi fédérale su l'élimination des inégalités frappant les personnes handicapées. En particulier, a) ils définissent l'offre de base qui assure la formation et la prise en charge des enfants et des jeunes à besoins éducatifs particuliers ; b) ils promeuvent l'intégration de ces enfants et de ces jeunes dans l'école ordinaire; [...]" (Art.1 but, p.1).

“[...] b) les solutions intégratives sont préférées aux solutions séparatives, ceci dans le respect du bien-être et des possibilités de développement de l'enfant ou du jeune concerné et en tenant compte de l'environnement et de l'organisation scolaires" (Art.2 Principes de base, p.1).

"Les niveaux d'exigence dans le domaine de la pédagogie spécialisée sont adaptés à partir des objectifs d'apprentissage fixés dans les plans d'études et des standards de formation de l'école ordinaire; ils prennent en compte les besoins et capacités individuels de l'enfant ou du jeune » (Art.8 objectifs d'apprentissage, p.4).

Cette remise en question est renforcée par la Loi sur l'enseignement obligatoire (LEO, 2011) qui montre l'intention de l'école de prendre en charge tous les élèves :

"1 L'école assure, en collaboration avec les parents, l'instruction des enfants. Elle seconde les parents dans leur tâche éducative.

2 Elle offre à tous les élèves les meilleures possibilités de développement, d'intégration et d'apprentissages, notamment par le travail et l'effort. Elle vise la performance scolaire et l'égalité des chances.

3 Plus particulièrement, elle vise à faire acquérir à l'élève des connaissances et des compétences, à développer et à exercer ses facultés intellectuelles, manuelles, créatrices, et physiques, à former son jugement et sa personnalité et à lui permettre, par la connaissance de soi-même et du monde qui l'entoure ainsi que par le respect des autres, de s'insérer dans la vie sociale, professionnelle et civique" "(Art.5 Buts de l'école, p.2).

Selon la même loi, le chapitre IX fait référence à la différenciation pédagogique: 
" 1 Le directeur et les professionnels concernés veillent à fournir à tous les élèves les conditions d'apprentissage et les aménagements nécessaires à leur formation et à leur développement. En particulier, les enseignants différencient leurs pratiques pédagogiques pour rendre leur enseignement accessible à tous leurs élèves.

2 Ils privilégient les solutions intégratives dans le respect du bien-être et des possibilités de développement de l'élève et en tenant compte de l'organisation scolaire ainsi que du fonctionnement de la classe.

3 Le conseil de direction prend les mesures utiles à l'intégration des élèves issus de la migration dans l'établissement et dans les classes qu'ils fréquentent. Il veille notamment à faciliter la communication entre l'école et les parents.

4 En complément aux mesures pédagogiques, les élèves peuvent être mis au bénéfice d'un accompagnement socioéducatif et d'un encadrement d'éducation spécialisée lorsque ces mesures sont nécessaires au bon déroulement de leur scolarité.

5 Le département veille à ce que les situations de handicap de l'élève ou autres circonstances analogues fassent l'objet de repérage précoce ou d'évaluation, en application de la législation sur la pédagogie spécialisée » (Art.98 Principes généraux, p.19).

La déclaration de la Conférence intercantonale de l'Instruction publique de la Suisse romande et du Tessin (CIIP) fixe les finalités et objectifs de l'école publique. Elle établit que l'école publique assume une mission globale et générale de formation qui intègre des tâches d'éducation et d'instruction permettant à tous les élèves d'apprendre, et d'apprendre à apprendre afin de devenir aptes à poursuivre leur formation tout au long de leur vie. Le plan d'étude Romand est organisé selon trois entrées :

Tableau 19

Structure du Plan d'études Romand

\begin{aligned} \hline & $\sim$ Langues \\ Domaines disciplinaires & $\sim$ Mathématiques et Sciences de la nature \\ & $\sim$ Sciences humaines et sociales \\ & $\sim$ Corps et mouvement \\ & $\sim$ Collaboration \\ & $\sim$ Communication \\ & $\sim$ Stratégies d'apprentissage \\ Capacités transversales & $\sim$ Pensée créatrice \\ & $\sim$ Démarche réflexive \\ & $\sim$ MITIC (Médias, Images, Technologies de l'Information et de la Communication) \\ & $\sim$ Santé et bien-être \\ & $\sim$ Choix et projets personnels \\ & $\sim$ Vivre ensemble et exercice de la démocratie \\ Formation générale & $\sim$ Indépendances (sociales, économiques et environnementales) \\ & $\quad$ Projet global de formation de l'élève \end{aligned}

Le Plan d'études Romand (PER) s'inscrit dans le contexte de la Constitution fédérale (art.62, alinéa 4) adopté par le peuple le 21 mai 2006. Le PER répond à la volonté d'harmonisation de l'école publique en déclinant les objectifs de l'enseignement dans une perspective globale et cohérente et en définissant en particulier les attentes fondamentales de fin de cycle. Le PER s'inscrit également dans 
le cadre de l'Accord Intercantonal sur l'harmonisation de la scolarité obligatoire (Accord HarmoS). Cet Accord traite de la durée et des objectifs des degrés scolaires, de l'enseignement des langues ainsi que des horaires blocs et des structures de jour.

\subsubsection{Cadre des pratiques de différenciation et participation}

\subsection{Contexte : L'établissement primaire de Payerne et environs}

Dans le chapitre IV de la LOI (2011) sont régies les fonctions des établissements scolaires. L'établissement est l'entité où se mettent en œuvre les politiques de formation. Les établissements sont groupés par région scolaire. Il est constitué d'un ensemble de classes localisées dans un ou plusieurs bâtiments et placées sous l'autorité d'un directeur. L'article 47 de cette loi montre que le conseil de direction se compose d'une direction et de doyens.

L'établissement primaire de Payerne et environs accueille les enfants de $41 / 2$ ans à $121 / 2$ ans domiciliés dans les communes de Payerne, Chevroux, Corcelles, Grandcour, Missy et Trey. Ses 63 classes sont réparties dans 10 bâtiments scolaires.

Le bâtiment scolaire où a été faite l'étude de cas est à Corcelles, qui appartient à établissement primaire de Payerne et environs. Corcelles-près-Payerne est une commune suisse du canton de Vaud, située dans le district de la Broye-Vully. L'enseignante, dans l'entretien, explique que la population est différente parce qu'il s'agit d'une école de village. Il y a les enfants des paysans qui sont habitués à travailler. La population scolaire est différente à Payerne, une ville où l'on retrouve beaucoup d'immigrants qui peuvent difficilement accompagner leurs enfants lorsqu'ils réalisent les devoirs en français. C'est pour cette raison que les écoles de la ville de Payerne offrent un service de devoir surveillé.

\subsection{Les membres de la classe : les enseignantes et les élèves}

Dans la classe de 5-6P (enfants de 9-10 ans) du bâtiment de Corcelles il y a deux enseignantes : Nathalie qui travaille avec les élèves lundi et mardi et Ysabel qui travaille avec les élèves du mercredi au vendredi. Pour réaliser cette étude, nous nous sommes concentrés sur la pratique d'Ysabel.

Ysabel est une enseignante qui a 30 années d'expérience en enseignement à l'ordre primaire. Elle est d'origine française. Elle a obtenu son diplôme en enseignement après avoir effectué trois années de formation dans une école normale en France. Quand elle est arrivée en Suisse elle a passé un diplôme international pour enseigner. Elle a dû ses unités de valeur à l'université pour a voire l'équivalence. Donc elle a reçu l'équivalence de diplôme d'enseignante. En ce qui a trait à son développement professionnel, elle a reçu une formation complémentaire sur les principes de la classe Montessori. Elle est maman d'un enfant qui est dyslexique- orthographique. Donc, elle a orienté ses 
recherches personnelles pour soutenir son enfant et ses apprentissages à cet égard ont grandement contribué à sa pratique en classe. De plus, elle participe aux formations organisées par, pour toute l'école.

Les élèves bénéficient de quatre périodes d'enseignement avec leur enseignante titulaire. De plus, chacune des classes bénéficie des services d'un soutien intégré. Pour effectuer ce travail dans la classe d'Ysabel, Michelle détient un diplôme en enseignement spécialisé. Cette formation lui permet de travailler avec des élèves qui présentent de grandes difficultés telles que la dyslexie, la dyscalculie, la dyspraxie et la dysorthographie. Pour tenter de répondre aux besoins particuliers de ces élèves, on élabore un programme adapté en début d'année en réunissant les parents, la maîtresse, les spécialistes concernés et l'enfant lui-même.

La classe d'Ysabel est composée de 19 élèves. Cinq élèves ont une langue maternelle autre que le français; ils sont d'origine portugaise, brésilienne et albanaise. Selon Ysabel, quatre élèves qui ont des difficultés d'apprentissage et des difficultés de comportement. Au niveau de devoirs, il n'y a pas de soutien familial. De plus, Ysabel traite d'un autre élève ayant de très grandes difficultés qui sera promu en septième année même s'il ne répond pas aux attentes de la sixième. Les enseignants recommandent une classe spécialisée et les parents s'y opposent. Il devra donc avoir un programme adapté. Enfin, au cours de l'entrevue, Ysabel mentionne que certains élèves sont un peu plus lent que la norme, mais peuvent réussir lorsqu'on leur octroie du temps supplémentaire pour accomplir les tâches. Dans l'ensemble, Ysabel reconnaît que ses élèves forment un groupe de bon niveau; la plupart d'entre eux obtiennent des résultats moyens de cinq sur six et une élève obtient des six sur six dans toutes les disciplines évaluées.

\subsection{Gestion de classe}

\section{Enseignement partagé : co-responsabilité à l'enseignement de tous les élèves de la classe.}

$\mathrm{Au}$ cours de la semaine, il y a deux enseignantes et l'enseignante spécialisée (à certaines périodes) qui interviennent dans la classe. Parce que l'une d'entre elles travaille à raison de 3 jours/semaines. Cela demande une bonne coordination entre les enseignants.

Ysabel enseigne les mathématiques, le français, le bricolage, l'éducation physique et la natation. Nathalie enseigne les mathématiques, la langue française et la musique. Pour le français, Ysabel est responsable de l'écriture, l'orthographe et la grammaire avec les élèves et tandis que Nathalie prend en charge la lecture, la conjugaison et le vocabulaire. Toutes deux enseignent les mathématiques. Ysabel travaille la numération et le calcul. Nathalie travaille la géométrie, la logique et les mesures. Ysabel dit que «c'est plus facile comme ça, chaque enseignant avance à son rythme et fait le test ».

Ysabel et Nathalie se réunissent en moyenne quatre fois par année. Elles s'entretiennent sur l'apprentissage de chaque élève: "qu'est-ce qui va ? Qu'est qui ne va pas ? ». Ensuite, au moins une fois par an, elles rencontrent les parents en dyade. «Pour chaque enfant, on fait une fiche. On se retrouve ma 
collègue et moi, on fait le point ensemble et c'est cette même fiche qu'on utilise pour la réunion avec les parents. Par exemple, s'il y a un élève qui nous semble éprouver des difficultés comme une confusion des lettres, on doit l'envoyer voir un spécialiste (orthophoniste) ».

En outre, elles tiennent un agenda commun afin de faciliter leur communication : «On peut savoir précisément ce que l'une ou l'autre a fait, les élèves le savent. On a là tous les résultats de chaque élève, on note si un enfant est malade ». En plus, l'agenda permet de coordonner les devoirs à la maison. Elles essayent de ne pas dépasser plus de 20 minutes de devoirs par soir.

De plus, elles s'assurent que les élèves n'ont pas plus de deux tests (ou évaluations) par semaine. Ysabel indique « qu'il y a des élèves qui accomplissent leurs devoirs en 40 minutes et d'autres en 10 ». Aussi, de devoirs varient selon les périodes de l'année. «C'est-à-dire, nous avons commencé tranquillement par de petites choses faciles... mais ensuite on rajoute et corse un peu plus».

Il n'y a pas de devoir les lundis et mercredis car il y des parents « qu'il y a des parents qui sont séparés et on estime que si on va a passer le week-end chez eux, ce n'est pas pour faire les devoirs. De plus, les mercredis après-midi sont utilisés pour faire du sport, de la musique, des arts... ».

Chaque vendredi à midi, Ysabel et Michelle (enseignante spécialisée) se réunissent pour planifier la semaine suivante. De cette façon toutes deux savent une semaine à l'avance sur quoi elles travailleront. Michelle travaille avec un petit groupe au sein de la classe s'il s'agit de la même matière ou en dehors de la classe si elle est différente.

\section{$\sim$ Des horaires et la gestion du temps.}

En général, les élèves vont en classe de $8 \mathrm{~h} 30$ à $12 \mathrm{~h}$ et de $14 \mathrm{~h}$ à $15 \mathrm{~h} 30:$ lundi, mardi, jeudi et vendredi. Sauf le mercredi où tous les élèves du canton reçoivent une demi-journée d'enseignement (de 8 h30 à midi). La journée se subdivise en cinq périodes de 45 minutes. Il y a un battement de cinq minutes entre les périodes pour permettre aux enseignants de préparer leur matériel.

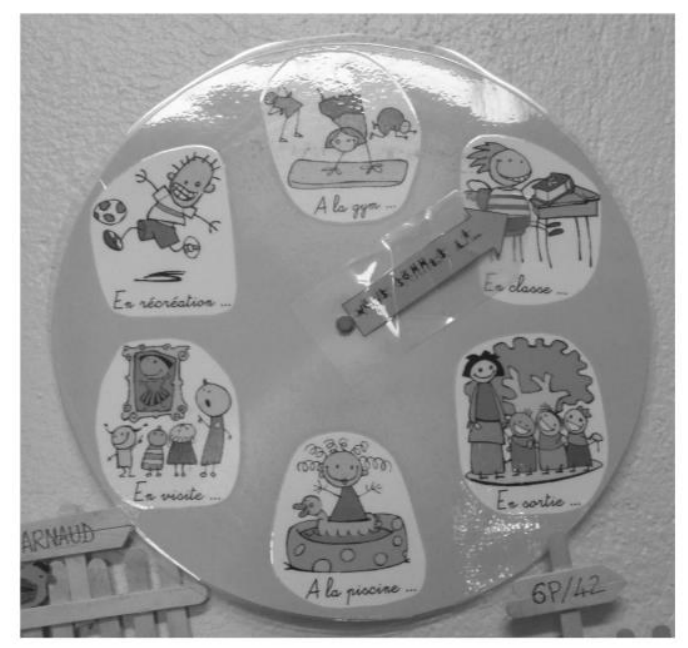

Image 86. Que fait la classe durant ces périodes ? [C4_AM_FOM]. 
Ysabel profite beaucoup du temps. Par exemple, en maths deux élèves qui terminent très rapidement se chargent de corriger les exercices de leurs camarades. Cela permet à Ysabel de consacrer plus de temps aux élèves qui ont besoin d'explications supplémentaires pour réaliser les tâches.

Il y a des moments pendant lesquels tous les élèves font la même chose mais chacun à son rythme. Aux élèves plus rapides : « leur donne quelque chose à faire : ils ont la responsabilité d'expliquer au camarade ou de le corriger, ou bien je leur donne un travail de recherche qui est plus long et que je ne donne pas nécessairement aux autres... Parce que tout le monde doit tous les jours travailler ».

\section{Espaces de travail : à l'intérieur ou à l'extérieur de la classe}

La disposition de la classe soutient différentes modalités de regroupement des élèves ainsi que différentes façons de travailler.
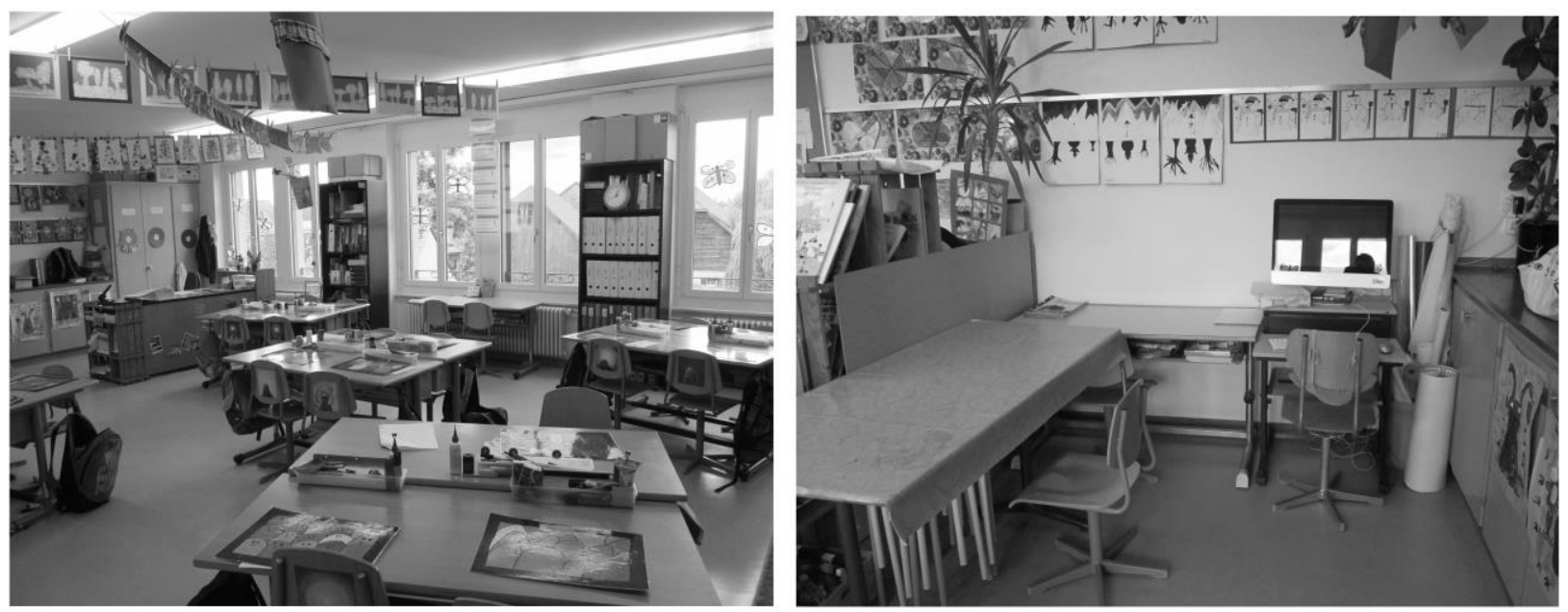

Image 87. Disposition de la classe [C4_O_FO].

" Des espaces alfferents aans la classe me permettent, des fols prenare un groupe juste lcl ou un groupe la. Je peux être en train d'expliquer les maths au tableau avec un premier groupe, tandis qu'un second groupe est avec Michelle et qu'un troisième travaille sur un exercice de recherche ». Des élèves sont répartis dans quatre groupes de quatre élèves et un groupe de trois. Dans la classe il y a deux espaces supplémentaires : une table avec deux chaises qu'utilise Michelle et une table avec des tabourets pour le travail en groupe. Il y a deux espaces supplémentaires hors de la classe. Ils sont utilisés par les élèves pour le travail en groupe ou pour travailler dans un environnement plus calme. 

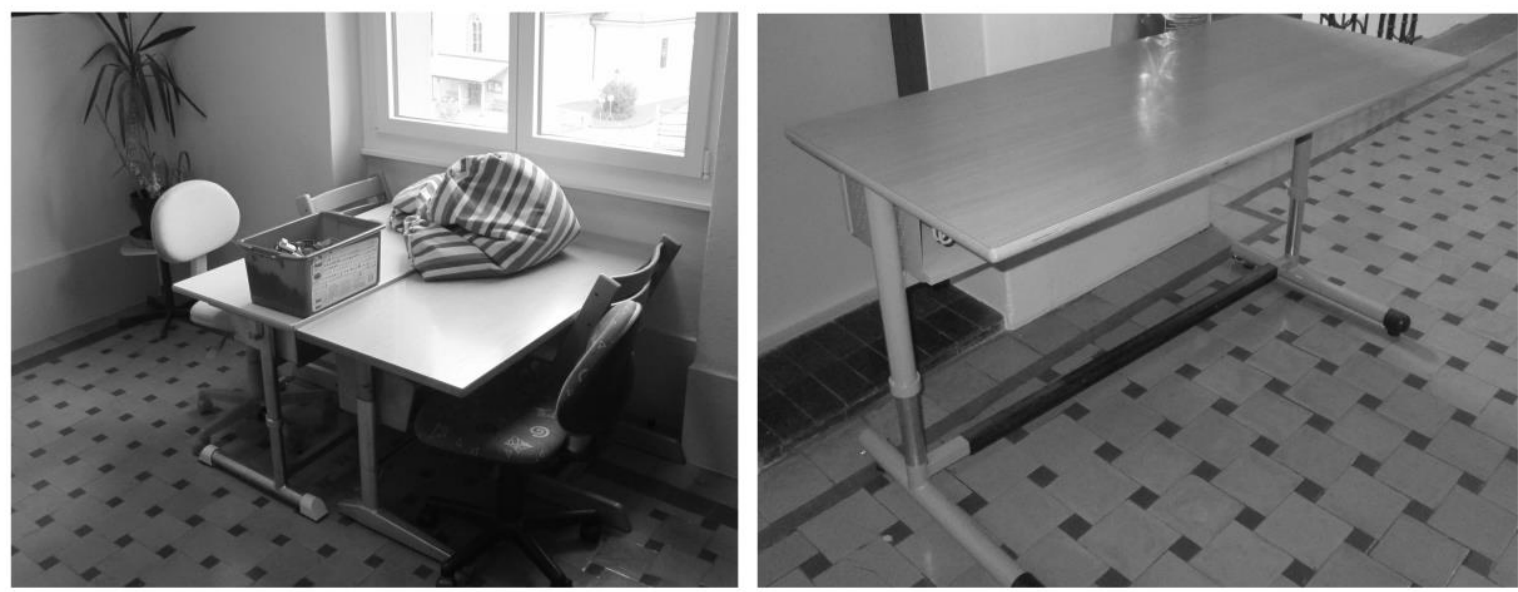

Image 88. Espaces supplémentaires à dehors de la classe [C4_O_FO].

Dans la classe, il y a beaucoup de ressources visuelles. Sur le mur, il y a des fiches sur lesquelles sont regroupés des règles d'orthographe, de grammaire, de mathématiques, etc. Les élèves peuvent ainsi les consulter lorsqu'ils sont à la tâche.
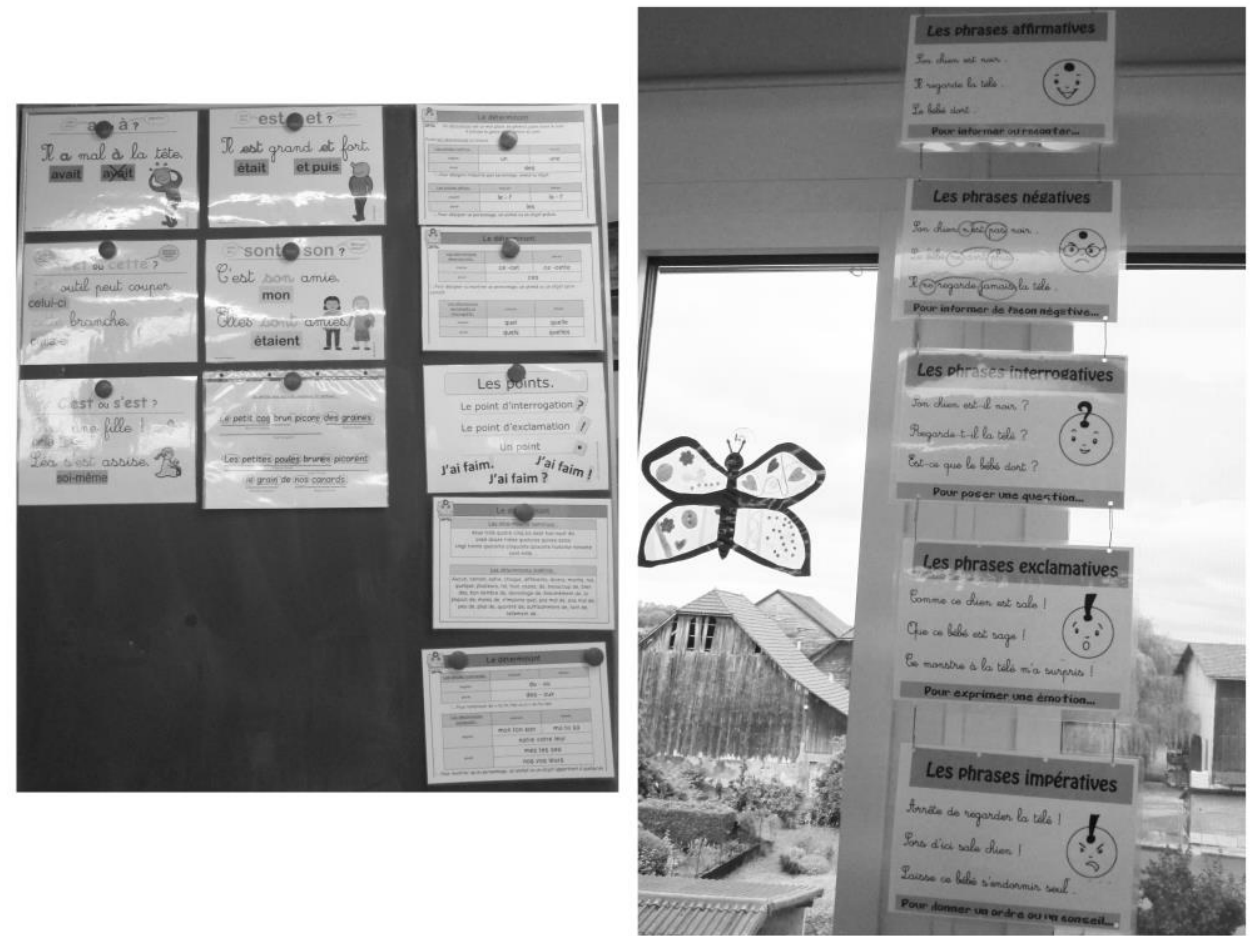

Image 89. Aides visuelles [C4_AM_FOM].

\section{$\sim$ Regroupements : nous apprenons tous des autres}

Les élèves sont placés dans des groupes mais ils ne travaillent pas tous les jours avec les mêmes camarades. Avant les vacances, des élèves changent de place s'il y a un quelconque problème de comportement. Il y aussi des changements ponctuels qui peuvent s'effectuer lorsque le besoin se fait sentir. 
Ysabel utilise différents types de groupe (par exemple une classe entière, de petits groupes, des binômes, chacun en autonomie etc.) selon la nature des activités et les buts qu'elle poursuit. Plus spécialement en mathématiques, des élèves peuvent travailler en autonomie, en dyade ou encore en équipe de trois ou quatre élèves. Ysabel explique " la disposition de la classe permet de travailler en groupe, une chose que j'aime beaucoup ».

Elle exploite aussi des groupes hétérogènes où des élèves plus performants sont jumelés à des élèves qui éprouvent des difficultés. "Souvent il y a un élève avec un niveau un peu plus faible à côté d'un plus fort, comme ça je peux dire 'explique à ta copine'. Parfois les explications des enfants sont meilleures que les miennes parce qu'ils le disent avec leurs mots... peut-être qu'ils ne comprennent pas ma façon d'expliquer parce que je suis très compliquée ou parce qu'ils ont relevé quelque chose que je n'ai pas pensé à dire parce que c'était évident pour moi ».

En français, par exemple, ils font la lecture pour toute la classe en petit groupe : « 5 livres différents sont lus en même temps. Chaque groupe doit partager sa lecture avec toute la classe, ils doivent faire découvrir le livre à l'autre... ». Ils travaillent ensemble une notion pour la présenter à la classe, chacune des équipes doit présenter un animal au reste de la classe.

Parfois en grand groupe, ils découvrent ensemble une nouvelle notion et Ysabel prend un petit groupe (qui a des difficultés) pour travailler un matériel plus concret. Ysabel explique que « travailler en petit groupe de 4 élèves te permet de voir les difficultés de chacun et de connaître leur niveau ». Elle fait des groupes en fonction des difficultés qu'éprouvent les élèves.

Ainsi, elle remarque plus facilement que les élèves du groupe vert doivent approfondir la technique de la multiplication. Le groupe jaune doit travailler le passage entre des unités et des dizaines etc.

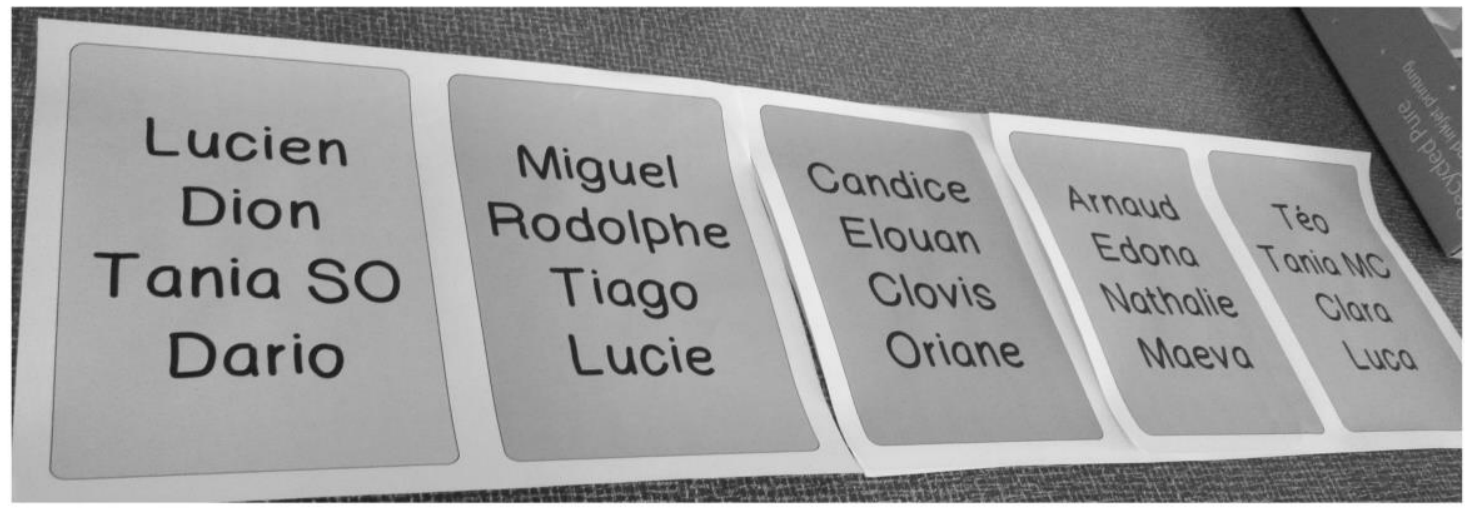

Image 90. Groupes de difficultés de maths [C4_AM_FOM].

«Je les appelle, les jaunes vont travailler, les oranges vont aller un moment avec Michelle ou bien faire telle activité avec moi ». Les groupes ne sont pas permanents, ils changent selon la difficulté et la matière. Les élèves savent seulement que ce sont des groupes de couleurs. 
Cela permet à la maîtresse d'appui ainsi qu'à Ysabel de dire à tous les élèves ayant la même difficulté comment il est possible de retravailler cette difficulté, le pluriel du verbe par exemple, avec un matériel qui est différent, de façon différente... Ysabel considère que cette modalité de regroupement lui permet réellement de s'adapter aux besoins de chacun.

\section{$\sim$ Responsabilités des élèves pour le bon fonctionnement de la classe.}

Chaque semaine, sont données à six élèves différentes responsabilités pour le bon fonctionnement de la classe. Par exemple, lors de la semaine d'observation :

- Lucie était la préposée pour le vieux papier.

- Téo était le chargé de contrôle de devoir.

- Clara était la préposée pour contrôler les vestiaires du gymnase.

- Elawan le chargé de distribuer et ramasser.

- Nathalie était la préposée pour arroser les plantes et nettoyer le tableau noir.

- Armand le chargé de nettoyer.

Il y a un élève de substitut dans le cas où un élève préposé serait absent.

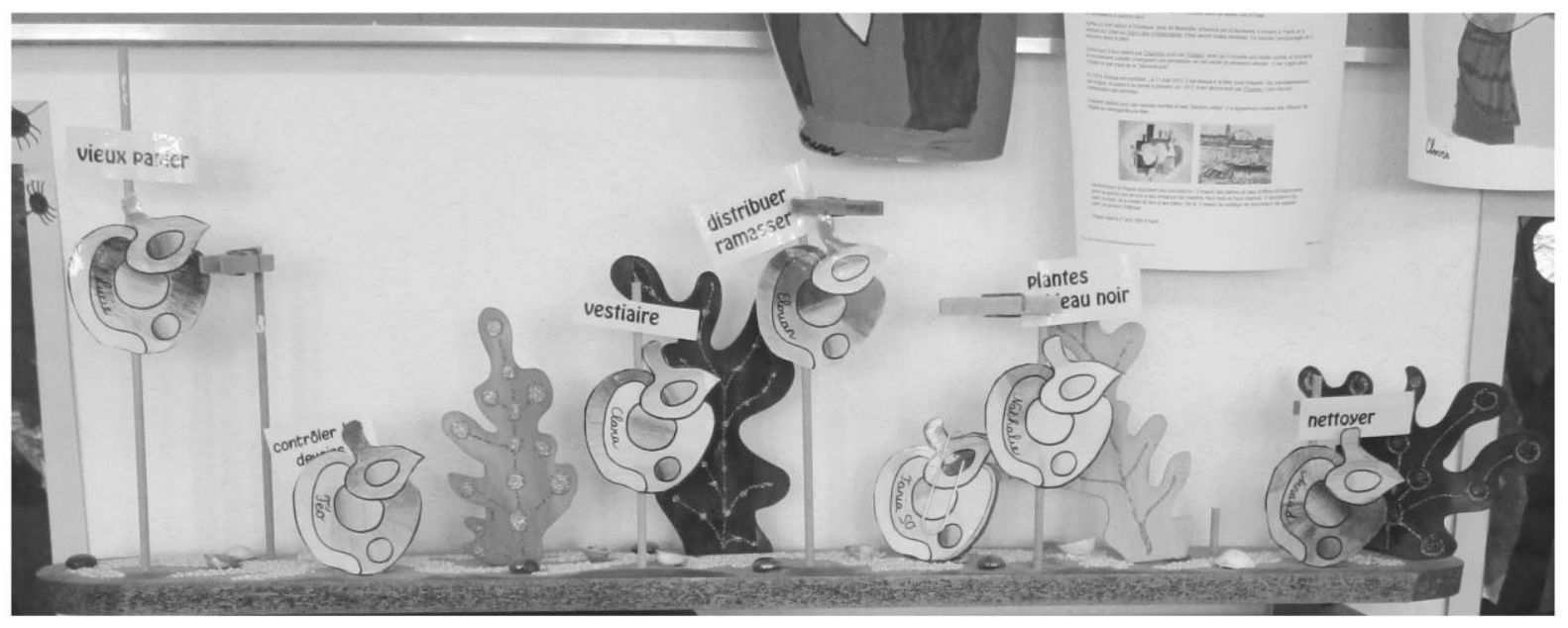

Image 91. Responsabilités des élèves [C4_O_FO].

\section{$\sim$ Communication : enseignante - famille}

Les principaux outils qu'Ysabel utilise pour communiquer avec la famille sont l'agenda de chaque élève et l'application WhatsApp.

Chaque semaine, les parents doivent obligatoirement vérifier et signer l'agenda. Les enseignantes y consignent plusieurs informations : celles relatives aux devoirs, aux notes ou appréciations obtenues (par exemple celles reçues lors de l'évaluation de lecture), aux sorties, aux spectacles etc. Elles traitent également des retards et des oublis des élèves, s'ils oublient leurs affaires de sport ou leur 
matériel scolaire. Elles s'occupent également des retards et des oublis des élèves, pour noter s'ils oublient leurs affaires de sport ou leur matériel scolaire. Souvent, les deux enseignantes téléphonent aux parents pour les informer de ce qu'il passe, notamment si les devoirs ne sont pas faits. Si un devoir n'est pas effectué au bout de la troisième ou quatrième fois, il y a une punition : il s'agit d'un travail supplémentaire à faire à la maison. Au moyen de l'agenda, les parents peuvent demander un entretien avec les enseignantes ou inversement, les enseignantes peuvent demander un entretien avec les parents pour s'entretenir avec eux sur quelque sujet que ce soit.

En plus de l'agenda, il y a un groupe WhatsApp. «Par exemple, si nous allons faire du bricolage et que j'ai besoin de marteaux, j'envoie un WhatsApp: 'Merci, de mettre un marteau dans le sac de votre enfant'. Nous partageons aussi des photos, si un enfant est malade. C'est un bon outil quand on l'utilise bien ».

\subsection{Méthodologie de travail : différentiation, matériel et évaluation}

\section{$\sim$ La concrétisation du plan d'études romand dans la classe}

Comme nous l'avons évoqué précédemment, les cantons romands font référence aux régions administratives où le français est la langue officielle. L'ensemble de ces cantons s'est doté d'un plan d'études commun dénommé le plan d'études romand (PER). Ysabel y fait allusion : "Je base ma manière d'enseigner dans les nécessités d'apprentissage de mes élèves, ainsi que dans le PER. Parce que pour moi c'est important qu'ils réussissent grâce à plusieurs méthodes ». Les objectifs sont les mêmes pour tous les élèves. Ils ne sont pas adaptés en fonction des besoins des élèves; cependant les moyens pour y parvenir sont adaptés aux besoins de chacun. Voilà pourquoi les élèves réalisent différentes productions ou présentations sur ce qu'ils ont appris en tenant compte de leurs besoins ou préférences d'apprentissage. Il y a certaines libertés. Ce n'est pas encore complètement à la carte. Par exemple, tous doivent faire une exposition mais chaque élève peut choisir le moyen et le thème. Ysabel ajoute « cette année 2015/2016, je n'ai pas d'élève avec un programme adapté. Il y a un élève de la classe qui, l'année prochaine, n'aura pas le même programme que les autres. Il aura le même livre, le même manuel, le même cahier, mais on ira peut-être pas aussi loin que les autres, parce que les bases ne sont pas encore consolidées ». " Alors, quand j'ai une nouvelle classe, je découvre qui va à rester au minimum, avec qui je dois travailler plus mais normalement, on a tous les mêmes objectifs ».

\section{$\sim$ Reconnaissance de la diversité dans la classe}

«J'explique à mes élèves que, dans la tête, l'intelligence est comme une pelote de laine. Parfois, ce n'est pas que nous ne sommes pas intelligents, c'est simplement que l'on n'a pas encore trouvé le bout de la pelote. Une fois qu'on l'a trouvé, on tire, on tire, on tire... ça roule! Nous avons toutes les idées! Souvent les élèves disent " je ne trouve pas le fil » et c'est pour cela que l'on cherche ensemble...» 
"Il est certain qu'ils n'apprennent pas au même rythme mais je sais qu'avant Noël, on doit avoir vu la multiplication. Cela ne signifie pas que la première semaine de décembre tout le monde fait la multiplication. Le rythme est le même pour tout le monde, mais avec une certaine liberté à l'intérieur. Quand tu vois un problème chez l'enfant, tu te dis : qu'est-ce qui ne marche pas? Pourquoi ça ne marche pas? Alors, tu dois trouver une autre manière d'exercer : ça peut-être un matériel different, une quantité d'exercices différentes, du temps supplémentaire... Par exemple, j'ai dans la classe un élève qui est brillant en maths mais qui est très lent, il a donc besoin du temps supplémentaire. De plus, il y a certains élèves qui, si je demande de faire 4 exercices, ne vont en faire que deux ou trois. Je leur dis donc : c'est bon tu as compris, passe à la feuille suivante. Pour ceux que tu n'as bien compris, je te donne une feuille supplémentaire. Elle n'est pas pour toute la classe, c'est un travail de notre part ».

\section{$\sim$ Langue française : production écrite et lecture}

Chaque élève a un cahier d'écrivain. Il a 15 jours pour écrire son texte. Dans la semaine qui précède, Ysabel donne la consigne, le défi d'écriture.

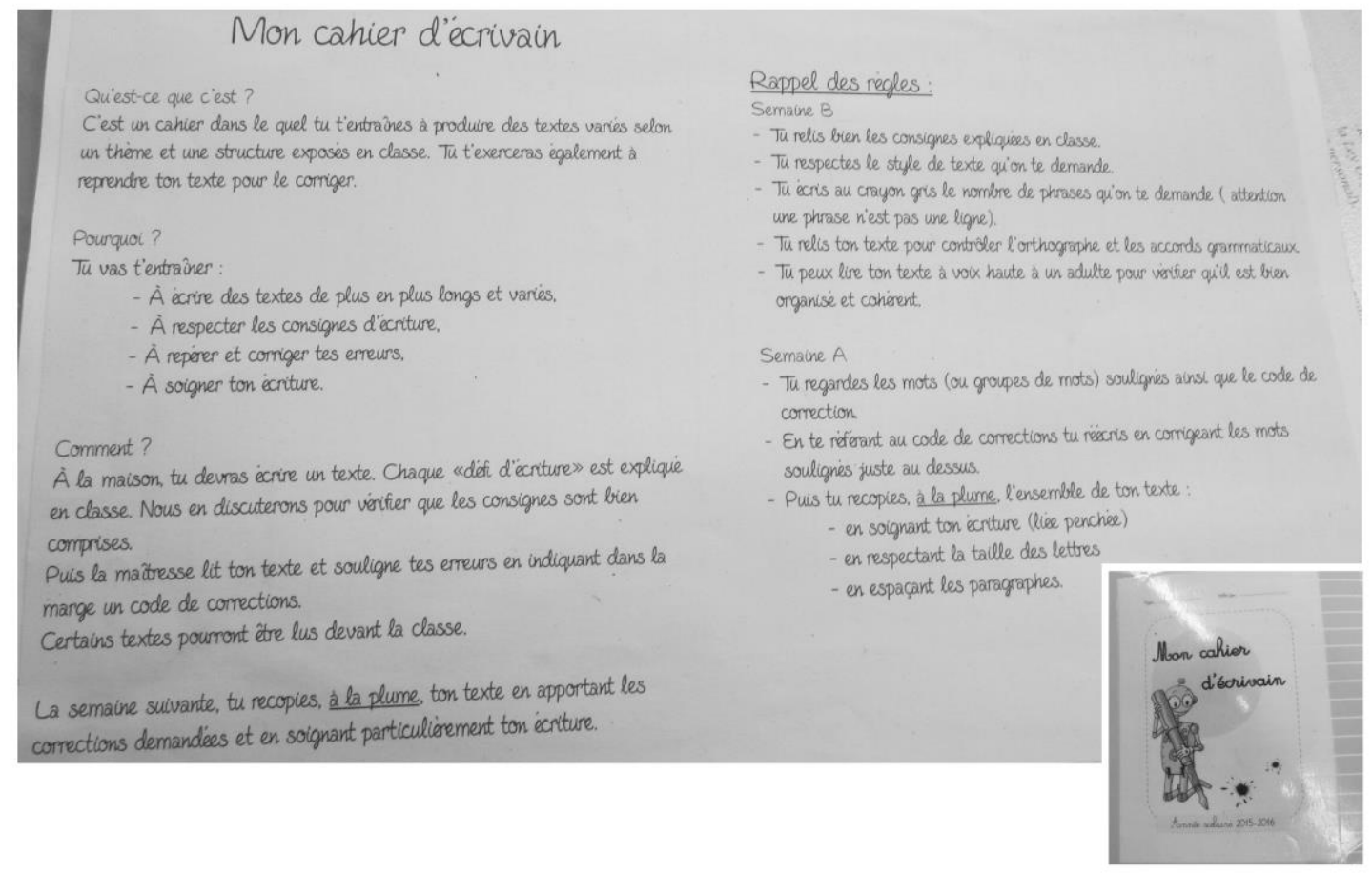

Image 92. Mon cahier d'écrivain [C4_AM_FOM].

Par exemple, le jour de l'observation les élèves doivent s'acquitter du défi d'écriture $n^{\circ} 17$ : écrire une lettre pour un nouvel élève de la classe de 5P-6P. Chaque élève déposera sa lettre sur le pupitre du nouvel élève qui pourra en prendre connaissance lors de son arrivée.

Avant d'entreprendre le travail d'écriture, Ysabel effectue un travail de préparation collectif : « qui a une idée? qu'est-ce que tu vas mettre ? Je vais parler de la gym... " Ysabel ajoute "Il y a une petite fille qui est très bloquée, elle n'a pas d'idée. Donc l'année dernière on a fait un cahier de jogging d'écriture. C'est-à-dire que je mets une consigne dans le tableau, très facile et simple : écris le nom de choses qui sont bleues. Pendant 5 
minutes, ils doivent écrire, écrire, écrire... des choses qui peuvent être bleues. Ensuite on s'attaque aux phrases, puis aux descriptions (décris ta maison, ta famille, ton animal...). Cette année on travaille vraiment sur la réalisation de textes ». Ysabel donne du travail et les élèves s'organisent. C'est un travail qu'ils font à la maison mais l'enseignante fait un petit sondage au cours de la semaine : «Qui a avancé ? Où en es-tu? Comme tu as procédé ? Il y a quelqu'un de bloqué ? Est-ce qu'il y a quelqu'un qui n'y arrive pas?»

Dans la semaine qui suit, chaque élève prépare un avant-projet du texte. Ysabel utilise différents bâtons sur lesquels le nom de chacun des élèves est écrit. Ces bâtons déterminent l'ordre de passage des élèves, pour lire les textes qu'ils ont produits. Ses camarades donnent ensuite des conseils ou font des suggestions pour améliorer chaque texte : information qui manque dans le texte, le temps verbal... Tous les élèves de la classe lisent le texte et prennent note des points à revoir ou améliorer. Quelques élèves tapent le texte à l'ordinateur, d'autres l'écrivent à la main. Ysabel leur explique que tout le monde doit écrire le texte final à l'ordinateur. Celui qui ne peut pas l'imprimer peut le mettre dans une clé USB ou aller chez un camarade.
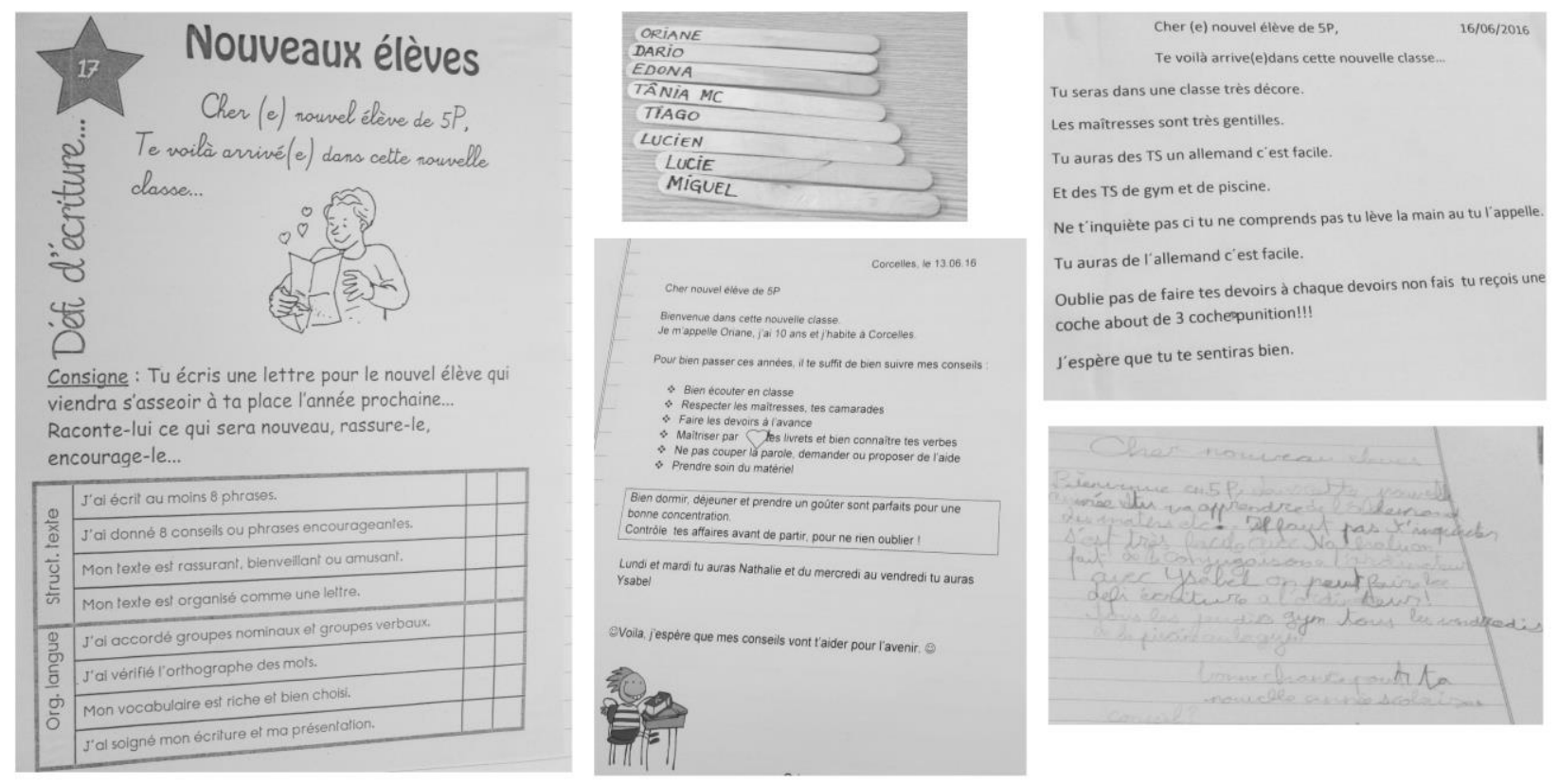

Image 93. Défi d'écriture $\mathrm{n}^{\circ}$ 17, bâtons avec le prénom de chaque élève et quelques textes des élèves [C4_AM_FOM]. 
Ysabel prend chaque texte et pointe les erreurs suivant le code de correction des productions écrites. Elle retourne le texte à chaque élève et ils font les corrections.

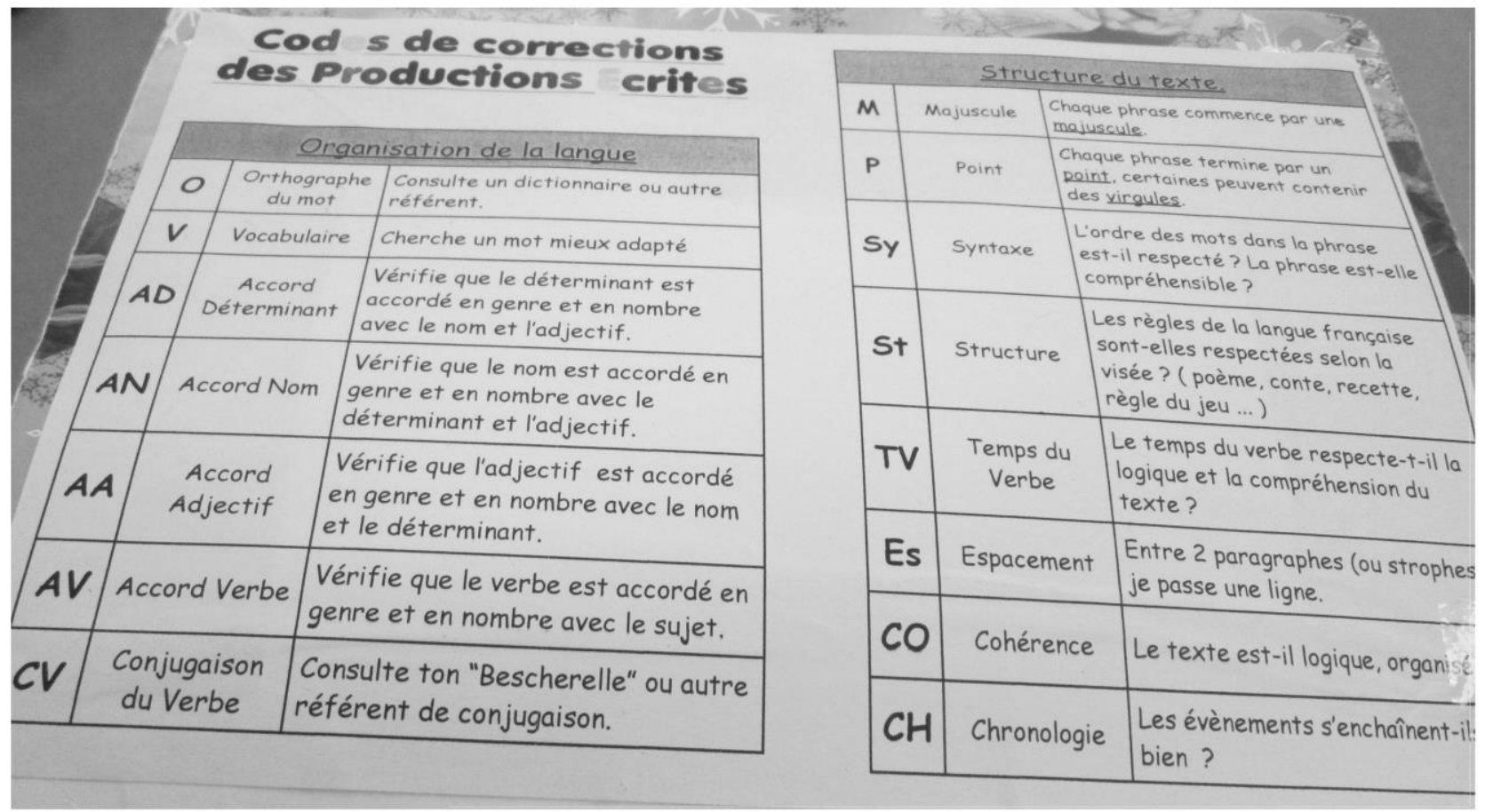

Image 94. Code de correction des productions écrites [C4_AM_FOM].

L'enseignante corrigera le texte une seconde fois avant que l'élève ne puisse taper le texte à l'ordinateur et le laisser sur le pupitre du nouvel élève.

L'ardoise est un matériel souvent utilisé par les élèves, Ysabel précise que « ça te permet d'utiliser moins de papier et en un coup d'œil, je peux tout de suite voir qui a compris et qui n'a pas compris. Comment s'écrit le mot... ? Qu'est-ce que c'est? : un verbe, un nom... ? Je vais chercher toutes les réponses incorrectes et je vais les montrer aux autres : pourquoi cette réponse est-elle fausse? Tout le monde peut donner une explication. On apprend beaucoup des erreurs des autres ».

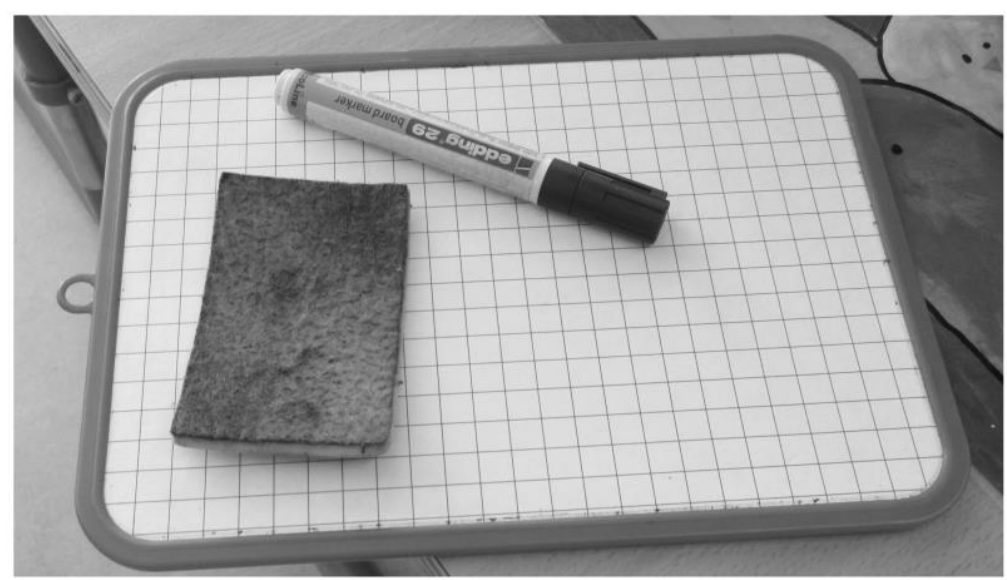

Image 95. Ardoise [C4_AM_FOM]. 
Tous les jours après la recréation (10h30), chaque élève prend un livre dans la bibliothèque de la classe. Ils ont le droit à 10 minutes de lecture pour le simple plaisir de lire. L'enseignante lit aussi son livre personnel dans son bureau. Quelques enfants parlent ou commentent à voix basse quand ils vont prendre le livre. Ils choisissent eux-mêmes leur livre.

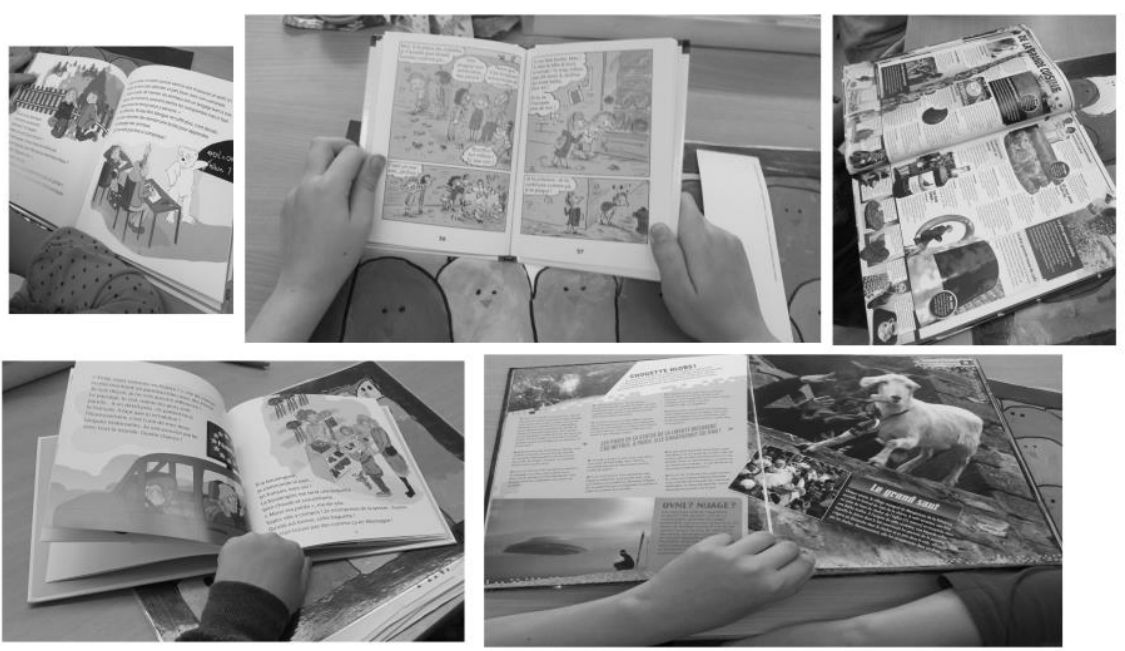

Image 96. Lecture pour le plaisir [C4_O_FO].

Ysabel ajoute que « De temps en temps, nous (ma collègue et moi), comptons une histoire à voix haute. C'est une lecture un peu plus compliquée et littéraire. Il y a des livres comme Momo, petit prince des Bleuets, Le Petit Prince, le Secret de Terabithia... que l'on montre en vidéo ou en film à la fin de l'année ».

Pour renforcer l'enseignement déjà dispensé, Michelle travaille en général avec un petit groupe en utilisant un autre matériel ou support. Par exemple, le jour d'observation, Michelle a travaillé le français avec un groupe de 4 élèves hors de la classe. Elle utilise un matériel plus visuel et qui réclame des manipulations.
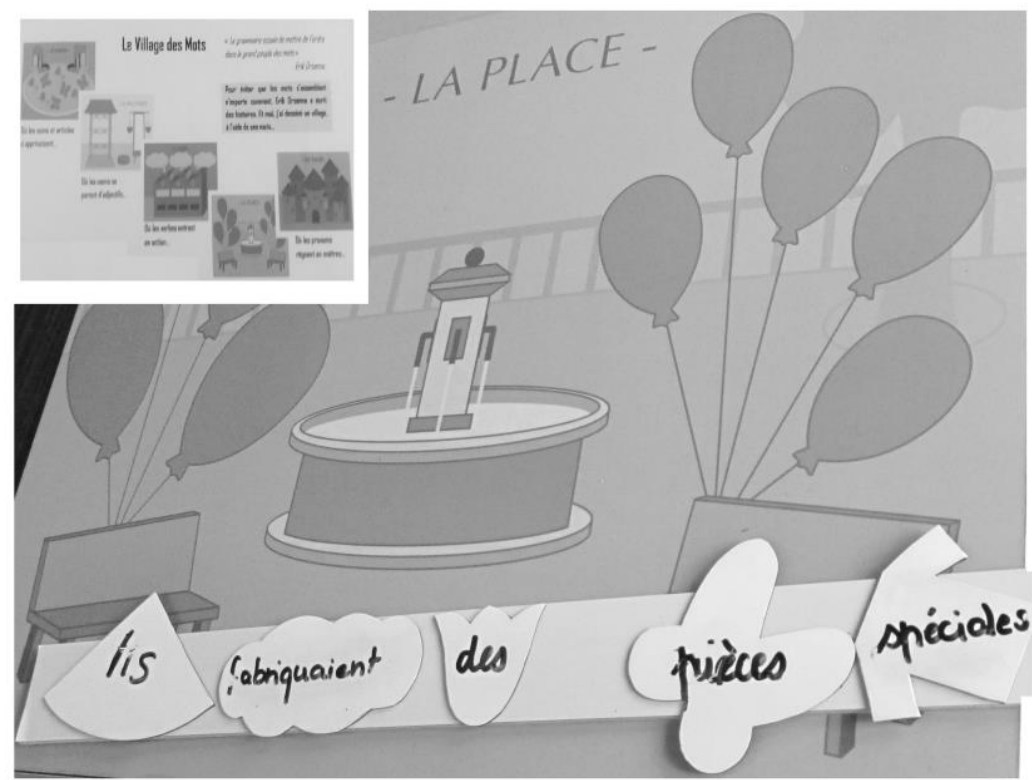

Image 97. Matériel visuel et manipulateur : Le Village des Mots [C4_AM_FOM]. 
Pendant ce temps-là, les élèves en classe travaillent le dossier de maths, chacun à leur rythme.

\section{$\sim$ Mathématiques : différentes techniques ou méthodes pour arriver à la même solution}

Les élèves et l'enseignante réalisent des corrections collectives des devoirs. Chaque élève a sa fiche de maths et l'enseignante dit à voix haute la solution. Celui qui a des doutes lève la main et demande une explication. "Pour la correction collective, soit je place l'élève qui a plus difficulté à côté de moi parce qu'il n'arrive pas forcément à suivre lorsque l'on corrige à l'oral, soit je le prends tout le temps à côté de moi et lui montre avec mon crayon... ". Chaque élève écrit "corr. coll". Ça veut dire : correction collective, mais attention, ce n'est pas l'enseignante qui a corrigé.

Dans la classe d'Ysabel, ils passent beaucoup de temps à faire des corrections collectives. Elle explique "Je demande à chacun de me donner sa technique. Je ne dis pas qu'il faut faire de telle ou telle manière. Je vérifie simplement la technique, ils me l'expliquent et ensuite chaque élève peut choisir :j'aime faire comme ça ou je préfêre faire comme ça. Des élèves se rendent compte qu'il y a différentes façons de faire et certaines peuvent être plus rapides et plus sûres, sans erreur. Donc on explique ces techniques ».

Par exemple, ils résolvent une multiplication de trois manières différentes. Ysabel explique «On compare les techniques d'apprentissage, je n'oblige pas à en utiliser une seule. Le plus important c'est qu'ils arrivent à faire leurs multiplications. Il y a des élèves qui les font en ligne, d'autres de tête ou par additions successives ». Un élève résout la multiplication au tableau. L'enseignante demande s'il y a une manière plus rapide et un autre élève propose. Ysabel donne aussi d'autres façons de faire. Elle répète parfois qu'ils peuvent utiliser différentes techniques ou méthodes pour parvenir à la même solution.

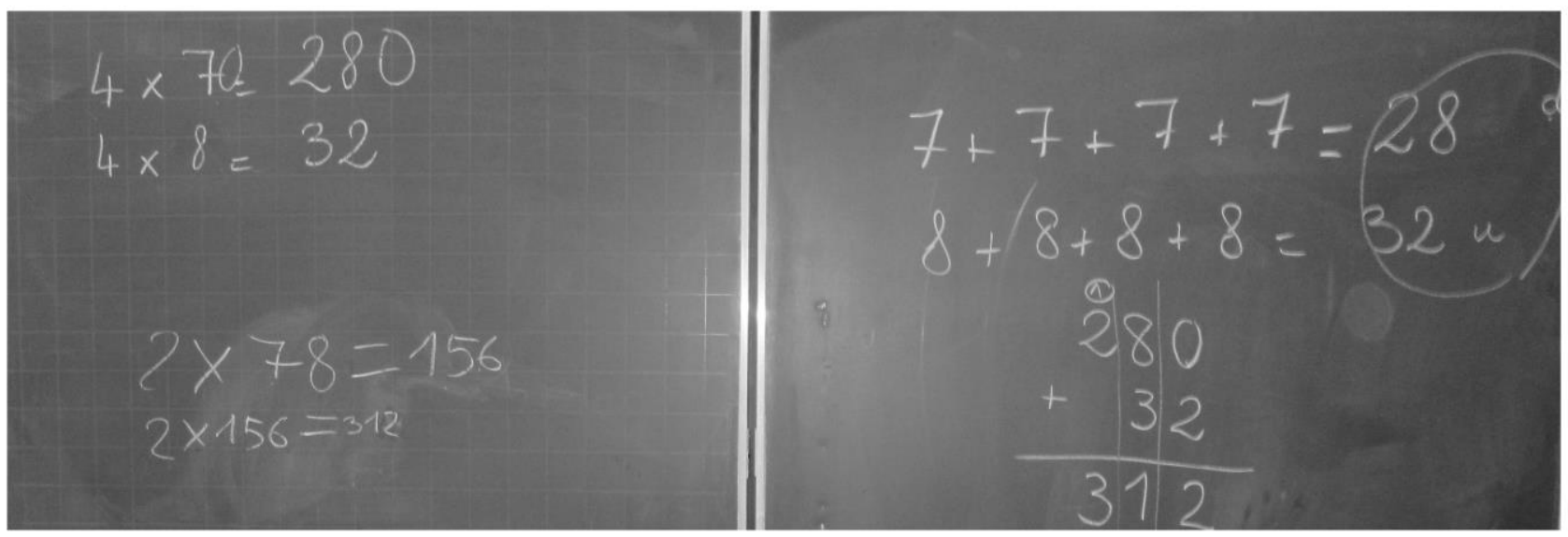

Image 98. Trois façons d'arriver à un même résultat [C4_O_FO].

Ensuite chaque élève travaille son dossier de maths, ils possèdent les mêmes fiches de maths mais c'est chacun à son rythme. 

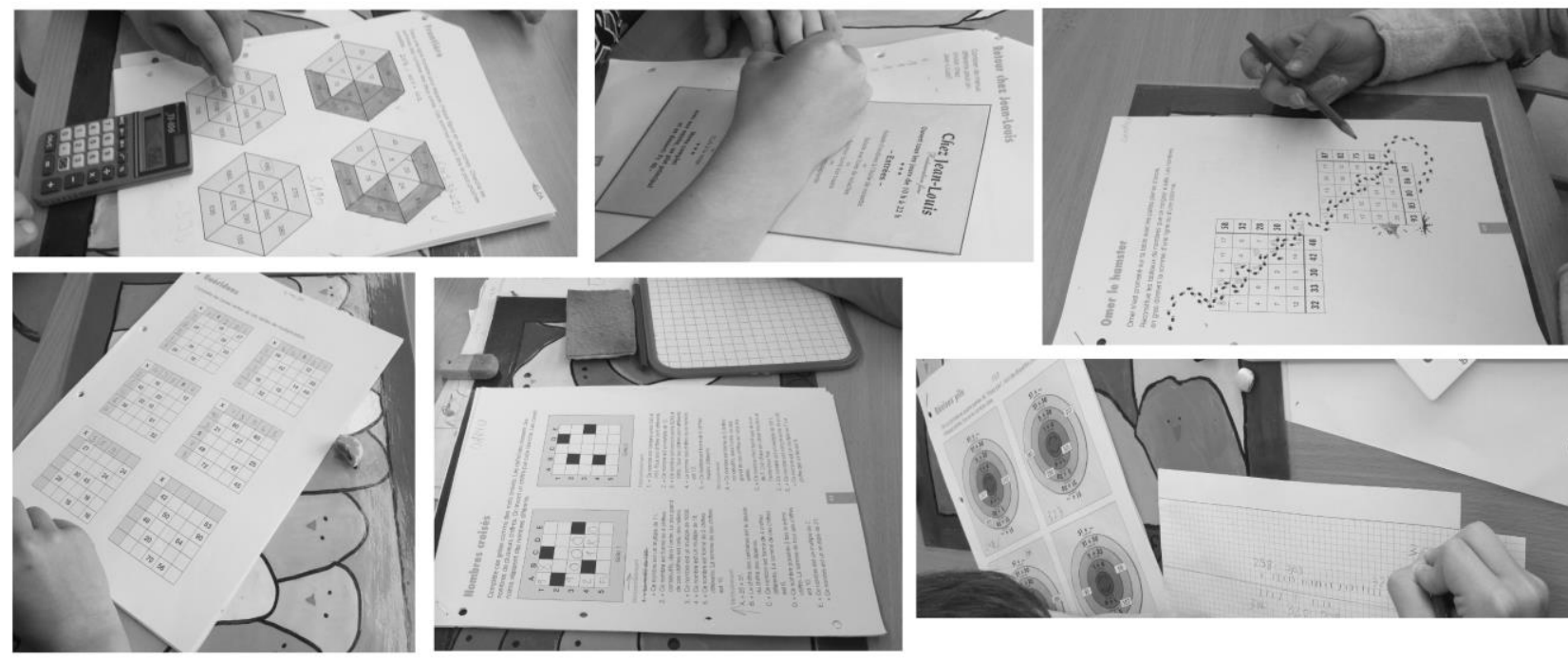

Image 99. Dossier de maths [C4_O_FO].

Il y a des élèves qui finissent très rapidement alors ils corrigent des exercices de leurs camarades. Leurs exercices à eux ont déjà été corrigé par l'enseignante. Pendant ce temps, Ysabel peut être à son bureau et corriger ou expliquer un exercice plus compliqué à d'autres élèves. Michelle fait de même sur une petite table, ou bien elle passe dans les rangs pour s'attarder plus particulièrement aux les élèves qui ont besoin d'aide. Il y a quelques élèves qui utilisent la calculatrice, d'autres non : voilà un élément de différenciation. Les feuilles des dossiers sont agrafées. Quand ils les terminent et qu'elles sont corrigées, ils les laissent sur la table d'Ysabel.
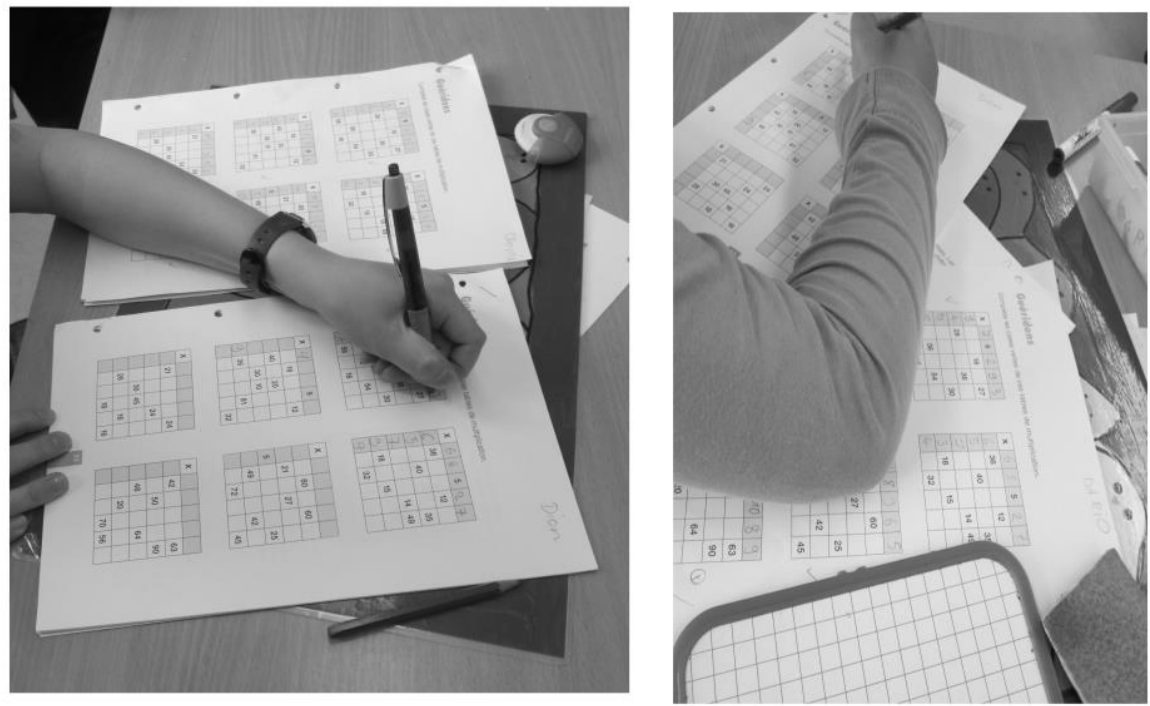

Image 100. Élèves correcteurs [C4_O_FO].

Pour les mathématiques, Ysabel utilise aussi l'ardoise. De plus, elle a fabriqué différents matériaux de manipulation pour les élèves ayant besoin d'aide. Ysabel explique «Il n'y a rien qui soit systématique. Quand je vois un élève qui éprouve une ou plusieurs difficultés, j'essaye de savoir si cela fonctionne ou non. C'est 
comme un fauteuil roulant, pour aller d'ici à là. Ce n'est pas obligatoire pour tout le monde. S'il n'a pas compris, je trouve un autre moyen ». Ysabel utilise aussi d'autres méthodes avec ces élèves en difficultés.

$\sim$ Ecrire un nombre : « Je dis : écrivez-moi le numéro 1.258. Ils doivent choisir : 1.000, 200, 50, 8 ".

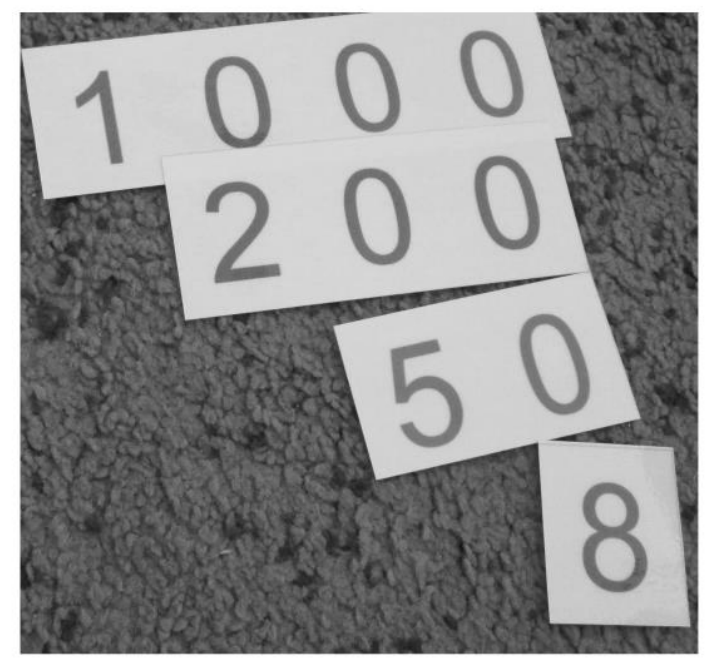

Image 101. Écrire le nombre 1.258 [C4_AM_FOM].

Ils peuvent voir qu'il y a une couleur pour les unités (de 1, de mille), une pour les dizaines, une pour les centaines, une pour le million. De plus, il y a les dizaines de mille, les centaines de mille...

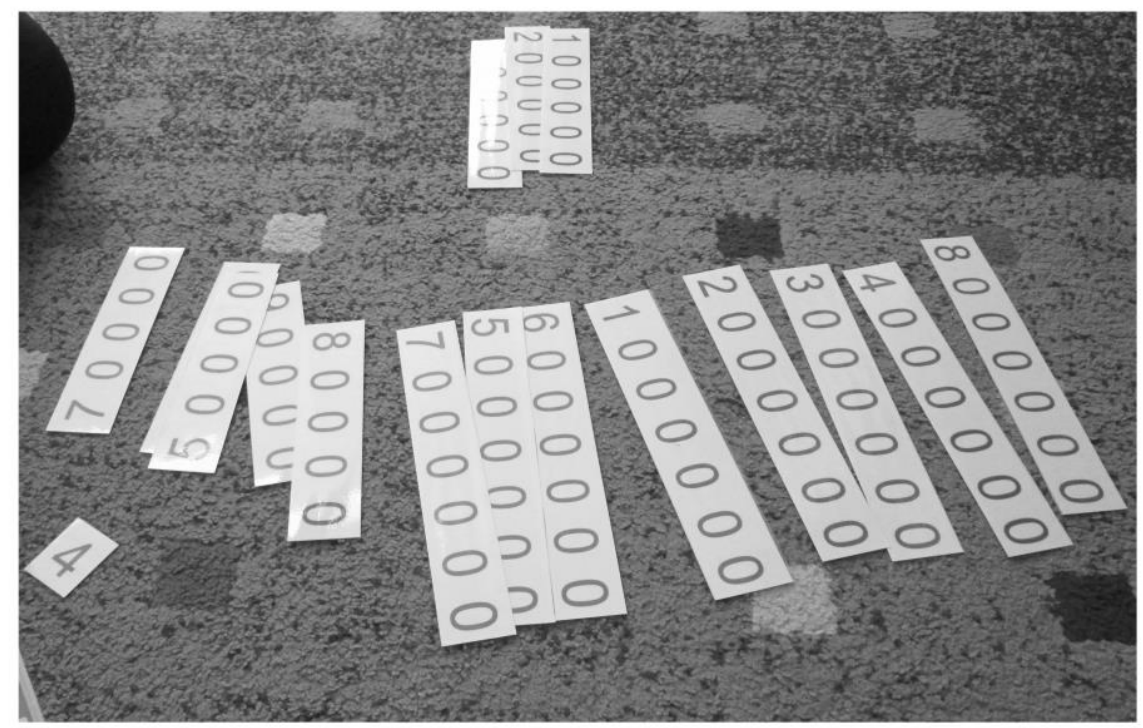

Image 102. Matériel pour construire des nombres [C4_AM_FOM]. 
L'enseignante a fabriqué cet autre matériel pour travailler les unités, les dizaines, des centaines et les milliers.

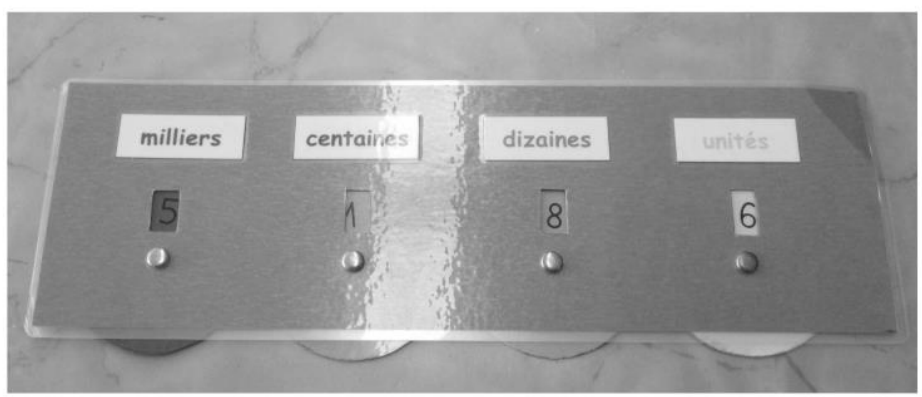

Image 103. Matériel pour travailler les unités, les dizaines, les centaines et les milliers [C4_AM_FOM].

$\sim$ Cubes: Une fois qu'on a écrit le numéro, on prend le matériel d'une autre classe pour faire la comparaison. Il y a des élèves qui font ça tout seuls sur leur bureau et d'autres qui vont à la table de maths, ceux-là font le même exercice que les autres, mais avec l'outil en plus.

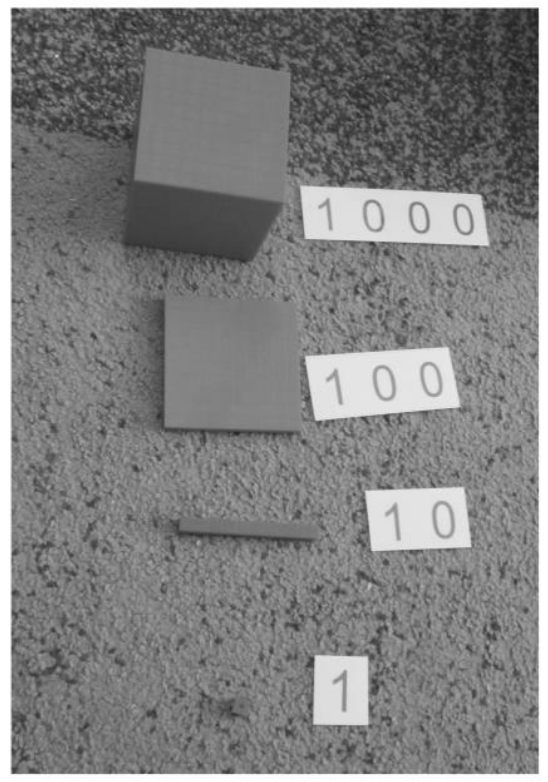

Image 104. Cubes [C4_AM_FOM].

$\sim$ Jeu de la multiplication : l'élève possède des cartes avec des nombres qui représentent le résultat d'une certaine multiplication. A partir d'une d'entre elles, l'élève doit réfléchir et placer les pingouins sur deux chiffres du plateau de jeu (la banquise). Ces chiffres-là, en les multipliant, doivent correspondre à la somme inscrite sur la carte qu'il a choisi. Il y a quelques cartes joker :

- L'esquimau te permet de déposer une carte sur la banquise.

- Attention l'ours t'empêche de déplacer ton pingouin !

- L'épaulard t'oblige à piocher une carte de la banquise !

- L'ours ne peut pas t'atteindre grâce à ton igloo! 
- Tu peux déplacer un second pingouin!

La partie se termine lorsqu'il n'y a plus de cartes. Ysabel ajoute «Ce jeu me plaît parce que, à l'inverse des autres jeux où l'on doit chercher le résultat à partir de deux nombres, dans ce jeu, on te donne dès le départ le résultat et tu dois chercher les nombres à multiplier pour l'obtenir. C'est à l'envers. ».
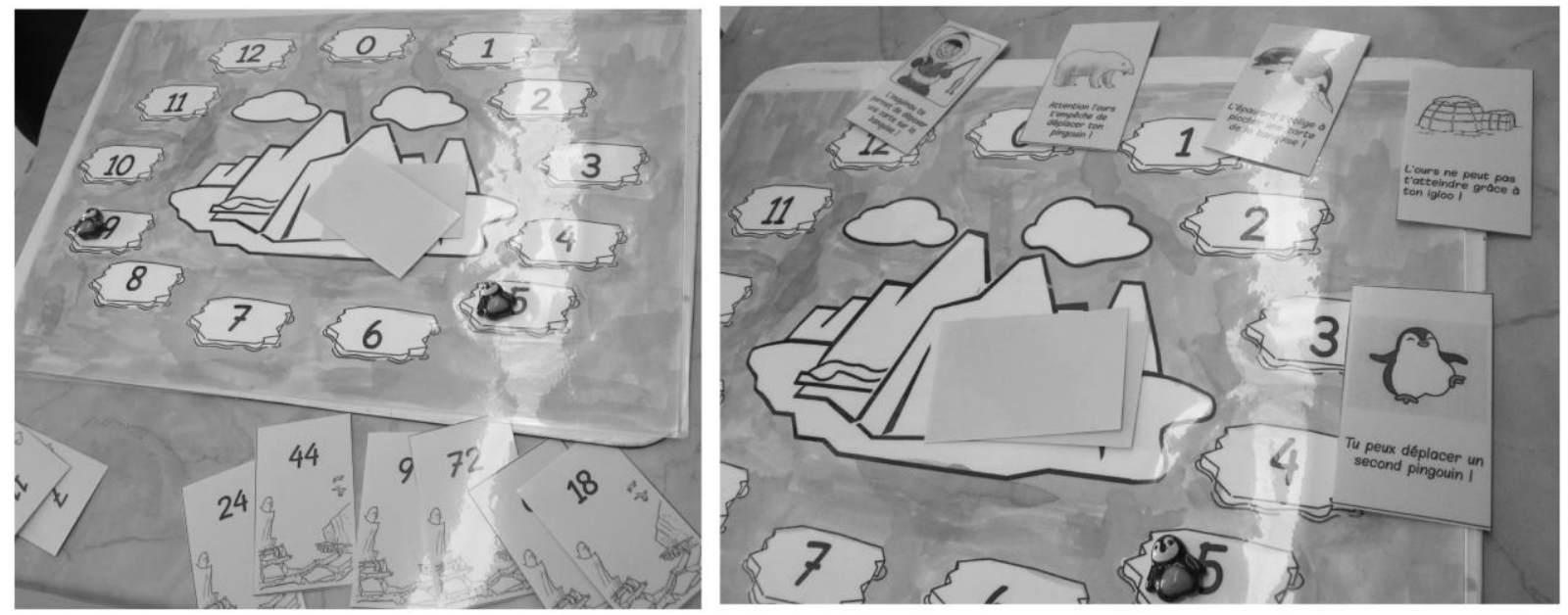

Image 105. Jeu de la multiplication [C4_AM_FOM].

En mettant en évidence les différents matériaux utilisables, Ysabel dit "Voilà les différentes techniques ou matériaux pour les exercices de multiplication. Chacun va utiliser celui qu'il préfère. C'est vraiment ça, la différenciation. Tout le monde fait le même exercice mais pas forcément avec le même matériel ».

\section{$\sim$ Évaluation}

Ysabel explique: " je ne suis pas d'accord avec les notes. Je préférais que l'on mette juste une appréciation qui dirait si c'est compris ou non, ou bien si c'est en en cours. Je sais qui n'y arrive pas ou bien qui a du mal à se lancer. Certains élèves ayant beaucoup de capacités ne travaillent pas. Ils ne font rien pour obtenir leur 6. Les notes n'ont pas de vraie valeur pour moi. Mais on se trouve dans un système qui utilise les notes... Ma collègue pense la même chose ». "Donc je peux respecter dans une certaine mesure le rythme de chacun mais je ne peux pas aller là où tous sont arrivés ".

"Je pars de ce qu'ils savent déjà, avant d'initier une unité. En général j'évalue l'apprentissage des étudiants à la fin d'une séquence d'enseignement. Mais si je vois qu'ils ne m'ont pas comprise je vais ajouter de petits exercices. Je vais évaluer avec les mêmes critères de notation, mais parfois je vais laisser plus de temps à une élève ou bien mettre le matériel à disposition. Cependant cela change la note: tu ne peux pas avoir un 6 si tu n'as pas fini pendant le temps supplémentaire. Tu peux obtenir un 5,5. Ce n'est pas vraiment different, mais en même temps il y a une différenciation ».

Il y a des choses que l'on ne peut pas évaluer à l'oral ou à l'écrit : la poésie, par exemple. S'il se trouve que quelqu'un ne comprend pas le texte, «j'utilise les playmobil de mes fils. Je dessine un décor avec une liste de consignes que l'élève va lire. De cette façon, il va à mieux comprendre ». Parfois j'enregistre aussi la lecture d'un texte puis je l'évalue à la maison. Une année j'avais un élève très dysorthographie et 
très dyslexique. Il avait une espèce d'ardoise et des lettres qu'il pouvait monter. Il faisait les phrases comme les autres, avec le mot écrit et la lettre à montrer. Ça peut être une différenciation. « J'ai aussi un élève qui souffre de dyspraxie et qui n'arrive donc pas à écrire. Il utilise l'ordinateur pour certaines productions ».

Cette année parmi les productions écrites, certaines sont tapées à l'ordinateur parce qu'ils sont difficiles au niveau de l'orthographe. Après «je souligne en rouge ce qui est faux et ils doivent chercher dans le dictionnaire pour la correction ».

Il y a ce qu'on appelle les épreuves cantonales de référence, c'est un travail qui est significatif et qui contient toutes les notions que l'on a vues. Elles sont pour toute la Suisse romande (qui parle en français). Par exemple, en mai toutes les classes de 6ème doivent passer l'épreuve. « Pour la correction, c'est un peu différent parce qu'on le fait tous ensemble. On corrige tout à Payerne. On corrige toutes les feuilles de tout le monde ».

Des élèves interviennent dans ce que j'appelle le partage. Ce sont des choses qui peuvent se corriger unes à unes. Par exemple, pour l'entraînement de maths, je demande à deux élèves de corriger (en tant que correcteurs pour la classe) les exercices de multiplication. Après pour les textes, c'est moi qui corrige.

À la fin de la semaine, Ysabel évalue le comportement et le note dans l'agenda de chaque élève. Chacun a dans son agenda une feuille avec 3 différents niveaux d'évaluation.
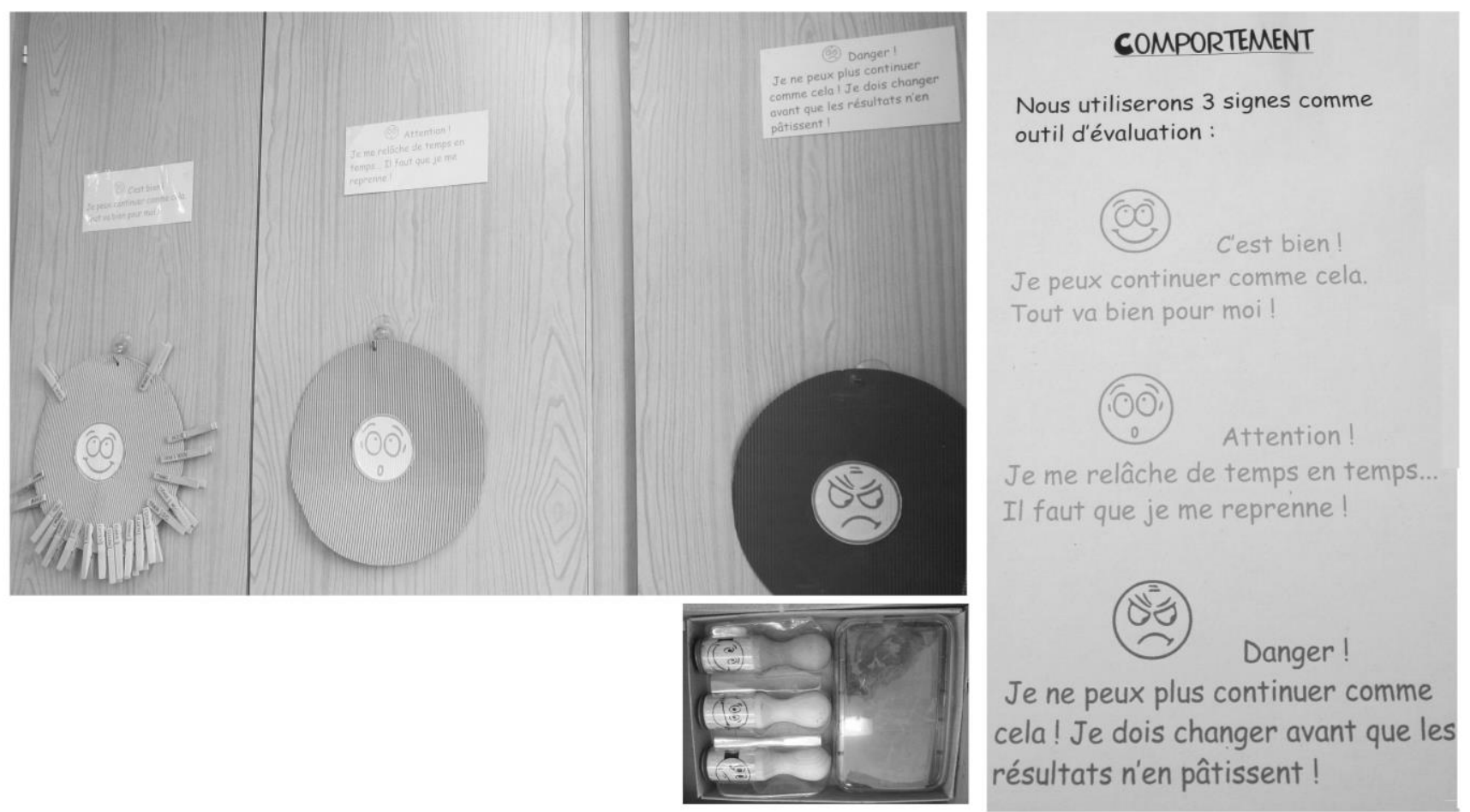

Image 106. Évaluation du comportement [C4_AM_FOM].

Si Ysabel remarque quelque chose, la première fois elle dit à l'élève « la règle c'est ça ». La deuxième, elle « le met dans l'agenda de la classe » et la troisième fois, elle «écrit un mot aux parents ». 
Si dans la semaine l'élève se corrige, par exemple «s'il a bavardé, je lui mets de l'orange, mais s'il s'excuse au près de ses camarades, qu'il fait attention et fait un effort pour se corriger alors je remets du vert à la fin de la semaine $»$.

En début de semaine, tout le monde recommence à zéro avec du vert. Au cours de la semaine, cela peut évoluer. 


\subsubsection{Croyances, attitudes et valeurs de l'enseignante}

\subsection{Reconnaissance de la diversité dans la classe}

Ysabel travaille de la même façon depuis quatre ou cinq ans, quand elle fait le vrai changement pour tous les élèves et non seulement pour certains élèves : ce n'est pas seulement pour des élèves qui ont de grandes difficultés.

"Le respect de chacun et de la justice. Le fait de tous faire la même chose n'est pas juste pour moi. La justice c'est que chacun puisse progresser. Tu ne peux pas demander à un poisson de grimper à un arbre. Tu dois respecter qu'un poisson est un poisson. Alors tu dois trouver à chacun un travail en fonction de ses capacités et de ses valeurs. S'il y a un élève qui a mal à la jambe, il ne peut pas venir faire du sport. Je lui trouve quelque chose à faire pour qu'il se rende utile. Par exemple, il est l'arbitre et il note le pontage de chaque équipe ». "Je trouve mon travail beaucoup plus amusant, beaucoup plus intéressant. Je réfléchis pour voir comment projeter une autre chose. Ce n'est pas juste chercher ce qu'il passe dans la tête de chacun, comment il peut y arriver. Ça c'est un défi pour moi. Tous les ans, je fais les multiplications mais les élèves sont différents, les façons de penser sont différentes, les moyens que je vais mettre en place sont différents ».

Alors, "je trouve que je verrais beaucoup plus des différences si je faisais une classe magistrale, le regard vers le tableau, en leur disant prenez vos crayons et écrivez... Je pense que je n'obtiendrais pas les mêmes résultats. Là, je vois les différences plus grandes entre les élèves. Ceux qui sont bons ne changent rien, ils restent bons. Mais ceux qui sont un peu plus faibles sont tirés par les autres et j'apprécie beaucoup ».

«Si j'ai à donner un conseil je dirais de ne pas tout changer en un seul cours mais petit à petit ».

En somme, Ysabel offre différentes modalités de travail en fonction des besoins d'apprentissage des élèves. C'est pour cela qu'elle demande différentes possibilités d'implication (en éliminant ou substituant des exercices, en offrant du temps supplémentaires, etc.). Les étudiants réalisent différemment de nombreuses activités en fonction de leurs besoins. Par exemple, pour faire une exposition, ils peuvent choisir le sujet de l'exposé, mais tout le monde doit le faire. Ils peuvent éventuellement choisir une poésie, mais tout le monde doit faire une poésie. Ysabel offre différentes activités : un petit jeu à faire, des fiches sur papier, différents matériels, ardoise, travail individuel, en groupe avec l'enseignante. Quant à l'évaluation, elle est différenciée selon ce qui a été fourni à l'élève : plus de temps ou du matériel.

\subsection{Enseignement partage et culture collaborative}

Un élément fondamental pour le développement du cas d'Ysabel est l'enseignement partagé, qui est présent à deux niveaux : 1) la coordination avec Ysabel et Nathalie ;2) la coordination avec Michelle, l'enseignante spécialisée. Car toute la classe bénéficie de la présence de Michelle dans la classe. 
Quant à la gestion du temps, nous avons vu qu'elle est souple: en fournissant des temps supplémentaires ou autres tâches, comme la correction des exercices des camarades. Cela permet à Ysabel et Michelle de travailler, en classe, avec d'autres élèves qui ont une plus grande difficulté. Cela exige une plus grande variété d'espaces dans la classe. C'est pour cela que nous pouvons différencier différents espaces de travail à l'intérieur et en dehors de la classe. Un autre élément que l'on peut souligner, ce sont les différents matériels et les aides visuelles au mur. Il s'agit de d'appuis que les élèves peuvent utiliser s'ils en éprouvent le besoin.

De plus, ces différents éléments (enseignement partagé, gestion du temps, espaces à l'intérieur ou en dehors de la classe, le matériel et les aides visuelles) favorisent différentes approches pour travailler et différents regroupements de travail (groupe, paires, individuelles...). Rappelons que tous les élèves doivent travailler les mêmes objectifs, mais par différents moyens.

Dans les différents regroupements de travail, nous pouvons trouver l'idée de culture collaborative, tous les élèves peuvent apprendre de leurs camarades. De cette façon, dans la classe, il y a des interactions guidées par la participation et la coopération. L'idée de culture collaborative se trouve aussi dans la participation démocratique.

\subsection{Participation démocratique : conseil de classe, conseil de délégués et participation de la famille.}

Cette manière de travailler a des répercussions sur la formation à l'égard d'une citoyenneté critique. Ysabel insiste sur la pensée critique et créatrice, et l'application de l'apprentissage. Dans la classe est encouragée la valeur du respect aux camarades. Des élèves vont donc faire de petites élections, par exemple on va choisir une poésie, on va voter, on va discuter.

On peut relever que des élèves interviennent pour de petites corrections des exercices de leurs camarades. Remarquons comme il y a un leadership partagé, grâce aux tâches qui sont formellement attribuées aux enseignantes et qui sont réalisées par les élèves. Ce leadership partagé se retrouve aussi dans la distribution de rôles hebdomadaires pour les élèves qui interviennent dans le bon fonctionnement de la classe.

Ysabel explique "Ma collègue et moi sommes très attentives à la manière dont chacun explique les choses ». Pousser certains élèves à corriger les autres ou leur ré-expliquer est aussi une valeur qui va progressivement en faire des citoyens. Ils travaillent sur la confiance et la responsabilisation. Par exemple, ils échangent les cahiers, l'un corrige le cahier de l'autre. "Vous êtres responsables de ce que vous corrigez. Si vous trouvez une faute et ne savez pas bien la corriger, il faut favoriser les réponses de votre voisin, il peut avoir une meilleure réponse dans son texte ". C'est aussi des citoyens qui s'intéressent à l'autre, qui se préoccupent de la réussite de l'autre... Une nouvelle citoyenneté plus solidaire et moins compétitive... 
Comme on le retrouve dans le Plan d'études Romand (PER), il y a une pratique citoyenne à l'école. Il s'agit de permettre à l'élève de s'impliquer de manière citoyenne dans l'école, notamment à travers des structures participatives : conseil de classe et conseil d'école.

Dans sa classe, Ysabel a instauré un conseil de classe. "Une fois par mois on peut essayer de dire les choses qui ne marchent pas très bien, les choses à améliorer ou bien formuler des suggestions ». Par exemple, s'il y a un problème de comportement "Je ne supporte plus ce comportement » ou «Mon voisin parle trop ", Cela a pour but d'améliorer le climat de la classe et favoriser la cohabitation.

$\mathrm{Au}$ conseil de classe tout le monde s'interroge sur des propositions, idées, projets etc., que les délégués doivent apporter le jour du conseil des délégués. Ils doivent respecter le tour de parole, lever la main et utiliser le micro.

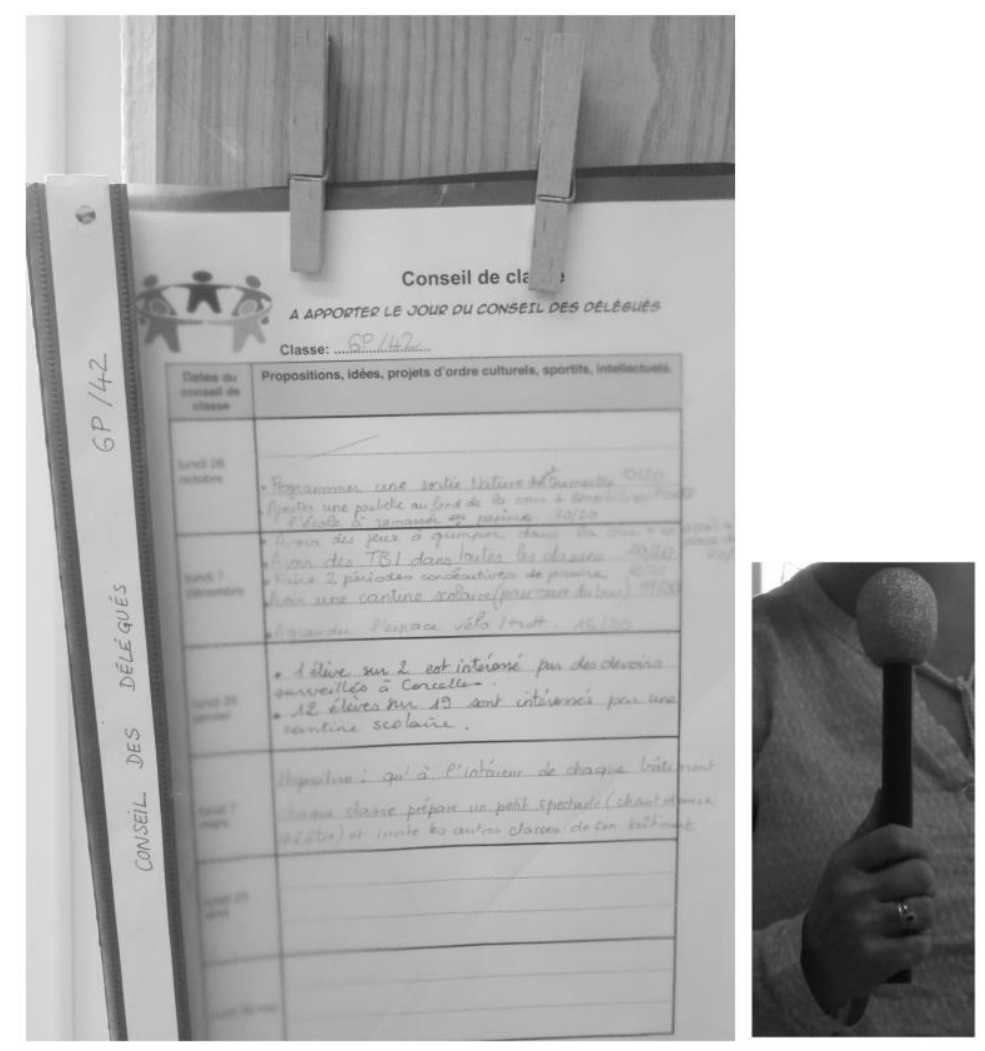

Image 107. Registre des propositions, idées, projets que des délégués doivent apporter au conseil d'école [C4_AM_FOM].

Le conseil des délégués est un conseil des bâtiments (conseil d'école). Chaque classe élit deux délégués pour une année scolaire. De plus, tous les délégués des établissements primaires de Payerne et ses environs (Château, l'Ancien-Hôpital, Rammes, Passerelle, Nouvelle, Ancienne Promenade, Chevroux, Corcelles, Grandcour et Missy) se retrouvent pour discuter de différents sujets à propos de chaque bâtiment. Par exemple : 
- Une poubelle pour les objets en plastique.

- Faire une fête pour inaugurer le nouveau bâtiment.

-Demander un ascenseur. Dans le bâtiment de Corcelles, il n'y a pas encore besoin d'ascenseur car lorsqu'un élève a un handicap physique, toute la classe change de lieu.

-Il y a un projet pour l'année prochaine de prendre le mur. C'est un projet né a la classe, proposé au conseil de délégués, après conseil d'établissement, au canton...

Le conseil des délégués a lieu six fois par an.

En ce qui concerne la participation des familles au

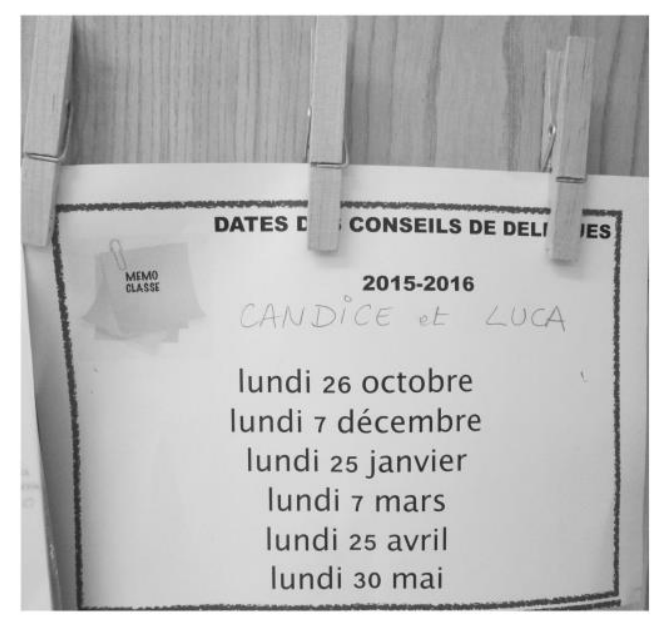

Image 108. Dates des conseils des délégués [C4_AM_FOM]. sein de la classe, Ysabel explique " une année, j'ai invité un papa à venir intervenir dans la classe pour parler de l'Islam parce qu'il était musulman pratiquant. J'ai aussi eu le fils du pasteur du village, il est donc venu ici et on a discuté. Tous les ans, je fais un travail sur le métier des papas et je les invite à chaque fois pour parler de leur métier ». Une fois par mois, il y a un atelier cuisine et c'est un papa ou une maman qui va présenter une spécialité de sa région ou de son pays. Ysabel ajoute « Je peux aussi faire en sorte qu'un parent m'accompagne si je vais à la piscine ou au marché quand ma collègue Nathalie ne peut pas m'accompagner ».

«Les parents de toutes les classes sont aussi invités tous les ans à Noël. On va à l'église puis on fait un goûter avec des gâteaux que les parents ont faits et du thé chaud. On passe un petit moment ensemble avant Noël. C'est un moment un peu festif ».

Il y a aussi l'exposition où les parents vont. C'est l'occasion de montrer la classe et tout le bâtiment. L'exposition est à la fin de l'année scolaire. Des élèves peuvent visiter leur classe pour l'année suivante, voir comment sont les tables, qui ils auront pour maîtresses... De plus, les parents peuvent venir avec leur(s) petit(s) frère(s) et/ou sœur(s) qui viendront l'année scolaire suivante pour montrer la classe, la maîtresse. Ça permet de rassurer un peu les enfants. 


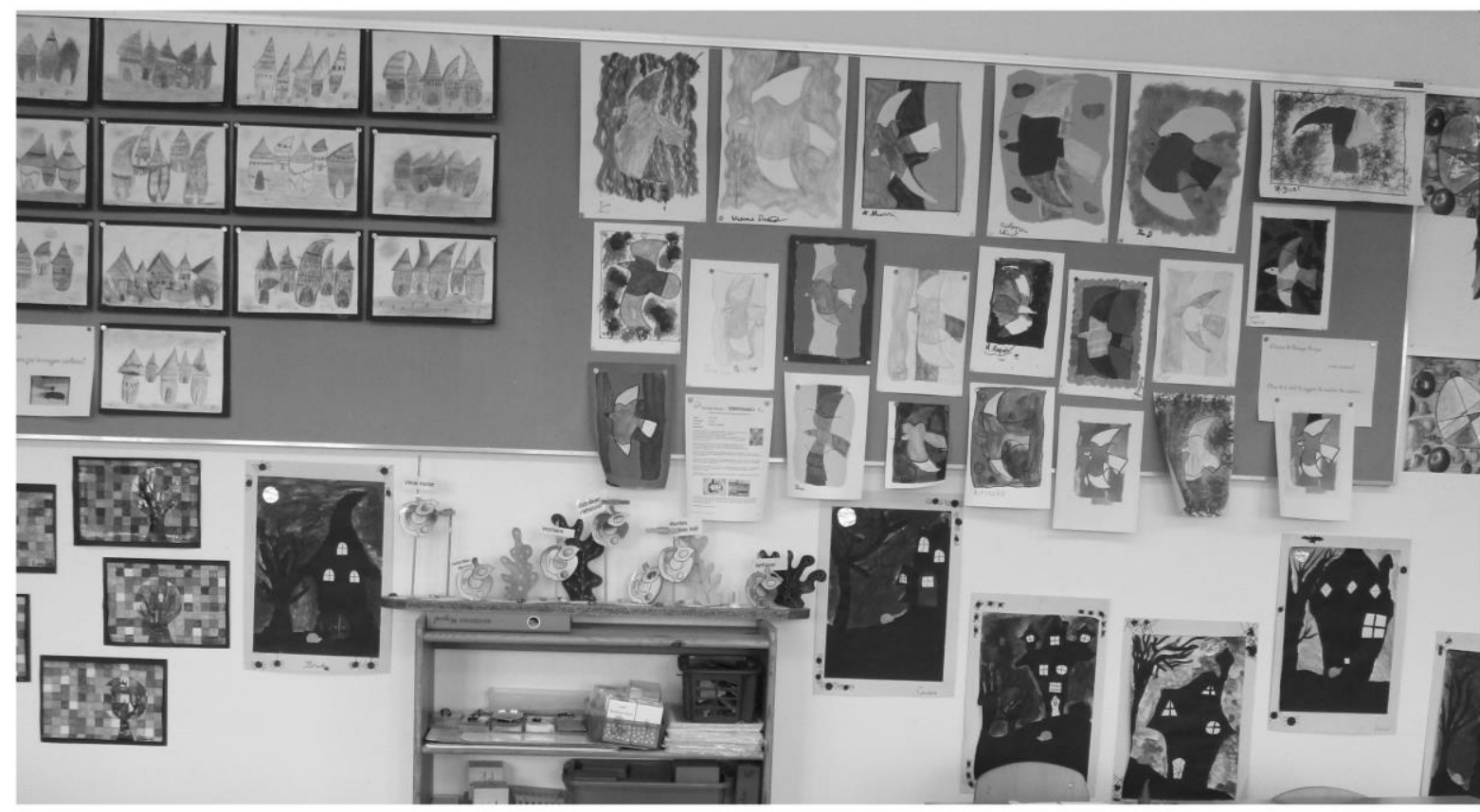

Image 109. Expo scolaire dans la classe d'Ysabel [C4_AM_FOM].

En somme, la participation démocratique est un élément important dans la classe et est présent dans le cas d'Ysabel : 1) les différents éléments comme l'enseignement partagé, la gestion du temps, espaces à l'intérieur ou en dehors de la classe, le matériel et aides visuelles, les différents regroupements, fournissent l'accessibilité et la participation de chaque élève dans son propre processus d'apprentissage ; 2) dans deux structures de participation : conseil de classe et conseil de l'école. Cette gestion démocratique repose sur le leadership partagé et la culture collaborative.

\subsection{Bien vivre ensemble : sens d'appartenance et lien au territoire}

Il y a beaucoup de sorties qui sont faites pendant l'année scolaire. Par exemple, quand ils ont étudié les arbres fruitiers, ils sont allés dans un verger. Il y a tout un travail qui a été fait sur l'énergie, ils sont allés à Payerne pour voir comme récupérer l'électricité avec l'énergie solaire. Après au niveau de la géographie, il y a des choses qui sont faites au village, par exemple : le plan de village. En sport, ils font des sorties dans le village, pour marcher dans la neige par exemple.

Pour travailler le bien vivre ensemble, tous les élèves du bâtiment font une sorte de randonnée dans la campagne au début de l'année. «Il y a des petits, il y a des grands. Dans les bâtiments en général on fait sortir tous les élèves mélangés. La consigne c'est 'un petit, un moyen, un grand' comme ça, il y a possibilité de faire connaissance, au détour d'une balade. On a plusieurs types d'activités de ce genre au cours de l'année, où les élèves, tous niveaux confondus, sont mélangés. On fait un bricolage spécifique à chaque classe pour décorer le bâtiment, pas pour l'emporter à la maison. C'est ensemble que l'on va décorer le bâtiment qui va rester ainsi toute une saison. Ensuite, pour chaque classe, on va fabriquer quelque chose ensemble. On s'est aperçus 
que ça aidait à la bonne ambiance dans la cour, il y a moins de disputes. Les grands reconnaissent les autres 'Ah c'est le petit que j'ai aidé à ouvrir son paquet chips' et les petits n'ont plus peur des grands 'C'est lui qui m'a donné la main pour traverser la rue' etc. Cela crée des liens. On remarque que ça fonctionne assez bien. On a travaillé déjà un temps comme ça».

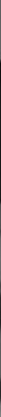

Image 110. Peinture faite pour groupe d'élèves mélange : petit, moyen, grand [C4_AM_FOM].

De plus, dans la classe, il y a certaines affiches avec des messages qui promeuvent le sens d'appartenance et le bien-vivre ensemble.
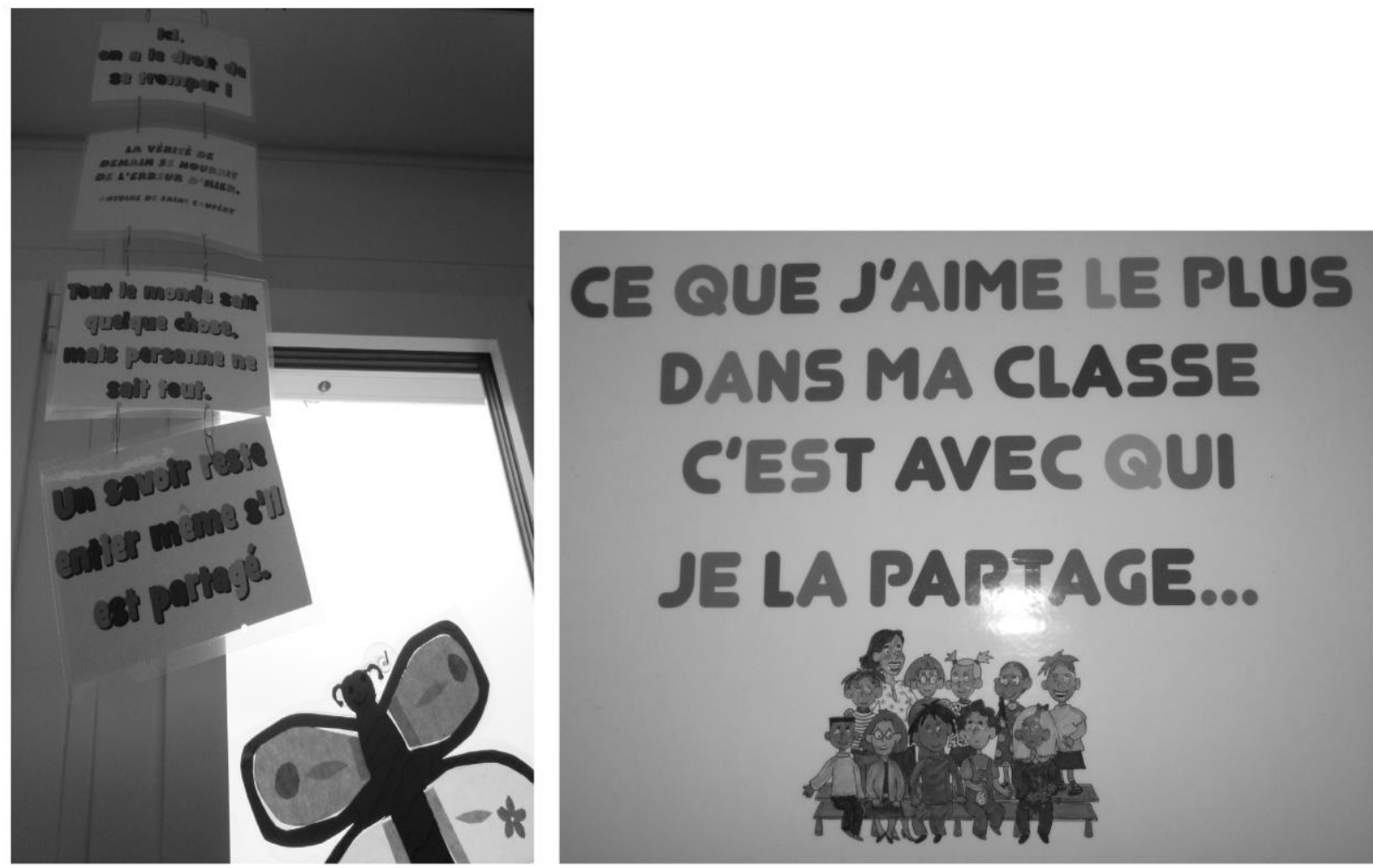

Image 111. Affiches avec des messages [C4_AM_FOM].

Notons que les élèves se sont engagés dans la gestion et les améliorations de l'établissement primaire de Payerne et ses environs, en encourageant le sens d'appartenance et le lien avec le territoire. Le sens d'appartenance est encouragé au niveau du bâtiment: par la représentation des 
élèves au conseil d'école et par différentes activités artistiques; au niveau de la classe, l'enseignante favorise la cohabitation. On peut donc dire que ces activités permettent aux élèves de participer à la vie scolaire et également de se sentir impliqués.

Le lien avec le territoire est présent aussi dans les activités réalisées durant l'année scolaire.

Ainsi, la citoyenneté critique est encouragée dans la classe (des petites élections, responsabilités, le respect envers les camarades...) et la participation démocratique dans les structures participatives énoncées. Nous avons vu que l'enseignante utilise une variété de stratégies éducatives. Elle ne va pas imposer son schéma pour résoudre quelque chose. Elle et les élèves partagent beaucoup ensemble sur les différentes manières ou techniques de résoudre un problème. Soulignons également, la participation de la famille et l'ouverture de la classe ainsi que l'utilisation d'éléments pour favoriser la communication interculturelle avec des familles.

Pour conclure on peut dire que le cas exposé travaille sur les principes de la différenciation pédagogique et la participation démocratique dans la classe inclusive.

Ci-dessous, le schéma des éléments constituants le récit du cas d’Ysabel (Figure 9). 


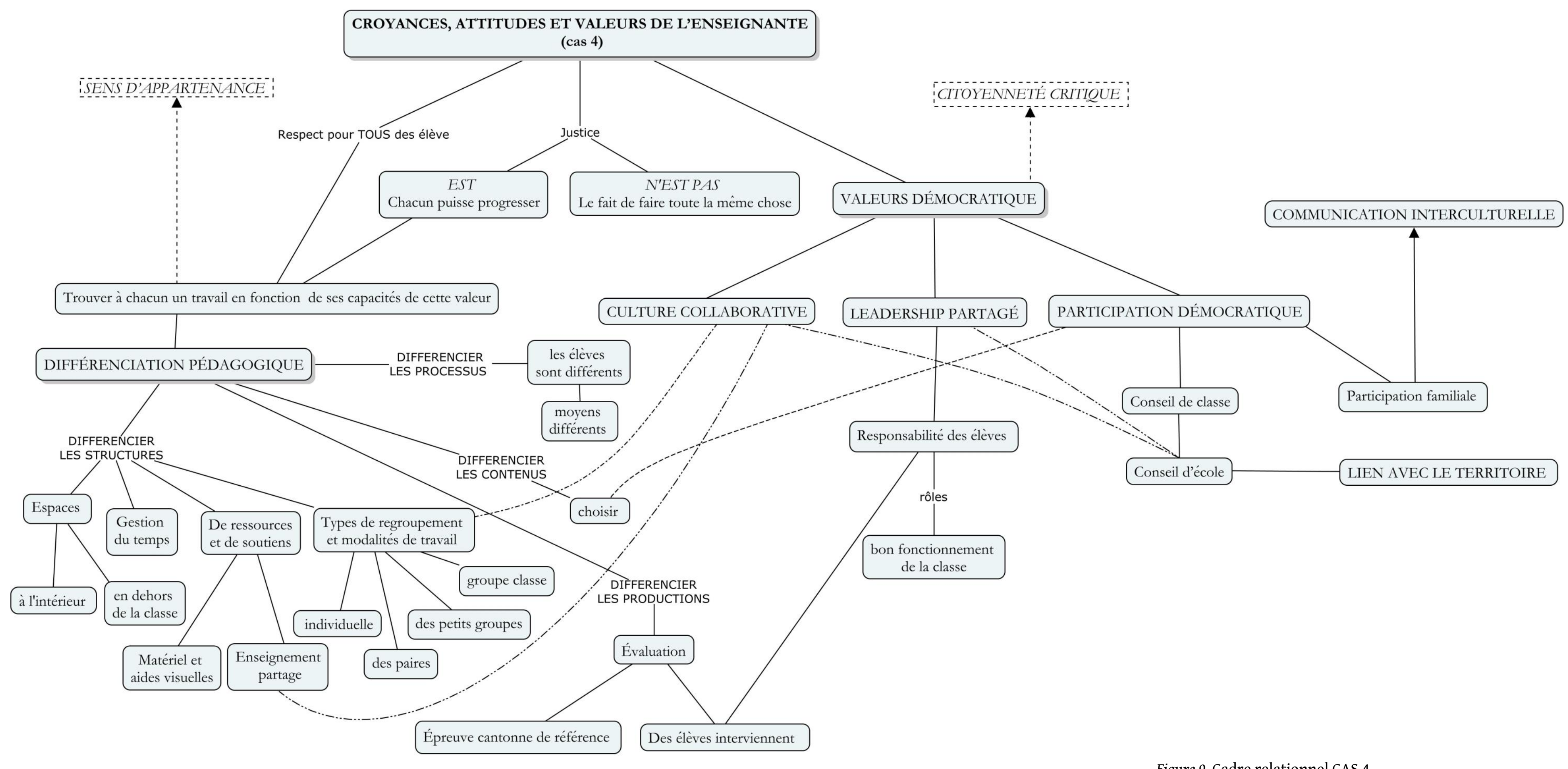

Figure 9. Cadre relationnel CAS 4 



\section{CAPÍTULO 5}

\section{$\sim$ Discusiones de los resultados}

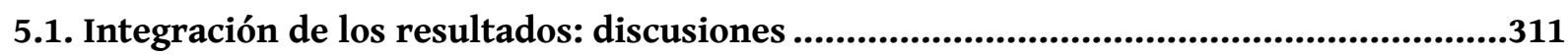

5.1.1. Teóricas: clarificación y relación conceptual

5.1.2. Empíricas: el cómo y el porqué de las prácticas educativas 



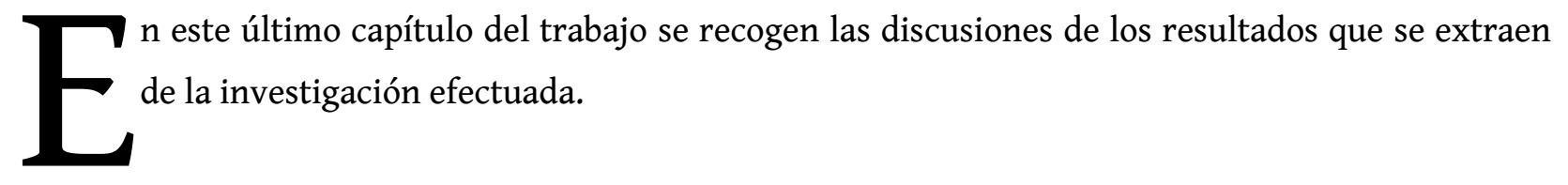

\subsection{Integración de resultados: discusiones}

Tal y como ya se ha presentado, el principal objetivo de esta investigación es contribuir y aumentar el conocimiento hacia la manera de articular la diferenciación pedagógica y la participación democrática en el aula inclusiva. Si se recuerdan, las preguntas de la investigación son las siguientes:

1) ¿Cómo se vincula la diferenciación pedagógica y la participación democrática en el aula inclusiva?;

2) ¿Cómo desarrollan los docentes la práctica de la diferenciación pedagógica y la participación democrática en sus aulas?;

3) ¿Por qué los docentes llevan a cabo la diferenciación pedagógica y la participación democrática en sus aulas? ¿Qué creencias, percepciones y experiencias vitales sustentan las propuestas didácticas de los docentes?

Vemos en los issues planteados cómo las respuestas que se deben contemplar y recoger en las discusiones giran en torno a dos bloques diferenciados, pero que se nutren entre si. Por una parte, encontramos las discusiones referentes a los resultados relacionados con los principios teóricos sobre la diferenciación pedagógica y la participación democrática que ayudan a dar respuesta a la primera pregunta de investigación. Por otra parte, localizamos las discusiones referentes a los resultados vinculados con el trabajo empírico que muestran e ilustran el cómo y el porqué los docentes llevan a cabo sus prácticas educativas en sus respectivas aulas desde el marco de la diferenciación pedagógica y la participación democrática, esto fundamenta la respuesta a la segunda y a la tercera pregunta de investigación. Siguiendo esta agrupación se presentan las discusiones de los resultados que se derivan de esta tesis doctoral. 


\subsubsection{Teóricas: clarificación y relación conceptual}

Este primer subapartado de las discusiones se centra en la clarificación y relación conceptual entre la diferenciación pedagógica y la participación democrática en el aula inclusiva.

A través del intento de reconstruir los antecedentes subyacentes en las prácticas de diferenciación se ha visto cómo han emergido conceptos afines a esta noción, como son los de individualización, personalización, enseñanza multinivel o diseño universal del aprendizaje. Tal como se ha planteado, algunos autores como Dottrens (1949), que utilizaban el vocablo de enseñanza individualizada, hacían esfuerzos por tratar de desvincular susodicho término del de trabajo individual o personal. Poco a poco los estudiosos procedentes del ámbito francófono (Fletcher, 1992) y del anglófono (Tomlinson, 2005) se han ido distanciando, cada vez más, del uso del término de enseñanza individualizada. De esta manera, parece haber aflorado, en el panorama internacional, el uso del vocablo diferenciación. El cual no implica diferenciar las actividades para cada uno de los alumnos de la clase, aspecto que se han encargado de matizar los estudiosos de este campo (Aylwin, 1992; Astolfi, 2004; Tomlinson, 2005), para de esta manera, separar el término diferenciación del de individualización. En el contexto hispánico, se ha visto cómo no es muy frecuente el uso del término diferenciación. Esto puede deberse a las connotaciones negativas (para algunos estudiosos) que tiene el concepto de educación diferenciada (single-sex), separada por sexos, pero defendida por algunos investigadores (Calvo, 2005 y 2009; Moreno, 2009; Setuáin, 2012; Sánchez, 2012; Aguiló, 2015; Ahedo, 2015). Es por ello que, desde el marco de una educación inclusiva, se han empleado otros conceptos como el de personalización de la enseñanza (García Hoz, 1976; Pujolàs, 2008; Huguet, 2006) o enseñanza multinivel (Collicott, 2000). En el ámbito internacional el concepto parece no estar exento de controversia, ya que para algunos la diferenciación pedagógica refuerza y perpetúa las desigualdades existentes a través de su función selectiva de "clasificación" de los niños (Hart, 1992). No obstante, tal y como se viene defendiendo en el presente trabajo, el propósito de la diferenciación pedagógica desde una perspectiva inclusiva no es ese.

Si nos centramos en la raíz de cada una de las palabras, podemos ver como la individualización se focaliza en el individuo, la personalización en la persona y la diferenciación o diversificación en la diferencia o en la diversidad encontrada en el aula. Se detecta pues, como en la base de todos estos conceptos descansa la idea de respetar las diferencias individuales o personales del alumnado, para que éstos puedan aprender y ser partícipes en su propio proceso de aprendizaje enmarcado en el aula ordinaria. Así pues, ante una escuela que se preocupa por reconocer y valorar la heterogeneidad del aula, es decir, atender y respetar la diversidad o la diferencia del alumnado que encontramos en ella, no resulta descabellado adoptar el término de aula diversificada o diferenciada (como se ha estudiado en este trabajo).

No obstante, si nos fijamos en los términos utilizados por los maestros de los casos abordados, se ha visto como, en el caso suizo (Caso 4) la maestra incluye en su vocabulario docente el manejo del 
término de diferenciación pedagógica (desde una perspectiva de la integración educativa) para hacer frente a la diferencia o diversidad en su aula. Es conveniente recordar que en la legislación cantonal o federal no se encuentra ninguna alusión al término de inclusión, sino que el término utilizado es el de integración (Ramel, 2015b). Por lo contrario, los 4 maestros estudiados en el contexto español no tienen interiorizado dentro de su vocabulario docente el vocablo de diferenciación pedagógica, éstos aluden a términos referentes a la diversidad o heterogeneidad en el aula. Sin embargo, un análisis minucioso de cada uno de los casos nos permite afirmar que en mayor o menor medida los elementos característicos de la diferenciación pedagógica, procedentes de la revisión bibliográfica, sí que se materializan y se evidencian en las prácticas didácticas de cada uno de los casos examinados.

Por tanto, se considera de vital importancia, para poder seguir avanzando en este campo, utilizar un concepto cercano y conocido por la mayoría de los docentes. También se precisa de una unificación conceptual, tanto en el ámbito internacional como nacional, para que los estudiosos que nos dedicamos a este ámbito podamos adoptar un lenguaje común que nos permita entendernos y avanzar en este terreno. Desde el marco de la educación inclusiva, se ha hecho el esfuerzo de clarificar el concepto de "educación inclusiva" o "inclusión educativa" (Echeita y Ainscow, 2011). Es por ello, por lo que proponemos adoptar un término que no evoque a confusión ni connotaciones negativas en ningún contexto, como el propuesto por Rousseau y Bélanger (2003) o Vienneau (2011): pedagogía de la inclusión.

En palabras de Vienneau (2011), la pedagogía de la inclusión se centra esencialmente en la gestión de las diferencias observadas entre el alumnado (p.ej., ritmo de aprendizaje, estilo cognitivo, tipo de inteligencia, etc.). Va dirigida al conjunto de alumnos de la clase ordinaria. La inclusión escolar defiende la idea de que cada estudiante es único, y que las escuelas y el proceso de enseñanzaaprendizaje deben organizarse de modo que cada alumno reciba una educación adaptada a sus características personales y a sus necesidades particulares (Ferguson, Desjarlais y Meyer, 2000 citado en Vienneau, 2011). "La pedagogía de la inclusión se sustenta en primer lugar en la cooperación y en la consideración del carácter único de cada estudiante; también en una pedagogía orientada a la participación y la autonomía; una pedagogía que favorezca la construcción y la integración de los conocimientos" (Vienneau, 2011, p.23). Por su parte, Rousseau y Bélanger (2003, p.3), establecen que: "la pedagogía de la inclusión escolar emerge de las necesidades crecientes de reconocer el valor humano de todos los individuos con o sin necesidades particulares". Aunado a lo anterior, añadir que la particularidad de la pedagogía inclusiva es la manera en que los docentes conceptualizan la noción de diferencia (Ainscow, Dyson y Weyner, 2013), así pues, los valores, actitudes y creencias de los maestros son básicos para desarrollar un tipo u otro de educación.

Como se ha visto, la diferenciación pedagógica y la participación democrática están plenamente vinculadas y son dos elementos clave que deben estar presentes para avanzar hacia prácticas de aula inclusivas y democráticas. Esta filosofía docente se sustenta principalmente en dos valores que guían 
las prácticas educativas, estos son: el reconocimiento y la valoración positiva de la diversidad y los valores democráticos (Prud'Homme et al. 2016). Y es que, tal y como señalan Fillion et al. (2016), la educación ciudadana, la convivencia y la participación social contribuyen a un ambiente o clima necesario para la diferenciación pedagógica (intercomprensión e interdependencia). Esta participación no se debe limitar o ceñir a que el alumno pueda gestionar de manera democrática su aula o reflexionar y deliberar de manera grupal a través de la cooperación, para que la escuela sea democrática (Apple y Beane, 1999; Bolívar y Guarro, 2007; Feito y López, 2008) dicha participación debe extenderse, también, a la concordancia entre la escuela, la familia y la comunidad (Bell et al. 2010; Calvo et al. 2016; Simón et al. 2016). De esta manera, se propicia una escuela incluida en el territorio (Sales et al. 2016; Moliner et al. 2017) y se fomenta una ciudadanía más crítica, responsable y participativa (Galichet, 2002; San Fabián, 2005; Bolívar, 2007).

Así pues, el término de la pedagogía de la inclusión que proponemos nos permite materializar en el aula los valores y principios que subyacen a una educación inclusiva y democrática, ya que parte de la manera en que los docentes gestionan la diversidad del aula, de cómo éstos diferencian el currículum y gestionan de manera democrática la vida social del aula.

\subsubsection{Empíricas: el cómo y el porqué de las prácticas de aula}

Este segundo subapartado de las discusiones se centra en cómo y porqué se desarrollan prácticas de aula guiadas bajo los principios de la diferenciación pedagógica y la participación democrática en el aula inclusiva.

Las actitudes, creencias y valores de los maestros son determinantes en el tipo de educación que ofrecen a su alumnado (Arnaiz, 1996; Berruezo, 2006; Curchod-Ruedi et al. 2012). Entre las creencias, actitudes y valores de los docentes objeto de estudio subyacen dos ejes principales a partir de los cuales descansan sus fundamentos pedagógicos. Se trata por un lado de la valoración y el reconocimiento de la diversidad y por otro lado de los valores democráticos. Estos valores descansan en el concepto de diferenciación pedagógica desde una visión inclusiva, tal y como se viene referenciando desde la teoría (Prud'Homme et al. 2016). Los resultados de este trabajo indican que al preguntar a los docentes objeto de análisis sobre el porqué de sus prácticas didácticas, éstas se basan principalmente en cómo estos entienden la educación, en sus creencias, actitudes y valores: para hacer una educación más justa, más solidaria, más participativa, más creativa y más abierta (caso 1); para dar valor a la persona, a lo humano y fomentar la convivencia, la participación, la parte emocional (caso 2); las creencias, valores y opiniones, la motivación docente y el sentir que todos los docentes del CRA llevan una misma línea de trabajo (caso 3); el respeto por cada uno y por justicia (caso 4). 


\section{$\sim$ Valoración y reconocimiento de la diversidad}

Primeramente, se hace un recorrido sobre los principales asertos que nutren este primer bloque de creencias, actitudes y valores relacionadas con el cómo los maestros articulan sus prácticas educativas.

Hay que recordar que, en este estudio se entiende por valoración y reconocimiento de la diversidad, al reconocimiento de la heterogeneidad del grupo humano que constituye la comunidad educativa como algo natural y ordinario, y la valoración positiva de aquellos factores de la diversidad que enriquecen la cohesión social. Esta cohesión se deriva de acciones comunes inclusivas basadas en la equidad social y educativa (Muntaner, 2000; Gimeno Sacristan, 2002; López Melero, 2004; Booth y Ainscow, 2011; Lozano, 2013). Tal y como se desprende del marco teórico que fundamenta esta tesis doctoral, recordar la importancia de la aceptación social (Leary, 2001) y el bienestar emocional (Bisquerra, 2000) del alumnado. Dado que estos aspectos contribuyen, considerablemente, a un buen ajuste académico (Gifford-Smith y Brownell, 2003).

La valoración y el reconocimiento de la diversidad del alumnado presente en el aula por parte de los docentes pertenecientes a los 4 casos estudiados es lo que les lleva a poner en práctica la diferenciación pedagógica en sus aulas y a huir de procesos de enseñanza-aprendizaje basados en la homogeneidad y caracterizados por una lección magistral uniforme dirigida a un alumno "medio" inexistente (Arnaiz, 2011; Gregory y Chapman, 2013; Beaudoin, 2013). Se ha visto como los maestros reconocen la diversidad del alumnado de sus aulas, más allá de si hay o no un dictamen o diagnóstico.

Para perpetrar las discusiones de los resultados referentes al hecho de cómo materializan la diferenciación pedagógica en el aula, se efectúa un recorrido por los 4 principales ejes de la diferenciación, propuestos por Leroux y Paré (2016). Éstos son: diferenciación de las estructuras, diferenciación del contenido, diferenciación del proceso y diferenciación del producto.

En primer lugar, nos centraremos en los indicadores que caracterizan la diferenciación de las estructuras, éstos son aquellos que están directamente relacionados con la organización del aula: agrupamientos, modalidades de trabajo, tiempo, espacio y recursos (Leroux y Paré, 2016).

Por lo que respecta a la tipología de agrupamientos, se ha visto cómo en todos los casos se utiliza una gran variedad de éstos según la modalidad de trabajo llevada a cabo y la finalidad que se persigue con cada una de ellas. En el caso 1, se trabaja: de manera individual para la redacción de los cuentos, cartas, textos semanales y exposiciones de libros; en pareja para llevar a cabo la dinámica de la lectura en pareja o cuentacuentos a infantil; en grupo para realizar el trabajo de investigación o técnicas simples de aprendizaje cooperativo en las asignaturas de matemáticas, naturales o sociales, el teatro a infantil y en media clase para la tertulia literaria dialógica. En cuanto al caso 2, mencionar que se trabaja: de manera individual para la resolución de operaciones matemáticas del cuadernillo; en pareja o en grupo para abordar los diferentes subtemas del proyecto de trabajo, en grupo de cuatro alumnos 
en los grupos interactivos y también se realizan asambleas de todo el grupo clase. Además, en los talleres interciclo se agrupan alumnos pertenecientes a diferentes aulas y cursos. En el caso 3 también se utilizan diferentes tipos de agrupamiento, pasando del trabajo individual (p.ej. dosier, plan de trabajo- aunque después se corrige en pareja y en grupo, rincones de trabajo, primer momento del Puzle de Aronson), por parejas (p.ej. leemos en pareja), pequeño grupo (p.ej. estaciones, murales, taller de ciencias, segundo y tercer momento del Puzle de Aronson, ginkama) hasta todo el grupo clase (p.ej. tertulia literaria dialógica). Pero destacar especialmente de este caso dos aspectos: 1) las distintas agrupaciones llevadas a cabo en el primer trimestre donde hay algunos alumnos que resuelven la tarea de manera individual (sabios), otros por parejas y otros en pequeño grupo y 2) la evolución de las agrupaciones del primer trimestre (sabios, parejas, pequeño grupo) respecto a las realizadas en el tercer trimestre donde se trabajan en macro-grupo y los últimos días disponiendo las mesas en forma de "U". En lo relativo al caso 4, la maestra también utiliza diferentes tipos de agrupamiento dependiendo de la actividad. Además, se realizan grupos de nivel (por colores) para trabajar conceptos que necesitan mejorar los miembros que conforman cada grupo. Se ha notado que en la mayoría de las propuestas de trabajo se requiere de una interacción para resolverla, siendo más reducidas la resolución de las actividades de manera individual. Como posteriormente se introduce este elemento organizativo está estrechamente vinculado con la categoría teórica de la cultura colaborativa. Y es que en palabras de Muntaner (2014), los grupos heterogéneos permitirán alcanzar un mayor nivel de colaboración entre el alumnado, lo cual aumentará la motivación y la ayuda mutua.

Si nos centramos en las diferentes modalidades de trabajo se ve cómo las propuestas metodológicas son las mismas para todo el grupo clase, éstas son abiertas y flexibles permitiendo el acceso y la participación de todo el alumnado en el aprendizaje (UNESCO, 2005). Siguiendo a Aylwin (1992), ya se ha visto cómo la diferenciación puede ser colectiva (misma forma de diferenciación, mismas operaciones, mismos pasos) o individual (cada subgrupo tiene sus propios objetivos, contenidos, formas de expresión, tiempo). En el caso 1 en lo que respecta a los grupos de investigación, vemos cómo se trata de una diferenciación individual, dado que cada subgrupo tiene unos contenidos a desarrollar (marcados en el bloque general de contenidos), potenciando la libre expresión de los conocimientos abordados. El leemos en pareja, el primer trimestre presenta una forma de diferenciación colectiva, dado que todas las parejas hacen los mismos materiales, pero, produciéndose diferentes interacciones en cada una de las parejas. Por el contrario, en el segundo, y, sobre todo, en el tercer trimestre esta dinámica se diferencia de manera individual, ya que cada tutor puede proponer el texto y las actividades que considere (aunque todos deben de seguir los pasos marcados por esta dinámica). Esto mismo vemos en la actividad del cuentacuentos a infantil, en el primer trimestre se trata de una forma de diferenciación más colectiva, que avanza hacia una diferenciación individual en el segundo y tercer trimestre (en el teatro a infantil, cada subgrupo trabaja una representación teatral). En la tertulia literaria dialógica, en los experimentos de ciencias naturales y en el trabajo a partir de las técnicas simples de aprendizaje cooperativo (en ciencias 
naturales, ciencias sociales y matemáticas) se presenta una diferenciación de tipo colectiva. En cuanto a los escritos (cartas, textos) y las exposiciones de libros adoptan una forma de diferenciación individual. En lo que atañe al caso 2, en algunos momentos del proyecto de trabajo existe una diferenciación colectiva (asambleas para escoger el tema o distribuir los subtemas a abordar por cada subgrupo, escritura colectiva del acta, ¿qué sabemos? y ¿qué queremos saber?, elaboración de la cueva, del eje cronológico, los juegos de Betxí) mientras que en otros momentos adopta una forma de diferenciación individual (búsqueda de material para el proyecto, trabajo en los subgrupos sobre los subtemas asignados, elaboración del dosier por parte de cada subgrupo o pareja). Los grupos interactivos y los talleres interciclo presentan una forma de diferenciación colectiva. En lo que respecta al cuentacuentos a infantil, éstos adoptan una forma de diferenciación individual, visto que cada pareja decide y prepara su cuento. En el caso 3 vemos una diferenciación colectiva en el plan de trabajo (todos hacen el mismo), leemos en pareja, puzle de Aronson, estaciones, rincones de trabajo (a excepción del rincón del cronista que adopta una diferenciación individual), tertulia literaria dialógica, talleres con las familias y ginkama. Notemos una diferenciación individual en el taller de ciencias (cada subgrupo trabaja unos minerales) y en el proyecto LóVA (aunque todos trabajan por un mismo objetivo compartido, cada subgrupo de profesiones $\mathrm{u}$ oficios aborda unos objetivos concretos a desarrollar). Mencionar la variación que sufre la dinámica de la tertulia literaria dialógica a medida que va avanzando el curso escolar, vemos que esa diferenciación es negociada según la necesidad del grupo. En el caso 4 observemos cómo el dosier de matemáticas se trata de una diferenciación colectivas, ya que todos tienen el mismo. No obstante, la maestra proporciona fichas suplementarias o materiales manipulativos a quien lo necesita tratándose esto de una forma de diferenciación individual. En lo que respecta al cahier d'écrivain vemos cómo se trata de una diferenciación colectiva (todos tienen el mismo desafío), aunque las producciones y formas de expresión varían según cada alumno (diferenciación individual). Los alumnos que lo necesitan trabajan con Michelle el material de Le Village des Mots tratándose este aspecto de una diferenciación de tipo individual. Continuando con las formas de diferenciación propuestas por Aylwin (1992), ésta también puede ser máxima (ofrece a cada alumno la elección de las fórmulas de enseñanza, contenidos, ritmos, formas de producción o evaluación) o mínima (ofrece al aula una variedad de interacciones, operaciones intelectuales, enfoques o actividades). Constatemos que en la mayoría de las modalidades de trabajo la diferenciación es mínima, dado que las actividades propuestas siempre van dirigidas al colectivo del grupo clase, siendo conscientes de la flexibilidad en las diferentes formas de expresión o materialización. Se podría señalar que la diferenciación es máxima en el tercer trimestre de la dinámica de leemos en pareja y en el segundo trimestre del cuentacuentos a infantil, visto que el alumnado es el que elige los textos y las actividades o confecciona el cuento (caso 1). Aunado a esta concepción es necesario recordar que tal y como señala Tomlinson (2005), la diferenciación pedagógica no es la enseñanza individualizada de los años 70, en la que se trataba de hacer algo distinto para cada uno de los alumnos que había en el aula. Se ha visto como en las aulas estudiadas 
no se hacen trabajos individuales, segregados o aparte (descontextualizados de la propuesta dirigida al grupo clase). Todos aportan y participan en la vida del aula según sus capacidades, ritmos e intereses de aprendizaje (Heacox, 2002; Rodríguez, 2012; Sanahuja et al. 2014; Kline, 2015).

En lo que respecta al tiempo, se ha constatado que, en todos los casos, en la medida que sea posible los tiempos son flexibles (Bernal, 2007) y se basan en los diferentes ritmos del alumnado (Kahn, 2010). Por ejemplo, en el caso 1 las exposiciones realizadas en la asignatura de cultura valenciana se efectúan a medida que van terminando los grupos. En la asignatura de valenciano tienen muy bien marcado que metodología guía cada una de las sesiones (lectura por parejas, cuentacuentos a infantil, tertulia literaria dialógica). Destacar en el caso de la tertulia literaria dialógica que el moderador es quien marca y distribuye los tiempos. Además, decir que ambos subgrupos de la tertulia literaria dialógica no siguen el mismo ritmo ni el mismo tiempo de lectura, ya que en cada una de ellas se producen comentarios y surgen aspectos o contenidos diferentes. En el caso 2, concretamente en los proyectos de trabajo, los tiempos son muy flexibles (Lacueva, 1998) adaptándose plenamente al ritmo de trabajo del alumnado. La mayor parte de la jornada escolar, a excepción de las horas que tienen asignadas con los especialistas (inglés, educación física, religión...) trabajan los diferentes aspectos del proyecto, según en qué fase o momento se encuentran. Además, en el momento de la planificación, el alumnado es quien reflexiona sobre las principales tareas que tienen que realizar para abordar el proyecto. Cuando los alumnos trabajan de manera individual sus cuadernos de matemáticas, cada uno lo hace a su ritmo, además la maestra escribe operaciones matemáticas en la pizarra que no realizarán todos los alumnos. En los grupos interactivos, los tiempos están muy marcados y transcurridos 10 minutos a la señal de la música el alumnado debe de cambiar de actividad (Chocarro y Sáenz, 2016), si algún alumno no termina la tarea lo tiene que realizar como deber en casa. Las maestras valoran muy positivamente esta actividad, ya que en una hora y treinta minutos los alumnos realizan 7 actividades o ejercicios diferentes, que de no ser por esta dinámica habría alumnos que estarían toda la hora y treinta minutos realizando tan sólo un ejercicio. Esto mismo ocurre en las estaciones ilustradas en el caso 3. Sin embargo, siguiendo en el tercer caso objeto de nuestro estudio, en los rincones de trabajo es el propio alumnado quien se gestiona individualmente el tiempo (Martín y Vieira, 2000; Gispert y Ribas, 2010) para la ejecución de los mismos a lo largo de dos sesiones. Asimismo, en este caso 3, en la dinámica de leemos en pareja, como las sesiones son de 45 minutos y no les da tiempo a hacer la evaluación, lo negocian y la hacen una vez al mes. El moderador es quien organiza los tiempos de la sesión destinada a la tertulia literaria dialógica. En el caso 4, se otorga tiempo suplementario a quien lo necesita. Además, en este último caso mencionado cada alumno trabaja su cuaderno de matemáticas a su ritmo. Los alumnos que terminan más rápido son los encargados de corregir los ejercicios a sus compañeros (liderazgo compartido), mientras la maestra trabaja con los alumnos que tienen alguna dificultad en la resolución de algún problema. En lo que respecta a los tiempos en el aula, recordar que la diferenciación pedagógica puede ser simultánea o sucesiva (Aylwin, 1992; Tomlinson, 2008; Caron, 2008; Leroux, Fontaine y Sinclair, 2015). 
En el caso 1, vemos una diferenciación simultánea en: algunos momentos de los grupos de investigación (trabajo por grupos, elaboración del producto), leemos en pareja (esta diferenciación es mayor en el último trimestre del curso), cuentacuentos a infantil (esta diferenciación es mayor en el segundo trimestre del curso) y experimentos. Notemos una diferenciación sucesiva en algunos momentos de los grupos de investigación (escoger el bloque de contenidos y confección de grupos, exposiciones), en la dinámica de leemos en pareja (1r trimestre), la tertulia literaria dialógica, exposiciones de libros, escritura de textos o cartas al Censal y el teatro a infantil. Por lo que respecta al caso 2, existe una diferenciación simultánea en los grupos interactivos, taller interciclo y en algunos momentos del proyecto de trabajo (etapa de búsqueda de la información, trabajo por grupos del subtema seleccionado- escritura del dosier, elaboración de murales, juego de Betxí a lo largo del tiempo). Sin embargo, en otros momentos del proyecto de trabajo (asambleas para escoger la temática, ¿qué sabemos y qué queremos saber?, exposición) la diferenciación es sucesiva al igual que en la actividad del cuentacuentos a infantil. En el caso 3 vemos que: en las estaciones de lengua y matemáticas, los rincones de trabajo, los murales colectivos, puzle de Aronson o rompecabezas, el taller de ciencias sobre los minerales y proyecto LÓVA ( $2^{\circ}$ y $3 r$ trimestre) la diferenciación es simultánea. En la tertulia literaria dialógica, el leemos en pareja, exposiciones de libros, proyecto LÓVA (1r trimestre) y la ginkama la diferenciación es sucesiva. En el caso 4 la diferenciación es simultánea en el momento del trabajo del dosier de matemáticas, visto que cada alumno va a su ritmo y los que van más rápidos corrigen a sus compañeros. Además, la maestra ofrece fichas suplementarias o trabajos de investigación más extensos que no necesariamente hacen todos los alumnos de la clase.

En los casos estudiados encontramos diferentes espacios de trabajo tanto dentro como fuera del aula (Aylwin, 1992). Las diferentes disposiciones físicas de las clases ilustradas favorecen las diferentes agrupaciones y modalidades de trabajo. La organización física de las aulas corresponde a espacios versátiles (Carrión y Sánchez Palomino, 2002) que favorecen el trabajo y la interacción, tanto si se trata de actividades individuales o grupales. En el caso 1, destacar el hecho de que el docente no tenga una mesa para él. Vemos una posición de horizontalidad entre el educador y el educando. Esta relación de horizontalidad también se da en la tertulia literaria dialógica, cosa que valora positivamente el alumnado, en el hecho de que el docente se sitúa como un alumno más en el círculo. Siguiendo con el caso 1, decir que, los alumnos pueden escoger diferentes espacios para trabajar, más cómodamente, en el momento de búsqueda de información para el proyecto de investigación de cultura valenciana, hay alumnos que trabajan en clase, otros en la biblioteca, otros en otra sala... Para el cuentacuentos a infantil también existe esta diferenciación espacial, en el sentido que algunos alumnos salen al patio para hacer la actividad, otros se quedan en el aula, si hace frío van al pasillo. En lo que atañe al caso 2, destacar que mayoritariamente éstos utilizan el aula como principal espacio de trabajo. Al realizar el proyecto cada alumno trabaja en la mesa de su equipo. El hecho de cambiar 
de espacio (mesa) en los grupos interactivos resulta un elemento motivador para el alumnado. Sí que es cierto que para la actividad del cuentacuentos pueden escoger el aula o aulas de infantil donde ir a contar el cuento (si tienen hermanitos, primos...). Además, disponen de un aula para ir a realizar los ensayos o preparar el cuentacuentos a infantil. Los talleres interciclo también se realizan en diferentes espacios (aulas y patio). En el caso 3, se promueve la diferenciación espacial. Al alumnado le agrada cambiar de espacio y de actividad en las estaciones. En lo que respecta al Proyecto LóvA, cada grupo de oficios o profesiones tiene asignado su espacio de trabajo, aspecto que ayuda en la organización del mismo, unos trabajan en el aula, otros en el pasillo y otros en el patio. Resaltar también los rincones de trabajo, algunos son en diferentes espacios del aula, otros en el patio o incluso hay uno que se realiza, durante algunas sesiones, en el bar de los Jubilados que está pared con pared del centro escolar. En el caso 4 disponen de dos espacios suplementarios, fuera del aula, para que el alumno, pueda hacer uso y trabajar en ellos, si lo necesita.

Esta variedad de modalidades de trabajo mediadas por los diferentes agrupamientos, diferentes tiempos y diferentes espacios promueven la motivación (Reeve, 2001) y el interés (Tomlinson, 2008) del alumnado hacia la tarea.

Otros elementos a tener en cuenta, en el aula inclusiva, son los recursos materiales y personales. En los casos estudiados tienen diferentes recursos o apoyos visuales que ayudan y guían al alumnado que lo necesita a efectuar la tarea. En el caso 1 resaltar que cada grupo, en su mesa, tiene un cartel con una imagen de los cargos del grupo y una breve explicación de las tareas. Otro apoyo visual a destacar es la pauta de la actividad de leemos en pareja, a medida que avanza el curso, la mayoría de alumnos, ya no la van necesitando. En dicha actividad, también disponen de un documento con frases, con elogios, para reforzar positivamente a los compañeros. En el caso de las exposiciones de las lecturas, en el aula, tienen una hoja registro para ir anotando las lecturas realizadas por el alumnado de la clase. Mencionar también, en este primer caso de estudio, el pizarrón donde, los encargados de ello, anotan los diferentes deberes (esta información también se encuentra en el blog del aula). En el aula del caso 2, encontramos algunos carteles (p.ej. guión de escritura de la carta) que ayudan al alumnado en la escritura. Además, también cuentan con algunas pautas para autoevaluar sus escritos de notas o cartas que son utilizadas principalmente en $1^{\circ}$ de primaria. Al escribir algún texto para el proyecto también se apoyan de manera visual en lo que la maestra va escribiendo, al dictado, a la pizarra. En el caso 3, o bien la maestra o bien el encargado de la semana, a menudo, escriben en la pizarra las instrucciones básicas para resolver la actividad, por ejemplo, en la actividad del taller de ciencias o en las estaciones, esto ayuda al alumnado a saber cómo resolver la tarea sin necesidad de estar todo el rato preguntando (Jorba y Cassellas, 1997). Asimismo, en las estaciones disponen de un cartel con el nombre de la técnica de aprendizaje cooperativo que tienen que utilizar para resolver la actividad. En los rincones de trabajo también tienen unos carteles indicativos (que el alumnado ha realizado) y una hoja registro para anotar los rincones realizados. En el caso 4, en el aula se encuentran diferentes 
carteles sobre escritura que puede consultar el alumnado cuando lo necesite. Además, la maestra ha ido fabricando diferentes materiales manipulativos para trabajar conceptos matemáticos. Hacer mención también, en este apartado, la utilización de las nuevas tecnologías de la información y comunicación (TIC) (Montserrat y Hernández, 2013). En el caso 1, cuentan con diferentes ordenadores de mesa o portátiles que el alumnado utiliza muy especialmente en los grupos de investigación de cultura valenciana. Aparte, el alumnado gestiona su propio blog de aula. El caso 2 (en ambas aulas) cuenta con la pizarra digital, la cual fue instalada a mediados del curso 2014/2015. Ésta fue utilizada muy especialmente en el proyecto de Betxí (tratamiento de las imágenes, visitas virtuales a la localidad mediante Googel Maps). El caso 3 destaca sobresalientemente por los numerosos recursos tecnológicos y el uso que se hace de ellos en el aula. En clase se encuentran diferentes ordenadores de mesa y cada alumno tiene una Tablet. En este caso el alumnado también tiene un blog de aula. En el caso 4, disponen de un ordenador en un rincón del aula.

Por lo que respecta a los recursos o apoyos personales destacar que en todos los casos existe una ayuda ofrecida por los iguales, brindada a partir del aprendizaje cooperativo (Johnson y Johnson, 1999; García, Traver y Candela, 2001; Pujolás, 2008; Muntaner, 2014). En el caso 2, destacamos la presencia de la maestra de pedagogía terapéutica, en algunas ocasiones, en el aula. Esta ayuda en la escritura, por ejemplo, en los proyectos de trabajo, a los alumnos que más lo necesitan. Las familias acuden al aula a ayudar en los quehaceres diarios (proyectos, grupos interactivos y talleres). Además, en los proyectos de trabajo siempre se invita algún experto sobre la materia que introduce otros discursos en el aula. En el caso 3, las familias también ayudan en lo que el alumnado necesita, por ejemplo, en el curso académico 2014/2015, las ayudas se concentraron en el proyecto LóVA. Destacar que está instaurado en todo el CRA, la presencia de dos maestros en el aula (Huguet, 2006) en diferentes zonas horarias de la jornada escolar. El maestro de apoyo (no es especialista de Pedagogía Terapéutica ni Audición y Lenguaje) brinda su ayuda y colaboración al conjunto del aula bajo la orientación del tutor (Berruezo, 2006; Benoit y Angelucci, 2011; Muntaner, 2014; Traver, 2014). Siguiendo con el caso 3, destacar que la docente ante el desafío que supone la heterogeneidad dentro del aula, ésta le solicita ayuda a la psicopedagoga para que le dé información y poder resolver el problema dentro del aula, como primer paso. Esto es, la psicopedagoga no se lleva al alumno en cuestión. Destacar de este hecho la importante labor que juegan los psicopedagogos u orientadores educativos en el asesoramiento y orientación psicopedagógica que permita avanzar hacia prácticas de aula inclusivas. En el caso 4, la maestra de apoyo y la maestra tutora del aula trabajan de manera coordinada. Además, la docente presentada y la otra maestra del aula tienen una agenda para hacer un seguimiento. Se puede ver que en los recursos o apoyos personales subyace una cultura colaborativa (Ortiz y Lobato, 2003; Guarro, 2005; Traver et al. 2010) a partir de la cual, los maestros van tejiendo redes de apoyo (Lieberman y Grlonick, 1997; Lieberman y Grlonick, 2005; De Ugarte, 2007). 
En segundo lugar, se aborda la diferenciación del contenido. Se trata de la variedad de textos, saberes y conocimiento, el grado de complejidad y los diferentes materiales didácticos (Leroux y Paré, 2016). Siguiendo a Tomlinson (2008), el contenido es aquello que un estudiante debe llegar a conocer (hechos), comprender (conceptos y principios), y ser capaces de hacer (habilidades) como resultado de un segmento concreto de estudio (una lección, unidad o experiencia de aprendizaje). El contenido es lo adquirido. Asimismo, engloba todos los medios que ponen al alumno en contacto con la información (libros de texto, lecturas suplementarias, vídeos, excursiones, ponentes, conferencias, experimentos, programas de ordenador...). En el caso 1, se diferencia el contenido en la asignatura de cultura valenciana, visto que cada grupo estudia más a fondo un bloque de contenidos, acudiendo cada uno de ellos a diferentes fuentes de información (Internet, libros, manuales...). En la dinámica de la exposición de libros, se diferencia el contenido en el sentido de que cada alumno escoge voluntariamente que y cuanto leer. Mencionar también la dinámica de leemos en pareja, ya que ésta sufre una variación o diferenciación desde el primer trimestre hasta el tercero. Siendo mayor la diferenciación del contenido en el tercer trimestre, en el cual los alumnos tutores elaboran los textos a abordar y las actividades (Duran et al. 2009), variando de esta manera el material a trabajar por cada uno de los alumnos tutorados. La actividad del cuentacuentos, también sufre una diferenciación. Destacar que en el segundo trimestre el alumnado redacta y elabora el cuento. En la tertulia literaria dialógica todos leen el mismo libro y comentan al respecto según sus experiencias e impresiones. En el caso 2, se diferencia el contenido en los proyectos de trabajo, los alumnos manejan diferentes fuentes de información (múltiples libros de texto, manuales, cuentos, vídeos, fuentes orales- abuelos, expertos). En los grupos interactivos también se diferencia los contenidos, ya que en una hora y treinta minutos realizan diferentes actividades de matemáticas y lenguaje. Dicha diferenciación de contenido también está presente en la actividad del cuentacuentos, donde los alumnos cuentan diferentes clásicos a infantil. Por lo que respecta al caso 3 decir que, se diferencia el contenido en la actividad del rompecabezas o Puzzle de Aronson (cada alumno realiza unos bloques de problemas matemáticos), en el taller de ciencias (cada grupo aborda el estudio de determinados minerales), en la lectura por parejas (para resolver las actividades cada pareja acude a diferentes fuentes, p.ej. mapas, Atlas, Internet...), estaciones y rincones de trabajo (otra manera de trabajar los contenidos) y en la dinámica de la exposición de libros (cada alumno escoge voluntariamente que y cuanto leer). La diferenciación del contenido en el caso 4 se evidencia en que si van a realizar diferentes exposiciones el alumnado escoge la temática y con ella las diferentes fuentes de información. Se percibe cómo en los momentos en que el alumnado puede escoger las temáticas a estudiar se va democratizando el currículum (Ashenden et al. 1988; Escudero, 2006).

En tercer lugar, se aborda la diferenciación del proceso. En palabras de Leroux y Paré (2016) se diferencia el proceso según el campo de interés del alumnado, los conocimientos previos y el nivel de competencias, las retroalimentaciones entre el alumno y el docente o el alumno y sus pares, nivel de desarrollo del alumnado (motor, cognitivo, social...), motivación y compromiso hacia la tarea y el 
modo de vida del alumnado. Siguiendo a Tomlinson (2008), el proceso es la oportunidad que tienen los alumnos de dar sentido a los contenidos. Los aprendices deben procesar las ideas para apropiarse de ellas. En todos los casos estudiados, y tal como ya se ha mencionado anteriormente, la diferenciación en las estructuras contribuye a fomentar la motivación y el interés del alumnado para hacer una escuela más agradable y divertida, en definitiva, escapar del aburrimiento y de la monotonía. Se ha visto con las diferentes prácticas documentadas que el compromiso y la motivación del alumnado hacia la tarea es elevada en la mayoría de las dinámicas o actividades ilustradas, éste decrece cuando el alumnado adopta un rol más pasivo. Por tanto, hay que potenciar que el alumnado sea el verdadero protagonista de su aprendizaje y se genere una sinergia de independencia del docente (Berruezo, 2006). Al hilo de lo anterior, se precisa recordar que el constructo alumno protagonista (enmarcada en el bloque de diferenciación pedagógica y participación democrática) es una de las categorías emergente en este estudio. Además, los maestros pretenden desarrollar un aprendizaje funcional y significativo (Ausubel, 2002) para el alumnado. Por ese motivo, siempre realizan actividades con sentido y por necesidad o utilidad en los quehaceres escolares (p.ej. la tarea de escribir una carta resulta más motivadora para el alumnado si escriben a niños de otros colegios, invitan a alguien a colaborar en el proyecto o para solicitar alguna cosa al ayuntamiento). Notemos también, cómo en todas las actividades propuestas las retroalimentaciones entre los iguales y entre los alumnos y los docentes son frecuentes. Extendiéndose éstas, en numerosas ocasiones, a retroalimentaciones ofrecidas por familiares $u$ otros agentes comunitarios. En el caso 1, se diferencia el proceso en la asignatura de cultura valenciana, visto que según las preferencias o el interés del alumnado se escoge la temática a estudiar. Además, según las preferencias del alumnado en referencia a la temática se configuran los grupos de trabajo. El interés también guía las elecciones del alumnado en la actividad del cuentacuentos a infantil, las exposiciones de libros y la dinámica de leemos en parejas, en ésta última, los alumnos reconocen la diversidad de sus propios compañeros (Prud'Homme et al. 2016), ya que éstos confeccionan las actividades y escogen los textos en función de los intereses y los conocimientos previos o capacidades de sus compañeros. En el caso 2, el interés está muy presente en los proyectos de trabajo, ya que toda la clase escoge que quiere estudiar (temática general) y que es lo que va a abordar cada uno de los equipos (subtemas específicos). Los proyectos de trabajo parten de los conocimientos previos, de las necesidades, motivaciones e intereses del alumnado (Díaz Navarro, 1995). La maestra (caso 2.1) ha comentado que, en otras ocasiones, otros alumnos que ha tenido, han estudiado el tema de la prehistoria porque al alumnado le genera interés aquellos aspectos lejanos a ellos mismos o sus tiempos. Pero, nunca hay dos proyectos iguales, ya que el transcurso del mismo lo marcan los alumnos, con su implicación, sus indagaciones y sus aportaciones. En la actividad del cuentacuentos también les genera un interés elevado el hecho de ir a contar un cuento a los más pequeños del centro educativo. En el caso 3 destacar los proyectos de centro y LÓVA (escoger roles o profesiones según su interés o motivación), los docentes siempre buscan un eje motivador para desarrollar los proyectos y la maestra extrapola 
dicha temática en las actividades de aula (leemos en pareja, ginkama, estaciones, rincones...). Igualmente, la maestra introduce, a lo largo del curso escolar, diferentes técnicas de aprendizaje cooperativo para captar el interés del alumnado y evitar la monotonía. Destacar el rincón del cronista, en el cual los alumnos escogen, según su interés, la temática de su localidad que quieren indagar. Del caso 4 subrayar el hecho que la maestra propicia diferentes caminos que les llevan a la misma solución, por ejemplo, promueve la resolución de una misma multiplicación siguiendo tres métodos diferentes. De esta manera, el alumnado puede optar por el que mejor se adopte a sus capacidades o habilidades.

En cuarto lugar, nos detenemos en la diferenciación del producto, es decir, las diferentes modalidades de expresión, destinatarios, proyectos o creaciones, modalidades de evaluación del aprendizaje y criterios y niveles de aprendizaje (cualitativos o cuantitativos) (Leroux y Paré, 2016). Tomlinson (2008), por su parte lo entiende como el vehículo mediante el cual el alumno muestra (y amplía) lo que ha llegado a comprender y a saber hacer como resultado de un segmento de aprendizaje de cierta magnitud. Se ha visto que las actividades o dinámicas propuestas son abiertas y flexibles en sí mismas, propiciando múltiples formas de producción o expresión. En el caso 1, en las distintas modalidades de trabajo existe una variedad en las producciones. En la actividad de los cuentacuentos a infantil, en el segundo trimestre, los alumnos escriben y elaboran el cuento. Existe una libertad por parte del alumnado a la hora de escoger como hacer el producto final, hay alumnos cuyo cuento está escrito en una hoja de libreta y otros hacen cuentos más elaborados en formato libro (p.ej. la colita del conejo está hecha de algodón, ventanas que se abren, elementos en movimiento), esto mismo ocurre en el teatro a infantil. El docente siempre intenta que cada alumno mejore y progrese según en el punto en que se encuentra. Estas mismas premisas las encontramos en las distintas modalidades de expresión de los proyectos de trabajo de la asignatura de cultura valenciana, el maestro reitera que cada grupo puede presentar el trabajo cómo le parezca más oportuno. Notemos cómo en los grupos de investigación se fomenta la construcción colectiva del conocimiento (Vygotsky, 1978), visto que cada grupo indaga sobre un aspecto del bloque general de contenidos presentado por el docente, que después comparten con el resto de compañeros. En la actividad de la exposición de libros también se ha visto cómo las producciones son muy variadas (desde simples carteles a carteles con texturas). En la dinámica de leemos en pareja, vemos cómo en el primer trimestre las producciones son las mismas, en el segundo trimestre los alumnos tutores proponen las actividades y en el tercer trimestre las producciones son muy variadas, planteando cada alumno tutor el texto y las actividades que debe realizar su alumno tutorado (Duran et al. 2009). En el caso 2, se ha comprobado cómo en los proyectos de trabajo se realiza una única producción, el dosier, pero de manera cooperativa. Esto es, cada grupo trabaja más a fondo una parte del contenido y lo plasman en sus hojas que conforman el dosier. Destacar también que otras producciones originadas dentro del marco de los proyectos de trabajo (eje cronológico, cueva rupestre, reproducción de homínidos, juego de Betxí a lo largo del tiempo...) son todo producciones cooperativas, cada alumno o grupo aporta su 
granito de arena para constituir lo que es la producción final y con ella la construcción colectiva del conocimiento (Vygotsky, 1978). Del caso 3, destacar ésta misma idea. Por ejemplo, en los murales de la prehistoria enmarcados en la película de Tadeo Jones (del proyecto de centro) o en el taller de ciencias sobre los minerales (cada grupo indaga sobre unos minerales que después comparte con el resto de grupos). En el caso del proyecto LóVA, notemos como las aportaciones y esfuerzos de cada uno de los grupos de oficios o profesiones hacen posible el éxito del producto final. Los carteles de las exposiciones de libros también son variados. En el caso del leemos en pareja o las estaciones las producciones son las mismas, es decir, las actividades, pero cada uno utilizan unas ayudas o apoyos diferentes para resolverlas. Los rincones de trabajo también son los mismos para todo el alumnado clase, resaltar especialmente el rincón del cronista, en el cual cada alumno indaga sobre un aspecto de su municipio. En el caso 4, también existe flexibilidad a la hora de expresar el conocimiento (p.ej. escritos a mano o a ordenador...). Añadir, que en este último caso también hacen producciones colectivas (p.ej. murales artísticos).

Los conocimientos previos y el nivel de competencias o el nivel de desarrollo del alumnado, son aspectos que los docentes tienen presentes en la evaluación, partiendo de unos objetivos mínimos que hay que adquirir. Es decir, los docentes se centran en lo esencial, lo básico, lo fundamental que el alumnado debe de aprender (Heacox, 2002; Tomlinson, 2008). Esto no significa rebajar los conocimientos o hacer más permisible la evaluación (Fernández Batanero, 2009), sino que los maestros sean capaces de articular aquello que el alumnado puede y debe comprender, recordar y asimilar dentro del campo de conocimiento. Por lo que respecta a la evaluación, destacar del caso 1 la presencia de la voz del alumnado en las exposiciones de cultura valenciana (conferencia de evaluación colaborativa -Campbell, 2008), las libretas de sus compañeros (rúbrica), las autoevaluaciones (Sanmartí, 2010) de la actividad de leemos en pareja y las reflexiones colectivas (evaluaciones cualitativas) para mejorar la dinámica del cuentacuentos a infantil. De las líneas anteriores se desprende una de las formas en la cual se materializa la evaluación democrática en el aula inclusiva (López, 2005; López et al. 2006; Murillo y Hidalgo, 2016). En el caso 2 la evaluación supone un dilema para las docentes. En los proyectos de trabajo se hace una evaluación escrita y/o oral para promover y facilitar las respuestas al alumnado. Además, se promueve la reflexión grupal del trabajo a partir de los escritos de la carpeta del equipo y las estrellas para ir mejorando en el trabajo diario. En el caso 3, el alumnado se autoevalúa en la actividad de leemos en pareja y también hacen uso de rúbricas o WebQuest. En el caso 4, para la maestra también le resulta conflictivo el hecho de poner al alumnado notas numéricas, ésta señala que preferiría destacar si el alumno lo ha adquirido o no.

En lo que respecta a la diferenciación recordar que según Tomlinson (2008), Caron (2008) y Leroux, Fontaine y Sinclair (2015) ésta puede ser, además de sucesiva o simultánea (tal y como ya se ha comentado), planificada o espontánea y mecánica o regularizada. Se ha notado cómo en la mayoría de las prácticas de los casos abordados la diferenciación es planificada. No obstante, muchas de las 
interacciones o los aspectos que surgen de la práctica didáctica no pueden ser planificadas o previstas por los docentes (p.ej. en los proyectos de trabajo los alumnos escogen el tema y a partir de ahí se va generando el mismo o la tertulia literaria dialógica se va condicionando según las intervenciones y aportaciones del alumnado). La diferenciación está regularizada a lo largo del curso, ajustándose a medida que se va realizando y derivándose diferentes modificaciones o variaciones de algunas modalidades de trabajo.

\section{$\sim$ Valores democráticos}

Seguidamente, se hace un recorrido sobre los principales asertos que nutren este segundo bloque de creencias, actitudes y valores subyacentes en las prácticas didácticas propuestas por los maestros cuyas aulas han sido objeto de estudio. Hay que recordar que, en este trabajo se entiende por valores democráticos a los principios necesarios para fundamentar la elección de una vida en sociedad (Pérez Tapia, 1996 y Campos 1997) orientada hacia un proyecto común (solidaridad, libertad, igualdad, justicia, respeto, desarrollo sostenible, inclusión, interculturalidad, etc.). Se lleva a cabo una revisión de los resultados que se derivan de las categorías teóricas tomadas en consideración en este estudio, recuérdese que éstas son: participación democrática, liderazgo compartido, cultura colaborativa, redes de apoyo, ciudadanía crítica, sentido de pertenencia, vinculación con el territorio y comunicación intercultural.

En primer lugar, centraremos la mirada en la categoría teórica referente a la participación democrática. Entendida como el mecanismo a través del cual las personas de una comunidad toman decisiones escuchando todas las voces y adquiriendo un compromiso como miembros activos en un proceso de cambio y transformación social hacia la equidad, inclusión y justicia social (Delors, 1993; Stainback y Stainback, 1999; Ainscow, 2001b; Arnaiz, 2003; Santos, 2006). En el caso 1, destacar la elección de los contenidos (diferenciación del contenido y del proceso- según interés, preferencias o motivaciones) a estudiar por parte del alumnado en los grupos de investigación de cultura valenciana. Vemos un claro ejemplo en el que el docente escucha la voz de su alumnado (Susinos, 2012; Susinos y Ceballos, 2012). Asimismo, señalar la sesión de los grupos de investigación en la cual entre todos acuerdan y deciden sobre la evaluación de las exposiciones (ítems de evaluación y forma de valoración- conferencia de evaluación colaborativa -Campbell, 2008). Por consiguiente, los alumnos tienen voz y voto en la evaluación (López, 2005; López et al. 2006; Murillo y Hidalgo, 2016), visto que las notas medias de los otros grupos son tomadas en cuenta por el docente (en cultura valenciana) y la valoración de las libretas mediante una rúbrica acordada entre todos al inicio del curso escolar. La tertulia literaria dialógica es otro escenario donde todos participan, todos aportan sus experiencias y comentarios desde el respeto y la escucha de todas las voces (Pulido y Zepa, 2010; Aguilar et al. 2013; Hargreaves y García-Carrión, 2016). En el leemos en pareja y el cuentacuentos a infantil el alumnado puede escoger y elaborar los materiales sobre los cuales versarán las sesiones. En el caso 2, vemos la asamblea (Poveda et al. 2003- denominada por éstos como la ronda; Pujolàs, 2003) como un órgano de 
participación y toma de decisiones colectivas. La diferenciación del contenido y del proceso (según el interés y la motivación del alumnado) citado anteriormente, referente a los proyectos de trabajo, vienen mediadas por la capacidad que tiene el alumnado en escoger y decidir el tema a estudiar, visto que entre todos deciden que es aquello sobre lo que quieren indagar (de manera justificada). En un segundo momento, negocian, mediante otra asamblea, que subtemas va a trabajar cada uno de los equipos. En la dinámica del cuentacuentos a infantil, el alumnado también puede elegir que cuento clásico van a contar a la clase que ellos acuerden. Además, dicha elección viene reflexionada, no vale cualquier cuento, se tiene que adecuar a las características del público, es decir, aquello que les puede gustar a los niños pequeños. También puede que el cuento sea propuesto por la clase de infantil en cuestión, según lo que éstos están trabajando. Además, en dicha actividad también son los alumnos, quienes escogen la pareja con quien quieren realizar esta actividad. Vemos como la forma de elección es diferente entre ambas aulas (en el caso 2.1 la elección es a mano alzada, en el caso 2.2. se escriben 4 opciones en un papel). Del caso 3 destacar la tertulia literaria dialógica como un espacio en que todo el alumnado puede participar y dar su opinión (Pulido y Zepa, 2010; Aguilar et al. 2013; Hargreaves y García-Carrión, 2016). En lo que respecta al proyecto LÓVA, todas las decisiones son tomadas y acordadas por el alumnado. Igualmente, en este proyecto los alumnos pueden escoger sus profesiones o roles según sus intereses o motivaciones (diferenciación del proceso). En el caso 4 se ha visto cómo se da la oportunidad al alumnado de hacer pequeñas elecciones siempre desde el respeto a sus compañeros. Destacar de este caso el consejo de clase en el cual los alumnos aportan proposiciones, ideas y proyectos que los delegados de clase deben de aportar al consejo de delegados (consejo de escuela).

Dentro del marco de la participación democrática en el aula, resaltar el hecho de la participación de las familias (categoría emergente en este estudio) en la misma o fuera de ésta (Hornby, 1990; Eccles y Harold, 1996; Kohl et al. 2000; Epstein, 2001). En los casos 1, 2 y 3 se realiza una reunión inicial con las familias donde se les explica la metodología y la forma de trabajar en el aula. En el caso 1, la participación de las familias es progresiva. Se ha visto que en $5^{\circ}$ de educación primaria el docente les invita, pero no de manera explícita. En el primer año que el alumnado está con el docente la participación de las familias queda relegada, en el hogar, a la actividad de leemos en pareja, actividad que es introducida a las familias en una reunión explicativa. Dicha participación de los familiares se hace más real, en el aula, el segundo año que el alumnado está con el maestro. La participación se materializa a través de los grupos interactivos (matemáticas), exposiciones, tertulia literaria dialógica (valenciano),... El caso 2 destaca notablemente por la participación de las familias en el aula. En este caso la participación de las familias también es gradual. Por ejemplo, en los proyectos de trabajo, cuando el alumnado cursaba $1^{\circ}$ de primaria, las familias ayudaban dentro del aula en algunas sesiones del trascurso del mismo. En $2^{\circ}$ de primaria, en los proyectos de trabajo, las familias juegan un rol importante, pero su colaboración y participación se centra en el periodo de búsqueda de información 
en el hogar. Esto se debe a que el alumnado va adquiriendo mayor autonomía. Sin embargo, en el proyecto de Betxí a lo largo del tiempo los abuelos son la principal fuente de información y su protagonismo en el mismo es notable. Para las personas mayores es muy gratificante, dar testimonio y compartir conocimiento, lo conciben como una responsabilidad (Belgrave, 2011; Whitehouse, 2013). De igual modo, presentan altos niveles de implicación, visto que traen al aula canciones, fotos, escritos sobre como jugaban, entre otros. En los grupos interactivos (los adultos son un elemento motivador), en el cuentacuentos a infantil (en $1^{\circ}$ de primaria los padres junto a su hijo cuentan un cuento a sus compañeros, en $2^{\circ}$ algún padre o madre va a ayudar en el ensayo, es decir, antes de que la pareja vaya a contar el cuento a la clase de infantil seleccionada) y en los talleres interciclo también ayudan los familiares. Resaltar que, tanto en el caso 2 como en el caso 3, la participación familiar no es constante a lo largo de todo el curso. Depende del trabajo de los padres en el sector cítrico, factor que dificulta la participación en el aula. Las madres entrevistadas coinciden en que la participación de las familias en el contexto escolar se da básicamente porque los docentes la propician y la facilitan (Moliner y Traver, 2016). Siguiendo en el caso 3 vemos como las familias tienen un papel importante en el proyecto LÓVA y en los talleres de los jueves (éstos pueden o bien participar en el taller o bien proponer ellos mismos alguno). Notemos en este caso como la participación de las familias y de los alumnos no solamente se enmarca entre las 4 paredes del aula, en este caso el centro cuenta con diferentes espacios de participación y toma de decisiones colectivas: jornadas de puertas abiertas y convivencia, comisiones mixtas de trabajo, ampliación de la representación de todos los colectivos escolares en los órganos de decisión de la escuela (Aguirre, Català, Doménech y Escobedo, 2015; CRA Benavites - Quart de les Valls y MEICRI, 2016). En el caso 4, la participación de las familias se limita en que éstas son invitadas al aula para que expliquen o compartan algún aspecto y en eventos festivos (p.ej. antes de Navidad).

Siguiendo con el liderazgo compartido, éste existe cuando hay un compromiso e implicación, a nivel de ideas y esfuerzos, de todos los miembros en el funcionamiento del aula, generando un clima de propósito compartido y de trabajo en equipo. Los líderes formales (docentes) van delegando autoridad y responsabilidades a las familias y al alumnado, de tal manera que las funciones se reparten entre los miembros del aula, quienes se responsabilizan de llevarlas a cabo (Bennet et al. 2003; González, 2003; Woods et al. 2004; Murillo, 2006; Mujis y Harris, 2006). En el caso 1 se ha visto cómo el maestro propone desde un primer momento que sea el alumnado quien gestione el aula y el grupo. Así pues, el alumnado adopta una serie de roles o funciones que debe desempeñar tanto para el buen funcionamiento del aula como de su propio grupo. Esto exige de un compromiso e implicación por parte de todos los miembros del aula, ya que deben saber atender y respetar las diferentes demandas que en ella se producen. En los grupos de investigación, se detecta también un liderazgo compartido, ya que los propios alumnos son los encargados de indagar y posteriormente explicar a sus compañeros el bloque de contenidos que han trabajado. En lo que respecta a la tertulia literaria dialógica, destacar el rol del moderador. Éste se encarga de gestionar los turnos de palabra, de 
propiciar la participación de todos los miembros en la lectura y de redactar un resumen de la sesión. Nombrar también que en la actividad del cuentacuentos a infantil, cada alumno de $5^{\circ}$ de primaria se responsabiliza de un alumno de infantil a quien le cuenta el cuento. Destacar también el rol del tutor, en la dinámica de la lectura en pareja, quien se responsabiliza y se compromete a preparar el material y tutorar a su alumno. En el caso 2, este liderazgo compartido se materializa en los encargados del día, éstos hacen una serie de tareas (asignadas cada día según las necesidades surgidas) que repercuten en el funcionamiento del aula. En el caso de los proyectos de trabajo se detecta como existe también un liderazgo compartido, en tanto y cuando los alumnos son los encargados de indagar y explicar los conocimientos a sus compañeros (primer contacto con el material que van aportando a la mesa de la información). Al mismo tiempo, conceptos que tradicionalmente son explicados o resueltos por los docentes, en este caso los alumnos buscan ayuda en alumnos del centro de cursos más avanzados. En los grupos interactivos, son los adultos los encargados de ayudar o explicar al alumnado de su mesa. En el cuentacuentos a infantil también hay dos niños que se encargan de preparar y contar el cuento a la clase seleccionada, suponiendo esto una responsabilidad. En el caso 3, igualmente existe la figura del encargado de la semana quien debe desarrollar una serie de tareas que repercuten en el buen funcionamiento del aula. A nivel de grupo, vemos como existe un liderazgo compartido entre los docentes y los coordinadores o directores de cada mesa, éstos son los encargados de organizar y ayudar, en la ejecución de la tarea, a su equipo. Asimismo, dentro del grupo éste también se encarga de distribuir o asignar otras funciones o tareas a los diferentes miembros del grupo. En lo que atañe a la tertulia literaria dialógica, destacar el rol del moderador, el cual reparte los turnos de palabra y propicia la participación de los diferentes miembros del aula. Para la ejecución del proyecto LÓVA, también se requiere de un liderazgo compartido, visto que cada grupo de alumnos adopta unas funciones $u$ oficios con el objetivo de conseguir un mismo objetivo compartido por todos los integrantes del aula. Acentuar del caso 4 las funciones que desempeñan los delegados de clase en el consejo de escuela. También el compromiso y la responsabilidad que adoptan los alumnos que terminan más rápido las tareas en el hecho de corregir y ayudar a sus compañeros. Destacar también que en este caso los alumnos también tienen asignados unos roles o funciones que repercuten en el buen funcionamiento del aula. Se detecta en este liderazgo, otro indicio que nos muestra el rol activo del alumnado, quedando relegado el papel del docente a mero dinamizador, facilitador o acompañante en el proceso de aprendizaje (Hernández, 2000; Viñales y Cuenca, 2016).

Acto seguido se aborda la cultura colaborativa, la cual es entendida como el conjunto de actitudes, valores y creencias asociados a la solidaridad que guían las relaciones de las personas que forman parte de un contexto educativo, basadas en la participación igualitaria, democrática y cooperativa (Ortiz y Lobato, 2003; Guarro, 2005; Traver et al. 2010). Dicha categoría teórica, está altamente relacionada con los agrupamientos y con los recursos o apoyos personales, nombrados anteriormente en el eje de la diferenciación pedagógica. Se generan, en el aula, diferentes interacciones que forjan 
relaciones y conflictos. Y con éstos, la necesidad de buscar el consenso o llegar a un acuerdo desde el respeto de los diferentes puntos de vista u opiniones. Al mismo tiempo, este constructo teórico, implica y facilita relaciones de horizontalidad, diálogo igualitario y respeto hacia la pluralidad de voces en el aula. Se ha verificado en todos los casos como se propicia la ayuda entre iguales (Cowie y Fernández, 2006; Duran y Blanch, 2008; Duran, Flores, Mosca, Santiviago, 2015), como medida para atender a la diversidad del aula. Análogamente, se ha visto en lo referente a la diferenciación del producto, como subyace la cultura colaborativa en la idea de la construcción colectiva del conocimiento (Vygotsky, 1978) partiendo de la idea de que todos pueden aportar. La participación de las familias también descansa en este constructo teórico, puesto que los padres o abuelos son los encargados de ayudar, explicar o aportar en el aula. Remarcar que, en el caso 3, esta cultura colaborativa está muy presente a nivel de centro. Cómo se ha visto en los recursos o apoyos personales, está instaurado en el CRA la presencia de otro maestro en el aula para apoyar y colaborar en la actividad. De esta categoría teórica también se desprende el concepto de redes de apoyos. Entendidas éstas como el conjunto de relaciones sociales, colaborativas e inclusivas, que la comunidad educativa establece con el entorno y que reconoce como significativas. Pueden ser relaciones formales o informales y constituyen una dinámica de apoyo mutuo basada en la igualdad y la horizontalidad. Las redes de apoyo ofrecen acompañamiento en función de las necesidades de la propia comunidad educativa. Entre los elementos compartidos destacan el estímulo para el desarrollo profesional docente a través del intercambio de experiencias, la circulación del conocimiento y el establecimiento de vínculos que trascienden el propio centro escolar (Lieberman y Grlonick, 1997; Lieberman y Grlonick, 2005; De Ugarte, 2007). De ahí que, el maestro del caso 1 realiza formaciones auspiciadas por el CEFIRE en las cuales muestra y comparte su forma de trabajar en el aula. De este mismo caso, comentar también la actividad de cartearse con alumnos de otros centros, ya que a partir de los contactos del maestro con otros docentes se genera esta actividad. En el caso 2, siempre se acude a agentes del entorno más cercano para que compartan en el aula su conocimiento o experiencias, se trata de redes informales que se trazan con los expertos o especialistas de la zona que pueden contribuir en el proyecto de trabajo (p.ej. paleontóloga e historiador). También se crean redes o sinergias de colaboración entre el CEIP Cervantes J. Dualde y la Escuela de Personas Adultas (E.P.A.) de Betxí. En el caso 3, destacar las redes de apoyo establecidas dentro del proyecto LóVA, a partir de las cuales la maestra de música se refuerza y apoya con los compañeros que hicieron el curso con ella y realizaron también mencionado proyecto en sus aulas.

Otro punto a mencionar es el referente a la ciudadanía crítica. Ésta apela al ejercicio de una ciudadanía que problematiza la realidad, reflexiona cooperativamente y propone acciones colectivas. Para ello es necesario un liderazgo compartido, un compromiso personal y social y una implicación activa en la planificación, toma de decisiones democrática y puesta en marcha de la acción (Benjamin, 2002; Sales, 2012). Tal como ha sido puesto de manifiesto por el docente del caso 1, con su forma de trabajar pretende que su alumnado se haga cada vez más crítico, es decir, se vaya forjando sus 
propios pensamientos $u$ opiniones, sin necesidad de acatar lo que viene dado. En el caso 2, se fomenta que las elecciones de las temáticas de los proyectos de trabajo sean razonadas y justificadas por el alumnado. $Y$ en referencia a dicha idea de ir forjando un pensamiento crítico en el alumnado resaltar dos hechos que nos pueden llevar a afirmar que efectivamente esta forma de trabajar lo propicia. Se trata del hecho que a los alumnos de ambas aulas (caso 2.1 y caso 2.2) les gusta escoger y decidir entre todos, mediante asamblea, el nuevo tema del proyecto que van a realizar. Hay que recordar que en ambas clases, para el proyecto de trabajo del tercer trimestre se propuso una temática (las abejas en el caso 2.1 y Betxí a lo largo del tiempo en el caso 2.2) aspecto que, en un principio, no fue especialmente del agrado del alumnado. Ante esta situación se optó por votar en asamblea si estaban de acuerdo o no en abordar las temáticas propuestas. Finalmente, en el caso 2.1 se acordó en estudiar los insectos, una temática general que servía para contextualizar y trabajar con el abuelo que había fabricado la colmena de cristal. Y en el caso 2.2 se aprobó ayudar a la alumna de prácticas para ejecutar su Trabajo Final de Grado (TFG). Por lo que respecta al caso 3, destacar los órganos de participación a nivel del CRA, donde todas las voces están representadas y se problematiza la realidad, reflexiona cooperativamente y propone acciones colectivas que atañen a toda la comunidad escolar. En el caso 4, la docente promueve siempre la justificación del porqué de las elecciones o razonamientos. Mencionar también el consejo de escuela donde los delegados aportan y tratan sobre las necesidades o problemáticas surgidas en la escuela. Notemos cómo este fomento de la ciudadanía crítica promueve básicamente dos de los tres tipos de ciudadanía propuestos por Fillion et al. (2016) como son una ciudadanía personalmente responsable y una ciudadanía participativa, quedando más relegada a un segundo plano una ciudadanía orientada hacia la justicia social (resolución de situaciones de injusticia).

Acerca del sentido de pertenencia, hay que recordar que ésta se entiende por la consciencia de vinculación emocional, histórica y cultural con la comunidad escolar y con su entorno. Reconocimiento positivo y apropiación de los lazos intra e intercomunitarios que genera la institución educativa. Sensación de que la experiencia vivida en la escuela deja una huella personal que, a su vez, es compartida por otros miembros del colectivo y es capaz de construir una identidad colectiva (Muntañola, 1996; Hellinger, 2001; Ander-Egg, 2005; Carvajal, 2011; Feito, 2010). Este constructo teórico se nutre del hecho de hacer partícipe al alumnado, tanto en el propio proceso de aprendizaje como en la gestión y participación de lo que ocurre en la vida social y democrática en la clase. En el caso 1, destacar la actividad del cuentacuentos a infantil, visto que al preguntar al alumnado si les gustaría cambiar de niño con quien hacen la actividad todos contestan que no, se crean lazos sociales y emotivos entre ambas aulas. En el caso 2, se potencian lazos sociales a partir de la actividad de los talleres interciclo, donde los alumnos comparten con los diferentes compañeros de otras aulas que configuran el $1 \mathrm{r}$ ciclo de educación primaria. Por lo que respecta al caso 3, mencionar que el proyecto LóVA, ayudó considerablemente a consolidar el grupo clase, ya que todos trabajaron 
duro para conseguir un objetivo compartido. Además, la maestra siempre intenta realizar ginkamas para potenciar la cohesión social del alumnado de su aula. Hay que resaltar de este caso el hecho de que tengan un nombre identificativo del aula. El sentido de pertenencia también se potencia en el caso 4, a partir de los diferentes representantes que asisten al consejo de escuela y con las actividades lúdicas potenciadas para que los diferentes alumnos de todo el bâtiment se conozcan.

Se puede decir que tanto la categoría de ciudadanía crítica, como la de sentido de pertenencia se van forjando a medida que el alumnado va experimentando, procesualmente, experiencias en el contexto escolar. Parecen categorías trasversales, es decir, esta forma de trabajar en la que está presente la participación democrática, la cultura colaborativa, el liderazgo compartido del docente a otros agentes (alumnos, familias y expertos), y sus continuas reflexiones, debates o búsqueda del consenso contribuyen a forjar un pensamiento más crítico y con éste una ciudadanía crítica comprometida. Lo mismo ocurre con el sentimiento de pertenencia. El ver que mi voz cuenta, puedo decidir en los órganos destinados a ello, puedo ayudar o ser ayudado por diferentes personas en el aula (alumnos, maestra), del centro (otras clases que vienen a explicar o vamos nosotros a explicar) o del entorno más inmediato (expertos, EPA, familiares: padres y abuelos), puedo participar en el aprendizaje... genera una identidad colectiva, cohesión social, lazos emocionales y afectivos, el sentirse valorado y reconocido.

Para terminar, con este bloque de creencias y valores, se abordan dos categorías teóricas que tienen menor presencia o fuerza (en los casos estudiados) en comparación con las otras categorías mencionadas. Se trata de la vinculación con el territorio y la comunicación intercultural.

La vinculación con el territorio, es entendida como la vinculación de la escuela con el territorio, se expresa en el desarrollo de relaciones sostenibles y de apoyo mutuo, mediante los cuales se percibe un sentido de pertenencia (aceptación y valoración) e implicación recíproca entre la comunidad escolar y su entorno (Anant, 1966; Hagerty et al. 1992). Del caso 1 destacar los conocimientos trabajados mediante los grupos de investigación de la asignatura de cultura valenciana, donde todas las temáticas estudiadas corresponden a la Comunidad Valenciana. Subrayar también, un texto del leemos en pareja referentes a las poblaciones de l'Alcalatén. Esta categoría está muy presente en el proyecto de Betxí a lo largo del tiempo efectuado en el caso 2.2, a partir del cual el alumnado ha estudiado los orígenes y la evolución efectuada por su localidad, para ello se han visitado diferentes lugares del municipio y se ha invitado a personas mayores- propiciando relaciones intergeneracionales en el aula (Puigví et al. 2016) y a un historiador para que les explicaran al respecto. En el caso 3, esta categoría se ilustra en los rincones de trabajo, específicamente en el rincón del cronista. A partir del referido rincón, la clase realizó sus aportaciones para la confección del libro del municipio elaborado por todo el aulario. En el caso 4, se evidencia una cierta vinculación en el territorio a partir de las diferentes excursiones que realizan en su entorno más inmediato cuando estudian algunos aspectos (p.ej. el huerto o la electricidad). 
La comunicación intercultural, es referida a aquellas interacciones comunicativas verbales y no verbales entre personas con diferentes referentes culturales. Es un proceso de negociación de significados, prácticas y valores en el que los participantes relativizan la propia cultura a la vez que generan comprensión de valores alternativos. La finalidad de este proceso es crear un mestizaje de saberes y prácticas culturales capaz de vincular a los sujetos en una propuesta de convivencia integradora. Tal objetivo requiere una competencia comunicativa basada en la empatía, la eliminación de estereotipos negativos y la mediación intercultural (Rodrigo, 1999; Touriñán, 2005; Lozano et al. 2008; Rizo, 2013). En el caso 1 se trabaja algunos textos en leemos en pareja referente a otras culturas. Esta categoría se evidencia en el caso 2.2 a partir del trabajo del proyecto de Betxí. Como hay una alumna que sus padres vienen de Rumanía (ella es nacida en Betxí) y sus abuelos no pueden asistir, al igual que el resto de abuelos de sus compañeros, a aportar sus experiencias y conocimientos del trascurso del tiempo en la localidad, la docente le cede un espacio para que la niña muestre y comente algunas fotografías de sus antepasados. Es una forma de visibilizar a su familia y de reconocer la diversidad cultural en el aula. Así pues, decir que dicha categoría es la que menor presencia y visibilidad tiene en los datos analizados en este trabajo.

Para terminar, resaltar también que los maestros cuyas prácticas de aula han sido examinadas están sometidos a una reflexión continúa sobre su propia práctica docente (Rosales, 1990). No siempre realizan los mismos métodos de trabajo en el aula, se adecuan a las circunstancias y a la naturaleza de éstas. Son maestros que se adaptan, son flexibles. Subrayar el hecho de que en el caso 3 se establezcan espacios colectivos de reflexión docente, ya que todos los maestros del CRA llevan una misma filosofía educativa de trabajo. 


\section{$\sim$ Conclusiones}

Algunas conclusiones generales: a modo de cierre

$\mathrm{U}$

na de las principales conclusiones que se desprende de los resultados teóricos radica en la conceptualización del término de diferenciación pedagógica. Se ha visto cómo, tanto en el ámbito francófono como en el anglófono, existe una larga tradición de investigadores que se han centrado en su estudio. Por otro lado, son más escasos los estudios realizados en relación a esta temática desde el ámbito hispanohablante. Y, en algunos casos, entendiendo connotaciones negativas del vocablo, tanto en el ámbito nacional como internacional (Hart, 1992).

Dado que, aparte de buscar un concepto común a nivel científico que nos permita entendernos y avanzar en esta materia, si queremos que estos avances tengan repercusiones en el contexto escolar, concretamente en las aulas, es necesario adoptar un lenguaje cercano y común al empleado por los maestros. Según establecen Susinos y Rodríguez (2011), el término de inclusión ya forma parte del lenguaje escolar políticamente correcto. Esto puede ayudar a que los docentes españoles sepan de qué se está hablando y se alienten a aplicar en su aula estrategias y metodologías que favorecen la inclusión educativa y social de su alumnado.

Además, notemos que los ejes analizados en este trabajo (valores y reconocimiento de la diversidad: diferenciación de estructuras, diferenciación del contenido, diferenciación de proceso y diferenciación de producto y valores democráticos: participación democrática, liderazgo compartido, cultura colaborativa, redes de apoyo, ciudadanía crítica, sentido de pertenencia, vinculación con el territorio y comunicación intercultural) favorecen una pedagogía que propicia una educación para todos, esto es, una educación inclusiva. Si recordamos la definición propuesta por la UNESCO (2005), la educación inclusiva responde a la diversidad del alumnado promoviendo su participación en el proceso de aprendizaje, así como en las actividades comunitarias de su entorno inmediato.

Asimismo, las conclusiones teóricas, apoyadas por los datos empíricos, muestran la vinculación entre la diferenciación pedagógica y la participación democrática en el aula inclusiva. Si pasamos a las conclusiones que se extraen de este trabajo a nivel empírico, se ha visto que con el propósito de mostrar de manera ordenada las discusiones se ha optado por presentar, por un lado, las creencias, actitudes y valores que subyacen en la práctica diferenciada y, por otro lado, las que subyacen en la 
participación democrática en el aula. Pero en este intento, se ha visto como hay una amalgama entre ambos presupuestos, dado que se entrecruzan los elementos que caracterizan a ambos ejes. Este hecho nos lleva a decir que, efectivamente, las aulas diferenciadas son aulas más participativas (Prud'Homme et al. 2016; Fillion et al. 2016) y a corroborar el constructo de aula democrática diferenciada propuesto por Waterman (2007) que se materializa en el concepto de pedagogía de la inclusión que proponemos.

En los casos estudiados se diferencian las estructuras, dado que los maestros proponen y llevan a cabo diferentes agrupamientos y modalidades de trabajo (incluso variando o diferenciando una misma modalidad de trabajo), el tiempo es flexible, proponen diferentes espacios (tanto dentro como fuera del aula) y emplean en sus aulas ayudas o recursos visuales y personales que ofrecen respuestas a la diversidad del alumnado en todo su conjunto. En la utilización de diferentes agrupamientos y los recursos personales, subyace una cultura colaborativa, a partir de la cual se propicia una ayuda mutua entre iguales y en las familias $u$ otros agentes que entran a colaborar y a aportar en el aula. Además, se propicia la construcción colectiva del conocimiento. Al hilo de lo anterior, vemos tanto un reposicionamiento del rol docente como del alumnado, generando relaciones de horizontalidad y propiciando la participación activa de todos los miembros de la comunidad educativa en el aula (esto es menos evidente en el caso suizo).

Por lo que respecta a la diferenciación del contenido, en los casos estudiados, se favorece el uso de diferentes materiales para acceder al conocimiento. Igualmente, se puede decir que esta diferenciación del contenido viene mediada por la diferenciación del proceso (según interés, preferencias o motivaciones del alumnado) lo que facilita una participación democrática de los integrantes del aula, tanto en la elección y negociación de los contenidos como, en algunos casos, en la confección de los materiales o actividades por parte del propio alumnado (esto es menos evidente en el caso suizo). En este hecho, es el propio alumnado quien reconoce la diversidad de características o preferencias de sus propios compañeros y las tiene en cuenta en sus elaboraciones. Concluir también que la diversidad en la diferenciación de las estructuras contribuye a fomentar la motivación y el interés del alumnado para hacer una escuela más agradable y a medida de sus propias características. Para ello, los docentes persiguen un aprendizaje funcional y significativo de su alumnado, con metodologías activas y participativas, que fomenten la cohesión grupal y con ésta el sentido de pertenencia.

Otro aspecto a concluir, que se desprende de los casos abordados, es que los maestros avalan diferentes formas y modalidades de expresión, para comprobar lo que su alumnado aprende. Los docentes, llevan a cabo una evaluación democrática en la que tienen en cuenta tanto la diversidad de su alumnado como la voz de estos, permitiendo una participación democrática a través de la coevaluación o toma de decisiones en la elaboración de instrumentos evaluativos (sobre todo en el caso 1). Asimismo, los conocimientos previos y el nivel de competencias o desarrollo del alumnado, se 
tienen en cuenta por parte de los docentes en la evaluación, partiendo de los conocimientos esenciales que son objeto de ser aprendidos.

De la participación democrática, se infiere que los docentes buscan la igualdad, la solidaridad, el respeto y la justicia. Existen estructuras instauradas como las asambleas, a nivel, de aula donde se establecen mecanismos que propician y favorecen dicha participación democrática. Además, en algunos casos se cuenta con órganos de participación a nivel de centro o escuela, propiciando no sólo la participación del alumnado en la toma de decisiones, sino también la de las familias u otros agentes de la comunidad educativa (sobre todo en el caso 3 ).

En referencia al rol adoptado, tanto por el docente como por el alumnado, se concluye que ambos requieren de un nuevo reposicionamiento, ya apuntado anteriormente, favoreciendo que se dé un liderazgo compartido basado en el compromiso y la implicación de los diferentes miembros de la comunidad educativa para conseguir sus objetivos compartidos. Así mismo, los resultados señalan como los constructos teóricos de comunicación intercultural y vinculación de la escuela con el territorio parecen aflorar tímidamente en los datos recogidos. Añadir, que las categorías de ciudadanía crítica y sentido de pertenencia parece que se van fraguando a medida que el alumnado va experimentando experiencias, en el contexto escolar, que contribuyen al pensamiento crítico, la participación democrática, la identidad colectiva, la cohesión social, lazos afectivos...

La última línea de conclusiones apunta a resaltar la continua reflexión que hacen los docentes, cuyos casos han sido abordados en este estudio, sobre su propia práctica didáctica. Éstos, con sus variaciones, cambios y mejoras asumen riesgos e incertezas que, en definitiva, les fortalece y les ayuda a desarrollar su perfil profesional e identidad docente.

Las modestas experiencias relatadas e ilustradas evidencian que la educación inclusiva y democrática no excede de la realidad de las aulas, lo que a priori (para algunos) parece una utopía educativa se convierte en realidad. En los cuatro casos que se han presentado de manera particularizada, los maestros incorporan en sus quehaceres educativos la inclusión y la democracia como valía que genera una manera de hacer y concebir el aula. Estos casos son muy buenos ejemplos, ya que evidencian que la educación inclusiva y democrática funciona a nivel local, a nivel particular, y a la vez ayudan a avanzar en los presupuestos generales del marco de la educación inclusiva y democrática.

Somos conscientes de que no existen recetas mágicas y preestablecidas, y que los profesionales de la educación se enfrentan a desafíos y condiciones particulares que complicadamente pueden ser extrapoladas, pero el hecho de mostrar los caminos que van trazando algunos profesionales pueden ayudar a otros a reflexionar y a mejorar en sus prácticas educativas. 


\section{Limitaciones del estudio}

Toda investigación presenta una serie de limitaciones o cuestiones que se deberían tener en cuenta y mejorar para seguir avanzando en el campo de estudio. Seguidamente, se detallan algunas de las limitaciones encontradas en este trabajo.

Una limitación o dificultad a resaltar, es que, tal y como se ha visto en las prácticas de aula registradas y documentadas ocurren multitud de aprendizajes, interacciones y situaciones diferentes en varios subespacios que configuran el aula y sus inmediaciones. En relación a este aspecto, resulta difícil para un solo investigador registrar o documentar todas las diferentes situaciones transcurridas.

Señalar que hubiese sido interesante realizar un grupo de discusión (focus group) conjuntamente con los 4 docentes (contexto español). A partir de éste se hubiera podido seguir indagando, de manera colectiva, sobre las creencias, percepciones y experiencias vitales que sustentan los propuestos didácticos de los maestros mencionados.

Otra limitación, alude al caso 4, el caso suizo. Este caso no se ha estudiado ni analizado con la misma profundidad que los 3 casos estudiados en el contexto español. Puesto que se efectuó durante una estancia de investigación. No obstante, sí que nos aporta y nutre en relación a nuestro objeto de estudio, ya que a través del caso podemos ver que indistintamente del contexto los parámetros que guían la diferenciación pedagógica están claramente consolidados en las creencias, actitudes y valores docentes.

Futuras líneas de investigación: propuestas para estudios posteriores

Tras finalizar esta tesis, se derivan de ella futuros trabajos o líneas de investigación a realizar para seguir ampliando el conocimiento en este campo de estudio.

Una de las principales derivaciones que se pretenden llevar a cabo, del trabajo presentado, es la confección y elaboración de un material para la formación de los profesionales de la educación. Esta línea de trabajo está contemplada dentro del plan de actuación acordado por el equipo de investigación Diversité et pratiques d'enseignement convenido en la pasada Biennale du LISIS (octubre del 2016). Se pretende realizar una obra colectiva donde se recojan los casos estudiados en el contexto español (aportaciones de la tesis doctoral) y los estudiados por los colegas canadienses. Además, otra de las actuaciones previstas, a nivel internacional, consiste en organizar un coloquio científico para 
compartir y discutir los ejemplos de prácticas enmarcadas en la diferenciación pedagógica y la participación democrática en el aula inclusiva.

Otra futura línea de trabajo o de investigación recae en replicar el estudio que se ha realizado en esta tesis, en aulas enmarcadas en la educación primaria, en el ámbito de la educación secundaria obligatoria. Esta actuación se concibe de vital importancia, debido a los altos índices de fracaso escolar y abandono en esta etapa educativa. Se cree que una educación delimitada dentro de los parámetros de la diferenciación pedagógica y la participación democrática puede ayudar a los docentes a mejorar en su práctica educativa. Esta actuación también fue acordada en la pasada Biennale du LISIS (octubre 2016) y, por ende, se espera que se realice tanto en el contexto español como en el contexto canadiense.

Todavía cabe señalar otra futura línea de investigación que se evidencia de los resultados obtenidos en este trabajo y que se ha puesto en marcha recientemente en el Grupo de Investigación de Mejora Educativa y Ciudadanía Crítica (MEICRI) de la Universitat Jaume I, ésta se centra en el estudio de cómo planificar, poner en marcha y analizar prácticas educativas curriculares vinculadas con el territorio desde un enfoque comunitario y a través de procesos reflexivos originados desde procesos de Investigación- Acción Participativa (IAP).

Fundamentalmente, se pretende que los avances realizados en este campo de estudio y los que se pueden realizar desde las líneas de trabajo apuntadas recaigan y tengan repercusiones sociales y educativas en la mejora y reflexión de las prácticas educativas llevadas a cabo en el contexto educativo. Una buena forma de comenzar con dicho cometido recae en la introducción de éstos parámetros en la formación de los futuros profesionales de la educación en los estudios universitarios. 


\title{
$\sim$ Conclusions
}

\author{
Quelques conclusions générales : afin de conclure cette étude
}

'une des principales conclusions qui se dégage des résultats théoriques, réside dans la
conceptualisation du terme de différenciation pédagogique. Nous avons vu, aussi bien à
l'échelle francophone qu'à l'échelle anglophone, qu'il existe une longue lignée de chercheurs qui se sont centrés sur ce sujet. Les études réalisées sur cette thématique dans le milieu hispanophone ont été nettement plus rares. Et, dans certains cas, elles comprenaient des connotations négatives du terme, aussi bien dans le milieu national que dans le milieu international (Hart, 1992).

Outre la recherche d'un concept commun au niveau scientifique qui nous permettrait de nous comprendre et d'avancer sur cette question, si nous voulons que ces avancées aient des répercussions dans le milieu scolaire, notamment dans les classes, il est nécessaire d'adopter un langage commun pour les maitres. Selon Susinos et Rodríguez (2011), le terme d'inclusion fait déjà partie du langage scolaire politiquement correct. Ceci pourrait aider les enseignants espagnols à savoir de quoi ils sont en train de parler et les encourager à appliquer au sein de leur classe des stratégies et des méthodologies qui favorisent l'inclusion éducative et sociale de tous les élèves.

De plus, notons que les thèmes analysés au sein de ce travail (valeurs et reconnaissance de la diversité : différenciation des structures, différenciation $\mathrm{du}$ contenu, différenciation $\mathrm{du}$ processus et différenciation du produit, et valeurs démocratiques : participation démocratique, leadership partagé, culture collaborative, réseaux d'aides, citoyenneté critique, sens d'appartenance, lien avec le territoire et communication interculturelle) favorisent une pédagogie propice à une éducation pour tous, c'est-à-dire une éducation inclusive. Si nous rappelons la définition proposée par l'UNESCO (2005), l'éducation inclusive répond à la diversité de l'effectif scolaire en encourageant sa participation dans le processus d'apprentissage ainsi que dans les activités collectives au sein de son milieu environnant.

De plus, les conclusions théoriques (tirés de l'étude empirique) montrent le lien entre la différenciation pédagogique et la participation démocratique dans la classe inclusive. Passons à présent aux conclusions qui se tirent de ce travail, au niveau empirique. Dans le but de montrer de manière ordonnée les discussions, nous avons opté pour présenter, d'une part, les croyances, les 
attitudes et les valeurs sous-tendent une pratique différenciée et, d'autre part, celles qui sous-tendent dans la participation démocratique en classe. Cependant dans cette entreprise, nous avons vu qu'il y avait un amalgame entre ces deux présupposés, dans la mesure où les éléments qui caractérisent ces deux axes s'entrecroisent. Cela nous permet donc de dire qu'effectivement, les classes différenciées sont des classes plus participatives (Prud'Homme et al. 2016; Fillion et al. 2016) reconnaître la pertinence du concept de classe démocratique différenciée proposée par Waterman (2007), cela se matérialise dans le concept de pédagogie de l'inclusion que nous proposons.

Au sein des cas étudiés, on peut différencier les structures, dans la mesure où les maîtres proposent et entreprennent différents groupements et modalités de travail (y compris en variant et en différenciant une même modalités de travail), le temps est flexible, ils proposent différents espaces (aussi bien à l'intérieur qu'à l'extérieur de la classe) et ils utilisent, en classe, des aides ou des ressources visuelles et personnelles qui répondent/offrent des réponses à la diversité des élèves dans tout son ensemble. De l'utilisation de différents groupes et des ressources personnelles, on comprend que les enseignantes tentent d'instaurer une culture de collaboration où les élèves peuvent s'entraider, partager leurs façons de faire, conseiller et s'intéresser aux efforts de ses pairs. Les enseignantes valorisent la contribution de chacun et celle de la famille ou de toutes personnes de la communauté. De plus, on favorise la construction collective de la connaissance. Pour revenir sur ce qui a été dit précédemment, on voit tout autant un repositionnement du rôle de l'enseignant que de celui des élèves, générant des relations d'horizontalité et favorisant la participation active de tous les membres de la communauté éducative au sein de la classe (moins évident dans le cas suisse).

En ce qui concerne la différenciation du contenu, toujours dans les cas étudiés, on favorise l'usage de différents matériaux pour accéder au savoir. On peut également dire que cette différenciation du contenu vient en partie de la différenciation du processus (selon les intérêts, les préférences ou la motivation du corps étudiant) ce qui facilite une participation démocratique des membres de la classe, aussi bien dans le choix et la négociation des contenus que, dans certains cas, dans la confection des matériels ou des activités par les élèves (moins évident dans le cas suisse). De ce fait, c'est l'élève lui-même qui reconnaît la diversité de caractéristiques ou préférences de ses camarades et qui les prend en compte dans ses productions. On peut en conclure que cette diversité dans la différenciation des structures contribue à stimuler la motivation et l'intérêt de l'élève et ce, toujours en tenant compte de ses particularités, afin de rendre l'école plus agréable. Pour cela, les enseignants poursuivent un apprentissage fonctionnel et significatif de l'élève, grâce à des méthodologies actives et participatives, qui favorisent la cohésion du groupe et le sentiment d'appartenance.

Un autre aspect qui découle des cas abordés, est que les maîtres utilisent différentes formes et modalités d'expression pour vérifier ce que l'élève apprend. Les enseignants effectuent une évaluation démocratique au cours de laquelle ils tiennent compte, aussi bien de la diversité de l'élève que de leur voix, permettant une participation démocratique au moyen de la co-évaluation ou la prise 
de décisions dans l'élaboration d'instruments évaluatifs (surtout dans le cas 1). Par ailleurs, compte tenu des savoirs essentiels qui doivent être appris, les connaissances acquises au préalable et le niveau de compétences ou encore l'épanouissement de l'élève sont pris en compte par les enseignants durant l'évaluation.

Ce qui découle de la participation démocratique, c'est que les enseignants prônent l'égalité, la solidarité, le respect et la justice. II existe des structures instaurées comme les assemblées faites en classe où l'on établit des mécanismes qui promeuvent et favorisent ladite participation démocratique. De même, dans certains cas, on compte sur des lieux précis, tels que les centres ou au sein de l'école, encourageant non seulement la participation de l'ensemble des élèves dans la prise de décisions mais également celle des familles ou d'autres membres de la communauté éducative (surtout dans le cas 3 ).

En se référant au rôle adopté, autant par les enseignants que le corps étudiants, on peut conclure que ce nouveau repositionnement, précédemment évoqué, favorise le leadership partagé basé sur l'engagement et l'implication des différents membres de la communauté éducative pour atteindre leurs objectifs communs. Par ailleurs, les résultats montrent comment les constructions théoriques de communication interculturelle et de rattachement de l'école au territoire semblent émerger timidement dans les statistiques recueillies. Ajoutons que les catégories de citoyenneté critique et le sens d'appartenance semblent peu à peu éclore à mesure que l'ensemble des élèves font des expériences qui, dans le contexte scolaire, contribuent à l'élaboration de la pensée critique, à la participation démocratique, à l'identité collective, à la cohésion sociale, aux liens affectifs...

La dernière ligne de conclusion vise à mettre en évidence la réflexion des enseignants, dont les cas ont été abordés dans cette étude, sur leur propre pratique didactique. Ceux-ci, avec leurs variations, leurs changements et leurs améliorations prennent des risques qui, en définitive, les renforcent et les aident à développer leur profil professionnel et leur identité d'enseignant.

Les modestes expériences relatées et illustrées démontrent que l'éducation inclusive et démocratique ne dépasse pas les murs des classes. Ce qui, a priori (pour certains), semble être une utopie éducative, se transforme en réalité. Dans les autres cas qui ont été présentés spécifiquement, les maîtres incorporent, dans leurs travaux éducatifs, l'inclusion et la démocratie comme valeur générant une manière d'être et de concevoir la classe. Ces cas sont de très bons exemples, étant donné qu'ils démontrent que l'éducation inclusive et démocratique fonctionne à l'échelle locale, à un niveau spécifique ; et également parce qu'ils aident à avancer dans les présupposés globaux dans le cadre de l'éducation inclusive et démocratique.

Nous sommes conscients qu'il n'existe pas de recette miracle ou déjà toutes faites, et que les professionnels de l'éducation font face à des défis et des conditions particulières qui peuvent difficilement être généralisées, mais le fait de montrer le chemin parcouru par certains professionnels peut aider les autres à réfléchir et améliorer leurs propres pratiques éducatives. 


\section{Limites de l'étude}

Toute recherche présente un nombre de limites et de questions qui doivent être prises en compte et améliorées afin de pouvoir progresser dans ce domaine d'étude. Ci-après, on détaillera certaines limites rencontrées au cours de ce travail.

Une limite ou difficulté à souligner est que, comme on l'a vu dans les méthodes de classe enregistrées et documentées, il y a une multitude d'apprentissages, d'interactions et de situations différentes dans les divers sous-espaces qui configurent la classe et ses environs. En ce qui concerne cet aspect, il s'avère difficile pour un seul chercheur de recenser ou de faire connaître chacunes des différentes situations observées.

Il aurait été intéressant de former un groupe de discussion (focus group) avec les quatre enseignants (dans le milieu espagnol). A partir de cela, on aurait pu continuer à creuser de façon collective sur les croyances, les perceptions et les expériences vitales dont émanent les propositions didactiques des enseignantes mentionnés.

Le cas 4 (le cas suisse) nous renvoie à une autre limite. Ce cas n'a pas été étudié ni analysé avec la même profondeur que les trois cas étudiés dans le milieu espagnol, puisqu'il a été effectué durant un séjour d'investigation. Toutefois il apporte à notre objet d'étude puisqu'à travers celui-ci nous pouvons voir que, indépendamment $d u$ contexte, les paramètres qui guident la différenciation pédagogique sont clairement consolidés par les croyances, les attitudes et les valeurs des enseignants.

Futurs axes de recherche : propositions pour des études ultérieures

Il est possible de d'identifier, au terme de cette thèse, de futurs travaux ou axes de recherche à réaliser afin de continuer à élargir les connaissances de ce domaine d'études.

L'une des principales raisons pour lesquelles cette étude a été menée à bien est la confection et l'élaboration d'un matériel destiné à la formation des professionnels de l'éducation. Cet axe de travail fait partie du plan d'action élaboré par l'équipe de recherche Diversité et pratiques d'enseignement convenu lors de la dernière Biennale du LISIS (octobre 2016). On entend réaliser une œuvre commune où l'on retrouverait les études de cas effectuées dans le milieu espagnol (contributions de la thèse doctorale) et celles effectués par des collègues canadiens. De plus, une autre mesure prévue à l'échelle internationale, consiste à organiser un colloque scientifique pour partager et discuter des exemples de pratiques s'insérant dans la différenciation pédagogique et la participation démocratique dans la classe inclusive. 
Un autre futur axe de travail ou de recherche serait de reproduire l'étude faite ici pour les classes de l'enseignement primaire, mais cette fois dans le secteur de l'enseignement secondaire obligatoire. Cet axe est d'importance vitale étant donné le taux élevé d'échec scolaire et d'abandon dans ce secteur. On pense qu'une éducation définie par les paramètres de la différenciation pédagogique et de la participation démocratique peut aider les enseignants à améliorer leur pratique éducative. Cette action fut aussi envisagée lors de la dernière Biennale du LISIS (octobre 2016) et par conséquent, on espère qu'elle sera réalisée aussi bien dans le milieu espagnol que canadien.

A noter qu'il y a encore un futur axe de recherche qui émane des résultats obtenus dans ce travail et que l'on a mis en place récemment dans le Groupe de Recherche de Mejora Educativa y Ciudadanía Crítica (MEICRI) de l'Université Jaume I. Cet axe se base sur la recherche et l'étude des différentes manières de planifier, de mettre en œuvre et d'analyser les pratiques éducatives scolaires en lien avec le territoire d'un point de vue communautaire et grâce à des processus de recherche-actionparticipative (RAP).

On cherche principalement à ce que les résultats trouvés dans ce domaine d'études et ceux que l'on peut encore trouver à partir des axes de travail apportés aient un impact socio-éducatif sur l'amélioration et la réflexion des pratiques éducatives effectuées dans le monde éducatif. Une bonne manière de commencer avec ladite tâche serait d'introduire ces paramètres dans la formation des futurs professionnels de l'éducation dans les études universitaires. 



\section{REFERENCIAS BIBLIOGRÁFICAS}





\section{REFERENCIAS}

\section{BIBLIOGRÁFICAS}

Accord intercantonal sur l'harmonisation de la scolarité obligatoire (concordat HarmoS). Recuperado de http://edudoc.ch/record/24710/files/HarmoS_f.pdf

Accord intercantonal sur la collaboration dans le domaine de la pédagogie spécialisée (AICPS). Recuperado de http://www.ge.ch/legislation/accords/doc/0102.pdf

Agencia Europea para el Desarrollo de la Educación del Alumnado con Necesidades Educativas Especiales (2012). Perfil profesional del docente en la educación inclusiva. Odense, Dinamarca: Agencia Europea para el Desarrollo de la Educación del Alumnado con Necesidades Educativas Especiales.

Aguado, T. (2011). El enfoque intercultural en la búsqueda de buenas prácticas escolares. Revista Latinoamericana de Inclusión Educativa, 5(2), 23-42. Recuperado de http://www.rinace.net/rlei/numeros/vol5num2/art1.pdf

Aguilar, C. Pallarés, V. y Traver, J.A. (2013). La tertulia literaria dialógica del barrio Sant Agustí-Sant Marc de Castellón. Aula de Innovación Educativa, 152, 72-74

Aguilar, S. y Barroso, J. (2015). La triangulación de datos como estrategia en investigación educativa. Revista de Medios y Educación. 47, 73-88 DOI: http://dx.doi.org/10.12795/pixelbit.2015.i47.05

Aguiló, A. (2015). Educación diferenciada: 50 respuestas para un debate. Madrid, España: Digital Reasons.

Aguirre, A. (2012). Diagnóstico social participativo, desarrollo local y participación social: un estudio de caso sobre participación juvenil en la Comarca Els Ports. Trabajo de investigación: Universitat Jaume I (material inédito).

Aguirre, A., Traver, J.A. y Moliner, L. (2012). La escuela incluida. Dinamizando la participación escolar en la comunidad mediante diagnóstico social participativo. EDETANIA, 41, 57-69.

Aguirre, A.; Català, J.; Doménech, A. y Escobedo, P. (2015). La línea del tiempo en la construcción de la escuela democrática: una herramienta para la transformación desde la participación horizontal. En N. Aldás, Eloísa; A. Salinas, Á. Iván \& A. Farné (Eds.) \#comunicambio: Comunicación y Sociedad Civil para el Cambio Social /\#com4change: Communication and Civil Society for Social Change (pp. 958-967). Madrid: Fragua.

Aguirre, A.; Sales, A. y Escobedo, P. (2014). Construyendo la escuela intercultural inclusiva desde el Diagnóstico Social Participativo. Quaderns Digitals.net XI Congreso Internacional, XXXI Jornadas de Universidades y Educación Inclusiva: La Escuela Excluida. Universitat Jaume I, Castellón. Recuperado de http://www.quadernsdigitals.net/index.php?accionMenu=hemeroteca.VisualizaArticuloIU.visualiza\&art iculo_id=11333\&PHPSESSID=e8d226141e1c280da89349fe41614ad0

Ahedo, J. (2015). El fundamento antropológico de la educación diferenciada. Estudios sobre educación, 28, 155-170 doi: $\underline{10.15581 / 004.28 .155-170}$

Ainscow, M. (1999). Tendiéndoles la mano a todos los alumnos: algunos retos y oportunidades. Siglo Cero, 30 (1), $181,37-48$.

Ainscow, M. (2001a). Desarrollo de escuelas inclusivas. Ideas, propuestas y experiencias para mejorar las instituciones escolares. Madrid, España: Narcea.

Ainscow, M. (2001b). Escuelas inclusivas: aprender de la diferencia. Cuadernos de pedagogía, 307, 44-49 
Ainscow, M., Dyson, A., Weyner, S. (2013). De la exclusión a la inclusión. Una revisión literaria internacional en el cambio para responder a los estudiantes con necesidades educativas en las escuelas. En clave pedagógica, 13, 13-30. Recuperado de http://rabida.uhu.es/dspace/bitstream/handle/10272/8169/De_la_exclusion_a_la_inclusion.pdf?sequen $\underline{\mathrm{ce}=2}$

Ajzen, I. \& Fishbein, M. (1980). Understanding attitudes and predicting social behavior. New Jersey: Prentice-hall, Inc.

Ajzen, I. (1988). Attitudes, personality and behavior. Milton-Keynes, England: Open university Press \& Chicago, il: Dorsey Press.

Albert, M.J. (2007). La investigación educativa: claves teóricas. Madrid: McGraw-Hill

Alegre, O. M. (2010). Capacidades docentes para atender la diversidad. Una propuesta vinculada a las competencias básicas. Alcalá, España: Eduforma.

Alemany, I. Villuendas, M. D. (2004). Las actitudes del profesorado hacia el alumnado con necesidades educativas especiales. Convergencias. Revista de Ciencias Sociales, 11 (34), 183-215

Allport, G. W. (1935). “Attitudes”. In C. Murchison(Dir.), A Handbook of Social Psychology (pp. 789-844). Massachussets; Clark University Press.

Alonso, L.E. (1998). La mirada cualitativa en sociología. Madrid, España: Fundamentos.

Álvarez, C. y San Fabián, J.L. (2012). La elección del estudio de caso en investigación educativa. Gazeta de Antropología, 28 (1) Recuperado de http://www.ugr.es/ pwlac/G28_14Carmen_AlvarezJoseLuis_SanFabian.html

Álvarez, C. y Urbano, D. (2013). Diversidad cultural y emprendimiento. Revista de Ciencias Sociales (RCS). XIX, (1), $154-169$.

Álvarez, M., Castro, P., Campos, M.A. y Álvarez, E. (2005). Actitudes de los maestros ante las necesidades educativas específicas. Psicothema, 17 (4), 601-606.

Anant, S. S. (1966). The need of belong. Canada's Mental Health, 14, 21-27.

Ander-Egg, E. (2005). Metodología y práctica del desarrollo de la comunidad. Buenos Aires, Argentina: Lumen/Humanitas.

Anderson, L. W. (1994). Individualized Instruction. In T. Husen \& T. N. Postlethwaite (Ed.), The International Encyclopedia of Education (pp. 2773-2779). Toronto, Canada: Pergamon.

Apple, M. W. y Beane, J. A. (1999). Escuelas democráticas. Madrid, España: Morata.

Area, M. y Pessoa, T. (2012). De lo sólido a lo líquido: las nuevas alfabetizaciones ante los cambios culturales de la Web 2.0. Comunicar, 19(38), 13-20.

Armstrong, A., Armstrong, D., \& Spandagou, I. (2010). Inclusive education: International policy and practice. London: Sage.

Arnaiz, P. (1996) Las escuelas son para todos. Siglo Cero, 27(2), 25-34.

Arnaiz, P. (2003). Educación Inclusiva, una escuela para todos. (Archidona) Málaga, España: Aljibe.

Arnaiz, P. (2004). La educación inclusiva: dilemas y desafíos. Educación, Desarrollo y Diversidad, 7 (2), 25-40.

Arnaiz, P. (2005). Atención a la diversidad. Programación curricular. San José, Costa Rica: EUNED.

Arnaiz, P. (2011). Luchando contra la exclusión: buenas prácticas y éxito escolar. INNOVACIÓN EDUCATIVA, 21, 2335.

Arnaiz, P. y Guirao, J. M. (2015). La autoevaluación de centros en España para la atención a la diversidad desde una perspectiva inclusiva: ACADI. Revista Electrónica Interuniversitaria de Formación del Profesorado, 18 (1), 45-101. 
Arnaiz, P. y Illán, N. (1996). Procesos de enseñanza-aprendizaje ante las necesidades educativas especiales. En N. Illán (Coord.). Didáctica y organización en la Educación Especial. Málaga, España: Aljibe.

Aronson, E. y colaboradores (1978). The Jigsaw Classroom. Beverly Hills, California: Sage Publications.

Arranz, E. (2004). Familia y desarrollo psicológico. Madrid, España: Pearson Educación.

Asensio, M.J. y Forteza, D. (2014). Una escuela centrada exclusiva(mente) en el libro de texto: una escuela que excluye. Quaderns Digitals. Net Revista de Nuevas Tecnologías y Sociedad ACTAS XI Congreso Internacional y XXXI Jornadas de Universidades y Educación Inclusiva. Mesa 3: Prácticas inclusivas I. Universitat Jaume I.

Ashenden, D., Blackburn, J., Hannan, W. y White, D. (1988). Manifesto for a democratic curriculum. In S. Kemmis y R. Stake. Evaluating curriculum, Victoria: Deakin University.

Asher, S. R., Rose, A. J. \& GabrieL S. W. (2001). Peer rejection in everyday life. In M. R. Leary (Ed.), Interpersonal rejection (pp. 105-142). Oxford, N.Y.: Oxford University Press.

Astolfi, J.P. (2004). L'école pour apprendre. Paris : ESF.

Aubert, A., García, C. y Racionero, S. (2009). El aprendizaje dialógico. Cultura y Educación, 21 (2), pp. 129-139

Aubert, A.; Flecha, A.; García, C., Flecha, R., Racionero, S. (2008). Aprendizaje dialógico en la Sociedad de la Información. Barcelona: Hipatia.

AuCoin, A. (2014). Strengthening Inclusion, Strengthening Schools. Building our future one step at a time. Revista de Educación Inclusiva, 7(2), 22-35.

AuCoin, A. et Vienneau, R. (2010). Inclusion scolaire et dénormalisation. In N. Rousseau (Dir.), La pédagogie de l'inclusion scolaire : pistes d'action pour apprendre tous ensemble (pp. 63-86). Québec : Presses de l'Université du Québec.

Ausubel, D.P. (2002). Adquisición y retención del conocimiento. Una perspectiva cognitiva. Barcelona: Paidós Ibérica Aylwin, U. (1992). La pédagogie différenciée fait son entrée au collège. Pédagogie collégiale, 5(3), 30-37

Baines, E.; Blatchford, P. \& Kutnick, P. (2016). Promoting effective group work in the primary classroom. A handbook for teachers and practitioners. London and New York: Routledge.

Barry, A. (2004). Différenciation et diversification : clarification conceptuelle et enjeux. Vie Pédagogique : Dossier, Une formation diversifiée et qualifiante, 130, 20-24

Bartolomé, M. (1983). Pedagogía Diferencial Aproximación a una ciencia. Universidad de Barcelona.

Bassey, M. (1999). Case Study Research in Educational Setting. Bickingham: Open University Press.

Batlle, R. (2013). El aprendizaje servido en España: el contagio de una revolución pedagógica. Madrid: PPC.

Bauman, Z. (2006). Modernidad líquida. Buenos Aires, Argentina: Fondo de Cultura Económica.

Baumeister, R., \& Leary, M. R. (1995). The need to belong: Desire for interpersonal attachments as a fundamental human motivation. Psychological Bulletin, 117, 497-529.

Beaudoin, N. (2013). Una escuela para cada estudiante. La relación interpersonal, clave del proceso educativo. Madrid, España: Narcea.

Beauregard, F. et Trépanier, N. (2010). Le concept d'intégration scolaire... mais ou donc se situe l'inclusion ? In M. Paré \& N. Trépanier (Eds). Des modèles de service pour favoriser l'intégration scolaire (pp.37-50). SainteFoy, Canadá : Presses de l'Université du Québec. 
Belgrave, M. (2011). The Effect of a Music Therapy Intergenerational Program on Children and older Adults' Intergenerational Interactions, Cross-Age Attitudes, and Older Adults' Psychosocial WellBeing. Journal of music therapy, 48(4), 486-508

Bell, R.; Illán, N. y Benito, J. (2010). Familia -Escuela - Comunidad: pilares para la inclusión. Revista Interuniversitaria de Formación del Profesorado, 69 (24,3), 47-57.

Benet, A., Sanahuja, A. y Moliner, L. (2016). Rincones, from the teachers' perspectives: a reflection on a primary education practice. 9th International Conference of Education, Research and Innovation, Sevilla (Espanya).

Benet, A; Ferrer, M; Gimeno, M.A. y Cayuela, E. (2014). Proyecto de dirección. Recuperado de: https://sites.google.com/site/crabqportal/noticies/projecte-de-direccio

Benjamin, S. (2002). The micropolitics of inclusive education. Buckingham: Open University Press.

Bennet, N.; Wise, C. Woods, P. \& Harvey, J. (2003). Distributed Leadership. London: NCSL.

Benoit, V. et Angelucci, V. (2011). Réflexions autour du concept de coenseignement en contexte inclusif. Education et francophonie. XXXIX (2), 105-121

Bergeron, L. (2015). La planification de l'enseignement a priori en fonction de la diversité des élèves. Une logique préventive et proactive. In N. Rosseau (dir.), La pédagogie de l'inclusion scolaire : Un défi ambitieux et stimulant (pp.375-397). Québec, Canada : Presses de l'Université du Québec.

Bergeron, L. Rousseau, N. et Leclerc, L. (2011). La pédagogie universelle : au cour de la planification de l'inclusion scolaire. Education et francophonie. XXXIX (2), 87-104

Bernal, J.L. (2007). El tiempo como recurso educativo. Aula de Innovación Educativa. 163-164, 38-40

Bernal-Guerrero, A. (1998). La diferenciación educativa en la escuela. Comunidad educativa, (247), 101- 112 Recuperado de http://institucional.us.es/revistas/cuestiones/13/art_9.pdf

Bernard, B. (2004). Resiliency: What we have learned. San Francisco, CA: WestEd.

Berruezo, P.P. (2006). Educación inclusiva en las escuelas canadienses. Una mirada desde la perspectiva española. Revista Interuniversitaria de Formación del Profesorado, 20(2), 179-207.

Bierman, K. L. (2004). Peer rejection: developmental processes and intervention strategies. Nueva York, NY: The Guilford Press.

Bisquerra, R. (2000). Educación emocional y bienestar. Barcelona, España: Praxis.

Bloom. B. (1979). Taxonomía de los objetivos de la educación. Argentina: Ateneo.

Bolívar, A. (2007). Ciudadanía democrática y comunitaria: Proyecto Atlántida. En A. Bolívar y A. Guarro (Eds.) Educación y cultura democrática (pp. 13-33). Madrid, España: Wolters Kluwer.

Bolívar, A. (2016). Educar democráticamente para una ciudadanía activa. Revista Internacional de Educación para la Justicia Social (RIEJS), 5(1), 69-87.

Bonvin, P. (2010). Intégration et inclusion à l'école. Dans le vif du débat des idées a l'épreuve du terrain. Primes, $13,11-15$

Booth, T. \& Ainscow. M. (2011). Index for inclusion. Developing learning and participation in schools. Bristol: CSIE.

Bourdieu, P. (1966). L'école conservatrice. L'inégalités sociale devant l'école et devant la culture. Revue internationale des sciences sociales, 7 (3), 367-388

Boutin, G. et Bessette, L. (2009). Inclusion ou illusion? Élèves en difficulté en classe ordinaire : défis, limites, modalités. Montréal, Canada : Éditions Nouvelles.

Bray, B., \& McClaskey, K. (2012). Personalization vs Differentiation vs Individualization. Recuperado de https://education.alberta.ca/media/3069745/personalizationvsdifferentiationvsindividualization.pdf

Brender, W.N. (2012). Differentiating Instruction for Students With Learning Disabilities. California: Corwin A SAGE Company. 
Brighton, C. M., Hertberg, H. L., Moon, T. R., Tomlinson, C. A., \& Callahan, C. M. (2005). The feasibility of high-end learning in a diverse middle school. Storrs, CT: National Research Center on the Gifted and Talented.

Bronfenbrenner, U. (1979). The Ecology of Human Development: Experiments by Nature and Design. Cambridge, England: Harvard University Press.

Caballo, M.B. y Castro, M.C. (1995). Ciudades educadoras. Nuevos horizontes para el desarrollo del bienestar social. Pedagogía social: revista interuniversitaria, 12, 121-132

Caena, F. (2014). Teacher competence frameworks in Europe: policy-as-discourse and policy-as-competence. European Journal of Education, 49, 3, 311-331. doi: 10.1111/ejed.1208

Calderero, J. F., Aguirre, A. M., Castellanos, A., Peris, R. M.A y Perochena, P. (2014). Una nueva aproximación al concepto de educación personalizada y su relación con las TIC. Teoría de la Educación. Educación y Cultura en la Sociedad de la Información, $15 \quad$ (2), 131-151. Recuperado de http://www.redalyc.org/pdf/2010/201031409007.pdf

Calvo, F. (2012). Escuela, espacio, poder: estudios sobre educación y territorio. Barcelona, España: UOC.

Calvo, M. (2005). Educación mixta, educación diferenciada: opciones en libertad. Nuestro tiempo, 612, 17-31

Calvo, M. (2009). Guía para una educación diferenciada. Córdoba, España: Toro Mítico.

Calvo, M.I.; Verdugo, M.A. y Amor, A.M. (2016). La participación familiar es un requisito imprescindible para una educación inclusiva. Revista latinoamericana de educación inclusiva. 10(1), 99-113.

Campbell, B. (2008). Handbook of Differentiated Instruction using the Multiple Intelligences. Lessons Plans \& More. Boston: Pearson Allyn \& Bacon.

Camps, V. (1997). Educar para la democracia. Perspectivas, 27(4), 104, 529-535

Cardona, A., Fandiño, Y. y Galindo, J, (2014). Formación docente: creencias, actitudes y competencias para el uso de TIC. Lenguaje, 42 (1), 173-208.

Cardona, M.C. (2000). Regular classroom teachers' perceptions of inclusion: implication for teachers' preparation programs in Spain. In D. Day y D. Veen (Eds.), Educational research in Europe (pp. 37-47). Lovaina: Garant \& European Educational Research Association.

Caron, J. (2003). Apprivoiser les différences : guide sur la différenciation des apprentissages et la gestion des cycles. Montréal : Éditions de la Chenelière.

Caron, J. (2008). Différencier au quotidien. Cadre d'expérimentation avec points de repère et outils-support. Montréal : Les Éditions de la Chenelière.

Carrion, J.J. y Sanchez Palomino, A. (2002). Estrategias organizativas de aula para atender a la diversidad. En A. Sánchez Palomino y J.A. Torres (Eds.). Educación Especial: Centros educativos y profesores ante la diversidad. Madrid, España: Pirámide.

Carvajal, A. (2011). Apuntes sobre desarrollo comunitario. Eumed.net, Universidad de Málaga, España.

Casey, M. K., \& Gable, R. K. (2012). Perceived efficacy of beginning teachers to differentiate instruction. Teacher Education Paper 7. Recuperado de http://scholarsarchive.jwu.edu/teacher_ed/7

Cassady, J. C., Speirs Neumeister, K. L., Adams, C. A., Dixon, F. A., Pierce, R. L. (2004). The Differentiated Classroom Observation Scale, Roeper Review, 26, 139-146

Cebreiro, B. y Fernández, M.C. (2004). Estudio de casos. En F. Salvador, J.L. Rodríguez, A Bolívar (Dir.): Diccionario enciclopédico de didáctica. Málaga, España: Aljibe. 
Cela, J., Gual, X., Màrquez, C. y Ustet, M. (1997). El tractament de la diversitat en les etapes infantil i primària. Barcelona, España: Associació de mestres Rosa Sensat.

Center for Applied Special Technology - CAST (2004). «Universal Design for Learning (UDL) toolkits: Planning for All Learners (PAL)», Recuperado de http://www.cast.org/about/timeline.html\#.VzhX1jYVjmQ

Cervantes, R. D., Cappello, H. M. y Castro, R. D. (2009). Análisis de las actitudes docentes hacia la educación científica. Un estudio del programa de enseñanza de las ciencias aplicado en escuelas primarias de Ciudad Victoria, Tamaulipas. Revista Internacional de Ciencias Sociales y Humanidades, SOCIOTAM, XIX (1), 926.

Chines, E., Cardona, M.C. y Gómez, J. M. (2015). Teachers' beliefs about diversity: an analysis from a personal and professional perspective. Journal of New Approaches in Educational Research. 4 (1), 18-23 doi: $\underline{10.7821 / \text { naer.2015.1.113 }}$

Chocarro, E. y Sáenz, M. (2016). Grupos interactivos: estrategia para la mejora de la convivencia, la participación y el aprendizaje. Revista Complutense de Educación, 27 (2), 585-601 doi: 10.5209/rev_RCED.2016.v27.n2.46911

Cisterna, F. (2005). Categorización y triangulación como procesos de validación del conocimiento en investigación cualitativa. Theoria, 14 (1): 61-71

Claparède, E. (1932). La Educación funcional. Madrid, España: Espasa-Calpe.

Code d'éthique de la recherche pour les Hautes Écoles Pédagogiques en Suisse romande et du Tessin (2002). Recuperado de https://www.hepl.ch/files/live/sites/systemsite/files/centre-soutien-recherche-relationsinternationales/pole-levees-fonds/code-ethique-recherche-rd-2002-hep-vaud.pdf

Code of Ethics American Educational Research Association (AERA, 2011) Recuperado de http://www.aera.net/Portals/38/docs/About_AERA/CodeOfEthics(1).pdf

Código de Buenas Prácticas (CBP) de la Escuela de Doctorado de la Universitat Jaume I (2015) Recuperado de http://ujiapps.uji.es/ade/rest/storage/BBNFTHHFRPNQKZMEKXZPTCSXSSEHNSKA

Cohen, E. G. (1999). Organizzare i gruppi cooperativi. Ruoli, funzioni, attività. Trento: Erickson.

Coie, J. D., Dodge, K. A. \& Coppotelli, H. (1982). Dimensions and types of social status: A cross-age perspective. Developmental Psychology, 18 (4), 557-570.

Collicott, J. (2000). Posar en pràctica l'ensenyament multinivell : estratègies per als Mestres. Suports: revista catalana d'educació especial i atenció a la diversitat, 4 (1), 87-100.

Combaz, G. (1999), Autonomie des établissements, diversification pédagogique et inégalités scolaires : effets sociaux des parcours pédagogiques diversifiés au collège. Revue française de pédagogie. 128, 73-88

Comisión Europea (2013). Supporting teacher competence development for better learning outcomes. Recuperado de: http://ec.europa.eu/education/policy/school/doc/teachercomp_en.pdf

Commune Corcelles-près-Payerne. Recuperado

http://www.corcelles.ch/net/Net_corcelles.asp?NoOFS=5816\&Sty=\&NumStr=04

Convery, A. \& Coyle, D. (1993). Differentiation: Taking the Initiative. Pathfinder: CILT a series for language teachers, vol. 18, CILT (Centre for Information on Language Teaching and Research), London, United Kingdom. Recuperado de http://www.eric.ed.gov/PDFS/ED382025.pdf

Corno, L. \& Snow, R. E. (1986). Adapting Teaching to Individual Differences Among Learners. In M. C. Wittrock (Ed), Handbook of Research on Teaching (pp. 605-629). New York : Macmillan.

Cortez, K.; Fuentes, V.; Villablanca, I. y Guzmána, C. (2013). Creencias docentes de profesores ejemplares y su incidencia en las prácticas pedagógicas. Estudios Pedagógicos XXXIX, 2, 97-113.

Cortina, A. (2007). Ética de la razón cordial. Educar en la ciudadanía en el siglo XXI. Oviedo, España: Nobel.

Cousinet, R. (1972). La escuela Nueva. Barcelona, España: Editorial Luis Miracle. 
Cowie, H. y Fernández, F.J. (2006). Ayuda entre Iguales en las escuelas: desarrollo y retos. Revista Electrónica de Investigación Psicoeducativa. № 9 Vol 4 (2), 291-310. Recuperado de http://www.investigacionpsicopedagogica.org/revista/articulos/9/espannol/Art_9_116.pdf

CRA Benavites - Quart de les Valls y MEICRI (2016). Jornada de portes obertes: compartint el lideratge del canvi. Quaderns Digitals. Net, 83, 66-76

Curchod-Ruedi, D., Ramel, S., Bonvin, P., Albanese, O., Doudin, P.A. (2012). De l'intégration à l'inclusion scolaire : implication des enseignants et importance du soutien social. ALTER, European Journal of Disability Research, 7, 135-147.

Day, C y Gu, Q. (2013). Resilient Teachers, Resilient Schools. Abingdon, Oxon: Routledge.

De Ugarte, D. (2007). El poder de las redes. Madrid, España: Ediciones El cobre (Colección planta 29).

Deci, E.L. \& Ryan, R.M. (2000). The "What" and "Why" of Goal Pursuits: Human Needs and the SelfDetermination of Behavior. Psychological Inquiry. 11 (4), 227-268.

Del Carmen, L. (2000). La atención a la diversidad: una cuestión de valores. Aula de Innovación Educativa, 26(1), 924.

Delgado-Acosta, C.R., Calero-Martín, C.G. y González-Bencomo, H. (2016). Potencialidad de los espacios públicos abiertos para las relaciones intergeneracionales. Un estudio de caso en la ciudad de Santa Cruz de Tenerife (Canarias, España). Documents d'Anàlisi Geogràfica, 62/1, 5-25.

Delors, J. (1996). La educación encierra un tesoro. Informe a la Unesco de la Comisión Internacional sobre la Educación para el siglo XXI. Madrid, España: Santillana Ediciones UNESCO.

Delval, J.A. y Lomelí, P. (2013). La educación democrática para el siglo XXI. México: Siglo XXI.

Denzin, N.K. \& Lincoln, Y., S. (1998). Entering the field of qualititative research. In N. K. Denzin \& Y. S. Lincoln, (Eds.), Collecting and interpreting qualitative materials (pp. 1-34). Londres: Sage.

Département de la formation, de la jeunesse et de la culture (DFJC) Recuperado de http://www.vd.ch/autorites/departements/dfjc/

Département de la formation, de la jeunesse et de la culture (DGEO). Recuperado de https://www.webvd.ch/vd_dgeo/etablissements/resultat.php?nom=Etablissement+primaire+de+Payerne+et+environs\&

Descampe, S., Robin, F. et Tremblay, P. (2014). Pratiques de pédagogie différenciée à l'école primaire. Service général du Pilotage du Système éducatif. Fédération Wallonie- Bruxelles : Enseignement et recherche scientifique.

Dewey, J. (1962). Schools of Tomorrow. Nueva York, E.P. Dutton.

Dewey, J. (1995). Democracia y educación. Madrid, España: Morata.

Díaz Navarro, C. (1998). La oreja verde de la escuela. Trabajo por proyectos y vida cotidiana en la escuela infantil. Madrid: Ediciones de la Torre.

Dottrens, R. (1949). La enseñanza individualizada. Neuchâtel, Suiza: Kapelusz.

Duk, C. y Narvarte, L. (2008). Evaluar la Calidad de la Respuesta de la Escuela a la Diversidad de Necesidades Educativas de los Estudiantes. Revista Electrónica Iberoamericana sobre Calidad, Eficacia y Cambio en Educación, 6(2), 137-156.

Duran, D. i Monereo, C. (2003). Incidència de la tutoria entre iguals, fixa i recíproca, en alguns factors afectius i relacionals. Suports. Revista catalana d'educació especial i atenció a la diversitat. 6 (2), 114-126. 
Duran, D. y Blanch, S. (2008). L'aprenentatge cooperatiu com a estratègia instructiva per a la inclusió. Suports: revista catalana d'educació especial i atenció a la diversitat, 12 (1), 6-12.

Duran, D., Flores, M., Mosca, A., Santiviago, C. (2015). Tutoría entre iguales, del concepto a la práctica en las diferentes etapas educativas. InterCambios, 2 (1), 31-39.

Duran, D., Torró, J. i Vila, J. (2003). Tutoria entre iguals. Barcelona. Universitat Autònoma de Barcelona: ICE.

Duran, D.; Blanch, S.; Corcelles, M.; Flores, M.; Merino, E.; Oller M. i Vidal, A. (2009). Llegim en parella. Tutoria entre iguals, a l'aula i a casa per a la millora de la comprensió lectora. Universitat: Institut de Ciències de l'Educació.

Dyson, A. \& Millward, A. (2000). School and Special Needs: Issues of Innovation and Inclusion. Londres, England: Paul Chapman.

Eccles J.S. \& Harold R.D. Family involvement in children's and adolescents' schooling. In: A. Booth, J.F. Dunn, (Eds.). Family school links: How do they affect educational outcomes? (pp. 3-34) Erlbaum; Mahwah, NJ.

Echeita, G. (2006). Educación para la inclusión o educación sin exclusiones. Madrid, España: Narcea.

Echeita, G. (2008). Inclusión y exclusión educativa. “Voz y quebranto”. REICE - Revista Electrónica Iberoamericana sobre Calidad, Eficacia y Cambio en Educación, 6(2), 9-18

Echeita, G. y Ainscow, M. (2011). La Educación inclusiva como derecho. Marco de referencia y pautas de acción para el desarrollo de una revolución pendiente. Tejuelo, 12, 26-46.

Edwards, C. J., Carr, S., Siegel, W. (2006). Influences of Experiences and Training on Effective Teaching Practices to Meet the Needs of Diverse Learners in Schools. Education, 126(3), 580-592

Elola, N. y Toranzos, L. V. (2000). Evaluación Educativa: una aproximación conceptual. Recuperado de http://bibliotecadigital.academia.cl/bitstream/handle/123456789/585/?sequence=1

Epstein, J. L. (2001) School, family, and community partnerships: preparing educators and improving schools. Colorado: Westview Press.

Escamilla, A. (2014). Inteligencias múltiples: Claves y propuestas para su desarrollo en el aula. Barcelona, España: Graó.

Escobar-Pérez, J. y Cuervo-Martínez, A. (2008).Validez de contenido y juicio de expertos: una aproximación a su utilización. Avances en Medición, 6, 27-36.

Escudero, J.M. (2006). La construcción de un currículo democrático y la cultura de colaboración del profesorado. Participación Educativa, 3, 19-41.

Escudero, J.M. (2011). Dilemas éticos de la profesión docente. CEE. Participación Educativa, Secc. Tribuna Abierta, 93-102.

Espiñeira, S. (2005). Una aplicación de la enseñanza afectiva: las estaciones de aprendizaje. Actas del XVI Congreso Internacional de ASELE. 731-740

Etablissement Primaire de Payerne et environs Recuperado http://www.grandcour.ch/bildung/schulen/primarschule/default.htm 
Faure, P. (1979). Un enseignement personnalisé et communautaire. Casterman : Tournai.

Feito, R. (2010). Escuela y democracia. Política y sociedad, 47 (2), 47-61.

Feito, R. y López, J.I. (2008).Construyendo escuelas democráticas. Barcelona, España: Hipatia.

Fernández Batanero, J.M. (2009). Un currículum para la diversidad. Madrid: Editorial Síntesis.

Fernández Batanero, J.M. (2012). Dirección y buenas prácticas educativas en centros de orientación educativa. En D. Cobos y A. Jaén (Dir.) I Congreso Virtual Internacional sobre Innovación Pedagógica y Praxis Educativa. Sevilla.

Fernández Batanero, J.M. (2013). Competencias docentes y educación inclusiva. Revista Electrónica de Investigación Educativa, 15(2), 82-99. Recuperado de http://redie.uabc.mx/vol15no2/contenido-fdzbatanero.html

Figueras, P. (2007). Ciudades educadoras, una apuesta por la educación. Participación educativa (1886-5097), (6), $22-27$

Fillat, M. y Silva, M.A. (2000). Talleres: Un modelo organizativo que facilita la atención a la diversidad. Aula de innovación educativa, 90, 58-62

Fillion, P.L., Bergeron, G., Prud'homme, L. y Traver, J. (2016). L'éducation à la citoyenneté démocratique: un enjeu fondamental associé au projet d'inclusion scolaire et aux pratiques de différenciation pédagogique. In L. Prud'homme, H. Duchesne, P. Bonvin, \& R. Vienneau (Eds.), L'inclusion scolaire : ses fondements, ses acteurs et ses pratiques. Bruxelles : De Boeck Supérieur.

Flecha, R. y Puigvert, L. (2002). Las comunidades de aprendizaje: una apuesta por la igualdad educativa. REXE: Revista de Estudios y Experiencia Educativas, I (I), 11-20

Fletcher, J. D. (1992). Individualized Systems of Instruction. In M. Alkin (Ed.), Encyclopedia of Educational Research (pp. 613-618). Toronto, Canada: Maxwell Macmillan.

Florian, L. (2013). La educación especial en la era de la inclusión: ¿El fin de la educación especial o un nuevo comienzo? Revista Latinoamericana de Inclusión Educativa, 7(2), 27-36.

Forlin, C. (2010). Reframing teacher education for inclusion. In C. Forlin (Dir.), Teacher Education for Inclusion: Changing paradigms and innovative approaches (pp. 3-12). New York: Routledge.

Forsten, C., Grant, J. \& Hollas, B. (2002). Differentiated instruction : different strategies for different learners. Peterborough : Crystal Spring Books.

Fournier, M. (1996). La pédagogie différenciée. Sciences humaines, Hors série 12, 25- 26.

Francisco, A. y Moliner, L. (2011). Porque la visibilidad importa. Una propuesta para trabajar la diversidad sexual en la ESO a través de la educación en medios. Revista de educación inclusiva. 4, (2), 147-158

Freinet, C. (1966). La Escuela popular moderna: guía práctica para la organización material técnica y pedagógica de la escuela popular. México: Xalapa, Universidad Veracruzana.

Freinet, E. (2005). Pedagogía Freinet: los equipos pedagógicos como método. Sevilla, España: MAD.

Fresne, R. (1994). Pédagogie différenciée : mode d'emploi. Paris : Nathan.

Friend, M. (2008). Co-teach! A Manual for Creating and Sustaining Classroom Partnerships in Inclusive Schools. Greensboro, NC : Marilyn Friend. 
Gale, T. y Densmore, K. (2007). La implicación del profesorado. Una agenda de democracia radical para la escuela. Barcelona: Octaedro.

Galichet, F. (2002). La citoyenneté comme pédagogie : réflexions sur l'éducation à la citoyenneté. Revue des sciences de l'éducation, 28, (1), 105-124 Recuperado de http://retro.erudit.org/revue/rse/2002/v28/n1/007151ar.pdf

García Hoz, V. (1981). Educación personalizada. Madrid, España: Ediciones Rialp.

García Hoz. V. (1976). Principios de Pedagogía Sistemática. Madrid: Rialp.

García, F. J y González, J. (2010). Evaluación de la competencia social entre iguales. La sociometría y otras medidas. Madrid: TEA Ediciones.

García, R., Traver, J.A. y Candela, S. (2001). Aprendizaje Cooperativo. Fundamentos, características y técnicas. Madrid, España: CSS-ICCE.

Gardner, H. (1983). Frames of Mind: The Theory of Multiple Intelligences. The Journal of Education CREATIVITY AND SOCIAL CRITICISM. 166(2), 199-205

Garrote, A., \& Sermier-Dessemontet, R. S. (2015). Social Participation in Inclusive Classrooms: Empirical and Theoretical Foundations of an Intervention Program. Journal of Cognitive Education and Psychology, 14(3), 375-388.

Gastón, E., Lafuente, M.a Á. y Santiago, G. (2010). Afrontando el reto: derechos, retórica y situación actual. Volviendo a Salamanca - Conferencia Mundial sobre Educación Inclusiva. Integración. Revista sobre discapacidad visual - Edición digital, 56. Recuperado de http://www.once.es/new/serviciosespecializados-en-discapacidad-visual/publicaciones-sobre-discapacidad-visual/nueva-estructurarevista-integracion/copy_of_numeros-publicados/copy_of_nueva-revistaintegracion/cronicas/afrontando-el-reto-derechos-retorica-y-situacion/?searchterm=\%C3\%A1ngel

Gifford-Smith, M. E. \& Brownell, C. A. (2003). Childhood peer relationships: social acceptance, friendships, and peer networks. Journal of School Psychology, 41, 235-284.

Gimeno Sacristán, J. (2002). Hacerse cargo de la heterogeneidad. Cuadernos de pedagogía, 311, 52-55

Giné, C y Ruiz, R. (1996). Los servicios de apoyo psicopedagógico. En C. Monereo, y I. Solé (Coord.). El asesoramiento psicopedagógico: una perspectiva profesional y constructivista. (pp. 113-125). Madrid, España: Alianza.

Gispert, D. y Ribas, L. (2010). Alumnado con dificultades en el aprendizaje de la lectura. Barcelona, España: Graó.

Gónzalez, M.T. (2003). Liderazgo en tiempos de cambio y reforma. Organización y Gestión Educativa, 6, 4-8.

Gouvernement du Québec. (2006). L'évaluation des apprentissages au secondaire. Recuperado de http://differenciation.org/pdf/Schema_aspects_differenciation_pedagogique.pdf

Gregory, G.H. \& Chapman, C. (2013). Differentiated Instructional Strategies: One Size Doesn't Fit All. Thousand Oaks, California: Corwin A SAGE Company.

Guarro, A. (2005). La transformación democrática de la cultura escolar: Una respuesta justa a las necesidades del alumnado de zonas desfavorecidas. Profesorado, revista de currículum y formación del profesorado, 9 (1), 1-48.

Guarro, A. (2016). Escuelas democráticas y coherencia institucional. Revista Internacional de Educación para la Justicia Social (RIEJS), 5(1), 35-55.

Guay, M. H. (2007). Recherche-action sur la différenciation pédagogique. Coopérative régionale de développement pédagogique de la Montérégie. Recuperado de $\underline{\text { https://www.google.es/url?sa=t\&rct=j\&q=\&esrc=s\&source=web\&cd=2\&ved=0ahUKEwjjuIqBk7DSAhUJvRQ }}$ 
KHbxfD0oQFggjMAE\&url=http\%3A\%2F\%2Fdifferenciationpedagogique.com\%2Fdata\%2Fplusloin\%2Fun_br ef_historique_de_la_differenciation_pedagogique.doc\&usg=AFQjCNHOc22LcXo9j7aVEYsw6NSjpdRIw\&cad=rja

Guay, M.H., Legault, G. et Germain, C. (2006). Pour tenir compte de leurs différences, Vie Pédagogique. 141, 1-4.

Guba, E. G. (1989). Criterios de credibilidad en la investigación naturalista. En J. Gimeno y A. Pérez (Comp.). La enseñanza: su teoría y su práctica (pp.148-165). Madrid: Akal.

Guba, E.G. \& Lincoln, Y.S. (1985). Naturalistic Inquiry, Beverly Hills, LA, CA: Sage.

Guba, E.G. \& Lincoln, Y.S. (1990). Fourth generation evaluation. London: Sage.

Habegger, S. y Mancila, I. (2006). El poder de la Cartografía Social en las prácticas contra hegemónicas o la Cartografía social como estrategia para diagnosticar nuestro territorio, Revista Araciega, 14.

Hagerty, B. M. K., Lynch-Sauer, J., Patusky, K. L., Bouwsema, M. \& Collier, P. (1992). Sense of belonging: A vital health concept. Archives of Psychiatric Nursing, 6(3), 172-177. Recuperado de http://dx.doi.org/10.1016/0883-9417(92)90028-H

Hall, T., Strangman, N. \& Meyer, A. (2003).Differentiated Instruction and Implications for UDL Implementation. National Center on Accessing the General Curriculum (NCAC): Effective Classroom Practices Report. Washington, DC: NCAC.

Hammerness, K., Darling-Hammond, L. \& Bransford, J. (2005). How teachers learn and develop. In L.DarlingHammond \& J. Bransford (Eds.). Preparing teachers for a changing world (pp. 358-389). San Francisco: Jossey Bass.

Hargreaves, L. y García-Carrión, R. (2016). Toppling Teacher Domination of Primary Classroom Talk through Dialogic Literary Gatherings in England. FORUM, 58(1), 15-26. doi: $10.15730 /$ forum.2016.58.1.15

Hart, R. (1993). La participación de los niños: de una participación simbólica a una participación auténtica. Santiago: UNICEF.

Hart, S. (1992). Differentiation. Part of the problem or part of the solution? The curriculum journal. 3(2), 131-142.

Heacox, D. (2002). Differentiating Instruction in the Regular Classroom: How to Reach and Teach All Learners, Grades 312. Minneapolis: Free Spirit.

Hellinger, H. (2001). Órdenes del amor. Barcelona, España: Herder Editorial S.L.

Hernández, F. (1998). Conceptualización del proceso de la investigación educativa. En L. Buendía, P. Colás y F. Hernández (Eds.) Métodos de Investigación en Psicopedagogía. Madrid, España: McGrau Hill Interamericana de España.

Hernández, F. (2000). Los proyectos de trabajo: la necesidad de nuevas competencias para nuevas formas de racionalidad. Educar, 26, 39-51.

Hornby, G. C. (1990) The organization of parent involvement. School Organization, 10, (2-3), 247- 252.

Huber, L. (2015). Manual thinking: la herramienta para gestionar el trabajo creativo en equipo. Barcelona, España: Urano.

Huguet, T (2006). Aprendre junts a l'aula. Una proposta inclusiva. Barcelona, España: Graó.

Hunt, D.E. (1979). Learning Styles and student needs: An introduction to conceptual level". En Students Learning Styles: Diagnosing and Prescribing Programs. (pp. 27-38). Reston, Virginia: NASSP. 
Hutner, T. L. \& Markman, A. B. (2016). Proposing an Operational Definition of Science Teacher Beliefs. Journal of Science Teacher Education, 27 (6), 675-691

Hyrkäs, K., Appelqvist-Schmidlechner, K \& Oksa, L. (2003). Validating an instrument for clinical supervision using an expert panel. International Journal of nursing studies, 40 (6), 619 -625.

Ibáñez, G. (1995). El proyecto de educación infantil y su práctica en el aula. Madrid, España: Muralla.

Iglesias, L. (1996). La organización de los espacios en la educación infantil. En M. Zabala, Calidad en la Educación Infantil. Madrid: Narcea.

Illán, M. (2011). El aula como espacio de relaciones humanas. Mediterráneo. Revista de la Consejería de Educación en Italia, Grecia y Albania, (3), p. 80.

Jefferson, G. (2004). Glossary of transcript symbols with an introduction. En G.H. Lerner (Ed.), Conversation analysis. Studies from the first generation (pp. 13-31). Amsterdam: John Ben-jamin's Publishing Company. doi: $10.1075 / \mathrm{pbns} .125 .02 \mathrm{jef}$

Jiménez Fernández, C. (1987). Cuestiones sobre Bases Diferenciales de la Educación. Madrid, España: UNED.

Jiménez Fernández, C. y González Galán, Mª (2011). Pedagogía diferencial y atención a la diversidad. Madrid, España: Editorial Universitaria Ramón Areces.

Jiménez, F. y Vilà, M. (1999). De Educación Especial a la Educación a la diversidad. Málaga, España: Aljibe.

Jiménez, J. R. y Pozuelos, F. J. (2001). Una escuela pública abierta a la comunidad. Investigación en la escuela, 44, 517.

Jiménez, V. \& Naranjo, M. (2014). Educational assessment of cooperative learning in the Program CL/LC: cooperating to learn, learning to cooperate. ECER The Past, the Present and the Future of Educational Research EUROPEAN EDUCATIONAL RESEARCH ASSOCIATION

Johnson, D. W., Johnson, R. T. y Holubec, E. J. (1999). El aprendizaje cooperativo en el aula. Buenos Aires: Paidós.

Johnson, D.W. y Johnson, R. (1999). El aprendizaje cooperativo en el aula. Barcelona: Paidós.

Johnson, G. M. (2000). Intergenerational transmission of expectations concerning the transition to adulthood. The Sciences and Engineering, 60 (11-B).

Jorba, J. y Cassellas, E. (1997). Estrategias y técnicas para la gestión social del aula. Vol. I La regulación y autorregulación de los aprendizajes. Madrid, España: Síntesis.

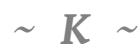

Kagan, S. (1999). Cooperative Learning. San Clemente: Resources for Teachers, Inc.

Kahn, S. (2010). Pédagogie différenciée. Bruxelles, Belgique: De Boeck. 
Karsten, A. (2012). "A Potpourri of Participation Models». Recuperado de http://www.youthpolicy.org/wpcontent/uploads/library/Participation_Models_20121118.pdf

Keller, F. S. (1968). “Good-bye, teacher ...” Journal of Applied Behavior Analysis, 1, 79 - 89.

Kelly, G. (1955). The psychology of personal constructs. Vol. I, II. Norton, New York. (2nd printing: 1991, Routledge, London, New York)

Kline, B. (2015). Content, Process, and Product: Modeling Differentiated Instruction. Kappa Delta Pi Record Volume 51, Issue 1.

Kohl, G. O.; Lengua, L. J. \& McMahom, R. J. (2000). Parent involvement in school. Conceptualizing multiple dimensions and their relations with family and demographic risk factors, Journal of School Psychology, 38 (6), 501-523.

Kopera, F., \& Wiscott, R. (2000). Intergenerational continuity: transmission of beliefs and culture. In B. Hayslip (Ed.), Grandparents raising grandchildren: Theoretical, empirical and clinical perspectives (pp. 65-84) New York: Springer.

Kreidler, W. (2007). La resolución creativa de conflictos (Manual de actividades). Unión Temporal: Centro persona y Familia - Fundación para el Bienestar Humano - SURGIR. Recuperado de: http://www.oei.es/valores2/926327.pdf

LACE (1999). Introducción al estudio de casos. Recuperado de http://www2.uca.es/lace/documentos/EC.pdf

Lacueva, A. (1998). La enseñanza por proyectos: ¿mito o reto? Revista Iberoamericana de Educación, 16, 165-190.

Laguía, M.J. y Vidal, C. (2008). Rincones de actividad en la escuela infantil ( 0 a 6 años). Barcelona, España: Graó

Laorden, C. y Pérez, C. (2002). El espacio como elemento facilitador del aprendizaje. Una experiencia en la formación inicial del profesorado. Pulso, 25, 133-146.

Larcher, C. et Peterfalvi, B. (2006). Diversification des démarches pédagogiques en classe de sciences. Démarche d'investigation. 100, 825-834

Latorre, M.J. y Blanco, F. J. (2007). Algunos conceptos clave en torno a las creencias de los docentes en formación. Docencia e investigación: revista de la Escuela Universitaria de Magisterio de Toledo. 32 (17), 147-170

Leary, M. R. (1990). Introduction to behavioral research methods. Belmont, CA: Wadsworth.

Leary, M.R. (2001). Interpersonal Rejection. New York: Oxford University Press.

Legendre, R. (2005). Dictionnaire actuel de l'éducation. Montréal: Guérin.

Legrand, L. (1995). Les différenciations de la pédagogie. Paris : PUF.

Leroux, M., Fontaine, S. et Sinclair, F. (2015). Retombées d'une formation sur la différenciation pédagogique réalisée avec des enseignantes du primaire. Formation et profession, 23(3), 17-32. doi: 10.18162/fp.2015.280

Leroux, M. et Paré, M. (2016). Mieux répondre aux besoins diversifiés de tous les élèves. Des pistes pour différencier, adapter et modifier son enseignement. Montréal: Chenelière éducation.

Levy, H.M. (2008). Meeting the needs of all students through differentiated instruction: helping every child reach and exceed standards. Clearing House: A Journal of Educational Strategies, Issues and Ideas, 81(4), 161164

Lieberman, A. y Grlonick, M. (1997). Las redes, la reforma y el desarrollo profesional de los docentes. En A. Hargreaves (comp.) Replantear el cambio educativo. Un enfoque renovador. Buenos Aires: Amorrortu. 
Lieberman, A. y Grlonick, M. (2005). Educational reform networks: changes in the forms of reform. En M. Fullan (Ed.) Fundamental Change. International Handbook of Educational Change. Dordrecht: Springer.

Llevot, N., y Bernad, O. (2015). La participación de las familias en la escuela: factores clave. Revista de la Asociación de Sociología de la Educación, 8(1), 57-70.

LOI sur l'enseignement obligatoire (LEO). Recuperado de http://www.rsv.vd.ch/rsvsite/rsv_site/doc.pdf?docId=870673\&Pvigueur=\&Padoption=\&Pcurrent_versio

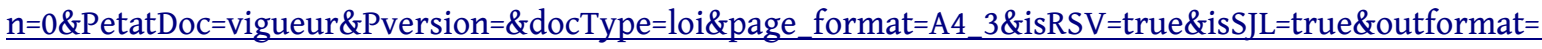
pdf\&isModifiante=false

López López, E., Tourón, J. y Gónzález Galán, Maㅗ (1992). Hacia una pedagogía de las diferencias individuales: reflexiones en torno al concepto de Pedagogía Diferencial. Revista Complutense de Educación, 2 (1), 83-92.

López Melero, M. (1990). La Integración Escolar otra Cultura. Málaga, España: Junta de Andalucía, Consejería de Educación y Ciencia.

López Melero, M. (1997). Escuela pública y atención a la diversidad. La educación intercultural: la diferencia como valor. En AA.VV. Escuela pública y sociedad neoliberal (pp. 15-150). Málaga, España: Aula libre.

López Melero, M. (2004). Construyendo una escuela sin exclusiones: una forma de trabajar en el aula con proyectos de investigación. Málaga, España: Ediciones Aljibe.

López, A.M. y Lacueva, A. (2007). Proyectos en el aula: cinco categorías en el análisis de un caso. REICE: Revista Electrónica Iberoamericana sobre Calidad, Eficacia y Cambio en Educación, 5, 78-120.

López, F. (1995). Necesidades de la infancia y protección infantil. Fundamentación teóricas, clasificación y criterios educativos. Madrid: Ministerio de asuntos sociales.

López, R., Salmerón, P. y Salmerón, C. (2010). Desarrollo y evaluación de la competencia social y ciudadana en educación inclusiva: efectos del aprendizaje cooperativo. Revista de Educación Inclusiva, 3(2), 29-46.

López, V.M. (2005). La participación del alumnado en la evaluación: la autoevaluación, la coevaluación y la evaluación compartida. Tándem. 17

López, V.M., González, M. y Barba, J.J. (2006). ¿Debe el alumnado participar en la evaluación? Propuestas y experiencias en Primaria y Secundaria. Recuperado de http://www.concejoeducativo.org/article.php?id_article=89

Low, C. (2007). A defense of moderate inclusion and the end of ideology. In R. Cigman (Ed.), Included or Excluded? (pp. 3-15). Londres, England: Routledge.

Lozano, A. (2000). Estilos de Aprendizaje y Enseñanza. Un panorama de la estilística educativa. Mexico: Trillas.

Lozano, J. (Dir), Cerezo, Ma C.; Angosto, R.; Ramón, J. y Álvarez, A. (2008). Aprendiendo el lenguaje con Nora: Colección de materiales didácticos para el acceso al lenguaje en contextos educativos multilingües. Granada. Grupo Editorial Universitario.

Lozano, J. (2013). La comunicación Escuela-Familia ante la integración del alumnado extranjero. En E. Soriano (ed.) Interculturalidad y Neocomunicación. (pp. 211-248).Madrid, España: La Muralla.

Luca de Tena, C., Rodriguez R. I., \& Sureda I. (2004). Programa de Habilidades Sociales en la Enseñanza Secundaria Obligatoria. ¿cómo puedo favorecer las habilidades sociales de mis alumnos? Archidona (Málaga): Aljibe.

Luengo, F. (2006). El proyecto Atlántida: experiencias para fortalecer el eje escuela, familia y municipio. Revista de Educación, 339, 177-194. 
Majó, F. (2016). El trabajo por rincones en clase: rincones de interés científico. Revista aula. De Innovación Educativa, 250, 71-74.

Malo, A. (2005). Parcours évolutif d'un savoir professionnel: une étude de cas multiples menée auprès de futurs enseignantes et enseignants du secondaire en stage intensif (Thèse de doctorat inédite). Québec : Université Laval.

Marchena, R. (2005). Mejorar el ambiente de las clases de Secundaria: un enfoque práctico para responder a la diversidad desde el aula. Málaga, España: Aljibe.

Martín, M.C. y Vieira, A. (2000). Atención a la diversidad. En R. Alcudia, M. del Carmen, P. Gavilán (Eds.). La atención a la diversidad en educación infantil: los rincones (pp.67-84). Barcelona, España: Grao

Martíneza Bonafé, J. (1990). El estudio de casos en la investigación cualitativa. En J. B. Martínez Rodríguez (Ed.), Hacia un enfoque interpretativo de la enseñanza (pp.57-68). Granada, España: Servicio de Publicaciones de la Universidad de Granada.

Martínez-Rojas, J. G. (2008). Las rúbricas en la evaluación escolar: su construcción y su uso. Avances en Medición, $6,129-138$

Masip, M. y Rigol, A. (2000). El aula, escenario de la diversidad. En M.M. Aldamiz- Echevarría y otros: Cómo hacerlo. Propuestas para educar en la diversidad Barcelona: Graó.

Maslow, A. (1954). Motivación y personalidad. Ediciones Díaz de Santos, S.A.

McCrea, J. M., Weissman, M., \& Thorpe-Brown, G. (2004). Connecting the Generations: A Practical Guide for Developing Intergenerational Programs. Pittsburgh: Generations Together.

Medina, A. y Salvador, F. (2009). Didáctica General Madrid: Pearson-Prentice Hall.

Meierhenry, W. C. \& Postlethwait, S. N. (1966). New and creative use of media in teacher education. American Association of College Teachers Education Yearbook, 19, 314-321.

Meirieu, P. (1996). Itinéraire des pédagogies de groupe : apprendre en groupe. Lyon : Chronique sociale.

Meirieu, P. (1997). La Escuela: modo de empleo: de los "métodos activos" a la pedagogía diferenciada. Barcelona, España: Octaedro.

Menéndez, S., Jiménez, L. y Lorence, B. (2008). Familia y adaptación escolar durante la infancia. XXI. Revista de Educación, 10, 97-110.

Merriam, S.B. (1988). Case Study Research in Education: A Qualitative Approach. San Francisco, CA: Jossey- Bass.

Messina, C. y Rodríguez, A. (2006). Sentimientos, sistema de creencias y comportamiento didáctico: un estudio etnográfico. Revista de Educación, 339, 493-516

Miles, M. B. \& Huberman, A. M. (1994). Qualitative Data Analysis: An expanded sourcebook. Thousand Oaks, California: Sage.

Moliner, L. (2015). La tutoría entre iguales. Aspectos teóricos y elementos básicos para su planificación. Castellón, España: Colllecció Educació.

Moliner, O. y Moliner, L. (2010). Percepciones del profesorado sobre la diversidad. Revista de educación inclusiva. 3 (3), 23-33.

Moliner, O. y St-Vincent, L.A. (2014). Dilemas éticos de los investigadores que acompañan procesos de investigación-acción en el marco de la escuela intercultural inclusiva. Revista Latinoamericana de Inclusión Educativa, 8(2), 49-68. 
Moliner, O. y Traver, J.A. (2016). Les partenaires des écoles pour le développement de l'inclusion scolaires: un regard sur les acteurs communauteaires. Dans D. Niclot (Ed.) L'inclusion scolaires : des rhétoriques aux pratiques; étude de cas en Europe et en Amérique Latine (pp.55-69). Reims : Éditions et presses.

Moliner, O., Sales, A. y Sanahuja, A. (2017). Social Mapping in the Context of a Community-build Day: Strategy to Strengthen Links with Community in a Small Rural School. Procedia - Social and Behavioral Sciences, 237, 305-310. doi: 10.1016/j.sbspro.2017.02.083

Moliner, O., Traver, J. A., Ruiz, M. P. y Segarra, T. (2016). Estrategias que inciden en los procesos de democratización de la escuela. Una aproximación teórica. Revista Electrónica de Investigación Educativa, 18(2), 116-129. Recuperado de http://redie.uabc.mx/redie/article/view/1110

Moliner. O., Moliner, L., Sanahuja, A. y Sanmateo, V. (2015a). Leemos en pareja: una experiencia en el aula de $3^{\circ}$ de Primaria. En R. Calvo y F.J. Cano (Eds.), El aprendizaje cooperativo como práctica docente: experiencias aplicadas (pp. 99-106). Valencia, España: Neopàtria.

Moliner. O., Moliner, L., Sanahuja, A. y Sanmateo, V. (2015b). Análisis de los elementos de la tutoría entre iguales que posibilitan avanzar hacia la construcción de una escuela intercultural inclusiva y democrática. Revista Latinoamericana de Inclusión Educativa, 9(2), 41-58.

Monjas I., Sureda, I. y García, F. J., (2008). ¿Por qué los niños y niñas se aceptan y se rechazan? Cultura y Educación. 20 (4), 479-492.

Monjas, M. I. (2008). Cómo promover la convivencia: Programa de asertividad y habilidades sociales (PaHS). Madrid, España: CEPE.

Monjas, Mª I., Martín-Antón, L. J., García, F. J. y Sanchiz, M. L. (2014). Rechazo y victimización al alumnado con necesidad de apoyo educativo en primero de primaria. Anales de Psicología, 30(2), 499-511.

Montserrat, S. y Hernández, J. (2013). Les TIC a l'aula: una realitat. Ítaca: Revista de Filologia,4, 15-24

Moreno, G. (2009). Educación diferenciada, ideario y libre elección de centro. Revista General de Derecho Canónico y Derecho Eclesiástico del Estado, 20.391-428

Moreno, J. y García, R. (2008). El Profesorado y la secundaria: ¿demasiados retos? Valenica: Nau Llibres.

Moriña, A. (2008). La escuela de la diversidad. Madrid, España: Síntesis.

Muijs, D. y Harris, A. (2006). Teacher led school improvement: teacher leadership in the UK. Teaching and Teacher Education, 22, 961-972.

Muntaner, J.J. (2000). Aportaciones de la Educación Especial a las escuelas eficaces. En A. Miñambres y G. Jové. La atención a las necesidades educativas especiales: de la educación infantil a la Universidad. (pp. 77 - 95) Universidad de Lleida.

Muntaner, J.J. (2014). Prácticas inclusivas en el aula ordinaria. Revista nacional e internacional de educación inclusiva, 7 (1), 63-79

Muntañola, J. (1996). Arquitectura como lugar. Barcelona, España: Ediciones UPC.

Murillo, F.J. (2006). Una dirección escolar para el cambio: del liderazgo transformacional al liderazgo distribuido, RINACE, 4(4). Recuperado de http://www.rinace.net/arts/vol4num4e/art2_htm.htm

Murillo, F.J. y Hidalgo, N. (2016). Editorial. Evaluación Democrática y para la Democracia. Revista Iberoamericana de Evaluación Educativa, 9(1), 5-7.

Murillo, F.J. y Krichesky, G.J. (2015). Mejora de la Escuela: Medio siglo de lecciones aprendidas. REICE. Revista Iberoamericana sobre Calidad, Eficacia y Cambio en Educación, 13(1), 69-102.

Murray, H. A. (1938). Explorations in Personality. New York: Oxford University Press. 
Naranjo, M. y Jiménez, V. (2015). La evaluación del aprendizaje cooperativo: un reto abordable. En Mayordomo y Onrubia (Coords.). El aprendizaje cooperativo. Barcelona, España: Editorial UOC.

Nixon, J., Allan, J. \& Mannion, G. (2001). Educational renewal as democratic practice: 'new' community schooling in Scotland. International Journal of Inclusive Education, 5(4), 329-352.

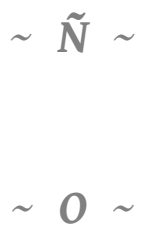

Okuda, M. y Gómez-Restrepo, C., (2005). Métodos en investigación cualitativa: triangulación. Revista Colombiana de Psiquiatría. vol. XXXIV / No. 1, 118-124.

Oliver, C. (2009). El valor formativo y las ataduras de las creencias en la formación del profesorado. Aquello que no se ve, pero se percibe en el aula. REIFOP, 12 (1), 63-75. Recuperado de http://www.aufop.com/aufop/uploaded_files/articulos/1240872744.pdf

Olson, J.M. \& Zanna, M.P. (1993). Attitudes and attitude change. Annual Review Psychology, 44, 117-154.

ONU (2002). Declaración Política y Plan de Acción Internacional de Madrid sobre el Envejecimiento. Segunda Asamblea Mundial sobre envejecimiento. Nueva York: Naciones Unidas. Recuperado de http://www.un.org/es/events/pastevents/ageing_assembly2/

Orden Hoz, A. (1975). Concepto, Método, Fuentes y Programa de Pedagogía Experimental y Diferencial. Memoria de acceso a Cátedra, inédito, Madrid.

Orem, R.C. (1980). El método Montessori de educación diferencial. Barcelona, España: Paidos.

Organisation de coopération et de développement économique (OCDE). (2004). Équité dans l'enseignement : élèves présentant des déficiences, des difficultés et des désavantages sociaux. Paris: Auteur.

Organisation de coopération et de développement économique (OCDE). (2011). Education at a Glance. OECD Indicators, OECD Publishing. DOI: http://dx.doi.org/10.1787/eag-2011-en

Ortiz, Mª C. y Lobato, X. (2003). Escuela inclusiva y cultura escolar: algunas evidencias empíricas. Bordón, 55, (1), $27-40$.

Paille, P. et Mucchielli, A. (2003). L'analyse qualitative en sciences humaines et sociales. Paris : Armand Colin.

Pallí, C. y Martínez, L. Ma. (2004). Naturaleza y organización de las actitudes. En T. Ibáñez (Ed.) Introducción a la psicología social (pp. 183-256). Barcelona, España: UOC.

Parcerisa, A. (1996). Materiales curriculares. Cómo elaborarlos, seleccionarlos y usarlos. Barcelona: Graó. 
Paré, M. (2011). Pratiques d'individualisation en enseignement primaire au Québec visant à faciliter l'intégration des élèves handicapés ou en difficulté au programme de formation générale. (Thèse de doctorat inédite). Université de Montréal. https://papyrus.bib.umontreal.ca/jspui/bitstream/1866/6293/2/Pare_Melanie_2011_these.pdf

Paré, M. et Prud'homme, L. (2014). La différenciation dans une perspective inclusive : intégrer les connaissances issues de la recherche pour favoriser la progression des élèves dans un groupe hétérogène. Revue suisse de pédagogie spécialisée, 2, 31-36.

Parkhurst, H. (1922). Education On The Dalton Plan. New York: E. P. Dutton \& Company. Recuperado de https://archive.org/details/educationontheda028244mbp

Peirats, J. y López, M. (2013). Los grupos interactivos como estrategia didáctica en la atención a la diversidad, ENSAYOS, Revista de la Facultad de Educación de Albacete, № 28, 197-211 Recuperado de http://www.revista.uclm.es/index.php/ensayos

Peiro, M., Piquer, A. y Ríos, I. (2015). La carta al almacén de naranjas. Escribir por necesidad. Revista aula. De Innovación Educativa, 245, 22-26

Pérez Juste, R. (1980). Memoria de Pedagogía Experimental y Diferencial. Memoria de acceso a Cátedra, inédito, Madrid.

Pérez Serrano, G. (1994). Investigación cualitativa I: Retos e interrogantes: métodos. Madrid, España:La Muralla.

Pérez Tapias, J. A. (1996). Claves humanistas para una educación democrática. Madrid, España: Anaya/Alauda.

Pérez, A. I. (2008). ¿Competencias o pensamiento práctico? La construcción de los significados de representación y de acción. En J. Gimeno (Ed.), Educar por competencias, ¿qué hay de nuevo? (pp. 59-103). Madrid, España: Morata.

Perraudeau, M. (1997). Les cycles de la différenciation pédagogique. Paris : Armand Colin.

Perrenoud, P. (1996). La pédagogie à l'école des différences. Paris: EFS.

Perrenoud, P. (2007a). Diez nuevas competencias para enseñar. Invitación al viaje. México: Graõ, Colofón.

Perrenoud, P. (2007b). Pedagogía diferenciada. De las instituciones a la acción. Madrid, España: Popular.

Plan d'études Romands (PER). Recuperado de https://www.plandetudes.ch/

Porter, G.L. \& Stone, J.A. (1998). An Inclusive School Model: A Framework and Key Strategies for Success. In J. Putnam. Cooperative Learning and Strategies for Inclusion. Baltimore: Paul Brookes Publishing.

Postlethwait, S. N. (1966). How to Prepare an Audio-Tutorial Lesson. Frederick, Maryland: A Division of Burgess Publishing Company.

Poveda, D., Sebastián, E. y Moreno, A. (2003). 'La ronda' como evento para la constitución social del grupo en una clase de educación infantil. Infancia y Aprendizaje, 26 (2), 131-146.

Prud'homme, L., Dolbec, A. et Guay, M.-H. (2011). Le sens construit autour de la différenciation pédagogique dans le cadre d'une recherche-action-formation. Éducation et francophonie, 39(2), 165-188.

Prud'homme, L., et Bergeron, G. (2012). Au-delà de la communication des contenus : une version plus flexible de l'enseignement. Prisme, 17, 12-13.

Prud'homme, L., LeBlanc, M. et Paré, M. (2013). Grille visant à soutenir l'observation en salle de classe : étude multicas de pratiques de différenciation pédagogique au Nouveau-Brunswick, au Québec et en Ontario. Document inédit.

Prud'homme, L., Vienneau, R., Ramel, S. et Rousseau, N. (2011). La légitimité de la diversité en éducation: réflexion sur l'inclusion. Valorisation de la diversité en éducation: défis contemporains et pistes d'action. Éducation et francophonie, ACELF, 39 (2), 6- 22.

Prud'homme, L., Paré, M., Leblanc, M., Bergeron, G., Sermier-Dessemontet, R., \& Noël, I. (2016). La différenciation pédagogique dans une perspective inclusive : quand les connaissances issues de la recherche rencontrent le projet d'éducation pour tous. In L. Prud'homme, H. Duchesne, P. Bonvin, \& R. 
Vienneau (Eds.), L'inclusion scolaire : ses fondements, ses acteurs et ses pratiques. Bruxelles : De Boeck Supérieur.

Przesmycki, H. (2004). Pédagogie différenciée. Paris : Hachette.

Puigdellívol, I. (1998). La Educación Especial en la escuela integrada. Una perspectiva desde la diversidad. Barcelona: Graó.

Puigví, R., Calvó, R., Posa, I. y Noguer, M. (2016). Teatro intergeneracional. Aula de Innovación Educativa, 253, 3943.

Pujolàs, P. (2001). Atención a la diversidad y aprendizaje cooperativo en la educación obligatoria. Málaga, España: Aljibe.

Pujolàs, P. (2003). Aprendre junts alumnes diferents. Barcelona: Eumo Editorial.

Pujolàs, P. (2008). 9 ideas clave. El aprendizaje cooperativo. Barcelona, España: Graó

Pulido, C. y Zepa, B. (2010). La interpretación interactiva de los textos a través de las tertulias literarias dialógicas. Signos, 43 (2), 295-309.

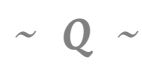

Quintana, J. M. (2001). Las creencias y la educación. Pedagogía cosmovisual. Barcelona, España: Herder.

$$
\sim \boldsymbol{R} \sim
$$

Ramel, S. (2015a). Intervention de la pensée représentative de futurs enseignant-e-s dans leurs prises de position envers l'intégration scolaire (Thèse de doctorat). Université de Lausanne, Lausanne, Suisse.

Ramel, S. (2015b) D’une rhétorique inclusive à la mise en œuvre de moyens pour la réaliser. Revue suisse de pédagogie spécialisée, 3

Ramel, S. Zamarra, G., Sanahuja, A. et Bico, A. (2016). Pratiques inclusives : des orientations de l'établissement au projet de l'élève. Mobilisation des connaissances issues de la recherche par les acteurs de l'éducation inclusive, Haute école pédagogique Vaud, Lausanne (Suisse).

Raymond, H. (1989). Du « soutien » à la différenciation. Cahiers Pédagogiques, « Différencier la pédagogie », p. 47

Real Academia Española. (2012). Diccionario de la lengua española (22 a ed.). Recuperado de http://lema.rae.es/drae/

Reeve, J. (1996). Motivating others: Nurturing inner motivational resources. Needham Heights, MA: Allyn y Bacon.

Rizo, M. (2013). Comunicación e interculturalidad. Reflexiones en torno a una relación indisoluble, Global Medial Journal, 10(19), 26-42 Recuperado de http://www.redalyc.org/pdf/687/68726424002.pdf

Robinson, V., Hohepa, M. y Lloyd, C. (2009). School Leadership and Student Outcomes: Identifying what works and why. Best Evidence Synthesis Iteration. Wellington: Ministry of Education.

Rochera, M. J. y Naranjo, M. (2007). Ayudar a autorregular el aprendizaje en una situación de evaluación. Electronic Journal of Research in Educational Psychology, 5, (13), 805-824

Rodrigo, M. (1999). La comunicación intercultural. Barcelona, España: Anthropos Editorial.

Rodríguez, R. (2012). La diversidad en el aula: hacia una enseñanza diferenciada. MOSAICO. Revista para la Promoción y Apoyo a la Enseñanza del Español. 30,11-18. 
Rojas, G. (2012). Interculturalidad y pedagogía diferenciada: senderos compartidos. Polis (Santiago), 11(31), 435447. doi: $\underline{10.4067 / \mathrm{S} 0718-65682012000100023}$

Rosales, C. (1985). Aportaciones para un renovado concepto de enseñanza diferenciada. Enseñanza \& Teaching: Revista interuniversitaria de didáctica, 3, 131-140

Rosales, R. (1990). Evaluar es reflexionar sobre la enseñanza. Narcea Ediciones: Madrid.

Rose, D. H. \& Meyer, A. (2002). Teaching Every Student in the Digital Age: Universal Design for Learning. Alexandria, VA : Association for Supervision and Curriculum Development.

Rose, R. \& Garner, P. (2010). The professional learning of teachers through experience in an international and intercultural context. In C. Forlin (dir.), Teacher Education for Inclusion: Changing paradigms and innovative approaches (pp. 23-33). New York: Routledge.

Roselló, S., García, F. J., Marande, G., Rubio, A., Milián, I. y Sanahuja, A. (2015). Un libro, un tesoro: Utilización de “Ámbar en cuarto y sin su amigo" para desarrollar actividades socioemocionales. Àgora de salut. 2, 77-85.

Rousseau, N. (2010). La pédagogie de l'inclusion scolaire, pistes pour apprendre tous ensemble. Québec: Presses de l'Université du Québec.

Rousseau, N. et Bélanger, S. (2004). Dix conditions essentielles à la mise en place d'une école inclusive. In N. Rousseau et S. Bélanger (éd.), La pédagogie de l'inclusion scolaire : pistes d'action pour apprendre tous ensemble (pp.347-358). Sainte-Foy, Canada : Presses de l'Université du Québec.

Ruijs, N. M. \& Peetsma T. D. (2009). Effects of inclusion on students with and without special educational needs reviewed. Educational Research Review, 4, 67-79.

Ruiz Olabuénaga, J.R. (1996). Metodología de la investigación cualitativa. Bilbao :Universidad de Deusto.

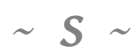

Sabino, C. (1992). El proceso de investigación. Caracas : Panapo.

Saint-Laurent, L. (2007). Enseigner aux élèves à risque et en difficulté au primaire. Montréal : Éditions de la Chenelière.

Sales, A. (2004). Hacia una escuela inclusiva e intercultural: los proyectos de trabajo como propuesta curricular y formativa. XXI. Revista de educación, 6, 139-154.

Sales, A. (2005). La diversitat cultural a l'escola: propostes pràctiques per a un currículum intercultural. Castellón, España: Collecció Educació.

Sales, A. (2012). Creando redes para una Ciudadanía Crítica desde la escuela intercultural inclusiva, Revista de Educación Inclusiva, 5(1), 51-68

Sales, A., Moliner, O. y Sanchiz, M.L. (2001). Actitudes hacia la atención a la diversidad en la formación inicial del profesorado. Revista Electrónica interuniversitaria de formación del profesorado. 2 (4)

Sales, A., Moliner, O. y Traver, J.A. (2010). La construcción de la escuela intercultural inclusiva desde procesos de investigación-acción. Castellón: Servicio de Publicaciones de la Universitat Jaume I.

Sales, A., Traver, J.A., Benet, A. y Sanahuja, A. (2016). A COMMUNITY WELLCOME DAY: Cultural Diversity and Critical Citizenship in a Included School. The Mobilities, Transitions, Transformations Intercultural Education at the Crossroads International Conference. Budapest, Hungary.

San Fabián, J. L. (2005). Participar en las organizaciones educativas: un ejercicio de ciudadanía. En M. A. Santos Guerra (Ed.), Escuelas para la democracia. Cultura, organización y dirección de instituciones educativas (pp. 177200). Santander, España: Consejería de Educación del Gobierno de Cantabria. 
Sanahuja, A. (2013). Necesidades básicas y motivos de rechazo de los niños y niñas del primer ciclo de educación primaria. Trabajo de investigación: Universitat Jaume I (material inédito).

Sanahuja, A., Moliner, O. y Moliner, L. (2014). Pedagogía diferenciada: ¿Un concepto en desuso o de plena actualidad? I Congreso Internacional de Necesidades Específicas de Apoyo Educativo, Universidad de Almería

Sánchez, A. J. (2005). Análisis filosófico del concepto valor. Humanidades Médicas, 5(2) Recuperado de http://scielo.sld.cu/scielo.php?script=sci_arttext\&pid=S1727-81202005000200009\&lng=es\&tlng=es

Sánchez, D.V. (2012). La educación diferenciada en Primaria, ¿se puede llamar coeducación? ReiDoCrea. Revista electrónica de investigación Docencia Creativa. Vol. 1, 76-79 Recuperado de http://digibug.ugr.es/bitstream/10481/21965/1/ReiDoCrea-Vol.1-Art.10-Sanchez.pdf

Sandín. M.P. (2003). Investigación Cualitativa en Educación. Fundamentos y Tradiciones. Madrid, España: McGraw Hill.

Sanmartí, N. (2010). Avaluar per aprendre. L'avaluació per millorar els aprenentatges de l'alumnat en el marc del currículum per competències. Recuperado de http://xtec.gencat.cat/web/.content/alfresco/d/d/workspace/SpacesStore/0024/fc53024f-626e-423b877a-932148c56075/avaluar_per_aprendre.pdf

Santamaria, L. \& Thousand, J. (2004). Collaboration, co-teaching, and differentiated instruction: A processoriented approach to Whole Schooling. International Journal of Whole Schooling Volume 1, Issue 1. pp. 13-27

Santos Guerra, M.A. (2000a). Entre bastidores. El lado oculto de la organización escolar. Archidona (Málaga): Aljibe.

Santos Guerra, M.A. (2000b). La escuela que aprende. Madrid, España: Morata.

Santos Guerra, M.A. (2000c). La participación es un árbol: padres y madres, desde la ciudadanía, hacen escuela. Kikiriki. Cooperación educativa, 55-56, 105-116.

Santos, M. (2006) Participación, democracia y educación: cultura escolar y cultura popular. Revista Educación 339, 883-901

Schneuwly, B.; Rosat, MC.; Pasquier, A. et Dolz-Mestre, J. (1993). Différencier-diversifier ou la didactique et l'hétérogénéité des élèves. In M. Lebrun et M.-C. Paret. L'hétérogénéité des apprenants. Un défi pour la classe de français. Actes du Ve Colloque international de didactique du français langue maternelle. Lausanne : Delachaux \& Niestlé.

Service de l'Enseignement Spécialisé et de l'Appui à la Formation (SESAF). Recuperado de http://www.vd.ch/autorites/departements/dfjc/sesaf/

Setuáin, B. (2012). El tratamiento jurisprudencial de la enseñanza diferenciada. Civitas: Revista española de derecho administrativo 154, 237-262

Shapiro, A. (1999). Everybody belongs: changing negative attitudes toward classmates with disabilities. New York: Routledge Falmer.

Sharan, S. \& Sharan, Y. (1976). Small group teaching. Englewood Cliffs, NJ, Educational Technology Publications.

Sharan, Y. (2010). Cooperative Learning: A Diversified Pedagogy for Diverse Classrooms. Intercultural Education, 21(3), 195-203

Simón, C., Giné, C. y Echeita, G. (2016). Escuela, familia y comunidad: Construyendo alianzas para promover la inclusión. Revista Latinoamericana de Inclusión Educativa, 10(1), 25-42.

Simons, H. (2011). El estudio de caso: Teoría y práctica. Madrid, España: Morata.

Skinner, B.F. (1954). The science of learning and the art of teaching. Harvard Educational Review, 24(2), 86-97.

Smith, L. M. (1978) An evolving logic of participant observation, educational ethnography and other case studies. In L. Shulman (Ed.). Review of research in education. Itasca, IL: Peacock

Stainback, S. y Stainback, W. (1999). Aulas inclusivas. Madrid, España: Narcea.

Stake, R.E. (1995). The art of case study research (pp. 49-68). Thousand Oaks, CA: Sage. 
Stake, R.E. (1998). Investigación con estudio de casos. Madrid, España: Morata.

Sternberg, R. J. (1985). Beyond IQ: A Triarchic Theory of Intelligence. Cambridge, England: Cambridge University Press.

Strotmann, W. (2012). Come On, Let's Try Together: An Intergenerational Approach in Vocational Preparation for Students in Germany, Journal of Intergenerational Relationships, 10 (1), 93-98

Suazo, S. N. (2006). Inteligencias Múltiples. Manual práctico para el nivel elemental. La Editorial, Universidad de Puerto Rico.

Subban, P. (2006). Differentiated instruction: A research basis. International Education Journal, 7(7), 935-947.

Su-Chuan, H. (2009). Meeting the challenges of diversity: beliefs of Taiwanese preservice early childhood teachers (Unpublished doctoral dissertation). University of North Texas, Denton, TX

Susinos, T. (2012). Las posibilidades de la voz del alumnado para el cambio y la mejora educativa. Revista de Educación, 359,16-23

Susinos, T. y Ceballos, N. (2012). Voz del alumnado y presencia participativa en la vida escolar. Apuntes para una cartografía de la voz del alumnado en la mejora educativa. Revista de Educación, 359, 24-44.

Susinos, T. y Rodríguez, C. (2011). La educación inclusiva hoy. Reconocer al otro y crear comunidad a través del diálogo y la participación. Revista Interuniversitaria de Formación del Profesorado, 70(25,1), 15-30.

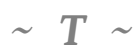

Taylor, S.J. y Bogdan, R. (1987). Introducción a los métodos cualitativos de investigación: búsqueda de significado. Barcelona, España: Paidós.

Theisen, T. (2002). Differentiated instruction in the foreign language classroom: Meeting the diverse needs of all learners. LOTE CED Communique, Issue 6. Recuperado de http://www.sedl.org/loteced/communique/n06.html

Tochon, F. (2004). Le nouveau visage de l'enseignant expert. Recherche et formation, 47, 9-23.

Tójar, J.C. y Serrano, J. (2000). Ética e investigación educativa. Revista Electrónica de Investigación y Evaluación Educativa, 6 (2_2).

Tomlinson, C.A. (2000). Differentiation of Instruction in the Elementary Grades. Recuperado de http://education.ky.gov/educational/diff/Documents/tomlin00.pdf

Tomlinson, C.A. (2005). Estrategias para trabajar con la diversidad en el aula. Buenos Aires, Argentina: Paidós.

Tomlinson, C.A. (2008). El aula diversificada. Dar respuesta a las necesidades de todos los estudiantes. Barcelona, España: Octaedro.

Touriñán, J.M. (2005). Educación en valores, educación intercultural y formación para la convivencia pacífica. Revista galega do ensino, 13/47, 1041-1102.

Traver, J.A. (2000). Trabajo cooperativo y aprendizaje solidario: Aplicación de la técnica puzzle de Aronson para la enseñanza y el aprendizaje de la actitud de solidaridad. (Tesis doctoral). Universitat Jaume I, Castellón, España.

Traver, J.A. (2007). "El Cuaderno de Trabajo en Grupo (QTG-R): una Herramienta para el Aprendizaje Cooperativo en la Enseñanza Universitaria". Actas de las VII Jornadas sobre Aprendizaje Cooperativo JAC07. Valladolid: Universidad de Valladolid (disponible en http://www.greidi.uva.es/JAC07/actas.html).

Traver, J.A. y Rodríguez, M. (2010). Els Quaderns d'Aprenentatge en grup. València: Novadors

Traver, J.A. y Rodríguez, M. y Caño, J.M. (2008). La carpeta del equipo: una herramienta para ayudar a trabajar en grupos cooperativos. Quaderns Digitals. Net Revista de Nuevas Tecnologías y Sociedad n51, Recuperado de 
$\underline{\text { http://www.quadernsdigitals.net/index.php?accionMenu=hemeroteca.VisualizaArticuloIU.visualiza\&art }}$ iculo_id=10448

Traver, J.A.; Sales, A. y Moliner, O. (2010). Ampliando el territorio: Algunas claves sobre la Participación de la Comunidad Educativa. REICE, Revista Iberoamericana sobre Calidad, Eficacia y Cambio en Educación, 8 (3), 96119

Traver, S. (2014). ¿Que el maestro de pedagogía terapéutica atiende al alumnado dentro del aula? y eso... ¿cómo se hace? Quaderns Digitals. Net Revista de Nuevas Tecnologías y Sociedad ACTAS XI Congreso Internacional y XXXI Jornadas de Universidades y Educación Inclusiva / Mesa 8: Apoyo educativo para la inclusión.Universitat Jaume I.

Trueba, B. (1999). Talleres integrales en educación infantil. Madrid, España: Ediciones de la Torre.

Tuckman, B. W. (1990). Conducting educational research. Nueva York: Harcourt, Brace Jovanovich.

Turabik, T. \& Gün, F. (2016). The Relationship between Teachers "Democratic Classroom Management Attitudes and Students"Critical Thinking Dispositions. Journal of Education and Training Studies, 4 (12), 45-57

$\sim U \sim$

UNESCO (1994). Declaración de salamanca y marco de acción para las necesidades educativas especiales. España: Ministerio de Educación y Ciencia.

UNESCO (2005). Guidelines for inclusion: Ensuring Access to Education for All. París, Francia: UNESCO.

UNESCO (2008). Los aprendizajes de los estudiantes de América Latina y el Caribe: Segundo Estudio Regional Comparativo y Explicativo. Santiago de Chile: Oficina Regional de Educación de la UNESCO para América Latina y el Caribe.

UNESCO. (2015). Replantear la educación ¿Hacia un bien común mundial? París, Francia: UNESCO. Recuperado de http://unesdoc.unesco.org/images/0023/002326/232697s.pdf

Valles, M.S. (1997). Técnicas cualitativas de investigación social. Madrid, España: Síntesis.

Vaud famille. Recuperado de http://www.vaudfamille.ch/N209486/systeme-scolaire-vaudois.html

Vázquez, J. (2004). La observación científica en el proceso de contrastación de hipótesis y teorías. Theoria: Revista de Teoría, Historia y Fundamentos de la Ciencia 19 (1), 77-95.

Vázquez, S., Bernal, J.L. y Liesa, M. (2014). La conceptualización del liderazgo: una aproximación desde la práctica educativa. REICE. Revista Iberoamericana sobre Calidad, Eficacia y Cambio en Educación, 12(5), 79-97.

Vélez, E. y Psacharopoulos, G. (1987). The external efficiency of diversified secondary schools in Colombia. Economics of Education Review 6 (2), 99-110 doi: $\underline{10.1016 / 0272-7757(87) 90044-6}$

Vermersch, P. (2010). L'entretien d'explicitation (6e éd.). Issy-les-Moulineaux: Éditeur esf.

Vienneau, R. (2006). De l'intégration scolaire à une véritable pédagogie de l'inclusion. In C. Dionne et N. Rousseau (Dir.), Transformation des pratiques éducatives. La recherche sur l'inclusion scolaire (pp. 7-32). Collection éducation-recherche. Québec, Canada : Presses de l'Université du Québec. 
Vienneau, R. (2011). Integración escolar, inclusión escolar y pedagogía de la inclusión. En Moliner, O. (Ed.), Prácticas inclusivas: experiencias, proyectos y redes. Castellón: Publicacions de la Universitat Jaume I, pp. 121 $-124$.

Viñals, A. y Cuenca, J. (2016). El rol del docente en la era digital. Revista interuniversitaria de formación del profesorado, 86, 103-114

Vogels, R. (2002). Ouders bij de Les. Betrokkenheid van Ouders bij de School van hun Kind. Den Haag: Sociaal en Cultureel Planbureau.

Vygotsky, L. (1978). Interaction Between. Learning and Development. In Gauvain \& Cole (Eds). Readings on the Development of Children (pp. 34-40). New York: Scientific.

Walker, R. (1983). La realización de estudios de casos en educación. Ética, teoría y procedimientos. En W. B. Dockrell y D. Hamilton (Ed.), Nuevas reflexiones sobre la investigación educativa (pp.42-82). Madrid, España: Narcea.

Wan, S. W-Y. (2017). Differentiated instruction: are Hong Kong in-service teachers ready? Teachers and Teaching. Theory and Practice, 23(3), 284-311.

Washburne, C. (1922). Educational measurements as a key to individualizing instruction and promotions. Journal of Educational Research, 5, 195-206

Waterman, S.S. (2007). The Democratic Differentiated Classroom. New York: Eyes on education.

Whitehouse, P. (2013). The challenges of cognitive aging: integrating approaches from science to intergenerational relationships. J Alzheimers Dis.36(2):225-32.

Wiersma, W. (1986). Individually Guided Education: An Alternative Form of Schooling. Recuperado de https://eric.ed.gov/?id=ED274421

Williams, A. \& J. F. Nussbaum (2001). Intergenerational Communication Across the Life Span. Londres: Lawrence Erlbaum.

Williams, G. \& Asher, S. R. (1993). Children without friends, Part 2: The reasons for peer rejection. En C. M. Todd (Ed.), Day care center connec-tions, 3(1), pp. 3-5. Urbana-Champaign, IL: University of Illinois Cooperative Extension Service. National Network for Child Care.

Williams, K. D. (2001). Ostracism: The power of silence. New York: Guilford Publications.

Wong, R. (2000). Motivation. A Biobehavioural Approach. Cambridge, England: Cambridge University Press.

Woods, P., Bennett, N., Harvey, J. y Wise, C. (2004). Variabilities and Dualities in Distributed Leadership: Findings form Systematic Literature Review. Educational Management Administrattion \& Leadership, 32, 439457 
Yacuzzi, E. (2005). El estudio de caso como metodología de investigación: teoría, mecanismos causales, validación, Inomics, 1: 296-306.

Yin, R. K. (1994). Case study research: Design and methods. Newbury Park, CA: Sage Publications.

Zakhartchouk, J.M. (2001). Pédagogie différenciée: Une indispensable clarification. Les langues modernes, 95(4), 32-37.

Zavala, G. (2007). Las posibilidades de la democracia. Algunas reflexiones para escuelas en búsqueda. México: Plaza y Valdés.

Zúñiga, M. (2010). Educación inclusiva. Relevancia de la Sensibilidad Pedagógica ante la Diversidad Educativa. Congreso Iberoamericano de Educación. METAS 2021. Un congreso para que pensemos entre todos la educación que queremos. Buenos Aires, República Argentina. 



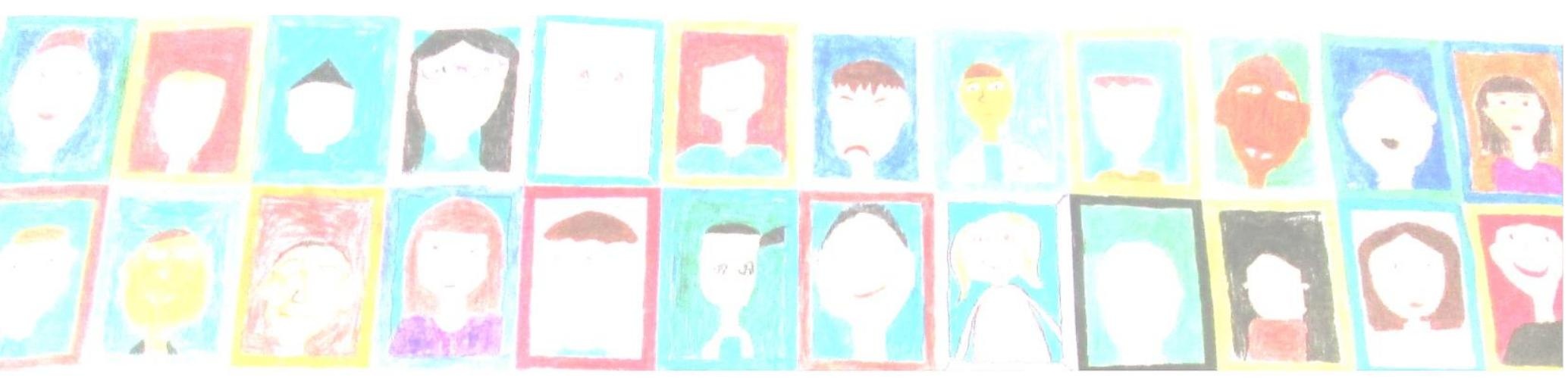

VI. ANEXOS

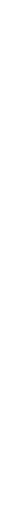





\section{ANEXOS}

\section{$\sim$ Relación de anexos que se presentan $\sim$}

Anexo 1: Carta informativa a los directores

Anexo 2: Consentimiento informado

Anexo 3: Autorización de las familias

Anexo 4: Guión entrevista inicial docentes

Anexo 5: Inventario de prácticas de aula

Anexo 6: Tabla de apoyo a la observación en el aula

Anexo 7: DCOS- Assessing Classroom Differentiation Protocol - Revised

Anexo 8: Guión de entrevista semiestructurada para alumnado

Anexo 9: Guión de entrevista semiestructurada para familias

Anexo 10: Guión de entrevista semiestructurada para estudiantes de prácticas del grado de Maestro

Anexo 11: Guión de entrevista semiestructurada maestra música CASO 3

Anexo 12: Guión entrevista semiestructurada final docentes

Anexo 13: Consentement informé

Anexo 14: Grille observation

Anexo 15: Inventaire de pratiques de classe

Anexo 16: Entretien : sélection de questions

Anexo 17: Informes ATLAS. ti: categorización por prácticas de aula

Anexo 18: Material ilustrativo CASO 1: MANOLO

Anexo 19: Material ilustrativo CASO 3: CRISTINA 



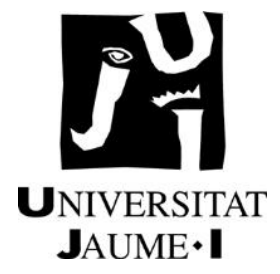

Castellón, 3 de febrero del 2015

Estimado director del C.E.I.P. Isidoro Andrés,

Tras una primera reunión con el tutor de $5^{0}$ de primaria de su centro, Manolo, y su aprobación y participación en el proyecto de investigación que planeamos nos ponemos en contacto con usted para explicarle las principales acciones que pretendemos realizar en dicha aula y contar con su autorización.

Esta investigación denominada Diferenciación pedagógica y participación democrática en el aula inclusiva: estudio de casos múltiples, está enmarcada dentro de un proyecto de tesis doctoral, realizada por la estudiante de doctorado Aida Sanahuja Ribés y dirigida por las profesoras Odet Moliner García y Lidón Moliner Miravet, del departamento de Educación, de la Universitat Jaume I de Castellón.

El objetivo general de este estudio es comprender en profundidad y con matices la manera de articular la pedagogía diferenciada desde la perspectiva de la educación inclusiva en educación primaria. Se trata de indagar sobre la pedagogía diferenciada como herramienta docente para combatir el fracaso escolar y las desigualdades, y de esta manera poder propiciar un aprendizaje óptimo en el alumnado.

Dentro del plan de trabajo las acciones más destacadas que se pretenden efectuar durante el curso académico 2014/2015 son:

- realizar un seguimiento de la clase en la cual es tutor Manolo,

- examinar situaciones de aula,

- analizar documentos y materiales de aula e

- indagar sobre las creencias, percepciones y experiencias vitales de dicho docente, para ver en que se sustentan sus propuestas didácticas.

La información se recogerá mediante instrumentos cualitativos tales como: observaciones, videos, entrevistas y análisis documental.

Así pues, quedamos a su disposición para resolver cualquier duda y esperamos contar con su colaboración. 
Anexo 2: Consentimiento informado

\section{CONSENTIMIENTO INFORMADO}

(Solicitud de consentimiento según capítulo II del REAL DECRETO 1720/2007, de 21 de diciembre, por el que se aprueba el Reglamento de desarrollo de la Ley Orgánica 15/1999, de 13 de diciembre, de protección de datos de carácter personal).

Aida Sanahuja Ribés, como estudiante de doctorado de la Universitat Jaume I de Castellón, redacto este documento de Consentimiento Informado con la intención de dejar constancia por escrito las características del proyecto e investigación que pretendemos realizar. Así mismo, a través de este documento solicito su colaboración y consentimiento en este estudio, así como su autorización para el análisis de los datos recogidos. Para ello le expongo la siguiente información:

En concreto,

1ํ.- Esta investigación, denominada Diferenciación pedagógica y participación democrática en el aula inclusiva: estudio de casos múltiples, está dirigida por las profesoras Odet Moliner García y Lidón Moliner Miravet, del departamento de Educación, de la Universidad Jaume I de Castellón.

2o.- El objetivo general de este estudio es comprender en profundidad y con matices la manera de articular la pedagogía diferenciada desde la perspectiva de la educación inclusiva en educación primaria. Se trata de indagar sobre la pedagogía diferenciada como herramienta docente para combatir el fracaso escolar y las desigualdades, y de esta manera poder propiciar un aprendizaje óptimo en el alumnado.

3‥- Dentro del plan de trabajo las acciones más destacadas que se pretenden son:

- realizar un seguimiento de los docentes que llevan a la práctica la pedagogía diferenciada en sus aulas,

- examinar situaciones de aula,

- analizar documentos y materiales de aula e

- indagar sobre las creencias, percepciones y experiencias vitales de los docentes que sustentan sus propuestas didácticas.

4º.- La información se recogerá mediante instrumentos cualitativos tales como: observaciones, videos, grabaciones de audio, fotografías, entrevistas y análisis documental.

Autorizo a realizar grabaciones en mi aula:

$\square$ Grabaciones de video (con las pertinentes autorizaciones de las familias).

$\square$ Grabaciones de audio.

No autorizo a realizar ningún tipo de grabación en mi aula.

Autorizo a realizar fotografías en mi aula.

No autorizo a realizar fotografías en mi aula. 
5․-Atendiendo a la Ley Orgánica de Protección de Datos 15/1999, sus datos serán incorporados y utilizados de en esta investigación según nos indique:

$\square$ No quiero que se revele ningún dato personal mío.

$\bigcirc$ Quiero aparecer con el pseudónimo:

$\square$ No me importa que mis datos sean públicos.

Cuando lo desees, podrás rectificarlos.

6º- La información recogida será confidencial, es decir, no será divulgada fuera del ámbito de la investigación. Los resultados serán difundidos en formato de artículo y comunicaciones en publicaciones científicas y congresos, ofreciendo la posibilidad al informante de colaborar. Los datos serán custodiados por la investigadora y no serán utilizados con otra finalidad que en las descritas en este documento.

7-- Esta investigación, en formato de tesis doctoral, ha sido aprobada por la Comisión de Investigación y Doctorado del Departamento de Educación de la Universidad Jaume I a fecha de 10 de octubre del 2013, y velarán por su desarrollo riguroso hasta el momento de su defensa.

8‥- Por último, queremos agradecer su colaboración en este trabajo de investigación no sólo por abrirnos las puertas de su aula sino también por la confianza que nos has depositado.

A través de este documento, la persona colaboradora se compromete a participar activa y voluntariamente en esta investigación. De esta forma se procede a la firma de este consentimiento informado:

Yo, declaro estar informado y autorizo a AIDA SANAHUJA RIBÉS a la recopilación, custodia y tratamiento de los datos necesarios para el desarrollo de este estudio. De esta forma:

Acepto participar en esta investigación.

Deseo recibir un resumen de los resultados de esta investigación al correo electrónico:

En Castellón de la Plana, a de de 2014

Colaborador/a en la investigación:

Investigadora:

Fdo.:

DNI:
Fdo.: AIDA SANAHUJA RIBÉS

DNI: 


\section{A LAS FAMILIAS DE LOS ALUMNOS Y ALUMNAS DE 5ํㅡㄹ EDUCACIÓN PRIMARIA}

Estimadas familias:

Este curso 2014/2015 la clase de vuestro hijo/a y la Universitat Jaume I van a colaborar muy estrechamente en un estudio. El aula que tutoriza Manolo ha sido seleccionada porque es considerada una clase donde se realizan buenas prácticas y por tanto objeto de análisis. Es por ello que pedimos vuestra colaboración y participación.

El proyecto de investigación se denomina Diferenciación pedagógica y participación democrática en el aula inclusiva: estudio de casos múltiples, forma parte de una tesis doctoral que está siendo realizada por Aida Sanahuja Ribés, y está dirigida por las profesoras de la Universitat Jaume I de Castellón, la Dra. Odet Moliner García y la Dra. Lidón Moliner Miravet, del departamento de Educación. Contamos con la aprobación del tutor para llevar a cabo este proyecto.

Con esta investigación se pretende estudiar la manera de atender en una misma aula a alumnos diversos, ya que partimos de la consideración de que cada alumno/a es único, por lo que presenta diferentes necesidades, estilos e intereses de aprendizaje.

A lo largo del curso se realizarán diferentes observaciones en el aula, entrevistas y grabaciones. Las grabaciones tienen el único objetivo de servir como material de análisis y formación. Esto se llevará a cabo por el propio grupo de investigación en las instalaciones del colegio y en horario lectivo.

Para ello, solicitamos su autorización para que su hijo/a participe en este estudio. Agradeciéndoles su colaboración que sin duda ayudará a seguir profundizando en estos temas tan relevantes actualmente. Si tiene alguna duda al respecto nosotras mismas se la aclararemos.

Muchas gracias por su colaboración. Reciban un cordial saludo.

8

D./Doña con DNI núm.

Padre/madre/tutor/a del alumno/a de $5^{\circ}$ de EP, (Táchese lo que NO proceda)

(Marque con una X en la casilla correspondiente la opción elegida).

$\square$ AUTORIZA que participe en el estudio y a ser grabado.

$\square$ No AUTORIZA que participe en el estudio, ni a ser grabado.

Castellón, a _-_ de Fdo. ELPADRE/MADRE/TUTOR/A de 2015 


\section{DOCUMENTO DE CESIÓN DE DERECHOS}

Don / doña.

mayor de edad, DNI por este documento autorizo expresamente a la Universidad Jaume I el uso, la difusión y la explotación sobre las imágenes grabadas durante el curso escolar 2014-2015 en el aula de $5^{\circ}$ de primaria del C.P. Isidoro Andrés, o parte de las mismas, para un material didáctico que formará al profesorado y a investigadores sobre la manera de atender en una misma aula a alumnos diversos, en los medios audiovisuales conocidos en la actualidad y los que pudieran desarrollarse en el futuro, con fines educativos y/o divulgativos, sin límite geográfico y por tiempo ilimitado.

Todo ello con la única salvedad y limitación de aquellas utilizaciones o aplicaciones que pudieran atentar al derecho al honor en los términos previstos en la Ley Orgánica 1/85, de 5 de Mayo, de Protección Civil al Derecho al Honor, la Intimidad Personal y familiar y a la Propia Imagen.

Por todo ello, acepto estar conforme con el citado acuerdo.

Firma del padre y/o madre del alumno/a

Firma de la doctoranda, Aida Sanahuja Ribés

Firma de la profesora del Departamento Educación, Dra. Odet Moliner García, Universitat Jaume I

Firma de la profesora del Departamento Educación, Dra. Lidón Moliner Miravet, Universitat Jaume I 


\section{ENTREVISTA INICIAL}

(Adaptada de Pare, M. 2011).

0. Clarificar el concepto de pedagogía diferenciada.

"una filosofía y un marco de acción docente que se sustenta en unas creencias y actitudes positivas de los docentes hacia la diversidad y que consiste en ajustar o flexibilizar la práctica educativa a las necesidades, ritmos, intereses y estilos de aprendizaje de cada alumno, sin perder la referencia del grupo clase (Sanahuja, Moliner y Moliner, 2014)."

1. En total, ¿cuántos años de experiencia docente en educación primaria tiene?

2. En total, ¿cuántos años de experiencia en la enseñanza tiene (todos los niveles)?

3. ¿A qué nivel está enseñando este año escolar 2014/2015?

4. ¿Cuál es el número total de alumnos en su grupo? Especifique cuantos son chicas y cuantos chicos.

5. ¿Cuántos estudiantes con necesidades específicas de apoyo educativo tiene en su aula? Es importante remarcar que entendemos las n.e.a.e no solamente como dificultades 0 discapacidades derivadas de discapacidad sensorial, motora o cognitiva (dificultades específicas de aprendizaje, discapacidad intelectual (leve, moderada, severa), altas capacidades intelectuales, TDAH, trastorno grave de conducta, trastorno psicopatológico (ansiedad, trastorno obsesivo-compulsivo...), trastorno generalizado del desarrollo (autismo, asperger...),deficiencia visual, discapacidad auditiva, trastorno del lenguaje (TEL) 0 discapacidad física)...) sino que también engloba la diversidad de necesidades y demandas, la diversidad de motivaciones e intereses, la diversidad de estilos de aprendizaje, la diversidad de creencias, la diversidad cultural (inmigrantes recién llegados, dificultades lingüísticas, nivel sociocultural bajo...)...

\section{1. ¿Están diagnosticados o no?}

5.2. ¿Cómo los hace participar en el aula? ¿Reciben algún apoyo? ¿Cuándo? ¿De quién? ¿Para qué?

6. ¿Con qué tipo de alumnado con necesidades específicas de apoyo educativo (entendido en sentido amplio tal y como se le ha comentado en la pregunta anterior) ha tenido experiencia en los últimos cinco años?

7. ¿Qué titulación académica tiene? 
8. Durante los últimos cinco años, ¿ha participado en uno o más cursos de formación complementaria sobre la educación para la diversidad (programación multinivel, ACI's, educación inclusiva, competencias básicas, inteligencias múltiples...)? ¿Y seminarios?

8.1. Sobre qué aspecto de la enseñanza ha recibido formación en dichos cursos o seminarios (gestión del aula, educación (pedagogía, didáctica), evaluación del aprendizaje y las habilidades, evaluación de las dificultades, plan de intervención (desarrollo, uso, revisión), participación/ colaboración en las escuelas).

8.2. ¿Sobre qué tipo de dificultades a centrado su formación? (dificultad o problemas de aprendizaje, dificultades o trastornos del comportamiento, discapacidad intelectual (leve, moderada, severa), trastorno psicopatológico (ansiedad, trastorno obsesivo-compulsivo...), trastorno generalizado del desarrollo (autismo, asperger...), deficiencia visual, discapacidad auditiva, trastorno del lenguaje (TEL), discapacidad física).

9. Actualmente desde el modelo de la pedagogía diferenciada ¿se siente capacitado/a para enseñar a estudiantes con necesidades educativas diversas? Considera que está:

1- Suficientemente formado/a

2- Más o menos formado/a

3- Insuficientemente formado/a

10. Explique de manera explayada todo lo que hace para gestionar el aula desde la respuesta a la diversidad de todo el alumnado. Es decir: ¿Cómo son sus clases? ¿Cómo gestiona el aula? ¿Cómo organiza al alumnado? ¿Utiliza algún criterio de agrupación? ¿Qué recursos o materiales utiliza? ¿Cómo son las evaluaciones? Etc.

10.1. De las cosas que ha descrito anteriormente, ¿Cuáles crees que son un reflejo de la pedagogía diferenciada?

10.2. ¿Tiene algún reto para mejorar su docencia en relación a la participación o al aprendizaje de todos los estudiantes? ¿Algún aspecto que le gustaría mejorar o cambiar de su práctica docente?

11. ¿Por qué gestiona así su aula? ¿Qué creencias, percepciones y experiencias vitales cree que subyacen detrás de su forma de trabajar?

12. ¿Le gustaría añadir alguna información más?

$\rightarrow$ Muchas gracias por su colaboración. Recordarle que esta información le será devuelta y podrá matizar o cambiar aquellos aspectos que considere oportunos. 
Identificación:

\section{Inventario de prácticas de aula}

Traducido y adaptado de Heacox, D. (2002). Differentiating Instruction in the Regular Classroom: How to Reach and Teach All Learners, Grades 3-12 Free Spirit Publishing Inc., Minneapolis.

Marque con una "X" a lo largo del continuum para ver dónde se sitúan sus prácticas docentes.

El currículum es mi primera prioridad y

dirige $\mathrm{mi}$ enseñanza.
Baso mi manera de enseñar en las necesidades de aprendizaje de los estudiantes, así como en el currículum.

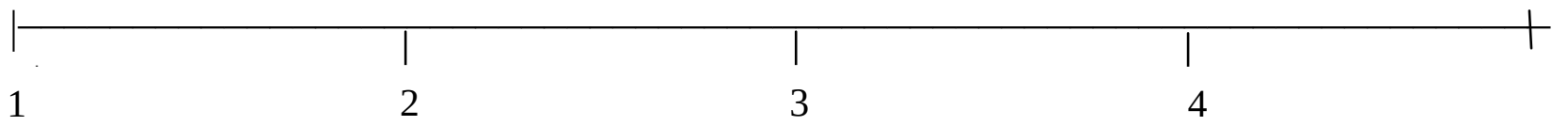

Los objetivos se ajustan a los estudiantes

en función de sus necesidades.

Los objetivos son los mismos para todos los estudiantes.

\begin{tabular}{llll|}
\hline & 1 & $\mid$ & $\mid$ \\
1 & 2 & 3 & 4
\end{tabular}

Hago hincapié en el dominio de contenidos.

Hago hincapié en el pensamiento crítico y creativo y la aplicación del aprendizaje.

\begin{tabular}{lllcl}
\hline & 1 & & \\
1 & 2 & 3 & 4 & 5 \\
Proporciono a los estudiantes diferentes & & Todos los estudiantes usan los mismos
\end{tabular}
recursos (libros, artículos, sitios Web). aprendizaje y habilidades.

$\begin{array}{llll}1 & & 1 & 1 \\ 1 & 2 & 3 & 4\end{array}$

Utilizo principalmente la clase expositiva dirigida a todo el grupo clase.

Uso varios formatos de agrupación del alumnado (por ejemplo, grupo clase, pequeños grupos, parejas, individual).

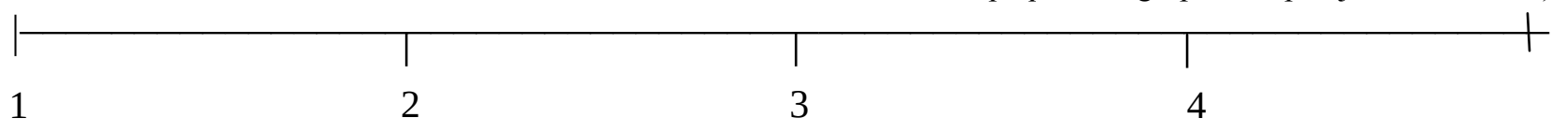

Todos los estudiantes aprenden al mismo ritmo.

El ritmo de la enseñanza puede variar, en función de las necesidades de aprendizaje de los estudiantes.

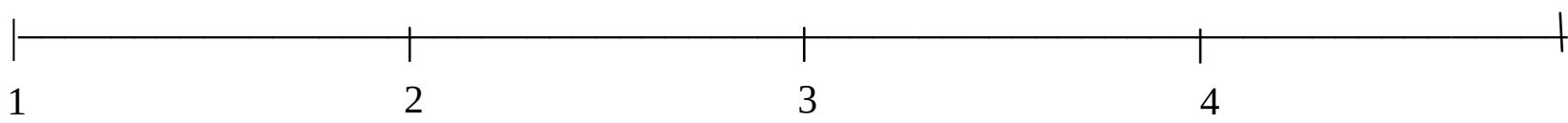

Doy a los estudiantes oportunidades para elegir las actividades en función de sus Todos los estudiantes realizan las mismas actividades. intereses.

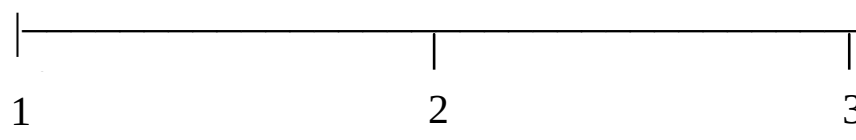

Todos los estudiantes realizan todas las actividades.

Los estudiantes realizan diferente número de actividades en función de sus necesidades o preferencias de aprendizaje.

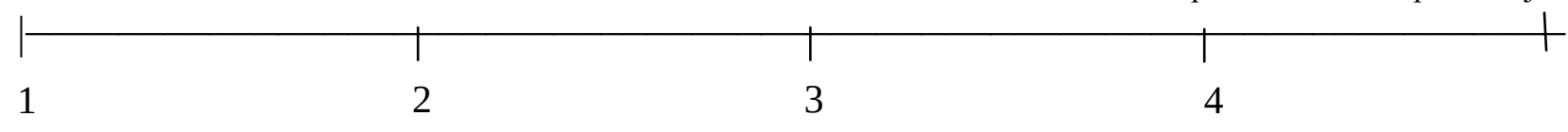


Uso una amplia variedad de estrategias educativas.
Uso poca variedad de estrategias educativas.
1
2

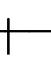

3

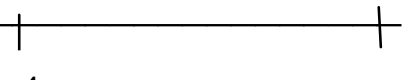

4

Exijo a todo el alumnado el mismo grado de implicación en las actividades.

Exijo diferentes posibilidades de implicación (acelerando, eliminando, sustituyendo...), según el caso.

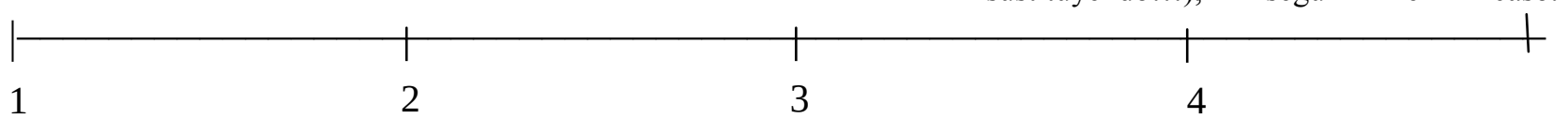

Todos los estudiantes deben realizar las mismas producciones o presentaciones de aquello que han aprendido.

Los estudiantes realizan diferentes producciones o presentaciones de aquello que han aprendido en función de sus necesidades o preferencias de aprendizaje.

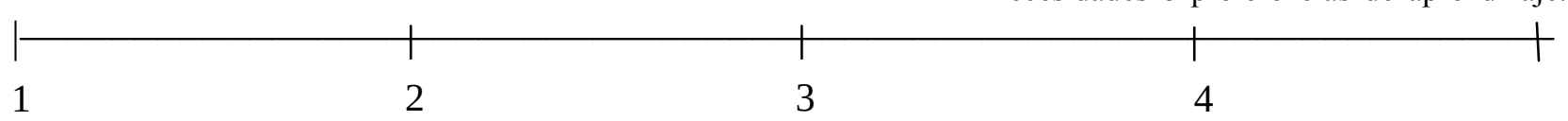

Para reforzar lo que ya se ha trabajado en clase utilizo un método de enseñanza similar, es decir, practican las mismas actividades.

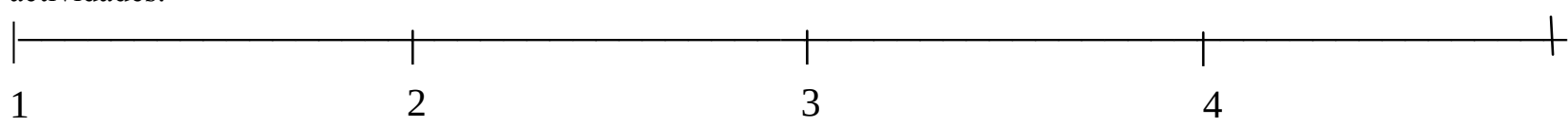

Las actividades de repaso son de un nivel de complejidad mayor, al tiempo que refuerzan las habilidades básicas y contenidos.

Las actividades de repaso que proporciono son de un nivel de complejidad menor, para reforzar las habilidades básicas y contenido.

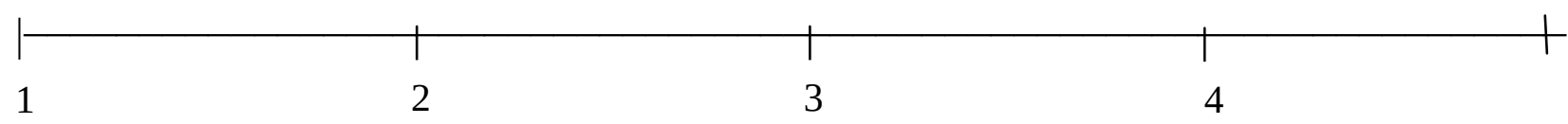

Antes de iniciar una unidad, uso estrategias de evaluación previas para determinar lo que los estudiantes ya saben.

Asumo que los estudiantes tienen poco o ningún conocimiento de los contenidos curriculares.

\begin{tabular}{l|l|l|l}
1 & 1 & 1 & \\
1 & 2 & 3 & 4
\end{tabular}

Por lo general evalúo el aprendizaje de los

Uso una evaluación continua para estudiantes al final de una secuencia de comprobar el aprendizaje de los estudiantes enseñanza. a lo largo de una secuencia de enseñanza.

\begin{tabular}{|c|c|c|}
\hline 1 & $T$ & $\mid$ \\
\hline 2 & 3 & 4 \\
\hline $\begin{array}{l}\text { Suelo utilizar la misma herramienta de } \\
\text { evaluación, producción o proyecto para } \\
\text { todos los estudiantes. }\end{array}$ & & $\begin{array}{l}\text { Tengo en cuenta las diferencias de lo } \\
\text { alumnos y utilizo varios instrumentos d } \\
\text { evaluación. }\end{array}$ \\
\hline
\end{tabular}

Suelo utilizar la misma herramienta de evaluación, producción o proyecto para todos los estudiantes. alumnos y utilizo varios instrumentos de evaluación. 


\section{TABLA PARA APOYAR LA OBSERVACIÓN EN EL AULA}

(Traducido y adaptado de Prud'homme, LeBlanc et Paré, 2013)

Estudio multicaso de prácticas de diferenciación pedagógica y el conocimiento profesional de los docentes de primaria que trabajan des de una perspectiva inclusiva.

1. Elementos observables que conciernen al rigor y la coherencia entre las intenciones, los contenidos y las actividades pedagógicas.

\begin{tabular}{|l|l|l|}
\hline $\begin{array}{l}\text { 1.1. El docente tiene intenciones claras y rigurosas de lo que los alumnos deben saber, } \\
\text { entender y ser capaces de hacer (Ej.: expresa sus intenciones a los alumnos, ayudar a } \\
\text { los alumnos a hacer conexiones entre las intenciones y tareas...). }\end{array}$ & Sí & No \\
\hline $\begin{array}{l}\text { 1.2. El docente enlaza los conocimientos previos del alumnado con los contenidos que } \\
\text { se van a trabajar. }\end{array}$ & Sí & No \\
\hline $\begin{array}{l}\text { 1.3. El docente se asegura de diferentes maneras que los alumnos no pierdan de vista } \\
\text { los objetivos y propósitos de la lección. }\end{array}$ & No \\
\hline Observaciones: & \\
& \\
\hline
\end{tabular}

2. Elementos observables que conciernen a la anticipación (la planificación) y la toma en consideración de la diversidad.

2.1. El docente pone gestos que demuestran que anticipa diferentes caminos que los alumnos pueden tomar para encontrar las intenciones pedagógicas (previo en la secuencia de los lugares donde los alumnos pueden elegir).

2.2. El docente ajusta (hechos que intervinieron durante la secuencia) para permitir a todos los alumnos seguir participando en la tarea (nivel de apoyo, complejidad, abstracción, etc.)

2.3 El docente anima o favorece la expresión de la diversidad de intereses, experiencias, conocimientos, representaciones, etc. que los alumnos pueden asociar con la tarea. (Se pone de relieve, por ejemplo, las similitudes y las diferencias que se pueden observar para realizar la tarea).

2.4 Si uno o varios alumnos manifiestan necesidades particulares que requieren de un plan de intervención, el plan de acción individualizado, un programa de educación especial, especifique los observables relacionados con estas medidas.

Observaciones:

3. Elementos observables que conciernen a las prácticas de enseñanza y de evaluación (Adaptado por Leroux et Paré, en redacción).

3.1. El docente proporciona situaciones de aprendizaje en la que se brindan diferentes oportunidades de explorar utilizando varios métodos de enseñanza en una secuencia (por ejemplo, tareas en talleres o centros de aprendizaje están presentes en el aula y pueden ser utilizadas por algunos alumnos, mientras que otros continúan su trabajo en la secuencia).

3.2. El docente proporciona diferentes momentos donde los alumnos pueden elegir sus actividades de aprendizaje ellos mismos, los recursos utilizados para llevar a cabo el trabajo o la presentación de dicho trabajo.

3.3. El docente varía el tipo de agrupamiento del alumnado.

\begin{tabular}{|l|l|l|}
\hline Sí & No \\
\hline Sí & No \\
\hline Sí & No \\
\hline Sí & No \\
\hline
\end{tabular}




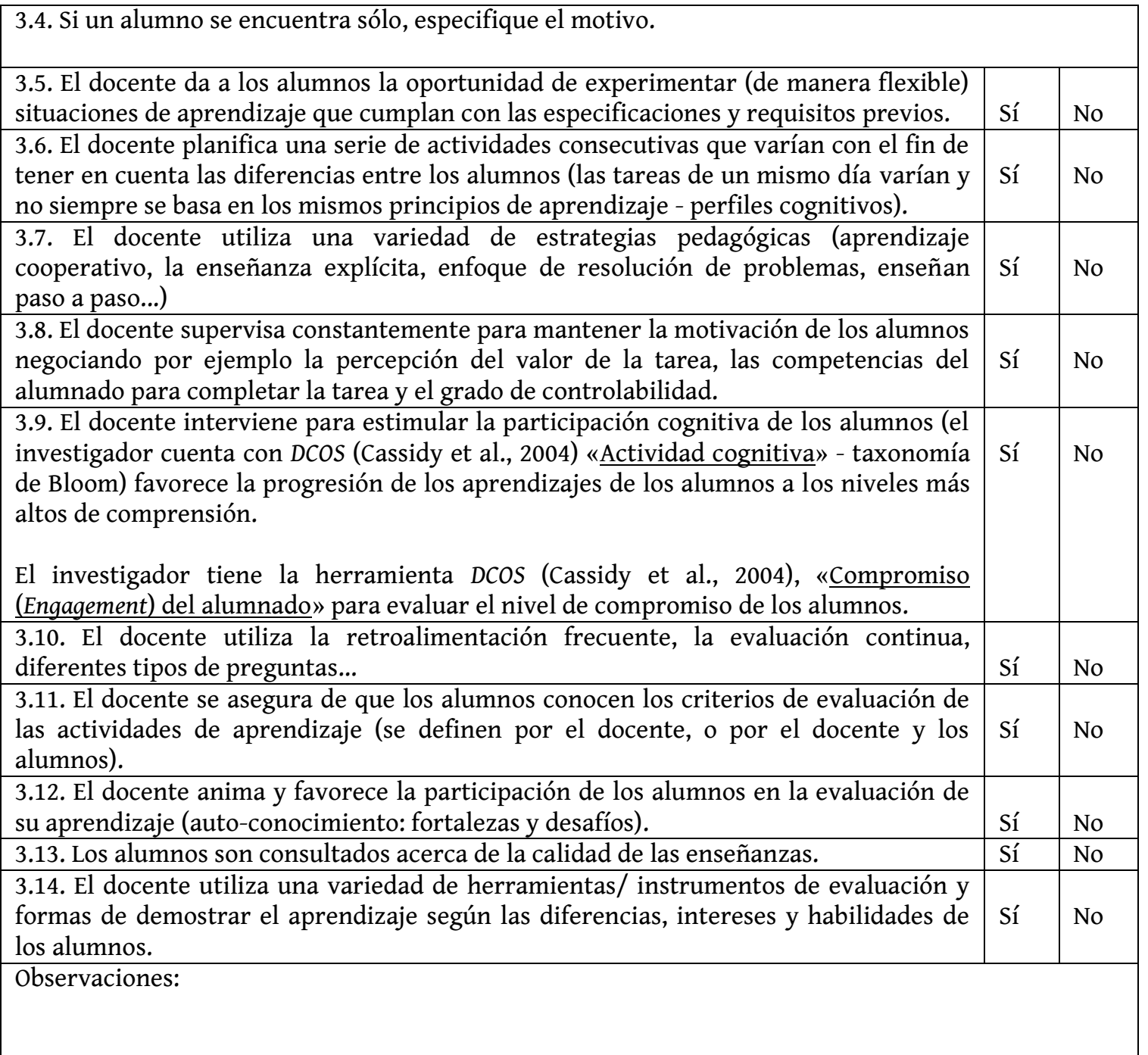

4. Elementos observables que conciernen a la gestión y el clima del aprendizaje (una gestión de clase más participativa se asocia a menudo con la práctica de la enseñanza diferenciada. Este concepto abarca diferentes elementos educativos relacionados con el tiempo, el programa de actividades, códigos, normas y procedimientos, el espacio, el sistema de relaciones, el sistema de responsabilidades, el sistema de evaluación y reconocimiento, los recursos humanos y materiales...).

\begin{tabular}{|l|l|l|}
\hline $\begin{array}{l}\text { 4.1. El docente anima o favorece una actitud positiva hacia la diversidad (reconoce, } \\
\text { toma partido y valora). }\end{array}$ & Sí & No \\
\hline $\begin{array}{l}\text { 4.2. El docente procura crear una comunidad de aprendizaje (interdependencia y } \\
\text { intercomprensión mutua: incita o anima a los alumnos a que se ayuden unos a otros, } \\
\text { en lugar de competir, para explotar los recursos de sus compañeros, para mejorar el } \\
\text { desempeño de sus funciones, para tratar de entender las ideas diferente a la suya -en } \\
\text { lugar de rechazar). }\end{array}$ & Sí & No \\
\hline $\begin{array}{l}\text { 4.3. El docente solicita la participación de todos los alumnos tanto en la gestión del } \\
\text { aula como en la organización y el contenido de las actividades (los alumnos tienen el } \\
\text { poder). }\end{array}$ & Sí & No \\
\hline $\begin{array}{l}\text { 4.4. El docente fomenta la autonomía del alumnado (autoeficacia). } \\
\text { interd docente favorece el aprendizaje cooperativo para fomentar el apoyo mutuo, la la } \\
\text { cómodos trabajanda intercomprensión mutua y para asegurar que los alumnos estén } \\
\text { 4.6. El docente es cálido y comprensivo hacia todos los alumnos (acogedor, escucha, } \\
\text { estimula, es consciente de su estado emocional, etc.). }\end{array}$ & No \\
\hline $\begin{array}{l}\text { 4.7. En la organización física de la clase hay menú de actividades, el horario, la rutina, } \\
\text { memorándums, celebración de la diversidad, las áreas de trabajo para el grupo / } \\
\text { subgrupo / individual, etc. }\end{array}$ & Sí & No \\
\hline 4.8. Los alumnos tienen indicaciones sobre el horario de las actividades. & Sí & No \\
\hline
\end{tabular}


4.9. El docente es eficaz en su gestión de los comportamientos (los alumnos están implicados en la resolución de dificultades que se presentan en el aula, los alumnos participan en la formulación de las reglas de la clase).

Observaciones:

5. Elementos observables que conciernen a los recursos atribuidos para efectuar adaptaciones, modificaciones y ofrecer un apoyo particular.

\begin{tabular}{|c|c|c|}
\hline 5.1. Si hay más de un adulto presente en la clase, especifique su papel. & Sí & No \\
\hline 5.1.1. ¿Trabaja en colaboración con el docente? & Sí & No \\
\hline 5.1.2. ¿El docente pretende desarrollar la autonomía del alumnado? & Sí & No \\
\hline 5.1.3. ¿Se preocupa por todos los alumnos? & Sí & No \\
\hline 5.2. Si uno o más alumnos salen de la clase, $\mathrm{e}$ & Sí & No \\
\hline
\end{tabular}

5.3. Consultamos a los alumnos que tienen dificultades respecto al apoyo que necesitan o que podrían necesitar.

5.4. El material asociado con el currículum se adapta adecuadamente (por ejemplo: audio o Braille,...) y están disponibles para todos los alumnos, tengan o no alguna discapacidades.

Observaciones:

\section{Referencias bibliográficas}

Cassidy et al. (2004). Differentiated Classroom Observation Scale Protocol.

Leroux et al. (2012). Grille d'observation de l'enseignante. Inédit.

Down (2006). Differentiated instruction implementation matrix.

Maeng (2011). Diffrentiated instruction implementation Matrix-Modified.

Booth et Ainscow (2002) Guide de l'éducation inclusive : développer les apprentissages et la participation dans l'école. CEEI

http://www.eenet.org.uk/resources/docs/Index\%20French\%20Quebec.pdf 


\section{Assessing Classroom Differentiation Protocol - Revised}

Revised from the original: Cassady, J. C., Speirs Neumeister, K. L., Adams, C. A., Dixon, F. A., Pierce, R. L. (2004). The Differentiated Classroom Observation Scale, Roeper Review, 26, 139-146.

1. Preparation: Before doing the observation, the observer will contact the teacher to find a time that is convenient for the observation. The following will need to be arranged before the observation date:

- Permission to observe from teacher

- Copy of lesson plan - let the teacher know in advance what types of things to include or if there is a particular format to use

- Teacher will visually identify targeted group of students in classroom (with color-coded name tags or teacher's chosen strategy)

- Teacher is made aware that there is a brief (5 minutes or so) pre-observation interview, and a short postobservation debriefing.

2. Pre-Observation Interview - Review Lesson Plan before the interview. For the interview, use questions/ record answers on the ACD Scoring Form - This is an informal interview that is merely to gain essential descriptive information in order to inform the observation.

3. Classroom Observation and Scoring - Use the Instructional Activity Codes below and on the next page to assist in recording what is seen in the observation during $5-10$ minute segments. Use the ACD Scoring Form to record the codes and assessments. There are other questions on the Scoring Form to complete during this phase as well.

4. Post-Observation Debriefing - Follow directions on the ACD Scoring Form

5. Reflection - Add final comments after leaving the classroom.

\section{Codes for Levels of Engagement, Activity, Learning Director, \& Classroom Management}

These are global ratings for each 5-minute segment. Thus, each segment will have only one rating for each of these domains, the rating that is most representative of that time period for that group.

\begin{tabular}{|c|c|c|c|c|}
\hline Student Engagement & $\begin{array}{l}\text { Pace of } \\
\text { Instruction }\end{array}$ & $\begin{array}{l}\text { Cognitive } \\
\text { Activity }\end{array}$ & "Learning Director" & $\begin{array}{l}\text { Classroom } \\
\text { Management }\end{array}$ \\
\hline $\begin{array}{l}\text { M - Moderate engagement }=21 \\
-79 \% \text { of students engaged in } \\
\text { learning }\end{array}$ & $\begin{array}{l}\text { S - Too slow = } \\
\text { students losing } \\
\text { interest or not } \\
\text { paying attention } \\
\text { R- Right = seems } \\
\text { to be right with } \\
\text { students able to } \\
\text { keep up but not } \\
\text { losing interest } \\
\text { F - Fast = } \\
\text { students having a } \\
\text { hard time } \\
\text { keeping up, may } \\
\text { be some } \\
\text { evidence of } \\
\text { giving up }\end{array}$ & $\begin{array}{l}\text { Ratings are made } \\
\text { in each segment } \\
\text { following the } \\
\text { given scale: } \\
1 \text { - Not evident } \\
2 \text { - Evident } \\
3 \text { - Well- } \\
\text { represented }\end{array}$ & $\begin{array}{l}\text { Who directs the } \\
\text { learning, or makes } \\
\text { the decisions about } \\
\text { the learning } \\
\text { activities. } \\
\text { Use this scale for } \\
\text { making your } \\
\text { segment ratings for } \\
\text { the identified } \\
\text { groups: } \\
1 \text { - Teacher directs } \\
\text { all learning. } \\
2-\text { Teacher directs } \\
\text { most learning. } \\
3-\text { Teacher and } \\
\text { student share } \\
\text { learning decisions } \\
4-\text { Student directs } \\
\text { most learning } \\
5-\text { Student directs } \\
\text { all learning }\end{array}$ & $\begin{array}{l}\text { Students were } \\
\text { on task and } \\
\text { productive. } \\
\text { Group } \\
\text { procedures were } \\
\text { clear, } \\
\text { established, and } \\
\text { understood by } \\
\text { the students. } \\
\text { Ratings are made } \\
\text { in each segment } \\
\text { following the } \\
\text { given scale: } \\
\text { L- Low - } \\
\text { Students unclear } \\
\text { on tasks } \\
\text { M-Moderate - } \\
\text { Some wasted } \\
\text { time } \\
\text { H - High - } \\
\text { Students on-task }\end{array}$ \\
\hline
\end{tabular}


Five-Ten Minute Segment Scoring Codes (use ACD Scoring Form)

During the observation period, please indicate for each 5-10 minute segment which of the following instructional activities listed below were in practice. There will be at least one per segment, and each segment will likely have more than one. The segment ratings should be marked separately for the two groups of students: "Identified" and "Not identified." In the event that there is no way to distinguish between the two groups, make whole-group ratings in the "Not Identified" group location only. If the entire class has been identified as having high ability in the general intellectual domain and/or in the particular subject being observed, record the observations in the "Identified" group location. Feel free to make a note on what the activity was.

In addition to the instructional activities, please also rate student engagement, cognitive level, "Learning Director," and classroom management for each 5-10 minute segment.

\section{Instructional Activity Codes}

\begin{tabular}{|c|c|c|}
\hline Instructional Activity- How & Code & Description \\
\hline Lecture /Teacher Presentation & $\mathrm{L}$ & $\begin{array}{l}\text { Teacher presenting to group of students; teacher demonstrating how to } \\
\text { execute a task (e.g., working a math problem on board, how to use lab } \\
\text { equipment); teacher may ask some questions of students }\end{array}$ \\
\hline Class Discussion & $C D$ & Discussion with whole class, students are primary discussants \\
\hline $\begin{array}{l}\text { Student Led Presentation, } \\
\text { Demonstration, Drama, or } \\
\text { Discussion }\end{array}$ & SL & $\begin{array}{l}\text { Student(s) presenting information to the class (either planned } \\
\text { presentation or on-demand task), demonstrating how to do a task, or } \\
\text { leading the discussion }\end{array}$ \\
\hline Student Responding & SR & $\begin{array}{l}\text { Student(s) answering questions posed by teacher (e.g. spelling bee, } \\
\text { review questions, working problems at the board, choral response) }\end{array}$ \\
\hline Small Group Work & GW & $\begin{array}{l}\text { Students working in small groups; could be discussing, working on } \\
\text { academic assignments, or on a cooperative task }\end{array}$ \\
\hline Manipulatives or Hands-On & M & $\begin{array}{l}\text { Student(s) working with concrete materials to illustrate abstract } \\
\text { concepts (e.g., math blocks, science models) }\end{array}$ \\
\hline $\begin{array}{l}\text { Use of Graphic Organizers or } \\
\text { Other Visuals }\end{array}$ & GO & Student(s) using visual tools to illustrate concepts \\
\hline $\begin{array}{l}\text { Activities Differentiated by } \\
\text { Readiness }\end{array}$ & ADR & $\begin{array}{l}\text { Student(s) working with planned activities differentiated according to } \\
\text { level of readiness }\end{array}$ \\
\hline Activities Other & AO & $\begin{array}{l}\text { Student(s) working with activities possibly differentiated by interest or } \\
\text { learning style, but not necessarily }\end{array}$ \\
\hline Seat work-Individual & SWI & Student(s) working at desk on academic materials (independently) \\
\hline $\begin{array}{l}\text { Teacher interacting with } \\
\text { individual student }\end{array}$ & TIS & Teacher working with/talking to/helping individual student \\
\hline $\begin{array}{l}\text { Teacher interacting with small } \\
\text { group }\end{array}$ & TIG & Teacher working with/talking to/helping small group of students \\
\hline Technology use-Students & TS & Technology being used by students for related learning activities \\
\hline Technology use-Teacher & $\mathrm{TT}$ & $\begin{array}{l}\text { Technology being used by the teacher for presenting instructional } \\
\text { content }\end{array}$ \\
\hline Assessment by Teacher & TA & Teacher is monitoring/ assessing student work \\
\hline Assessment activity & A & $\begin{array}{l}\text { Student(s) engaged in a formalized assessment activity (e.g., test; } \\
\text { performance) }\end{array}$ \\
\hline Other & 0 & List "other" activities \\
\hline Instructional Activity - What & Code & Description \\
\hline Student Choice & $\mathrm{C}$ & Student(s) can select topic, resource, activity, product \\
\hline Independent Study & IS & Student(s) do independent investigations and research \\
\hline Real Audiences & RA & Student(s) present to/prepare for outside reviewers or audiences \\
\hline Advanced Content & AC & $\begin{array}{l}\text { Content is advanced, e.g. from supplementary materials, above grade } \\
\text { level, from primary sources, not adopted texts }\end{array}$ \\
\hline
\end{tabular}


ENTREVISTA ALUMNOS: prácticas observadas, participación y pedagogía diferenciada.

(Adaptado del material de trabajo del grupo MEICRI- Mejora educativa y Ciudadanía Crítica)

\section{AGRUPAMIENTOS}

1.1. ¿Cómo trabajáis? ¿En grupo o individualmente? ¿Cuánto tiempo dedicáis a cada forma de trabajo? ¿Trabajáis mejor de alguna forma? ¿Qué creéis que os aportan esa o esas formas de trabajar?

1.2. ¿Los grupos siempre son con las mismas personas? ¿Os gusta?

1.3. ¿Cómo pensáis que podríamos mejorar la forma de trabajar en referencia a esa forma de trabajo individual o en grupo?

\section{OBJETIVOS}

2.1. ¿Creáis que con esta práctica llegáis a conseguir lo que se espera de las clases? ¿Cómo se podría mejorar?

\section{METODOLOGÍA}

3.1. ¿Pensáis que esta forma de trabajo es la mejor forma? Conocéis formas de trabajo mejores? ¿Cómo lo mejoraríais?

\section{Actividades}

4.1. ¿Durante la actividad tenéis que trabajar de diferentes formas? ¿Algunos tenéis que asumir unas responsabilidades y otros unas diferentes? ¿Se van cambiando?

4.2. ¿Qué roles o funciones desempeña cada alumno?

\section{EVALUACIÓN}

5.1. ¿Cómo se evalúa el trabajo? ¿Qué cosas se evalúan? ¿Quién lo hace? ¿Sabéis porque se evalúa así? ¿Os parece bien? ¿Conocéis maneras de hacerlo mejor?

\section{GESTIÓN DEL AULA (espacio y tiempo)}

6.1. ¿Cómo se emplea el espacio? ¿Siempre es el mismo? ¿Os sentís cómodos trabajando en esos espacios?

6.2. ¿Durante las sesiones siempre se dedica el mismo tiempo a todas las cosas? ¿Gestionaríais el tiempo de manera diferente?

\section{COMPETENCIAS DE COMUNICACIÓN DEL PROFESORADO}

7.1. ¿Las informaciones que os da el maestro las entendéis bien? ¿Os gusta como os comunica las cosas?

\section{DESARROLLO PROFESIONAL Y COMUNITARIO}

8.1. ¿Las prácticas tienen alguna relación con vuestro entorno? 


\section{PARTICIPACIÓN DE LOS ALUMNOS}

- ¿El maestro escucha vuestros puntos de vista y vuestros deseos en relación a vuestros aprendizajes?

-¿Podéis aportar ideas y propuestas que después se llevan a cabo en el aula? ¿Pon algún ejemplo?

-El maestro, ¿cómo os hace participar en el aula?

¿QQué os parece trabajar en grupos cooperativo (lápices al centre o 1-2-4)? ¿Podéis participar más en el aula?

- Ahora me gustaría que valorarais vuestra participación en el aula en cada una de las diferentes actividades que realizáis:

$\frac{\text { Caso } 1}{\rightarrow \text { Cuentacuentos o teatro a }}$
infantil.
$\rightarrow$ Leemos en pareja.
$\rightarrow$ Tertulia literaria dialógica.
$\rightarrow$ Los cargos /roles que
desempeñáis.
$\rightarrow$ Evaluación de trabajos o
libretas.

Caso 2

$\rightarrow$ Trabajo por proyectos.

$\rightarrow$ Grupos interactivos.

$\rightarrow$ Talleres de 1er ciclo.

$\rightarrow$ Cuentacuentos.
Caso 3

$\rightarrow$ Estaciones.

$\rightarrow$ Tertulia literaria dialógica.

$\rightarrow$ Leemos en pareja.

$\rightarrow$ Trabajo por proyectos.

$\rightarrow$ Los cargos/roles que desempeñáis.

$\rightarrow$ Las Tablets ¿Qué os parece no tener libros de texto?

\section{DIFERENCIACIÓN DE LA ENSEÑANZA}

- ¿Quién trabaja más en clase o desarrolla más actividad vosotros o vuestro maestro? ¿Por qué?

- ¿Aprendéis todos de la misma manera y al mismo ritmo, o procesáis la información de diferente manera y a distinta velocidad unos de otros?

- ¿Todos hacéis las mismas cosas o podéis elegir lo que queréis aprender o cómo aprenderlo?

¿¿Podéis escoger lecturas según vuestros intereses? ¿Os gusta o preferiríais que os las diera el maestro?

-¿Qué hacéis para escoger lecturas, proyectos (p.ej. Cultura Valenciana),...?

- ¿Hacéis diferentes productos o presentaciones de aquello que habéis aprendido en función de vuestras necesidades o preferencias de aprendizaje?

- ¿Todos os evalúan de la misma forma?

\section{PARTICIPACIÓN DE LAS FAMILIAS}

-¿Generalmente vuestras familias en que participan en el aula? ¿Quién viene?

-¿Qué os parece que participen en el aula? ¿Os gusta?

-¿Qué os aporta que vengan a clase vuestros padres, madres, abuelos...? ¿Aprendéis más?

- ¿Cómo los invitáis al aula?

-¿Os gustaría que participaran más? ¿En qué?

- ¿Cómo pensáis que se sienten ellos (madres, padres, abuelos...) al venir a vuestra clase?

-¿En casa cómo os ayudan a preparar por ejemplo la lectura en parejas? ¿Os ayudan o lo hacéis vosotros solos? 


\section{ENTREVISTA FAMILIAS}

\section{- PARTICIPACIÓN DE LAS FAMILIAS}

- ¿Generalmente las familias en que participáis en el aula?

-¿Qué pensáis que facilita o propicia esta participación de las familias en el aula?

-¿Qué aporta la participación de las familias en el aula?

-¿Qué recursos y procedimientos utiliza la maestra para invitaros a venir al aula?

-¿Hacen alguna reunión inicial y os informan sobre cómo vais a participar?

-¿Cuántos cursos hace que las familias participáis en el aula?

- ¿Y las familias podéis proponer proyectos o actividades a las maestras para que se realicen en el aula? ¿Se llevan a cabo las propuestas?

- ¿Cuál es vuestra valoración del funcionamiento del aula?

- ¿Cómo os hace participar la maestra en el aula? A PARTIR DE LAS DIFERENTES ACTIVIDADES MENCIONADAS

\section{- PARTICIPACIÓN DE LOS ALUMNOS}

-Los niños trabajan en grupos cooperativos mediante técnicas cooperativas ¿Qué pensáis vosotras? ¿Qué os parece esta forma de trabajar?

-¿Pensáis que se favorece la autonomía del niño?

-¿Qué opináis sobre el hecho de no tener libros de texto? Porque en esta clase lo elaboran todo los niños. ¿Aprenden más?

-Partiendo de la base de que todos no aprendemos igual ¿Qué os parecen las diferentes propuestas que se ofrecen en el aula (lectura por parejas, proyectos, grupos interactivos, tertulia literaria dialógica...)? ¿Cómo las valoráis?

¡¿Cuál es vuestro papel en cada una de las metodologías?

Caso 2 Caso 3

$\rightarrow$ Trabajo por proyectos.

$\rightarrow$ Grupos interactivos.

$\rightarrow$ Talleres de 1er ciclo.

$\rightarrow$ Cuentacuentos.

- ¿Cómo lo preparáis en casa?

$\underset{\text { Caso } 3}{\rightarrow \text { Estaciones. }}$

$\rightarrow$ Tertulia

dialógica.

$\rightarrow$ Leemos en pareja.

$\rightarrow$ Trabajo por proyectos.

- ¿De esta forma piensas que se atiende mejor a la diversidad del aula y a los diferentes ritmos de cada alumno?

- ¿Quién tiene mayor protagonismo en el aula la maestra o los alumnos?

¿¿La voz de los estudiantes se tiene en cuenta? ¿Se les escucha? ¿Pueden tomar decisiones?

- ¿Los alumnos pueden elegir lo que quieren aprender?

¿Qué os parece que los alumnos puedan elegir lo que quieren aprender? 


\section{ENTREVISTA ABUELOS}

\section{Caso 2.2}

Las preguntas que les haré no tienen nada que ver con Betxi a lo largo del tiempo, les preguntaré sobre lo que ustedes piensan sobre el hecho de haber venido al colegio y sobre su participación en este proyecto.

1. ¿Qué les ha parecido venir al aula de sus nietos o sus nietas? ¿Qué les ha parecido venir aquí al aula? ¿Entrar dentro del aula y participar?

2. ¿Habían venido alguna otra vez antes a la escuela? ¿A qué?

3. ¿Qué piensa que propicia o facilita vuestra participación en la escuela?

4. ¿Qué les ha parecido la experiencia de haber venido hoy?

5. ¿Cómo les invitaron para venir al aula?

6. ¿Qué les parece que los niños estén estudiando Betxi a lo largo del tiempo? ¿Qué les parece la temática? 


\section{ENTREVISTA FINAL: estudiantes prácticas magisterio}

\section{AGRUPACIONES HETEROGÉNEAS}

-¿He visto que la maestra promueve diferentes tipos de agrupación (parejas, pequeño grupo, gran grupo, asambleas)? ¿Por qué lo hace? ¿Qué crees que pretende?

-¿Utiliza algún criterio para formar el grupo?

\section{OBJETIVOS Y CONTENDIDOS CURRICULARES}

-¿Planifica los contenidos curriculares teniendo en cuenta las diferencias entre los alumnos de la clase? ¿Establece diferentes niveles de competencia?

-¿Prioriza los objetivos y contenidos más significativos y funcionales para el grupo-clase? Esto es, establecer los contenidos esenciales que se han de aprender.

- ¿Establece objetivos individuales con los diferentes alumnos y objetivos de toda la clase?

- Una vez los alumnos han escogido el proyecto o temática que quieren trabajar ¿desarrolla objetivos y contenidos?

\section{METODOLOGÍA PARTICIPATIVA, COOPERATIVA Y DIFERENCIADA}

- ¿La maestra escucha los diferentes puntos de vista y deseos en relación al aprendizaje del alumnado?

- ¿Fomenta que el alumnado asuma la responsabilidad de su propio aprendizaje?

- He visto que pone en práctica diferentes metodologías de trabajo ¿Por qué? ¿Qué pretendes en cada una de ellas?

- ¿Con las diferentes actividades que propones respetas los diferentes ritmos e estilos de aprendizaje de cada alumno?

¿¿Por qué trabajan mediante grupos cooperativos? ¿Qué te parece esta forma de trabajar? ¿Favorece la autonomía del niño?

- He visto que en frecuencia estimula al alumno a hacer elecciones en función de sus intereses y motivaciones ¿Cómo repercute en su formación como ciudadano crítico?

- ¿Cómo tiene la maestra en cuenta la voz o la participación del alumnado a partir de las diferentes propuestas que hacéis en tu clase?

Caso 1

$\rightarrow$ Cuentacuentos o teatro a infantil.

$\rightarrow$ Leemos en pareja.

$\rightarrow$ Tertulia literaria dialógica.

$\rightarrow$ Los cargos / roles que desempeñáis.

$\rightarrow$ Evaluación de trabajos o libreta.
Caso 2

$\rightarrow$ Trabajo por proyectos.

$\rightarrow$ Grupos interactivos.

$\rightarrow$ Talleres de 1er ciclo.

$\rightarrow$ Lectura a infantil. 


\subsection{PARTICIPACIÓN DE LAS FAMILIAS}

¿ ¿Generalmente las familias en que participan en el aula?

-¿Qué piensas que facilita o propicia la participación de las familias en tu aula?

- ¿Qué aporta la participación de las familias (o abuelos) en el aula?

-¿Qué recursos utilizan para invitar a las familias al aula?

-¿Hacen alguna reunión inicial para informar sobre cómo van a participar?

-¿Cuántos cursos hace que las familias participan en el aula?

- ¿Las familias pueden proponeros proyectos o actividades para que se realicen en el aula? ¿Se llevan a cabo sus propuestas?

- ¿Cuál es la valoración que tienen las familias sobre el funcionamiento del aula?

\section{EVALUACIÓN DIFERENCIADA}

-¿Además de los contenidos valora también los procedimientos y las actitudes?

-¿Evalúa tanto el proceso como el producto de aprendizaje? He visto que los productos son muy variados de unos alumnos a otros ¿Cómo los valora?

- ¿Los alumnos conocen los criterios de evaluación?

- ¿Intervienen en ella?

- ¿Las familias participan en el proceso de evaluación?

- ¿Cómo han ido evolucionando los resultados de los diferentes alumnos? ¿Con las diferentes metodologías que has utilizado has atendido a los diferentes ritmos y necesidades de cada uno de tus alumnos? ¿Todos han evolucionado?

¿¿Qué ha significado las prácticas en tu formación como futura docente? 
Anexo 11: Guión de entrevista semiestructurada maestra música caso 3

\section{Entrevista proyecto LóvA}

1. Me gustaría que me explicaras un poco el proyecto LÓVA, en qué consiste, porqué lo pusiste en marcha...

2. Los niños en las entrevistas me comentaban que habían podido escoger ellos las profesiones. ¿Qué oficios había?

3. ¿Con esta distribución por oficios se responde a las habilidades, necesidades, intereses... del alumnado?

4. ¿Piensas que este proyecto que tiene un fin en sí mismo capta la motivación y el interés del alumnado hacia la actividad?

5. ¿Has recibido alguna formación sobre cómo llevar a cabo el proyecto LóvA en el aula?

6. ¿Cómo recibieron las familias esta propuesta? En algunas sesiones me contaban, los alumnos que han venido las familias a ayudarles en el proyecto LÓVA.

7. ¿Os ha gustado la experiencia?

8. ¿Quieres añadir alguna información relevante o interesante sobre el proyecto LóVA? 
Anexo 12: Guión entrevista semiestructurada final docentes

\section{ENTREVISTA MAESTROS}

(Después de las observaciones)

\section{AGRUPACIONES HETEROGÉNEAS}

- ¿He visto que promueves diferentes tipos de agrupación (parejas, pequeño grupo, gran grupo, asambleas)? ¿Por qué lo haces? ¿Qué pretendes?

¿¿Utilizas algún criterio para formar el grupo?

\section{OBJETIVOS Y CONTENIDOS CURRICULARES}

-¿Planificas los contenidos curriculares teniendo en cuenta las diferencias entre los alumnos de tu clase? ¿Estableces diferentes niveles de competencia?

-¿Priorizas los objetivos y contenidos más significativos y funcionales para el grupo-clase? Esto es, establecer los contenidos esenciales que se han de aprender.

- ¿Estableces objetivos individuales con los diferentes alumnos y objetivos de toda la clase?

- Una vez los alumnos han escogido el proyecto o temática que quieren trabajar ¿desarrolláis objetivos $y$ contenidos?

\section{METODOLOGÍA PARTICIPATIVA, COOPERATIVA Y DIFERENCIADA}

- ¿Escuchas los diferentes puntos de vista y deseos en relación al aprendizaje del alumnado?

- ¿Fomentas que el alumnado asuma la responsabilidad de su propio aprendizaje?

- He visto que pones en práctica diferentes metodologías de trabajo ¿Por qué? ¿Qué pretendes en cada una de ellas?

- ¿Con las diferentes actividades que propones respetas los diferentes ritmos e estilos de aprendizaje de cada alumno?

¿¿Por qué trabajáis mediante grupos cooperativos? ¿Qué te parece esta forma de trabajar? ¿Favorece la autonomía del niño?

- He visto que en frecuencia estimulas al alumno a hacer elecciones en función de sus intereses y motivaciones ¿Cómo repercute en su formación como ciudadano crítico?

- ¿Cómo tenéis en cuenta la voz o la participación del alumnado a partir de las diferentes propuestas que hacéis en tu clase?

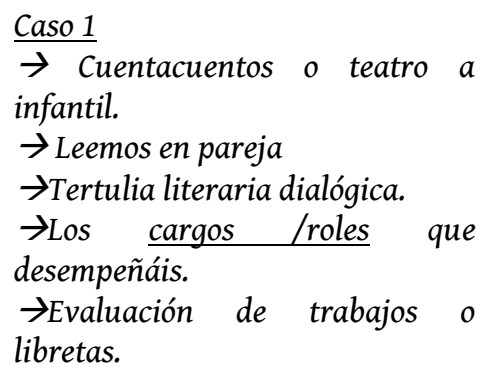

Caso 2

$\rightarrow$ Trabajo por proyectos

-CARPETAS-

$\rightarrow$ Grupos interactivos.

$\rightarrow$ Talleres de 1er ciclo.

$\rightarrow$ Cuentacuentos. $\frac{\text { Caso } 3}{\rightarrow \text { Estaciones. }}$
$\rightarrow$ Tertulia literaria dialógica.
$\rightarrow$ Leemos en pareja.
$\rightarrow$ Trabajo por proyectos.
$\rightarrow$ Los cargos /roles que
$\begin{array}{ll}\text { desempeñáis. } & \\ \rightarrow \text { Las } & \text { Tablets. }\end{array}$ 


\subsection{PARTICIPACIÓN DE LAS FAMILIAS}

-¿Generalmente las familias en que participan en el aula?

-¿Qué piensas que facilita o propicia la participación de las familias en tu aula?

-¿Qué aporta la participación de las familias (o abuelos) en el aula?

-¿Qué recursos utilizáis para invitar a las familias al aula?

-¿Hacéis alguna reunión inicial para informar sobre cómo van a participar?

-¿Cuántos cursos hace que las familias participan en tu aula?

- ¿Las familias pueden proponeros proyectos o actividades para que se realicen en el aula? ¿Se llevan a cabo sus propuestas?

- ¿Cuál es la valoración que tienen las familias sobre el funcionamiento del aula?

- ¿En el caso de la lectura en parejas los padres o madres ayudan a preparar esta actividad a sus hijos/as cuando éstos son tutores?

- ¿Hiciste alguna reunión inicial?

- Me comentaste que en $5^{\circ}$ no participan los padres en la exposición de las lecturas. ¿En $6^{\circ}$ si? ¿Por qué?

¿Qué pretendes con sus participación?

\section{EVALUACIÓN DIFERENCIADA}

-¿Utilizas diferentes estrategias de evaluación que permitan a todos los alumnos mostrar sus habilidades?

- ¿Además de los contenidos valoras también los procedimientos y las actitudes?

- ¿Evalúas tanto el proceso como el producto de aprendizaje? He visto que los productos son muy variados de unos alumnos a otros ¿Cómo los valoras?

- ¿Los alumnos conocen los criterios de evaluación?

-¿Intervienen en ella?

-He visto que los alumnos también se evalúan tanto a ellos mismos como a sus compañeros ¿Cómo tienes en cuenta esta nota? ¿Reflexionáis sobre la evaluación? ¿Por qué lo haces?

-¿Las familias participan en el proceso de evaluación? (Comentaste que en cada examen lo proporcionas a las familias para que hagan una reflexión conjunta ¿Qué pretendes?)

- ¿Cómo han ido evolucionando los resultados de los diferentes alumnos? ¿Con las diferentes metodologías que has utilizado has atendido a los diferentes ritmos y necesidades de cada uno de tus alumnos?

¿Todos han evolucionado?

-¿Cuál es el índice de aprobados?

¿Alguna propuesta de mejora? 
Anexo 13: Consentement informé
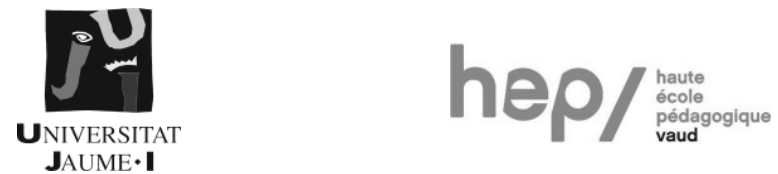

lisis

Laboratoire international sur l'inclusion scolaire

\section{CONSENTEMENT INFORMÉ}

(Demande d'autorisation en vertu du chapitre II du REAL DECRETO 1720/2007, de 21 de diciembre, por el que se aprueba el Reglamento de desarrollo de la Ley Orgánica 15/1999, de 13 de diciembre, de protección de datos de carácter personal).

Aida Sanahuja Ribés, étudiante de doctorat de l' Université Jaume I de Castellón (Espagne), rédige ce document de consentement informé en vue de faire connaître par écrit les caractéristiques du projet de recherche prévu. De même, avec ce document je vous demande de collaborer et consentir à ce projet. Je vous demande également votre autorisation pour l'analyse des données collectées.

\section{Concrètement,}

1․- Ce projet de la recherche, appelé «Différenciation pédagogique et participation démocratique dans la classe inclusive : étude multicas ", est destiné aux professeures Odet Moliner García et Lidón Moliner Miravet, du département d'éducation de l'Université Jaume I de Castellón (Espagne) et a reçu l'appui du professeur Serge Ramel de l' Haute école pédagogique de Lausanne (Suisse).

2o.- Le but de ce projet est de mieux comprendre la différenciation pédagogique et participation démocratique dans la classe inclusive. Pour ma thèse, en Espagne, j'ai étudié la différenciation pédagogique et la participation démocratique dans trois salles de classe. Le but est d'étudier un cas particulier, ici le cas suisse, et non de comparer car l'enjeu principal est de voir les différentes manières de travailler suivant les paramètres de la différenciation pédagogique et la participation démocratique dans la salle de classe inclusive pour la formation des enseignants-e.

$3^{\circ}$.- Les démarches principales à effectuer sont les suivantes :

- répondre à un entretien,

- compléter un inventaire de pratiques en la salle de classe,

- autoriser l'observation scientifique effectuée pendant une journée entière dans la salle de classe,

- vérifier le récit fait de votre cas.

$4^{\circ}$-- Les informations sont collectées à l'aide d'outils qualitatifs : observation, enregistrement audio (de la session), photos (de la zone de classe, du matériel etc. Notez qu'aucune photo des élèves ne sera faite), documents.

$\square$ Je vous autorise à effectuer une observation scientifique dans la classe. 
$\square$ Je vous autorise à faire des enregistrements audio dans la classe.

$\square$ Je vous autorise à faire photos de la zone de classe, du matériel, etc.

5․-Selon la Ley Orgánica de Protección de Datos 15/1999, vos données seront intégrées et utilisées dans cette recherche comme l'indique la mention suivante :

$\square$ Je ne souhaite pas que l'on divulgue des informations d'ordre personnel sur ma personne.

$\square$ Je souhaite apparaître sous le pseudonyme:

$\square$ Je ne me soucie pas que mon nom soit rendu public.

Vous pouvez rectifier.

$6^{0}$ - L'information collectée sera confidentielle c'est-à-dire qu'elle ne sera pas divulguée outre le domaine de la recherche. Les résultats seront répandus dans un format d'article et de communications dans des publications scientifiques et des congrès, en offrant la possibilité à l'informateur de collaborer. Les données seront gardées par l'investigatrice et ne seront pas utilisés dans un autre but que celui décrit dans ce document.

7- Cette recherche, en format de thèse doctorale, a été approuvée par la Commission de Recherche et le doctorat du Département d'éducation de l'Université Jaume I le 10 de octobre de 2013. Ils veilleront à son développement rigoureux jusqu'au moment de sa soutenance.

$8^{\circ}$.- Pour finir, nous voulons vous remercier pour votre collaboration.

Par ce document, la personne collaboratrice s'engage à participer activement et volontairement à cette recherche. De cette manière nous procédons à la signature de ce consentement informé:

Moi, déclare être informé-e et autorise AIDA SANAHUJA RIBÉS à la collecte, l'utilisation et le traitement des données nécessaires à l'élaboration de cette étude. De cette façon:

Je suis d'accord pour participer à cette recherche. Je souhaite recevoir un résumé des résultats de cette recherche au courriel suivant:

$$
\text { Lausanne, le _- juin } 2016
$$

Collaborateur:

Chercheur:

Signature:

Carte d'identité:
Signature:

Carte d'identité: 


\section{GRILLE VISANT À SOUTENIR L'OBSERVATION EN SALLE DE CLASSE}

(Adaptation de Prud'homme, LeBlanc et Paré, 2013)

Étude multi cas de pratiques de différenciation pédagogique et du savoir professionnel d'enseignants du primaire oeuvrant dans une perspective inclusive.

1. Éléments observables concernant la rigueur et la cohérence entre les intentions, les contenus et les activités pédagogiques.

1.1. L'enseignante a des intentions claires et rigoureuses de ce que l'élève doit connaître, comprendre et être en mesure de faire (Ex : elle exprime ses intentions aux élèves, elle aide les élèves à faire des liens entre les intentions et les tâches, ...).

1.2. L'enseignante active les connaissances antérieures des élèves qui sont en lien avec la tâche (les tâches à accomplir).

1.3. L'enseignante s'assure de différentes manières que les élèves ne perdent pas de vue les buts poursuivis et les finalités de la leçon.

Observations:

\section{2. Éléments observables concernant l'anticipation (la planification) et la prise en compte de la diversité}

2.1. L'enseignante pose des gestes qui démontrent qu'elle a anticipé différents chemins que pourraient prendre les élèves pour rencontrer les intentions pédagogiques (elle a prévu dans la séquence des lieux où les élèves peuvent faire des choix).

2.2. L'enseignante ajuste fait des interventions en cours de séquence) pour permettre à tous les élèves de demeurer engagés dans la tâche (degré de soutien, de complexité, d'abstraction, etc.

2.3. L'enseignante favorise l'expression de la diversité des intérêts, des expériences, des connaissances, des représentations, etc. que les élèves peuvent associer à la tâche. (Elle met par exemple en évidence les similitudes et les différences qui s'observent pour accomplir la tâche).

2.4. Si un ou des élèves manifestent des besoins particuliers qui nécessitent un plan d'interventions, un plan d'actions individualisées, un programme d'adaptation scolaire, précisez les éléments observables en lien avec ces mesures.

Observations:

3. Éléments observables concernant les pratiques d'enseignement et d'évaluation (Adapté de Leroux et Paré, en rédaction).

3.1. L'enseignante propose des situations d'apprentissage tout en ayant le loisir d'exploiter diverses modalités pédagogiques au cours de ladite séquence (par exemple, des tâches en ateliers ou en centres d'apprentissage sont présentes dans la classe et elle peut y recourir pour certains élèves pendant que d'autres poursuivent leur travail dans la séquence).

3.2. L'enseignante propose des moments où les élèves peuvent choisir eux-mêmes leur activité d'apprentissage, les ressources à utiliser pour réaliser un travail ou le mode de présentation d'un travail.

3.3. L'enseignante varie le type de regroupement des élèves.

\begin{tabular}{|l|l|}
\hline Oui & No \\
\hline Oui & No \\
\hline Oui & No \\
\hline Oui & No \\
\hline
\end{tabular}

3.4. Si un ou des élèves se retrouvent constamment seuls, précisez la raison. 
3.5. L'enseignante offre aux élèves la possibilité de vivre des situations d'apprentissage (suffisamment flexibles et souples) qui respectent caractéristiques et préalables.

3.6. L'enseignante planifie une série d'activités consécutives qui varient de manière à prendre en compte des différences entre les élèves (les tâches dans une journée varient et ne s'inspirent pas toujours des mêmes principes d'apprentissage - profils cognitifs).

3.7. L'enseignante utilise une variété de stratégies pédagogiques (apprentissage coopératif, enseignement explicite, approche par résolution de problème, enseignement pas-à-pas ...).

3.8. L'enseignante veille constamment à maintenir la motivation des élèves en traitant par exemple de la perception de la valeur de la tâche, de la compétence de l'élève à réaliser la tâche et de son degré de contrôlabilité.

3.9. L'enseignante intervient pour stimuler l'engagement cognitif des élèves (L'assistant disposera d'un autre outil tiré encore du DCOS, le Cognitive activity, qui s'appuie sur la taxonomie de Bloom) en favorisant la progression des apprentissages des élèves vers des niveaux de compréhension supérieurs.

(L'assistant de recherche disposera de son côté d'un outil tiré du Differentiated Classroom Observation Scale Protocol [DCOS], le "Student Engagement » (Cassidy et al., 2004), pour évaluer le degré d'engagement des élèves).

3.10. L'enseignante exploite la régulation (rétroaction fréquente, évaluation continue, différents types de questionnement).

3.11. L'enseignante s'assure que les élèves connaissent les critères d'évaluation des activités d'apprentissage (définis par l'enseignante ou par l'enseignante et les élèves).

3.12. L'enseignante favorise la participation des élèves dans l'évaluation de leurs apprentissages (travail sur la connaissance de soi : forces et ses défis).

3.13. On consulte les élèves au sujet de la qualité des leçons.

3.14. L'enseignant utilise une variété d'outils d'évaluation et de façons de démontrer les apprentissages qui touchent les différences dans le caractère, les intérêts et l'éventail des habiletés des élèves.

Observations:

4. Éléments observables concernant la gestion de classe et climat d'apprentissage (Une gestion de classe plus participative est souvent associée à la pratique de différenciation pédagogique. Ce concept recouvre différents éléments pédagogiques en lien avec le temps, le programme d'activités, les codes, les règles et procédures, l'espace, le système de relations, le système de responsabilités, le système d'évaluation et de reconnaissance, les ressources humaines et matérielles ...).

4.1. L'enseignante encourage une attitude positive face à la diversité (reconnaître exploiter et valoriser).

4.2. L'enseignante cherche à créer une communauté d'apprentissage (interdépendance et intercompréhension : elle incite les élèves à s'entraider plutôt qu'à compétitionner, à exploiter les ressources de leurs pairs pour mieux accomplir leur tâche, à chercher à comprendre les idées différentes des siennes plutôt qu'à les rejeter).

4.3. L'enseignante sollicite la participation des élèves autant dans la gestion de classe que dans l'organisation et le contenu des activités (les élèves ont du pouvoir).

4.4. L'enseignante encourage l'autonomie des élèves en tant qu'apprenant (auto efficacité).

4.5. L'enseignante favorise l'apprentissage coopératif pour encourager l'entraide, l'interdépendance et l'intercompréhension et pour que les élèves soient à l'aise de travailler avec des élèves différents d'eux.

4.6. L'enseignante est chaleureuse et compréhensive envers tous les élèves (accueillante, fait preuve d'écoute, d'encouragement, soucieuse de leur état émotionnel, etc.).

4.7. L'aménagement physique de la classe il y a affichage : menu, grille horaire, routine, aide-mémoire, célébration de la diversité, aires de travail pour collectif/sousgroupe/individuel, etc. 


\begin{tabular}{|c|c|c|}
\hline 4.8. Les élèves ont des repères sur l'horaire des activités. & Oui & No \\
\hline $\begin{array}{l}\text { 4.9. L'enseignante est efficace dans sa gestion des comportements (les élèves sont } \\
\text { impliqués dans la résolution des difficultés qui se présentent en classe, les élèves sont } \\
\text { impliqués dans la formulation des règles de la classe). }\end{array}$ & Oui & No \\
\hline \multicolumn{3}{|l|}{ Observations: } \\
\hline
\end{tabular}

5. Éléments observables concernant les ressources attribuées pour effectuer des adaptations, des modifications et offrir un soutien particulier.

\begin{tabular}{|c|l|l|}
\hline 5.1. Si plus d'un adulte présent dans la classe, précisez son rôle & Oui & No \\
\hline 5.1.1. Est-ce qu'il travaille en partenariat avec enseignante? & Oui & No \\
\hline 5.1.2. Est-ce qu'il cherche à rendre les élèves autonomes? & Oui & No \\
\hline 5.1.3. Est-il concerné par tous les élèves? & Oui & No \\
\hline 5.2. Si un ou des élèves quittent la salle de classe, précisez la raison. & Oui & No \\
\hline
\end{tabular}

5.3. On consulte les élèves ayant des difficultés au sujet du soutien dont ils ont besoin et des caractéristiques de la personne qui pourrait le fournir

5.4. Le matériel associé au curriculum est adapté de façon appropriée (par exemple, en grand caractère, sur audio ou en braille..) et disponible pour les élèves handicapés et les autres.

Observations:

\section{Référence:}

Cassidy et al. (2004). Differentiated Classroom Observation Scale Protocol. Leroux et al. (2012). Grille d'observation de l'enseignante. Inédit.

Down (2006). Differentiated instruction implementation matrix.

Maeng (2011). Diffrentiated instruction implementation Matrix-Modified.

Booth et Ainscow (2002) Guide de l'éducation inclusive : développer les apprentissages et la participation dans l'école. CEEI 
Anexo 15: Inventaire de pratiques de salle de classe

Identité:

\section{Inventaire de pratiques de salle de classe}

Traduit et adapté de Heacox, D. (2002). Differentiating Instruction in the Regular Classroom: How to Reach and Teach All Learners, Grades 312 Free Spirit Publishing Inc., Minneapolis.

Marquez un «X» le long du continuum pour voir où se trouvent leurs pratiques d'enseignement.

Le Plan d'Études Romand est ma

première priorité et dirige mon enseignement.

Je base ma manière d'enseigner dans les nécessités d'apprentissage des étudiants, ainsi que dans le Plan d'Études Roman

\begin{tabular}{l|l|l|l}
\hline & $\mid$ & 1 & $\mid$ \\
1 & 2 & 3 & 4
\end{tabular}

Les objectifs s'adaptent aux étudiants en fonction de leurs nécessités.

Les objectifs sont les mêmes pour tous les étudiants.

\begin{tabular}{|lll|l|}
\hline & $\mid$ & 1 & $\mid$ \\
1 & 2 & 3 & 4
\end{tabular}

J'insiste sur le domaine de contenus.

J'insiste sur la pensée critique et créatrice, et l'application de l'apprentissage.

$\begin{array}{lllll} & & & \\ 1 & 2 & 3 & 4\end{array}$

Je procure à différents étudiants des

Tous les étudiants utilisent les mêmes recours en fonction de leurs nécessités recours (un livre, un article, un site Web).

d'apprentissage et d'habileté.

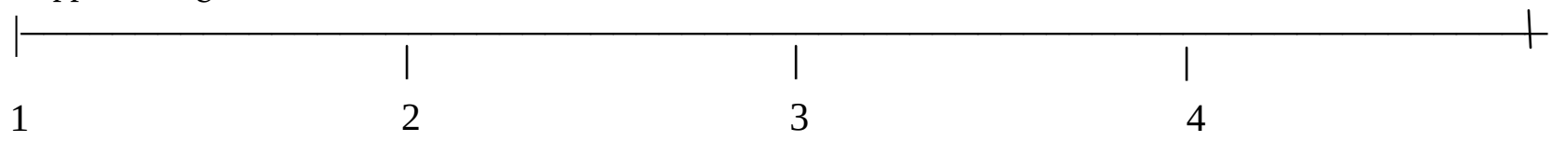

J'utilise principalement la classe explicative dirigée à tout le groupe.

J'utilise différents formats du groupe de l'ensemble des élèves (par exemple une classe, de petits groupes de plusieurs élèves, des binômes, en autonomie... etc).

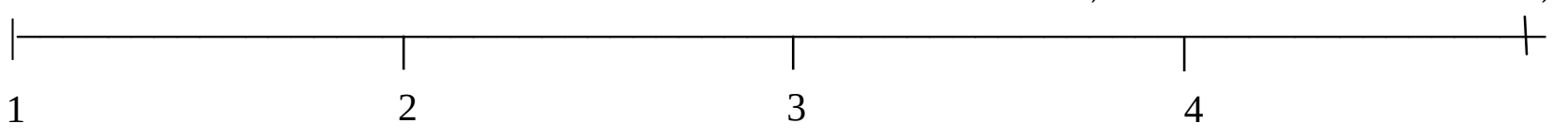

Tous les étudiants apprennent au même rythme.

Le rythme de l'enseignement peut varier, en fonction des nécessités d'apprentissage des étudiants.

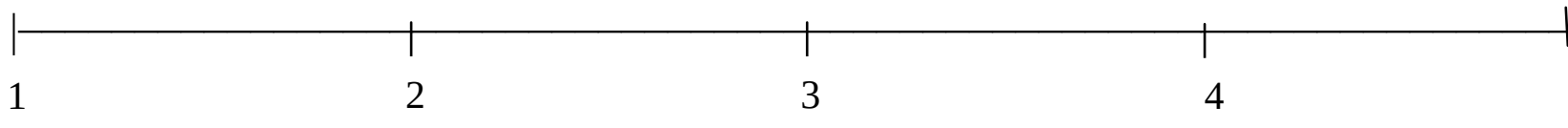

Je donne aux étudiants les opportunités de choisir les activités en fonction de leurs intérêts.

Tous les étudiants réalisent les mêmes activités.

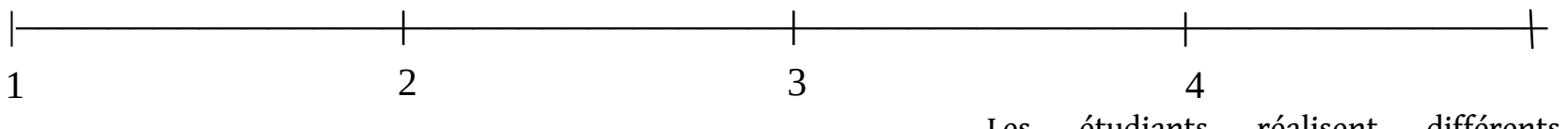

Tous les étudiants réalisent toutes les

Les étudiants réalisent différents nombres d'activités en fonction de leurs activités. nécessités ou préférences d'apprentissage.

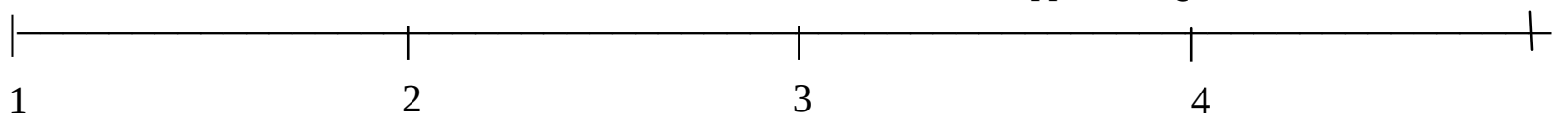


J'utilise une ample variété de stratégies éducatives.

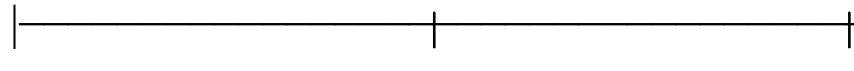

12

je demande à tous les éleves le même degré d'implication dans les activités.

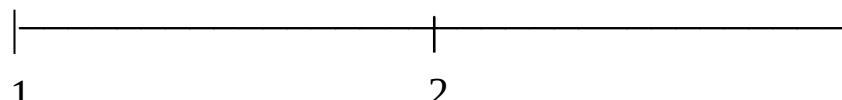

Tous les étudiants doivent réaliser les mêmes productions ou présentent ce qu'ils ont appris.
J'utilise peu de variétés de stratégies éducatives.

\section{4}

Je demande différentes possibilités d'implication (accélérant, éliminant, substituant ...), selon le cas. +...), selon le cas.

4

Les étudiants réalisent différentes productions ou présentent ce qu'ils ont appris en fonction de leurs nécessités ou préférences d'apprentissage

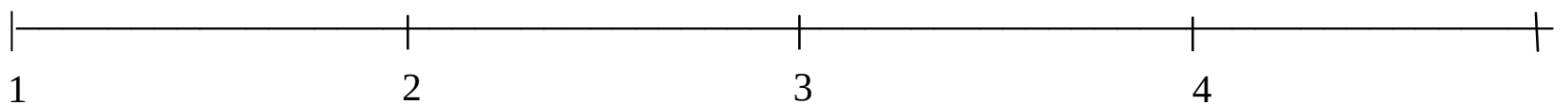

Pour renforcer ce qui a déjà été étudié dans une classe, j'utilise une méthode d'enseignement similaire c'est-à-dire qu'ils pratiquent les mêmes activités.

Pour renforcer l'enseignement déjà expliqué, j'utilise une méthode d'enseignement différente de celle que j'ai utilisée la première fois.

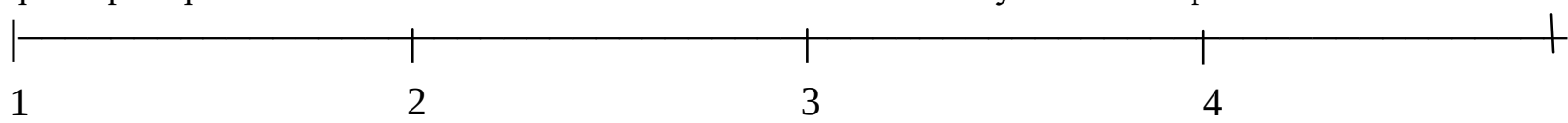

Les activités de révision proposées sont d'une plus grande complexité, elles

Les activités de la révision que je fournis sont d'un niveau de moindre complexité, pour renforcer l'habileté basique et le contenu. contenus.

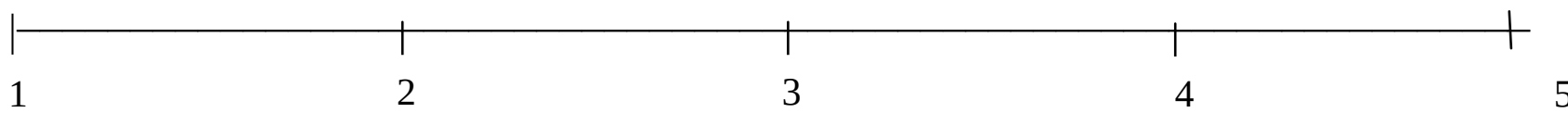

Avant d'initier une unité, j'utilise des J'assume que res étudiants ont peu ou aucune connaissance des contenus curriculaires.

préalables d'évalua déterminer ce que les étudiants savent déjà.

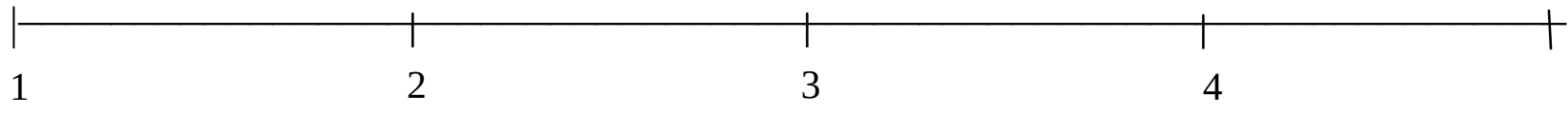

En général j'évalue l'apprentissage des étudiants à la fin d'une séquence d'enseignement.

J'utilise une évaluation continue pour vérifier l'apprentissage des étudiants le long d'une séquence d'enseignement.

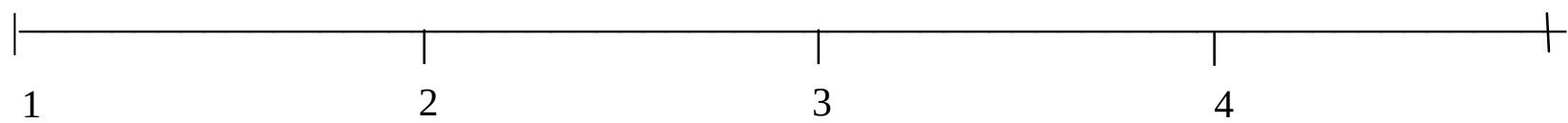

J'ai l'habitude d'utiliser le même outil d'évaluation, de production ou de projet pour tous les étudiants.

Je tiens compte des différences entre élèves et utilise quelques instruments d'évaluation.

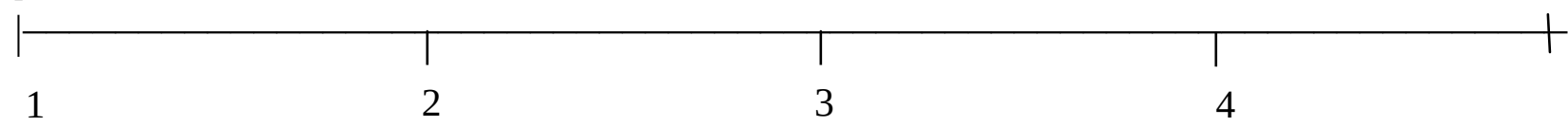




\section{a. CONTEXTE}

1. Formation: Combien avez-vous d'années d'expérience en enseignement à l'ordre primaire ? Quel diplôme avez-vous reçu au terme de votre formation en enseignement ? Au cours des cinq dernières années, avez-vous participé à une ou plusieurs formations complémentaires concernant l'éducation pour la diversité ? Et des séminaires ?

2. Brève description de la localité et de l'école.

3. Brève description de la classe (niveau, nombre total d'élèves dans votre groupe, d'élèves handicapés ou en difficulté ...)

4. Brève description physique de la classe (des espaces, gestion du temps, soutiennent, ...)

\section{b. GROUPES HÉTÉROGÈNES}

5. Promouvez-vous différents types de groupe (paires, un petit groupe, un grand groupe, des assemblées) ? Utilisez un critère pour former le groupe ? Pourquoi ?

\section{c. OBJECTIFS ET CONTENU DU PLAN D'ÉTUDES ROMANDS- PER}

6. Planifiez-vous les contenus du Plan d'Études Romands (PER) en prenant en compte les différences entre les élèves? Établissez-vous différents niveaux de compétences?

7. Priorisez-vous les objectifs et les contenus les plus significatifs et fonctionnels pour le groupe-classe?

8. Planifiez-vous les contenus du Plan d'Études Romands (PER) en relation avec le territoire?

\section{d. MÉTHODOLOGIE PARTICIPATIVE, COOPÉRATIVE ET DIVERSIFIÉE}

9. Promouvez-vous différents types de méthodes ou stratégies dans la classe ? Est-ce que vous pouvez spécifier les différents types de méthodes ou de stratégies utilisés?

10. Respectez-vous les différents rythmes et styles d'apprentissage de chaque élève en proposant différentes types d'activités?

11. Est-ce que l'élève peut faire des élections en fonction de ses intérêts et motivations? Comment répercute-t-il dans sa formation comme critique citadin?

12. Est-ce que l'élève peut participer à la gestion de classe?

13. Comment travaillez-vous avec l'enseignant-e specialisé-e?

14. Est-ce que les familles participent dans la salle de classe ? Précisez comment sont impliquées les familles.

\section{e. ÉVALUATION DIFFÉRENCIÉE}

15. Utilisez-vous différentes stratégies d'évaluation permettant à tous les élèves de montrer leur habileté?

16. Les élèves connaissent-ils les critères d'évaluation ? Interviennent-ils d'une quelque manière que ce soit au moment de l'évaluation (auto-évaluation, co- évaluation...) ?

17. Comment ont évolué les résultats des élèves avec les différentes méthodologies que vous avez utilisées?

18. Sur quelles croyances et valeurs se repose votre manière d'enseigner? 
Anexo 17: Informes ATLAS. ti: categorización por prácticas de aula

INFORMES ATLAS. ti: CATEGORIZACIÓN POR PRÁCTICAS DE AULA

(Acceso restringido: sólo para expertos y miembros del tribunal)

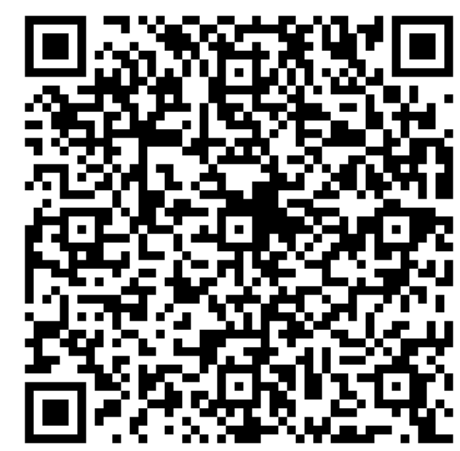

22

\section{Relación de informes presentados}

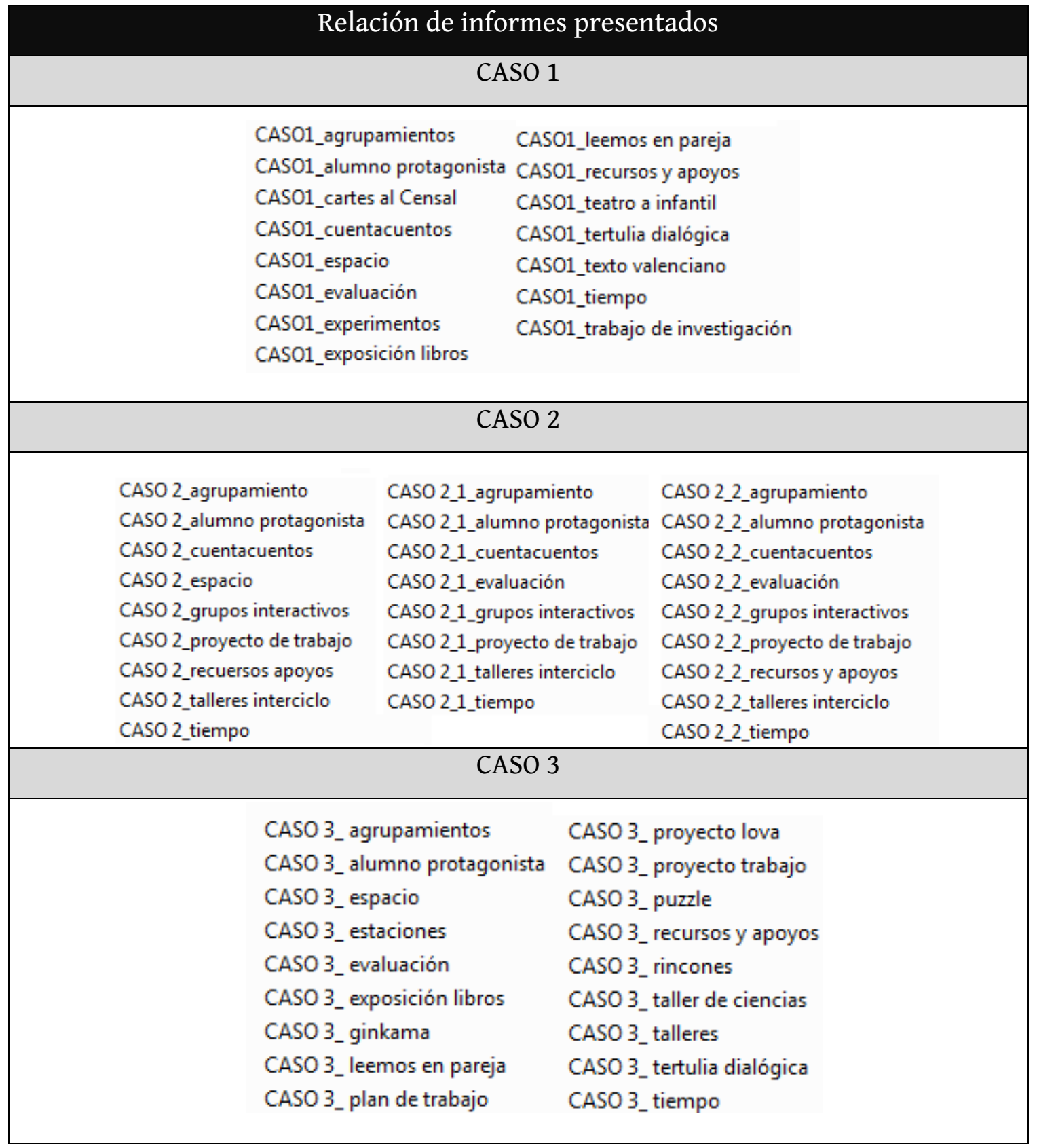


Anexo 18: Material ilustrativo CASO 1: MANOLO

\author{
MATERIAL ILUSTRATIVO CASO 1: MANOLO
}

(Acceso restringido: sólo para expertos y miembros del tribunal)

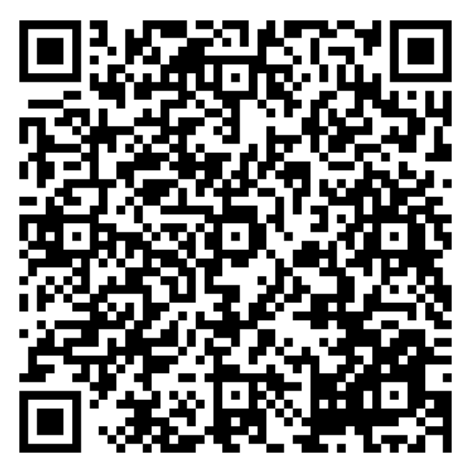

Relación de material presentado

4.2.1.1.4.1. Los grupos de investigación

$\sim$ Equipos trabajando en los grupos de investigación [C1_O_FO].

$\sim$ Equipos presentado el contenido de Cultura Valenciana [C1_O_FO].

$\sim$ Acuerdo criterios evaluación Cultura Valenciana [C1_O_GA].

$\sim$ Fragmento acuerdo nota evaluación de grupo Cultura Valenciana [C1_O_GV].

4.2.1.1.4.2. Leemos en pareja

$\sim$ Fragmento de una sesión de leemos en pareja [C1_O_GV].

$\sim$ Actividad de leemos en pareja [C1_O_FO].

4.2.1.1.4.3. Tertulia literaria dialógica

$\sim$ Fragmento de una sesión de tertulia literaria dialógica [C1_O_GV].

4.2.1.1.4.4. Exposiciones de libros

$\sim$ Fragmento de una exposición de libro de lectura [C1_O_GV].

$\sim$ Exposiciones de libros de lectura [C1_O_FO]

4.2.1.1.4.5. Cuentacuentos y teatro a infantil

$\sim$ Actividad del cuentacuentos y del teatro a infantil [C1_O_FO]. 
Anexo 19: Material ilustrativo CASO 3: CRISTINA

MATERIAL ILUSTRATIVO CASO 3: CRISTINA

(Acceso restringido: sólo para expertos y miembros del tribunal)

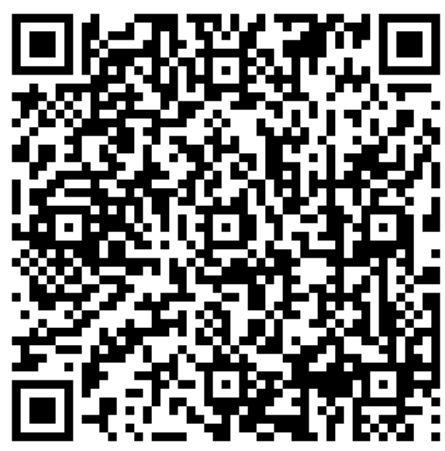

Relación de material presentado

4.2.3.1.4.3. Leemos en pareja

$\sim$ Actividad de leemos en pareja [C3_O_FO].

$\sim$ Fragmento de una sesión de leemos en pareja [C3_O_GV].

4.2.3.1.4.4. Puzle de Aronson o rompecabezas

$\sim$ Actividad del Puzle [C3_O_FO].

$\sim$ Fragmento de una sesión de puzle de Aronson o rompecabezas [C3_O_GV].

\subsection{Estaciones}

$\sim$ Estaciones de aprendizaje [C3_O_FO].

$\sim$ Fragmento de una sesión del trabajo por estaciones [C3_O_GV].

4.2.3.1.4.6. El taller de ciencias

$\sim$ Actividad de taller de ciencias [C3_O_FO].

$\sim$ Fragmento de una sesión del taller de ciencias [C3_O_GV].

4.2.3.1.4.7. Tertulia literaria dialógica y exposición de libros

$\sim$ Fragmento de una sesión de exposición de libros y tertulia literaria dialógica [C3_O_GV].

4.2.3.1.4.8. Proyecto LÓVA

$\sim$ Equipos trabajando en el proyecto LóVA [C3_O_FO].

$\sim$ Fragmento de un ensayo de los autores con los músicos [C3_O_GV].

\subsection{Ginkama}

Actividades ginkama [C3_O_FO].

4.2.3.1.11. Rincones de trabajo

$\sim$ Rincones de trabajo [C3_O_FO].

$\sim$ Fragmento de una sesión del trabajo por rincones [C3_O_GV]. 




\section{LISTA DE TABLAS, FIGURAS, \\ CUADROS, IMÁGENES Y \\ CÓDIGOS QR}

\section{$\sim$ TABLAS}

Tabla 1. Principales diferencias entre integración e inclusión...........................................................................13

Tabla 2. Status continuum de la inclusión social ...........................................................................................22

Tabla 3. Categorías y subcategorías de motivos de rechazo..................................................................................23

Tabla 4. Clarificación conceptual: Individualización vs. Diferenciación vs. Personalización...........................45

Tabla 5. Individualización vs. Diferenciación vs. Personalización ....................................................................46

Tabla 6. Revisión de algunas definiciones: literatura francófona........................................................................47

Tabla 7. Revisión de algunas definiciones: literatura anglófona ......................................................................49

Tabla 8. Revisión de algunas definiciones: literatura hispánica ........................................................................52

Tabla 9. Sistema de utilización de los conceptos de diferenciación y de diversificación en

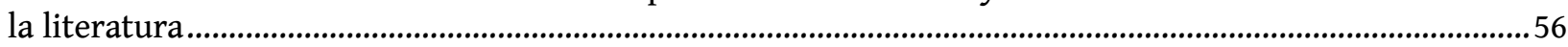

Tabla 10. Características del aula democrática diferenciada ..................................................................... 65

Tabla 11. Diferenciación de las estructuras ............................................................................................67

Tabla 12. Diferenciación del contenido y del proceso: algunas estrategias metodológicas .............................71

Tabla 13. Desarrollo cronológico del trabajo de investigación ..............................................................................94

Tabla 14. Participantes en el estudio distribuidos por casos ..............................................................................96

Tabla 15. Datos recogidos distribuidos por casos ......................................................................................... 100

Tabla 16. Sistema de códigos para la identificación de la procedencia de los datos.....................................106

Tabla 17. Definición de las categorías teóricas: diferenciación pedagógica.....................................................107

Tabla 18. Definición de las categorías teóricas: participación democrática .....................................................108

Tableau 19. Structure du Plan d'études Romand .............................................................................................280

\section{$\sim$ FIGURAS}

Figura 1. Origen y evolución de las representaciones y prácticas de diferenciación pedagógica...................38

Figura 2. Ejemplos de dilemas en la planificación de la enseñanza ante la diversidad del

alumnado

Figura 3. Esquema general de la enseñanza diferenciada

Figura 4. Puntos de convergencia y de interdependencia entre la inclusión escolar, la educación ciudadana

y la diferenciación pedagógica.

Figura 5. Diferenciación pedagógica desde una perspectiva inclusiva: modelo teórico relacional .............117

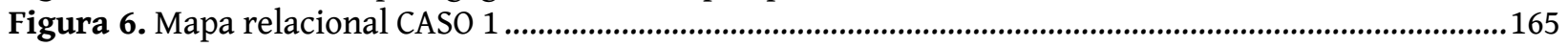

Figura 7. Mapa relacional CASO 2 ................................................................................................221

Figura 8. Mapa relacional CASO 3 ..............................................................................................275

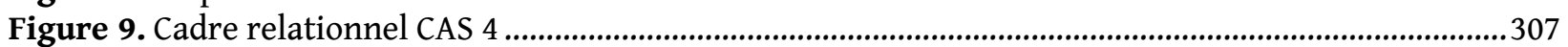

\section{$\sim$ CUADROS}

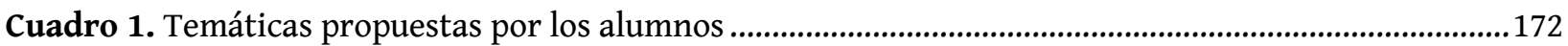

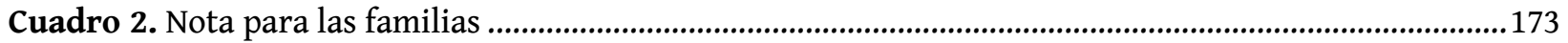

Cuadro 3. Distribución de los subtemas entre los equipos de trabajo ........................................................178

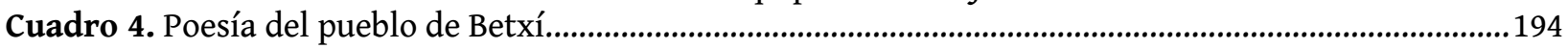

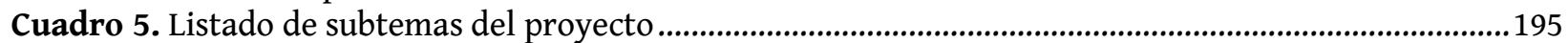




\section{IMÁGENES}

CASO 1

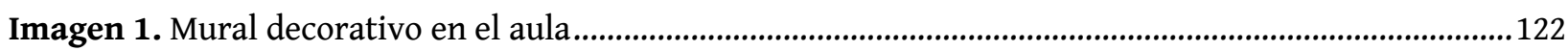

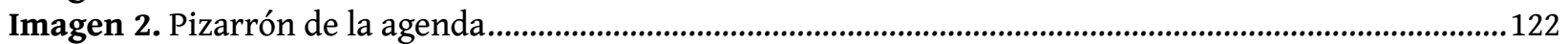

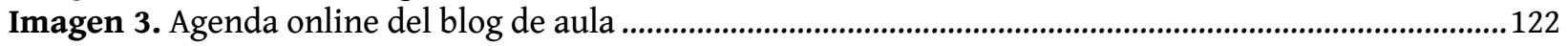

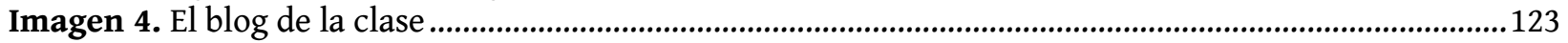

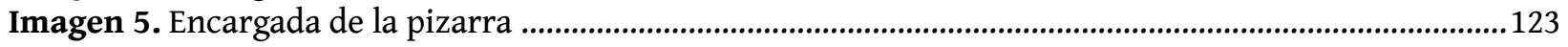

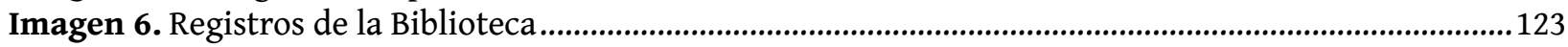

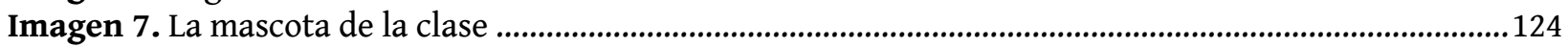

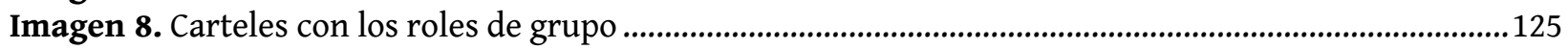

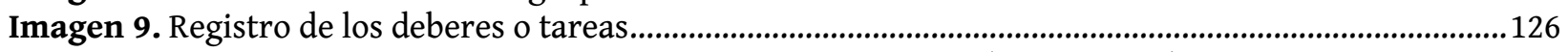

Imagen 10. Alumnado realizando la actividad de leemos en pareja ( $1 \mathrm{r}$ trimestre) ..................................132

Imagen 11. Alumnado realizando la actividad de leemos en pareja (3r trimestre) ...................................133

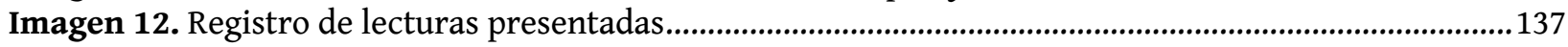

Imagen 13. Exposición de las lecturas en el pasillo ...............................................................................138

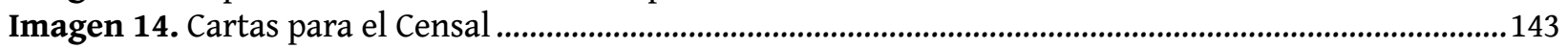

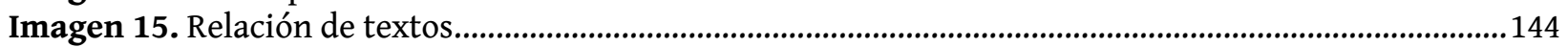

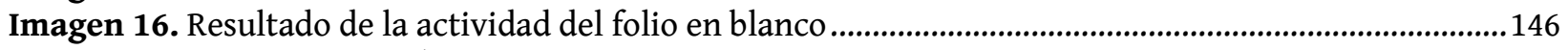

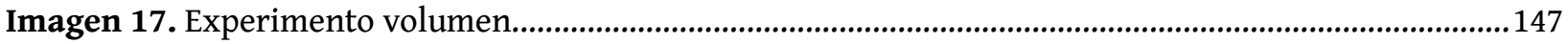

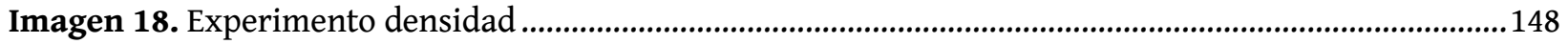

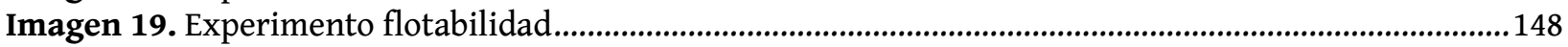

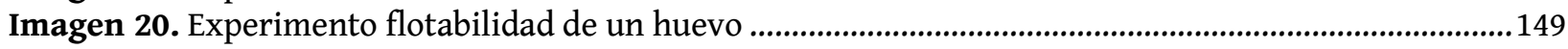

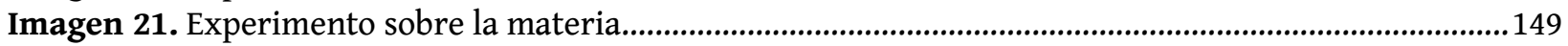

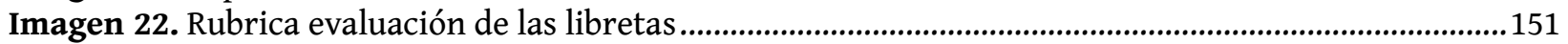

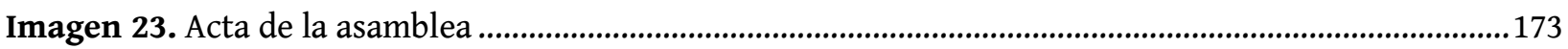

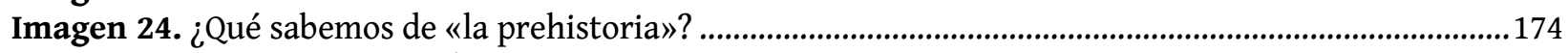

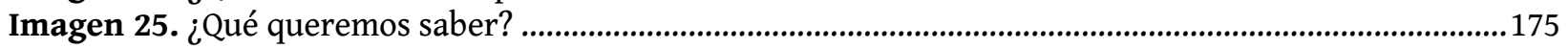

Imagen 26. Planificación de las tareas del proyecto de la prehistoria..................................................175

Imagen 27. Información que el alumnado trajo para el proyecto ..........................................................176

Imagen 28. Entrevista a la experta en paleontología ............................................................................177

Imagen 29. Respuestas de la experta en paleontología ............................................................................177

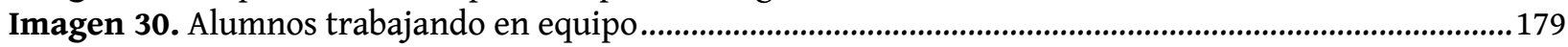

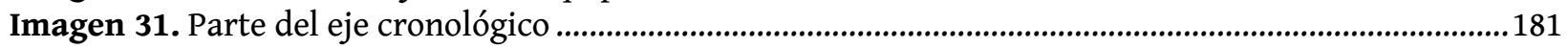

Imagen 32. Representaciones a tamaño real de los homos y australopitecos .............................................182

Imagen 33. Reproducción de la cueva de Altamira ................................................................................182

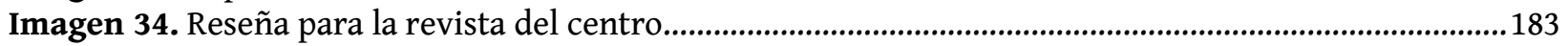

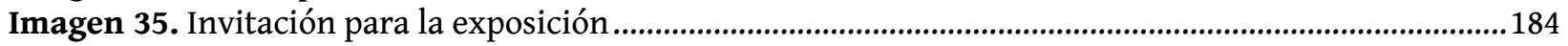

Imagen 36. Murales generados a lo largo del proyecto .........................................................................185

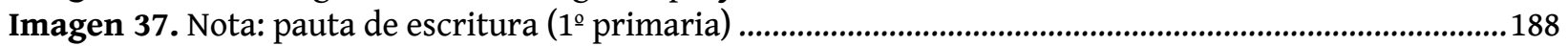

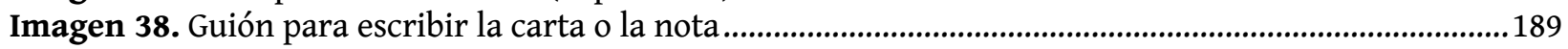

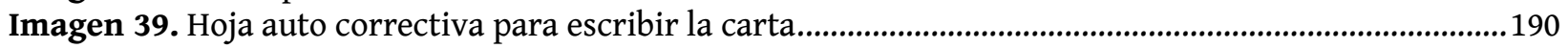

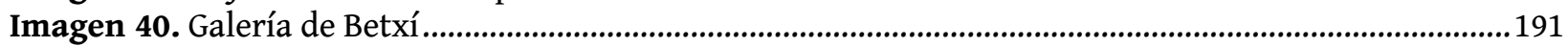

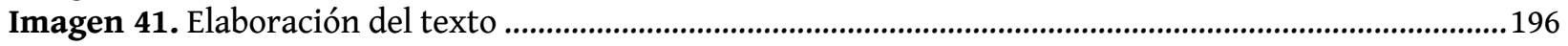

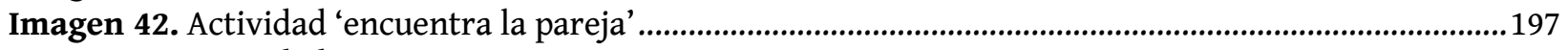

Imagen 43. Actividad 'organizamos por parejas' .....................................................................................197

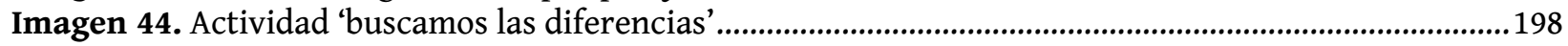

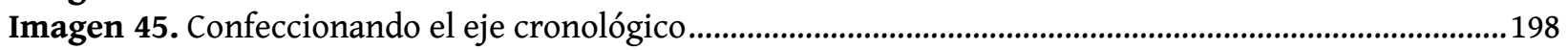

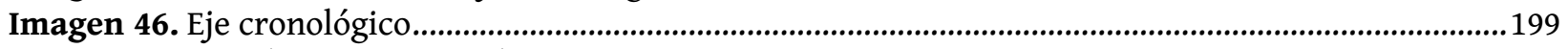

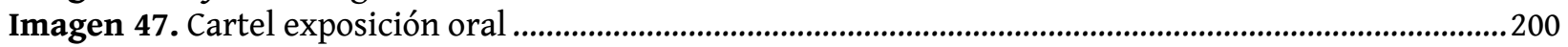

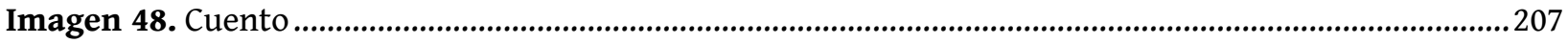

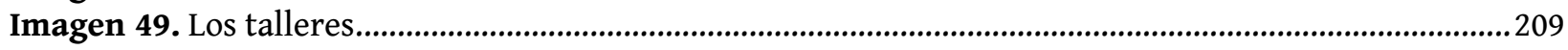




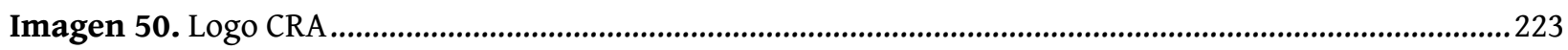

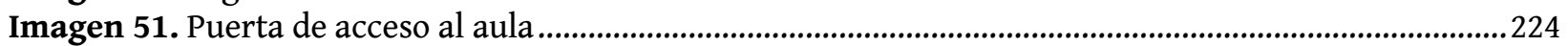

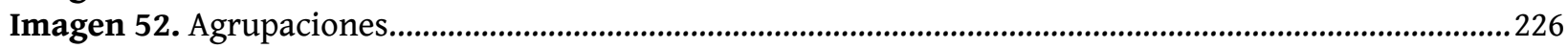

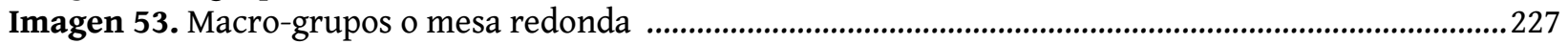

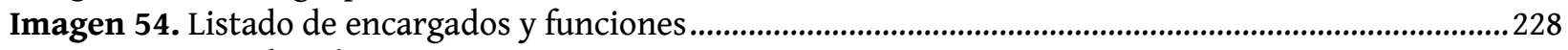

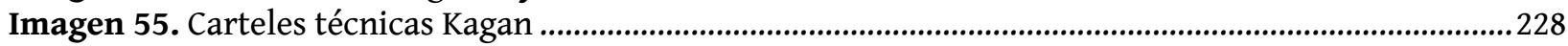

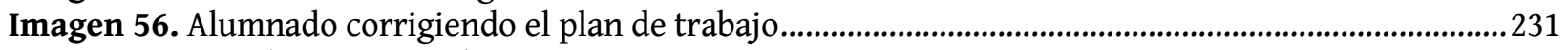

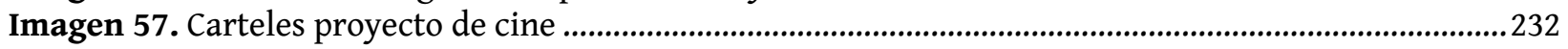

Imagen 58. Murales sobre la prehistoria enmarcados en la película de Tadeo Jones ..................................2233

Imagen 59. Pautas actividad leemos en pareja .....................................................................................235

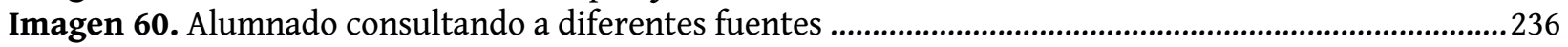

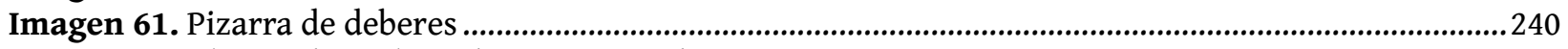

Imagen 62. Alumnado realizando estaciones de matemáticas .............................................................242

Imagen 63. Hoja con el nombre de los minerales y gemas del mundo ......................................................243

Imagen 64. Pasos a realizar en el taller de ciencias................................................................................244

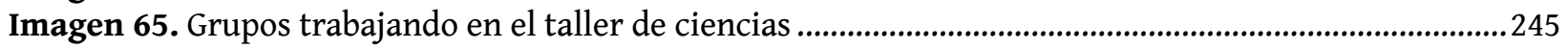

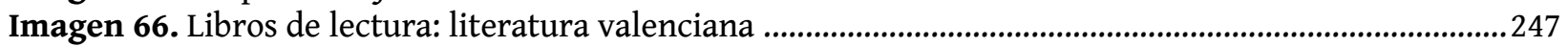

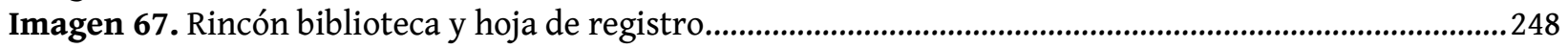

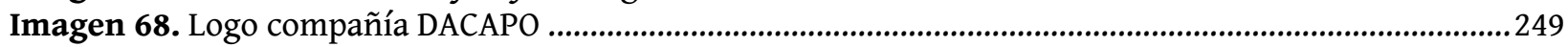

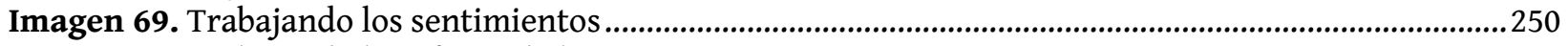

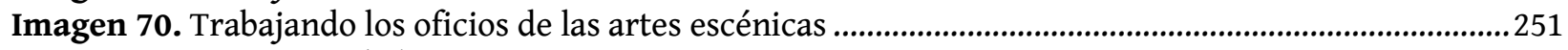

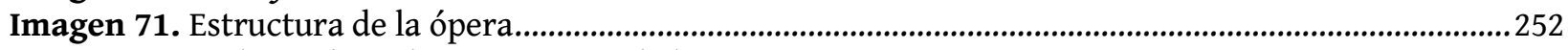

Imagen 72. Trabajando en la preparación de la ópera ..............................................................................253

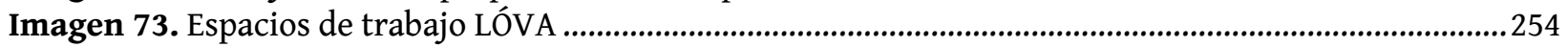

Imagen 74. Alumnado realizando actividades de cohesión grupal ...........................................................258

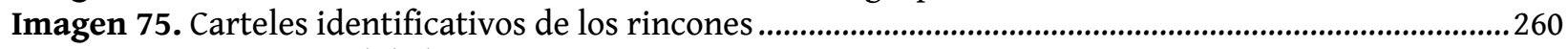

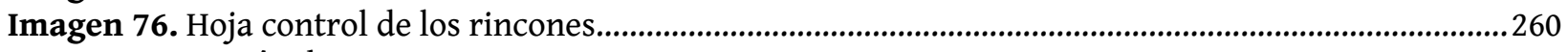

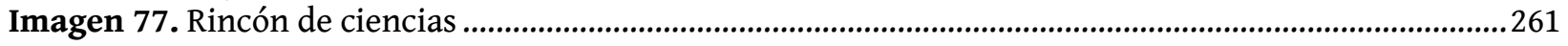

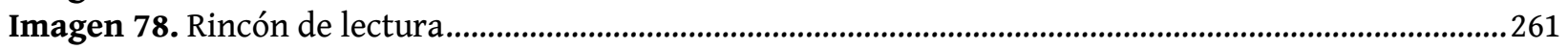

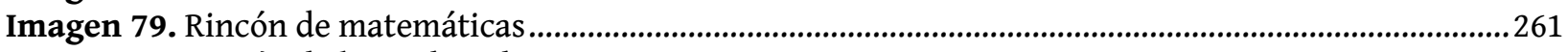

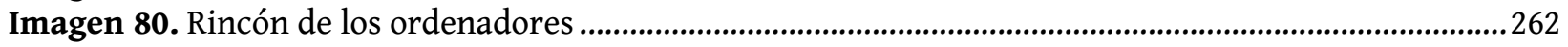

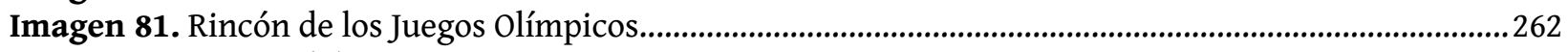

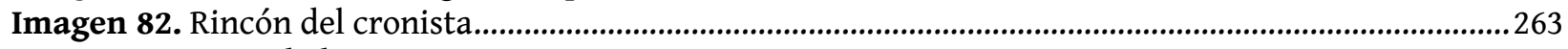

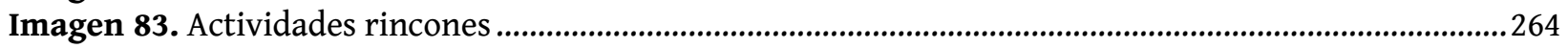

Imagen 84. Ejemplo de rúbrica para evaluar el plan de clase ..............................................................266

Imagen 85. Cartel que ilustra el espíritu del aula .............................................................................270

\section{$\sim$ CASO 4}

Image 86. Que fait la classe durant ces périodes ?..............................................................................283

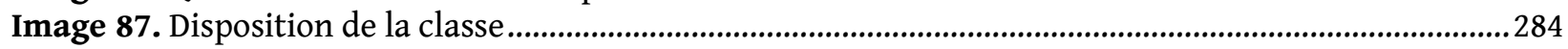

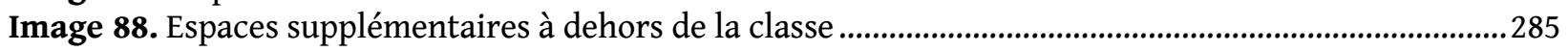

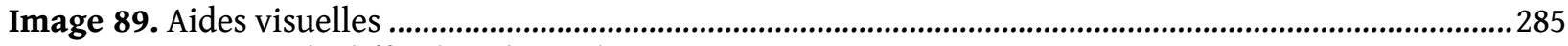

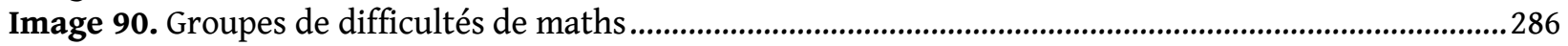

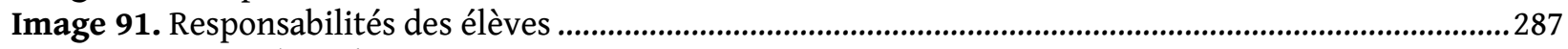

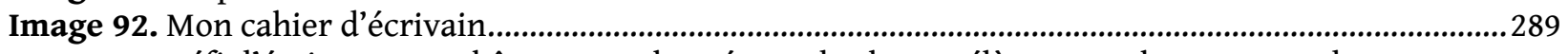

Image 93. Défi d'écriture $\mathrm{n}^{\circ} \mathbf{1 7}$, bâtons avec le prénom de chaque élève et quelques textes des

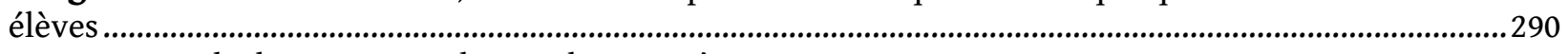

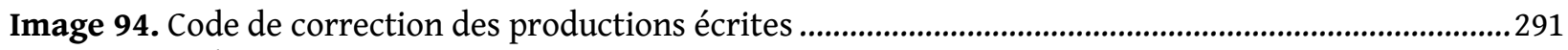

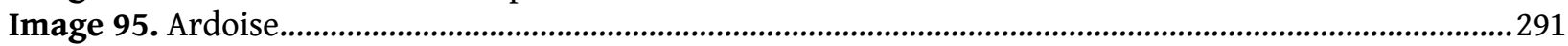




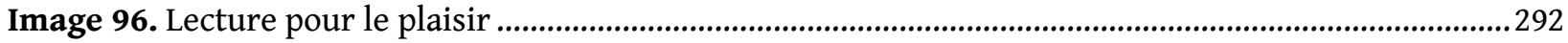

Image 97. Matériel visuel et manipulateur : Le Village des Mots ............................................................292

Image 98. Trois façons d'arriver à un même résultat ........................................................................293

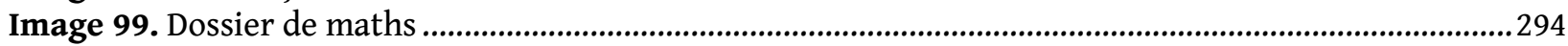

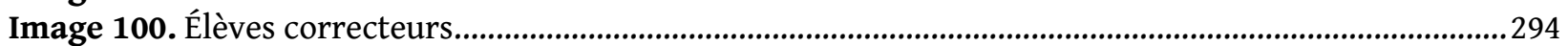

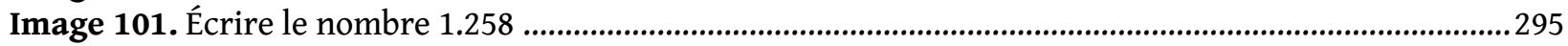

Image 102. Matériel pour construire des nombres ........................................................................295

Image 103. Matériel pour travailler les unités, les dizaines, les centaines et les milliers ...........................296

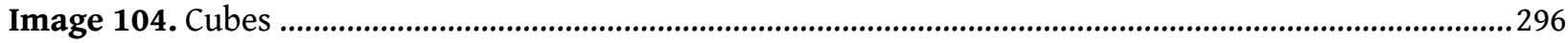

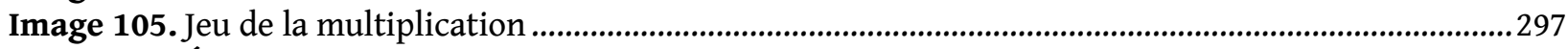

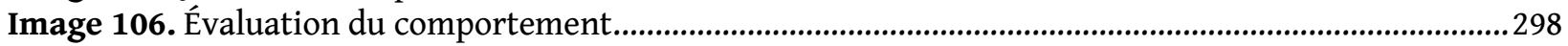

Image 107. Registre des propositions, idées, projets que des délégués doivent apporter au conseil

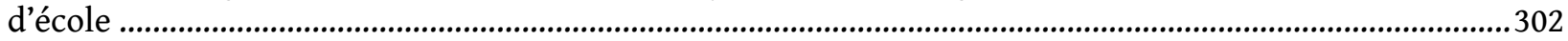

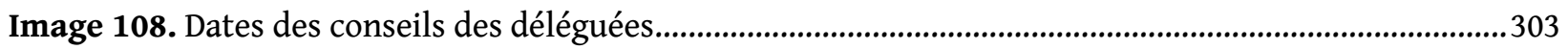

Image 109. Expo scolaire dans la classe d'Ysabel...................................................................................304

Image 110. Peinture faite pour groupe d'élèves mélange : petit, moyen, grand ........................................305

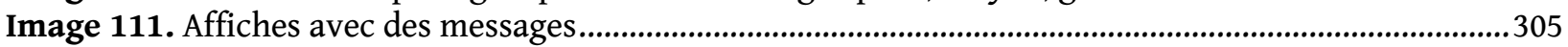

\section{$\sim \operatorname{CóDIGOS~QR~~~}$}

1. EL PROGRAMA CA/AC: (“Cooperar para Aprender / Aprender a Cooperar”) PARA APRENDER A ENSEÑAR

EN EQUIPO. Implementación del aprendizaje cooperativo en el aula........................................................71

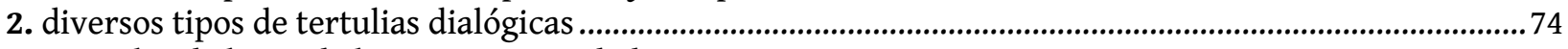

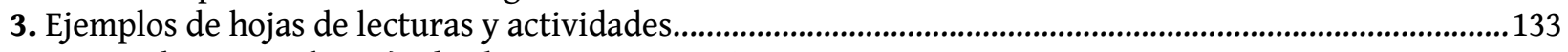

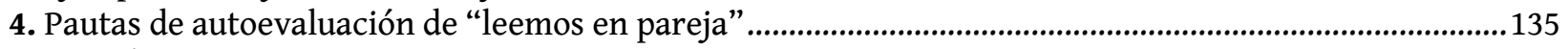

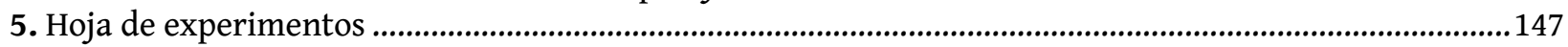

6. Dosier de la prehistoria elaborado por el alumnado...........................................................................180

7. Lecturas suplementarias proporcionadas por la maestra ...........................................................181

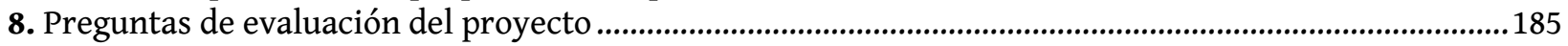

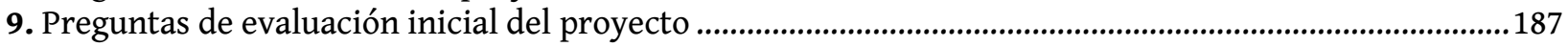

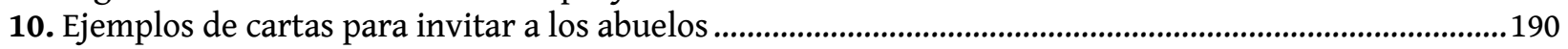

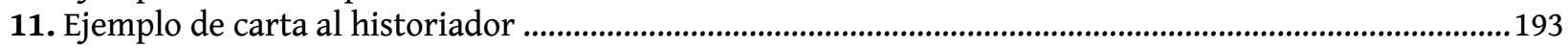

12. Dosier de ¿Cómo pasa el tiempo? Betxí, nuestro pueblo elaborado por el alumnado ............................196

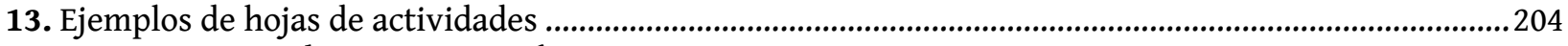

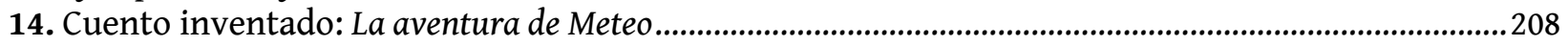

15. Ejemplos de materiales del proyecto de cine trabajado en el aula ......................................................232

16. Hoja con instrucciones para seguir la lectura en pareja en casa y en clase ...........................................235

17. Ejemplos de lecturas y actividades del leemos en pareja ...............................................................236

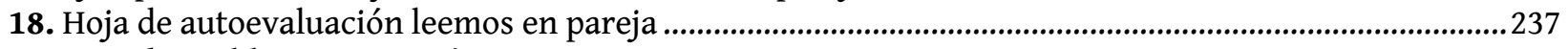

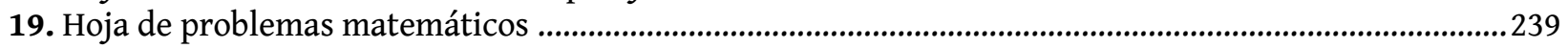

20. Ejemplos de actividades para las estaciones de matemáticas..........................................................242

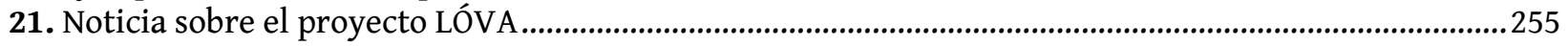

22. Informes ATLAS. ti: categorización por prácticas de aula ..............................................................408

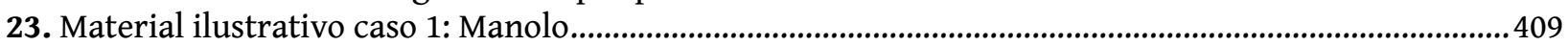

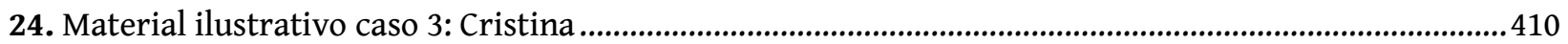


Esta tesis terminó de imprimirse

en LLAR digital,

en el mes de mayo del 2017. 


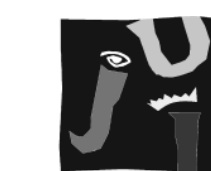

UNIVERSITAT

JAUME•I

lisis

Laboratoire internationa

sur I'inclusion scolaire

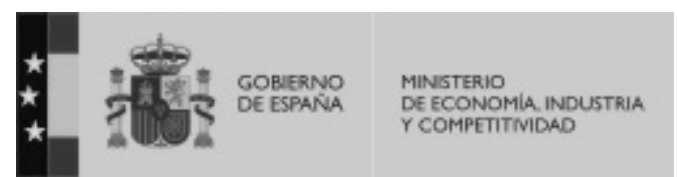





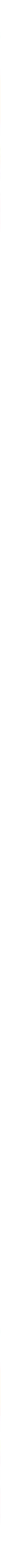

